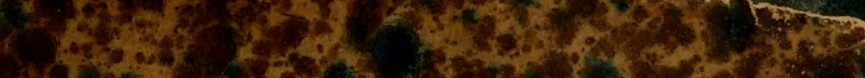

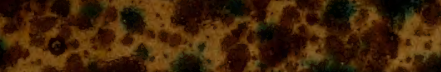

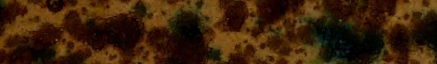

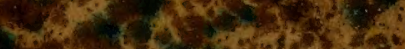

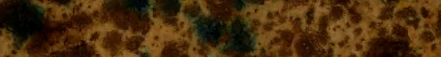
(1)

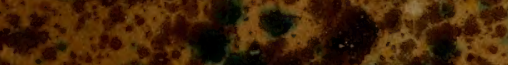

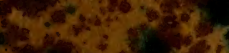

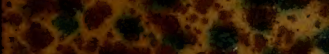
1. $6 x^{3}+x^{2}$

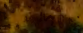

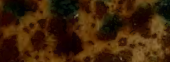

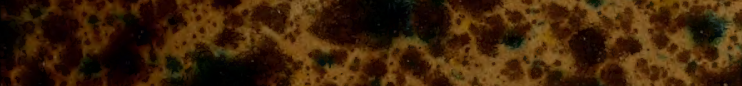

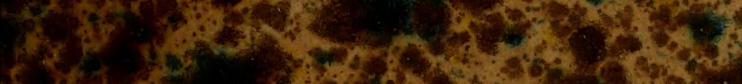

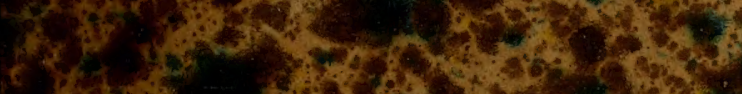

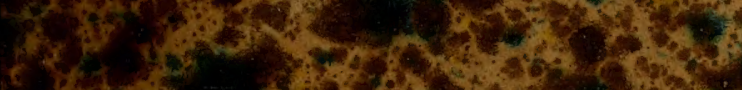 res.
}

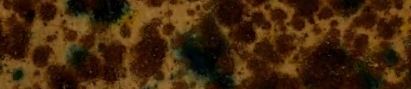

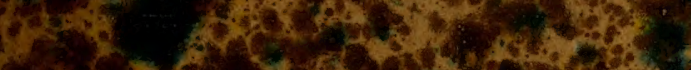

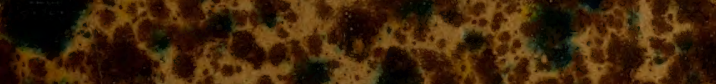

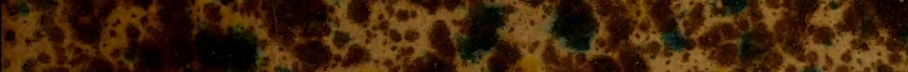

tegention tos.

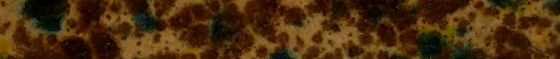

S.

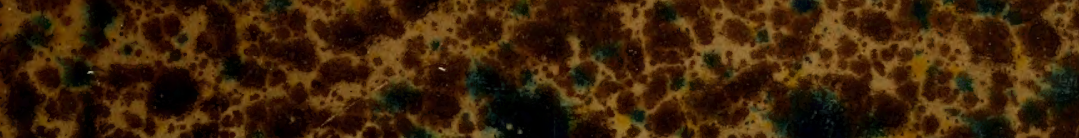

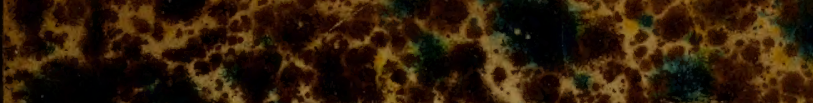

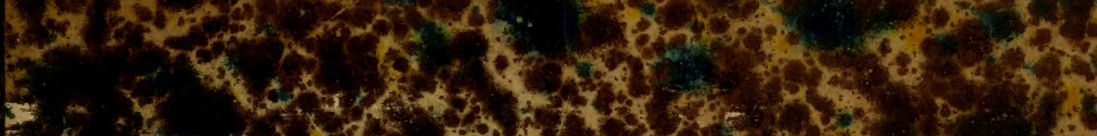

30
3

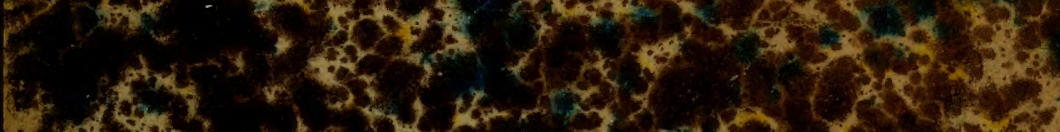

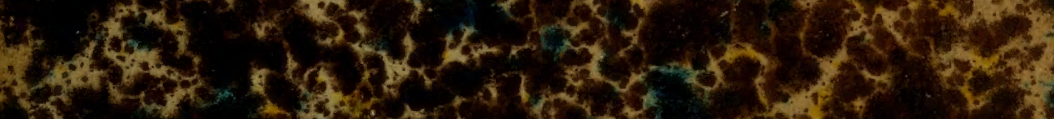

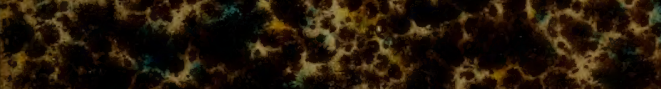
4. $x^{2}+\sin ^{2}+x_{0}$ 25. $\log \left(\frac{1}{2}\right)$
$-x^{2}, x^{2}$

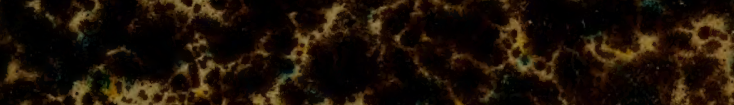
$\operatorname{lin}^{2}$

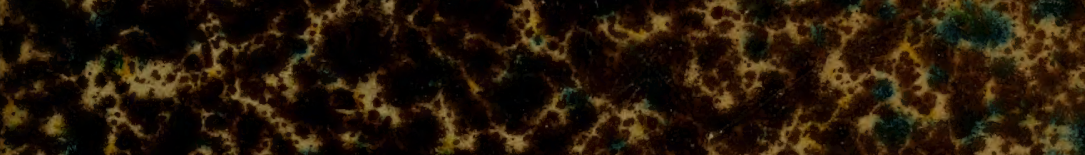

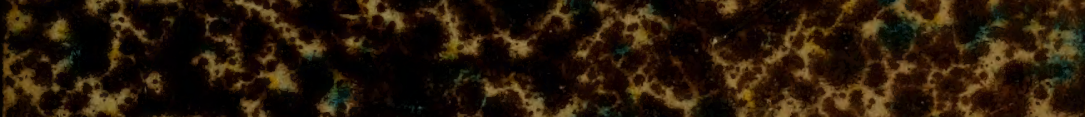

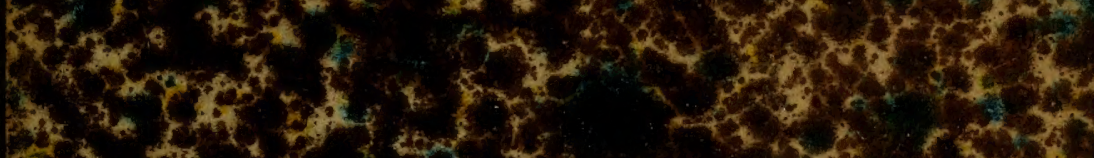

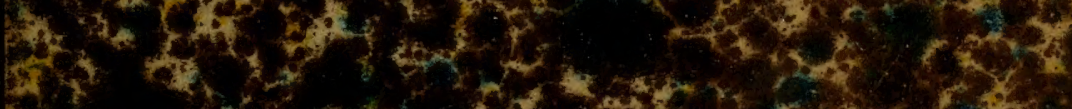

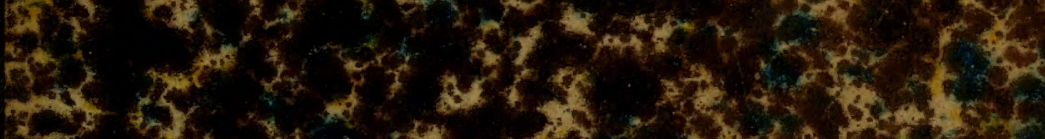

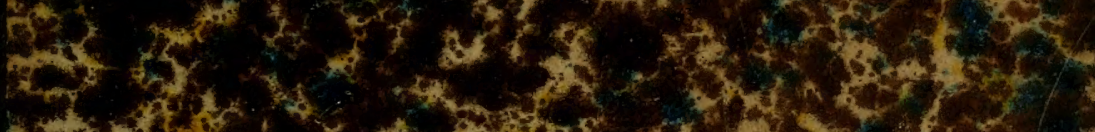

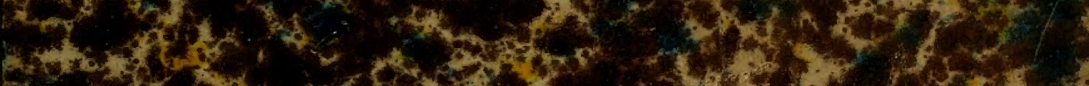

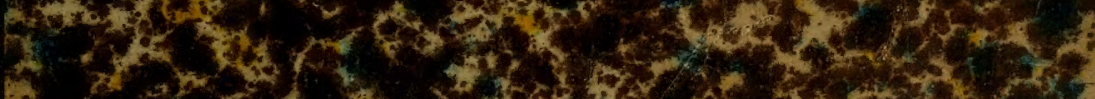

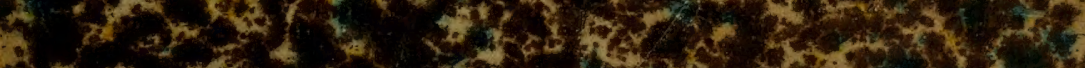

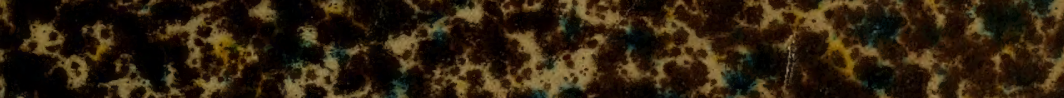

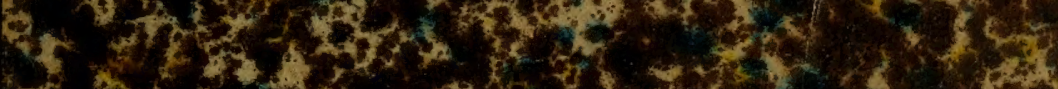

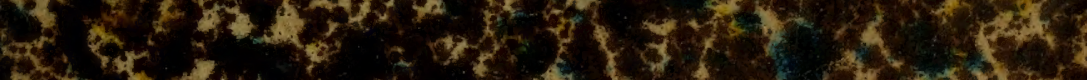

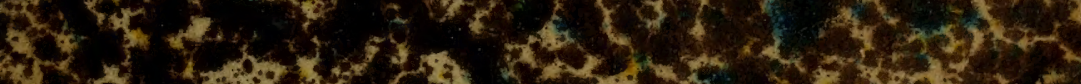

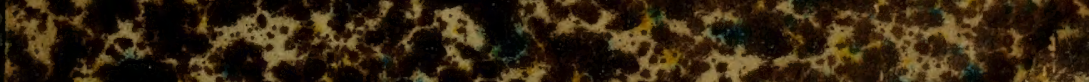

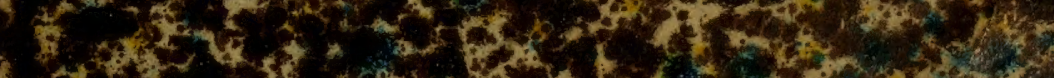

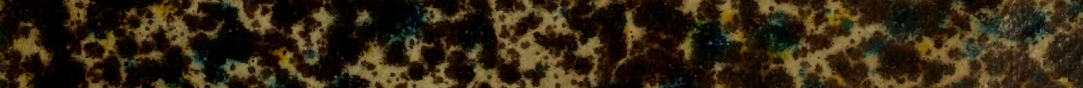
2. 


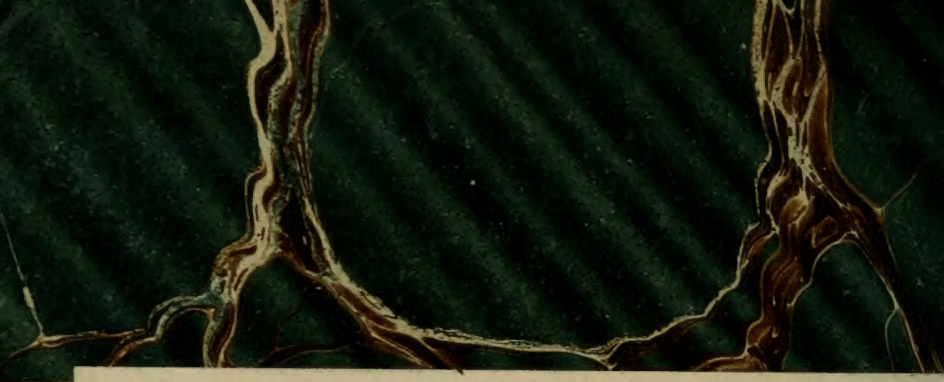




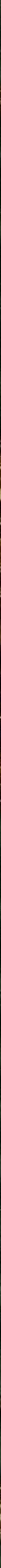





FLORE FORESTIERE 
Nancy, imprimerie de veuve Raybois, rue du faub. Stanislas, $\mathbf{5}$. 


\section{FLORE FORESTIÈRE}

DESCRIPTION E'T HISTOIRE

\section{DES \\ VÉGÉTAUX LIGNEUX}

QUI CROISSENT SPONTANÉMENT EN FRANCE

ET DES

ESSENCES IMPORTANTES DE L'ALGÉRIE.

SUIYIES D'UNE

MÉTHODE ANALYTIQUE

POUR EN DÉTERMINER LES PRINCIPALES ESPĖCES PENDANT L'HIVER

et prẻcédées

D'UN DICTIONNAIRE DES MOTS TECHNiques

PAR

M. Auguste MATHIFU

Inspecteur des forêts

Professeur d'histoire naturelle à l'Ecole impériale forestière

Ancien êlève de cette Ecole

\section{$2^{\circ}$ EDDTTION}

REVUE ET AUGMENTÉE

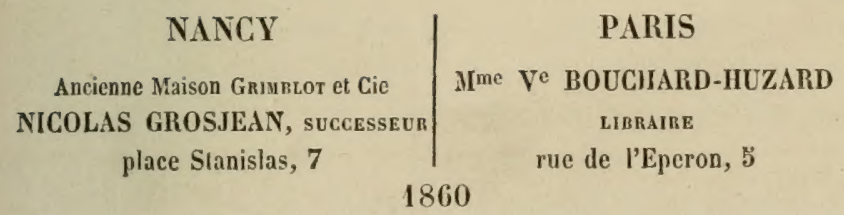




$$
\begin{aligned}
& F 8 \\
& M 37 \\
& 1860
\end{aligned}
$$




\section{PRÉFACE}

\section{IEV SODV}

\section{DE LA DEUXIÉME EDITION}

Les végétaux indigènes ont étẻ décrits bien souvent déjả et il ne manque pas de bonnes Flores, générales ou locales, où l'on peut les éludier. Mais les ouvrages de ce genre ont tous élé écrits au point de vue de la bolanique proprement dite, sans autre but que de déterminer et de nommer les espèces; ils embrassent, en outre, pour la contréc à laquelle ils s'appliquent, la tolalité des plantes herbacées et ligneuses qui y croissent ef s'adressent plutòt au savant ou à l'amateur de botanique qu'au forestier, a moins qu'une vocalion spéciale ne l'altire vers l'élude des végétaux.

Ce sont ces considérations qui m’ont engagé à entreprendre la Flore foresticre, dont je publie la seconde édition. J'ai cherché à y exposer avec méthode l'ensemble de la végétation ligneuse indigène et, sans me borner à la description des espéces, je me suis efforcé d'y réunir tout ce qui m'a paru digne d'intérêt sur leurs exigences, leur mode de végétation, la structure et les transformations de leur écorce, la structure, les qualités et les usages de leur bois, la nature enfin de leurs produits accessoires.

Le cadre que j'ai adopté ne l'a point élé sans hésitations 
el je ne m'en suis pas dissimulé les inconvénients. En faisant l'histoire des végélaux ligneux indigènes, j’ai parfois été conduit a parler d'espéces fort peu importantes au point de vue forestier, tandis que, d'un autre còté, j’ai dù passer sous silence les arbres exotiques si répandus de nos jours dans les jardins, les pares, les promenades publiques et mème le long des grandes routes et toutes ces plantes lıerbacées spéciales aux forèts, dont l'abondance donne au tapis végétal qui en couvre le sol un cachet caractéristique, suivant la composition minérale et les propriétés physiques qui en dérivent, suivant l'état des massifs, l'exposition, la latitude et l'altitude.

J'ai néannoins accepté ces inconvénients, quoiqu'à regret, parce que je n'ai pas tardé à m'apercevoir que, pour les faire disparaitre, mon travail prenait une trop grande extension et qu'une fuule de familles, de genres et d'espèces, qu'un cadre plus modeste me permeltait de négliger, venaient sans cesse accroître la nomenclature et ses difficultés. Une dernière considération enfin m'a paru décisive: dans un livre de cetle nature il faut un plan nellenent arrèté qui indique à l'avance ce que l'on y doit chercher, ce que l'on n'y peut trouver, et c'était renoncer i celte qualité essentielle que de laisser à une appréciation arbitraire l'admission ou l'exclusion des végétaux à decrire.

Je dois toutefois avouer et signaler quelques légeres infractions au plan que je me suis tracé.

La premiẻre concerne l'Algérie.

La viggétation ligneuse de cette contrẻe, dont j'excepte la région saharieme, offre avec celle du littoral de la Medilerrance, en France, une frappante analogie, et, a part de rares especes propres a l'Afrique, les éléments diune Flore Foresticre Aleriente se tromvaient presque en 
entier dans mon livre. J'ai mis à profit celte coïncidence pour rẻaliser, dans cette seconde édition, le désir, exprimé dans la première, d'y comprendre la description et l'histoire des végélaux ligneux d'une contrée dont l'importance forestière est désormais hors de doute et de remplacer ainsi, auprès des agents déjả nombreux qui l'habitent, les notions d'une tradition vague et souvent inexacte par des données précises et certaines. Il m'a suffi, pour atleindre ce but, de signaler, parmi les plantes françaises, celles d'entre elles qui se retrouvent en Algérie el d'ajouter çd et lá, quelques nouvelles descriptions pour les rares espèces exclusivement africaines. Afin de ne pas trop accroître le nombre de ces additions, je ne les ai fait porter que sur les végétaux forestiers importants, soit par les dimensions, soit par l'abondance, et, pour ne pas rompre l'unité du livre, je les ai placées en notes, en regard des genres ou des familles auxquelles se rapportent les espèces qu'elles concernent.

Une seconde infraction est née de l'impossibilité d'ètablir une limile précise entre les végétaux ligneux et les végétaux herbacés. Tout se nuance dans la nature et entre l'arbre le plus majestueux et l'herbe la plus humble il est une foule d'étals intermédiaires, qui rendent souvęnt douteux les droits d'une espéce à être acceptée parmi les plantes ligneuses.

J'ai résolu la difficulté en admettant, parmi les espèces litigieuses, celles d'entre elles que signale une abondante répartition sur le sol forestier ou qui font partie de familles entrant de droit dans mon cadre; j'ai exclu au contraire celles qui, par l'exiguité de la taille, la rareté ou la station en dehors des forèts n'offrent qu'un intérêt mẻdiocre, toutes les fois que pour elles seules il fallait introduire des familles nouvelles dans la nomenclature. C'est par ces motifs que 
quelques sous-arbrisseaux des familles des Polygalées, Ombellifẻres, Composẻes, Labiées, Salsolacées efc., ont élẻ négligés.

Enfin, tout en renonçant à traiter des végélaux exoliques, je n'ai point cru devoir les repousser tous. Quelques-uns d'entre eux, introduits depuis une antiquité très-reculéc, sont tellement propagés par la culture; quelques autres, d'importation plus récente, se sont si complétement naturalisés, qu'à l'exemple de tous les auteurs j'en ai joint la description à celle des végètaux indigènes.

Après avoir exposé le plan que j’ai suivi, il me resle a en justifier l'exécution de deux reproches qui ne peuvent manquer de lui ètre adressés, à des points de vue très-diffẻrents, il est vrai, par les botanistes el par les forestiers.

Les botanistes qui, par hasard, feuilleteront mon livie, s'étonneront de n'y trouver que des espéces déjả décrites et de n'y rencontrer aucune de ces nouveautés par lesquelles toute flore se recommande à leurs yeux. Ce n'est pas cependant que la matière soit épuisée et, qu'en adoptant surlout les vues de quelques descripteurs modernes, certains genres de végétaux ligneux, le genre chène entre autres, ne puissent ètre une mine féconde de celte nature. Mais, sans rechercher ici si cette spécification des plantes, poussée parfois jusqu'à la subtibilité, n'est pas plutòt un obstacle qu'un progres, je ferai remarquer que mon but principal est d'exposer à des éléves et à des praticiens l'ensemble des connaissances acquises sur les vigélaux li gneux el de leur donner le moyen de les déterminer facilement; dans ces conditions, l'on m'accordera, je l'espere, que je devais éviter avec soin toute citation d'espèces que le temps on de hautes autorités scientifiques n'ont point suffisamment consarres el que, a plus forte raison, je devais m'interdire toute création de ce genre. 
Il est un point cependant sur lequel je me suis permis d'innover et que je crois ne pouvoir plus être négligé dorénavant en bolanique descriptive, toutes les fois qu'il s’agira de végétaux ligneux. Je veux parler des bois et des caractères que l'on tire de l'observation de leurs tissıs élémentaires, fibres, rayons, vaisseaux, canaux résinifères et parenchyme ligneux. L'examen attentif de la totalité des bois indigènes m'a démontré que la structure en demeure constante pour tout un genre et mème pour toute une famille, quand celle-ci est bien naturelle, et je suis resté convaincu que les mélbodes trouveront dans les caractères de cet ordre un puissant auxiliaire pour se perfectionner. Cette structure, d'ailleurs, règle le plus souvent Jes qualités et les usages des bois, permet de les distinguer facilement entre eux et cette partie de l'bistoire des végélaux se raltachait trop intimement à mon sujet pour que je l'aie négligée.

J'ai donc fait suivre les caracteres de chaque genre de la description succincte du bois des especes qui le composent et, quand cela m'a été possible, j’ai aussi indiqué les moyens de reconnaitre entre eux ceux des especces d'un même genre, toutes les fois au moins que l'importance forestière des végétaux m'a paru l'exiger.

On objecterait a tort, je crois, que cette partie de l'étude des plantes est du domaine de l'anatomic et n'est nullement de celui de la botanique descriptive. Il ne sagit pas ici de décrire, avec le microscope, la forme et les nombreuses modifications des organes élémentaires; il suffit d'en observer la distribution relative et pour cela il ne faut que l'ocil nu, la loupe tout au plus. Très-cerlainement les caracteres de cet ordre sont d'une appréciation beaucoup plus facile que ceux qui sont tirés de la structure de 
l'embryon, dont aucun bolaniste, cependant, ne songera i nier l'importance en nomenclature.

Et d'ailleurs, la marche dans celte voie n'a-t-elle pas été ouverte depuis longtemps? De Candolle n'a-t-il pas pris pour base de sa méthode naturelle la présence ou l'absence des vaisseaux, lorsqu'il créa les embranchements des végétaux vasculaires et des végétaux cellulaires? 'Tous les botanistes, depuis Desfontaines, n'ont-ils pas employé, pour distinguer les monocotylédonés des dicotylédonés, la disposition des faisceaux fibro-vasculaires, épars dans les premiers, rangés en zones circulaires concentriques dans les seconds? Il n'y avait donc qu'à suivre la voie tracée par d'aussi illustres maitres et à appliquer aux familles et aux genres ce qui l'était aux embranchements et aux classes.

C'est ce que j’ai tenté de faire pour les végétaux ligneux de France, a l'exemple de beaucoup d'auteurs allemands (II. Schacht, T. IIartig, Nordlinger, etc.) qui, depuis longtemps déjả, ont suivi cette marche avec succès pour les végétaux forestiers de leur patrie.

J'aborde maintenant les griefs les plus graves et qui me touchent le plus, ceux des forestiers. Quelques-uns trouveront mon livre trop scientifique; il aura pour eux le tort d'être écrit dans le langage botanique, qui leur est peu familier; il les obligera, pour reconnaitre les arbres de la plus grande dimension, à examiner, même attentivement, leurs moindres parties, fleurs ou fruits, malgré la difficulté souvent insurmontable de se les procurer et l'impossibilité de les observer en toutes saisons.

Ces oljections naissent d'une méprise. La botanique ne s'impose pas en toules circonstances el n'exclut pas l'habilude du coup-d'wil pour distinguer les végétaux; mais elle doit étre le point de dípart et la regrle de celte habitude, 
que le forestier ne saurait assez s'efforcer d'acquérir. Par clle seulement il pourra se soustraire a cet empirisme aveugle et trop souvent subi, qui, dans son impuissance de faire connaitre tous les végétaux de la forêt, semble poser en principe qu'il est suffisant d'en distinguer quelques essences principales; source permanente d'erreurs et de confusions de langage les plus déplorables, cause d'embarras inextricables pour celui que ses fonctions appellent du nord au midi et qui, en présence d'une végétation nouvelle, croit retrouver partout les mèmes végétaux, malgré les différences, insaisissables pour lui, qui les caractérisent.

Si l'on se rend á ces raisons et si l'on admet l'utilité de la botanique ainsi entendue, on m'en tolérera bien le langage technique, je l'espère, car aucune science ne peut s'en passer. Il ne faut pas au surplus s'en effrayer; j'ai cherché à le réduire au moindre nombre de mots possible et j'ai placé en tête de l'ouvrage, et complété pour cette seconde édition, un vocabulaire des termes qui peuvent avoir besoin d'explication. Quelques légers efforts, toute étude en demande, auront bientot mis au fait de leur emploi.

J'ai, en outre, apporté un soin tout particulier à la description des feuilles, qui sont les organes les plus nombreux, les plus apparents et les plus durables des plantes; enfin, pour faciliter la détermination des espèces en toute saison, j'ai ajouté à cetle seconde édition une clef analytique qui permettra de distinguer, en hiver, les principales d'entre elles rien que par l'examen des rameaux et de leurs bourgeons.

Malgré ces raisons en faveur de la bolanique et les précautions que j'ai prises pour en faciliter l'application à l'úlude des végélaux ligrneux, si quelques esprits prévenus en repoussent encore l'emploi el condamnent le 
livre sur son tilre, je crois devoir en appeler à leur jugement mieux éclairé. Peut-ètre qu'en laissant de côté toute la partie botanique de la Flore ils y trouveront encore, pour les essences que la pratique leur aura permis de reconnaître, des renseignements qui ne leur paraitront pas dépourvus de tout intérêt.

C'est maintenant pour moi un devoir et un plaisir d'adresser mes remerciements les plus vifs aux Agents, trop nombreux pour que je les nomme ici, qui m'ont aidé de leurs renseignements ou qui, en enrichissant les collections de l'Ecole forestière, ont mis à ma disposition des matériaux abondants et précieux. Je leur dois, pour celle nouvelle édition, des rectifications et des additions importantes et, c'est avec confiance, que je sollicite de tous la continuation de ce bienveillant concours pour améliorer encore el compléter l'histoire des végétaux forestiers indigènes.

Mon but sera complétement attcint si, en contribuant à faire micux connaître les forêts, j'ai concouru à les faire aimer; si je suis parvenu à diriger l'attention des agents forestiers vers l'élude des végétaux qui les entourent et à leur faire comprendre que la botanique, ả part le charme que certains esprits trouvent dans son culte, est de toutes les sciences celle dont les progrès intéressent le plus la culture des hois, dont elle est l'introduction obligée; qu'elle est indispensable enfin à quiconque n'uublie pas que, des nombreuses qualités qui font le forestier instruit, celle de sylviculteur est la plus éminente. 


\title{
DICTIONNAIRE DES MOTS TECHNIQUES
}

\author{
EMPLOYÉS DANS LA FLORE FORESTIÈRE
}

Accrescent. Involuere, ealice ou style qui, après la fécondation, ne se dessèche pas,' mais s'aceroît et accompague le fruii.

Acienlaire. Semblable à une aiguille.

Acaminć. Extrémité d'une feuille, ctc., dont les bords, en changeant de direction et devenaut concaves, se rencontrent moins vite et donnent naissance à une pointe plus ou moins allongée.

Adhérent. Se dit du calice el de l'ovaire soudés l'un avec l'autre.

Adrentif. Un bourgeon adventif est celui qui naît en des places indéterminées des rameaux, des branches, de la tige ou des racines et qui se développe immédiatement.

Aigu. Extrémité d'un organe qui se termine insensiblement en pointe, sans que les bords changent de direction avant de se rencontrer.

Aiguilles. Nom sous lequel on désigne souvent les feuilles des conifères.

Aiguillon. Production de l'enveloppe subéreuse, naissant en des places quelconques de l'écorce et n'ayant aucune adhérence avec le système fibro -vasculaire.

ile. Expansion foliacéc ou membraneuse qui accompagne certains fruils el certaines graines, borde quelquefois les pétioles ou se prolonge le long des rameaux. Les deux pélales latéraux de la corolle papilionacée portent aussi le nom d'ailes.

Ailé. Bordé d'une ou de plusieurs ailes.

isselle. Sommet de l'angle rentrant formé par deux branches, ou par une feuille et le rameau qui la supporte, ou par une veine et la nervure médiane.

A kène. (On écrit aussi achaine.) Fruit indéhiscent, à péricarpe sec el mince, mais distinct, à graine unique.

Albumen. Voir Périsperme.

Alterne. Insertion des feuilles lorsqu'elles sont disposées une à une le long des rameaux, quelle que soit la valeur de la spirale que l'on peut tracer par la base de chacune d'elles.

Lorsqu'il s'agit de fleurs, le mot alterne s'applique aux parties d'un 
verlicille qui corresponelent aux intervalles des parties du verlicille immédiatement voisin.

Amante. Porlion de la graine renferméc sous l'épisperme el composce, suivant les espèces, de l'embryon seul ou de l'embryon el du périsperme.

Amentacé. Qui a l'inflorescence en chaton. Voir ce mot.

Ampléxicaule. Qui embrasse la tige, le rameau.

Anastomosé. S'applique aux nervures el aux veines dont les ramificalions se réunissent les unes aux autres.

Androcée. Région de la fleur formée par les ćlamines, disposées en un ou en plusieurs verticilles.

Angiosperme. Dont les graines sont entourées d'un péricarpe.

Anisostémone. Exprime que le nombre des étamines est autre que celui des pélales el des sépales.

Anthère. Corps vésiculaire à deux loges, plus rarement à une ou à quatre, qui contient une matière pulvérulente, le Pollen, servant à la fécondation.

A pétale. Dépourvu de pétales, de corolle.

A piculé. Terminé par une pointe courte et grêle.

Apocarpé. Fruil à une seule loge, formé par un carpelle unique.

Appliqué. Se dit d'un organe placé suivant toute sa longucur sur un autre, sans adhérence.

Apprimé. Voir appliqué.

Aranéenx. Couvert de poils longs, mous, couchés et entrelacés, simulant une toile d'araignée.

Arbre. Végétal ligneux, àtige simple et nue s’élevant à $7^{\mathrm{m}}$ au moins en dessous des premières branches.

Arbrisseau. Végétal ligneux, rameux dès la base, dout la hauteur lotale va de 1 ì $7 \mathrm{~m}$.

rouste. Pelit arbre ne dépassant pas la taille d'un arbrisseau, mais ayant la tige simple et nue à la base.

Arille. Enveloppe accessoire plus ou moins complicte de la graine, extérieure à son épisperme. L'arille vraic provient d'une expansion du funicule, qui s'est accrue de la base au sommet, à partir du hile; l'arilie fausse est due à un bourrelet du micropyle qui s'est développé de haut en bas.

Ascendant. S'applique à un organe étalé horizontalement, courbé ct redressé à l'extrémité.

Aubier. Ensemble des couches de bois les plus externes et les plus jeunes, qui n'onl pas encore aequis leur lignification définitive. L'aubier est blanc el se reconnaît aisément dans les bois durs et colorés, où son infériorité en qualité est le mieux marquée; il est loin d'en être de même dans les bois qui restent blanes et dans les bois mous.

Axile (Placentation). Lorsque les bords de la fenille carpellairc ou des feuilles carpellaires qui forment les parois de l'ovaire se sont complétement réunis, les graines, habituellement allachées dans l'angle sutural, sont disposies sur un cordon, dit placentaire, qui correspond a l'axe de la fleur. Cetle placentation est appeléc axile.

Axillaire. Silué à l'aisselle.

Baceiforme, Qui ressemble à une baic: 
EBaie. Fruit clıarnu, formé de plusieurs carpelles réunis et contenant plusieurs graines.

EBasilaire. Siltié à la base.

oBi-. ladical signifiant deux ou deux fois.

Milabié. Divisé en deux lèvres.

BBois. Portion de la tige qui va de la moelle à l'écorce el se compose, jour presque tous les arbres dicotylédonés de nos contrées, d'autant de couches que l'arbre a d'années. Les éléments anatomiques du bois sont essentiellement le tissu fibreux et les rayons médullaires; on peut y rencontrer en outre du parenchyme ligneux, des vaisseaux, des canaux résinifères; les principes chimiques en sont principalement la cellulose $\mathrm{ct}$ la lignine.

Eois a'automne. Portion externe de chaque couche annuelle, plus dure et plus colorée que la portion interne dans la majorité des bois, jamais moins en tout cas.

Bois de printemps. Portion interne de chaque couche anauelle; c'est la première formée, la plus molle, la moins colorée.

Boois parfait. Région centrale plus ou moins élendue du corps ligneux, dont le bois est aussi complétement pénétré de liguine, de résine et souvent de matière colorante que l'espèce le comporte.

HBactée. Feuille plus ou moins modifiée dans sa taille, sa forme, sa consistance et sa coloration, à l'aisselle de laquelle naîl la fleur.

Bzractéole. Diminulif de bractée.

BBuisson. Arbrisseau bas et rameux.

Calice. La plus externe des deux enveloppes florales. Le calice est généralement vert; il est formé de sépales, libres ou soudés cntre cux. Toute enveloppe florale simple est considérée comme un calice.

Campanulé. En forme de cloche.

Canaux résinifères. Cavités ou glandes creuses en forme de vaisseaux, revêtues d'une paroi finement cellulaire et spéciales à l'écorce el aux bois de cerlains conifères. (Voir page 340 ).

Capillaire. Grêle el allongé comme un cheveu.

Capitule. Inflorescence dont tous les axes sont réduits, de sorte que les fleurs qui la composent sont toutes rapprochices les unes contre les autres.

Capsule. Fruit sec, déliscent, à plusieurs loges.

Carêne. Partie inférieure d'une corolle papilionacée, formée de deux pétales, le plus souvent soudés entre eux par un de leurs bords.

Carpelle. Organe femelle élémentaire, formé d'un ovaire simple, d'un style unique et d'un stigmate. Une fleur peut renfermer un ou plusieurs carpelles et, dans ce dernier cas, ces carpelles peuvent rester libres et distincts ou se souder entre eux pour former le pistil.

Cellulose. Principe immédiat neutre $\left(\mathrm{C}^{12} \mathrm{H}^{10} \mathrm{O}^{10}\right)$ qui constitue les membranes des tissus végétaux.

Centrale (Plucentation). Disposition des ovules ou des graines autour d'un placentaire central, dans un ovaire uniloculaire.

Chaton. Sorte d'inflorescence voisine de l'épi, dont l'axe est articulé à la base et dont les fleurs, toujours dépourvues de corolle et mème nues, sont unisexuées. 
Cherefu. Filaments griles el déliés qui terminent les raciues el en sont les dernieres ramifications.

Chlorophylle. Matière colorante verte des végélaux.

Cilié. Bordé de poils fins el droits comme des cils.

Claviforme. En forme de massue.

Cloisons. Lames séparatives des loges des fruits, des anthères.

Coloré. Exprime tout autre coloration que la verte, considérée comme normale.

Composée (Feuille). Dont le pétiole se ramifie en pétioles secondaires, qui supportent des folioles indépendantes les unes des autres.

Composé (Fruil). Formé de carpelles, libres ou soudés entre eux, rapprochés sur un mème axe el provenant de fleurs distincles.

Concolore. De mème conleur el nuance.

Condupliqué. Etat des feuilles dans le bourgeon, lorsqu'elles sont pliées en deux dans toutc leur longueur suivant la nervure médiane.

Côue. Fruit composé, formé d'un axe el d'écailles nombreuses, à la base desquelles sont deux ou plusieurs fruits ou graines.

Conné. Disposition de fenilles opposées, soudées el confondues par leurs bases, de manière à représenter une feuille unique, au centre de laquelle passe le rameau.

Connectif. Tissu jaune-verdàtre qui réunit les 2 loges d'une anthère.

Connivent. Dont les extrémités lendent à se rapprocher.

Conroluté. Eiat des feuilles dans le bourgeon lorsqu'clles sont enroulées sur elles-mèmes en cornet suivant leur longueur.

Cordiforme. Se dit d'uue feuille dont la base est élargie et échancrée en son milieu.

Corolle. La plus interne des deux enveloppes florales; la corolle est généralement colorée et se compose de pétales, libres ou soudés entre cux. La suppression de l'une des deux enveloppes porte sur la corolle.

Corymbe. Inflorescence formce d'axes secondaires, simples ou rameux, partint de différents points de l'axe primaire pour aboutir a une mème surface, plane ou convexe.

Cotonnexx. Couvert de poils allongres, mous, entremêlés et crépus comme le coton.

Cotylédon. Corps ordinairement féculent ou oléagineux, scuvent volumineux, faisant partie de l'embryon dont il est une feuille plus ou moins modifiée; il sert à le nourrir pendant la germination. Le nombre des colylédons est de 1 ou 2, rarement plus (cerlains conilères).

Conchée. Tige appliquée sur le sol, mais ne s'y enracinant pas.

Coussinet. Petile saillie du ramean, sur laquelle la feuille est ou élait insérće.

Crénelé. Bordé de dents arrondies, qui ne sont dirigées ni vers le sommel, ni vers la base.

Crustacé. Consistance d'une caveloppe qui est dure, mince el fragile.

Cunéiforme. Se dit de la base d'un organe, fenille, écaille, ele., dont les bords sont droits et se réunissent sous un angle aigu, de manière à rappeler la forme d'un coin. 
Cupule. Involucre en forme de coupe, embrassant le fruit à la base et formé de pelites écailles soudées entre elles.

Cupuliforme. En forme de coupe.

Cuspidé. Terminé en pointe rigide et acẻrée.

Cylindracé. Se rapprochant de la forme cylindrique.

Cyme. Inflorescence définie dans laguelle les fleurs s'épanouissent du centre à la circonférence.

Bécombaute. Tige dressée à la base, recourbée vers la terre par l'extrémité.

Bécomposé. S'applique à une feuille composée dont les folioles sont supportées pas des axes de $5^{e}$ ordre.

Décurrent. Se dit du limbe d'une feuille dont la base se prolonge, avec adhérence, sur le rameau.

Délniscence. Ouverture régulière d'une cavité, afin que le contenu s'en éclappe.

Béhiscent. Qui s'ouvre.

Denté. Bordé de dents aiguës non dirigées vers le sommet.

Denté en seie. Voir Serré.

Denticulé. Diminutif de denté.

Diadelphe. Signifie l'union d'un nombre quelconque d'étamines par les filets en 2 faisceaux distincts.

Dialypétale. Mot substitué à celui de polypétale comme étant plus correct; s'applique à une corolle formée de plusieurs pétales non soudés entre eux.

Dichotome. Qui se divise plusieurs fois de suite en 2 rameaux opjosés.

Bieotylédonéc. Plante dont l'embryon est pourvu de 2 cotylédons.

Didynames. Elamines, au nombre de 4 , dont 2 sont plus grandes.

Bigité. Folioles, lobes ou nervures qui rayonnent à partir d'un foint.

Dioique. Plante dont les fleurs sont unisextries et dont les sexes sont séparés sur des pieds différents.

Biplostémones. Etamines en nombre double de celui des sépales el des pélales.

Piscolore. De deux couleurs ou nuances différentes.

Bisque. Bourrelet circulaire, plus ou moins saillant, du réceptacle de la fleur, sur lequel s'insèrent, quelquefois, les différentes parties d'un même verticille.

\$istique. Placé alternativement à droite et à gatıche, dans un mème plan.

Divariqué. S'écartant l'un de l'autre sous un angle très-ouvert.

Drageon. Rejet naissant sur la racine traçante.

Drupacé. Qui se rapproche d'une drupe.

Drupe. Fruit charnu, à un seul noyau uniloculaire.

Ellipsoide. Solide engendré par une ellipse.

Elliptique. Surface qui a la forme d'une ellipse géométrique.

Embryon. Portion essentielle de la graine, formée d'un végétal en miniature, qui, par la germination, se développe et perpétue l'espèce. On y remarqque une radicule, une ligelle, 1 ou 2 colylédons et au sommet une plumule ou gemmule qui en est le 1 er bourgeon terminal.

II. 
Eudoearpe. Partie interne du péricarpe, circonscrivant la loge ou les loges qui contiennent les graines.

Entier. Sans aucunè division.

Entreucud. Portion de rameau comprise entre 2 feuilles conséculives.

Euveloppe herbacée. Région fondamentale de l'écorce, qui ne manque jamais à l'origine, mais disparait souvent plus tard. Elle se trouve immédiatement sous l'épiderme on sous l'enveloppe subéreuse, si celle-ci est développée; se compose de lissu cellulaire làchement uni et rempli de chlorophylle; les rayons médullaires y aboutissent.

Enveloppe subéreuse. Portion de l'écorce qui s'organise ordinairement entre l'épiderme et l'enveloppe herbacée el peut persister et s'accroître plus ou moins rapidement pendant toute la vie du végétal, ou disparaître de bonne heure. Elle est formée de cellules étroilement unies entre elles, dépourrues de chlorophylle et constituant un tissu imperméable, le Liẻge.

Eyarses. On désigne ainsi des feuilles qui ne sont ni opposées, ni verticillées, ni distiques. Dans le fait, elles sont insérées suivant une spirale, $d$ 'indice quelconque.

Epi. Inflorescence indéfinie composée d'un axe le long duquel sont disposées des fleurs sessiles, généralement hermaphrodites.

Epicarpe, Epiderme ou membrane externe du fruit.

Epigé. S'applique aux cotylédons qui sont poussés hors de terre par la germination et qui se transforment en feuilles.

Epigyne. Insertion des étamines placées sur l'ovaire.

Epiderme. Membrane mince et transparente qui recouvre lous les organes des plantes. L'épiderme de l'écorce tombe de bonne heure, souvent au bout d'un an, et n'est point remplacé.

Epine. Pointe rigide et dure, appartenant au système fibro-vasculaire du végétal et oceupant une position déterminée par la nature des organes transformés, rameaux, stipules, coussinets, feuilles, etc, dont elle tire son origine.

Epipétale. Inséré sur la corolle.

Episperme. Enveloppe immédiate de la graine.

Espèce. Collection de tous les individus qui se ressemblent entre eux plus qu'ils ne ressemblent à d'autres et qui, par la génération, en reproduisent de semblables; de telle sorte qu'on peut par analogie les supposer tous issus origiıairement d'un mème individu. (A. de Jussieu).

Essenee. En langage forestier, ce mol s'applique aux grands végélaux ligneux el devient synonyme d'espèce.

Etamine. Organe sexuel male, appartenant au $5^{\text {me }}$ verlicille de la fleur complète, ì partir de l'exlérieur; elle est formée d'un support appelé filet et d'une anthère, corps vésiculeux, généralement à 2 loges, uni surmonte te filet el contient la substance fécondante sous forme d'une matière pulvérulente nommée pollen. Le filet peut manquer.

Etendard. Pétale supéricur, à limbe ordinairement dressé, de la corolie des papilionacées.

Extrorses. Anthere dont la déhiscence se fait par la face exté. rieure

vasciculo. Groupé en faisceau. 
Feuille. Appendice, généralement étalé et plan, de nature herbacée, naissant avec le rameau qui le supporle; on y distingue, à l'état le plus complet, un limbe, un pétiole et des slipules.

Feuillus (Bois). Sous ce nom, on désigne, en langage forestier, les arbres dont les feuilles ont un limbe bien développé et sont généralement caluques. Les bois feuillus correspondent aux végélaux angiospermes de la nomenclature.

Fibres. Organes élémentaires des végélanx, dont la réunion forme le tissu fibreux, c'est-à-dire, la masse principale et la plus compacle du bois, celle que l'on dirait pleine à l'oil vu.

Fide (bi-, tri-, multi-). Divisé jusqu'au milieu en deux, trois ou en un grand nombre de parties.

Filet Portion de l'élamine, généralement grêle et allongée, qui supporte l'anthère.

Fistuleux. Creusé d'un canal longitudinal en son centre.

Fleur. Appareil de fécondation et de reproduction, composé, sous la forme la plus complète, d'organes accessoires ou enveloppes florales, calice et corolle, et d'organes essentiels ou reproducteurs, ćtamines et carpelles.

Foliole. L'une des fenilles dont l'ensemble constilue la feuille composée; on donne aussi ce nom aux pélales et aux sépales.

Eollicule. Fruit sec, uniloculaire, à graines nombreuses, ne s'ouvrant que par une seule suture, la ventrale.

Fovilla. Malière fécondante du grain de pollen.

Fructifère. Qui porte les fruits.

Fruit. Ovaire ficondé et parvenu à malurité ; se compose essenlicllement d'une enveloppe nommée péricarpe et de la graine, formée ellemème de l'épisperme et de l'anıande, dans laquelle se trouve l'embryon.

Frutescent. Qui ressemble à un arbrisseau et s'élève sans appui.

Funicule. Support de la graine.

Eusiforme. En forme de fuseau.

Gaine. Réunion des écailles qui entourent la basc des aiguilles des pins; se dit encore de la base d'une feuille, lorsqu'elle se prolonge sur le rameau qu'elle entoure.

Galbule. Cône globuleux, formé d'un petit nombre d'écailles. Voir Cône.

Gamo-pétale ott-sépale. Formé de pétales ou de sépales soudés entre elux.

Géminé. Inséré par 2 sur le mème point.

Gemmule. Partie supérieure de l'embryon; c'est le premier bourgeon terminal de la plante, celui qui en formera la première pousse.

Geure. Collection des espèces voisines.

Clabre. Dépourvu de poils.

Clabrescent. Presque glabre.

Gland. Fruit sec, indéliscent, presque toujours uniloculaire et monosperme par avortement, disp̧osé, 1 à 5 , dans un involucre cupuliforme, péricarpoïde ou foliacé:

Glaucescent. Presque glauque.

Glauque. D'un vert grisâtre, presque toujours dî à une fine efflorescence. 
Cousse. Fruit sec, uniloculaire, léhiscent en 2 valres, dont chacune supporte des graines disposées sur un seul cỏté.

Graine. Partie essentielle du fruit, renfermée dans le péricarpe en nombre variable suivant les espèces.

Grappe. Inflorescence indéfinie composée d'un axe primaire allongé el d'axes secondaires, simples ou rameux, égaux.

Grimpant. Qui ne s'élève qu'à l'aide d'un appui et s'y soutient de diverses manières, par torsion, par des vrilles, des rudicelles, etc.

Gymuosperme. A graines nues, c'est-à-dire, non contenues dans un péricarpe.

Hermaphrodite. Fleur qui réunit les organes des deux sexes.

Mile. Cicalrice laissée sur la graine par son support.

IIspide. Couvert de poils raides et dressés.

Hilbride. Produit du croisement de deux espèces différentes, mais voisines; l'hylbride est fréquemment stérile, et, dans le cas de fécondité, rentre pius ou moins rapidement dans l'un des types dont il descend.

1II yogé. S'applique aux cotylédons qui ne sortent pas de terre par la germination el qui pourrissent sans produire de feuilles cotylédonuires.

HIy yogyue. Insertion des étamines sur le réceptacle, en dessous de l'ovaire.

Imparipenné. S'applique à une feuille composée pennée, terminće par une foliole unique.

Indéfinies. Elamines en nombre illimité, au delà de 18.

Indéhiscent. Qui ne s'ouvre pas.

Indice d'iusertion. Fraclion par laquelle on indigue la nature de la spirale suivant laquelle les feuilles, dites éparses ou allernes, sont insérées; le numúrateur exprime le nombre de tours que l'on décrit pour réunir 2 feuilles superposées, le dénominateur, le nombre des feuilles que l'on a rencontrées en chemin.

Inéquilatéral Se dit d'une feuille qui n'est point symétriqque de chaque côté de sa nervure médiane.

Inerme. Dépourvu d'épines ou d'aiguillons.

Infère. S'applique à un ovaire surmonté par les divisions du calice et, par conséquent, soudé avec son lube.

Enflorescence. Disposition des fleurs; s'entend principalement des groupes que forment les fleurs, lorsqu'au lieu de naitre chacune à l'aisselle d'une feuille vérilable, elles ne se produisent qu'a l'aisselle d'une bractée, qui peut être très-réduite ou même avortée.

Infundibuliforme. En forme d'entonnoir.

Insertion. Mode suivant lequel les feuilles sont distribuées sur les rameaux; hauteur à laquelle semblent naitre les différentes parties de la fleur relativement à l'ovaire.

lntrorse. Anthère s'ouvrant par la face qui regarde l'axe de la fleur.

Involucre. Réunion de bractées, libres ou soudées entre clles, disposées en un ou en plusieurs verticilles.

Involucre fructifere. Euveloppe de bractées qui persiste el contient un ou plusieurs fruits.

Involuté. A bords enroulés en dedans.

Imbriqué. Se recouvrant comme les ardoises d'une toiture. 
Isostémones Etamines dont le nombre est égal à celui des pétales et des sépales.

Labié. Prolongé en lèvre.

Lacinié. Découpé en lanières.

Lancéolé. Elliptique-allongé et terminé en pointe aux deux extrémités.

Liber. Porlion la plus interne de l'écorce des arbres, dont la structure et l'accroissement présentent de grandes différences suivant les espèces. Blanc et nacré tant qu'il est en activité, il est tantôt essentiellement formé de fibres, tantôt complétement cellulaire ; il peut se développer avec activité el former plusieurs couches par année ou, au contraire, posséder peu de vigueur et rester toujours représenté par une seule et même couche.

Eibre. Sans adhérence.

Eignine. Malière surhydrogénée, de composition mal définie, qui incruste les tissus de l'aubier et le transforme en bois parfait; elle varie en quantité ct en nature suivant les essences.

Limbe. Portion de la feuille qui est plane el supportée par le pétiole; partie élargie él étalée des pétales et des sépales, qu'ils soient libres ou soudés.

Lobe. Portion du contour de la fenille plus profondément séparée que ne le sont les dents, sans que, néanmoins, la profondeur des incisions soit déterminée. S'applique aussi aux portions saillantes de certains fruits.

Hobé. Garni de lobes.

Lobule. Petit lobe.

Loculaire (uni-, bi-, pluri-, mulli-). Contenant une, deux, plusieurs ou beaucoup de loges.

Loculicide. Mode de déhiscence d'une capsule qui s'ouvre suivant des fentes, dont clacune correspond au milieu d'une loge, de sorte que chaque valve emporte avec elle une cloison en son milieu.

Loges. Cavitẻs du fruit, de l'anthère.

Mailles ou Maillures. Taches nacrées el miroitanles que les rayons medullaires produisent quand ils sont de dimensions cunvenables el que le bois est débité en long, suivant leur direction.

BIÊte (fleur). Qui n'a d'autres organes sexuels qu'une ou plusicurs élamines.

Marcescent. Organe qui persiste, quoique desséché.

NFéiostémones. Etamines dont le nombre est inférieur à celui lles pétales ou des sépales.

Micropyle. Petite ouverture du sommet de l'ovule, par laquelle se fait la fécondation.

nLonadelphes. Etamines en nombre quelconque, réunies par les filets en un sẻul faisteau.

Banoigne. Plante dont les fleurs sont unisexuées et dont les deux sexes sont réunis sur le mème pied.

Ilonosperme. A une seule graine.

Itueroné. Terminé par une pointe grêle, raide et droite.

sileronulé. Diminutif de mucroné.

NFulti-. Radical qui exprime l'idée d'un grand nombre.

Nitique. Qui n'est ni cuspidé, ni apiculé, ni mucroné. 
Nectaire. Organe glanduleux de la fleur.

Vervure. Prolongement et ramification principale du pétiole dans le limbe des feuilles.

Nu (bourgeon). Dépourvu d'écailles.

Nuculaine. Fruit charnu à plusieurs noyaux ou à un seul noyau pluriloculaire.

Nue (fleur). Dépourvue d'enveloppes florales.

Mos. Radical qui exprime une idée d'inversion.

(1)blong. Wa ellipse très-allongée.

(1)bovele. Eu ovale reuversé.

OHigosperme. Qui contient un petit nombre de graines.

Ombelle. Inflorescence, généralement accompagnée d'un involucre, dont tous les axes partent d'un mème point et sont igalement lougs. Ces axes peuvent être simples ou divises à leur tour en ombelles plus petiles, dites Ombellules.

Ombilic. Dépression qui se trouve à la base ou au sommet de certains fruils.

Ombiliqué. Pourvu d'un ombilic.

Onglet. Base allongée et rétrécie d'un pétale ou d'un sépale.

Ouguiculé. Effilé en onglet.

Opposé. Se dil de deux feuilles insérées en face l'une de l'autre à la mème hauteur; s'applique aussi aux parties des verticilles floraux conséculifs qui n'alternent pas entre elles.

Oppositipenné. Disposition de folioles opposées deux à deux et insérées à droite el à gauche du pétiole commun d'une feuille composée.

Ovaire. Portion inférieure plus ou moins renflee du carpelle ou du pistil, qui contient les ovules et devient fruil après la fécondation.

Ovale. Ellipse renfléc à sa partie inférieure.

Oroidle. Solide engendré par un ovale.

Orule. Etat de la graine avant la fécondation.

Orulé (uni-, bi-, mulli-). Qui contient un, deux ou beaucoup d'ovules.

Palmé, Palmati-. Voir Digité.

Panicule. Inflorescence dans laquelle les axes secondaires, simples ou composés, partent de différents points de l'axe primaire et sont de longueur décroissante de bas en haut, de manière à donner à l'ensemble une forme conique.

Papilionacée. Forme de corolle irrígulière, de $\breve{b}$ pétales, dont le supérieur est appelé étendard, dont les deux latéraux sont symétriques et nommés riles, et dont les deux inférieurs, égalemeal symétriques, tantôt libres, tantòl soudés, constituent la carène.

Parasite. Qui vit sur un antre, de sa propre nourriture; on $\mathrm{em}$ ploic abusivement ce mot pour désigner une foule de plantes qui envahissent le sol forestier au détriment des essences principales ou qui se développent sur les vieilles écorces des arbres.

Parenchyme. Amas de tissu cellulaire.

parenchyme ligueux. Tissu composé de cellules allongées, mais non effilèes en pointe comme les fibres, qui se trouve associe an lissu filreux el aux vaisseaux de certains bois. Il est rare qu'on puisse le dis- 
tinguer à l'œil nu ou mème à la loupe; lorsque cela est possible, on le reconnait à sa couleur plus claire et plus mate.

Pariétale. Mode de placentation dans laquelle les ovules sont allachés à la face interne des parois de l'ovaire, qui, dans ce cas, n'est point cloisonnè.

Paripenné. S'applique à une feuille composée dont les folioles sont. opposées par paires jusqu'à l'extrémité.

Trartite. Désigne les divisions du contour de la feville qui cépașun ¿a moitié du limbe sans alteinơre la nervure médiane.

[pachorere. Pourvu de peu de theurs.

Poilu. Parsemé de poils longs et mous.

Pectiné. Disposé comme les dents d'un peigne; s'applique soit aux divisions étroites et allongées d'un organe, soit aux feuilles, diles aiguilles, de quelques coniferes.

Fédicelle. Diminutif de pédoncule.

Pédoncule. Support de la fleur.

Pelté. Disposition d'une expansion quelconque, feuille, éraille, etc., qui est altachée par son centre à un support et lui est perpendiculaire, comme l'est la têle d'un clou à sa pointe.

Pennati-. Radical qui indique une disposition pennée.

Penué. Disposé comme le sont les barbes d'une plume de chaque côlé de leur tige.

Pentamère. Fleur dont les verticilles, au moins les extérieurs, sont de 5 parties.

Perfolice (feuille). dont le limbe est traversé par la tige.

Péricarpe. Enveloppe du fruit, provenant des parois développées de l'ovaire et composée de trois régions: l'épicarpe ou membrane externe; mésocarpe zone moyenne qui, en devenant charnue, prend le nom de sarcocarpe; l'endocarpe, membrane interne qui circonserit la cavité simple ou multiple contenant les graines.

Périderme externe. Lorsque l'écorce s'est dépouillée de son épiderme, il peut se faire que l'enveloppe subéreuse, mise à nu, persiste, s'accroisse avec plus ou moins d'activité el en constitue la portion superficielle. Cette enveloppe prend le nom de Périderme externe.

Périderme interne. On appelle ainsi des lames ou des couches de tissu subéreux, qui, suivant les essences, s'organisent, à un cerlain àge, dans des zones délerminées de l'écorce, et qui, en s'opponant à la diffusion de la séve vers le dehors, en raison de leur imperméabilité, font dessécher el mourir tout ce qui les recouvre.

Périgone. (Duuble, simple, nul.) S'applique à l'ensemble des enveloppes florales.

Périgyne. Inséré sur le calice, autour de l'ovaire.

Périsperme. Corns qui accompagne souvent l'embryon, mais sans adhérence avec lıi. Il est destiné à le nourrir pendant la germınation, dans le cas où le corps cotylédonaire est insuffisant pour cet objet.

Pétale. Nom des folioles qui composent la corolle.

Pétaloide. De la consistance et de la coloration des pétales.

Pétiolaire. Qui tire son origine du pétiole; se dit des écailles des bourgeons. 
Pétiole. Support de la feuille.

Pétiolé. Pourvu d'un pétiole.

Pétiolulé. A peine pétiolé.

EPistil. Organe rentral et femelle de la fleur, résultant de la soudure des carpelles entre eux.

Pirotant. Qui s'enfonce verticalement dans le sol.

Placentaire. Cordou le long duquel les ovules sont attachés.

Placentation. Mode d'insertion des ovules dans l'ovaire ou des graines dans le péricarpe.

Plumule. Voir Germule.

Pluri-. Radical exprimant l'idée de pluralité.

Pollen. Matière pulvérulente, ordinairement jaune, contenue dans l'anthère. Chaque grain est une pelite vésicule qui renferme la substance fécondante, la fovilla.

Polycarpé. Fruit formé de plusieurs carpelles libres entre eux, groupés sur un mème réceptacle el provenant d'une fleur unique.

Poly-. Voir Pluri.

Polygame. Végétal dont les fleurs sont tantòt hermaphrodites, tantôt unisexuées, sur le mème pied ou plutòt sur des pieds différents; on l'appelle Polygame-monoïque s'il se compose de pieds à fleurs hermaphrodites et d'autres pieds réunissant des fleurs màles et des fleurs femelles; Polygame-dioïque s'il présente des pieds hermaphrodites, des pieds mâles el des pieds femelles distincts.

Polystémones. Elamines en nombre plus que double de celui des pétales et des sépales.

Pomme. Fruit charnu pluriloculaire à pépins ou à noyaux, provenant d'un ovaire adhérent alt calice et, par conséquent, surmonté par les divisions marcescentes ou accrescentes de ce dernier.

Pousse. Ce nom s'applique au rameau encore herbacé de l'annće; on désigne aussi par là la hauteur de l'allongement annuel.

Préfloraison. Position absolue on relative des parties de la fleur dans le bourgeon.

Primine. Membrane propre la plus extérieure de l'ovule.

Prompt bourgeon. Bourgeon qui se développe immédiatement après sa formalion.

Procombant. Voir Couché.

Proventif. Bouryeon axillaire qui ne produit pas de rameau exlérieur et reste à l'état d'ocil dormant pendant un temps plus ou moins considérable, ne s'allongeant annuellement que par sa base, afin de ne pas être séparé du corps ligneux par les accroissements qui l'enveloppent annuellement. Sous l'action de certaines circonstances, ces bourgeons peuvent se ranimer et ce sont eux qui produisent le plus souvent les rejets et les braiches gourmandes.

Pruineux. Couvert d'une efflorescence semblable à de la poussière.

P'ulérulent. Diminutif de pubescent.

Pubescent. Garni de poils mous, assez courts, peu serrés, semblables à du duvet.

F*ulvérulent. Paraissant couvert de poussière ou semblable à de la poussière. 
Tace. Variélé devenue héréditaire.

प्Racine. Portion inférieure d'un végétal qui se dirige de haut en bas et s'enfonce dans le sol pour fixer et nourrir la plante.

Radicant. Tige ou branche rampante qui s'enracine de distance en distance.

Badicelle. Portion jeune et grêle de la racine, qui se termine par le chevelu.

Fisadicule. Extrémité inférieure de l'embryon, qui n'est autre que le premier bourgeon à racine.

Ramean. Division de la branche.

Thamule. Rameau de la dernière année.

Rampant. Voir Radicunt.

Rayous médullaires. Lames rayonnantes de lissu cellulaire, qui se trouvent dans tous les bois, mais varient beaucoup, suivant les essences, en épaisseur, en longueur, en hauteur. Ce sont les rayons qui produisent, par un débit convenable, les bois maillés.

réceptacle. Extrémité du pédoncule sur laquelle s'insèrent les parlies de la fleur.

IRéféchi. Recourbé vers la terre.

Rtégulier. Appliqué à la fleur indique que chacun de ses verlicilles est formé de parties semblables et symétriquement disposées.

Iféuiforme. Feuille, foliole, graine, elc., plus large que Iongue, en forme de rein ou de croissant dont les sommets sont largement arrondis et dont le point d'insertion est au milieu du bord concave.

TRéticulé. Etat d'une surface couverte d'un réseau saillant de nervures.

FRytidome. Portion exléricure de l'écorce, morte et desséchée, parce qu'elle ne reçoit plus de séve, séparée qu'elle est de la région intérieure active par l'interposition de lames ou de couches plus ou moins épaisses et plus ou moins nombreuses de lissu subéreux imperméable (périderme interne). Le mol de rhytidome, proposé par M. Hugo Mohl m'a paru devoir être adoplé, parce qu'il désigne une région bien définie de l'écorce.

Tosacée. Corolle régulière, composée de bै pélales libres et élalís dès la base.

Eotacé. Corolle à tube presque nul et à limbe étalé, régulier, ressemblant à une corolle rosacée dont les pétales seraient légèrement soudés par la base. Se dit aussi du calice.

Togueux. Etat d'une surface ridée et raboteuse.

Samare. Fruit sec, jndéhiscent, uniloculaire, au moins par avortcment, monosperme et pourvu d'une expansion foliacée ou membraneuse.

Sarcocarpe. Nom de la portion intermédiaire du péricarpe, lorsqu'elle devient charnue.

Sarmenteux. Tige ligneuse longue et grêle, sans direction déterminée, couchée ou grimpante.

Scabre. Rude au toucher.

Searieux. Nince, sec el translucide.

Sépale. Nom des folioles qui composent le calice.

Sépaloide. De la consislance foliacée et de la coloration verle des sépales. 
Septicide. Mode de déhiscence d'une capsule dans laquelle les cloisons se dédoublent, de sorte que chaque valve, en tombant, en emporte une moitié sur clıacun de ses bords.

Séqué. Divisé jusqu’à la nervure médiane.

Serré ou denté en scie. Bordé de dents aiguës, dirigées vers le sommet.

Sessile. Inséré saus l'intermédiaire d'un support.

Sétacé. Semblable à un poil, à une soie.

Simple. Se dit d'une feuille dont le limbe est tout d'une pièce et dont les divisions, quelque profondément séparées qu'elles soient, ne sont jamais entièrement indépendantes, comme le sont les folioles d'une feuille composée.

Sinué. Contour modifié par des échancrures peu profondes et des lobes peu saillants, les unes et les antres étant arrondis.

Sinus. Echancrure qui sépare deux lobes.

Suns-arbrisseau. Arbrisseau de petite taille, ne dépassant pas $1^{\mathrm{m}}$ de hauteur.

Soyeux. Etat d'une surface couverte de poils couchés et plus ou moins bri lants.

Spathe. Bractée très développée et enroulée sur elle-mème en cornet, s'ouvrant au sommet pour meltre en liberté l'inflorescence qu'elle renferme.

Spatulé. Limbe élargi en spatule à l'extrémité.

Sperme (nono-, bi-, poly-, multi-). Qui contient une, deux, plusieurs ou beaucoup de graines.

Spinescent. 'Terminé en épine.

Spiralé. Les feuilles qui ne sont ni opposées, ni verticillées, sont spiralées, c'est-à-dire que par leur base on peut tracer autour du rameau une spirale régulière qui les réunit tontes. (Voir Indice d'insertion.)

Siuammiforme. En forme d'écailles.

Stigmate. Extrémité papilleuse du style, destinée à fixer le pollen sur l'organe femelle.

Stipité. Inséré par l'intermédiaire d'un support.

Stipulacé ou stipulaire. Qui provient d'une stipule.

Stipules. Petils appendices, tautòt foliacés et persistants, tantôt ćcailleux el callucs, qui se trouvent souvent de chaque côté de la base du pétiole.

Strobile. Voir Cône.

Style. Portion du carpelle qui unit le sligmate à l'ovaire.

Sub. Placé devant un mot signifie presque.

Subéreux. De la nature du liége.

Subulé. Linéaire et terminé en pointe rigide comme une alène.

Supère. Le calice supere est celui dont le tube est soudé avec l'ovaire et dont le limbe libre couronne ce dernier. L'ovaire supère est libre et insérć au-dessus du ealice et des élamines.

Buture. Ligne suivant lag̣uelle deux parties se sont soudées. Dans un ovaire simple on nomme sucure ventrale la ligne suivant laquelle les bords de la feuille carpellaire, destinée à en former les parnis, se sont réunis. Cette suture ventrale est naturellement opposée à la nervure 
médiane, que l'on nomme souvent par extension sulure dorsale; c'est elle qui supporte les graines. Dans un ovaire pluriloculaire, les sutures ventrales, ramenées vers le centre, ne peuvent être visibles, mais on en aperçoit d'autres qui résultent de la réunion des carpelles adjacents et que l'on appelle sutures lalérales; elles alternent nécessairement avec les nervures ou sutures dorsales.

Syncarpé. Fruit formé de plusieurs carpelles provenant d'une même fleur et soudés entre eux.

Tétra-. Quatre ou quatre fois.

Tétramère. Se dit d'une fleur dont les verlicilles, au moins les extérieurs, sont formés de quatre parties.

Thyrse. Inflorescence ovoüde dans l'ensemble, formée d'un axe primaire allongé, Ic long duquel sont insérés des axes secondaires, simples ou rameux, dont les moyens sont les plus longs.

Tige. Ce mot ne convient à la rigueur qu'à l'axe primaire des plantes, produit de la tigelle, allongée annuellement par les bourgeons terminaux; on l'applique usuellement à l'axe principal de tous les végélaux, qu'ils proviennent de graines, de rejets, de drageons, etc.

Tissu fibreux. Voir Fibre.

Tomenteux. Couvert de poils crépus, serrés et entremêlés en une sorte de feutre.

torulenx. Garni de nœuds suivant sa longueur. Les coussinets rendent souvent les rameaux toruleux.

Traçant. Direction d'une racine latérale qui se prolonge au loin sous la terre sans s'y enfoncer beaucoup.

Tri- Trois ou trois fois.

Fronc. Tige des végétaux dicotylédonés ligneux; sa forme est celle d'un cône renflé vers le milieu.

Thbe pollinique. Le grain de pollen se prolonge en son point de contact avec le stigmate en un tube qui pénètre dans cet organe el de là suit le style pour parvenir aux ovules qu'il féconde par sa fovilla.

Turbiné. En forme de toupie ou de poire.

Uni-. Exprime l'unité.

Urcéolé. En forme de bourse renflée en son milieu.

Vacuole. Petıte cavité sphérique ou ellipsoïle qui se forme dans l'écorce de cerlains conifères et contient de la térébenthine.

Vaisseaux. Tubes, de la naturt des fausses trachées, qui se trouvent disséminés, soil solitaires, soit groupés par faisceaux, au milieu du tissu fibreux de tous les bois feuillus. Leur diamètre, beaucoup plus grand que celui des fibres, les fait reconnaitre très-aisément sur une section transversale, soit à l'oeil nu, soit à l'aide de la loupe.

Salve. Portion séparée, par la déhiscence, du péricarpe d'un fruil, de la paroi d'une anthère.

Gariation. Modification de l'espèce plus légère encore que celle qui constitue la variété.

Variété. Modification de l'espèce qui généralement ne se perpétue pas ou ne se maintient qu'autant que les circonstances qui l'ont fait naître persistent. Il eu est cependant qui semblent devenir indéfinimeat héréditaires.

Veines et veinules. Ramifications extrèmes des nervures. 
Velonté. Couvert de poils dresiés, courls el serrés comme ceux du velours.

Velu. Garni de poils longs, doux, un peu obliques.

Verrupueux. Garni de verrues.

Verticille. Ensemble de parties disposées circulairement autour d'un axe.

Verticillé. Disposé en verlicille.

Volubile. Tige grimpante qui s'enroule aulour d'un support suivant une spirale dont la direction est constante pour chaque espèce; on se suppose en son centre pour la déterminer. 


\section{FLORE FORESTIÊRE}

\section{TABLEAU}

DES PRINCIPALES DIVISIONS DU RİGNP VÉGtitaL. 


\section{TABLEAU DES PRINCIPALES}

\section{EMBRANCIIEMENTS.}

\section{DIVISIONS.}

Embryon di-multicotylédoné. 'Tige composée de 2 systèmes distincts, l'un cortical, l'autre ligneux; ce dernier Dicotrlédonées... s'accroissant à la périphérie par couches concentriques.

Embryon monocotylidoné.Tige non séparable en zone ligneuse et en zonel corticale, formée

\section{Plantes sans fleurs véritables, dépourvues d'étamines, de carpelles ou d'ovules.}

Eimbryon simple sans organes distincts, réduit ì ure cellule unirgue

(spore).

de faisceaux épars, sans canal et sans rayous médullaires.
Fleurs à périgo double, simple, rarement nul. Ovules contenus dans un ovaire; embryon di-cotylédoné. Bois pourvu de vaisseatux.

Feuilles à nervur généralement rameuses, à limb habituellement b développé.

Bois fouillus.

Fleurs unisexuce nues, amentacé ovules nus, nor. renfermés dans

ovaire ; embryc di-multi-cotylédo: Bois dépourvu e vaisseaux. Fenill squammiformes aciculaires, généralement persistantes.

Bois résineux Arbres verts. 


\section{SIONS DU REGNE VÉGÉTAL.}

3-DIVISIONS.

CLASSES.

ORDRES.

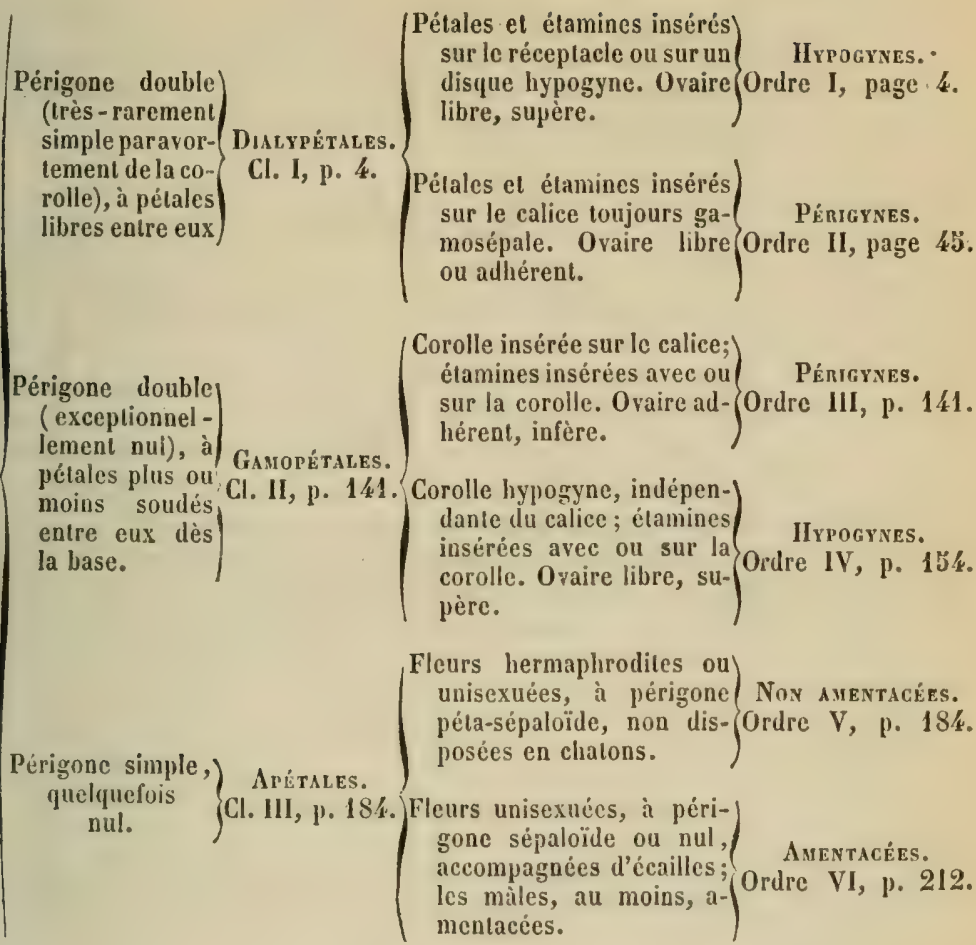

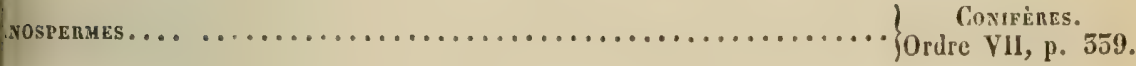

jue renferment pas de vigélaux ligneux indigenes. 


\section{DIVISION I.}

\section{DICOTYLEDONGES.}

Embryon di-multi-cotylédoné ; lige rameuse, forméc d'un système lıneux et d'un système cortieal distincts ; le premier s'accroissant à la périphérie par couches concentriques et offrant un conal et des rayons médullaires.

\section{S0US-DIVISI0N I.}

\section{DICOTYLÉDONÉES ANGIOSPERMES.}

Fleurs à verticilles généralement pentamères, à périgone double, simple, plus rarement nul. Graines cnveloppées l'un péricarpe; embryon muni de 2 cotylédons opposés. Tige rameuse, dont le bois est formé de fibres, de rayons médullaires, de vaisseaux, souvent aussi de parenchyme ligneux. Feuilles à nervures ordinairement rameuses et anastomosées, à limbe simple ou composí, entières, dentées, lobées, etc., presque toujour's caduques (Bois feuillus).

\section{CLASSE I.}

DIALYPÉTALES.

Fleurs à périgone double (très-rarement simple par avortement de la corolle), à pétales libres entre eux.

\section{ORDRE I.}

\section{DIALYPETALES IIYOGYNES.}

Pétales et étamines insérés sur le réceptacle ou sur un disque hypogyne, sans adhérence avec le calice; ovaire libre, supere. 


\section{ORDRE I.}

DIALYPÉTALES IIYPOGYNES. 
Un ou plusieurs carpelles $\left(\right.$ Étamines indéfinies. $\left\{\begin{array}{c}\text { Plantes herbacées à feuilles alternes, ou ligneu } \\ \text { à verticilles de } 5 \text { parties, contenant plusicura }\end{array}\right.$ libres, formant autant

d'ovaires simples, uniloculaires.

Étamines isostémones. $\left\{\begin{array}{r}\text { Arbrisseaux, rarement herbes, à feuilles alterr } \\ \text { régulières, à étamines paraissant opposées a }\end{array}\right.$

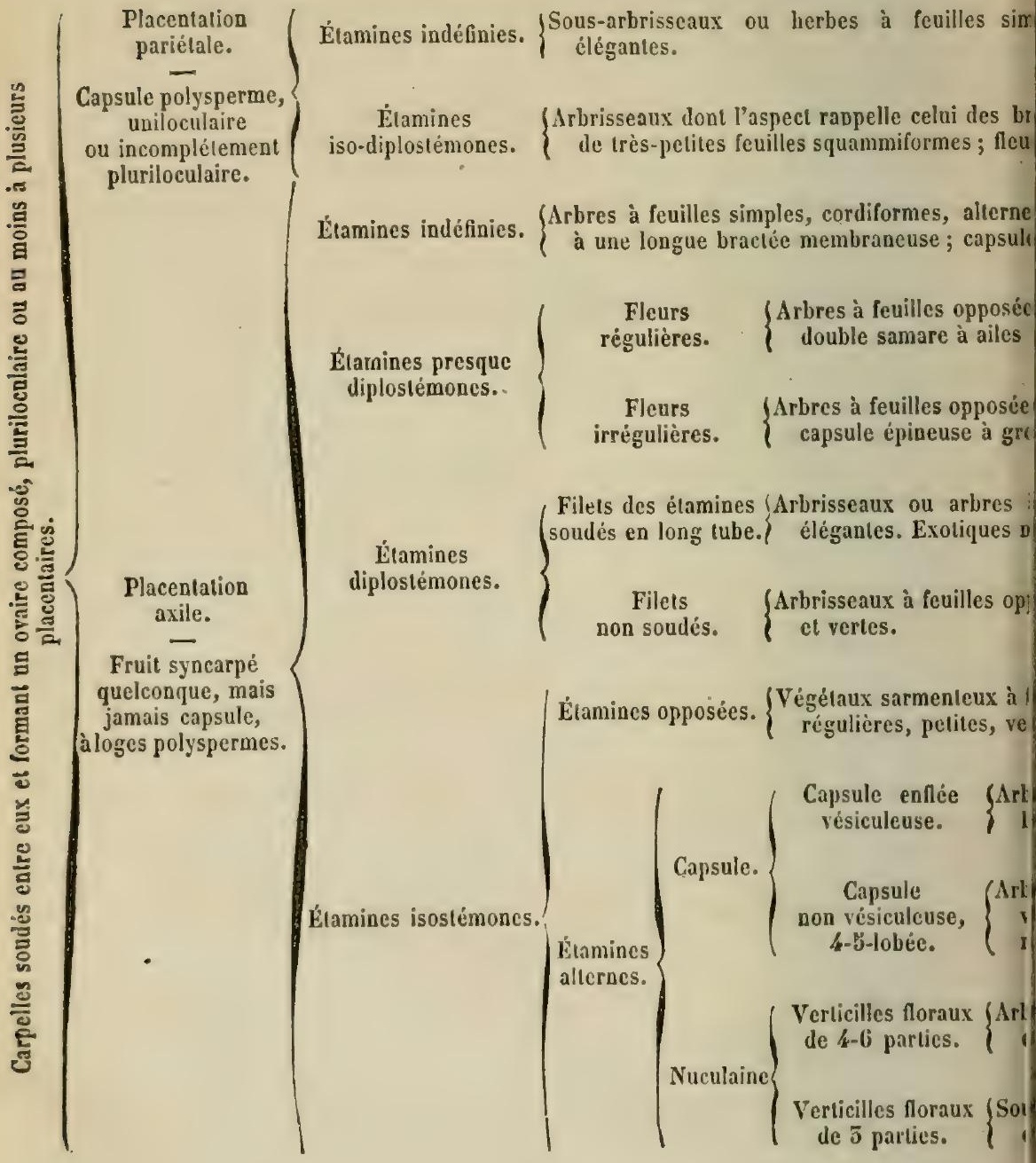




\section{ALES HYPOGYNES.}

lenteuses à feuilles opposécs; fleurs généralement rígulières, $\}$ Rexonctracires.
es libres. $\left.\begin{array}{l}\text { ples ou composées, bordées de fines denis sélacées; fleurs } \\ \text { es et aux sépales, ne contenant que } 1 \text { seul carpellę. }\end{array}\right\} \begin{gathered}\text { Bennérndes. } \\ \text { Fam. II, pase } 9 .\{\text { Epine-vinelte. }\end{gathered}$ resque toujours opposées; à fleurs régulières, grandes, Cistinées. \{Cisle. Fam. III, page 11. Helianthèe.

ou des cyprès, en raison de leur feuillage très-léger, composé\} TAmınısc'xées. \{Tamarix. ères, rosées; semences aigreltées. Fam. IV, page 15.\{.Myricaire:

Irs régulières, blanchâtres, dont l'axe d'inflorescence est soudé) Tı́tacées. te indéhiscente (carcérule).

Fam. V, jage 19.\{Ti!leul.

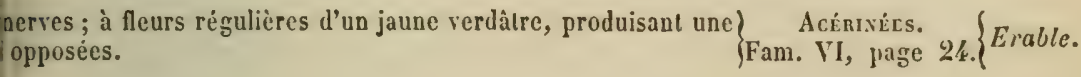
sées-palmées; fleurs irrégulières, cn thyrses dressés, élégants; $\begin{aligned} & \text { HrrocastavéEs. } \\ & \text { ines. Exotiques naturalisés. }\end{aligned}$
Fam. VII, page 52. Marronnier. alternes, composées ou décomposées; à fleurs régulières, $\}$ IIÉlucées.
s. verticillées, simples, entières; à neurs régulières, petiles $\} \begin{gathered}\text { Conaníes. } \\ \text { Fram. IX, page } 36\end{gathered}$ Corroyère.

Iernes, simples, palminerves, ou composées-palmées; à fleurs Ampélidées. inflorescences oppositifoliées. Fam. $\mathrm{X}$, page 57. $\{$ Vigne. à feuilles opposées, composées-pennées; à fleurs régulières,
produisant des capsules dont les graines sont à parois osseuses. F Fam. XI, pagé $59 .\{$ Staphlylier. à feuilles opposées, simples; à fleurs régulières, petiles,
ou brunâtres, produisant une capsule dont les graines soni $\}$ Célastrinées.
l'une arille.

à feuilles alternes, coriaces, persistantes, simples, ordinairement l lacınéEs. ; ì fleurs régulières, petiles el blanches. Fam. XIII, page 42.\{Houx.

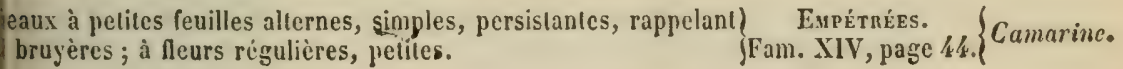




\section{$-8$ \\ FAMILLE I. \\ REXONCULACfES. JUSS.}

Fleurs hermaphrodites, généralement régulières; calice de 3-6, le plus somvent de כ̌ sépales carlucs; corolle d'autant de pétales, quelquefois nulle et représentée par un calice pétaloüde; étamiues inclíinies, à authères introrses ou extrorses, s'ouvrant par 2 fentes; plusieurs carpelles lihres, rarement un scul, produisant autant de fruits distincts, indéhiscents monospermes (akiènes), déhiscents oligospermes (follicules) ou charnus polyspermes; graines pourvues d'un périsperme.

Plantes herbacées, rarement ligneuses, à feuilles preague tonjours alternes (opposées dans les espèces ligneuses indigines), non : tipulées, à jétiole presque engainant à la hase, à sucs àcres, souvent toxiques, géuéralcment volatils et disparaissant par la dessiccalion.

\section{gexre UNiQue. - CLEMATITE. CLEIIATIS, Lin.}

Calice pétalü̈le, rígulier, \{-วั-sćpalé ; corolle nulle; anthères extrorses; carpelles nombreux, lilres, uniovulés, produisant autant d'aliène's monospermes, terminé par le style acerescent en longue arète sonvent plumense; fenilles opposées. - Végétans rarement herbacés, habituellement ligneux, et sarmenteux, ì bourgeons très-petits, abrités par une seule écaille.

Buis très-lécer, à couches lestomenes; vaisseaux dominants; les uns, très-gros, it canal continu, formant une large zone interne; les antres, petits, externes; rayons peu nombreux, larges, inégaux, indélinis, hauts.

Les climatites ont de longues tiges gríles et sarmenteuses, qui enlacent les autres virgetaux et s'y fixent par les pétioles qui s'enroulent comme des vrilles. Elles conrent quelquefois des espaces aseez grands et entravent la végétation des plants yuelles dominent. Vertes, leurs feuilles sont résicantes, rénénenses pour le bétail; desséchées, elles peurentedre employées sans ineonvénients comme fourage:

A. Fleurs difpourvues d'involucre, en pranicules.

B. Liteurs il sépales tomenteux sur les deux faces; feuilles à nervares barbues.......... C. nes nues. 1. 
$B^{\prime}$. Sépales glabres en dedans; feuilles entièrement glabres............................ Flawmule. 2 $\Lambda^{\prime}$. Fleurs munies d'un involucre de 2 bractées, solitaires......................... C. cinneusz. 5

§ I. Fleurs dépourvues d'involucre, en panicules.

1. Clématite des haies. Clematis vitalba. Lin. Ilerbe-auxgueux; Bois a fumer; Liane.

Feuilles oppositi-imparipennces, de 5-9 folioles longuement pétiolées, ovales-aiguës, cordiformes à la base, entières ou incisées par quelques forles dents, barbues sur les nervures. Fleurs inodores, à 4 sépales blancs, oblongs, tomenteux sur les deux faces; slyles accrescents, contournés, plumeux, terminant les akènes. - Plante longuement sarmenteuse (son nom de Vitalba est la contraction des mots vitis alba, vigne blanche), à écorce grise, fibreuse, el à bois très-léger, gris-jaunâtre. Commune dans les bois, les haies, les broussailles, particulierement sur les terrains calcaires. Flor., juin-juillet. Fructif., octobre.

2. Clématite flammile. Clematis flasuula. Lis. Clémalite odo. rante.

Feuilles simplement ou doublement pennées, à folioles ovales ou lancéolées-linéaires, entières, glabres. Fleurs odorantes à 4 sépales blancs, oblongs, pubescents en dehors, tomenteux sur les bords, glabres en dedans; akènes surmontés d'une arète plumeuse. - Plante sarmenteuse et grimpante comme la précédente, mais plus grèle dans toules ses parties; commune dans la région des oliviers; Corse et Algérie. Flor., juillet-août. Fructif., octobre.

§II. Fleurs munies d'un involucre de 2 bractées, solitaires.

3. Clématite cirrhense. Clematis cinnirosa. Lir.

Feuilles fasciculées, très-variables, ovales-aiguës, cntières, dentées, lobées ou tri-séquées, à segments pétiolulés et à 5 lobes incisés-dentés. Fleurs grandes, blanches, odorantes, axillaires, solitaires et pendantes, plus ou moins longuement pédicellées all-dessus d'un involucre en coupe, formé de 2 braclées soudées entre elles; 4 on 5 sépales glabres en dedans, velus en dehors; akènes surmontés d'une arêle plumeuse. Plante à liges sarmenteuses très-grèles. Iaies et buissons du litloral en Corse; Algérie. Flor., juin-juillet.

\section{FAMILLE II.}

Berbéridées. Vent.

Fleurs hermaphrodites, régulières ; calice, corolle et androcée formés chacun d'un double verticille de 3 partics alternantes, cn tout de 6 verticilles simulant 3 verticilles de 6 parties oppo- 
sées; anthères biloculaires, déhiscentes par une valve qui se soulève de bas en haut; 1 seul carpelle, produisant un fruis sec on charnu, 1-3-sperme. Graine pourvue d'un périsperme. - Végétaux herbacés ou ligneux, à feuilles simples ou compesẻes, bordées de dents sétacées; bourgeons nus.

\section{geNae UงıUg. - ÉPINE-VINETTE. BERBERIS Lin.}

Un involucre de 3 petites bractées sous le calice qui est pétaloïle; 2 glandes à la base de chaque pétale ; fruil bacciforme; 2-3-sperme. - Arbrisseaux à feuilles simples, caduques, alternes ou fasciculées (par avortement des rameaux), dont la nervure médiane est seule dominante et produit immédiatement des veines finement réticulées.

Bois homogène, jaune vif, légèrement brunâtre au cœur. Fibres petites; vaisseaux fins, décroissant insensiblement en grosseur et en nombre du lord interne au bord externe, épars ou disposés peu visiblement en lignes simples réticulées; parenehyme nul; rayons médiocrement larges, indéfinis.

A. Feuilles fasciculées à l'aisselle d'une épine plus courte qu'elles; fruit rouge ............... E. соммunz.. 1 $A^{\prime}$. Feuilles fasciculées à l'aisselle d'une forte épine plus longue qu'elles; fruil noir bleuâtre...... E. DE. L'ETNa. 2

1. Épine-Vinerte comumune. Berneris rulgaris. Lin. Vinellier.

Feuilles obovales, obtuses, atténuées à la base en un court pétiole, dentées-sétacées, glabres, alternes sur les pousses qui s'allongent ou fasciculées à l'aisselle d'une épine élalée plus courte qu'elles; celle épine simple, tri-multipartite, s'élargit souvent dans les parties inférieures des rameaux en un limbe sec et membraneux. Fleur's jaunes, en grappes latérales multiflores, pendantes, sortant du centre des rosettes de feuilles, à odeur fade. Fruit bacciforme, oblong et rouge. - Arbrissean de 1-2n', dont les tiges nombreuses dès la base, dressées, faseiculées, grises et légèrement cannelées, sont armées d'épines grêles dues à des feuilles transformées. Haies el bois de toute la France, particulièrement dans les sols calcaires. Se retrouve sur quelques poinls de l'Algérie. Flor., maijuin. Fructif., octobre.

L'épine-vinette commune, sans avoir une véritable importance forestière, n'est pas dépourvue de tout intérèt. Le bois et surtout le liber de sa souche et de ses racines contiennent abondamment une matière tinctoriale d'un jaune vif, la berbérine, employéc quelquefois dans l'industrie; les feuilles renferment du bioxalate de potasse qui leur donne la saveur acide de l'oseille; les fruits murs ont un goù aigrelet agréable, du en partic à de l'acide citrique; l'on 
en fait des conserves estimées et les confiseurs les emploient. Enfin le bois, malgré ses faibles dimensions, et en raison de sa belle couleur jaune, peut servir à la marqueterie. Complétement desséché à l'air, du bois d'une tige de 60 ans et de 8 centimètres de diamètre a donné en densité : 0,92 ; d'une tige de 23 ans et de 5 centimètres de diamètre : 0,73 . (Coll. Ec. for.)

Les étamines sont très-irritables; lorsqu'elles sont étalées, il suffit d'en exciter très-légèrement la base, avec la pointe d'une épingle, pour qu'elles se redressent brusquement contre le stigmate.

2. Wine-Winette de l'Etua. Berberis Annensis. Rozm. zt Scirvir. B. eretica Viv. Duby.

Feuilles ovales oblongues, en faisceaux à l'aisselle d'une forte épine 5-5-partite plus longue qu'elles. Fleurs jannes, en grappes panciflores dépassant à peine les feuilles. Fruits oblongs, d'un noir bleuâtre à la maturité. - Arbrisseau de 5-6 décimètres, très-rameux, à rameaux flexueux décombants. Région montagneuse de la Corse et de l'Algérie (bjurdjura). Flor., mai-juin.

FAMILLE III.

CISTINÉE. Juss.

Fleurs régulières, hermaphrodites; calice persistant ì 5 ś sépales, dont 2 extérieurs plus petits, quelquefois plus grands que les 3 intérieurs, ou nuls; corolle rosacée, fugace, de 5 pétales; étamines indéfinies; ovaire formé de $3-10$ carpelles, à cloisons nulles ou incomplètes et à placentation pariétale; capsule polysperme. - Plantes herbacées ou ligneuses, à feuilles simples, croissant dans les lieux secs, découverts et rocailleux et appartenant presque toutes à la flore méditerranéenne.

A. Capsule à $5-10$ valves............. Genar 1. Cistz.

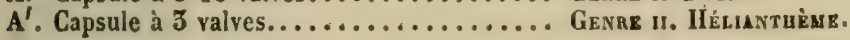

genRe I. - Ciste, cist US. Lin.

Calice 3-5̌-sépalé; capsule incomplétement 5 -10 loculaire, à déhiscence loculicide, très-rarement septicide. - Sous-arbrisseaux à tiges ligneuses, très-rameuses, dont les plus grandes espèces atteignent $1^{\mathrm{m}}-1^{\mathrm{m}} \mathrm{j} 0$ de hauteur au plus, à fevilles opposées non stipulées, à fleurs toujours dressées après la floraison, de 3-8 centimètres de diamètre, élégantes, blanches, roses, purpurines ou jaunes. 
Bois très-dur, très-compacte et très-lıomogène, blanc passanı an rougeâtre assez vif au cour, marryué de taches plus foncces dues à des formations de tissu cellulaire; tissu fibreux dominant, ì fibres petites, serrées, dont les parois sont très-épaisses; vaisseaux rarcs, égaux, fins, isolés, presque uniformément séparlis; rayons très-fins, indéfinis.

Du bois de ciste ladanifère, d'une tige de 28 ans et de 6 centimètres de diamètre, complétement desséché à l'air libre, a donné 1,21 de densité. (Coll. Ec. for.)

Plusieurs cistes sont aromatiques ct excrètent par leurs jeunes pousses et leurs feuilles une gomme-résine odorante, connue sous le nom de Ladanum et utilisée en pharmacie; la récolte en est négligée en France.

A. Calice de 5 sépales. - Fleurs blanches, style très-court, capsule loculicide.

B. Feuilles pétiolées; pédoncules velus; capsule כ้-loculaire............. C. A FeuLles Dz LAขRER. I

B1. Feuilles subsessiles; pédoncules glabres et glutineux; capsule 10-locu-

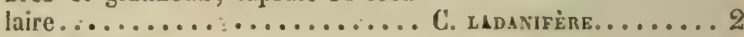

^'. Calice de 5 sépales.

B. Sépales extérieurs un peu plus petits que les intéricur's; slyle allongé; capsule b-loculaire, loculicide.

C. Feuilles pétiolées. - Fleurs roses. C. buavchatra...... 5

$C^{\prime}$. Feuilles sessiles.

D. Feuilles planes, grises-tomenteuses sur les 2 faces. Fleurs roses.................. cotonneux....... \&

$D^{\prime}$. Feuilles crispées sur les bords, au moins les inférieures.

E. Toules les feuilles crispées, fleurs purpurines........ C. cnéru.......... \&

$\mathbf{E}^{\prime}$. Feuilles, inféricures seulement, crispées; fleurs blanches............... C. de Pouzolz.......6

B'. Sépales exléricurs plus grands que les intéricurs; style très-court.

C. Capsule loculicide, b-loculaire.

D. Feuilles sessiles; fleurs jaunes. C. uḱrıssḱ........7

$D^{\prime}$. Feuilles pétiolées.

E. Rameaux floraux munis ì la base de braclées écailleuses.

F. Feuilles à pétiole non ailé; fleurs d'un blanc jau-

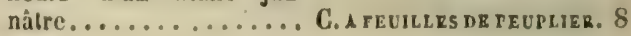


F1. Fenilles à pétiole court et ailé; fleurs blanches.... C. A lovgues fevilues.. 9

E'. Rameaux floraux dépourvus à

la base de bractées écail-

leuses.

F. Feuilles rugueuses ot grisâtres en dessus; lleurs jaunâtres............. C. A FRULLLES DE SAUGR. 10

$F^{\prime}$. Feuilles verles, glabres et luisantes en dessus; fleurs blanches............ C. xénox........ 11

C. Capsule seplicide, par le sommet seulement. - Feuilles sessiles; fleurs blanches............. C. oe Montreldier. . 12

\section{\$1. Calice de 3 séprales, par avortement des 2 extérieurs.}

1. Ciste à fenilles de Kaurier. Cistus laurifolius. Lin.

Feuilles pétiolées, ovales-lancéolées, lisses el glabres en dessus, blanches-soyeuses en dessous dans la jeunessc. Fleurs blanches, trèsgrandes, en ombelles ou cn corymbes, à pédoncules velus; styles trèscourls. Capsule "j-loculaire, loculicide. - Sous-arbrisseau de $1^{\mathrm{m}}$ el plus d'élévation, à lige rameuse d'un rouge-brun, glabre inférieurement, à rameaux poilus. Collines sèches de la France méridionale, Flor., juin.

2. Ciste ladanifìre. Cistus ladatiferus. Liw.

Feuilles subsessiles, lancéolćes-linéaires, lisses, galabres el visqueuses en dessus, blanchitres-lomenleuses en dessous. Fleurs très-grandes, blanches, à style très-court, ordinairement solitaires sur des pedoncules glabres et glutineux. Capsule loculicide, 10-loculaire. - Sous-arbrisseau de 1 in à $1 \mathrm{~m} 30$, à tiges brunes, gercurées, écailleuses à la base, glabres el glutineuses au sommet. Provence, cnvirons de Montpellier; Mlgérie. Flor., juin.

\section{\$II. Calice de 5 sépales, les extéricurs un peu plus petits;} style allongé. Capsile 5-loculaire, loculicide.

3. Ciste blanchâtre. Cistus incanus. Lis.

Fevilles pétiolées, à pélioles dilatés-connés à la base, de forme rariable, spatulées ou lancéolées-aiguës, rugueuses et blanches-cotonneuses, surtout en dessous. Fleurs grandes, roses, 1-5 en ombelles. - Sous-arbrissean visqueux el très-aromalique, de $1^{\mathrm{m}}$, à liges dressées, rameuses, glabres vers le bas, soyeuses ct blanchâtres vers le haut. Corse. Flor., mai-juin.

4. Ciste cotonneux. Cistus albidus. Liv.

Feuilles sessiles, planes, à bords entiers, ovales-lancéolées, densément grises-fomenteuses sur les 2 faces. Fleurs grandes, roses, solitaires ou en ombelles de $2-5$. - Sous-arbrisseau tuufiu, alteignant à peine $1 \mathrm{~m}$, it écorce de couleur canclie, s'exfoliant en membranes minces; rameaux gris-tomenteux à l'extrémité. Collines sèches et pierreuses du littoral de la Méditerranéc, de Fréjus à Perpignan; Corse el AIgéric. Flor., mai-juin. 
5. Ciste crépu. Cistus crispus. Lir.

Feuilles sessiles, toutes crispées sur les bords, ovales-lancéolées, ré. ticulées-rugueuses, surtout en dessous, à pubescence éloilée. Fleurs assez grandes, purpurines, presque sessiles, réunies 5 ou 4 en ombelle compacte. - Sous-arbrisseau très-odorant, de $0 \mathrm{~m} 30$ au plus de hauteur, à tige dressée, rameuse-lorlucuse, couverte d'une écorce brune; rameaux velus-blanchàtres. Collines sèches des bords de la Méditerranée. Flor., mai-juin.

6. Ciste de Pouzola. Cistus Pouzolzir. Delille.

Feuilles sessiles, les inférieures rugueuses, crispées sur les bords; les supérieures planes, ovales-lancéolées. Fleurs médiocres, blanches, disposées 2-5 en grappe allongée unilatérale. - Sous-arbrisseau de 2-5̆ décimètres, à rameaux gris-tomenteux. Alais, Montpellier, Narbonne, etc. Algérie. Flor., juin.

\section{\$ III. Sépales extérieur's plus grands que les intérieurs. Style très-court; capsule loculicide, 5-loculaire.}

7. Ciste hérissé. Cistus minsurus. Lair.

Feuilles sessiles, lancéolées-aiguës, planes et non crispées sur les bords, ciliées, vertes, presque glabres sur les 2 faces. Fleurs très-grandes, toujours dressées, mème avant la floraison, jaunes, disposées $2-30$ en grappe allongée unilatérale. - Sous-arbrisseau de 0 mb0 au plus, odorant, à tige dressée très-rameuse, noirâtre, poilue-tomenteuse supérieurement. Bretagae auprès de Landernau; échappé d'un parc voisin où il est cultivé; originaire d'Espagne. Flor, , juillet.

8. Ciste a feuilles de peuplier. Cistus populifolius. Lix.

Feuilles pétiolées, à pétiole non ailé, corliformes-aiguës, à bords presque ondulés, glabres, lisses el vertes en desasus, réticulées en dessous. Fleurs très-grandes, d'un blanc jaunâtre, penchées avant la floraison, 1-4 en corymbe dont l'axe est muni à la base de larges bractées écailleuses, obovales. - Sous-arbrisseau de $1^{\mathrm{m}}$ à $1^{\mathrm{m}} \overline{\mathrm{j}} 0$, à tige rameuse, rameaux bruns, cassants, glabres. Languedoc, Montagnes des Corbières, Montagne noire (Aude). Flor., juin.

9. Ciste à Ionguer fenilles. Cistus lovgifolius. Jam.

Feuilles à pétiole court et ailé, oblongues-tancéolées, à bords ondulés, glabres en dessus, réticulées-tomenteuses en dessous. Fleurs toujours dressées, mème avant la floraison, grantes, blanches, 5-b̆ en corymbe dont l'axe est muni à la base de bractées lancéolées, écailleuses. Sous-arbrisseau de $1^{\mathrm{m}}$ à $1^{\mathrm{m}} \mathbf{3} 0$, a tige raneuse, lorluense, noire el glabre jusqu'aux extrémités. Montagnes des Corbieres près de Narbonue. Flor., juin.

10. Ciste it feuilles de sauge. Cistcs salviefolius. Iix. Miouzes (Languedoc).

Feuilles pétiolées, rugueuses el grisâtres en dessus, blanchìlres-l0menteuses en dessons, ovales-subaiguës on obovales-obluses. Fleurs grandes, jaunàtres, peuchées avaut leur épanouissement, sulitaires ou 
par 2 au sommet de longs pédoncules dépourvus de bractées écailleuses à la base. - Sous-arbrisseau de $0 \mathrm{~m} 50$ au plus, balsamique, très-rameux, diffus, à tiges glabres, finement verruqueuses, d'uu brun-canelle ; rameaux tomenteux supérieurement. Collines sèches et picrreuses du midi; remonte à l'est jusqu'à Lyon, à l'oeıest jusqqu'à la Rochelle. Corse et Algérie. Flor., mai-juir.

11. Ciste lédon. Cistus lebon. Lay.

Feuilles à pétiole élargi, vertes, glabres et luisantes en dessus, veluessoyeuses et réticulées en dessous, oblongues-lancéolées, à bords crispés. Fleurs moyennes, toujours dressées, mème avant la floraison, blanches, en corymbes de 3-10, dont l'axe commun est dépourvu à la base de bractées écailleuses. - Sous-arbrisseau de 8 décimètres, à odeur forte et balsamique, souvent visqueux, très-rameux; rameaux noirs et glabres iџférieurement, velus à l'extrémité. Provence el Languedoc. Flor., mai-juin.

§IV. Sẻpales extérieurs plus grand̋ que les intérieurs; style très-court; capsule septicide, ì 5 valves déhiscentes au sommet seulement.

12. Ciste de Wontpellier. Cistus Murspelensis. Lis.

Feuilles sessiles, lancéolées-linéaires, à bords enroulés en dessous, crépues, vertes et légèrement velues sur les 2 faces. Fleurs médiocres, blanches, 2-5 en grappes allongées unilatérales. - Sous-arbrisseau de $1^{\mathrm{m}}$ et plus, à lige rameuse, brune, visqueuse el poilue au sommet. Lieux arides de la France méridionale; Corse et Algérie. Flor., juin.

GRNRE I1, - HÉLIANTIĖME. HELIANTHEMUM. Tournef.

Calice de 3-ò sépales; capsule incomplétement 3-loculaire, loculicide. - Petits sous-arbrisseaux de 1 à 2 décimètres de hauteur ou herbes, à feuilles généralement stipulées, fleurs ordinairement penchées après l'épanouissement, blanches ou jaunes, plus petites que celles des cistes.

Particulièrement abondants dans les lieux secs et découverts du midi de la France, les hélianchèmes, par l'exiguité de leur taille, méritent à peine de prendre rang parmi les végétaux ligneux et leurs nombreuses espèces ne seront pas décrites ici.

\section{FAMILLE IV.}

rayariscrnées. A. St Hil.

Fleurs régulières, hermaphrodites; calice gamosépale à 5 divisions; corolle de ¿ pétales marcescents; étamines 5 ou 10 , plus ou moins monadelphes à la base, insérées sur le réceptacle 
ou sur un disque hypogyne; anthères introrses, biloculaires, longitudinalement déhiscentes. Ovaire 1-loculaire, multiovulé, ì placentation pariétale, produisant une capsule jolysperme à 3 valves, dont chacune porte au milieu de sa base un placentaire cuurt ou allongé. Graines aigrettées, sans périsperme. - Arbrisscaux et quelquefois arbres entièrement glabres, ì rameaux cflilćs, allongés, ramules très-grêles, feuilles très-petites, éparses, caduques, embrassantes-squammiformes et imbriquées, leur donnant l'aspect des cyprès. Bourgeons nus. Fleurs petites, rosées, en grappes simples, cylindriques, nombreuses.

Bois blanc, blanc jaunâtre, passant au cœur au rose rougcâtre assez vif, demi-lourd, demi-dur. Tissu fibreux dominant; vaisseaux inégaux, assez gros au bord interne, décroissant en grosseur et en nombre jusqu'au bord externe, où ils sont petits; faiblement groupés en courtes lignes irrégulières, disposíes entre elles par zones concentriques, surtout apparentes ì la limite extrëme des accroissements. Rayons aljondants, médiocrement épais, courts et en fuseau ou indéfinis.

Les tamariseinées offrent beaucoup d'anologies avec les saules par leur mode de végétation, par leurs fruits capsulaires, leurs graines nombreuses, petites, aigrettées, par leur station au bord des eaux, par leur facile reproduction de boutures. Ils se trouvent particulièrement sur les sols sablonncux du littoral de la Méditerranée, de l'Océan et le long de certains cours d'eaux; en Algéric ils boisent parfois à eux sculs des surfaces considérables. Leur rapide eroissanec, leur abondante reproduction par semenees et rejets, la réussite certaine des boutures les rendent très-propres à consolider les sables mobiles, à fixer les attérissements des fleuves et des deltas. Cependant la fragilité de leur bois ne leur permet pas de résister, sans abri, aux vents violents qui viennent de la mer. On les cultive souvent comme arbrisscaux d'ornernent.

L'écoree est astringente et produit un rhylidome libérien assez densément, longuement et profondíment gerẹuré.

A. 3 étamines sur un disque liypogyne; bractíes garêles, ne dépassant pas les fleurs; graines à aigrrelle sessile......................... Tамалих...1

$\Lambda^{\prime} .10$ étamines sur le réceplacle; bractées robustes, débordant les fleurs; graines à aigrelle stipilie..... Mraicara...2 
GENRE t. $^{-}$TAMARIX. TAMARIX. Lin.

Calice כ̋-fide; étamines כ̆, très-courtement monadelplıes ì la base, insérées sur un disque liypogyne; 3 styles; graines à aigrette sessile, fixées au fond de la capsule.

A. Fcuilles étroitement blanches-scarieuses sur les bords; étamines saillantes, à anthères apiculées.

B. Feuilles un peu glaurues; fleurs globuleuses dans le bouton; capsule insensiblement atténuée de la base au sommet........... T'. de Fravce.... i

$\mathrm{B}^{\prime}$. Feuillés vertes; fleurs ovoïdes dans le boulton; capsule brusquement rétrécic au-dessus de la base................. T'. D'Avglemerne. 2

$\mathrm{A}^{\prime}$. Feuilles largement blanches-scarienses sur les bords; étamines non saillantes, à anthères muliques..................... T. D'AFrigue....

直. Tamarix de France. Tamanix gallica. Liv.

Feuilles très-petites, imbriqquées, élargies à la base, acuminẻes, à bords étroitement blancs-scarieux, un peu glauques. Fleurs petiles, rosées, globuleuses dans le bouton, formant le long des ramules de vombreuses grappes simples, grèles, cylindriques, peu denses, constituant dans l'ensemble une sorte de vasie panicule; étamines débordant la corolle, assez longuement apiculées. Capsule insensibjement alléntéc de la base an sommet, [yyramilale. Lilloral de la Méditerranée en France, en Corse, en Algérie; delta du Rliône. Flor., mai-juillet.

Ce tamarix est habituellement un arbrissean d'une vegétation rapide; en Algérie, ou il est abondant, il devient en 20 ans un arbre de $10^{\mathrm{m}}$ de hauteur sur $1^{\mathrm{m}}$ et meme $2^{\mathrm{m}}$ de circonférence. A cet igge il entre en retour et se pourrit rapidement.

Le bois cst cassant, prend beaucoup de retrait et se gerec profondément; il n’a pas de durée.

Il fournit un médiocre combustible et un maurais charbon. L'écorce est astringente et pourrait servir de tan.

2. Tamarix d'Angleterre. TAMAnIX Anglics. WeBB.

Très-voisin du précédent, dont il n'est peut-ètre qu'une variété. Feuilles vertes, un peu rétrécies à la base, acuminóes. Fleurs ovoïdes dans le bouton; étamines débordant la corolle, à anthères brièvement apiculées. Capsule brusquement rétrécie au-dessus de la base qui est ovoìde trigone. - Arbrisseau de mème port que le précédent, mais de moindres dimensions. Commun sur les côtes de l'Ocẻan, de Bayonne à Dunkerque. Flor., juin.

Du hois d'une lige de 28 ans, de 25 cent. de diameire, 
complétement desséché à l'air et provenant de la forèt de Saint-Trojean (lle d'Oléron), pèse 0,7̋̈. (Coll. Ec. for. Envoi de M. Hossari.)

\section{Tamarix d'Afrique. Tamarix Africaya. Poinet.}

Feuilles vertes, largement blanches-scarienses sur les bords, clargies à la base, acuminées. Fleurs plus grandes que daus les espèces précédentes, ovoüles daus le bouton, disposées en grappes simples nombreuses, oblongues-cylindriques, épaisses et serrées le long des rameaux; étamines ne débordant pas la corolle, à anthères obtuses à l'extrémité. Capsule ovoüle trigone, insensiblement alténuée au sommet. - Arbrisseau de $2-5^{\mathrm{m}}$ de hauteur, sur $50-8$ décimètres de tour, à feuillage plus fourni et moins grèle que celui des espèces précédentes. Còtes de la Provence, du Languedoc el de la Corse; commun en Algérie, où il alteint de plus grandes dimensions qu'en France. Flor., juin-aoutt.

Un échantillon provenant d'une tige de 18 ans et de $0^{\mathrm{m}} \overline{3} 0$ de diamètre, d'Algérie, a pour densité 0,59 . (Coll.Ec. for. Envoi de M. Royer.)

\section{genre myricaire. - MYRICARIA. Dese.}

Calice 5-partite; étamines :ั, monadelphes sur les $\frac{2}{3}$ de leur longueur, insérées directement sur le réceptacle. Style nul. Graines à aigrette stipitée, insérées sur la partie inférieure d'un placentaire pariétal.

Ryricaire d'Allemagne. Myrigaru germanica. Desv. Tamarix d'Allemagne. T. germanica. Lin.

Fouilles glauques, linéaires-obtuses, ponctuées. Fleurs roses, pédicellées, en grappes simples, allongées, làches à la base, denses et atténuées au sommet, terminant les ramules et rameaux el formant par leur réunion une panicule resserrée, pyramidale; étamines en 2 verticilles, alternativement plus courles et plus longues, non saillantes. Capsule allongée, lyramidale. - Sous-arbrisseau de 1-2m, très-glauque, à tiges dressées, rameuses, rameaux raides et droits, un peu anguleux. Bords du Rhin; rives des torrents et des rivières du Dauphiné, des Pyrénées centrales, de l'Ariége. Flor., juin-juillel.

Le myricaire d'Allemagne est, dans la région qu'il habite, l'une des premières plantes qui apparaissent sur les attérissements sablonneux que les fleuves déposent le long de leur cours. 


\section{FAMILLE V.}

TILTACÉES. JuSS.

Fleurs hermaphrodites régulières, à 5 sépales caducs, alternant avec autant de pétales; étamines indéfinies, à anthères liloculaires, longitudinalement déhiscentes; ovaire à है loges biovulées, à placentation axile; I style; fruit sec, indéhiscent, uniluculaire, 1-2-sperme (carcérule) par avortement de la plupart des ovules et refoulement des loges moins une; embryon à périsperme charnu, huileux.

geNRE UNIQUE. - TILLEUL. TILIA. Lin.

Mêmes caractères que ceux de la famille. - Arbres de grande taille, à feuilles alternes, cordiformes inéquilatérales, pourvues de stipules écailleuses caduques. Fleurs blanchâtres en corymbes paucillores, dont le pédoncule commun est longuement soudé à la nervare médiane d'une bractée allongée, membraneuse. Bourgeons ovoüdes obtus, revêtus d'écailles herbacées, vertes ou rouges, stipulaires, alternes, dont la deuxième ou la troisième, très-développée, est complétement embrassante et cache les suivantes.

Bois mou et léger, homogène, à accroissements peu distincts, blanc légèrement rougeâtre. Tissu libreux à parois minces, mélangé de cellules ligneuses abondantes (non distinctes à l'oil ou à la loupe); vaisseaux dominants, égaux, fins, isolés ou disposés en séries simples, rayonnantes, à peu prè̀ uniformément répartis; rayons égaux, minces et longs.

Les tilleuls ont une nervation caractéristique, composée de nervures primaires palmées, parmi lesquelles la médiane, qui est dominante, produit des nervures secondaires pennées, droites et fourchues à l'extrémité, et dont les latérales, moins développées, se ramifient du còté inféricur seulement en nervures secondaires simples. Tout ce réscau est relié par des veines disposées en zones concentriques dont la base de la feuille serait à peu près le centre.

L'inflorescence des tilleuls mérite une mention spéciale. Elle nait sous forme de corymbe sur la pousse de l'année même, à la base d'une feuille et à côté du bourgeon préparé pour l'annéc suivante. L'irrégularité de cette double production à une mème aisselle n'est uqu'apparente, ct l'on 
peut constater que l'inflorescence résulte de l'évolution d'un bourgeon floral qui s'est immédiatement développé à la base de la première écaille du bourgeon axillaire normal.

De tous les régétaux indigènes, les tilleuls sont ceux dont le liber est le plus fortement organisé. Ce liber se compose de faiscenux fibreux, anastomosés entre eux en une sorte de réseau dans les mailles duquel se prolongent les rayons, et que séparent des zones régulières et minces de tissu cellulaire; le nombre de ses couches est double de celui des années. A la chute de l'épiderme, vers deux ans, l'enveloppe subéreuse, qui ne fait que s'étendre sans s'épaissir, constitue un périderme lisse jusqu'i $20-40$ ans. A cet àge, l'enveloppe subéreuse et l'enveloppe cellulaire verte se détachent par suite du développement de lames de périderme dans l'épaisseur des fetiillets les plus anciens du liber, et ceux-ci forment un rhytidome (ćcorce extérieure morte) brun, longitudinalement gerẹuré, non écailleux.

A. Feuilles glabres sur les deux faces; aisselles des nervures barbues en dessous de poils roussâtres.

B. Feuilles glauques en dessous; fruit à parois minces et fragiles, à côles non saillantes.................. T. A Petites feuilles.. 1

B1. Feuilles verles sur les deux faces; fruit à parois épaisses et résistantes, à côles saillantes...............

A'. Feuilles mollement velues en dessous, à poils blanchâtres aux aisselles des nervures; fruit à parois épaisses et résislantes, à côles plus ou moins saillantes. T. A Grardes feureces. 5

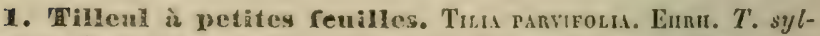
vestris, Desf. T. microphylle, Vent. T. Europce, var. \% Lin.

Feuilles généralement petites, longuement pétiolées, cordiformes-inéquilatérales, brusquement acuminées, aigument dentées en scie, glabres sur les deux faces, vertes en dessus, glaurgues-bleutres 'n dessous, où elles sont garnics aux aisselles de poils roux. Bourgeons de deux écailles apparentes seulement, la deuxiene complétement embrassante. Fleurs petiles, 4-10, en corymbes dressés el acconpagnés d'une bractéc menbraneuse, oblongue, longnement pétioléc; stigmates élalés. Fruils globuleux, gris- (omenteux, a parois mines et fragiles, à côtes peu ou point apparentes. - Grand arbre a cime ovö̈de conique, fortement rameuse. dont les branches inféricures sont étalées horizontalement; à tige élevée et nue en massif, se ramiliant à peu de distance an-dessus du sol à l'état d'isolement. Disséminé dans les bois, particulièrement sur les sols calcaires; quelque:fois planté sur les promenades. Filor., milieu de juillet (quinze juors plus lard que le tilleul i larres feulles). Fructif., velubre. Uisscimination, fin de l'aulonme el hiver. 
Le tilleul ì petites feuilles est un arbre de premiere grandeur, dont le port rappelle assez bien celui du chine rouvre, quoique sa ramification soit plus régulicre, plus fournie, son feuillage plus abondant et plus unilormément réparti ; sa longévité est très-prolongée, son couvert complet. Les rameaux et les bourgeons sont glabres et varient du rouge au brun, du jaune au vert. Un tilleul de cette espèce, planté sur la place principale de Gérardmer (Vosges), mesure $28^{\mathrm{m}} \mathrm{g}: 3$ de hauteur sur $5^{\mathrm{m}} 80$ de circonférence, à $1^{\mathrm{m}}$ du sol; il cube $5 \%$ stères, et son àge est d'au moins 250 ans.

L'écorce est grise et reste lisse jusqu'à 20-50 ans; puis elle se marque de longues et fines gerẹres longitudinales, séparées par de larges intervalles unis, non écailleux. A un àge avancé clle ressemble, rers le pied de l'arbre, à celle des vieux chènes.

La fécondité est précoce et commence rers 20-230 ans; i partir de ee moment, elle se soutient abondante et régulic̀re chaque année. Il faut $46-50000$ fruits sees et débarrassés des bractées et pédoncules pour 1 kil.; les graines seules forment un peu plus de moitié de ce poids. Conservés dans du sable, ces fruits maintiennent leur faculté germinative jusqu'au printemps suivant; semés à celle époque, ils ne germent habituellement qu'au bout d'un an.

Au moment de la germination, le péricarpe devient irrégulièrement déhiscent et le jeune plant se développe à la manière de ceux des conifères, poussant hors de terre son périsperme aminci, qui enveloppe les cotylédons comme d'une coiffe. Ces derniers produisent deux feuilles opposées, grandes, profondément palmati-b’-lobées.

Le plant eroit lentement; vers $50-60$ ans, les aceroissements en hauteur diminuent, mais ceux en diamètre se soutiennent encore pendant très-longtemps. Néanmoins la production du tilleul en futaie reste inférieure à celle du hètre, et, comme il exige des sols de bonne qualité pour prospérer, on doit en conclure que sa culture n'est point avantagcuse.

L'euracinement est profond, étendu; d'une souche considérable partent 2 ou 5 racines principales qui s'enfoncent en terre et produisent de longues et assez fortes racines latérales tracantes. En raison de la difficulté d'extraction, on n’en obtient que $12-15$ p. 0 0 0 du volume superficiel.

Port. Taille.

Ecorce.

Fructificalion.

Germination.

Croissance.

Enracinement. 
Rejels. Exploité en taillis, le tilleul est doué d'une force de reproduction remarquable. Les rejets, nombreux et robustes dans les premières années, prennent naissance en dessous de la section, souvent sur les parties souterraines de la souche. Leurs feuilles, alors grandes et vertes sur les deux faces, ne présentent qu'au bout de 2 à 5 ans les caractères distinctifs de l'espèce. Malgré le rapide développement des premières années, la production du tilleul en taillis ne dépasse pas eelle d'essences à bois beaucoup plus précieux.

Plautation. D'une transplantation facile, mème à un âge avancé, supportant bien la taille, cet arbre est assez souvent planté dans les promenades, quoiqu'on lui préfère pour cet usage le tilleul à grandes feuilles. Ils ont cependant l'un et l'autre l'inconvénient de perdre lcurs feuilles de bonne heure. La reproduction par boutures est difficile.

Station et sol. On rencontre ce tilleul dans les plaines et surtout dans les pays de collines à sol calcaire; il s'élève peu dans les montagnes où il ne dépasse pas l'altitude du chène. Il aime les sols frais, réussit encore dans les sols humides; il redoute ceux qui sont meubles et secs.

Bois. Le bois est léger, mou, homogène, peu durable; mais il travaille et se fend peu, se coupe dans tous les sens sans éclater sous l'outil et n'est que peu sujet à la vermoulure. Impropre aux constructions, il est utilisé par les menuisiers et les ébénistes pour les charpentes des meubles, par les sculpteurs et les tourneurs; on en fabrique des sabots. II pèse, en moyenne : bois de lige de 150 ans, vert, 0,819 ; séché à l'air, 0,472 (T. Ilartig). D'après les expériences du mème auteur, du bois de tilleul de 150 ans, desséché, et d'une densité de 0,472 , comparé à du bois de hêtre de 120 ons, d'une densité de 0,704 et à l'état sec, a donné les chiffres suivants qui expriment sa valeur calorifique.

\begin{tabular}{|c|c|c|c|}
\hline \multirow{2}{*}{ Plus haut degré de chalcur.... } & & & \\
\hline & & & $\begin{array}{l}65, \\
68\end{array}$ \\
\hline \multirow{2}{*}{ Durée de la chaleur croissante.. } & & 77 & $31,6: 10$ \\
\hline & & $100:$ & $67: 10$ \\
\hline \multirow{2}{*}{ Durée de la chaleur décroissante. } & & 81: & 56,5 : \\
\hline & & 100 & \\
\hline \multirow{3}{*}{ Total de la chaleur développée. } & & & \\
\hline & & 107 : & \\
\hline & & $77: 100$ & $51,6: 1$ \\
\hline
\end{tabular}

C'est, en conséquence, un combustible médiocre qui 
prend rang parmi les bois blanes, peupliers et saules, et qui, bien plus avantageux pour le chauflige des appartements à foyers ouverts, où l'on utilise surtout la chaleur rayonnante, est très-inférieur dans l'industrie où la chaleur ascendante est principalement cmployée. Le charbon de tilleul est léger; sa puissance calorifique est à celle du charbon de hêtre, pour des volumes égaux, comme 68: 100 (Werneck); il vaut presque le charbon de bourdaine pour la fabrication de la poudre et il sert à dessiner comme celui du fusain.

L'écorce du tilleul, pourvue d'un liber abondant, fibreux, tenace et très-durable, occupe le premier rang parmi les produits accessoires des forc̀ts. Après l'avoir débarrassée de son rhytidome, si celui-ci est déjà développé, on l'enlìve, au moment de la séve du printemps, sous forme de longues lanières longritudinales de $\mathbf{3}-4$ centimètres de large; puis on en fait des boltes qu'on laisse macérer (rouir) dans l'eau pendant quelques mois, afin de détruire tout le tissu cellulaire interposé. Les couches fibreuses, devenues libres, sont employées à fabriquer des nattes, tapis, paniers, chapeaux, chaussons, cordes, etc. Autrefois elles servaient de papyrus. La Russie exporte annuellement des produits de ce genre pour une somme assez importante. Le meillcur liber est celui des jeunes tilleuls de $12-15 \mathrm{ans}$, et, pour les arbres àgés, celui des couches les plus internes. Ce liber est encore remarquable par une matière mucilagincuse, qui y est plus abondante que dans tout autre végétal ligneux de nos pays.

Les fleurs du tilleul sont employées en pharmycie pour infusions; on y trouve du sucre, du tannin, de l'acide malique, de l'acide tartrique et une huile essentielle. La graine nue conticnt environ 48 p. $0 / 0$ de son poids d'une huile grasse non siccative analogue à celle d'amandes. Les feuilles forment un médiocre fourrage.

2. Tilleul intermédiaire. TILIA intramedia. DC. T. europoen, var. $\alpha$. Lin.

Très-voisine du tilleul à petites feuilles, celle espèce se distiugue à ses feuilles plus courtement pétiolées, vertes-concolores sur les deux faces; à ses fruits plus gros, dont les parois sont épaisses, résistantes et les côles saillantes. - Disséminé et rare dans les bois. Flor., fin de juin, commencement de juillet.

3. Tilleul ì grandes feuilles. T'ún grandifolia. Ehrн. T. eu-

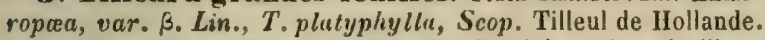

feuilles plus grandes que celles du lilleul à petites feuilles, verles-

Produils accessoires. 
concolores sur les deux faces, glabres en dessus, mollement velues en dessous, arec les aisselles garnies de poils blanchatres. Bourgeon revétu de 5 écailles apparentes, imbriquées, la troisième complétement embrassante. Corymbes de 2-7 fleurs assez graudes. Fruils assez gros, de forme variée, globuleux, ovoïdes, pyriformes, à parois épaisses et ligneuses, à cites plus ou moins saillantes à la maturité. - Arbre de mème port que le tilleul à petites feuilles, mais à pousses plus robustes, variant du vert au rouge (lilia carallina, Reichb.), lisses ou verruqueuses; pubescentes ainsi que les bourgeons en été, glabres ou à peu près en hiver.

Var. A. Rouge. Rubra. T. mubr. DC. Corymbes paucillores de 2 ou 5 flcurs, accompagnés de bractées courtement pétiolées ou subsessiles. Fruits à cóles peu sensibles. Jeunes pousses lisses et rouges.

Disséminé dans les bois de plaine, de collines et de montagnes où il ne dénasse pas l'altitude de $1100 \mathrm{~m}$.; très-fríquemment planté sur les promenades, avenues, elc. Flor., fin de juin el commencement de juillet. Fructif., oclobre.

Le tilleul à grandes feuilles a une longévité plus gorande encore, des dimensions plus considérables que le tilleul a petites feuilles. T. IIartıg en cite un en Prusse qui était díjà désignné sous le nom de : Vicux tilleul, dans un document du XII ${ }^{\circ}$ siècle; Baudrillard en mentionne un autre, auprès de Helle (Poitou), de $20 \mathrm{~m}$. d'élération et $15 \mathrm{~m}$. de circonférence. Ces deux espèces ont, à cela près, beaucoup d'analogies et l'histoire de l'une peut ètre considérée eomme étant celle de l'autre. Cependant le tilleul à larges feuilles produirait, dit-on, du bois encore inférieur à celui du tilleul ì petites fevilles et son écoree serait moins estimée.

\section{FAMILLE VI.}

ACERINELS. DC.

Fleurs régulières, hermaphrodites, quelquefois nolygames par avortement des ovaires; calice caduc, gamosípale, il 1-9, ordinairement כ̃ divisions, alternant avec autant de pétales; $4-12$, lc plus souvent 8 étamines insérées sur un renflement circulaire dı réceptacle (disfue); anthìres biloculaires, Iongitudinalement déhiscentes ; ovaire bilobé, biloculaire, à loges 1-2-spermes; placentation axile. Samare double, pourvue de longues ailes lalérales; graine sans périsperme. - Arbres it feuilles non stipulées, opposées. 
gexne ungue. - ERABLE, ACER. Lin.

Calice à $\breve{~ d i v i s i o n s ; ~ c o r o l l e ~ d e ~} 5$ pétales; 8 étamines; feuilles opposées, simples, palminerviées (Erables indigènes). - Arbres de grande ou de moyenne taille à rameaux opposés, dont les feuilles, longuement pétiolées, sont 3-7 lobées et constituées par 3-7 nervures palmées, d'égale force à peu près, donnant naissance sur leurs 2 côtés à des nervures secondaires pennées qui se ramifient en ríseau veineux. Les fleurs, petites et d'un jaune verdâtre, sont disposées en grappes ou en corymbes terminaux. Les bourgẹons sont enveloppés de 4-8 paires d'écailles pétiolaires, opposées, croisées et imbriquées.

Bois lourd et dur, blanc ou très-faiblement coloré, homogène (le nom d'Acer, fort, fuit, dit-on, allusion à la qualité du bois des érables). Tissu fibreux dominant, à parois épaisses; vaisseaux petits, égaux, isolés ou simplement rapprochés par 2-4, uniformément répartis, entourés de parenchyme ligneux (non distinct à la loupe); rayons égaux, médiocres, petits ou très-petits, moyennement longs, peu hauts. Malgré l'homogénéité des tissus, les accroissements annuels sont assez apparents, parce que chacun d'eux est limité à l'extérieur par une zone opaque et mince, mais bien marquée, de fibres d'une nature spéciale, remplies de fécule:

L'écorce est variable avec les espèces; son liber se développe régulièrement par couches annuelles dans la jeunesse, mais reste plus tard bien en arrière des accroissemendsigneux, de sorte que l'on n'en trouve que 20-2ö couches sur un arbre de 100 ans.

Les feuilles contiennent beaucoup de matières inorganniques : desséchées elles peuvent en renfermer jusqu à $2 S$ p. $0 / 0$ de leur poids. C'est 3 fois plus que les feuilles de chene, près de 5 fois plus que celles du hètre, 12 fois plus que celles du sapin.

La séve des érables est chargée de sucre identique i celui de cannes. On l'obtient en pratiquant au premicr printemps et vers le pied de l'arbre, préfúrablement du còté du sud, 2 trous de tarière qui pénètrent jusqu'au milicu de l'aubier. Il s'en écoule pendant 6 semaines une séve limpide, dont la quautié et la richesse en principes solubles vont toujour's en décroissant. D'un érable syeomore de $50-40$ ans on peut obtenir de la sorte $5 / 4-46$ kil. 
de sivve, contenant 5,1 a 4,7 p. 0/0 de sucre, que lon isole en concentrant et faisant cristalliser. Cés chiffires n'ont d'ailleurs rien d'absolu et varient comme les circonstances qui influent sur la régétation. Cette extraction ne se fait qu'en sacrifiant l'aceroissement et parfois la vic des arbres; elle est néanmoins opérée sur une grande échelle dans l'Amérique du nord sur l'érable à sucre (Acer' saccharinum. Lin.).

Outre cette séve limpide et sucrée, les érables contiennent, dans les faisceaux des nervures et des pétioles et dans ceux du liber, des sucs propres particuliers, aqueux chez les uns (E. Sycomore), blancs laiteux chez les autres (E. plane et champètre).

A. Feuilles mates blanchàtres en dessous; inflorescence penchée

B. Feuilles à 5-7 lobes dentés.

C. Lobes séparés profondément par des sinus très-aigus; inflorescence en grappe pendante............. E. Srcosore.......

$C^{\prime}$. Lobes séparés peu profondément par des sinus anguleux ouverts, presque droits; inflorescence en corymbe penché....................

B'. Feuilles à 5 lobes entiers, séparés par des sinus anguleux, à angle droit; inflorescence en corymbe penché...... E. DE Montpellizr. . Б

$A^{\prime}$. Feuilles vertes plus ou moins luisantes en dessous; inflorescence en corymbe dressé.

B. Feuilles à 5-b̆ lobes, séparés par des sinus en angles aigus légèrement arrondis au sommet.....................

B'$^{\prime}$. Feuilles à 5 lobes, séparés par des sinus arrondis très-ouveris............ E. prave.......

1. Erable Syeomore. Acer pseudoplatanus. Lin. Grand érable; Erable de monlagne; Faux-platane.

Feuilles grandes, cortiformes à la base, "̈-lobées, à lobes ovales ì peine acuminés, fortement et inégalement deutés, séparés profondément par des sinus très-aigus; fermes, glabres, luisantes et d'un vert sombre en dessus; mates, glauques et poilues le long des nervures principales en dessous. Fleurs verdâtres, a limbe dressé, paraissant aq̣ès les fremières feuilloss, disposées en grand nombre par grappes pédonculées, allongées, pendantes. Samares bossues-anguleuses a la base, à ailes étranglées inférieurement et dressées-étalées. - Arbre de grande taille, is écorce d'un stris jaunàtre mal, lisse jusqu'à $50-40$ ans, s'écaillant ensuite dans le genre de celle du platane, mais moins régulièrement et moins complétement et par plaques plus petites; bourgeons gros et ovoïles obtusément ly-angulaires, glabres, à écailles lierbacées, vertes, 
étrnitement bordées de noir-brun; les latéraux redressés-élalés sur le rameau; sucs propres aqueux. Bois montagueux. Flor., mai. Fruclif., septembre.

L'érable sycomore est un arbre de première grandeur, qui, en massif, développe une longue tige nue, cylindrique, rarement droite, et une cime assez semblable à celle du hètre, quoique moins fournie en rameaux, qui sont opposés et assez robustes. Il a une grande longévité; ses larges feuilles lui forment un couvert épais.

Isolé, cet érable fleurit et fructifie vers 20-50 ans, abondamment et annuellement; ses fruits, mürs en septembre, se disséminent en octobre ou restent sur l'arbre une partie de l'hiver. Il en faut 21-25000 pour un kilogramme.

Le plant lève en avril, si le semis a été fait cn automne;

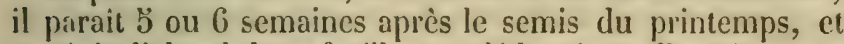
produit d'abord deux feuilles cotylédonaires allongées, enlières, bientòt suivies d'autres feuilles ovales-lencéolées, fortement dentées, mais point encore palmatilobées. Rarement il dépasse 2 décimètres au bout de la première année. La racine, peu pivotante, pousse beaucoup de ramifications latérales et de chevelu.

La croissance est active dans la jeunesse et devient parfois gènante, comme celle des bois blancs, pour les autres essences avec lesquelles il s'élève en mélange. $\Lambda 50$ ans, sa liauteur est double de celle d'un hêtre de même âge, plus tard cette croissance se ralentit et, à l'exploitabilité, les produits sont sensiblement égaux.

L'enracinement de l'arbre consiste en une forte souche, d'où partent beaucoup de longues racines qui s'amincissent rapidement, de sorte que la masse du bois est concentríe ct que l'extraction est facile. On en retire $20-23$ p. 0/0 du volume superficiel.

Les souches produisent des rejets abondants et vigoureux, mais néanmoins ce mode de reproduction n'est pas longtcmps soutenu.

Le sycomore est disséminé dans les forèts et rarement il entre pour une portion notable dans la composition des peuplements; il y est le plus souvent mélangé au hètre dont il a toutes les exigences. Son abondance et sa bonne venue sont l'indice d'un sol fertile, riche en principes nutritifs minéraux.

Il préfère les pays accidentés aux plaines, et dépasse, dans les montagnes, la région des sapins.

Fructification.

Germinalion.

Croissance.

Enracinement.

Slation el sol.

Port.

\section{Croissance.}

Enracinement.

Slation el sol. 
Eeorce. L'écorec conserve sa surlace lisse et vive, d'un gris jaunàtre, pendant longtemps; puis des lames de périderme se développent dans son enveloppe herbacie et forment un rhytidome brun rougcatre assez clair, qui tombe par ćcailles peu étendues. On y trouve à peine des traces de tannin.

Bois. Le bois du sycomore a la fibre fine, très-homogine; il est blane on trìs-légèrement rougentre, a les rayons médullaires assez épais; il prend un beau poli, se tourmenir et se gerce peu, n'est pas sujet à la vermoulure. C'esi par ces motifs un excellent hois de travail, recherché par les menuisiers, mécaniciens, tourneurs, luthiers, saboticrs; mais il se pourrit rapidement à l'air et ne peut servir aux constructions.

Du bois d'une tige de cent ans, coupée en séve, pése en moyenne : vert, 0,914 ; complétcment desséché à l'air, 0,7 k. (T. Ilartig). Son retrait, en passant à l'état see, est cle 8,1 p. $0 / 0$ du volume vert, lequel contient 26 p. 0/0 d'eau.

La valeur calorifique de ee hois, d'une densité de 0,7 / , comparce à celle d'un hêtre de 0,72 , l'un et l'autre de 100 ans et complétement desséchés à l'air, est expriméc par les chiffres suivants (T. Hartig) :

\begin{tabular}{|c|c|c|c|}
\hline \multirow{3}{*}{ Plus haut degré de chaleur.... } & & & \\
\hline & & & \\
\hline & & & \\
\hline \multirow{2}{*}{ Durée de la chaleur croissante. . } & & & \\
\hline & & & \\
\hline \multirow{2}{*}{ Durée de la clıaleur décroissante. } & & & \\
\hline & & & \\
\hline \multirow{3}{*}{ Total de la chaleur dévelnppée. } & & & \\
\hline & rayo & & \\
\hline & & $107: 100$ & $110: 10$ \\
\hline
\end{tabular}

L'examen de ces chiffres fait voir que l'érable sycomore est un bon bois de chauflige, qui produit un haut degré de chalcur, longtemps soutenu, mais dont la combustion décroit rapidement, par suite de la prompte extinction des charbons. Il fournit un charbon équivalent à celui du hètre.

2. Erable at feuilles d'obier. Acra opulrolium. Vilans. Duret; Ayard (Dauphiné).

Feuilles assez grandes, cordiformes à la base, à $\mathfrak{b}-\mathbf{7}$ lobes courls et larges, à peine acuminés ou même arrondis-oblus, irrégulièrement crénelés, séparés par des sinus peu profonds, anguleux, ouverts; coriaces, verles el glabres en dessus, mates el glauques en dessous, ou elles sont lantòt glabres avec les nervures principales velues, tantît grises-tomen- 
teuses sur toute la surface (Erable napolitain, A. Neapoliumun, Tenore; $A$. oblusalum, Willd). Fleurs d'un jaune verdàtre, en corymbe sessile, penché. Samares très-renflées-bossues à la base, à ailes dresséesctalćes ou presque parallèles, non étranglées inférieurement. - Arbre de (i-7"' d'élévation, souvent buissonnant, d'un port irrégulier et à cime étalíe, dont l'écorce, lisse el grise jusqu'à l'âge moyen, devient plus tard gercurée-écailleuse, assez épaisse el brun jaunàtre; hourgeons fusiformesàgus, arrondis, enveloppés d'écailles sèches et brunes, grises-tomenteuses à bords glabres; fleurs paraissant avec les feuilles; sues propres aqueux. 1)isséminé dans les forêts montagueuses du sud et du sud-esi jusqu'à une altitude consilérable; Jura, Alpes du Dauphiné el de la Provence, Cévcnnes, Pyrénées. La variéti, Erable napolitain, représente à peu près seule en Algérie la famille des acérinées. Flor., mars-avril.

Le bois de l'érable à feuilles d'obier est très-voisin de celui del'érable sycomore; il est cependant plus coloré, d'un rougeàtre clair au coeur avec l'aubier mal limité, blane, souvent teinté de jaune citron. Dur et compacte, il est estimé en menuiscrie et en charronnage, mais il parait être très-exposé a la pourriture, si on le conserve en lieu humide. Une dessiceation trop lente y détermine, plus que dans toute autre espiece du genre, des marbrures bigarrées de jaune et de brunatre, qui sont l'indice d'un commenecment de décomposition.

C'est un bon combustible, d'une densité moyenne. Complétement desséché à l'air il a fourni les chiflires suivants : Buis de 195 ans, végétation extrèmement lente, provenant des Basses-Alpes, pèse 0,677 (Coll. de l'Éc. for. Envoi de M. de Beer). Bois de 49 ans, végétation moyenne, de Corse, pèse 0,759. (Coll. de l'Ee. for. Envoi de II. Simon). Bois de 20 ans et de 15 centimètres de diametre, appartenant à la variété : Erable napolitain, d'Algérie, pése 0,80 (Coll. de l'Ec. for. Envoi de M. Royer).

3. Eirable plane. Ager platanoïoes. Lix. Plainc.

Feuilles grandes, rarement entierement planes, minces el de consistance herlacée, vertes concolores, grlabres et luisantes sur les detux faces, cordiformes à la base, à $\breve{-7} 7$ lobes bordés de quelques longues dents; lubes el dents acuminés-lrès-aigus, séparés par des sinus ouverts trèsarrondis. Fleurs d'un jaune verdâtrc, à périgone étalé, disposées en corymbes Iressés, presque sessiles. Samares planes à la base, à ailes éialées, nou rétrécies inférieurement. - Arbre de grande taille, ayant licaucoup d'analogie arec l'érable sycomore pour le port, mais dont l'écorce, lisse cl male dans la jeunesse el d'un goris rougeâtre plus prononcé yue celle de ce dernier, ne s'écaille pas plus tard el forme un rhytidome finement el longitudinalement gerçuré; bourgeous gros, les latéraux exactement appliqués, a ćcailles glabres, lierbacies, rouges ou vertes, 
terminées de brun; sucs propres blancs laiteux. Disséminé dans les bois accidentés ou montagneux de toute la France, mais plus rarement que l'érab'e sycomore. Flor., avril-mai. Fructif., septembre.

Croissance. L'érable plane n’a pas la croissance aussi active et aussi soutenue que celle du sycomore; toutes circonstances égales, à 100 ans, il reste en arrière sur ce dernier de : $\frac{1}{3}$ pour la hauteur, $\frac{1}{6}$ pour le diamètre, presque $\frac{1}{2}$ pour le volume.

Station et sol. Il se trouve dans les mèmes localités, souvent en mélange avec lui et atteste également, par sa bonne venue, une grande richesse du sol en principes inorganiques solubles; néanmoins il n’atteint pas des régions aussi élerées, et il supporte un plus haut degré d'humidité. Ses fleurs, plus précoces d'au moins 15 jours, paraissent avec les premières feuilles.

Bois. Le bois de l'érable plane ressemble beaucoup à celui du sycomore, mais il est d'un blanc moins pur, souvent rougeâtre, ses rayons sont plus fins et il est plus exposé à la vermoulure. Moins estimé comme bois de travail, il parait l'emporter' comme combustible, car sa densité est un peu supérieure. Du bois d'une tige de 100 ans, coupée en séve, pèse en moyenne : vert, $0,9 \overline{5} 6$; complétement desséchè à l'air, $0,7 \overline{5} 7$. Son retrait est de 9 p. $0 / 0$ du volume vert, lequel renferme 24 p. $0 / 0$ d'eau (T. Ilartig).

4. Erable champêtre. Acen caupestre. Liv. Azcraille (Lorraine). Feuilles plus petites que celles des espèces précédentes, cordiformes à la base, à 5 -5 lobes sinués-lobés, obtus, séparés par des sinus profonls en angles aigus faiblement émoussés au sommet; assez fermes, légèrement pubescentes, surtout en dessous sur les nervures, vertes, à peine luisantes sur les denx faces, un peu plus claires en dessous. Fleurs d'un vert jaunâtre, petites, en corymbes pauciflores dressés, courtement jérlonculés. Sumares légèrement convexes à la base, à ailes opposées en ligne droite el non rélrécies inférieurement, généralement veloulées dans la région le la graine, quelquefois grlabres (lirable des collines. $\boldsymbol{A}$. cullimum, Wallr.). - Arbre de moyenne taille, dont les jeunes rameaux sont plus on moins recouveris d'un liége jaune brun qui les rend ailésanguleux et dont lą tigge est revêtue d'une écorce d'un brun jaunâtre, assez finement gerçurée-écailleuse. Bourgeons petits, à écailles herbacées et vertes a la hase, seches et brunes au sommet, légèrement velues; sucs propres blancs laiteux. Communément disséminé dans les taillis de plannes et de collines. Flor., mai. Fructif., septembre-octobre.

Cruissance. L'érable champètre dépasse rarement 10-1 5\% d'élévation ; sa croissance est peu active, et, toutes circonstances égales, elle est à celle de l'úrable sycomore, i 100 ans, dans les relations suivantes : hauteur, 50 : 100 ; diamètre, 66 : 
100 ; volume, $53: 100$ (T. Hartig.). II repousse bien de souches et de racines.

L'enveloppe subéreuse se développe activement dans les premières années et forme un liége irrégulier, caractéristique sur les jeunes rameaux; à 5 ou 6 ans, celte rapide production s'arrête; plus tard, l'enveloppe subéreuse et lenveloppe verte tombent, des lames de périderme jaunâtre se forment dans l'épaisseur du liber qui devient brun, ct il en résulte un rhytidome assez épais, densément fendillé-écailleux.

Le bois est blane, légèrement jaunàtre ou rougeâtre, quelquefois flambé de brun au cœur dans les vieux arbres; il est compacte, très-homogène et formé de fibres très-fines, de vaisseaux petits, de rayons minces; lourd et dur, il est particulièrement remarquable par une grande ténaciré et recherché pour une foule àobjets qui exigent cette qualité : manches de fouets, outils, etc. ; il est utilisé par le charronnage pour le méme motif. Peu sujet à la vermoulure, à travailler et à se gercer, susceptible d'un beau poli, il est employé par les menuisiers, luthiers, tourneurs. C'est un très-bon combustible, dont la densité surpasse celle des érables planes et sycomores.

Du bois de tige, coupé en séve, à 120 ans, pèse en moyenne : vert, 1 ; desséché à l'air, 0,79 . Il subit, par la dessiccation, un retrait de $9,3 \mathrm{p} .0 / 0$ du volume vert et perd 29 p. 0/0 d'eau (T. Hartig).

5. Erable de Montpellier. Acen moxspessulanum. Lin.

Feuilles pelites, à pétioles grèles, à peine cordiformes à la base, à 3 lobes égaux, Iriangulaires-obtus, entiers ou à peine crénelés, séparés par des sinus anguleux, ouverts presque à angle droit; coriaces, glabres, verles et luisantes en dessus, mates et glauques en dessous avec les aisselles barbues. Fleurs d'un jaune verdâtre, petites, en corymbes sessiles, finalement penchés. Samares très-convexes à la base, à ailes dressées-convergentes, rétrécies inférieurement. - Arbre de $15^{\mathrm{m}}$ d'élévation au plus, restant souvent à l'élat de buisson, à port élalé et diffus, à rameaux grèles et à feuilles vertes persistantes jusqu'au commencement de l'hiver ; écorce lisse, gris jaunâtre, longitudinalement gerçurée à un âge avancé; bourgeons petits, presque glabres, à écailles sèches et brunes; fleurs paraissant avant ou avec les premières feuilles. Lieux secs, pierreux el rocheux de la France méridionale; remonte à l'est jusqu'à Lyon, à l'ouest jusqu'à Poitiers et Angoulème; rare en Algérie (Djurdjura). Flor., avril. Fructif., septemire.

Cet érable, malgré ses petites dimensions et la lenteur de son accroissement, est précieux par sa proprićté de croitre 
dans les sols les plus sees, jusque dans les moindres fissures des rochers. Son bois, plus dur, plus lourd encore que celui de l'érable champêtre, auquel il ressemble du reste, quoique avec une coloration rougeâtre plus intense, sert à des ouvrages de tour et de menuiserie. Il fournit un execllent combustible.

Du bois d'une lige de 104 ans, de 29 cent. de diamètre, provenant de la forêt de Braconne (environs d'Angoulème), pèse, entièrement desséché à l'air libre : 0,89 (Coll. Ec. for. Envoi de M. Paul Grandjean).

\section{FAMILLE VII.}

HIPPOCASTANEES. DC:

Fleurs hermaphrodites ou polygames par avortement des ovaires, irrégulières; calice "̋-denté; corolle de ä pétales inégaux ou de 4 par avortement du cinquième; 6-8 étamines, géuéralement 7, insérées sur un disque hypogyne; anthères biloculaires, longitudinalement déhiscentes. Ovaire à 3 loges biovulées, à placentation axile, produisant une capsule loculicide, a valves épaisses-coriaces, ne renfermant, par suite d'avortements, que 1 ou 2 graines très-grosses, à large lile, dépourvues de périsperme et dont les cotylédons sont très-épais et soudés entre eux. - Arbres exotiques naturalisés, à feuilles opposées non stipulées, composées-palmées.

Canal médullaire elliptique; bois léger, mou, blanc, trèshomogène, dont les accroissements sont peu distincts; fibres trèsfines, à parois minces; vaisseaux abondants, très-petits, isolés ou disposés $1-8$ en lignes simples, entourés de parenchyme ligneux (uon apparent à l'ail nu ou à la loupe); rayons extrèmement minces, indéfinis.

GENRE UNIQUE. MARRONNIER, ESCULUS, Lin.

Calice campanulé; 4 ou ỹ pétales; 7 étamines et 1 style simple, courbés-ascendants ; capsule épineuse.

Arbres d'assez grande taille, à pousses roloustes, opposies, terminćes par de très-gros bourgeons ovoüdes-aigus, d'un rouge brun, dont les écailles sont pritiolaires, opposées-imlriquées, coriaces, enduites d'une abondante excrétion résincuse. Les leuilles sont composées de lolioles digitées, 
dont chacune offre une nervure médiane dominante, de chaque côté de laquelle partent de nombreuses nervures secondaires droites et parallèles entre elles. L'inflor'escence, ćlégante et mixte, est en thyrse redressé formé de petites cymes scorpioildes. Les fruits sont remarquables par leur analogie apparcnte avec ceux lu châtaignier, quoique, dans le fait, ils soient bien différents. Dans le fiuit du marronnier, l'enveloppe verte épincuse est un péricarpe, les marrons revêtus d'un épisperme brun luisant en sont les graines. Dans le châtaignier, au contraire, l'enveloppe verte épineuse est un involucre, la chàtaigne (marron, pour les variétés greffées et cultivées) est un fruit, dont l'enveloppe sc̀che et d'un brun luisant représente le péricarpe.

La graine des marronniers germe comme les glands et les châtaignes, c'est-à-dire que le corps cotylédonaire reste en ierre (hypogé) et s'y pourrit sans produire de feuilles.

L'écorce se conscrve longtemps lisse et vive à la surface; l'enveloppe subéreuse et l'enveloppe verte s'y maintiennent sans prendre beaucoup d'accroissement, tandis que le liber s'augmente annuellement par couches continues comme celui du tilleul. Mais, à un àge avancé, un périderme se développe en lames dans l'épaisscur des féullets les plus extéricurs du liber, le liége et le parenchyme vert se dessèchent et tombent, et il se forme un rhytidome libérien, longuement et longitudinalement geręuré, écailleux.

ETarromier d'Inde. Asculus mprocastanum. Lin.

Feuilles opposées, longuement péliolées, composées de 7 grandes folioles digitées, sessiles, obovales, cunéiformes-allongées à la base, brusquement acuminées au sommet, inégalement dentées, vertes en lessus, plus claires en dessous ou les aisselles sont barbues; finalement glabres. Fleurs hermaphroditcs et mảles, en longs thyrses pyramidaux itressés, à 4 pétales chiffonnés, blanes, tachés de rouge et de jaune. Capsules sphériques, épineuses, en pelit nombre pour chaque intlorescence. - Arbre pouvant alteindre $20 \mathrm{~m}$. de hauteur et $1 \mathrm{~m}$. de diamètre, a cime ovale-pyramidale produisant un convert très-épais, et à pousses robustes pourvies de gros bourgeons ovoüdes-aigus, visqueux, dont les écailles sont nombreuses, sèches el brunes, imbriquées. Planté comme arbre d'ornement. Flor., avril-mai. Fructif. et dissém., octobre.

Le Marronnier d'Inde est un magnifique arbre d'ornement, dont la floraison et la foliation sont très-précoces. Uriginaire de la Perse, il a été introduit à Vienne en $1: 373$, ¿ l'aris en libl̈̈, et bien que complétement naturalisé dès l'origine et d'une croissance assez rapide, il n'est pas un

Origine. 


\section{4}

HIPOOCASTANRES.

Station. Sol. arbre forestier et il ne mérite point de le devenir. Arbre de plaines ou de régions accidentées peu élevées, il prospère particulièrement dans les terres légères un peu fraiches; il redoute un haut degré d'humidité ou de compacité.

Floraison. Il fleurit vers $\mathbf{1 5}$ ans; fructific régulièrement et assez abondamment chaque année. Ses graines, semées en auGermination. tomne, germent en février; mais elles succombent souvent sous l'effet des dernières gelées, de sorte que le semis de printemps est préférable. Le jeune plant pousse immédiatement les feuilles caractéristiques et peut, dès la première année, s'élever à $0^{\mathrm{m}} 7 \check{\text {. }}$. L'arbre est d'une transplantation facile, certaine; il supporte mal la taille.

Enracinement. L'enracinement est peu profond et consiste en une courte souche d'où partent de longues et nombreuses racines tracantes.

Bois. Le bois du marronnier est l'un des plus mauvais que l'on puisse produire, soit pour l'industrie, soit pour le chautlage. Il est blane jaunâtre et très-mou, ne se coupe pas net sous l'outil, se pourrit très-rapidement et ne convient guère qu’à faire de la volige pour les layetiers; néanmoins il travaille et se gerce peu.

D’après Varennes de Fenille, sa densité moyenne est : vert, 0,83 ; sec, 0,47 .

Du marronnier de 50 ans, d'une densité de 0,54 , comparé à du hètre de 80 ans, d'une densité de 0,67 , l'un et l'autre complétement desséchés, a donné les résultats suivants sur sa valeur calorifique ('T. IJartig).

Plus haut degré de chalcur......
Durće de la chaleur croissante... $\begin{aligned} & \text { ascendante } \\ & \text { rayonnante } \\ & \text { ascendante } \\ & \text { rayonnante }\end{aligned}$
Durce de la chalcur décroissante.
Tolial de la chaleur développée.... $\begin{aligned} & \text { rayonnante } \\ & \text { ascendante } \\ & \text { rayonante }\end{aligned}$

Poids égaux. Vol. égaux.

$110: 100 \quad 88: 100$

$100: 100 \quad 80: 100$

$65: 100 \quad \xi 0: 100$

$64: 100 \quad 51: 100$

$110: 100 \quad 88: 100$

$115: 100 \quad 92: 100$

$117: 100 \quad 95: 100$

$108: 10086: 100$

$93: 10076: 100$

C'est done un combustible qui donne rapidement un coup de feu assez vif, mais peu durable, et qui se consume ensuite lentement. Encore les chiffres précédents le rendent-ils meilleur que sá réputation, et, s’il n'est complétement sec, il brule dillicilement, arec peu de flammes et sans produire de charbon. 
L'écorce contient 1, 8 p. 0/0 de tannin (Davy); ce tannin et l'acide gallique sont abondants dans les péricarpes. L'écorce et les feuilles produisent en outre des matières tinctoriales jaunes, brunes et noires.

L'amande des marrons d'inde contient (d'après M.P. H. Lepage) :

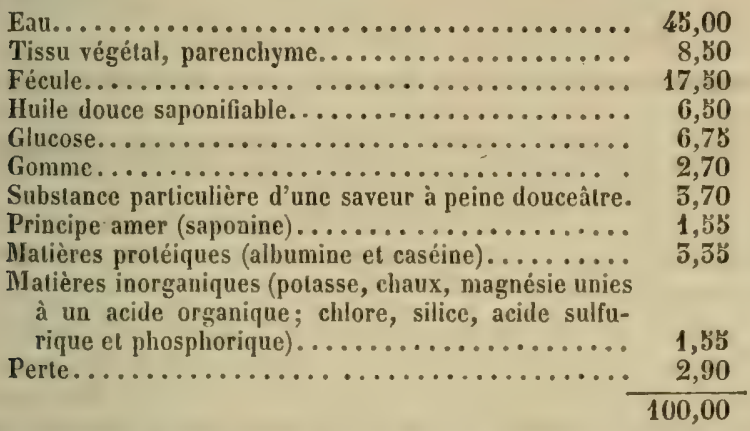

Le marron fournit une fécule à peu près aussi abondante que celle de la pomme de terre, d'une extraction facile et de qualité supérieure; on en retire une poudre qui remplace les savons de toílette, et, malgré son âpreté, le gibier s'en nourrit volontiers, les chêvres et les moutons s'accoutument à le manger. Mais la production de ce fruit est trop restreinte, la culture de l'arlire qui le produit trop peu avantageuse pour que l'industric l'utilise avec suite et que l'on puisse jamais trouver en lui unc ressource alimenlaire de quelque importanec.

\section{FAMILLE VIII. \\ MéLiACÉEs. Juss.}

Fleurs régulières, hermaphrodites ou polygames; calice a 4 ou 5 divisions qui alternent avec autant de pétales de la corolle; étamines en nombre double, à filets soudés en un long tube qui supporte les anthères; celles-ci biloculaires, longitudinalement déhiscentes. Ovaire pluriloculaire, à placentation axile, à styles soudés en un seul, produisant une baie ou une drupe syncarpée dont le noyau est pluriloculaire, ou une capsule loculicite; graines pourvues ou dépourvues de périsperme. - Arbres à feuilles non stipulées, alternes, le plus sourent composées ou décomposées. 
Calice ë-partite; 5 pétales; 10 étamines; drupe à noyau ¿̈-sillonné, divisé en $5 ّ$ loges monospermes. Graines périspermées.

Bois à tissu fibreux peu abondant; vaisseaux dominants, gros, éraux, uniformément répartis, dont chacun occupe juste l'intervalle de deux rayons; ceux-ci minces, indéfinis.

Telia azédarac. Melia azenaracir. Liv. Margousier; Lilas des Iudes.

Feuilles caduques, bi-pennées, à folioles opposées avec impairc, courtement pétiolées, lancéolées-acuminées, itrúgulièrement bordées de dents en seie espacies; glabres, vertes el un peu luisantes en desius, plus claires en dessous. Fleurs en panicules axillaires dressées, longuement púlonculées; pétales oblongs-linéaires, étalés, d'un lilas bleuâtre, au centre desquels s'élève le tube staminal aussi long qu'eux et d'un violet foncé. Fruil peu charnu, presque globuleux, de la grosseur d'un grain moyen de raisin, veri, puis jaune. Arbre de $10-15 \mathrm{~m}$, à tige droite, cylindrique, à rameaux terminés par des bouquets de feuilles, dont l'écorce devient largement et superficiellement gerçurée-écailleuse. Dans de mauvaises conditions, il reste à l'état d'arbrisseau. Originaire de la Perse, naturalisé comme arbre de décoration et subspontané dans la France méridionale et en Algéric. Flor., mai-juin.

Arbre élégant par son fenillage et par ses fleurs qui sont odorantes, à croissance rapide, mais exposí à perdre ses branches sous l'action des vents.

Le bois est d'un rouge analogue à celui de l'acajou, son mubier cst jamattre et nettement tranché; il est assez dur, d'un travail facile et peut être utilisé en menuiscric.

Les firuits ont une saveri donceitre, puis amère; leurs graines sont oléagineuses et, dans les contrées où l'azédarae i'st commun, ils foumissent de l'huile à brúler.

\section{FAMILLE $1 X$. \\ CORIARIÉE. DG.}

Fleurs rigulières, hermaphrorlites el, par avortement, polysames-monoïgues ou dioïgues; calice et corolle accrescents et devenant chumus, le premier alterues, petits, glanluleux; 10 étimincs à anthères biloculaires, longitudimalement déliscentes, ayant les loges séparées par lé Jás; ovaire "̋-loculaire, surmonté de §" stigmates papilleux, dont les carpelles se séparent it la maturiti en atutant de fruits 
secs indéhiscents, 1-spermes, mais restent enveloppés par la rorolle devenue charnue ct par le calice membraneux, de manière à simuler une baie. Graines sans périsperme.

genre unigue. Corroyère. Coriaria. Niss.

Mêmes caractères que ceux de la famille. - Arbrisseaux ì feuilles opposées ot verticillées par 3, simples, entières, it ? nervures, dont une médiane principale et 2 latérales basilaires; rameaux tétragones; bourgeons écailleux, petits, nombreux $(3 \mathrm{ct}$ plus) à l'aisselle de chaque feuille. Fleurs petiles, vertes.

Bois a tissu fibreux fin et serré; vaisseaux inégaux : internes, médiocres, formant une zone étroite; cxternes petils, groujés en faisceaux composés qui représentent, sur la section transversale, des lignes rameuses, courtes, éparses; rayons médiocres, indéfinis:

Corpoyère à feuilles ale myrthe. Coniana mrotifolia. Lay. Redoux; Redoul.

Feuilles très-courtement péliolées, opposées ou ternées, ovales-lancéolées, entières, fermes el glabres; fleurs petites, vertes, disposées en grappes dressées, terminales, sortant des bourgeons latéraux; pétales glanduleux plus courts que le calice; $b$ longs stigmates filiformes. Fruit bacciforme, vert, puis noir luisant. - Arbrisseau de 1 à $2^{\mathrm{m}}$, glabre, ćmettant constamment de terre de nombreux rejels droits, allongés, verts, 4-angulaires, qui se ramifient par faisceaux, en raison de la multiplicité des bourgeons axillaires, s'épuisent rapidement, ct, au bout de 5 ou 4 ans, ne donnent plus naissance qu'à de grêles ramilles, puis meurent. Coteaux de la France méridionale, particulièrement dans les haies et au bord des routes, dans les lieux frais el fertiles; Alyérie. Flor., juin-juillet.

Ce petit arbrisseau n'a pas de valcur forestière; néanmoins ses feuilles contiennent du tannin et, comme son nom le rappelle, les corroyeurs les emploient desséchées et mises en poudre, et souvent mélangées au tan, pour la préparation des cuirs; on en fait aussi une teinture noire. Les fruits contiennent un principe vénéneux, peu éludić encore, et peuvent quelquefois occasionner la mort.

FAMILLE $X$.

AIPÉLIDÉES. Kunth.

Fleurs régulières, ordinairement hermaphrodites; calice pelit,

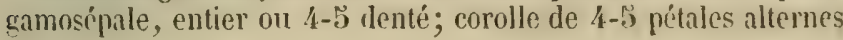


avec les dents du calice; $4-\Im$ étamines opposées aux pétales, insérées sur un disque hypogyne, ì anthères hiloculaires, longitudinalement déhiscentes. Ovaire 2-5̆-loculaire, à loges 2-ovulées, placentation axile, produisant une baie à $2-6$ graines (pépins) dont l'épisperme est osseux, le périsperme oléagineux. - Arbrisseaux toujours sarmenteux et grimpants, à feuilles alternes, péliolées, simples, palmatilobées ou composées-palmées, à stipules écailleuses, caduques.

gente unique, - VIGNE. VITIS, Lin.

Calice 5̃-denté; こ̃ pétales réunis par leurs extrémités, à onglets

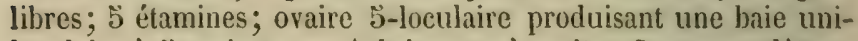
loculaire à כ̌ graines. - Arbrisseaux à petites fleurs verdàtres, odorantes, en thyrses opposés aux feuilles et souvent réduits à leurs axes, qui deviennent des vrilles.

Bois dur et peu lourd, très-légèrement brunâtre ; tissu fibreux rare, fin, à parois épaisses; vaisseaux très-abondants, inẻgaux; les internes très-gros, isolés, formant une zone large, les externes petits, en séries rayonnantes. Rayons assez larges, d'épaisseur croissante, indéfinis, très-hauts.

Vigne commune. Vitis vivifera. Lin.

Feuilles longuement pétiolées, profoudémeut cordiformes à la base, palmati-b̈-lobées, à lobes aigus, sinués-dentés; glabres, velues ou mème tomenteuses, surtout en dessous; inflorescence en thyrses d'abord dressés puis pendants, souvent réduits à leur axe et formant une vrille. Fleurs petites, hermaphrodites, verdàtres, odorantes. Baies de couleur variable, couvertes d'une efflorescence glauque. - Originaire de l'Orient, cultivée depuis la plus haute antiquité et souvent subspontanée dans les haies et aux bords des bois, surtout dans la France méridionale. Flor., juin.

Ramification. La tige sarmenteuse de la vigne ne résulte pas d'un axe primaire allongé par une évolution sucessive de bourgeons terminaux. Chaque entre-noud produit une feuille et se termine par un bourgeon floral d'où sort un thyrse complet ou une vrille seulement, suivant la vigueur de la végétation. L'allongement ultéricur est dù au développement immédiat du bourgeon axillaire, duquel nait un nouvel axe d'un accroissement vigoureux, qui rejette de còté l'infloreseence ou la vrille terminale, et semble prolonger l'axe précédent, tout en faisant néanmoins avec lui un certain angle qui trabit son origine. Ce mode de développement produit, en se répétant, les sarnents flexueux de la vigne et l'apparence oppositifoliée de ses fleurs. 
L'écorce est grise, fibreuse, formée par le liber, qui chaque année organise 5 ou 4 couches de longs faisceaux fibreux, séparés par du issu cellulaire, et repousse au dehors le liber de l'année précedente à l'état de rhytidome.

Comme toutes les espèces soumises à une longue culture, la vigne a fourni une multitude de variétés (cépages); mais, à l'état sauvage, elle présente beaucoup plus de constance dans ses caractères et ne produit que de petits fruits peu sucrés (lambrusco, dans le midi de la France).

La culture de la vigne, qui demande une température moyenne estivale d'au moins $18-20^{\circ}$ et succombe sous un froid de $-20^{\circ}$, caractérise une vaste région qui, vers le sud, se confond avec celle des oliviers, mais s'étend beaucoup plus loin que cette dernière vers le nord, ne laissant en dehors d'elle que quelques départements du nord et du nord-ouest. Dans ses parties moyennes et septentrionales, la région de la vigne est aussi celle des chènes rouvres $\mathrm{et}$ pédonculés, mais ceux-ci, à leur tour, atteignent une altitude plus considérable et une aire plus septentrionale. Les coteaux lui sont particulièrement favorables.

\section{FAMILLE XT. \\ STAPHYLEACÉES. Bartl.}

Fleurs régulières, hermaphrodites; calice gamosépale, à 5 divisions; corolle de 5 pétales alternes avec les sépales et avec les étamines, insérés, ainsi que ces dernières, sur un disque hypogyne; anthères introrses, biloculaires, longitudinalement déliscentes. Ovaire 2-3-loculaire, à placentation axile, surmonlé d'autant de styles à stigmates entiers, produisant le plus souvent une capsule vésiculeuse foliacée, 2-3 loculaire et 2-3 lobée au sommet; déhiscence partielle, par les sutures ventrales des lobes terminaux. Graines à placentation centrale, peu nombreuses ou, par avortement, solitaires dans chaque loge, subglobuleuses, tronquées au hile, à épisperme épais, osseux, luisant; faiblement périspermées. - Arbrisseaux à feuilles opposées, stipulées, oppositi-imparipennées, à folioles dentées, subsessiles, pourvues d'une nervure médiane et de 50-7 paires de nervures secondaires arquées, parallèles. 
GeXRe UxiQue. - STAPIIYLIER. STAPII YLEA. Lin.

Mêmes caractères que ceux de la famille.

Bois blanc et dur, ì lissu fibreux fin; vaisseaux petits, égaux, isolés, en nombre décroissant du bord interne à l'externe ; rayons minces, indélinis. Canal médullaire gros, circulaire.

Staphylier pemué. Starmuea pixita. Liv. Faux-pistachier; PisIachier saurage; Nez coupé.

Feuilles opposées, longuement pétiolées, pourvues de 2 stipules membraneuses, linéaires, caduques et composées de $\mathbf{b - 7}$ folioles elliptiques-lancéolées, acuminées, finement et aigùment serrées, glabres, d'un vert clair en dessus, un peu plus pâles en-dessous. Fleurs en grappes axillaires longuement pédonculées et pendantes; blanches ou légèrement rungeàtres à l'extérieur, à sépales, pétales et étamines dressés, égaux. Capsule vésiculeuse herbacée, à graines ligneuses, brunes et luișantes, de la taille d'un gros pois. - Arbrisseau de 2-5m, glabre, produisant de la souche des rejets droits, nombreux, robustes, fréquemment terminés par 2 bourgeons axillaires entre lesquels le bourgeon extrème est avorté; écorce d'un gris brun finement fendillée sur la tige, lisse, d'un brun verdâtre strié de blanc sur les branches, verte sur les rameaux qui sont assez trapus. Bourgeons déprimés-bicarénés, coniques, enveloppés de 2 écailles opposíes, vertes, soudées entre elles et confondues en une seule. Forèts des bords du Rhin (Haut et Bas-Rhin); fréquemment planté dans les jardins. Flor., mai. Fructif, août.

Cet arbrisseau est trop rare pour avoir de l'importanec, Son bois a le grain fin, d'un blane verdâtre et peut servir à des ouvrages de tour. Provenant d'une tige de 18 ans et de: 4ỉ millimètres de diamètre, il pèse, à l'état see, 0,8 . (Coll. Ec.For.). Les graines sont oléagineuses; donces atl gont, elles laissent ensuite une saveur acre.

\section{FAMILLE XII.}

\section{Celdastrinées. R. Brozun.}

Fleurs régulières, licrmaplirodites. Calice gamosépale, ì 4 on ¿ divisions, persistant. Corcille de 4 ou 5 pétales alternes, insirés avec les étamines contre un disque charnu hypogyne; étamines 4 ou 5, alternes avec les pétales, à anthères introrses, biloculaires, longitudinalement déhiscentes. Ovaire ì $2-5$ loges, 2-10-ovulées, à placentation axile, surmonté d'un style courl, épais, dont le stigmate est 2-ü-lobé; produisant un fruit d'anlant de loges, 1-2-spermes, qui est généralement une capsule loculicide. Graines pourvues d'une enveloppe supplémentaire, charmue (fiusse arille) et d'un périsperme oléngineux. 
Gexre UNique. - FUSAIN. EVONYMIUS. Tourn.

Ovaire à demi enfoncé dans le disque, produisant une capsule 3-5-lobée-loculaire, à déhiscence loculicide, dont les graines sont blanches et entourées d'une fausse arille charnue, vivement colorée en rouge orangé. - Arbrisseaux à feuilles simples, peu visiblement stipulées, très-finement dentées, formées d'une nervure médiane dominante et de nervures secondaires pennées, (5-8 paires), arquées, irrégulières, rameuses. Bourgeons ovoïdes, à écailles opposées-imbriquées. Sucs âcres et amers.

Bois très-homogène, à accroissements peu distincts, d'un jaune clair uniforme. Fibres fines; vaisseaux abondants, très-fins, égaux, solitaires, presque uniformément répartis, plus serrés cependant au commencement, plus espacés à la fin de chaque couche; rayons excessivement fins.

A. Feuilles moyennes, de $4-6$ centimètres de long; capsules à lobes arrondis sur le dos: ramules verts et $\{$-angulaires............ F. D'Eunope..... 1 $A^{\prime}$. Feuilles grandes, de 7-18 centimètres de long; capsules à lobes tranchiants sur le dos; ramules bruns, arrondis.......... F.a tanges Feuilles. 2

1. Fusain d'Europe. Evonymus europeus. Lis. Bonnel de Prêtre.

Feuilles opposées, légèrement pétiolées, elliptiques-lancéolées, trèsfinement dentées, glabres, mates, vertes en dessus, plus pâles en dessous. Fleurs petites, à verticilles généralement tétramères, verdàtres, disposées 2-4 en petites cymes corymboïdes, latérales, opposées, pédonculées et redressées, mème à la maturité ; pétales oblongs, blanchâtres. Capsule à 4 lobes arrondis sur le dos, d'un beau rose mat à la maturité ; graines d'un rouge orangé vif el luisant. - Arbrisseau de $2-4^{\mathrm{m}}$, et mème petit arbre de $4-7 \mathrm{~m}$ d'élévation sur $0 \mathrm{~m}, 50$ de circonférence, à jeunes rameaux lisses et d'un vert mat, souvent pourvus de 4 nervures longitudinales de tissu subéreux qui les rendent tétragones; bourgeons pelits, ovoïdes, 4-angulaires, à écailles herbacées, verlàtres. Commun dans les bois et les haies de la plaine et des régions de collines. Flor., avril-mai. Fructif., septembre-octobre.

Le fusain se plait particulièrement dans les sols frais, profonds et fertiles. Son bois est très-propre à de menus ouvrages de marqueterie et de tour et peut, en beaucoup de cas, remplacer le buis, auquel il ressemble par sa couleur, l'homogénéité et la finesse de son grain, la netteté avec laquelle il se coupe sous l'outil. II est néanmoins bien moins dur et moins lourd. Du bois d'une tige de 50 ans, de 7 centimètres de diamètre, pèse, complétement séché à 
Usages l'air, 0,67 (Coll. Ec. For.). Carbonisé en vase clos, on en accessoires. fabrique le lusain avec lecquel on dessine; il produit l'un des meilleurs charbons pour la fabrication de la poudre. La matière rouge des arilles sert à teindre les marocains.

2. Fusain à Iarges fenilles. Evonymus latifolius. Scop.

Feuilles plus grandes, à pétioles plus robustes que chez le fusain d'Europe. Fleurs à verlicilles généralement pentamères, disposées 10-20 en cymes ombellées, 2 ou 5 fois dichotomes, latérales, opposées, supportées par de longs ę grèles pédoncules, dressées, puis pendantes; pétales orbiculaires, brunatres. Capsules du double plus grosses que celles de l'espèce précédente, généralement à $\$$ lobes, minces et tranchants sur le dos. - Arbrisseau de $\{-5 \mathrm{~m}$ el plus, à rameaux étalés-divariqués d'un rouge brun foucé, recouverts d'une légère cfflorescence glauque, assez robustes, arrondis. Bourgeons grands, allongés-lrès-aigus, à ícailles séches d'un brun rongeâtre. Forèts de l'Isère, de l'Aiu et du Var. Flor., mai-juin. Fructif., septembre.

\section{FAMILLE XIII.}

\section{ücines, Brong.}

Fleurs régulières, hermaphrodiles; calice gamosépale, persistunt, à $4-6$ divisions; corolle de $4-6$ pétales alternes, libres ou un peu soudés entre eux ì la base ; 4-6 étamines alternes, ì anthères introrses, biloculaires, longiiudiualement déhiscentes. Oraire bipluri-loculaire, chargue loge uniovulée, à placentation axile; style nul ou très-court; stigmate en autant de lobes qu'il y a de loges. Nuculaine à 2 ou plusieurs noyaux monospermies; graine à périsperme charnu, abondant. - Arbrisseaux à feuilles simples, non stipulées, persistantes (1).

\section{genre unique, - IIOUX. ILEX. Lin.}

Fleurs généralcment lútramères; caliec petit, urcéolé ; corolle rutacée. - Arbrisseaux ou petils arbres ì feuilles alternes, trèscoriaces, luisantes, persistantes, à nervaiion pennée, composée

(1) Les pétales des ilicinées sont souvent légèrement soudés cntre cux par la base el forment une corolle gamopétale; la place de celle famille devrait done étre parmi les gamopétales périgynes, mais outre que celle sondure n'est pas couslante, elle est tonjours tres-peu élendue cl loutes les autres aflinilés maintiennent les ilicinées dans les dialypétales péribyiles. 
d'une nervure médiane dominante et de 6-10 paires de nervures sccondaires peu apparentes, irrégulières et rameuses.

Bois dur, homogène, lourd, blanc, à accroissements peu dislincts. Tissu fibreux à parois épaisses ; vaisseaux égaux, trèsfins, groupés en lignes simples (d'un seul rang) ou composées (de plusieurs rangs), rayonnantes-flexueuses, représentant un réseau à mailles interrompues, étirées dans le sens des rayons; parenclyme ligneux abondant, mais dispersé et sans relation constante avec les vaisseaux (invisible à l'œil nu ou à la loupe). Rayons assez larges, peu longs.

Houx commun. Itex AQUifoliun. LiN.

Feuilles courtement pétiolées, ovales on elliptiques, aiguës, coriaces el épaisses, glabres, très-luisantes et d'un vert foncé en dessus, peu luisautes el d'un vert pàle en dessous; le plus souvent dentées-épineuses sui les bords, parfois complétement entières, surtout sur les pieds àgés; de $1 \overline{3}-16$ mois de persislance. Fleurs b'anches, pelites, axillaires, solitaires ou fasciculées, courtement pédonculées. Fruit charnu, globuleux et ombiliqué au sommet, de la taille d'un gros pois, à \& noyaux triangulaires; d'un rouge corail à la maturité. - Arbrisseau ou petit arbre à lige droile el élevée, ou diffuse et étalée, suivant les circon stances sous lesquelles il rérgète, à écorce lisse, verte sur les jeunes rameaux, grise sur les branches et sur la tige. Aljondant dans certaines foréts, surtout daus les régions montagneuses. Flor., mai-juin. Fructif, août-septembre.

Le houx atteint dans quelq̧ues contrées (France centrale, Corse, Algérie surtout) les dimensions d'un arbre à tige droite et à cime pyramidale, de $8-10^{\mathrm{m}}$ de hauteur sur $0^{\mathrm{m}} \mathrm{b} 0$ de diamètre; en beaucoup d'autres lieux, il ne constitue qu'un arbrisseau de $2-4^{\mathrm{m}}$ de hauteur' (Vosges) ou mème un buisson bas et trainant (forèt de Ilaguenau). Il croit ou au moins résiste longtemps sous le couvert, a une longevité considérable, une végétation lente; il repousse bien de souches, supporte la taille très-aisément en se maintenant trèstouffu et sert à faire d'impénétrables haies de clòture. Sa transplantation est difficile.

Le bois de lioux est lourd, dur, très-homogène, finement maillé, blane, très-légèrement teinté de rougeâtre au coeur dans les vieux arbres. Du bois de tige de 110 ans, de 25 centimètres de diamètre, complétement desséché à l'air et provenant d'Algérie, pèse, 0,81 . (Coll. Ec. For. Envoi de II. Royer). Il convient pour une foule d'emplois : dents d'engrenage, outils, ourrages de marqueterie et de tour, cannes, cle. Il prend très-bien la couleur noire, reçoit un beau poli et ressemble alors à l'ébène.

'Taille.

Croissanec.

Bois. 
Usages L'enveloppe herbacée du houx se maintient vivante, s'acaccessoires. croit et renferme plusieurs principes immédiats : un principe amer cristalisable (ilicine), du tannin, de la résine et une matière très-visqueuse appelée glutine ou glu. Pour séparer cette dernière, on broie l'écorce dans un mortier, on l'abandonne ensuite à elle-mème pendant une quinzaine de jours dans un lieu humide, puis on la lave à grande cau. On mêle alors au résidu de l'huile de noix et l'on obtient la glu, avec laquelle on prend les petits oiseaux. Les fruits contiennent des acides, du sucre, de la pectine et sont violemment purgatifs.

Les habitants de la Forèt noire font, avec les feuilles desséchées du houx, une infusion qu'ils boivent en place de thé. Le maté, hoisson si généralement employée dans le Paraguay et dans une grande partie de l'Amerique du sud, se fait d'ailleurs le plus souvent avec la feuille d'un végétal du mème genre (ilex paraguariensis. St-Ilil.).

\section{FAMILLE XIV.}

\section{EMPÉTREES. Nuttal.}

Fleurs régulières, très-petites, dioïques ou polygames; calice persistant de 3 sépales libres; corolle marcescente de 3 pétales alternes avec les sépales; 3 étamines alternes avec les pétales, à anthères extrorses, biloculaires, longitudinalement déhiscentes. Ovaire sur un disque, à 3-6-9 loges uniovulées, à placentation axile, produisant une nuculaine à 3-9 noyaux libres ou soudés, 1 -spermes. Graines pourvues d'un albumen abondant, charnu. Petits sous-arbrisseaux à feuilles alternes, non stipulées, uninerviées, petites, épaisses, persistantes et rapprochées ; rappnelant les bruyères par leur port et leurs exigences.

\section{geNRE UxiQue. CAMARINE. EMPETRUM, Lin.}

Caractères de la famille.

Bois à vaisseaux fins, presque éçaux, épars, uniformément répartis; rayons fins.

Camarine à fruits noirs. Empetrum nigrum. Lis.

Fenilles persistantes (2 it 4 ans), nombreuses, petites, presque sessiles, linéaires-oblongues, semi-cylindriques, obluses, coriaces, glabres ; d'un vert foncé, luisantes el sans nervures en dessus, plus claires et marquées d'uue vervure blanche ea dessous; éparses ou rapprochées presque en 
verticilles. Fleurs petiles, blanches ou roses, sessiles, axillaires vers l'estrémité des rameaux, accompagnées de 6 braclées; étamines saillantes: slyles courts, terminés par un stigmate à lobes rayonnants. Fruil charnu globuleus, ombiliqué au sommet, noir, à saveur douceàtre-aciduléc. - Très-petit sıus-arlbrisseau glabre, d'un verl foncé, à liges brunes, rameuses, cuucluées, nues à la base, très-feuillées vers les extrémilés, qui sont ascendantes. Tourbieres des hautes-Yosges, du haut-Jura, de la haule-Anvergne, des hautes-Alpes et des hautes-Pyrẻnées. Flor., aıril-mai.

\section{ORDRE II.}

\section{DLALYPÉTALES PÉRIGYNES.}

Pétales et étamines insérés sur le calice, soit direclement, snit far l'intermédiaire d'un disque périg̨ne; calice toujours ganısépale; ovaire libre et supère on adhérent et infère. 
SOUS-0RDRE I.

Dialypétales périgynes à ovaire

libre, supère.

Placentalion axile.
SOUS-ORDRE II.

Dialypétales périgynes à ovaire adhérent, infère.
Elamines diplostémones.

Elamines isostémones.

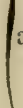

\section{Elamines}

opposées aux Arbres ou arbrisseaux à fleurs régulières, divisions du calice. opposées, ì stipules linéaires, parfois sp

- Etamines

alternes avec du calice.
à feuilles simples ou composées, alternes

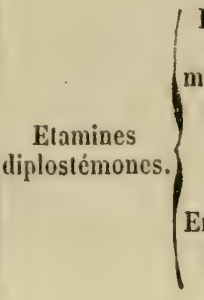

Embryon droit,
10 élamines

Arbres, arbrisseaux et sous-arbrisseaux à

très-rarement

libres.

Embryon courbé,

Ђ̆-10 étamines Arbres à fleurs papilionacées ou presque r

libres.

gousse et dont les feuilles simples ou com

Un seul carpelle, Arbres ou arbrisseaux, quelquefois épincu produisant une
drupe. alternes, dentées, stipulées.

Elamines

indéfinies.

Plusicurs

carpelles distincts; Arbrisscaux et sous-arbrisseaux, souvent : fruit
polycarpé.

Etamines iadéfinies.

\section{Placentation} axile.

I seul slyle. Arbrisseaux à fleurs régulières; produisa:

Plusicurs styles. Arbres et arbrisseaux, souvent épineux, à

et dont les feuilles sont alternes, simples (:

(feuilles sont opposées, simples, entières, I

Placentation (Sous-arbrisseaux à fleurs régulières, prod pariétale. $\quad$ feuilles sout alternes, simples, palmatilc

Elamines isostémones.
Placentation
axile.
Baic, à graines (Sous-arbrisseaux sarı) cartilagineuses. $\left\{\begin{array}{r}\text { en ombelle simple } \\ \text { en }\end{array}\right.$ Nuculaine, à noyauj Arbrisseaux à fleurs osseux, 2-loculaire. feuilles opposées, 


\section{SOUS-ORDRE 1 .}

DALYPÉTAES PRIGYYes A OYARE LIBRE, SUPËE.

FAMILLE XV.

RHAMNÉES. R. Brown.

Fleurs rigulières, hermaphrodites, quelquefois uniséxuées par avortement, petites, verdâtres, solitaires ou fasciculées, axillaires; calice à 4 ou 5 divisions; corolle de 4 ou 5 pétales alternes, parfois très-petits ou même nuls, insérés avec les étamines sur un disque adhérent au tube calicinal; étamines 4. ou 5, upposées aux pétales, à anthères introrses, biloculaires, longitudinalement déliscentes. Ovaire libre ou enfoncé dans le disque ct soudé avec lui par la base, 2-4-loculaire, chaque loge uniovulée. Styles 2-4, plus ou moins soudés entre cux. Nuculaine à 1 seul noyau 2-4-loculaire, rarement à 2-4 noyaux libres, ou samare syncarpéc. Graine périspermée. - Arbrisseaux à feuilles simples, alternes ou opposées; à stipules linéaires, parfois spinescentes.

A. Calice rotacé; pétales enroulés; ovaire à demi enfoncé dans le disque. Feuilles trinerviées, alternes, à stipules épincuses.

B. Samare syncarpéc, à aile circulaire.......... Paliun .... 1

B'. Nuculaine, à noyaı $2-3$ loculaire........... Jusurañ...2

$\Lambda^{\prime}$. Calice à tube ureéolé; pétales plans; ovaire libre; nuculaine à 2-4 noyaux distincts. Feuilles alternes ou opposées, à nervation pennée; stipules linéaires, uon épineuses.

B. Fleurs dioï ques ou polygames, généralementtétramères; style 2-3-tide. Graines à parois crustacées-fragiles; hourgeons écailleux....... Nenrnun ... 5

B'. Fleurs hermaphrodites, généralement pentamères; I style. Graines à parois ligneuses; bourgeons

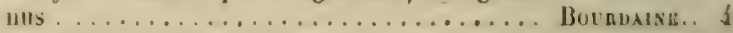

gexne 1. - PALIULE. PALIURUS. Tourref.

Fleurs peutamères; calice à tube rotacé; pétales curoulés en drotans; ovaire ì demi enfoncé dans le disque et lui adliérant; 3 Nles; samare syncarpée, 3-loculaire, à ále circulaire-périmériyue, dont les nervures sont rayonnantes.

liofs. 'Tissu fibreux dominant, it farois épaisses; raisseaux 
assez petits, égaux, uniformément répartis, isolés ou réunis par 2 ou 3. Rayons fins, égaux.

Paliure épineux. Paliunus aculateds. Las. Rhammus paliurus. Lin. Argalou; Porle-chapeaux.

Feuilles caduques, alternes et distiques, courtement pétiolées, obliquement ovales, aiguës ou obtuses, très-légèrement dentées, glabres; formées de trois nervures dominantes, dont une médiane et deux latérales basilaires, arquées-convergentes; slipules épineuses, inégales, l'une allongée, droite et dressée, l'autre courte, arquée, réfléchie. Fleurs en petiles grappes globuleuses, axillaires; calice à divisions lancéolées, étalées; corolle à pétales spatulés. Samare d'un rouge brun, hémisphérique, couronnée par une expansion orbiculaire, plissée-rayonnée et on-

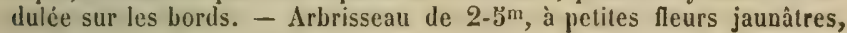
à tige dressée, rameuse, à rameaux et ramules grêles, divariqués, flexueux. Bourgeons très-petits, à 2 écailles spinescentes. Ecorce d'un gris brun, lisse d'abord, faiblement gerçurée plus tard. Abondant dans les terrains incultes et arides, particulièrement calcaires, de la région méditerranéenne; assez rare en Algéric. Flor., juillet-août. Fructif., automne.

Le paliure épineux se reproduit par drageons ; ses nombreuses épines le rendent très-propre à faire de bonnes haies. Son bois est dur, d'un jaune clair, passant insensiblement au rougeâtre dans le coeur. Pris sur une tige de 11 ans, de $0^{\text {m }} 03$ de diamètre et complétement desséché à l'air, il pèse 0,85. (Pyr. orient. Coll. Ec. For.) Ses faibles dimensions lui enlèvent toute importance.

\section{gENRE II. - JUJUBIER. ZIZYPIIUS. Tournef.}

Fleurs pentamères; calice à tube rołacé; pétales enroulés en dedans. Ovaire eufoncé dans le disque et lui adhérant; 2 styles; fruit charnu, à noyau unique, 2-3 loculaire ou 1-loculaire par avortement.

Bois de structure identique à celle du bois de paliure. Zin.

gujuhier commun. Zizyphus vulgaas. LaM. Rhamnus zizyphus.

Feuilles caduques, alternes-distiques, courtement pétiolées, obliquement ovales, obtuses, dentées, furmées de 5 nervures dominantes, dont une médiane et 2 latérales basilaires, arquées-convergentes; 2 stipules spinescentes, inégales, souveul avortées, caduques. Fleurs petites et jaunàtres en grappes paucillores, axillaires; calice a divisions subtriangulaires; pétales spatulés. Fruil ovoïde, presque sessile, de la taille d'une grosse olive, ronge à la maturité, de saveur douce et sucrée. Arbre de moyenne taille, à rameaux tortucux, ramules grêles, effilés et flexueux, se ramiliant plusieurs fois dans le cours d'une année; son écorce 
est hrune, profondement grercurée-écailleuse et rappelle heaucoup celle, des pins. Fréquemment cultivé comme fruitier el subspontané dans la région méditerranéenne : France, Corse el Algérie. Flor., avril-mai. Fructif., fin de septembre.

Taille. Le jujubier peut s'élever à $6-8^{\mathrm{m}}$ et atteindre $1-1^{\mathrm{m}} 80 \mathrm{de}$ circonférence. Il drageonne très-facilement, mais se reproduit peu par rejets de sotsehe. Cet arbre fournit l'un de ces exemples, bien plus frécquents qu'on ne l'avait supposé, de hourgeons multiples à chanue aisselle ; il en offre jusquà 3 , disposés en triangle et dont le supérieur est le principal.

Bnis. Son hois est dur, compacte, homogèue, susceptible d'un très-beau poli. Jaune à l'état d'aubier, il est d'un rouge au moins aussi vif que celui de l'acajou à l'état parfait; il cst employé, comme ce dernier, en ébénisteric et désigné sous le nom d'acajou d'Afrique. Du bois de tige de 76 ans, de $0^{\mathrm{m}} \overline{\mathrm{J} 0}$ de diamètre, complétement desséché i l'air libre, pèse 1,09. (Coll. Ec. For. Envoi de N. Royer). Il fournit un excellent chauffage, un sharbon de première qualité.

Fruit. Le fruit, mucilagineux et sucré, est comestible et connu sous le nom de jujube. On en fabrique une boisson alcoolique; les pharmaciensen font la pâte pectorale du mème nom (1).

(1) L'Algérie possède deux autres espèces` de jujubier; je citerai la suivante en raison de son abondance.

Gujubier des lotophages. Zizrrues rotus. DesF. Bois souterrain.

Feuilles plus petites que celles du jujubier commun, orales ou elliptiques-oblongues, obtuses, finement crénelées, glabres; pétioles, ramules et calices veloulés. Fruit sub-globuleux, jaune rouge, de la taille d'une cerise. Buisson de 5-4m, à branches tortueuses, inclinées, garnies d'aiguillons géminés. Flor, fin de mai. Fructif., fin d'octobre. Commun en Algerie, dans les plaines ou sur les còteaux, principalement dans les provinces d'Oran et d'Alger; peuple seul ou mélangé avec les oliviers, les lentisques, etc., des étendues assez considérables.

Le jujubier des lotophages, malgré ses dimensions peu élevées ne manque jas d'intérêt; ses racines traçantes très-longues, généralemedt plus grosses que le sujet qui les a produites, sont d'une extraction facile et donnent un volume de très-bon bois de chauffage, qui dépasse souvent toute prévision. La disposition à drageonner n'esi pas moins remarquable et parfois l'abord de cet arbrisseau est rendu presque innossible par l'entourage serré des drageons épineux qu'il a produits. Les fruits, véritables lotus des anciens, sont comestibles et recherchés comme ceux du jujubier commun. 
Gr.Nn H. - NERPRUN, RHABNTS, Lin.

Fleurs diö̈ques ou polygames, le plus souvent tétrameres, rarement pentamères: calice à tube urcéolé, persistant ; pétale's plans, quelquefois nuls. Ovaire libre. Styles 2 ou 3. Nuculaine. à 3 ou 4 noyaux distincts, à parois cristacées-fragiles; graines munies d'un sillon dorsal. - Arbrisseaux ì feuilles alternes ou upposées, cadurpues ou persistantes, très-généralement dentées, à nervation pennée; à stipules linéaires, plus ou moins caduques; souvent épineux par transformation des rameaur ct poursus de bourgeons écailleux, à écailles imbriquées, spiralées.

Bois lourd et dur. Fibres à parois épaisses; vaisseaux égaux, très-fins, tous groupés avee du parenchyme ligneux en faisceaux composés, quii forment des lignes ondulées-rameuses, générnlement rayonnantes, produisant sur la tranche un élégant dessin réliculé, plus clair que le tissu fibreux sur leyuel il ressort nettement. Rayons fins et courts.

Les fruits des nerpruns sont tous plus ou moins purgatifs; ils contiennent, avant la complète maturité, des matières colorantes, vertes ou jaunes, utilisées dans les arts et dans l'industrie.

A. Feuilles alternes.

B. Feuilles persistantes.

C. Feuilles à bords cartilagincux dentés; nervation vaguement pennée. Arbrisseau non épinellx................ N. Alatmane........ 1

C'. Feuilles à bords entiers, uninerviées. Arbrisseau spinescent. . N. A feviltes d'Outrier, 2

$\mathbf{B}^{\prime}$ Feuilles caduques.

C. Fevilles pourvues de chaque còté de $10-15$ nervures pennées, droiles et parallèles. Arbrisseau non épineux, dressé.... N. des Atres........ 3

$\mathrm{C}^{\prime}$. Feuilles pourvues de chaque côté de quées, parallèles. Très-petit arbrisseau non épineux, rampant..................

$A^{\prime}$. Feuilles opposées, caduques, pourvues de chaque còté de 2 -4́ nervures pennées, arquées-convergentes. Arbrisseau épineux.

B. Fevilles assez grandes (limbe ite 2 -

N. Nan, ........ \& 
3 cent. de targe), à nervures saillantes en dessous el à pélioles beaucoup plus longs que les sti-

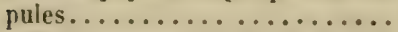

B1. Feuilles moyennes (limbe de 1 cent. $1 / 2$ de large), à nervures médiocrement saillantes, à pétioles un peu plus longs que les stipules.. N. Des tervtun:ens.....6 6

B". Feuilles petites (limbe de 1 cent. au plus de large), à nervures peu saillantes, à pélioles ne dépassant pas les stipules..........

N. DES ROCHERS.......? ?

\section{$\S$ I. Feuilles alternes persistantes.}

1. Nerprun alaterne. Riramus alaternus. Liv.

Feuilles courtement pétiolées, de forme variable, ovales, clliptiques oll obovales, à sommet aniculé et bords cartilagineux làchement dentés ou denticulés; fermes et coriaces, glabres, vertes et luisantes en liessus, plus claires et presque males en dessous, à nervalion pennée, diffuse. Fleurs tétra-pentamères, en pelites grappes bractéolées, multifores, axillaires; divisions du calice lancéolées-aiguës, plus courtes que le tube, réfléchies dans les fleurs mâles, dressées dans les fleurs femelles; pélales nuls. Fruit rouge, puis noir, 2-5 sillonné. - Arbrisseau ou petit arbre à tige dressée, rameuse, à rameaux alternes non épineux. Commun sur les côteaux secs, surtout calcaires, du midi de la France et de la Corse; remonte vers le nord jusqu'à Grenoble et Vicnne du côté de l'est, jusqu’à Angers et Poitiers du cóté de l'ouest; abondant en Algérie. Flor., marsarri!. Fructif., octobre-novembre.

Taille. Le nerprun alaterne est un arbrisseau forestier dont les feuilles persistent 18 mois à $\mathbf{2}$ ans, dont la croissance est lente, la longévité considérable. II peut atteindre $6-8^{\mathrm{m}}$ d'élivation, $1^{\mathrm{m}}$ et mème plus de circonférence; il repousse abondamment de souche.

Ecorce. Son écorce, verte sur les ramules, puis grise et lisse, se marque plus tard de fines stries longitudinales, et, lors qu'elle est àgée, resscmble beaucoup à celle du chine yeuse avec lequel cet arbrisseau a aussi beaucoup d'analogic par le feuillage. Cette écorce est alors d'un brun noir, rugucuse et densément gerçurée en long et en travers.

Bois. Le bois de lalaterne est très-lourd; celui d'une tige de 124 an. et de $0^{m} 23$ de diametre, provenant de Port-Vendres a donné, séché à l'air, une densité de 1,04 (Coll. Ec. For.). Il est très-homogène, d'un grain extrèmement fin; blane jaunâtı à l'état d'aubier, variant du brun clair comme le chẻne au brun marron foncé plus ou moins veiné à l'état 
parfait. Il prend beaucoup de retrait et exhale, quand on le travaille, une odeur désagréable. Sa fibre est courte et cassante. Il est très-propre à des ouvrages de tour, de marqueterie et de menue ébénisterie.

2. Nerprun à feuilles dyolivier. Rramnus oleoïdes. Lin.

Feuilles petites, oblongues ou ohovales, souvent apiculées, entières, uninerviées et réticulées-veinées. Fleurs tétramères, en faisceaux axillaires; divisions du calice plus longues que le tube ; corolle nulle ou trèspetile. Fruits d'un vert jaunâtre à la malurité. - Petil arbrisseau de $1^{\mathrm{m}}$ au plus, à tige dressée ou diffuse, très-rameuse, à rameaux alternes, spinescents. Environs de Narbonne; Allas en Algérie. Flor., mai.

\section{$\S$ II. Feuilles alternes caduques.}

\section{Werprun des Alpes. Rinamus alpiva. Liv.}

Feuilles pétiolées, elliptiques ou elliptiques-orbiculaires, arrondies ou légèrement acuminées au sommet, souvent un peu cordiformes à la base, finement et densément dentées; vertes-jaunâtres, légèrement luisantes en dessus, plus claires el mates en dessous; à nervure médiane produisant de chaque côté de nombreuses nervures secondaires, 10-13, droites, parallèles, saillantes. Fleurs diö̈ques-polygames, tétramères, en faisceaux axillaires pauciflores; divisions du calice triangulaires-aiguës, aussi longues que le tube; pétales oblongs. Fruit obové, 2-3-sillonné, noir à la maturité. - Arbrisseau tortueux, haut de $1-5^{\mathrm{m}}$, à rameaux inermes el à bourgeons assez gros, ovoïdes-aigus, d'un brun violacé. Ecoree d'un gris brun, lisse ou finement fendillée sur la tiģe, d'un brun violacé luisant sur les rameaux. Bois des régions montagneuses : Jura, Côte-d'Or, Lozère, Alpes, Pyrénées, Corsc. Flor., mai-juin.

\section{Verprun nain. Ruannus pumila. Lin.}

Feuilles courtement pétiolées, ovales, obovales ou lancéalées-obovales, finement dentées; nervures secondaires arquées, parallèles, au nombre de $5-7$ de chaque côté de la nervure médiane. Fleurs tétramères, en petils faisceaux axillaires pauciflores à la base des jeunes rameaux; calice à divisions lancéolées, plus longues que le tube; pélales étroits ou nuls. Fruit obové, noir. - Sous-arbrisseau diffus, à tige couchée très-ramense, tortueuse, longue de 5 - 15 centimètres seulement, croissant dans les fentes des rochers des Alpes, des Pyrénées, des Monts Dore (Auvergae), du Mont-d'Or (Doubs). Flor, juin.

\section{$\S$ III. Feuilles opposées, caduques.}

5. Nerprun purgatif. Ruamus catuantica. Lin. Noirprun; Epine de Cerf.

Feuilles à pétioles 2-5 fois plus longs que les stipules, ovales, clliptiques ou obovales, courtement acuminées, dentées, d'un vert assez foncé el glabres en dessus, diun vert pitts pâle et pubescentes sur les nervures ca dessous; à nervation pennée, composće d'une nervure médiane el de 


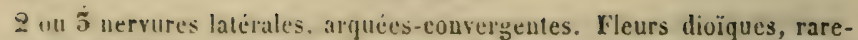
ment fulygames, tétramieres, en faisceaux axillaires bien fournis à la base des jeunes rameaux; divisions du calice lancéolie's, igalant le lube; peiales pelits. Fruit spheirique, non sillonné, noir a la malurilé. - Arbrisseau de 2 à $5^{\mathrm{m}}$, ou petil arbre de $6-8^{\mathrm{m}}$ de hauleur sur $0^{\mathrm{m}}, 50$ de circonférence, à lige tris-rameuse, rameaux opposés, élalés, souvent epineux à l'estrémilé par arortement du bourgeon teminal. Bourgeons d'un brun-noir, à écailles presque spiralécs, glabres, finemeat ciliécs sur les bords. Rejandu dans les taillis de presque toule la France. Flor., mai-juin. Fructif, automne.

Port. Le nerprun purgatif' a presque le port de l'épine noire, mais ses rameaux opposés le font distinguer aisément.

Lcorce. L'écoree, d'abord lisse ct luisante, d'un brun noirâtre, est formée par l'enveloppe subéreuse et s'enlève circulairement par membranes comme celle du cerisier; plus tard, les plus anciennes conches du liber forment un rhytidome gereuré, rematrquable par l'abondance et la grosseur des firisceaux fibreux qui le constituent. Cetle icorce contient, fraiche, une matière colorante jaune; desséchée, une matière brune.

Buis. Le bois est élégamment réticulé stu la scction transversale et présente un éclat lustré analogue à celui de la paille; il est blane grisatte dans l'aubier qui est nettement limité, jutune, passant au rougeatre clair dans le cour, ù l'état frarfint. Il est lourd et dur, susceptible de poli et convenable pour de inenus ouvrages de tour et de maryueterie. Un chontillon d'une tige de 27 ans, et de 16 cent. de diamètre. complétement desséché à l'air et provenant de Nancy, a pour densité 0,708. (Coll. Lic. For.).

Fruits. Les fruits, de saveur douceatre d'abord, puis amère et mauséabonde, sont fortement purgatifs, et servent, surtout en pharmacie rétérinaire, à la préparation du sirop de nerprun. On en retire aussi, lorsquils sont mùrs, la couleur connue sous le nom de vert de vessic; il suffit d'y ajouter de l'alun. Arant leur maturité, ils donnent une conleur jaune; après, une couleur brune.

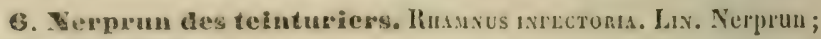
Ciraine d'Arignon.

Vuisin du précedent; feuilles plus petites, dont le pétiole dẹpasse a 1. ine les stipules; vvales ou clliptiques, a nervures secondaires moins saillantes. Fleurs en faisceaux axillaires moins fournis, tétramères; calice in divisions lancéolées beaucoup plus longues que le tube, qui devient tout a fait plan a la base du fruit. Fruit brun. - Arbrisseau

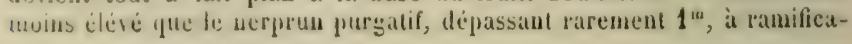


tion tris-diffuse et serrée, à rameaux opposés, épineux; écorce noiråtre. Croît daus les lieux arides et escarpés de la France mérilionale. Flor., mai. Fruetif., automne.

Le fruit de ce nerprun, comnu sous le nom de Graine d'Avignon, est l'objet d'un commerce assez important. Il contient, avant sa maturiti, une inatière tinctoriale jaune, fréquemment employée pour la coloration des parquets, utilisée en teinture, et qui, mélangée à de l'argile blanche trèsdotice et à de l'alun, forme une pàte d'un jaune doré que les peintres connaissent sous le nom de stil de grains. A la maturité ses fruits peuvent donner du vert de vessie.

3. Veroran des rochers. Rhamus saxatius. Liv.

Voisin des précédents, mais beaucoup plus pelit. Feuilles petites, dont le pétiole ne dépasse point les stipules, souvent fasciculeies, par déaut d'allongement des rameaux, étroitement ovales ou elliptiques, à nervires latérales peu ou point saillantes. Fleurs eu faisceaux axillaires, pauciflores; divisions du calice lanciolées à peine plus longues que le tube yui resle concave à la base du fruit. Fruit globuleux, noir, luisant. Sous-arbrisseau de 5-8 décimètres de hanteur au plus, à tige difiuse, rumeaux noirâtres, très-nombreux, disposés eu un huissou hérissé d'ćpines de tous côtés. Croît dans les rochers; euvirons de Gap et de Lyou. Flor., mai-juin.

Les fruits ont les mèmes usages que ceux du nerpron des teinturiers.

GENRE IF. - BOURDAINE. FRANGULA. TUUme.

Fleurs hermaphrodites, peutamères; calice à tube urcéolé, persistant; pétales plans; ovaire libre; style 1; nuculaine it 2 noyaux dont les parois sont ligneuses. Graines munies d'une échancrure latérale. - Arbrisseau à feuilles alternes, caduques, entières, à nervation pennée ; rameaux non épineux et bourgeons très-petits, nus ou accompagnés de quelques écailles stipulaires linéaires, non enveloppantes.

Bois assez mou et médiocrement lourd, d'une toute autre structure que celui des nerpruus. Fibres à parois peu épaisses; vaisseaux entourés de parenchyme ligneux (invisible à l'œil nu), décroissant en grosseur et en nombre du burd interne, où ils sunt assez petits et serrés, au lord externe où ils devientient Irès-petits et espacés, isolés ou réunis en petit nombre en séries simples et rayonuantes. Rayons minces.

IBourdaine commune. Fratgura vulgaris. Reichb. Bourgède; Aune noir. 
Fcuilles alternes, caduques, pétiolées, largement elliptiques, acuminées ou arrondies à l'extrémité, entières, glabres ou légèrement pubescentes inférieurement sur les nervures; vertes presque males en dessus, plus claires et luisantes endessous; nervures secondaires saillantes, nombreuses ( 8.10 de chaque côlé), presque droites, parallèles. Fleurs blanchâtres en faisceaux axillaires pueu fournis ; calice à divisions lancéolées dresscées, égalant le tube; pétales ovales, onguiculés. Fruit globtleux, de la grosseur d'un pois, lisse et brillant, vert, rouge, puis noir. - Arbrisseau de $2-4^{\mathrm{m}}$, rarement petit arbre de $5-7^{\mathrm{m}}$ d'élévation sur $0^{\mathrm{m}} \overline{0} 0$ de circonférence, à tige ou rejets droits, effilés, à peine rameux; à rameaux alternes, non épineux, cassants; à écorce d'un brun violacé, lachelée de leuticelles grises, finalement grise, d'abord lisse, puis se crerant par pustules en losanges qui se réunissent plus tard en gercures longitudinales. Commun dans les bois et les haies de presque toute la Frauce, particulièrement sur les sols frais et aux bords des eaux. Floraison successive, prolongée, avril-juillet, de sorte que l'on trouve en mème temps pendant l'été des fleurs et des fruits à lous les degrís de maturité sur le même rameau.

Charbon. La bourdaine est un arbrisseau drageonnant, dont le charhon, très-léger, 0,184 , est le plus estimé pour la fabrication

Bois. Ile la poudre de chasse. Le bois est homogène, assez mou, hlanc grisâtre ou jaunâtre à l'état d'aubier, qui est nettement tranché et peu abondant, d'un rouge orangé ou rosé uniforme et assez vif à l'état parfait. Celui d'une tige de 28 ans et de 10 centimètres de diamètre, complétement desséché à l'air et provenant de IIaguenau, a donné une densité de 0,65. (Coll. Ec. For.). Ce hois se divise facilement en minces lanières avec lesquelles on fait des articles de vannerie fine.

Produits L'ćcorce fournit une matière colorante rougeàtre qui accessoires. rappelle celle de la garance; elle est violemment purgeative.

Les fruits donnent une couleur verte que l'on a utilisće quelquefois en teinture. Il ne parait pas qu'ils aient les propriétés purgatives prononcées de ceux des nerpruns.

\section{FANILLE XVI.}

\section{TÉRÉBINTHACÉES. JuSS.}

Fleurs régulières, hermaphrodites ou le plus souvent diö̈gues ou polyganes par avortement; calice à 3-5 divisions; corolle quelquefois nulle, ordinairement de $3-5$ pétales alternes avee les divisions du calice, insérés à la base du calice ou devant un disque entourant l'ovaire; étamines en nombre égal aux pétales (espèces indigèncs), alternes et insérées avec cux, à antheres 
introrses, biloculaires, longitudinalement déhiscentes. Ovaire formé d'un seul carpelle 1-rarement 2-ovulé, ou de plusieurs carpelles qui habituellement avortent tous moins un seul, mais restent représentés par leurs styles. Fruit indéliscent, généralement charnu, drupe ou nuculaine; graines à placentation axile, non périspermées. - Arbres ou arbrisseaux à feuilles composées ou simples, alternes, non stipulées, à fleurs petites et jaunâtres, ordinairement paniculées.

Les sucs des térébinthacées sont tantôt limpides, tantòt laiteux-visqueux, composés de résine tenue en dissolution par une essence, qui est souvent d'unc àcreté extrème et détermine des accidents forts graves, Jorsqu'clle est appliquée sur la peau, et à plus forte raison prise à l'intérieur. Ces sues néanmoins offrent à l'industrie des matières utiles: les laques et vernis copals, la térébenthine de Chio, etc. Le nom de la famille est mème tiré de ce dernier produit, quoique ce soient les conifères et non les térébinthacées qui fournissent les térébenthines véritables.

A. Flcurs diöques apétales. Arbres à fenilles composées-pennées avec ou sans impaire; fruit 1-loculaire, 1 -sperme..................... Pistachizr. 1

$\Lambda^{\prime}$. Fleurs pélalées.

B. Fleurs pentamères. Arbrisseaux ou arbres à fevilles simples ou composées-pennées; hermaplurodites ou dioïques; fruit 1-loculaire, 1 -sperme....... Susac. ... 2

B'. Fleurs 3-4-mères. Sous-arbrisseaux à feuilles simples, enlières; hermaphrodites; fruit à $2-4$ noyaux 2-spermes................ Caxúléc...5

\section{geNRE I. - PISTACHIER. PISTACIA. Lin.}

Fleurs dioïques, apétales. Fleur mâle : calice 5̌-fide; ร̌ étamines insérées au fond du calice, opposées à ses divisions; un rudiment d'ovaire. Fleur femelle : calice 3 -4-fide ; ovaire uniloculaire par avortement, 1-ovulé; 3 stigmates. Drupe peu charnue, à un seul noyau monosperme. - Arbres à feuilles alternes, composées, dont les folioles sont entières et ont la nervation formée d'une nervure médiane et de nombreuses nervures sccondaires pennées, droites, parallèles, fourchues ou rameuses à l'extrémité ; ì sues chargés de térébenthine et appartenant à la région méditerranéenne.

Bois lourd et dur. Tissu fibreux dominant, ì parois épaisses. Vaisseaux inegaux : les internes moyennement gros, assez serrés, 
formant une zone ètroite settement limitée; les médians et les externes petits, groupés en faisceaux composés qui forment dt: courtes lignes obliques ou rayonnantes. Rayons égaux, lins, presque indéfinis.

A. Feuilles imparipennées, à pétiole non ailé, caduques.

B. Feuilles de 7-11 folioles; fruits de la grosseur

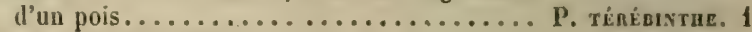

B'. Fevilles de 5-5 folioles; fruils de la grosseur d'une olive...................... P. cэsaux....2 A'. Feuilles paripennées, à pétiole ailé, persistantes. P. Learisque. 3

\section{§. Feuilles imparipennées, caduques.}

1. Pistachier téróbinthe. Pistacia terebiatius. Ifin.

Feuilles caduques, péliolées, oppositi-imparipennées, de 7-11 folioles sessiles, obliquement ovales-obtuses, ovales ou elliptiques-lanciolées, mucronées, entières, glabres, assez coriaces, verles et luisantes en dessus, mates et plus pâles en dessous. Fleurs en thyrses latéraux, uaissant sur les jeunes rameaux en dessous des feuilles te presque aussi longs que celles-ci; anthères et stigmates pourpres; calice brun. Drupe presque sèche, apiculée, globuleuse, rouge, puis brune, de la grosseur d'un pois. - Arbre de moyeune taille, à cime ćtalée-arrondie, dont l'écorce, d'un gris rougeâtre et lisse d'abord, forme un rhytidome libérien rugueux-écailleux, d'un brun rougeâtre. Bourgeons assez gyros, ovoïdes, obtus, glabres, à écailles d'un rouge brun, obluses, alternes, imbriquées. 'Terrains secs et rocheux de la France méridionale : Dauphiné méridional, Provence, Languedoc, Roussillon, Corse; Algérie. Flor., avril. Fructif., septembre.

T'aille. Port. Le pistachier térébinthe n'a point d'importance forestière en France, mais il en aequiert en Algérie, où il constituc des peuplements, soit seul, soit mélangré aux chènes, aux lentisques, etc. Il peut devenir un arbre de $8-15^{\mathrm{m}}$ de hatteur sur $1-2^{\mathrm{m}}$ et plus de circonférence; son trone, droit et eylindrique, se dénude jusqu'à $1-\breve{b}^{\mathrm{m}}$ du sol et produit une cime arrondie bien fournie et d'une grande envergure. Sa longévité est très-prolongée.

Bois. Le bois est blane, blane grisattre ou rougeatre et se colore at coeur de brun, brun verdatre ou mème devient noir comme l'ébène; il est agréablement veiné (comme la plupart des bois de cette famille), en raison de la coloration inégale et variée de l'ensemble de ses conches et de chacune d'elles en particulier. La différence entre les gros et les pectits vaisscaux est bien prononcée, et ees derniers y forment par lear groupenent des lignes obliques qui rappellent le 
bois des ormes. Il est compacte, suseeptible de recevoir un très-beau poli et sert en ébénisterie, marqueterie, sculpture; il est aussi propre au tom. Un moreeau d'une tige de 78 ans, de 17 centimètres de diamètre, complétement séché à l'air et provenant d'Algéric, pèse 0,88 (Coll. Ec. For., Envoi de M. Royer).

C'est un bon bois de chauflage.

Il exsude de l'écoree du pistachier térébinthe des gouttelettes d'une térébenthine blanche très-odorante; elles sont tellement abondantes que, par les fortes chaleurs, on ne peut pas toujours profiter de l'ombrage de cet arbre. Ces gouttelettes se solidifient bientòt et forment la résine connue sous le nom de lek (laque) ou d'alk, qui parait cmployée en Algérie comme le mastic de Chio, que l'on retire du pistachier lentisque.

Le fruit du térébinthe est comestible; sa saveur est aigrelette, rafraichissante.

2. Pistachier commun. Pistacia rera. Lin.

Feuilles 1-5-\$ foliolées, alternes, eaduques; folioles plus grandes que celles du P. térébinthe, plus coriaces, plus fortement veinées-réliculées rn dessous, rétrécies à la base. Fruit du double plus ģros. - Arbre de $7-10^{\mathrm{m}}$ de hauteur, cultivé et subspontané en Provence, en Languedoc, en Roussillon, en Corse. Flor., mai.

Cet arbre, originaire de la Syrie, est répandu sur tout le littoral de la Néditerranée où on le cultive comme fruitier. Sa drupe, de couleur roussâtre, contient une grosse amande d'un vert clair, oléagineuse, la pistache, que l'on mang'e crue ou confite de différentes manières (1).

(1) Pistachier te 1'atias. Pistacia atlantica. desf.

Feuilles caduques, composées de 7-9 folioles oblongues lancéolées, alténuées à la base, mucronécs au sommet, légèrement ondulées sur les bords, très-glabres; pétiole grèle, rebordé. Anthères et styles pourpres. Drupe ovale-globuleuse, de la grosseur d'un pois, d'abord d'un flavepourpre, devenant bleuâtre à la maturité, légèrement acide, comestible. Grand et bel arbre de $20^{\mathrm{m}}$ d'élévation sur $4^{\mathrm{m}}$ de circonférence, développant une cime très-ample et très-touffue. Commun en Algérie, mais généralement à l'état d'isolement; s'avance jusque dans le désert où il est très-précieux par son ombrage et par le fourrage que ses feuilles et ses jeunes pousses procurent, et s'élève jusqu'à une altitude de $1400^{\mathrm{m}}$. II produit en abondance la mème térébenthine que le Pistachier térébinthe.

Produits accessoires. 


\section{§ II. Feuilles paripennées, persistantes.}

3. Pistachier lentisque. Pistacia lentiscus. Lin.

Feuilles alternes, persistantes, oppositi-ou alterni-paripennées, de 6-12 folioles elliptiques ou oblongues-lancéolées, mucronées, entières, coriaces, glabres, d'un vert sombre et luisant en dessus, d'un vert pàle et mat en dessous; pétiole étroitement ailé. Fleurs en épis cylindriques, dressés, naissant 1 ou 2 à l'aisselle d'une feuille et au plus de la longueur d'une foliole; verdàtres, à anthères purpurines. Drupe sèche, globuleuse-comprimée, apiculée, de la grosseur d'un pois, rouge, puis noire. - Arbrisseau ou arbre peu élevé, à odeur résineuse prononcée, dont l'écorce est d'un brun rougeâtre et devient avec l'àge rugueuse-écailleuse. Lieux sees et arides de la région méditerranéenne. Flor., avril-mai. Fructif., novembre.

Bois. Le lentisque est un arbre de plaine ou de coteaux, qui croit seul ou en mélange avec les oliviers, myrthes, etc., et forme, en Corse, une partie du peuplement de ces broussailles appelées maquis. Il est très-abondant en Algérie.

Taille. Cet arbre peut atteindre, au maximum, 4- $6^{\mathrm{m}}$ d'élévation

Enracinement. sur 1-1 ${ }^{\mathrm{m}} 80$ de circonférence; sa souche est très-volumineuse, imet de nombreuses et fortes racines, longuement traçantes et drageonnantes, el repousse vigoureusement. Le tempérament est robuste.

Bois. Le bois, qui est veiné, a l'aubier blanc ou blanc grisâtre, le cœur rougeâtre et mème brun jaunâtre ou verdàtre; les vaisseaux du bord interne sont rares et à peine plus gros que les autres et la zone qu'ils forment se distingue diflicilement; ceux de la région médiane et externe sont groupés de manière à former sur la tranche des lignes rayonnantes légèrement flexucuses d'un seul rang. Celui d'une tige de 50 ans, de 52 centimètres de diamètre, complétement desséché à l'air, et provenant d'Algérie pèse 0,84 . (Coll. Ec. For. Envoi de Nl. Royer). Il est dur, se polit bien, sert pour la menue ébénisterie, mais il se pique lacilement des insectes.

Ce hois occupe le premier rang parmi les combustibles; il brùle vivement, dure longremps au feu et produit un charbon abondant qui se maintient incandescent jusqu’à combustion complète.

P'roduils aucessoires.

Les fruits contiennent une huile limpide principalement propre à l'éclairage.

Enfin le lentisque fournit la résine connue sous le nom de mastie de Chio, très-employée en Orient, où l'habitude 
de la micher est universellement répandue, utilisée en outre pour la préparation de vernis trés-brillants; on peut provoquer son écoulement par de légères entailles pratiquées dlans la tige des lentisques. Le lentisque n'est point assez abondant en France pour qu'on s'occupe de l'extraction de ce produit; la récolte parait en ètre négligée en Algéric.

\section{GeNнв II. - SUDAC. RIIUS. Lin.}

Fleurs hermaphrodites ou dioïques; calice à 5 divisions; corolle de 5 pétales étalés, insérés devant un disque qui entoure l'ovaire ; こ étamines insérées avec les pétales et alternes. Ovaire uni-loculaire, uni-ovulé ; 3 styles. Drupe presque sèche, ì noyaux osscux. - Arbres ou arbrisseaux à sucs résineux ou laiteux, à feuilles caduques, alternes, simples ou composées, dont la nervation est la même que celle des pistachiers; à fleurs petites et vcrdâtres; bourgeons à peine écailleux et racines traçantes, très-drageonniantes.

Bois peu lourd, veiné. Vaisseaux inégaux, assez gros au bord interne, où ils forment une zone bien limitée, petits et peu nombreux dans la zone médiane et externe où ils sont isolés ou groupés en petit nombre, suivant de courtes lignes simples rayonnantes. Rayons fins.

A Feuilles simples, entières............. S. fustet....... 1 A Feuilles composées, imparipennées....... S. DES corroyeuds.. 2

1. Sumac fustet. Ruus cotrnus. Lin. Arbre à perruque.

Feuilles alternes, caduques, pétiolées, simples, obovales ou orbiculaires, alténuées à la base, obluses au sommel, entières, glauqques et males sur les deux faces. Fleurs hermaphrodites en panicule très-làche; pédiçlles d'abord très-courts, mais s'allongeant considérablement et devenant très-grêles; presque tous stériles, et, dans ce cas, couverls de longs poils élalés rougeâtres qui rendent la panicule plumeuse; calice à segments ovales, obtus; pétales spatulés, jaunàtres. Drupe obovée, glabre, ridée, luisante et brune à la maturité, de la grosseur d'un petit pois. - Arbrisseau touffu et rameux, à ramules assez robustes, rapprochés, presque fasciculés à l'extrémité des branches; bourgeons pelits, triangulaires-comprimés, enveloppés de 2 écailles latérales opposées, à dos caréné. Collines sèches du Dauphiné et de la Provence. Flor., juinjuillet.

Le sumac fustet est souvent cultivé comme arbrisseau d'ornement à cause de ses vastes et nombreuses panicules plumeuses. Il est riche en térébenthine très-limpide, et exhale par ses parties vertes, lorsquion les froisse, une forte 
Huis. odeur aromatique. Son bois est moyennement dur ; pris sur une lige de 12 ans et de $0^{\mathrm{m}} 0 \mathrm{~S}$ de diamètre, provenant d'Espagne, il pise, à l'état sec, 0,76 (coll. Ec. For.). D'un blane jaunitre nettement limité, dans l'aubier, il est reiné et assez vivement coloré nu cocur de verdatre, de brun, de brun verdattre et de vert jaunàtre. Il prend un beau poli et sert à de menus objets d'ébénisterie et de marqueterie.

produils accessoires.

L'écorce, d'abord d'un gris rougeitre et lisse, devient brune rougeàtre et rugucuse écnilleuse vers 10 ans; clle sert au tannage dans les pays où le végétal est commun. Les racines donnent une matière tinctoriale jaunc ou rousse.

2. Sumac des corroyeurs. Ruus corranta. Lsw. Vinaigrier; Roux ou Roure des corroyeurs.

Feuilles alterues, cadurgues, péliolées, oppositi-imparipennées, de 7-18 folioles sessiles, ovales-lancéolées, à base souvent cntière, mais largement et for!ement dentées sur le reste de leur contour; velues ainsi que le péliole commun, les axes d'inflorescence el les ramcaux; males et plus pâles en dessous qu'en dessus, passant au rougge vif en aulomne; pétiole souvent ailé entre les folioles supérieures. Fleurs dioïrues-polygames, en thyrses terminaux étroils, allongès, dressés; pédicelles courls, munis sous chaque fleur de 5 bractéoles; calice à segrments ovales-obtus; pétales oblongs et blanes, plus longs que les divisions du calice. Drupe subglobuleuse, comprimée, densément hérissée-laineuse, d'un brun pourpre à la maturilé. - Arbrisseau à lige dressée, de 5 à $4^{\mathrm{m}}$ de hat teur sur 20-50 centimètres de circonférence, à ramification peu fournie et consistant en quelques grosses pousses velues, qui offrent un canal médullaire très-développé, circulaire. Sues laiteux. Bourgeons globuleux, densément laineux. liégion méridionale de la France. Ilor., juin-juillet. Fructif., décembre.

Ce sumac est trop disséminé en France pour y ètre important; il le devient en Algérie par son abondance. Le

Bois. bois est blane gristitre, nuancé au coeur de brunâtre, de brun verditre elair; il est mou, assez léger, spongieux, cassant et par conséquent sans valeur. Parlaitement desséché a l'air et provenant d'Algérie, d'une tige de 8 ans, de! centimètres de diametre, il pise 0,68 (Coll. Ee. For. Envoi de M. Royer).

Produits accessoires.

L'écorce contient une matière tinctoriale jaune ou rouge, qui sert à la teinture des cuirs et des étolles; on y trouve en ontre, ainsi que dans toutes les parties de la plante et particulierement dans les feuilles, de l'acide tannique que l'on utilise pour la grejuaration des cuir's narocains, et lorsyu'elle est abondante, elle devient l'objet d'un commeree assez important. Les léuilles, dessechées cl réduites en poulre, sont 
employées au tannage sous le nom de Sumac. Les fruits sont comestibles; ils ont une saveur acidulée-agréable (1).

GENRE H. - CAMÉLÉE. CNEORUM. Lin.

Fleurs hermaphrodites ; calice à 3-4 divisions ; corolle d'aulant de pétales alternes avec les divisions du calice et bcaucoup plus longs qu'elles; 3 ou 4 étamines alternes ; ovaire $3-4$ loculaire, dont claque loge est 2-ovulée. Style simple. Nuculaine presque sèche, généralement à 3 loges, dont cliacune contient 2 graines séparées par une fausse cloison. - Sous-arbrisseaux ì feuilles persistantes, simples, alternes, enlières, uninerviées; à sucs âcres et violemment purgatifs.

Camélée triconue. Cineorum tricoccon. Lin.

Feuilles oblongues, atténuces à la base, obluses ou mucronulées au sommet, sessiles, entières, à bords enroulés en dessous; coriaces, glabres, luisantes sur les deux faces; plus pâles en dessous qu'en dessus, uninerviées. Fleurs courtement pédonculées, jaunes, réunies 2 ou 5 à l'aisselle des feuilles supérieures; calice à segments ovales-obtus ; pétales oblongs. Nuculaine d'un vert noir à la maturité, surmontée d'un style

(1) Gumac thézéra. Ruus pentaphyla. Desf.

Feuilles persistantes, pétiolées, 5- j-foliolées, palmées; folioles sessiles, linéaires-cunéiformes, entières ou souvent.tridentées-trifides vers le sommet, glabres, d'un vert grisâtre mat sur les 2 faces; pétioles rebordés sur les côtés; fleurs dioïques, en petites panicules axillaires et terminales formant par leur ensemble une panicule composée et feuillée. Drupe globuleuse, lisse et luisante, de la taille d'un gros pois, trituberculée au sommet, rouge à la maturité. - Arbrisseau rameux dès la base, garni d'épines effilées, alteignant $4^{-7} \mathrm{~m}$ de hauteur sur $0^{\mathrm{m}} \mathbf{6 8}-\mathbf{1}^{\mathrm{m}}$ et plus de circonférence; port de l'aubépine. Algérie. Flor., avril. Fructif., novembre.

Le sumac Thézéra se rencontre sur plusieurs points de l'Nigérie, soit à l'état isolé, soit en massif et mélangé avec les lentisques, les oliviers, etc. Il paraît préférer les régions accidentées, mais non montagneuses, les sols graveleux, secs et profonds.

La végélation est lente, le bois est lourd, compacte, rouggeâtre, susceptible de poli; il est bon combustible et produit un charbon estimé.

C'est l'écorce, néanmoins, qui donne à ce sumac toute sa valeur. Celle écorce, assez mince, grisâtre, s'exfoliant par plaques, est très-recherchée dans l'industrie el forme, sur les marchés d'Afrique, une branche importante de commerce. Elle renferme une matière tincloriale d'un rouge vif et du tannib, et sert principalement à la préparation des cuirs marocains.

Les fruits sont acides et comestibles. 
simple, persistant; à 5 lobes, alternant avec autant de sillons et se séparant aisément en 5 drupes. - Sous-arbrisseau de $1^{\mathrm{m}}$ au plus, à rameaux grèles el verts. Lieux secs de la région méditerranéenne; France et Algérie. Flor., juin.

\section{FAMILLE XVII.}

\section{PAPILIONACÉES. Lin.}

Fleurs hermaphrodites; calice 1-2-labiẻ ou à 5 divisions; corolle papilionacée; étamines en nombre double des pétales, 10, insérées sur le calice, monadelphes ou diadelphes (9 soudées, la $10^{\mathrm{e}}$ libre), très-rarement libres; anthères introrses, longitudinalement débiscentes. Un seul carpelle libre, produisant une gousse. Graines non périspermées. Embryon droit. Feuilles alternes, le plus souvent composées stipulées. - Plantes herbacées, sous-arbrisseaux, arbrisseaux et arbres, même de la plus grande taille, à feuilles trifoliolées ou impari-pennées, représentées quelquefois par une foliole unique, que l'analogie fait considérer' comme feuille composée réduite, unifoliulée. Les folioles sont presque toujours entières.

La famille très-naturelle des papilionacées fournit, par ses espèces ligneuses, des bois identiques de structure et de qualités. Ils sont lourds, dur's, nerveux, jaunes ou jaunâtres, se colorant au cœur de teintes souvent foncées. Leur tissu fibreux est très-dominant, composé de fibres très-serrées, à parois épaisses. Les vaisseaux, la plupart du temps inégaux, sont associés à du parenchyme ligneux et groupés en faisceaux composés qui forment, sur la tranche transversale, des lignes arquées, flexueuses, obliques ou périphériques, représentant souvent un élégant dessin réticulé. Les rayons sont médiocrement ou assez épais, peu hauts, sensiblement égaux.

Dans les premiers genres de la famille la composition des faisceaux est très-complexe, le parenchyme est abondant, le réseau qu'ils forment est très-prononcé; mais celte composition se simplifie peu à peu et, dans les derniers, les faisceaux ne sont plus formés que d'un petit nombre de vaisseaux et de fort pen de parenchyme ligneux; ils n'offrent plus qu'une ébauche de dessin réticulé.

La plupart des feuilles des papilionacées sont fourragères, et beaucoup de graines de cette famille sont comestibles; ce sont celles dont les cotyléclons sont épais et féculents. Néanmoins, les feuilles de certaines espèces el les graines à 
cotylülons minces $\mathrm{ct}$ foliacés sont violemment purgatives et ioxiques. Telles sont, au moins pour l'homme, les feuilles de l'anagyre fétide, du cytise faux-ébénicr, de la coronille arhrisseau, connue par ce motif, sous le nom de séné-bâtard, les fenilles et les graines du baguenaudier.

Les graines conservent longtemps leur faculté germinative et leurs cotylérions, suivant qu'ils sont épais et féculents, ou minces et lierbacés, sont hypogés ou épigés lors de la germination. Tous ceux des papilionacées ligneuses indigènes sont dans ce dernier cas.

Les arbres, arbrisseaux et sous-arbrisseaux de cette famille sont des végétaux de plein soleil, qui ne supportent pas le couvert et se reneontrent bien plus fréquemment sur les terrains vagues et nus que dans les forèts. Cependant, quelques espèces sont très-répandues dans les bois, mais dans les vides et clairières, sur les lisières ou dans les coupes dont le repeuplement n'est pas immédiat; elles y deviennent, dans ce eas, envahissantes et nuisilles (genèts). Les papilionacées affectionnent particulièrement les sols sees, calcaires; néanmoins certaines espèces sont à cet égard parfaitement indifférentes (quelques genéts), et l'une d'elles (genêt à balais) est même l'une des plantes silicicoles les plus caractéristiques.

A. Etamines libres. Arbrisseaux à fcuilles כ̃-foliolées, gousses non articulées, fleurs jaunes, tachées de noir............................

A'. Etamines monadelphes. Arbres, arbrisseaux e!
sous-arbrisseauxà feuilles $\mathbf{1 - 5}$-foliolées, gousses Avagrae..... non articulées.

B. Calice coloré, divisé jusqu'à la base en 2 segments. Arbrisseaux très-touffus et très-épineux, à fenilles aciculaires, fleurs jaunes. . Arove....... \&

$\mathbf{B}^{\prime}$. Calice vert, non divisé jusqu’à la base en 2 segments.

C. Calice tubuleux, à b’ dents courtes.

D. Calice persistant, enflé à la maturité. Sousarbrisseaux très-épineux, à feuilles unifoliolées, fleurs bleues........ Eruvacée.....

D'. Calice se rompant circulairement au moment de la floraison. Sous-arbrisseaux épineux; à feuilles 5 -foliolées, fleurs jaunes .................. Calrcotomr.... \& 
C1. Calice en forme de spathe. Arbrisseaux à rameaux jonciformes, non épineux, à feuilles 1 -foliolées, fleurs jaunes....... Spartikr...

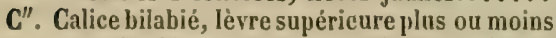
profondément bidentée, l'inférieure tridentée.

D. Siyle enroulé ou fortement arqué ; calice à 2 lèvres courtes, divariquées, faiblement dentées. Sous-arbrisseaux non épineux, à feuilles 5-foliolées, à fleurs jaunes... SAnotnamnв . 6

$D^{\prime}$. Style non enroulé et simplement arqué au sommet.

E. Gousse non tuberculeuse-glanduleuse.

F. Calice à lèvres dressées du même côté, la supéricure profondément 2-séquée. Sous-arbrisseaux épineux ou non épineux, à feuilles le plus souvent 1-foliolées; fleurs jaunes.......................

F'. Calice à lèvres divariquées, la supérieure tronquée ou simplement 2dentée. Arbres, arbrisseaux et sousarbrisseaux non épineux, à feuilles 5-foliolées; fleurs jaunes ....... Crrıse...... 8

E'. Gousse tuberculeuse-glanduleuse. Sousarbrisseaux non épineux, à feuilles 3-foliolées, fleurs jaunes......... AdÉnocanpe ...9

C'II. Calice campanulé à 5 divisions profondes. Sous-arbrisseaux ou plantes vivaces à feuilles 5 -foliolées, folioles dentées;

fleurs roses, blanches ou jaunes...... Bugrave.... 10

A". Etamines diadelphes. Arbres oll arbrisseaux a feuilles oppositi-imparipenaées.

B. Gousse non articulée.

C. Gousse comprimée. Arbres à stipules fortement épineuses; fleurs blanches ou roses. Rodinisr..... 11

$C^{\prime}$. Gousse enflée-vésiculeuse. Arbrisseaux non épineux, à fleurs jaunes........... Baguenaudien. 12

B1. Gousse articulée, grêle, cylindrique, se rompant transversalement en troncons. Sousarbrisseaux à fleurs jaunes.......... Cononille....

Section I. - Etamines libres; gousse non arliculée.

GenRe I. - ANAGYRE. ANAGYRIS. Tournef.

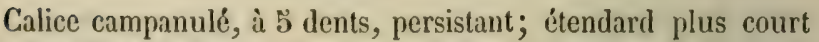
que les ailes; celles-ci plus courtes que la carène, dont les 2 pétales sont libres. Style droit. Gousse allongée, compriméc, 
PAPILIONACÉES.

polysperme. - Arbrisseaux non épineux, 3-foliolées, à fleurs jaunes.

Bois jaunâtre, à accroissements peu distincts. Vaisseaux ne formant pas de zone au bord interne de chaque couche; groupés avec du parenchyme ligneux en lignes ondulées, obliques, qui simulent un réseau à mailles ébauchées. Rayons médiocrement épais.

Anagyre fétide. Anagrris foetida. Lin. Bois puant.

Feuilles 5-foliolées, pétiolées; folioles sessiles, elliptiques, mucronulées, entières, d'un vert glauque sur les deux faces, glabres en dessus, très-finement couvertes de poils appliqués en dessous. Fleurs yrandes, jaunes, avec l'étendard taché de noir, en grappes courtes pauciflores, feuillées à la base. Gousses grandes, irrégulières, de $12-20$ cent. sur 15.20 mill., brunes, glabres, pendantes, contenant 5-8 grosses graines allongées, réniformes, violetles. - Arbrisseau de $5-4^{\mathrm{m}}$ de hauteur sur 50-10 cent. de circonférence au plus, à écorce grisâtre, fétide ainsi que les feuilles, à rameaux arrondis non striés. Coleaux arides et rochers de la Provence et de la Corse. Très-commun en Algérie. Flor., févriermars.

Les feuilles de cet arbrisseau sont émétiques et purgatives. Section II. Etamines monadelphes; gousse non articulée;
feuilles $1-3$-foliolées.

(Végétaux souvent épineux par transformation des rameaux.)

geNRE I1, - AJONC. ULEX. Lin.

Calice bilabié, persistant; pétales également allongés; étendard redressé, ailes étalées; style courbé au sommet. Gousse ovale, enflée, égalant ou débordant à peine le calice, oligosperme. - Sous-arbrisseaux à rameaux et ramules verts, très-épineux, à feuilles aciculaires, persistantes et ì fleurs jaunes, axillaires.

Les 30144 premières feuilles sont tri-foliolées et pourvues d'un limbe plane; mais dans les suivantes, ce limbe avorte et les pétioles plus ou moins dilatés se transforment en pointes simples, effilées et rigides (Phyllodes) qui désormais constituent tout le feuillage. Insertion $\frac{3}{8}$.

Bois jaunàtre, sans zone interne de vaisseaux plus gros et plus serrés, et par conséquent à accroissements peu distincts; vaisseaux groupés avec du parenchyme et constituant des faisceaux irrégulièrement épais, qui dessinent un él'́gant réseau à larges mailles presque complètes; rayons inégaux, fins-moyens, indéfinis, 
A. Sous-Arbrisseau d'un vert cendré, à épines robustes.

B. Ailes plus longues que la carc̀ne.

C. Calice mollement velu; fleurs grandes

(13 mill. de long.)............. A. n'Eunope...... 1

$\mathrm{C}^{\prime}$. Calice à poils appliqués; fleurs moyen-

nes $(10-11$ mill. de long.)......... A. de Le Galk... 5

$B^{\prime}$. Ailes plus courtes que la carène; fleurs

petites (7-8 mill. de long.)........... A. a petites fleurs. 4

A'. Sous-arbrisseau d'un vert brillant; à épines grêles, très-nombreuses et touflues; fleurs petites (7-8 mill. de long.), à ailes un peu plus courtes que la carène............

A. $\operatorname{varn} . \ldots \ldots .2$

1. Ajone al'aurope. Ulex eunop.cus. Liv. Landier; Jone marin. Feuilles aciculaires, persistantes, d'un vert cendré, portant à leur aisselle un rameau toujours terminé en épine. Fleurs solitaires ou géminées, d'un jaune clair, grandes, accompagnées de bractéoles largement ovalesaiguës; calice jaunâtre, couvert de poils mous, semi-élalés; corolle à carène droite évidemment plus courte que les ailes. Gousse de $15-20$ mill. sur 6-7, très-velue-soyeuse, brune, aux $5 / 4$ cachée dans le calice, contenant 5-6 graines olivâtres, échancrées à l'ombilic qui est ovalc. Sous-arbrisseau de $\mathrm{I}^{\mathrm{m}}-\mathrm{I}^{\mathrm{m} 300}$, à tige irrégulière, revètue d'unc écorce grise, longitudinalement gerȩurée; à rameaux et ramules dressés, verts, sillonnés, velus, tout hérissé d'épines raides et divergentes, formant un buisson robuste, très-touffu, toujours vert. Terrains vagues el landes de Ia France occidentale, de Bayonne en Normandie. Flor., avril-juin. Fructif., été de la floraison.

L'ajone d'Europe est extrèmement commun dans toutes les landes sablonneuses de l'ouest et couvre souvent ì lui seul de vastes étendues de terrains vagues; on le retrouve ẹa et lia, disséminé sur d'autres partics de la lirance, mais il $\dot{s} y$ maintient difficilement et n'y est probablement pas indigène. Les jeunes pousses, forment un excellent fourrage, lorsqu'elles sont hachées.

Le bois, blane jaunâtre veiné de brunâtre au coeur, cst dur, lourd, d'un grain assez grossier. Celui d'une tige de 1 th ans et de $0^{\mathrm{m}} 09$ de diamètre, parfaitement desséché à l'air et provenant de la Gironde, pèse 0,91 (Coll. Ec. For.). II donne un bon combustible pour le chauffige des fours et quelquefois il est cultivé pour cet usage. On en forme des haies excellentes, impénétrables, d'une taille facile.

2. Aone nain. Ulex nanus. Liv. Bruyère jaune. Vignol (Manche). l'us petit que le précédent dans toutes ses parties; feuilles et rameaux épineux qui naissent à leur aisselle beaucoup plus grêles el plus serrés; d'un vert luisant. Fleurs de moitié moindres, d'un jaune foncé avec l'é- 
lendard veiné de xouge, pourvues de bractéoles proportionnellement plus petites, ovales-oblongues. Calice à pubescence peu serréc, courte, exactement appliquée; carène courbéc, plus large et un peu plus longue que les ailes. Gousse de 8-9 mill. sur échancrées, à ombilic orbiculaire. - Arbrisseau de 0 măo, à rameaux velus, diffus, couchés ou ascendants, à épines très-nombreuses et grêles et à racine rampante. Landes de l'ouest, de Bayonne jusqu'en Brelagne; çà et là dans le reste de la France; s'avance vers l'est jusqu'à Lyon. Flor., juillet-octobre. Fructif., annce qui suit la floraison.

\section{3. jone de Ge Gall. Ulex gallir. Planchon.}

Feuilles et rameaux ép̧ineux d'un vert cendré, presque aussi robustes que dans l'ajone d'Europe. Fleurs intcrmédiaires entre celles de ce dernier et de l'ajone nain, d'un jaune orangé, pourvues de bractéoles petites, ovales-oblongues; calice légèrement pubescent, à poils appliqués; ailes à peine plus longues que la carène. - Sous-arbrisseau à rameaux ascendants, moins robuste que l'ajone d'Europe, plus fort que l'ajonc nain, et probablement hybride de ces deux espèces. Se trouve disséminé parmi ces dernières; Morbihan, Belle-Hle-en-Mler. Flor. août-novembre.

4. Jone at petiteg leurs. Unex paniflones. Porna. Ajonc de Provence.

Voisin de l'ajone d'Europe pour le port el la coloration d'un vert cendré, de l'ajonc nain pour la petitesse des fleurs, ressemble plus encore à l'ajone de Le Gall, mais bien distinct; calice légèrement pubescent, à poils courts et couchés; corolle non veinée, dont la carène est droite, plus large et plus longue que les ailes. Gousse dépassant le calice, à graines non échancrées, à ombilic orbiculaire. - Sous-arbrisseau intermédiaire cntre les deux premiers du genre pour la taille, mais ne pouvant être considéré comme leur hybride, puisqu'il ne se rencontre point parmi cux; à épines robustes, feuilles courtes, tiges presque glabres, racine non rampante. Lieux stériles du littoral de la Méditerrauée, d'où il s'élève jusqu'au sommet des Albères (Pyrínées orientales). Flor., avril. Fructif., mai. lefleurit en automne.

GENRE IIr. - ERINACÉE. ERINACEA. Clus.

Calice persistant, tubuleux, à 5 dents courtes, finalement vésiculeux. Pétales longuement onguiculés; style arqué; stigmates en tête; gousse oblongue, saillante, oligosperme. - Arbrisseaux ì feuilles unifoliolées, épineux.

Bois identique à celui des sarothamnes.

Frinacée épineuse. Eniracea pungens. Borss. Anthyllis erinacea. Lin.

Feuilles uni-foliolées, très-caduques, courtement pétiolées, linéaires, velues-soycuses, opposées, sauf la supérieure qui est alterne. Fleurs d'un hleu rougeâtre, solitaires ou rélinies 2 ou 5 sur un court pédoncule axillaire; calice muni de poils appliqués, à tube ovale, enfé. Gousse de 20 mill. sur 5 , brune, couverte de poils appliqués, contenant $\&-6$ graines 
ovales, comprimées, olivâtres, luisantes. - Sous-arbrisseau de 1-2 décimètres de hauteur, à tige striée, tortueuse, très-rameuse, trichotome, à rameaux très-serrés, dressés, étalés, fortement épineux, à peine feuillés, formant un buisson touffu, hérissé d'épiues de toutes parts. Pyrénćes orientales, Corse, Algérie. Flor., mai.

\section{GENRE IY. - CALYCOTOME. CALYCOTOME. Link.}

Calice ovoïde couronné par š petites dents et se rompant circulairement par le milieu au moment de la floraison; étendard dressé, carène recourbée; style arqué; gousse comprimée, à suture ventrale élargie et étroitement ailée de chaque côté. Sous-arbrisseaux épineux, à feuilles 3̈-foliolées, à tleurs jaunes.

Bois identique à celui des sarothamnes.

A. Fleurs solitaires ou en faisceaux, au nombre de 2-\{. Rameaux glabres................. C. f́ptneux.. 1

$\mathbf{A}^{1}$. Fleurs en faisceaux, au nombre de 8-15. Rameaux gris, couverts d'un duvet pulvérulent........ C. vELU.....2

1. Calycotome épineux. Calycotone spinosa. Link. Sparlium spinosum. Lin. Cytise épineux; Arjalac.

Feuilles pétiolées, 5 -foliolées, à folioles subsessiles, obovales, obtuses, glabres en dessus, pourvues en dessous de quelques petits poils appliqués. Fleurs assez grandes, jaunes, solitaires ou fasciculées en petit nombre, 2-4, portées sur des pédicelles pourvus ì leur extrémité d'une bractée trifide. Gousse de 53 mill. sur 8 , aplatie, glabre, luisante et noire à la maturité, à suture ventrale seule étroitement ailée. - Sousarbrisseau de $1^{\mathrm{m}} \mathrm{y}^{0}-2^{\mathrm{m}}$, à tige dressée, torlueuse, très-rameuse, couverte d'une écorce gercurée-membraneuse d'un brun rougeàlre, à rameaux et ramules glabres, striés, divariqués, fortement spinescents. Lieux arides el montueux de la régrion méditerranéenne. Corse, trèscommun en Algérie où il peuple de vastes surfaces, mélangé aux palmiers uains et aux lentisques. Flor., mai-juir.

2. Calycotome velu. Calycotome villosa. Link. Cyjtisus lanigerus. $D C$.

Se distingue du précédent par ses feuilles velues-soycuses en dessous, par ses fieurs fasciculées en plus grand nombre, 8-13, vers les extrémilís des rameaux, et dont les pédicelles sont accompagnés d'une bractée presque entière; par ses calices velus et par ses gousses, de 2j-50 mill. sur 6 , qui sont très-velues, largement ailées-ondulées sur la suture ventrale, étroitement ailées sur la dorsale. - Sous-arbrisseau de $1^{\mathrm{m}}$ environ de hauteur, à tige dressée, trìs-rameuse, à rameaux striés, légèrement gris-tomenteux, divariqués, spinescents. Curse, Algérie. Flor., avril-mai. 
genre v. - SPARTIER. SPARTIUM. Lin.

Calice persistant, fendu dans toute sa longueur, en forme de suathe. Etendard grand, dressé; ailes étalées; carène de 2 pétales libres. Style courbé au sommet. Gousse linéaire oblongue, comprimée, polysperme. - Sous-arbrisseaux non épineux, à rameaux allongés, fistuleux, joncilormes, à feuilles uni-foliolées, à fleurs jaunes.

Bois comme celui des sarothamnes, mais à canal médullaire assez développé.

Spartier d'espagne. Spartium junceum. Lin. Genêt d'Espagne.

Feuilles rares, très-espacées, subsessiles, à une seule foliole oblonguelancéolée, glabres en dessus, parsemées en dessous de petits poils appliqués. Fleurs grandes, jaunes, odorantes, solitaires, formant une sorte de groppe lâche à l'extrémité des ramcaux. Gousse de 60-80 mill. sur 7, finement rebordée sur les 2 sutures; preque glabre, noire et luisante à la maturité, contenant 12-18 graines ovoïdes, jaunàtres, luisantes. Arbrisseau de $2-4^{\mathrm{m}}$ de hauteur el même plus, à tige dressée, rameuse; à rameaux dressés, allongés, cylindriques, compressibles, finement striés, d'un vert glauque, à peine feuillés. Lieux secs de la France méridionale; Algérie. Flor., mai-juillet.

Le spartier d'Epagne est fréquemment cultivé comme arbrisseau d'ornement, en raison de l'abondance et de l'odeur' suave de ses fleur's. Le liber' en est très-fibreux et l'on retire de celui des ramules une matière textile de bonne qualité, dont on fait de la toile ou des cordes, suivant sa finesse. C'est une ressource d'autant plus précicuse que cet arbrisseau croit dans les terrains les plus secs, où la culture du chanvre et du lin est impossible. Ses pousses servent encore de liens dans le jardinage et donnent un assez bon fourrage. Les graines, comme celles de la plupart des genèts, sont purgatives.

\section{gENRE VI. - SAROTIAMNE. SAROTIIAMNUS. Wimmer.}

Calice persistant, bilabié, à lèvres courtes, divariquées, la supérieure faiblement 2-dentée. Etendard redressé ; style très-long, enroulé sur lui-même ou fortement courbé; stigmate terminal; gousse oblongue, comprimée, polysperme. - Sous-arbrisseaux non épineux, à feuilles 3 foliolées, dont l'indice d'insertion est $\frac{2}{5}$; à fleurs jaunes.

Bois d'une structure semblable à celle de l'ajonc, mais à fibre 
plus fine, à faisccaux moins épais, ofl'rant sur la tranchı un dessin réticulé ì mailles plus petites et souvent incomplètes.

A. Feuilles inférieures pétiolées, 5-foliolées; les supérieures sessiles, unifoliolées............ S. comaun.... 1 $\mathrm{A}^{\prime}$. Toutes les feuilles pétiolées el כ̃-foliolées...... S. anвonescent 2 $\mathrm{A}^{\prime \prime}$. Toutes les feuilles sessiles, 5 -foliolées ........ S. pungatrf... 5

1. Garothamue commun. Sarothimes rulgaris. IVimar. Sparlium scoparium. Lin. Genista scopariu. DC. Genèt à balais.

Feuilles inférieures pétiolées, 5-foliolées, à folioles elliptiques ou obovales, pubescentes surtout en dessous; feuilles supérieures uni-foliolées, sessiles. Fleurs grandes, de 20 mill. de longr, glabres, jaunes, axillaires, solitaires ou géminées, à carène courbée, obluse; style velu inférieurement, earoulé en ressort de montre, élargi supéricurement. Gousse comprimće, de 40 - 48 mill. sur 8 , noire, fortement ciliée sur les deux sutures, à S-12 graines olivâlres, luisantes. - Sous-arbrisseau de $2-\tilde{\nu}^{\mathrm{m}}$, à lige irrégulière, recouverte d'une ćcorce lisse, d'un gris verdàtre el à ramules nombreux, dressés, allongés, souples, verts, cannelés-anguleux; lourgeons très-petits, d'un brun verdàtre, bi-écailleux et bilobés. Eminemment silicicole et social et répandu daus toute la France. Flor., maijuin.

Le sarothamne commun est, dans le langage ordinairc, le genèt par excellence et, bien que les exigences de la nomen-clature lui aient depuis longtemps déjà imposé le premier de ces noms, l'usage persiste à lui maintenir son ancienne dénomination. Extrèmement commun sur les terrains vagues siliceux, feldspathiques et sehisteux, il envahit les sols forestiers découverts, aceuse leur appauvrissement, mais non leur stérilité comme la bruyère, et devient souvent funeste aux jeunes peuplements sur lesquels il forme des fourrés serrés. Dans plusicurs parties de la France, Bretagne, Ardennes, ete., on le laisse se développer librement sur les terrains improductils et au bout de quelques années on y pratigue l'écobuage ; les cendres qu'il abandonne permettent d'obtenir une récolte de graminées, de seigle particulièrement.

Le bois du genêt à balais est verdâtre, grisâtre ou jaunitre, et se colore au centre d'un beau brun marron, veiné. Celui d'une tige de 10 ans et de 7 centimètres de diamètre, desseché à l'air, pèse 0,9\%. (Coll. Lic. for.) Il donne une lamme vive et claire et convient très-bien au elauffage des linurs. Les ramules servent a faire des balais. L'écoree fournit des cordes grossieres; toute la plante enfin renferme du tamin et peut être utilisće sous ce rapport. 
2. Sarothamue artuorescent. Sarotilanus arboneus. WVebi. Genèl arborescent.

Feuilles toutes péliolées et 5 -foliolées, mème les florales; fleurs plus petiles que dans l'espèce précédente, longues de 13-17 mill., à carène droite; style glabre, enroulé sans former le cercle complët, non élargi au sommet. Gousse glabre ou presque glabre, noire, luisante, à graines noires, mates. - Arbrisseau de $2-4 \mathrm{~m}$; à tige dressée très-rameuse, à rameaux sillonnés, verts et glabres sur les cûles, grisâtres-tomenteux lans les sillons. Coteaux des Pyrénćes-orientales, Algéric. Flor., juin.

3. Sarothamme purgatif. Sarotuanues purgans. Gr. et God. Spartium purgans, Lin. Gronista purgans. $D C$. Genèt purgatif; Genèt griot.

Feuilles très-pelites, rares, toutes sessiles, 5-foliolées, les florales exceptées qui sont simples. Fleurs beaucoup plus petites que dans les espèces précédentes, de 12-14 mill. de long, axillaires, solitaires et formant une grappe nue au sommet des rameaux; carène un peu courbée; style glabre, arqué, non enroulé ni élargi à l'extrémité. Gousse de 2025 mill. sur 6-7, noire, un peu velue, à graines olivâtres, luisantes. Sous-arbrisseau de 4 -6 décimètres, à tige dressée, très-rameuse, dont les nombreux rameaux sont dressés-rapprochés, cylintliques, striés, à raies alternativement vertes el glabres ou grises el tomenteuses, à peine feuillés, nus inférieurement. Lieux sees, découverts, monlueux de la France centrale et méridionale. Flor., mai-juin.

\section{GBNRE VIr. - GENÊT. GENIST A. Lin.}

Calice persistant, tabuleux, ì 2 lèvres non divariquées, dont la supérieure est divisée en 2 lobes jusqu'il la base, l'inféricure 3-dentée; étendard étroit, le plus souvent non redressé. Carène droite; style courbé au sommet; stigmates obligues. Gousse allongée, comprimée. - Sous-arbrisseaux épincux ou inermes, 1-3-foliolés, à fleurs jaunes.

Bois identique à celui des sarothamnes.

A. Feuilles inférieures uni-foliolées.

B. Rameaux non épineux.

C. Rameaux ailés, herbacés.........

G. sagitté...... I

$C^{\prime}$. Rameaux non ailés.

D. Tiges couchées, radicantes, à rameaux et ramules n'étant pas droits, ni allongés, ni dressés...

$D^{\prime}$. Tiges dressées, rameaux et ramules droits, allongés, dressés.

E. Tiges bien feuillées, terminées par des fleurs nombreuses en panicule composée, pyramidalc.

F. Gousse de 20-23 mill, de long. à sommet lancéolé........ 
$F^{\prime}$. Gousse de 50 mill. de long, à sommet arrondi........ G. De Delanbre... 4 $\mathrm{E}^{\prime}$. Tiges peu feuillées, garnies de fleurs latérales formant de longues grappes composées, cylindriques, grèles............

G. CENDRÉ....... ๖

B'. Rameaux épineux.

C. Rameaux tuberculeux, épineux au sommet seulement...............

G. aspalatmoïde... 6

C'. Rameaux pourvus d'épine
divariquées ou étalées.

D. Fleurs non disposées en capilules ombelliformes terminaux.

E. Fleurs insérées sur des rameaux épineux peu ou point feuillés.

F. Fleurs insérées sur des épines latérales peu feuillées, sinples ou peu rameuses; formant dans l'ensemble une longue grappe composée, épineuse, multiflore........

G. épine-fleurie... 7

$F^{\prime}$. Fleurs insérées sur des épines latérales non feuillées, presque toujours simples; formant une courte grappe composée, épineuse, pauciflore.................

E'. Fleurs insérées sur des rameaux non épineux, feuillés.

F. Epines toutes simples; flcurs peu nombreuses en grappes courtes, terminales; feuilles glabres.................

G. D'Angleterre... 9

$F^{\prime}$. Epines simples ou rameuses; pes allongées, terminales; feuilles velues............

G. de Consz..... 8

$D^{\prime}$. Fleurs en capitules ombelliformes terminaux ; rameaux pourvus, jusqu'au-dessous des fleurs, d'épines grèles, ramenses.............. 1. Espacne .... 11

$\AA^{\prime}$. Feuilles inférieures 3 -foliolécs.

B. Rameaux épineux.

C. 1 ou 2 fleurs terminales; sous-arbrisseaux très-touffus, hérissés d'épines de toutes parts...............

C1. Fleurs latérales, formant une grappe; sous-arbrisseaux à peine épineux... G. ÉPHÉDnöior.... 13

B'. Rameaux non épineux.

C. lieuilles coriaces, linéaires, à bords enroulés en dessous ...........

G. I FEUILLES DE LIN 14 
C'. Feuilles molles, obovales-obtuses, planes.................... G. вLancnatnв....

\section{§ I. Genêts à feuilles 1-foliolées, non-épincux.}

1. Genêt sagitté. Genista sagittalis. Lin. Genêt herbacé.

Feuilles sessiles, écartées, non stipulées, ovales ou lancéolées, poilues. Fleurs longues de 10-15 mill., courtement pédicellées, formant au sommet de chaque rameau un épi dense, ovoïde, non feuillé; calice velu; étendard el ailes glabres, carène légèrement pubescente en dessous, tous d'égale longueur. Gousse velue, de 15̋-20 mill. sur 5 , brune, bosselée. contenant 5-6 graines ovoïdes, olivâtres, luisantes. - Sous-arbrisseau de 1-5 décimètres, social et gazonnant, à tiges rampantes, radicantes, émettant chaque année des rameaux noinbrcux, dressés, herbacés et annuels, garnis de 5 ailes foliacées très-développées, interrompues à l'articulation des feuilles. Très-commun sur les pelouses, les pâturages et les clairières; forêts des régions de collines ou de montagnes de presque toute la France, quelle que soit"la nature minérale du sol. Flor., mai-juin.

2. Genêt poilu. Genista rilosa. Lin.

Feuilles un peu coriaces, subsessiles, à stipules dentiformes à peine visibles; obovales, atténuées à la base, obtuses à l'extrémité, pliées en gouttière, longues de 10-15 mill.; glabres en dessus, couvertes en dessous de poils blancs-soyeux applliqués. Fleurs solitaires ou géminées, latérales, courtement pédonculées, de 10 mill. de long, formant à l'extrémité des rameaux de longues grappes lâches, feuillées, uni-latérales; calice et étendard couverts de poils blancs appliqués; celui-ci débordant la carène qui n'est soyeuse qu'au bord inférieur. Gousse de 20-2: mill. sur 4, soyeuse, bosselée, noircissant à la maturité, contenant 5-7 graines globuleuses-comprimées, olivâtres. - Arbrisseau de 5-̋̋ décimètres, rarement de $1^{m}$ de haut, à tiges couchées à la base, à rameaux redressés, tuberculeux, diffus, flexueux, bruns, arroudis, à ramules verts et sillonnés. Très-commun dans les bois des régions montuouses ou montagneuses de toute la France et sur tous les terrains, pourvu qu'ils soient secs. Flor., mai-juin.

3. Genêt des teinturiers. Genista tinctoria. Lin. Génestrole.

Feuilles sessiles, nombreuses, accompagnées de 2 très-petites stipules subulées; étroitement lancéolées-aiguës ou ovales obtuses, glabres et luisantes sur les deux faces, plus rarement pubescentes, à bords velus; celle's des ramules longues de 10-12 mill., celle des rameaux de 25-50. Fleurs solitaires, axillair's, de 10-1\% mill. de long, presque sessiles, formant à l'extrémité des ramules de courtes grappes dressées qui, par leur réunion, constituent une panicule composée, pyramidale; calice et corolle glabres; étendard et carène égaux. Gousse de 23.50 mill. sur 4 , glabre, très-rarement velue-tomeateuse (G. perreymondi. Lois.), luisante, brune, un peu arquée, à sommet lancéolé, contenant 6-12 graines orbiculaires-comprimées, olivàtres, mates. - Sous-arbrisseau dont la souche seule ou les prarties inférieures de la tige sont ligneuses et émettent des rejets droits, annuels, peu ligneux, qui se ramifient en ramules 
droils, verts, arrondis, striés, dressés-étalés, de plus en plus grèles, el bien garnis de fenilles de taille décroissante. Pelouses sèches, clairières et bords des bois des régrions de collines ou de montagnes de toute la France. Flor., mai-juillet.

Les sommités fleuries de ce genèt étaient autrefois employées en teinturerie.

4. Genêt de Belarbre. Genista delanbrer. Lecoọ. et Lam.

Très-voisin du genêt des teinturiers, se distingue par sa taille moins élevée, ses feuilles, ses fleurs, ses fruits plus grands. Gousses arrondies au sommet; graiues plus grosses, ovoüdes, d'un brun marron foncé el luisant. Montagnes voleaniques de l'Auvergne; Pyrénćes. Hlor., juilletaoût.

5. Genêt cendré. Genista cinenea. DC.

Feuilles rares, non stipulées, petites, de $\lfloor-10$ mill. de long, sessiles, ćtroitement lancíolées, oblongues ou obovales, velues-soyeuses en dessous. Fleurs solitaires ou géminées, faiblement pédicellées, naissant de très-courts ramules latéraux, à peine fenillés à la base ef formant, par leur réunion, de longues grappes dressées, làches el grêles; calice velu-soyeux; étendard égalant la carène, à nervure médiane pubescente, glabre sur tout le reste, ainsi que les ailes; carène velue-soyeuse. Gousse de 15-20 mill. sur 4 à 5 , velue-soycuse, contenant $2-5$ graines ovoüdes, luisantes, olivàtres. - Sous-arbrisseau de $\ell_{x-S}$ décimetres, d'un vert blanchâlte, à feuillage rare et grêle, à lige dressie, très-rameuse, produisant des ramules rapprochés, grêles, allongés, Iressés, striés et verts. Alpes du Dauphiné et de la Provence, Pyrénées-Orientales. Flor., maijuin.

Ce genèt sert au chauffage; on fait des balais avec ses jeunes rameaux.

\section{§II. Genèts unifoliolés, épineux.}

6. Gienêt aspalathöide. Genista aspalatioüdes. Lam. G. Salzmanni et Lobelii. $D C$.

Feuilles rares, petites, subsessiles, non stipulées, obovales ou linéaires oblongues, pubescentes. Fleurs solitaires vu fasciculćes par $2-4$, pédiecllés, disposées latéralement vers l'extrémité de rameanx épineux au sommet. Calice velu; étendard pubesecnt, égalant la carène qui est velue. Gousse de $10-15$ mill. sur $/ 4$, couverte de pelits poils appliqués, contenant 2-4 graines globuleuses-comprimées, brunes. - Sous-arbrisscan de 1-3̈ décinctres, à lige dressée tortucuse, très-rameuse, dont les rameaux, profondément striés, sont tuberculeux et terminés en ramules verts, numbrenx, dressés, spinescents à l'extrémité el forment dans l'ensemble un huisson touffu, à peine feuillé, hérissé de toutes parts. T'oulon, Marscille, Corse, Algérie. Flor., juin.

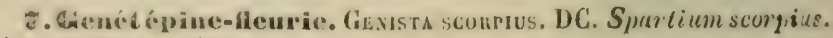
Iin. Genct scorpion. 
Feuilles rares, petites, de \& à bै mill. de long, subsessiles, accompa gnées de 2 stipules épincuses; terminées en pointe spinescente, pourvues en dessous de quelques poils appliqués; celles des rameaux stériles linéaires-lancéolées, celles des rameaux florifères ovales ou obovales, Flcurs pédicellées, de 12 mill. de long, en faisceaux axillaires, légèrement feuillés à la base, rapprochés el nombreux, disposés à l'extrémité des rameaux et sur des ćpines latérales, et formant, dans leur ensenble, une longue grappe composéc, épineuse; calice et corolle glabres; étendard un peu plus grand que la carène. Gousse de 20-3 J mill. sur b, glabre, contenant 3-7 graines ovoüles-comprimées, olivâtres. - Sousarbrisseau de 1 à $2 \mathrm{~m}$, glabre, très-pen feuillé, à lige dressée très-rameuse, rameaux étalés, entrelacés, striés, épineux au sommet et garnis de nombreuses épines latérales, robustes, simples ou rameuses, divariquées. Collines sèches et stériles; France méridionale, Corse, Algérie. Flor., mai-juillet.

\section{Aienêt de Corse. Genista consica. DC.}

Feuilles rares, petites, subsessiles, pourvues de 2 stipules spinescentes; obovales ou oblongues, glabres ou pubescentes dans la jeunesse. Fleurs pédicellées, solitaires, ou 2-6 en petits faisceaux non feuillés à la base, insérées sur des ramules courts, épineux, latéraux, placés au-dessous de l'épine qui termine chaque rameau; calice et corolle glabres; étendard égalant la carène. Gousse de 15-50 mill. sur 4-5, glabre, contenant $4-8$ graines ovoïdes, noires. - Sous-arbrisseau de 2-6 décimètres, glabre ou pubescent, à peine feuillé, à tige dressée, très-rameuse, à rameaux étalés-dressés, entrelacés, striés, spinesceuts au sommet et garnis d'épines latérales étalées, assez robustes, courtes et généralement simples. Coteaux du littoral de la Corse. Flor., juin.

9. Genêt d'Angleterre. Genista anglica. Lín.

Feuilles petites, de stériles étroitement lancéolées-niguës, celles des rameaux fertiles légìrement obovales, aiguës ou obtuses; stipules nulles. Fleurs petites, longues de 9 à 10 mill., pédicellées, solitaires et latérales, formant de petiles grappes feuillées; calice et corolle glabres; étendard plus court que la carène. Gousse de 12-15 mill. sur 5 , courbéc en $\mathrm{S}$, presque cylindrique, glabre, brune et mate, contenant 6-10 graines ovoïdes, noires, luisantes. - Sous-arbrisseau de 4-10 décimètres, glabre, à tige dresséc, trèsrameuse; rameaux grêles, nus à la base, arrondis, armés d'épines grêles el simples, étalées-dressées el revètus d'une écorce brune el membraneuse; ramules verts et striés, les floraux incrmes. Commun sur les coteaux arides et dans les bois de presque toute la France; manque complétement dans le nord-cst. Flor., avril-juin.

10. Genêt d'Memagne. Genista germanica. Lin.

Feuilles assez graudes, de $12-13$ mill. de long, subsessiles, lancéolécs, molles, un peu luisantes, ciliées. Fleurs petites, de 10 mill. au plus, pédicellées, disposées 6 -1! en petites grappes dressées, oblongues, non feuillées, terminant des ramules scrés, grèles, dressés el fcuillés dans la plus grande partie de leur longueur; calice longuement velu; corolle pubescente, à étendard beaucoup plus court que la carène. Gousse de 8-10 mill. sur 5, velue, brune, contenant 2 ou 5 graines ovö̈des-com- 
primées, brunes, luisantes. - Sous-arbrisseau de 5-8 décimètres, velu, à tiges et rameaux grisâtres, dressés, non feuillés, armés d'épines ćlalées, grèles, simples ou rameuses, et produisant à leur extrémité des ramules verts, striés, dressés, densément feuillés et inermes. Forèts à sols sablonneux ou pierreux de différentes parties de la France. Flor., maijuin.

11. Cienêt d'Ëspagne. Grista inispanica, Liv.

Feuilles peu nombreuses, subsessiles, oblongues-linéaires, aiguës ou obtuses, de 10-12 mill., longuement velues, non stipulées. Fleurs petites, de 7 à 8 mill., pédicellées, disposées 6-12 en capitules ombelliformes terminaux; calice longuement et mollement velu ; étendard glabre, égalant presque la carène qui est pubescente. Gousse de 9 à 10 mill. sur 5 , longuement poilue, noire, contenant 1 ou 2 graines ovoïdes, brunes. Sous-arbrisseau de 1 à 2 décimètres, à tige dressée très-rameuse, nue inférieurement; rameaux très-gुrèles, grisâtres, diffus, non fcuillés, terminés par des ramules verts, striés, très-velus, médiocrement feuillés; épines grêles, très-rameuses, contractées à leur extrémité en une pointe fine, garnissant les rameaux et ramules, mème ceux qui portent fleurs. Coteaux sees du Dauphiné méridional, des Cévennes, de la Provence et des Pyrénées; Algérie. Flor., mai-juin.

\section{$\S$ III. Genêts tri-foliolés, épineux.}

\section{Genêt éphédroide. Genista epuedroïdes. DC.}

Feuilles peu nombreuses, les inférieures 5-foliolées, les supérieures uni-foliolées, courtement pétiolíes, non stipulées; folioles linéaires ou linéaires-oblongues, légèrement velues-soyeuses. Fleurs petites, latérales, courtement pédicellées, formant dans leur ensemble une sorte de grappe; calice revêtu de poils appliqqués; étendard plus court que la carène, l'un et l'autre velus-soyeux. Gousse de 10 mill. sur $\mathfrak{3}$, velue-soyeuse, contenant 1-5 graines globuleuses. - Sous-arbrisseau de 5-10 décimètres, à tige dressée, rameuse; rameaux rapprochés, dressés, striés; les florifères grêles, raides, à peine spinescents au sommet. Liltoral de la Corse. Flor., avril-mai.

13. Genêt très-épineux. Genista honmida. DC.

Feuilles peu nombreuses, 5 -foliolées, opposées, pétiolulées, accompagnées de 2 stipules spinescentes, à folioles linciaires-oblongues, presque aciculaires, plices en gouttiere, velues-soyeuses. Fleurs courtement pédicellées, solitaires ou géminées au sommet des ramules, longues de 15-15 mill.; calice velu; ćtendard pubescent égalant la carène qui est ciliéce au borl infírieur. Gousse de $15-20$ mill. sur 5 , jaunâtre, soyeuse, contenant 1-5 graines ovoïdes, brunes, dont le funicule est dilaté sur le hile (ce caraclère, qui ne se rencontre dans aucune des espèces précédentes, se retrouve dans toutes celles qui suivent). - Très-petit sousarbrisseau de 1 à 2 décimètres, d'un vert blanchitre, à tige dressée, grisâtre, extrèmement rameuse, trichotome, dont les rameaux verls, striés, épineux, très-serrés, forment une touffe lérissée de toutes parts. Moutagnes des environs de Lyon. Flor., juin. 


\section{$\S \mathrm{IV}$. Genêts tri-foliolés, non épincux.}

14. Genêt à feuilles de lin. Genista linifolia. Lin.

Feuilles abondantes, sessiles, non stipulées, coriaces, à folioles linéaires-oblongues, de 20-50 mill. de long, à bords fortement enroulés en dessous, soyeuses, surtout inférieurement. Fleurs pédicellées, longues de 10 mill., disposées 6-8 en grappes courtes, ovoïdes et denses, terminales, feuillées à la base seulement; calice velu-soyeux; étendard plus long que la carène, l'un et l'autre velus. Gousse de 15-20 mill. sur 6 à 7 , brune, tomenteuse, renfermant 2 ou 5 graines ovales comprimées, brunes. - Sous-arbrisseau de $2-\not 3$ décimètres, à tige dressée, cannelée, dont les rameaux sont dressés, raides, épars, très-feuillés supérieurement. Toulon, îles d'Hyères, Algérie. Flor., mars-avril.

15. Genêt blanchâtre. Genista candicans. Liv. Cytisus candicans. $\boldsymbol{D C}$.

Feuilles abondantes, pétiolées, peu visiblement stipulées, à folioles planes, herbacées, longues de \$-20 mill., pétiolulées, obovales, obtuses et mucronulées au sommet, atténuées à la base, légèrement pubescentes, plus pâles en dessous qu'en dessus. Fleurs de 13 à 14 mill. de long, disposées 4-8 en capitules ombelliformes accompagnés de 2 feuilles subopposées et terminant de grèles rameaux latéraux; calice velu; élendard et carène glabres, celle-ci un peu plus courte. Gousse de 20-25 mill. sur 5’, très-velue, brune-verdâtre, contenant 4-6 graines orbiculaires-comprimées, noires, luisantes. - Sous-arbrisseau ou arbrisseau de $1-5^{\mathrm{m}}$ de hauteur, d'un port élégant, à tige dressée, rameuse, grise, divisée en rameaux et ramules strićs, verts, bien feuillés. Région méditerranéenne, en France, en Corse el en Algérie. Flor., avril-mai.

\section{GENRE VIII. - CYTISE. CYTISUS. Lin.}

Calice persistant, à 2 lèvres divariquées; la supérieure non divisée en 2 lobes jusqu'à la base, mais simplement bidentée ou tronquée; étendard ovale, dressé ; carène arquée; style cuurbé au sommet, à stigmate oblique. Gousse allongée, comprimée. Petits arbres, arbrisseaux ou sous-arbrisseaux extrêmement voisins des genêts, tri-foliolés, rarement uni-foliolés, non épineux et à fleurs jaunes (pour les espèces indigènes).

Bois à peu près de même structure que celui des genres précédents, mais à accroissements distincts, parce que chaque couche commence par une zone, souvent étroite, de vaisseaux plus gros et plus serrés.

A. Calice court, campanulé.

B. Feuilles tri-foliolées.

C. Fleurs en longues grappes pendantes. 
D. Feuilles d'un vert glauque en dessous ............... C. Faux-Ébénier...... 1

$D^{\prime}$. Feuilles également verles sur les deux faces.............. C. nes Atpes....... 2

C'. Fleurs non en grappes pendantes.

D. 4-6 fleurs en pelites grappes terminales ............... C. A FEULLLes SESSHres. 5

D'. 1-5 fleurs axillaires latérales formant sur le rameau une sorte de grappe dressce, feuilléc...............

B'. Fenilles unifoliolées.............. C. A trois fleurs..... 4

C. ranpant........ $\Lambda^{\prime}$. Calice allongé, tubuleux.

B. Fleurs disposées au nombre de $2-4 \mathrm{cn}$ faisceaux latéraux.

C. Pédicelles égalant le calice....... C. allongé........

$C^{\prime}$. Pédicelles n’égalant que la moitié du

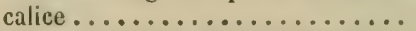

$B^{\prime}$. Fleurs en enpitules ombelliformes terminaux.

C. Tiges dressées.............. C. EN TĖTE....... \&

C'. Tiges couchées ............. C. covcné.........?

\section{$\S$ I. Calice court, campanulé.}

1. Cytise fanx-ébénier. Crtisus laburnum. Lin. Cytise aubours; Albois; Cytise à grappes.

Feuilles très-longuement pútiolées, 5-foliolíes, à folioles péliolulées, elliptiques, apiculées, vertes et glabres en dessus, plus pàles el couvertes de petits poils appliqués en dessons, surtout dans la jeunesse. Fleurs srandes, odlorantes, d'un jaune clair, en longues grappes latírales, lâches et pendantes, feuillées à la base, à pédicelles allongés, soyeux ainsi que l'axe de la grappe el les calices. Gousse de 50-60 mill. sur 8, velucsoyeuse, puis juresque glabre, d'un gris brunâtre clair, bosselée-étranglée, à suture ventrale éraisse, obtusément 5-carénéc, contenant $5-7$ graines réniformes-orbiculaires, déprimées, brunâtres. - Arbrisseau ou arbre de ${ }^{\prime}-10^{\mathrm{m}}$ de hauteur, à ramificalion rare et composée de quelques branclies seulement, par suite de l'arrêt de développement de presque tous les hourgeons laléraux, qui ne produisent que des pousses contractéestuberculenses à feuilles fasciculées; à rameaux arrondis, écorce lisse et rerle. Forèts des collines el montagnes calcaires de l'est de la France : Lorraine, Còte-d'Or, Jura, Bresse, Lyonnais. Souvent subspontanć. Flor., avril-mai.

Le cytise faux-ébénier est frérquemment cultivé comme arbre d'agrément, ì cause de la beauté de ses fleurs el de I'orleur suave qu'elles répandent. Malgré les bonnes qualités de son hois, il est trop rlisséminé dans les forèts pour y être de quelque importance. 
Ce bois présente des vaisseaux assez gros et scrrés au bord interne de chaque couche, décroissant dans la région moyenne et externe en vaisseaux petits et faiblement groupés par courtes lignes obliques ou concentriques qui n'offrent qu'une ébauche de dessin réticulé. Il a l'aubier blanchàtre ou jaunâtre, nettement limité; le cœur fortement coloré, variant du jaune brunåtre au brun verdâtre et au brun noiràtre, ce qui l'a fait comparer à l'ébène; il est brillant, dur, lourd, très-souple et très-élastique, il prend un beau poli et serait recherché par les tourneurs, ébénistes etc., s'il était plus commun.

L'écorce reste lisse el verte jusqu'à un âge avancé ; elle passe alors au brun verdàtre et se recouvre d'un périderme subéreux, mince, coriace et membraneux comme du parchemin, qui s'enlève quelquefois par lames circulaires et sous lequel l'enveloppe cellulaire verte reste toujours active.

Les feuilles, les gousses et les graines ont des propriétés purgatives prononcées; cependant les ruminants les broutent sans inconvénients.

2. Cytise des Alpes. Crtisus alpinus. Mirl.

Très-roisin du précédent et souvent confondu avec lui; se recunnait à ses feuilles également vertes sur les deux faces, tout à fait glabres ou simplement garnies sur les bords et sur le pétiole de petits poils mous étalés; à ses fleurs plus petites, d'un jaune plus foncé, en grappes plus longues et plus grêles, dont les axes et les calices sont glabres ou couverts de poils étalés; à ses gousses toujours et complétement glabres, luisantes, à sulure ventrale aigûment 5-carénée. Assez commun dans les forêts du Jura ế des Alpes du Dauphiné. Flor., juin-juillet.

Le bois est identique à celui du cytise faux-ébénier, mais le dessin réticulé formé par les vaisseaux groupés est plus régulier et plus complet; les vaisseaux de la zone interne sont plus gros. Du hois d'une tige de 55 ans, complétement desséché à l'air, et provenant de la forèt de Bouverans (Jura), à $1100^{\mathrm{m}}$ d'altitude, pèse 0,75 . (Coll. Ec. For'. Envoi de MM. Gurnaud et Cardot).

3. Cytise à feuilles sessiles. Crtisus sessilifolius. Lin.

Feuilles petites, 5 -foliolées, glabres, d'un vert glauque, les supérieures sessiles, les inférieures et celles des rameaux stériles pétiolées; foliole médiane orbiculaire-rhomboïdale, folioles latérales transversalement elliptiques, les unes et les autres sessiles et apiculées. $4-6$ fleurs pédicellées et complétement glabres, en grappes terminales courtes, dressées, non feuillées. Gousse de 30-40 mill. sur 10, glabre, d'un brun verdàtre, contenant $\check{b}-10$ graines ovales, comprimées, noires. - Arbrisseau 
de 1-2m, à tige dressée, rameuse, brune, à ramules tuberculeux, verts, striés, grèles, glabres, très-feuillés. Commun dans les haies et aux bords des bois des collines sèches de la région des oliviers; souvent cultivé dans les jardins d'agrément. Flor., mai-juin.

4. Cytise à trois flenrs. Crtisus triflorus. L'Iléntr.

Feuilles courtement pétiolées, trifoliolées, à folioles obovales-mucronulées, pétiolulées, couvertes de longs poils roussâtres, caducs ; finalement presque glabres. Fleurs pédonculées, habituellement ternées à l'aisselle des feuilles supérieures, formant sur le rameau une sorte de grappe feuillíe ; calice velu; étendard glabre, strié et taché de brun, plus court que la carène qui est légèrement velue inférieurement. Gousse de 50-55 mill. sur 5 , velue, brune, contenant 6-\$ graines jaunâtres. Petit arbrisseau de 1-2m, à tige dressée, rameuse; rameaux étalés, nombreux, allongés, effilés, sillonnés. Région méditerranéenue en France, en Corse el en Algérie. Flor., mai.

5. Cytise rampant. Crtisus decumens. Walpers. Genista prostrata. Lam.

Feuilles petites, subsessiles, 1 -foliolées; foliole obovale, obluse ou apiculée, velue ou glabre. Fleurs solitaires ou géminées, à pédoncules aussi longs ou plus longs qu'elles, placées au sommet de ramules latéraux raccourcis, tuberculeux et feuillés, et formant sur les rameaux des sortes de grappes feuillées unilatérales; calice velu, corolle glabre. Gousse velue ou glabre, de 20-50 mill. sur 6, noircissant à la malurité; graines ovoïdes, comprimées, noires. - Sous arbrisseau plus voisin des genêts que des cytises par le port et dont la hauteur n'excède pas 1-2 décimètres; tiges couchées et élalées sur le sol, radicantes, formant une louffe aplatie dont les rameaux sont ascendants, tuberculeux, les ramules verts et sillonnés. Collines sèches et calcaires : Lorraine, Champagne, Cỏte-d'Or et Jura. Flor., mai-juillet.

\section{§II. Calice allongé, tubuleux.}

6. Cytise allongé. Cytisus elongatus. IVardst. er Krt.

Feuilles pétiolées, 5 -foliolées, à folioles obovales, mucronulécs, couvertes sur les deux faces de poils appliqués. Fleurs réunies par 2-4 en faisceaux latéraux et feuillés à la base, qui garnissent les rameaux sur une parlie de leur longueur; pédicelle à peu près aussi long que le calice; celui-ci couvert de poils étalés-dressés. Gousse de $23-30 \mathrm{mill}$. sur $b$, noire et velue, à valves convexes; graines orbiculaires-comprimées, fauves et luisantes. Sous-arbrisseau de $1^{\mathrm{m}}-1 \mathrm{~m}$ j0, ne noircissant pas par la dessiccalion, a tige dressée et rameuse, dont les rameaux sont grêles et couverts de poils appliqués. Collines calcaires de l'Ardêche, près de Tournon. Flor., avril-mai.

2. Cytise velu. Cyrisus minsutus. Lin.

Voisin du précédent, dont il se distingue par les folioles plus larges, glabres en dessus; par le pélicelle des fleurs qui n'égale que la moitié du ealice; par ce dernier couvert de poils très-étalés; par la gousse plus grande el plus large, à valves planes. Sous-arbrisseau de $0^{\mathrm{m}}, 50$, noircis- 
sant un peu par la dessiccation, à tiges dressées ou ascendantes, dont les rameaux sont couverts de poils très-étalés. Alpes du Dauphiné, it Bernin. Flor., mai-juin.

8. Cytise en tête. Crtisus capitatus. Jace.

Feuilles pétiolées 5 -foliolées, velues, à folioles obovales mucronulées, d'un vert sombre en dessus, plus pâles en dessous. Fleurs courtement pédicellées, longues de 20 mill., réunies en assez grand nombre à l'extrémité des ramearx où elles forment une sorte de capitule ombelliformo entouré de feuilles; calice velu, corolle glabre dont l'étendard est beaucoup plus long que les ailes. Gousse de 50-55 mill. sur 5้-6, velue, noire, dont les graines sont ovoïdes, fauves, luisantes. - Sous-arbrisseau de 4-6 décimètres, à tiges dressées, à rameaux étalés-dressés, effilés, striés, très-feuillés, couverts de poils étalés. Bois montagneux du Jura el de la Côte-d'Or; Lyon. Flor., juin-juillet.

9. Cytise couché. Cytisus supinus. Lin.

Voisin du précédent; se distingue à ses inflorescences moins fournies, à ses fleurs dont l'élendard est orangé ; à ses tiges moins élevées, de 1-4 décimetres, couchées, souvent radicantes, dont les rameaux sont euxmeemes grêles et étalés, à l'exception des floraux qui sont redressés. Collines sèches et bords des bois; Champagne, France centrale, Daupliné et Pyrénées; Toulouse. Flor., mai.

GENRE IX. - ADÉNOCARPE. ADENOCARPUUS. DC.

Calice persistant, à 2 lèvres non divariquées dont la supérieure est divisée jusqu’à la base en deux lobes; étendard orbiculaire, étalé ; carène courbée ; style arqué ; stigmates en tête; gousses couvertes de tubercules glanduleux. - Sous-arbrisseaux du midi de la France, à feuilles 3 -foliolées, non épineux et à fleurs jaunes.

Bois identique à celui des genêts; dessin réticulé vague.

A. 1-4 fleurs en capitules ombelliformes, terminaux...................... A grandes Fleurs.. 1

A'. Fleurs en grappes simples plus ou moins allongées, terminales.

B. Fleurs en grappes courtes, oblongues ; calice non tuberculeux-glanduleux.. A. тกANsposé.......2

B'. Fleurs plus nombreuses, en grappes allongées, cylindriques; calice tuberculeux-glanduleux................ A fruilzes pr.tées.. 5

1. Adénocarpe à grandes fleurs. Adenocarpus grandiflorus. Boiss.

Feuilles peu nombreuses, très-petites, courtement pétiolées, 3-foliolées; folioles de 5 à 4 millimètres de long, obovales, arrondies ou échancrées au sommet, à peu près glabres, à bords enroulés en dessous. Fleurs longues de $12-14$ mill., jaunes, disposées $1-4$ en petils capilules 
ombelliformes terminaux; calice velu non glanduleux. Gousses de 15-23 mill. sur 5, couvertes de tubercules glanduleux, brunes, contenant 1-3 şaines irrégulièrement orbiculaires-comprimées, brunes et luisantes. Sous-arbrisseau à peine feuillé, de 1-5 décimètres, trapu, à tige trèsrameuse, dont l'écorce est grise, fibro-membraneuse, dont les rameaux et I’amules sont courts, droits, divariqués-entrelacés, arrondis et blanchàtres, sub-épineux à l'extrémité. Coteaux arides de la région méditerranéenne. Flor., juin.

2. Alénocarpe transposé. Adenocarpus connutatus, Guss. A. Telonensis. $D C$.

Feuilles d'un vert gai, pétiolées, 5 -foliolécs; folioles longues de 12 à 15 mill., obovales-oblongues, mucronulées, souvent pliées en gouttière. Fleurs de 10 mill. de long, en grappes courtes, oblongues, terminales, dressées; calice velu non-glanduleux. Gousse de 20-50 mill. sur 5 , couverte de glandes stipitées, brune, contenant 4 -10 graines ovoïdes-comprimées, tronquées vers le hile, brunes, marbrées de noir et luisantes. Sous-arbrisseau de $4-6$ décimètres, médiocrement fevillé, à tige droite, rameuse, blanchàtre, à ramules allongés, grèles, striés-anguleux, verts et pubescents. Bruyères, lieux stériles et montueux de la France méridionale, particulièrement dans la Lozère et dans l'Ardèche. Flor., maijuillet.

3. Adénocarpe à feuilles pliées. Adexocanpus complicatus. GaY. Spartium complicatum. Lin.

Voisin du précédent dont il se distingue particulièrement par ses fleurs plus nombreuses, formant une longue grappe lâche terminale et par le calice tuberculeux-glanduleux. - Sous-arbrisseau de $\$$-10 décimètres, à tigc dressée, rameaux étalés, blanchîtres, à ramules allongés, striés, angulcux, ver's, pubescents. Pyrénées occidentales, Landes, Lot, Limousin. Flor, avril-mai.

\section{geNRE $x_{\text {. }}$ - BUGRANE. ONONIS. Lin.}

Calice persistant, campanulé, à 5 divisions profondes. Etendard grand, strié; style coudé au milieu de sa longueur._PJantes herbacées, annuelles ou vivaces, ou sous-arbrisseaux souvent épineux, à feuilles 3-foliolées, munies de larges stipules sourlées au pétiole et dont les folioles sont dentées; fleurs jaunes ou roses.

Tissu lignenx identique à celui des genêts.

La racine s'accroît irrégulièrement et non par couches continues, si ce n'est pendant la première année; aussi la moelle en devient-elle fort excentrigue et la section transversale rappellet-elle, par les contours les plus bizarres, la structure des lianes intertropicales.

A. Pédoncules pluriflores. Sous-arbrisseaux entièrement ligneux...................... Anmisssav. 1

A). Pédoncules uniflores. Végétaux à souche ligneuse, à rameaux el ramules annuels. 
B. Fenilles presque glabres, peu ou point visqueuses.

C. Feuilles linéaires-oblongues; fleurs de 17 mill. de long ................... B. Épineuse. . 2

C'. Feuilles obovales; fleurs de 12 mill. de long.. B. Des Ancirns. 5

$B^{\prime}$. Feuilles velues-visqueuses, obovales; fleurs de 17-20 mill. de long................ B. mavpante. \&

\section{§I. Pédoncules pluriflores.}

1. Eugrane arbrisseau. OnONis Fruticosa. Lin.

Feuilles courtement pétiolées, 5-foliolées, glabres et d'un vert clair uniforme sur les deux faces; munies de stipules engainantes, membraneuses; à folioles sessiles, oblongues, atténuées à la base, coriaces, deutées. Fleurs grandes, purpurines, portées sur de longs pédoncules 2-3-flores, formant par leur réunion une grappe dressée, composée, terminale. Gousse heaucoup plus longue que le calice, de $20-25$ mill. sur 6 ou 7, brunâtre, velue-glanduleuse, contenant 2-4 graines réniformes, brunes et mates. - Sous-arbrisseau de 5-10 décimètres, à lige dressée Irès-rameuse, à ramules grisâtres. Alpes du Dauphiné et de la Provence. Souvent cultivé dans les jardins d'agrément. Flor, juin-août.

\section{$\S$ II. Pédoncules uniflores.}

2. Higntrane clampetre. Ovoxis cinpestris. Kocir. Ononis spinosa. Lin.

Feuilles courtement pétiolées, les inférieures 5-foliolées, les supérieures $\mathbf{1}$-foliolées, presque glabres ou à peine glanduleuses, à folioles linéaires-oblongues, dentées supérieurement. Fleurs solitaires, latérales, assez grandes, roses veinées, quelquefois blanches, formant sur les rameaux des sortes de longues grappes très-feuillées. Gousse ovale, jaunâtre, ne dépassant pas le calice et contenant 2-4 graines ovoïdes, brunes, tuberculeuses. - Plante de 5-5 décimètres, à racine fortement pivotante; tige ligneuse inférieurement, rameaux ascendants, épineux, p'us ou moins velus-glanduleux, annuels. Commun aux bords des roules, sur les terrains vagues et sur les pâturages de toute la France. Flor., juinjuillet.

3. Bugrane des anciens. Ononis Antrguonum. Lin.

Espèce voisine de la précédente, dont elle se distingue par les feuilles obovales, les fleurs et les gousses beaucoup plus petites, ces dernières lenticulaires, monospermes. - Sous-arbrisseau à liges plus grêles, flexueuses, armées d'épines plus fines. Lieux secs de la région méditerranéenne en France et en Corse. Flor., juin-juillet.

4. Bbugrane rampante. Oronis nepens. Lin. Arrête-Bœuf,

Feuilles courtement pétiolées, tri-foliolées inférieurement, uni-foliolécs supérieurement, pubescentes-glanduleuses; folioles obovales, dentées. Fleurs solitaires, latérales, assez grandes, roses veinées, formant sur le rameau une sorte de grappe allongée, feuillée. Gousse ovale, pubescente- 
glanduleuse, jaunàtre à la maturité, plus courte que le calice, contenant une ou deux graines brunes. - Plante vivace, velue, très-glanduleuse, fétide, à racines fortes et rameuses, longuement traçantes et drageonnantes, à tiges couchées, ligneuses et radicantes à la base, redressées au sommet, inermes on peu épineuses, annuelles. Commune dans les champs, les terres en friches de toute la France, surtout dans les sols argilo-calcaires. Flor., juin-juillet.

Les racines, robustes et allongées, de la bugrane rampante envahissent parfois les terres, et dans les sols sablonneux peuvent s'enfoncer jusqu'à $5^{\mathrm{m}}$ de profondeur. C'est de la difficulté à les trancher avec le soc de la charrue lors des labourages que vient le nom d'arrète-bouf, sous lequel ce végétal est souvent connu.

\section{SECTION III. - Etamines diadelphes (9 soudées, 1 libre),} gousse non arliculée, feuilles imparipennées.

\section{GENRE XI. - ROBINIER, ROBINIA. Lin.}

Calice campanulé, presque bilabiẻ, à 5 dents; stigmate terminal; gousse sèche, comprimée, polysperme, à suture ventrale e̊paissie. - Arbres à feuilles oppositi-imparipennées, alternes, dont les stipules sont souvent transformées en épines; à fleurs blanches ou roses, en grappes simples.

Bois lourd et dur; vaisseaux entourés de parenchyme ligneux (peu apparent, même à la loupe); ceux du bord interne gros, rapprochés et formant une zone poreuse distincte; ceux de la région médiane et externe assez gros, groupés en petits faisceaux qui forment sur la section transversale des lignes concentriques arquées ou anguleuses; rayons médullaires assez épais, assez longs, peu hauts, peu serrés.

1. Robinier faux-acacia. RoBINIA PSEUdo-AGACIA. LIN.

Feuilles oppositi-imparipennécs, à $3-12$ paires de folioles entières, ovales ou elliptiques, aiguës, arrondies ou même légèrement échancrées à l'extrémité où elles sont mucronulées; d'un vert gylauque en dessous, de consistance molle, finalement glabres; accompagnées sur les rameaux stériles de stipules transformées en forles épines, aiguës et comprimées. Fleurs blanches très-odorantes, en grappes bien fournies, oblongues-cylindriques, pendantes, dont les pédoncules ne sont pas visqueux. Gousse de 80 mill. sur 12 mill., brune, un peu luisante, à sulure ventrale tri-nerviéc-carénée, contenant 10-12 graines ovoüles-comprimées, d'un brun foncé luisant. - Arbre de grande taille, dont la tige, généralement divisée, se termine par une cime arrondie, ample, à branches étalées ; dont l'écorce, brune roussître, est marquéc de crevasses longritudinales 
larges el jrofondes, sćparćes par des côles lamelleuses-rugueuses. Trèssouvent cultivé et l'une des rares espèces naturalisées, peut-être la seule, que la culture forestière se soit quelque peu appropriée. Flor., juin. Fruclif., septembre. Dissémination, fin de l'hiver.

Originaire de l'Amérique du nord, le robinier fut cultivé pour la première fois en France en l'an 1601, par J. Robin, en la mémoire duquel Linné créa le nom de Robinia. Au siècle dernier, on préconisa outre mesure les avantages que sa culture devait réaliser ; comme les résultats ne répondirent point entièrement aux espérances, une réaction inćvitable s'en suivit et on l'a depuis trop négligé.

Le robinier a une grande longévité et peut atteindre 20$27^{\mathrm{m}}$ d'élévation sur $2-5^{\mathrm{m}}$ de circonférence, mais il lui faut pour cela l'isolement. Elevé en massif, il s'éclaircit de lui-mème de très-bonne heure et ne parvient jamais à de grandes dimensions.

Cet arbre fructifie abondamment tous les ans, et ses graines, comme celles de toutes les légumineuses, conservent longtemps leur faculté germinative, bien que les plus fraiches produisent, comme toujours, les plants les plus vigoureux. Le kilogramme en contient $52-56,000$.

Les graines germent $10-14$ jours après le semis du printemps. Le jeune plant lève avec 2 feuilles cotylédonaires, entières, semi-ovoïles, et mesure déjà $2 \%-45$ centimètres de hauteur au bout d'un an. La végétation est très-rapide dans les premières années et la période de plus forte croissance, pour des arbres isolés, va de $25-45$ ans, en moyenne. Le maximun de production est bien plus promptement atteint sur une surface donnée, en raison de l'éclaircissement qui s'opère et du ralentissement de végétation que l'état de massif occasionne.

La racine du robinier est d'abord profondément pivotante ; mais elle s'oblitère rapidement et produit de trèslongues et grêles racines latérales traçantes qui drageonnent sur tout leur parcours et assurent la perpétuité des taillis. Les jeunes souches produisent des rejets vigoureux.

Tous les sols lui conviennent; il préfére néanmoins ceux qui sont légers et un peu frais.

Les bourgeons du robinier ne sont point apparents; à chaque aisselle, entre les stipules, se trouve une cavité tapissée de toutes parts de poils serrés et roussâtres, qui, après la chute de la feuille, s'ouvre généralement par une

Fruclificalion.

Germination.

Croissance.

Enracinement.

Sols.

Bourgeons. 
petite fente. C'est dans son intérieur que se développent, non pas un seul bourgeon, comme c'est le cas habituel, mais 2-5 bourgeons très-petits, nus, superposés de telle sorte que le plus élevé est le mieux développé et dont l'évolution printannière est très-tardive. C'est sans doute là une des causes de la rusticité du tempérament de ce végétal.

La tige et les rameaux s'épuisent à leurs extrémités sans produire de bourgeons terminaux et l'accroissement en hauteur se continue par les bourgeons axillaires supérieurs; aussi la tige ne se prolonge pas dans la cime, mais s'y partage en quelques grosses branches principales.

Epines. Les branches stériles et les rejets du robinicr sont armés de robustes épines qui proviennent de la transformation des stipules et sont disposées, comme ces dernières, de chaque côté de la base de la feuille. Ces épines sont presque en totalité formées de tissu subéreux et ne communiquent au système fibro-vasculaire du rameau que par un faisceau extrèmement grèle qui est à leur base ; aussi sont-elles peu adhérentes et se rapprochent-elles beaucoup de la structure des aiguillons. Elles présentent un grand obstacle à l'exploitation.

Couvert. Le feuillage est léger, et, comme les massifs ne sont jamais scrrés, il en résulte que le robinier ne couvre pas le sol, qu'il lui donne peu de détritus, emportés encore la plupart du temps par les vents. Les branches sont très-fragiles et quand cet arbre s'élève dans des situations non abritées, il est constamment mutilé par les vents, le givre, la neige.

Ecorce. L'écorce se dépouille, dès les premières années, de son enveloppe subéreuse et de son enveloppe verte, et organise, dans les feuillets du liber, un périderme interne, produisant un rhytidome profondément gerçuré, dont l'épaisseur s'aceroît notablement avec l'àge. On n'y trouve que quelques traces d'acide tannique.

Bois. Le bois de robinicr est lustré, jaune ou jaune brunàtre, à aubier nettement limité, blane jaunàtre; ses aceroissements annuels sont très-distinets. Il est dur, lourd, nerveux, ćlastique, et, ce qui est fort remarquable, d'une durée égale ì celle du vieux chêne dès ses premières années. Sa résistance verticale, supérieure d'un tiers à celle du chène, le place au premier rang des bois de charronnage pour la fabrieation des rais. Il est préférahle à tous autres pour échalas, tutcurs, cercles, gournables (chevilles) employies dans les 
constructions maritimes. Il prend un beau poli, est recherché en menuiserie et pour ouvrages de tour. On ne l'emploie point dans les constructions, parce que ses tiges sont rarement assez régulières pour qu'on en retire des pièces de grandes dimensions. Il est sujet à la vermoulure.

Du bois d'une tige de 20 ans et de 16 cent. de diamètre, ayant crủ à Nancy et complétement desséché à l'air, pèse 0,75. (Coll. Ec. For.)

D'après T. Hartig, du robinier de 50 ans, pesant 0,77 à l'état complétement sec, comparé à du hètre de 50 ans, pesant 0,66 et dans le même état de dessiccation, a donné les résultats suivants pour la valeur calorifique.

\begin{tabular}{|c|c|c|c|c|}
\hline \multirow{2}{*}{ Plus haut degré de chaleur.... } & & $\begin{array}{l}\text { Poids égaux. } \\
92: 100\end{array}$ & $\begin{array}{l}\text { Vol. ég } \\
106,7\end{array}$ & \\
\hline & & $108: 100$ & $12 \%$ & \\
\hline \multirow{2}{*}{ Durée de la chaleur croissante.. } & & & 125 & \\
\hline & & $153: 1$ & 154 & \\
\hline \multirow{2}{*}{ Durée de la chaleur dẻcroissante. } & & $97: 1$ & 112,7 & \\
\hline & & $145: 1$ & & \\
\hline \multirow{2}{*}{ Total de la chaleur développée. } & asc & $94:$ & 109 & \\
\hline & ray & $106: 100$ & 125 & \\
\hline & & $100: 100$ & 116 & \\
\hline
\end{tabular}

C'est done un excellent combustible, qui produit une chaleur vive, très-longtemps soutenue et qui convient tout particulièrement au chauffage par foyers ouverts, en raison de la très-grande proportion de sa chaleur rayonnante.

De tout ce qui vient d'ètre dit, il résulte clairement que la production du robinier ne saurait ètre avantageuse en futaie, qu'elle peut l'ètre beaucoup en taillis à courte révolution; que cet arbre est très-propre à fixer et à boiscr les sables mouvants, à maintenir les terrassements des travaux d'art.

Les feuilles, vertes ou sèches, fournissent un bon fourrage. On peut en obtenir des matières tinctoriales jaunes.

La séve a une saveur sucrée prononcée, analogue à celle de la réglisse; mais elle contient en outre, au moins dans la racine, un principe vénéneux, produisant des symptômes analogues à ceux de l'empoisonnement par les baies de Belladone.

genRe xir. - BAGUeNaUdIER. COLUTEA. Lin.

Calice campanulé à 5 dents; étendard grand, dressé; stigmate latéral; gousse cnflée-vésiculeuse, herbacée-membraneuse, po-

Ulililé du robinier.

Produils accessoires. 
lysperme. - Arbrisseaux non épineux, à feuilles imparipennées et d fleurs jaunes; offrant souvent à chaque aisselle 2 bourgeons superposés, dont l'inférieur est le plus petit.

Bois blanc verdâtre ou jaunâtre, à vaisseaux décroissant de taille du bord interne au bord externe, où ils sont groupés en petits faisceaux disposés suivant des arcs concentriques.

Baguenandier arborescent. Colutea andonescens. Lis.

Feuilles oppositi-imparipennées, à 5-6 paires de folioles obovales, obtuses ou échancrées à l'extrémilé, glabres en dessus, légèrement revètues de poils courts et appliqués, glauques en dessous. Fleurs axillaires, grandes, jaunes, formant, au nombre de 2-6, une grappe longuement pédonculée, plus courte néanmoins que la feuille. Gousse grosse, vésiculeuse, éclatant avec explosion quand on la presse entre les doigts, contenant 20-50 graines lenticulaires, lisses, brunes. - Arbrisseau de $5.5 \mathrm{~m}$, à tige droite, rameuse, dont l'écorce est grise ou brune, verdàtre, lisse ou légèrement fibreuse. Forêts montueuses à sol sec et calcaire, aux expositions chaudes, en Alsace, Lorraine, Champagne, Bourgogne, dans le Lyonnais, le Dauphiné, la Provence, les Cévennes, etc.; Algérie dans l'Allas. Souvent cultivé dans les jardins d'agrément. Flor., mai-juin.

SEction IV. - Etamines diadclphes; gousse articulée se divisant en articles transversaux monospermes; feuilles oppositi-imparipennées.

GENRE XII. - CORONILLE. CORONILLA. Lin.

Calice campanulé, court, à 5 dents, dont les 2 supérieures sont rapprochées; carène aiguë, terminée en bec. Gousse articulée, grêle, cylindrique ou anguleuse. - Plantes herbacées ou sous-arbrisseaux.

Bois à vaisseaux moyens, plus serrés au bord interne de chaque couche, où ils forment une zone étroite; faiblement groupés en petits arcs concentriques dans la région médiane et externe. Rayons fins, presque indéfinis.

A. Ramules flexueux, non compressibles.

B. Etendard à onglet 2 fois aussi long que le calice. C. ankrisseav. 1

$B^{\prime}$. Etendard à onglet aussi long que le calice..... C. GLavQue .. 2 A'. Ramules droils, effilés, compressibles, jonciformes. C. joxcironas 5

1. Coronille arbrisseau. Cononilla emerus. Lin. Coronille fauxséné; Séné-bâtard.

Feuilles pétiolées, imparipennées, à 3 -9 folioles pétiolulées, entières, olovales-arrondies ou un peu écliancrées à l'extrémité, minces, glabres, glauques en dessous. Fleurs jaunes, striées de pourpre sur l'étendard, réunies 2-3 à l'extrémité d'un péloncule axillaire presque aussi long ou 
plus long que la feuille; pétales à onglets allongés, grêles, 2 fois aussi longs que le calice. Gousses de $\mathfrak{b}-10$ centimètres, pentantes, grêles, presque cylindriques, se rompant peu neltement en 7-10 articulations, dont chacune contient une graine cylindrique-oblongue, noire. - Sousarbrisseau de 1-1m弓̋ , entièrement glabre, à liges dressées, rameuses, grises, à rameaux et ramules grêles, flexueux-notleux, verts et striés. Disséminé cà et là dans les bois, principlement sur les sols calcaires, dans la Lorraine, l'Alsace, la Bourgogne, le Lyonnais, le Dauphiné, la Provence, les Cévennes, les Pyrénées, la Gascogne, etc. Fréquemment cullivé dans les jardins d'agrément. Flor., mai-juin.

2. Coronille glauque. Cononilua guava. Lin.

Feuilles imparipennées, à $5-7$ folioles cunéiformes, obtuses ou un yeu échancrées au sommet, un peu épaisses, très-glauques; fleurs réunies 3-8 sur un pédoncule axillaire 2 fois aussi long que la feuille, jaunes, odorantes, dont les pétales ont l'onglet égal au calice. Gousses de 12-18 mill., pendantes, se désarticulant aisément en $\mathbf{2 . 5}$ articles, dont chacun contient une graine brune, linéaire-oblongue, comprimée. - Sous-arbrisseau très-glabre, glauque, touffu. Environs de Narbonne, de Montpellier, etc. Flor., juin-juillet.

3. Coronille jonciforme. Cononilla juncea. Lin.

Fcuilles imparipennées, à $\mathbf{5 - 7}$ folioles écartées, linéaires-oblongues, cartilagineuses-transparentes sur les bords. Fleurs réunies 7-8 sur un pédoncule axillaire grêle, terminé en pointe au sommet; jaunes, à onglets égaux au calice. Gousses de 15025 mill., pendantes, tétragones, se rompant en 2-7 articles, dont chacun contient une graine linéairc-oblongue, brune. - Sous-arbrisseau de $1^{\mathrm{m}}$ au plus, glabre el glanque, trèsrameux, à rameaux jonciformes, lisses, peu feuillés. Collines de la Provence; Algérie. Flor., mai-juin.

\section{FAMILLE XVIII.}

\section{Côsalpisiées. $R$. Brown.}

Fleurs hermaphrodites, dioïques ou polygames; calice a 5 divisions; corolle papilionacẻe, ou presque régulière, ou nulle ; 5-10 étamines libres, à anthères introrses, biloculaires, longitudinalement déhiscentes. Un seul carpelle libre, produisant une gousse; graines peu ou point périspermées, à embryon courbé. - Arbres à feuilles simples ou composées, alternes, stipulées, appartenant à la France méridionale.

A. Feuilles simples, caduques; fleurs papilionacées;
gousse sèche, déhiscente par une sulure....... Gasier.... 1
A'. Feuilles paripennées, persistantes; corolle nulle;
gousse pulpeuse, indéhiscente.............. Ganovbier. 2 
GENRE I. - GAINIER. CERCIS. Lin.

Fleurś hermaphrodites; calice caduc, urcéolé, à 5 dents ; corolle papilionacée, de 5 pétales libres; 10 étamines libres; gousse très-comprimée, polysperme. - Arbres à feuilles simples, entières, caduques, à l'aisselle desquelles on trouve parfois 2 bourgeons superposés, dont l'inférieur est le plus petit.

Bois à vaisseaux du bord interne médiocrement gros, serrés, formant une zone étroite, distincte; ceux du milieu et du bord externe fins, associés à du parenchyme ligneux et groupés en faisceaux qui dessinent des lignes périphériques serrées, ondulées. Rayons fins.

Gainier arbre de udée. Cencis siliquastrum. Liv.

Feuilles simples, pétiolées, palmatinerviées, réniformes-arrondies, mates, glabres. Fleurs roses ou blanches, paraissant avant les feuilles, assez longuement pédicellées, en faisccaux serrés le long des branches et de la partie supérieure du tronc, à élendard plus court que les autres rétales. Gousse de 7-10 centimètres sur 15 mill., d'un brun rouge, trinerviée sur la suture ventrale, contenant 10-14 graines ovoüdes, noires. - Arbre de $5-8 \mathrm{~m}$ de hanteur, dont la tige est irrégulière et recouverte l'une écorce noirâtre à gereures fines, profondes, serrées, longitudinales et transversales; rameaux flexueux. Région méditerranéenne; fréquemment cultivé comme arbre d'ornement. Flor., avril-mai.

Le bois de l'arbre de Judée a l'aubier blanchåtre, le coeur d'un jaune légèrement brunâtre et lustré. Provenant d'une tige de 15 ans, de 9 cent. de diamètre, qui avait crù à Nancy, il a donné, desséché à l'air, une densité de :0,68. (Col. Ec. For.). La rareté de l'arbre lui enlève tout intérêt forestier.

\section{geNRE il. - CAROUdier. CERATONIA, Lin.}

Fleurs polygames ou diö̈rucs; calice petit, こ-partite, ceduc; corolle nulle; étamines 5 , libres, opposées aux divisions du calice; carpelle arquué ; stigmate sessile. Gousse épaisse et coriace, remplie d'une substance pulpeuse; indéhiscente, polysperme.Arbres à feuilles paripennées, persistantes.

Bois lourd et dur. Tissu fibreux dominant; vaisseaux sensiblement égaux, groupés en petit nombre avec du parenchyme ligneux en faisceaux circulaires épars; à peine plus serrés et plus petits au bord externe. Rayons fins, peu hauts.

Caroubier commun. Ceratona silinua. Lin.

Feuilles composćes de 6-10 folioles coriaces, ovales, obtuses ou échan- 
crées au sommet, entières, vertes et luisantes en dessus, plus páles et mates en dessous; nerrures secondaires pennées, droites, parallèles, serrées, alternativement plus longues et réunies deux à deux à l'extrémité par des ramifications latérales. Fleurs très-petites, nombreuses, en grappes cylindriques dressées, axillaires, courtement pédonculées; calices rouges ; élamines étalées, à filels allongés. Gousse de 10-20 centimètres sur 1-2, pendante, flexueuse, épaisse, à pulpe intérieure sucrée, contenant 12-16 graines ovoïdes-comprimées, brunes. - Arbre peu élevé, à trone épais, cime étalée-arrondie, écorce lisse et mince, d'un brun rougeâtre clair. Rochers des bords de la Méditerranée en Provence ; Corse, Algérie. Flor., août-septembre. Fructif., juillet-août de l'année suivante.

Le caroubier'est originaire de l'Orient et s'est naturalisé sur tout le littoral de la Néditerranée; il est trop rare en France pour y être de quelque importance, mais il en acquiert dans les contrées où il devient commun, en Espagne et en Algérie. Il peut s'élever à $16-20^{\mathrm{m}}$, et atteindre $\overline{5}^{\mathrm{m}}$ de circonférence.

Il croit dans tous les terrains, pourvu qu'ils ne soient pas marécageux ; repousse abondamment de souche, a une longévité considérable, un couvert épais.

Le bois est dur, lourd, susceptible d'un beau poli ; il a l'aubier blane, abondant, nettement tranché; le cœur d'un rouge rosé clair et veiné. Pris sur une tige de 54 ans et de 18 centimètres de diamètre, venant d'Algéric, il pèse, complétement desséché à l'air, 0,89. (Coll. Ec. For. Envoi de MI. Royer). Ce bois est bon pour la fente, recherché pour le charronnage, la menuiserie et l'ćbénisteric; mais il dure peu exposé à l'humidité. C'est un bon combustible, dont on fabrique un charbon estimé.

Le fruit, connu sous le nom de caroube, se récolte avec soin. Sa pulpe est sucrée, nutritive, surtout rafraichissante, et, comme telle, recherchée par les habitants des contrées méridionales; mais sa plus grande utilité est de servir à la nourriture des bestiaux, des pores, et mème de tenir lieu d'orge ou d'avoine pour les chevaux.

L'écorce fournit du tan.

\section{FAMILLE XIX.}

AMYGDALĖes (Rosacearum tribus). Juss.

Fleurs hermaphrodites, régulières; calice gamosépale, à 5 divisions, libre, caduc; corolle rosacée, pérygyne; étamines 20-25,

Produils accessoires 
insérées avec les pétales; anthères introrses, biloculaires, longitudinalement déhiscentes. Ovaire formé d'un seul carpelle libre, bi-ovulé, style simple. Fruit apocarpé charnu à noyau (drupe), creusé d'un sillon qui représente la suture ventrale, monosperme par avortement. Graines non périspermées. - Arbres ou arbrisseaux, parfois épineux par transformation de rameaux, à feuilles alternes, simples, dentées, éparses, penninerviées, dont les nervures secondaires sont droites, parallèles, rameuses et réunies au sommet; à stipules caduques, bourgeons spiralés, écailleux, dont les écailles sont imbriquées.

Bois identiques dans toute la famille, lourds, durs, colorés de rouge brun et veinés au cœur; sujets ì se gercer et à se tourmenter. Fibres à parois épaisses, entremêlées de quelques cellules ligneuses (non reconnaissables à la loupe); vaisseaux fins, plus serrés et un peu plus gros au commencement de chaque couche, où ils forment une zone, étroite ou assez large, qui rend les accroissements ligneux distincts; isolés ou groupés, au nombre de $2-8$ au plus, en pelits faisceaux simples, uniformément épars ou ayant une tendance à se disposer en lignes périphéri ques ou obliques. Rayons fins ou moyens.

L'écorce des amygdalées est formée à la surface d'un périderme gris ou brun lustré, qui s'accroit et s'enlève par couches minces, transversales, dans le genre de celui du bouleau. Elle reste lisse et vive pendant longtemps et ce n'est qu'à un âge avancé, et vers le pied seulement, qu'un périderme libérien s'organise et produit un rhytidome noiràtre, longitudinalement gercuré.

Les amygdalées contiennent dans l'amande de leurs fruits, et queliquefois dans les feuilles et les jeunes écorces, de l'acide cyanhydrique; on trouve aussi dans ces amandes une huile grasse très-douce. Les tiges et les branches excrètent souvent en abondance une gomme (cérasine), presque identique à la gomme arabique, mais peu soluble, le devenant néanmoins par une ébullition prolongée.

Les genres de cette famille très-naturelle, créés par l'usage et en quelque sorte imposés par lui à la nomenclature, ne reposent que sur des caractères peu importants et devraient, à la rigueur, être confondus en un seul ou en deux au plus. Ce sont eux qui, réunis à ceux de la fạmille des Pomacées, sont désignés collectivement, en langage forestier, sous la dénomination des Fruiticrs. 
A. Feuilles condupliquées, c'est-à-dire, pliées en deux suivant la nervure médiane dans le bourgeon.

B. Drupe veloutée, à peine charnue, à sarcocarpe non comestible; noyau sillonné sur les faces, contenant une grosse amande................ AMsNdur.. 1

B'. Drupe charnue-succulente.

C. Noyaux anfractueux; drupe glabre on veloutée. pécner.... 2

C1. Noyau presque lisse; drupe glabre et luisante,

non efflorescente................. centsien, . 3

$A^{\prime}$. Feuilles convolutées, c'est-à-dire, enroulées suivant leur longueur; noyau presque lisse.

B. Drupe couverte d'une eflorescence glauque...... pnunier... \&

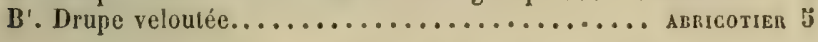

genre I. - AMANDIER. AMYGDALUS. Tourn.

Drupe oblongue-comprimée, à peine charnue, à noyau sillonné sur les faces; feuilles condupliquées.

Amandier commun. Amrgdaus comunts. Lis.

Feuilles à pétioles glanduleux, oblongues-lancéolées, obtusément dentées, glabres, luisantes en dessus. Fleurs paraissant avant les feuilles, blanches ou roses, solitaires ou géminées le long des rameaux, subsessiles. Fruit velouté, vert à la maturité, à sarcocarpe irrégulièrement déhiscent. - Arbre de $8-12^{\mathrm{m}}$, à branches étalées, produisant chaque année 2 généralions de ramules nombreux, grêles, droits, flexibles, d'un vert clair et glabres. Originaire du Levant, peut-être aussi de l'Algérie, où on l'a trouvé en pleine forêt; cultivé comme fruitier daus la région des oli viers et dans celle de la vigne; subspontané dans la première. Flor., février-mars. Fructif., aoûl-septembre.

L'amandier commun a produit par la culture un grand nombre de variétés de fruits : amandes douces, amères, à Variétés. coque dure, à coque molle, etc., dont l'amande seule est comestible et que tout le monde connait.

Le bois de cet arbre est remarquablement dur et plein ; il prend un très-beau poli; mais il est très-raide et disposé à se gercer et à se tourmenter. L'aubier est blanc, nettement limité, le cœur est veiné, brun-marron foncé et présente souvent cette particularité que la plus forte coloration de chaque couche correspond au bois de printemps. Les rayons sont médiocrement épais et produisent de fines et nombreuses maillures blanchâtres très-apparentes. Celui d'une tige de 50 ans et de $\breve{50}$ cent. de diamètre, complétement desséché à l'air et provenant de la Corse, pèse 1,05, (Coll. Ec. For.).

Ce bois est employé en marqueterie; il est très-bon combustible. 
GENRE II. - PÈCIIER. PERSICA. Tourn.

Drupe globuleuse, charnue-succulente, glabre ou veloutéc ; noyau fortement anfractueux sur les faces; feuilles condupliquées dans le bourgenn.

Pêcher commun. Persica vulgaris. Afili.

Feuilles à pétiole court, non glanduleux, lancéolées, aigûment dentées; fleurs d'un rose vif, paraissant avant les feuilles, solitaires on géminées le long des rameaux, presque sessiles. Fruit charnu, succulent, jaunâtre, habituellement rouge sur une face, cotonneux (pêche) ou lisse et glabre (brugnon). - Petit arbre de $4-6^{\mathrm{m}}$, à ramules lisses et glabres, effilés, verts ou rougeâtres. Originaire de la Perse; cultivé en espalier ou en plein vent dans toute la France. Flor., mars. Fructif., août-septembre.

Le bois de pècher ressemble beaucoup à celui de l'amandier, mais il est moins lourd, moins dur, moins coloré. Celui d'une tige de 14 ans, de 8 cent. de diamètre, pèse, complétement desséché à l'air, $0,7 \overline{3}$. (Coll. Ec. For.). Il est employé en ébénisterie et en marqueterie.

\section{GENRE III. - CERISIER. CERASUS. Tourn.}

Drupe globuleuse, glabre et luisante, sans efflorescence glauque; noyau à peu près lisse sur les deux faces; feuilles condupliquées.

A. Fleurs fasciculées.

B. Pétioles bi-glanduleux; fruits doux sucrés.. C. Mertsier..... 1

B'. Pétioles non glanduleux; fruits acides..... C. A veurts Acidrs 2 A'. Fleurs en corymbes simples............ C. Manale .... 3 A". Fleurs en longues grappes simples........ C. A grappes.... \&

\section{$\S$ I. Fleur's fasciculées.}

1. Cerisier Merisier. Cenasus aviur. Moexcr. Prunus avium. Lin. Cerisier des oiscaux; Cerisier des bois; Cerisier sauvage.

Feuilles ovales, ou obovales-acuminées, doublement dentées-glanduleuses, un peu plissées, d'un vert mat, plus claires et pubescentes en dessous; pétioles munis vers le sommel de deux glandes rougeâtres. 2-6 fleurs faseiculces, blanclıes, paraissant avec les feuilles, mais sortant de bourgeons dont les écailles ne deviennent jamais foliacées. Fruits globuleux, d'un rouge clair ou rouge noir, à saveur sucrée. - Grand arbre à tige droite, se prolongeant jusqu'à l'extrémité de la cime qui est pyramidale et dont la ramification yeu abondante est formée par des rameaux divariqués-dressés, tris-souvent verticillés comme ceux d'un sapin; à 
ćcorce grise satinće, s'enlevant par Janières circulaires; à racines pivotantes, nou drageonnantes. Dissćminć dans les bois montagneux de toute la France; Algérie. Flor., avril-mai. Fructif., juin-juillet.

Malgré quelques opinions contraires, qui assignent à ce cerisier l'Asic pour patrie, on s'accorde génćralement à le considérer comme indigène. Il est disséminé dans la plupart des forèts, mais n'y conslitue jamais seul de peuplements étendus.

Le merisier peut, dans de bonnes conditions, atteindre vers l'àge de $603-70$ ans, $20-25^{\mathrm{m}}$ d'élévation sur $1^{\mathrm{m}} 50-2^{\mathrm{m}}$ de circonférence. Sa croissance est assez active et, vers 40-5ั0 ans, sa tige, à l'état d'isolement, égale au moins celle du hètre en dimensions et en volume; mais sa cime produit moitié moins le bois de branches et, passé ce tcrme, il reste bien en arrière de cette essence.

L'enracinement est puissant, composé de fortes et longues racines profondément enfoncées, non drageonnantes.

La floraison est abondante chaque année; mais sa précocité l'expose aux gelées printanières et la fructification n'est pas constante et soutenue. Les noyaux, semés dès l'été, g'erment au printemps suivant. Les jeunes plants se développerit avec deux feuilles cotylédonaires entières, lenticulaires et s'accroissent lentement dans les premières années.

Le cerisier n'est pas exigeant sur le choix du terrain et prospère encore là où d'autres essences languissent; il préfère néanmoins les régions montueuses, les sols calcaires, les expositions chaudes. Il s'étend en montagnes jusque dans la zone du hêtre, mais sans la dépasser.

Le bois du cerisier est rouge brunâtre clair, veiné, légèrement maillé et luisant; quand on le débite vert, il se colore vivement en rouge ocreux sur la section; il est tenace, dur et lourd, et peut servir à de menues charpentes intéricures; mais il s'altère rapidement à l'air. Sous l'action de l'eau de chaux, dans laquelle il est bon de le tenir plongé pendant 2-3 jours, ou de l'acide azotique il prend une teinte d'un rouge assez vil qui rappelle celle de l'acajou. Recevant bien le poli, il est employé par les ébénistes et les menuisiers pour la confection des meubles, surtout par les tourneurs qui en faloriquent des bois de chaises et de fau-

- teuils; les luthiers et tabletiers en tirent aussi parti ; enfin lorsqu'il est jeune il fournit de bons cercles. Coupé vert il pèse 0,83 ; desséché 0,74 . Il prend un retrail de $\frac{1}{16}$ (Varennes de Fenille).

Origine.

Taille.

Croissance.

Enracinement.

Fruclification.

Germination.

Station et sol.

Bois. 
D'après Werneck la puissance calorifique du cerisier de 60-80 ans est à celle du hétre de 120 ans, l'un et l'autre à l'état sec :: 78,5 : 100 pour des poids égaux. C'est done un combustible de médioere qualité.

Prnduils L'écorce contiendrait 10 pour $0 / 0$ de tannin, d'après accessoires. Gassicourt.

Le cerisier merisier est fréquemment cultivé comme arbre fruitier et parait ètre la souche de tous les cerisiers à fruits doux et sucrés, guignes et bigarreaux ; c'est avec ses fruits que l'on fait le kirsch, dont le plus estimé s'obtient avec ceux du type sauvage ou peu modific, de saveur sucrée-amère.

2. Cerisier à fruits acides. Cerasus acrna. Goèrty. Prunus cerasus. Lin.

Feuilles ovales-oblongues, acuminées, doublement dentées-glanduleuses, toujours glabres, luisantes, à pétiole non glanduleux. Fleurs fasciculées, paraissant avant les feuilles, sortant de bourgeons dont les écailles
intérieures deviennent foliacées. Fruits globuleux, déprimés, rouges, acides. - Arbre peu éleré, de $7-8^{\mathrm{m}}$, à tèle arrondie, branches étalées, rameaux et ramules effilés, élalés ou pendants, à racines tracantes trèsdrageonnantes. Cultivé et quelquefois subspontané aux bord́s des bois. Flor., avril-mai. Fructif., jün-août.

Ce cerisier, originaire de l'Asic mineure, a produit de nombreuses variétés; il cst considéré comme la souche de tous les cerisiers à fruits acides, tels que : cerises aigres, griottes, gobets, etc. Son bois est identique à celui du merisier, dont il se distingue par des taches médullaires brunes (Nordlinger).

\section{$\S$ II. Fleurs en corymbes simples.}

3. Cerisier mahaleh. Cenasus manuler. Mul. Prunus mahaleb. Lin. Bois de Ste-Lucie; Quénot; Malagué.

Feuilles pétiolées, ovales-arrondies, courtement acumincies, un peu cordiformes à la base, finement et obtusément dentées-glanduleuses, glabres, fermes, luisantes sur les 2 faces, plus claires en dessous. Fleurs paraissant aree les premières feuilles, hlanclies, très-odorantes, disposées 4-6 en corymbes simples, dressés, légérement feuillés à la base. Drupe petite, ovoüle-globuleuse, de la taille d'un pois, acerbe, noire. - Arbrisseau très-rameux, à rameaux nombreux, étalés, dont l'écorce est d'un brun cendré luisant, circulaircment zonéc. Coteaux pierreux et rocheux des terrains calcaires; parait manquer dans le midi. Flor., mai. Fructif., juillet-août.

Taille.

Le cerisier mahaleb peut atteindre 5 ou s. mètres de hau- 
teur et mème devenir un petil arbre de 10-12m. Malgré ses faibles dimensions et la lenteur de sa croissance il n'est pas dépourvu d'intérèt, par l'aptitude qu'il a de prospérer dans les terrains les plus sees et jusque dans les lentes des rochers. Son bois a les vaisseaux et les rayons fins; les premiers, à peine plus gros au bord interne, ont une tendance à se disposer suivant des zones concentriques qui subdivisent chaque couche annuelle. Il est dur, lourd, homogène, jaunàtre, veiné de jaune brunàtre ou de brunàtre clair; d'un grain très-fin et susceptible d'un très-beau poli ; ses accroissements sont peu distincts. Il a une odeur vive et agréable, qu'il conserve très-longtemps et qui le fait reconnaitre de suite. Il est employé pour de menus ouvrages de tour et d'ébénisterie. Les jeunes rameaux, lorsqu'ils sont droits, sont recherehés pour tuyaux de pipes.

Du bois d'une tige de 17 ans et de 13 centimètres de diamètre, de Nancy, pèse, complétement séché à l'air, 0,86 (Coll. Ec. For.).

\section{$\S$ III. Fleurs en longues grappes simples.}

A. Cerisier à grappes. Cenasus padus. DC. Prunus padus. Lin. Putier; Bois puant.

Feuilles grandes, péliolées, à pétiole bi-glanduleux au sommet, obovales-acuminées; finemeut et très-aigùment dentées-non-glanduleuses, vertes, glabres, un peu rugueuses et non brillantes en dessus, plus pâles el même glauques et pubescentes anx aisselles des nerrures en dessous. Fleurs blanches, odorantes, en longues grappes simples, cylindriques, pendantes, feuillées à la base. Drupes globuleuses, de la grosseur d'un pois, noires, acerbes. - Arbrisseau ou petit arbre de $8.10 \mathrm{~m}$, à rameaux étales, peu nombreux, presque verticillés, dont l'écorce, à peine zonée circulairement, est brunc ou brun-veadatre, ponctuée de blane sur les rameaux; noirâtre, luisante et longitudinalement gerçurée arec l'àge sur la tige; racines tracantes, drageonnantes. Bois lumides du Nord, du Nord-Est, de l'Est et du Centre de la France, particulièrement dans les terrains siliceux ou graniliques, devient rare dans le Midi; commun nẻanmoins dans les Pyrénées. Flor., mai. Fructif., juin.

Le bois de ce cerisier ressemble assez à celui du cerisier des oiseaux, mais l'aubier en est plus abondant et le cœur d'un rougeâtre plus clair; il exhale, ainsi que toutes les parties de la plante, surtout à l'ćtat vert, une odeur désa-

Bois.

Sol.

Bois. gréable.

Du bois d'une tige de 24 ans, de 9 cent. de diamètre, pèse, complétement desséché à l'air, 0,71 (Coll. Ec. For.). 
On plante fréquemment le cerisier à grappes dans les jardins d'agrément.

\author{
GENRE Tr. - PRUNIER. PRUNUS. Lin.
}

Drupe globuleuse ou oblongue, succulente-charnue, glabre, couverte d'une efflorescence glaunue; noyau presgue lisse on finement rugueux sur les faces; feuilles convolutées. - Petits arbres ou arbrisseaux parfois épineux, à fleurs blanches.

A. Jeunes pousses glabres.

B. Fleurs fasciculées par 2-\$3. Fruil globulcux, jaunâtre, de la grosseur d'une prune de reine-claude................... P. DE BRIAvçon. 1

$B^{\prime}$. Fleurs géminćes; fruit oblong, rougeâtre ou violet.................... P. nonestıeze.2

$\mathbf{A}^{\prime}$. Jeunes pousses pubescentes.

B. Fleurs le plus sourent géminées, à pédoncules pubescents-tomenteux ; fruil globuleux, gros comme une prune mirabelle............ P. sturagi.... 3

B'. Fleurs le plus souvent solitaires, à pédoncules glabres ou à peine pubescents ; fruit globuleux, bleuâtre, de la taille d'un pois à celle d'une petite cerise.................

P. ÉpIneux.... \&

1. Prumier de griançon. Prexus brigantiaca. Vilz. Prunier des Alpes.

Feuilles largement orales, acuminées, subcordiformes à la base, doublement et aigument dentées, luisantes et glabres, pubescentes en dessons sur les nervures; stipules linéaires, glabres. Fleur's petites, subsessiles, paraissant avant les feuilles, par faisceaux de $2-3$ le long des rameaux; calice glabre en dedans. Fruit ovale-globuleux, jaunattre clair, acide, de la grosseur d'une prune de reine-claule, à noyau presque lisse. - Arbrisseau de $2.5 \mathrm{~m}$, recouvert d'une écorce d'un roux-brun, à rameaux élalés, non épineux, ramules lisses, glabres, verdâtres. Commun dans les Alpes du Dauphiné, particulièrement dans le Briançonnais. Flor., mai. Fructif., septembre.

On retire des amandes de ce prunier une huile comestible légèrement amère, connue dans le pays sous le nom d'huile de marmolte.

2. Prumier domestique. Prunus domestica. Lin.

Feuilles elliptiques, aiguës, crénelées-dentées, pubescentes sur les deux faces, finalement glabres en ilcssus, leggèrement rugueuses; slipules linéaires, persistantes. Fleurs paraissant avant les feuilles, ordinairement géminées, à pédoncules pubescents; pétales d'un blanc verdatre; calice velu intérieurement. Fruit oblong, penché, rougeàlre ou violet, ì noyau allongé, ruguenx. - Arbrisseau ou arbre de 5-7m, à rameaux élalés, raniules dressés, non épineux, ordinairement glabres. Racines traçantes, 
Irageonnantes. Haies el bords des bois de toute la France. Flor., marsavril. Fructif., juillet-septembre.

Ce prunier est très-variable et n'est probablement pas indigène; on ne le rencontre en effet que dans le voisinage des vergers, jamais dans l'intérieur des forèts. On suppose qu’il est la souche de tous les pruniers cultivés à fruits allongés, qui, en se ressemant, rentreraient plus ou moins dans leur type primitif.

Le bois de ce prunier est lourd, dür, à grain fin, et se reconnait aisément à sa coloration prononcée, d'un rouge brun veiné et nuancé de rouge cramoisi ou de rouge violacé. Il est employé pour ouvrages de tour, de menue ébénisterie; il était autrefois recherché pour la marqueterie. Ses couleurs s'avivent par l'eau de chaux. Du bois d'une tige àgée pèse, complétement clesséché à l'air, 0,71. (Coll. Ec. For.)

3. Prumier sauvage. Pruxus insititia. Lin. Pruneaulier.

Feuilles ovales-lancéolées, jubescentes, surtout en dessous sur les nervures, finalement glabres en dessus; slipules linéaires, pubescentes. Fleurs assez grandes, d'un blanc verdâtre, naissant avant ou avec les feuilles, crdinairement géminées; pédoncules pubescents; calice glabre inlerieurement. Fruits noirs ou jaunes marbrés de rouge, globuleux, gros, penchés, à noyaux rugueux. - Arbrisseau ou petit arbre de 2- $ّ$ m, à branches étalées, ramules dressés, robustes, veloutés, subépineux. IIaies et bords des bois de toute la France; Algérie. Flor., mars-avríl. Fructif, juillet-septembre.

Ce prunier n'est sans doute pas plus indigène que le prunier domestique et parait être comme lui échappé des cultures. Il serait, dans ce cas, le retour au type sauvage des pruniers à fruits arrondis, clont il est considéré comme la souche.

4. Rrunier épineux. Pnunus sprvost. Lrv. Epine noire; Prunellier.

Feuilles obovales ou obovales-lancéolées, dentées, plus ou moins pubescentes, finalement presque glabres. Fleurs petiles, blanches, paraissant avant ou quelquefois avec les feuilles, solitaires ou géminées, à péloncules glabres ou à peine pubescents; calice glabre intérieurement. Fruit globulcux, de la taille d'un gros pois à celle d'une pelite cerise, bleuàtre, très-âpre et acerbe, à noyau ruğucux. - Arbrisseau rameux de 1-4"'t de hauteur, à ramules pubescents, dont l'écorce est d'un brun noir et Iustré (épine noire). Varie beaucoup stuivant les sols et les conditions de sa végélation; forme tantòt un buisson étalé très.diffus et très-épinenx, à feuilles el fruits petits; tantôt un arbrisseau assez élancé, peu épincux, à feuilles plus grandes, fruils plus gros (prunier arbrisseau, 
prunus fruticans, Weihe.). Très-commun dans les haies cl clans les bois. Flor, avril. Fructif., sep:embre-octobre.

Le prunier épineux a des racines fortement traçantes et drageonnantes, et devient par ce moyen facilement envahisBois. sant. Son bois, très-dur, mais sujet à travailler, est agréablement veiné et vivement coloré de brun rougeàtre. Il scrt à la marqueterie.

Produits Les fruits, connus sous le nom de prunelles, senelles, accessoires. chelosses, agrènes, suivant les contrées, entrent dans la préparation de quelques liqueurs alcooliques; lorsqu'ils sont parfaitement murs, on les emploie frauduleusement pour donner de la couleur aux vins de mauvaise qualité.

L'écorce renferme du tannin et donne des teintures noires lorsqu'on en combine les sues avec des sels de fer.

\section{GEXRE v. - ABRICOTIER. AR.IENIACA. Tourn.}

Drupe globuleuse, succulente-charnue, veloutée; noyau à peu près lisse sur les faces; feuilles convolutées dans la jeunesse.

\section{Abricotier commun. Anueniaca rulgaris. LaM.}

Feuilles à péliole glanduleux, ovales ou ovales-arrondies, acuminces, doublement denteces, subcordiformes à la base; glabres, luisantes en dessus. Fleurs paraissant arant les feuilles, solitaires ou géminées, courtement pédicellées; calice rougeâtre, pétales blanes. Fruit velouté, jaune lavé de rouge sur une face. - Arbre de $6-8 \mathrm{~m}$, à tìle arrondic, rameaux torlueux. Originaire d'Armétie el de Perse, cultivé en espalier et en plein vent dans les régions des oliviers et de la vigne. Flor., février-mars. Fructif., juillet.

\section{FAMILLE XX.}

ROSACÉES. Juss.

Fleurs liermaphrodites, régulières; calice libre, gamosépale, versistant, à 5 divisions, rarement 4 ; corolle rosacée, périgyne ; étarnines indéfinies, insérées avec les pétales; anthères biloculaires, introrses, longitudinalement déhiscentes. Carpelles nombreux, distincts, uni-bi-pluri-ovulés, produisant autant de fruits secs ou charmus, indéhiscents monospermes ou déhiscents oligospermes, disposés sur un réceptacle plan ou convexe, ou renfermés dans le tube accrescent et charmu du calice, et constituant par leur réunion un fruil prolycarpé. Graine non périspermée. 
- Herbes ou sous-arbrisseaux à feuilles simples ou composées, alternes, généralement stipulées ; souvent pourvus d'aiguillons; ne présentant d'intérêt forestier que par l'abondance de certaines espèces et l'obstacle qu'elles opposent aux repeuplements.

A. Carpelles apparents, non renfermés dans le tube charnu et accrescent du calice.

B. Fruits secs; sous-arbrisseaux inermes.

C. Fruits déhiscents par la suture ventrale, oligospermes. Herbes ou sous-arbrisseaux à feuilles simples, rarement composées........... SPInÉE.... I

Cl. Fruits indéhiscents, monospermes. Ilerbes on sous-arbrisseaux à feuilles composées; fleurs pourvues d'un double calice............. Potenthle. 2

B'. Fruits charnus, drupes, groupés en un fruit polycarpé.-Sous-arbrisseaux aiguillonnés, à feuilles composées...................... Rosce.... 3

1'. Carpelles produisant des fruils secs, 1 -spermes, akèves, renfermés dans le tube accrescent ct clrarnu du calice. Sous-arbrisseaux aiguillonnés, à feuilles impari-pennées........................ Rosign ....

GENRE I. - SPIRÉE. SPIRE.I. Lin.

Calice à כ̃ divisions; corolle de 5 pétales; carpelles nombreu. disposés en un verticille unique.-Plantes herbacées viraces ou sous-arbrisseaux inermes, à feuilles simples ou composées, stipulées ou extipulées, à fleurs blanches ou roses, hermaphrodites, quelquefois dioïques.

Beaucoup d'espèces ligneuses exotiques sont cultivées dans les jardins d'ornement et se retrouvent çà et là subspontanées dans leur voisinage; mais l'on n'admet, parmi les spirées frutescentes, qu'une seule espèce indigène, et encore son indigénat n'est-il pas bien certain.

Spirée à feuilles dé millepertuis. Spira iryericifolia. LiN.

Feuilles de 2 à 5 centimètres de long, obovales-oblongues, allénuées à la base, subsessiles, arrondies, entières ou dentées à l'extrémité, minces et herbacées, mates et glabres en dessus, glauques et légère. ment pubescentes en dessous. Fleurs petites, blanches, supportées par des pédicelles longs el très-grèles, disposées 4-8 en faisceaux latéraux feuillés à la base et serrés le long des rameaux. - Sous-arbrisseau de $1 \mathrm{~m}$ à $1 \mathrm{~m} \xi 0$, touffu, drageonnant, à rameaux grèles, revêlus d'une ćcorce feuilletéc-fibreuse d'un rouge brun. Spontané dans quelques forèts : environs de Paris, Loirct, Cher, Allier, Vienne et IIaute-Vienne. Hor., mai. 
GEXRE 4 . - POTENTILLE. POTENTILLA. Lin.

Calice double; l'extérięur (cilicule) à J̃ divisions plus petites, l'intérieur à 5 ò divisions alternes avec les précédentes et plus grandes; pétales 5 , arrondis ou obcordiformes. Carpelles nombreux, produisant autant de fruits secs, indéhiscents, monospermes (aliènes), disposés sur la surface d'un réceptacle conrexe. - Plantes presque toutes lierbacées, à feuilles composées, stipulées ; n'offrant qu'une seule espèce ligneuse indigène.

Potentille arorissean. Potextilla fnuticosa. Lin.

Feuilles oppositi-imparipennées, $8-7$-foliolées; les $\overline{0}$ folioles supérieures conflucutes; folioles sessiles, oblongues ou lancéolées, entières, glabres et mates en dessus; glauques, longuement et molloment veluessoyeuses en dessous; stipules membraneuses, soudées au pétiole. Fleurs jaunes, en corymbes composés, généralement denses, à l'extrémité des rameaux; divisions du calicule plus étroites, mais aussi longues que celles du calice. - Sous-arbrisseau de $1^{\mathrm{m}}$, à tige, rameaux et ramules dressés, revêtu d'une écorce membraneusc, roussâtre. Fréquemment cultivé comme arbrisseau d'ornement, croit spontanément dans les IIautesPyrénées. Flor., juillet.

GEXRE UI. - RONCE. RUBUS. Lin.

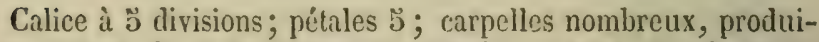
sant autant de petites drupes groupées autour du réceptacle et plus ou moins réunies entre elles pour former un fruit polycarpé, tuberculeux, improprement appelé mùre (mûre sauvage, mûre de haie, molle). - Sous-irbrisseaux plus ou moins aiguillonnés, à souche ligneuse produisant de longs rejets presque sarmenteux, souvent radicants, qui (sauf une exception) sont bisannuels, stériles et feuillés la première année, flcurissent, fructifient, puis meurent la seconde année; dont les feuilles sont comprosées, pennées ou le plus souvent 3-5digitées, et les fleurs, blinnches ou roses, disposées en petites cimes groupées entre clles en corymbes ou en grappes indéfinies. On olserve souvent it l'aisselle des feuilles 2 bourgeons superposés dont le supéricur est le principal.

Les ronees sont des végétaux qui se multiplient avec une grande rapidité et une extrème abondance dans les forêts dont le massif a été entamé; elles y couvrent le sol d'un fourré inextricable, très-redoutable pour les repeuplements faits ou à faire et lont il est fort diflicile de se débarrasser. Leurs firuits sont comestilles, et ceux d'une espèce, la ronce 
frambroisier, forment, avec les fraises, fournies également par des plantes de la famille des rosacées, un menu produit forestier abandonné aux habitants pauvres des communes riveraines des forêts.

L'étude des ronces est extrèmement difficile et les botanistes qui se sont le plus occupés de ce genre sont portés à y reconnaitre un grand nombre d'espèces, dont les car actères sont loin d'ètre suflisamment établis. Le but de ce livre dispense d'entrer dans les détails d'une spécification, encore incertaine, de toutes ces formes et permet de la borner à l'ébauche suivante.

A. Stipules libres. Ronce à tiges lierbacées, annuelles, feuilles ternées, fruits rouges.......... R. DEs nochens. 1

A'. Stipules soudées au pétiole. Ronces à tiges ligneuses, bisannuelles.

B. Feuilles 5-7-pennées; fruit rouge........ R. Frasmoisier. 2

$B^{\prime}$. Fetuilles 5-5-palmées; fruit bleu ou noir.

C. Tiges grêles, arrondies. Fruit bleu, couvert d'une efflorescence glauque.......... R. BLevatre...5

G'. Tiges très-variables, généralement pentagonales. Fruit noir, luisant, sans efflorescence...................... R. ARBRISSEAU . . 4

1. Ronce des rochers. Rubus saxatilis. LiN.

Feuilles 5 -foliolées-palmées, à folioles ovales-rhomboïdales, inégalement dentées, molles, pubescentes, vertes sur les deux faces; les latérales sessiles. Stipules adnées à la tige. 5-6 fleurs blanches, en grappe ombellée terminale, et souvent une fleur isolée ou deux à l'aisselle des feuilles supérieures. Fruit rouge pellucide, acide, formé de $\mathbf{5 \cdot 6}$ drupes, relativement grosses, insérées sur un réceplacle discoïde. - Plante grêle, à rejels rampants, radicants, dont les extrémités foliifères périssent chaque hiver, mais produisent de leurs bases des rameaux florifères dressés, hauts de 10-50 centimètres. Cà et là dans les forèts des régions de collines et de montagnes de presque toule la France. Flor., mai-juin.

2. Ronce framboisier. Rurus insus. Lir.

Feuilles inférieures formées de les supérieures ternées; folioles obliquement ovales, acuminées, dentées, molles, blanches-tomenteuses en dessous, la terminale cordiforme à la base, longuement pétiolée, les latérales sessiles. Fleurs petites, blanches, à pétales étroilement obovés, dressés. Fruit aromatique, rouge, velu (framboise), à carpelles nombreux, adhérents, se délachant tout d'une pièce du réceptacle qui est conique. - Sous-arbrisseau de $1^{\mathrm{m}}$ à 1 mbo, à liges stériles, dressées-arquées, arroudies, glauques, couvertes d'aiguillons droits, fins, sétacés, non vulnérants; à racines traçantes, drageonnantes. Très-commun dans les bois montagneux de tous les terrains. Flor, juin-juillet. 
La très-grande facilité avec laquelle la ronce franıboisier drageonne la rend très-redoutable pour les jeunes peuplements. Elle forme, à elle seule, des fourrés très-scrrés, dont l'extirpation est à peu près impossible, car les tentatives laites dans ce but ne tendent généralement qu'à provoquer le drageonnement. Ces fourrés disparaissent d'eux-mèmes au bout de $8-10$ ans.

3. Honce blenâtre. Rubus crsius. Liv.

Feuilles toutes trifoliolées, les latérales sessiles; calice appliqué sur le fruit; celui-ci bleuàtre, couvert d'une efllorescence glauque, composé d'un petit nombre de carpelles assez gros, insírés sur un réceptacle conique. - Espèce assez constante, à tiges rampantes, grêles, cylindriques, glanques, munies sur presque toute leur longueur d'aiguillons droits, fins, sétacés, non vulnérants, et, à leurs extrémités, d’aiguillons crochus. Très-commun dans les champs et au bord des chemins. Flor., mai septembre.

4. 助once arbrissean, Rubus Fruticosus. Liv.

Il est incontestable que sous ce nom sont confondues des espèces nombreuses et réelles, incomplétement connues jusqu'alors. A part lo caractère commun tiré du fruit, qui est luisant el dépourvu d'efflorescence glaurque, on observe en efîel que la ronce arbrisseau, entendue dans le scus linnéen, présente des diflérences nombreuses daus chacun de ses organes. Ainsi les tiges sont dressées-lécombantes ou rampantes, plus ou moins longues, grềles ou robustes, arrondies, penlağonales ou creusées de $\ddot{b}$ sillons; glabres, velues, glanduleuses; armées d'aiguillons nombreux ou rares, forts ou faibles, droits ou crochus, vulnérants ou non. Les feuilles ne varient pas moins; généralement quinées sur les rameaux stériles, ternées sur les florifères, mais aussi parfois toutes ternćes, elles sont de formes différentes; vortes, glabres ou velues, blanches-tomenteuses sur la face inférieure ou sur toules les deux à la fois. Les fleurs, blanches ou roses, offrent des inflorescences diverses, des pétales de forme el de grandeur varices; enfin, les fruits eux-mêmes sont plus ou moins gros, composés d'un nombre plus ou moins grand de carpelles. Très-commune dans les forêts, dans les haies, aux bords des chemins et dans les licux vagues. Flor., juillet-août.

\section{GEXRE IV. - ROSIER. ROSA. Lin.}

Calice à tube urcéolé, très-poilu intérieurement, à b̀ divisions; corolle grande; carpelles nombreux, produisant autant de fruits distincts, secs, incḱhiscents, monospermes (akènes), contenus dans le tube calicinal développé et devenu charnu - Sousartrisscaux à feuilles oppositi-imparipemées, à stipules soudées atl pétiole et à tiges aiguillonnées.

bois ì tissn filreux dominant. Vaisscanx inégaux, isolés, assez s!ros au bord interne, déeroissant daus la région médiane et ex- 
erne où ils sont très-fins et rares; à peu près uniformément espacés. Rayons assez larges, indéfinis.

La végétation des rosiers a beaucoup d'analogie avec celle des ronces. La souche émet des rameaux souterrains qui produisent annuellement des rejets aériens vigoureux, stériles la première année, florifères au bout de 2 à 5 ans; seulement ces rejets ne périssent pas comme ceux des ronces après avoir fructifié.

Sans compter les rosiers cultivés que l'on rencontre assez souvent à l'état subspontané, le nombre des rosiers indigènes sauvages est considérable; mais toutes les espèces ne sont pas encore nettement limitées. Cette considération et le peu d'importance forestière de ec genre permettent de ne parler que des espèces les plus communes et le plus généralement admises.

A. Stipules des rameaux fleuris el stériles semblables, étroites; carnelles sessiles dans le calice fructifère.

B. Siyles libres, non soudés en colonne.

C. Fleurs grandes, purpurines. Calice fruclifère à divisions presque entières, rouge et dressé à la malu-

$\mathrm{C}^{\prime}$. Fleurs blanches, rosées ou jaunâ. R. de Frayce..... 1 tres; calice fruclifère à divisions entières, noir el dressé à la maturité..................

B'. Styles soudés en une colonne aussi longue ou presque aussi longue que les élamines; fleurs blanches ou à peine rosées.

C. Divisions du calice à peine plus longues que le bouton, un peu pennatiséquées, terminées en pointc non appendiculée.

D. Colonnedes styles glabre. Feuilles caduques............... R. des Chran's.... 5

D). Colonne des styles hérissée, velue. Feuilles vertes en hiver...... C'. Divisions du calice allongées, penna-
tiséquées, terminées par un appendice foliacé. Colonne des styles

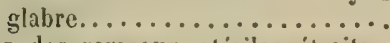

R. Pimprenelle....

R. roujouns vent....

$\mathbf{A}^{\prime}$. Stipules des rameaux stériles étroites, celles des rameaux flcuris dilatées. Carpelles, au moins ceux du centre, pédicellés.................. 
B. Pédicelles plus courts que les carpelles.

Divisions du calice entières.

C. Rameaux inermes. Calice fruclifère réléchi à la malurité. Fleurs roses .................. R. uns Alres.... . 6

C'. Rameaux aiguillonnés. Calice fructifère dressé à la malurité.

D. Fleurs roses; feuilles cendrées, pubescentes en dessous.. ...

D). Fleurs purpurines; feuilles glauques, purpurines dans la jellnesse.................

B'. Pédicelles égaux aux carpelles ou plus longs. Divisions du calice pennatiséquées.

C. Feuilles glabres ou pubescentes en dessous seulement.

D. Feuilles non glanduleuses en dessous, si ce n'est quelquefois sur les nervures. Fleurs roses ou blanches-rosées.............

D'. Feuilles fortement glanduleuses-
odlorantes en dessous.
L. Folioles cunéiformes à la base;
fleurs blanches ou blanches-
rosées; aiguillons presque
égraux..................

D'. Feuilles fortement glanduleuses-
odlorantes en dessous.
L. Folioles cunéiformes à la base;
fleurs blanches ou blanches-
rosées; aiguillons presque
égraux..................

D'. Feuilles fortement glanduleuses-
odlorantes en dessous.
L. Folioles cunéiformes à la base;
fleurs blanches ou blanches-
rosées; aiguillons presque
égraux..................

D'. Feuilles fortement glanduleuses-
odlorantes en dessous.
E. Folioles cunéiformes à la base;
fleurs blanches ou blanches-
rosées ; aiguillons presque
éraux..................

D!. Feuilles fortement glanduleuses-
odlorantes en dessous.
L. Folioles cunéiformes à la base;
fleurs blanches ou blanches.
rosées; aiguillons presque
égaux...................

R. DES CHIENS..... 9 fleurs d'un rose vif; aiguillons très-inégaux............

C'. Feuilles au moins pubescentes en dessus, tomenteuses en dessous ou sur les deux faces.

D. Feuilles mollement tomenteuses sur les deux faces; fleurs blanches-rosées, à pétales non ciliés.

$D^{\prime}$. Feuilles pubescentes en dessus, grises-tomenteuses en dessous; lleurs d'un rose vif, à pétales cilits ................ siles.

1. Ekosier ale wrance. Rosi gallica. Liv.

Feuilles de 'b-7 folioles, arrondies ou elliptiques, d'un vert foncé en dessus, d'un vert pile co dessous, fermes, a dents larges, étalées, sousdentees et glanduleuses; stipules à oreilleltes divergentes. Fleurs grandes, odorantes, purpurines, généralenent solitaires, dont les divisions calicinales sont allontzeses, légèrement penualiséquées, terminées par un 
appendice étroit, foliacé; ces divisions sont réfléchies et cadurques il la maturilé. Styles libres assez allongés, plus courts néammoins que les élamines; calices fruclifères rouges, dressés. - Sous-arbrisseau de $1^{\mathrm{m}}$, à racines longuement tracantes, drageonnantes, formant un buisson làche, à tiges grèles, presque dépourvues d'aiguillons quand elles sont àgées; armées, dans la première année, d'aiguillons très-inégaux, les uns sétacés souvent glanduleux, les autres plus gros, comprimés et légèrement arqués. Disséminé dans les lieux secs de différents points de la France, surtout dans l'Est. Flor., juin.

2. Mosier pimprenelle. Rosa pimpinellifolia. Ser.

Feuilles de 5-9 folioles pelites, ovales ou arrondies, obluses, simplement dentées non glanduleuses. Fleurs généralement solitaires, blanches, rarement rosées ou jaunâtres; divisions du calice entières, non appendiculées, à peine plus longues que le boulon, persistantes et redressées à la malurité; styles libres, plus courts que les élamines. Calice fructifère dressé, d'un noir pourpre. - Petit arbrisseau de 1-2 ${ }^{\mathrm{m}}$, très-rameux, touffu, pourvu d'aiguillons rares ou extrèmement nombreux, très-ínégaux, droits, subulés ou sétacés. Collines sèches et régions montagneuses peu élevées de toute la France. Flor., juin.

\section{Hosier des champs. Rosa Artensis. IIuns.}

Fevilles de 5-7 folioles arrondies ou elliptiques, minces, glabres, d'un vert glauque en dessous, à dents écartées, simples, non glanduleuses, mucronées, non conniventes au sommet. Fleurs blanches, solitaires ou en corymbes; divisions du calice linement penuatiséquées, terminées en pointe et dépassant à peine le bouton, réfléchies après la floraison, caduques à la maturité; styles soudés en une colonne mince et glabre, aussi longue que les étamines. Calice fructifère rouge el llressé. - Sousarbrisseau à tiges grêles, rampantes, pourvues d'aiguillons presque égaux, dilatés et comprimés à la base, courbés en faulx. IIaics, buissons et forèts de toute la France; s'élève jusqu'aux régions alpestres. Flor., juin.

\section{Etosier toujours vert. Rosa SEIPERrineNs. LIN,}

Feuilles de 5-7 folioles elliptiques, acuminées, fermes, glabres, vertes et brillantes sur les deux faces, persistantes en hiver, simplement dentées non glanduleuses, à dents étroiles, acuminées, connirentes au sommef. Fleurs à peine odorantes, blanches, en corymbe; divisions du calice presque entières, pointues et non appendiculées au somnet, dépassant à peine le bouton, réfléchies après la floraison, puis caduques; styles soudés en colonne hérissée, un peu plus courte que les étamines. Fruit rougeâtre ou orangé, dressé. - Petit arbrisseau à tiges et rameaux allongés, décombants, armé d'aiguillons épars, robustes, élargis el comprimés à la base, un peu courbés en faulx. Région méditerranéenne; remonte le Rhône jusqu'à Lyon et le littoral de l'Océan jusqu'à Angers. Flor., juin.

5. Resier à longs styles. Rosa stýlosa. Destaux.

Feuilles de ou en dessous seulement, bordées de dents simples, aiguës, connirentes surtout vers le sommet. Fleurs solitaires ou en corymbe, blanches ou blanches-rosées; divisions du calice pennaliséquécs, aussi longues que 
les pétales développés, réfléchies, eadug̨ues à la maturité; slyles somlés en colonne glabre. Fruit rouge, dressé. -- Arbrisseau robuste ct touffu, armé d'aiguillons courls, forls, comprimés à la base, fortement arquís. Cà et là dans les haies et les broussailles. Flor., mai-juillet.

\section{Sectiox II. Stipules superricures des rameaux fleuris dilatées; celles des rameaux stériles linéaires, étroiles. Carpelles, au moins ceux du centre, pédicelles.}

\section{§ I. Carpelles du centre brièvement pédicellés.}

\section{Rosier des Alpes. Rosa alpina. Lin.}

Feuilles de 7-11 folioles elliptiques-oblongues, males, glabres ou pubescentes en dessous, à dents très-aiguës, glaudulenses, simples ou sous-dentées; stipules des rameaux florifères cunéiformes à la base, trèsdilatées à l'extrémité; celles des rameaux stériles planes, à oreillettes divergentes. Fleurs ordinairement solitaires, d'un rose vif, penchées avant et après l'épanouissement; divisions du calice entières, dépassant la corolle, persistantes et redressćes à la maturité. Calice fructifère rouge, penché.- Arbrisseau de $1 \mathrm{~m}_{-} \mathrm{Im}^{\mathrm{m} 30}$, pourvu, sur les rejels de l'année seulement, d'aiguillons droits, sétacés, caducs; inerme sur tout le reste. Régions montagneuses : Vosges, Jura, Auvergne, Cévennes, Alpes et Pyrénées. Flor., juin.

* Rosier cannelle. Rosa cinnanomea. Lin.

Fevilles de $3-7$ folioles elliptiques-oblongues, aigùment el simplement dentées-non-glanduleuses, grisâtres et pubescentes en dessous. Stipules des rameaux stériles linéaires-oblongues, conniventes par leurs bords et comme tubuleuses, à oreillettes étalées. Fleurs ordinairement solitaires, roses; divisions du calice presque toujours entières, aussi longues que la corolle, terminées par un appendice foliacé, persistantes à la maturité. Calice fruclifère globuleux, de la grosseur d'un pois, rougge, dressé. Arbrisseau de $1^{\mathrm{m}}-1^{\mathrm{m} 500} 0$, à rameaux d'un brun cannelle, armé d'aiguillons inégaux; les uns droits, sétacés, caducs, les autres, dans le voisinage des feuilles, plus forls el léçèrement arqués. Disséminé çà et là : Lorraine, Jura, environs de Paris, Creuse, Puy-de-Dôme. Flor., juin.

8. Rosier à fenilles rouges. Rosa nubrifolia. Vilz.

Feuilles de "3-7 folioles elliptigues, à dents simples, aiguës, non glanduleuses, dont les supérieures sont conniventes; stipules des rameaux stériles planes, à oreillettes divergentes. Fleurs petites, purpurines, ordinairement en corymbe. Divisions du calice simples, rarement penatiséquées, dépassant la corolle, lerminées par un appendice foliacé, caduques à la maturité. Fruits globuleux, rouges, dressés. - Arbrisseau glauque, dont les bractées, les stipules, les pétioles et les jeunes feuilles ont une teinte purpurine; armé d'aiguillons peu nombreux, comprimés, légèrement ariués. Régions montagneuses élevées : hautes-Vosges, hant-Jura, Cantal, Lozére, Puy-de-Dòme, Nlpes el Pyrénées. Flor., juin. Fruclif., août. 


\section{§ II. Carpelles du centre longucment pédicellés.}

9. Rosier des chiens. Rosa canina. Liv.

Feuilles de 3-7 folioles, ovales ou elliptiques, à dents aiguës, simples ou sous-dentées, peu ou pas glanduleuses, glabres ou pubescentes, vertes et luisantes, ou glaurues el mates. Fleurs roses ou blanches-rosées; solitaires ou en corymbe ; divisions du calice pennatiséquées, dépassant la corolle, réfléchies après la floraison, finalement caduques. Calice fruclifère elliptique, rouge et dressé. - Arbrisseau robuste de $1-5^{\mathrm{m}}$, touffu, armé d'aiguillons presque égaux, très-forts, dilatés et comprimés à la base, courbés en faulx. Très-commun dans les bois et les haies de toute la France, se retrouve en quelques points de l'Algéric. Flor., juin; le calice ne devieut pulpeux qu’après les premiéres gelées.

Ce rosier, très-variable, cst généralement celui qu’on dèsigne sous le nom d'églantier, nom souvent appliqué à tous les rosiers sauvages, quoique botaniquement il ne convienne qu'à une espèce exotique à fleurs d'un jaune pourpre (rosa eglanteria. Lin.). La dénomination de canina, que Linné lui a donnée, rappelle la croyance où l'on était autrefois que sa racine guérissait la rage. C'est sur lui que l'on greffe les rosiers cultivés.

10. Ktogier ales haies. Ros sepium. ThumL.

Feuilles de "̋-7 folioles obovales, cunéiformes à la base, aiguës à l'cxtrémité, à denls sous-dentées, très-étalées; brillantes sur les 2 faces et couvertes en dessous de glandes odorantes. Fleurs blanches ou blanchesrosées, solitaires ou en corymbes; divisions du calice pennatiséquées, appendiculées au sommet, étalées, finalement caluques. Calice fruclifère rouge, dressé. - Arbrisseau rameux, couverl d'aiguillons presque égaux, élargis et comprimés à la base, tous arqués. Lieux secs et rocailleux. Flor., juin.

11. Rosier rubigineux. Rosa nubiginosa, Liv.

Feuilles de 5-7 folioles ovales on presque orbiculaires, arrondies à lá base, pointues ou obtuses à l'extrémilé, à dents sous-dentées, écartćes; luisantes sur les deux faces et couvertes en dessous de glandes nombreuses odorantes. Fleurs petiles, d'un rose vif, solitaires ou en corymbe; divisions du calice pennatiséquées, appendiculées au sommet, réfléchies, finalement caduques. Calice fructifère rougre et dressé à la maturité. Arbrisseau de $1-2^{\mathrm{m}}$, três-rameux et touffu, pourvu d'aiguillons trèsinégaux, nombreux, droils ou crochus; à reflels souvent ferrugineux en raison des glandes rougeâtres et nombrenses qui le recouvrent. Ces glandes exhalent une odeur de pomme de reinette très-prononcée. IIaies et buissons des lieux sees et chauds. Flor., juin juillet.

12. Rosier tomentenx. Rosa tomentosa. Smitil.

Feuilles de $5-7$ folioles ovales ou elliptiques, aiguës, arrondies à la base, à dents étalées, dressées et sous-dentées, mollement cendrées- 
tomenteuses sur les deux faces, mais surtout en dessous où l'on roit aussi quelques glandes sessiles. Fleurs d'un rose clair, solitaires ou on corymbe; dirisions du calice peunatiséquées, appendiculées au sommet, réfléchies, finalement caduques. Calice fructifêre rouge et dressé à la maturité. - Arbrisseau de 1-2 ${ }^{\text {ma }}$, rameux el touffu, armé d'aiguillons presque égaux, robustes, élargis à la base, à peu près droits. Haies et bois des régions accidentées ou montagneuses peu élevées. Flor., juilletaoût.

13. Rosier pomifère. Rosa pomfera. Hermann.

Feuilles de 5-7 folioles grisîtres, pubescentes en dlessus, tomenteuses en dessous, oblongues-elliptiques, à dents sous-dentées, très-étalées. Fleurs solitaires ou géminées, d'un rose vif, à pétales ciliés ; divisions du calice pennaliséquées, appendiculées au sommel, redressćes et persistantes à la malurité. Calice fructifère ğros, globuleux, hérissé-glanduleux, rouge et penché. - Arbrisseau à aiguillons jresque égaux, droits, peu ou point dilatés à la base. Disséminé çà et là, en Lorraine, en Alsace, en Aurergne; dans le Jura, les $\Lambda$ pies, les Pyrénées. Flor., juinjuillet.

SOUS-ORDRE II.

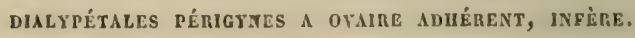

\section{FAMILLE XXI.}

POMACÉES.

Fleurs hermaphrodites, régulières. Calice tubuleux, soudé à l'ovaire, à 5 divisions; corolle rosacée, à pétales alternes avec les divisions du calice; étamines intéfinies, insérées avec les pétales, à anthères introrses, biloculaires, longitudinalement déhiscentes. Ovaire adhérent au calice, 5-plus rarement et par avortement 1-4-loculaire, dont chaque loge est bi-ovulée et quelquefois pluri-ovulée; styles en nomilsre égal à celui des loges. Fruit syncarpé charnu, couronné par les dents du calice (pomme), à endocarpe membraneux ou cartilagineux (pomme à pépins) ou ligneux, et, daus ce cas, partigé en autint de noyaux libres ruzil y avait de loges (pomme à noyaux). - Arbres ou arbrisseaux quelquefois épineux par transformation de rameaux, à fenilles alternes simples ou composées, à nervation pennée, munies de stipules cadurgues ou persistantes, et it fleurs blanches ou roses; bourgeons écailleux.

La famille très-naturelle des pomacées produit des bois de structure identigue pour tous les genres et qu'il est souvent très-difficile de distinguer entre eux. Ils ont les fibres étroites, ì 
parois épaisses, non groupées entre elles en faisceaux, entremêlées de parenchyme ligneux souvent abondant (non apparent à la loupe); les vaisseaux fins ou très-fins, isolés, épars, un peu plus serrés au bord interne, plus espacés au bord externe; les rayons fins. De cette structure résultent des bois lourds, durs, compactes, très-homogènes, peu disposés à la fente, peu ou point maillés.

La coloration varie du blanc au rougeâtre clair et au rouge brun foncé; elle est tantôt uniforme, tantôt irrégulière et elle rend, dans ce cas, les bois flambés vers le cœur, sans que la nuance plus vive qui s'y remarque soit le signe distinctif du bois parfait.

On remarque fréquemment dans ces bois des taches caractéristiques, brunes ou rougeâtres, de tissu cellulaire interposé dans le tissu fibreux. Elles s'observent particulièrement dans les alisiers, sorbiers, aubépines, néfliers et coignassiers; elles manquent dans les pommiers et poiriers.

En langage forestier, les pomacées sont comprises, avec les amygdalées, sous la dénomination collective de Fruitiers.

A. Fruils à noyaux.

B. Carpelles soudés par leur moilié inféricure avce le calice, saillants et libres par la partie supérieure.

C. Feuilles entières, tomenteuses en dessous, caduques. Fleurs en corymbes pauciflores, à 2-5 styles. Arbrisseaux inermes...... Cotongaster... 1

C'. Feuilles dentées, glabres, luisantes, persistantes. Fleurs en corymbes multiflores, à J styles. Arbrisseaux épineux......... Busson-andent. 2

$\mathrm{IB}^{\prime}$. Ovaire entièrement adhérent au calice.

C. Feuilles jennatilobées ou-partites; fruit peu charnu, rouge, couronné par les dents desséchées du calice. Fleurs moyennes, en corymbes. Arbrisseaux épineux..... AunÉRเš...... J

C'. Feuilles dentées; fruit largement excaréombiliqqué au sommet, courouné par les divisions très-accrues du calice; fleurs grandes, solitaires. Arbrisseaux ou petits arbres épineux ou inermes........... NérLikr..... \&

$\Lambda^{\prime}$. Fruits à pépins.

B. Fruit pyriforme, à $\mathfrak{b}$ loges, dont chacune contient $10-15$ graines. Feuilles simples, dentées; fleurs' grandes, solitaires ou fasciculées. Arbrisseaux ou petits arbres inermes. Colgnassien.... 5

B'$^{\prime}$. Fruit à loges 2-spermes.

C. Pétales suborbiculaires; loges du fruit sans fausse-cloison. 
D. Fleurs graniles, en ombelles ou en corymbes simples. Fruil charnu. Feuilles simples, dentées.

E. Fruit turbiné (poire); styles complétement libres; corymbes. Arbres épineux ou inermes .............. Pornere....... t

E'. Fruil globuleux, à 2 ombilics (pomme), styles soudés à la base. Ombelles. Arbres épineux ou inermés....... p'oswren..... 7

$\mathrm{D}^{\prime}$. Fleurs moyennes, en corymbes composés. Fruit peu charnu, devenant souvent pulpeux et comestible en blossissant.

E. Feuilles simples, dentées ou lobées.

$\mathrm{E}^{\prime}$. Feuilles composées, imparipennées. Alisien...... Arbres inermes .............. Sormien .......

C. Pétales oblongs-linéaires; loges du fruit incomplélement divisćes par unc faussecloison; fruits pelits, globuleux; feuilles simples, dentées. Arbrisscaux inermes.. Auḱlaxcmer... !)

\section{Section I. Fruits à noyaux.}

(Le surcocarpe provient du calice accru; les noyaux représentent l'ovaire.)

GENRE 1. - COTONEASTER. COTONEASTER. Medik.

Calice turbiné, ì ¿̀ lobes courts; 2 ou 3 styles. Carpellez libres entre eux et soudés avec le tube calicinal jusrju’ì Icur moitié seulement. Fruit globuleux, ì 2 ou 3 noyaux monospermes, dont la moitié supérieure est libre, saillante ct simplement recouverte sans adhérence par les dents, devenues charnues, du calice. - Arbrisseanx inermes, à feuilles caduques, blanches-tomenteuses en dessous, très-entières, dont les fleurs, petites et rosíes, sont disposées en corvmles pauciflores. Bourgeons recouverts d'un petit nombre d'écailles, qui laissent voir entre elles les poils des féeuilles qu'elles protégent.

A. Corymbes penchés après la floraison; calice

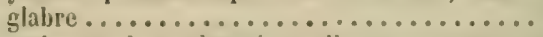

C. commun.... 1

$\mathbf{A}^{\prime}$. Corymbes toujours dressés; calice tomenteux... C. cotonneux. 2

1. Cotoníaster commun. Cotoxeastel vulgaris. Lindar. Mespilus coloneruster. Lin.

Feuilles subsessiles, ovales-orbiculaires, obtuses ou éclancrées el mucronulées au sommet; vertes, presque glabres en dessus, grises-10. menteuses en dessous. Fleurs pretites, roses, splitaires ou en corymbes 
Je 2.3, d'abord dressées, puis penchées; pédoncules pubescents; calice glabre, à divisions arrondies. Fruit réfléchi, du volume d'un gros pois, glabre, luisant, rouge, de saveur fade. - Petit arbrisseau de $0 \mathrm{mb0}$ à $1^{\mathrm{m}}$ de hauteur, tortueux, rameux, à rameaux allongés, souvent réfléchis, rugueux, d'un brun foncé, dont les pousses d'un an ne sont velues que vers l'extrémité. Rochers et pierrailles des régions moutagneuses, atx expositions chaudes : hautes-Vosges, Jura, haute-Auvergne, Alpes el Pyrénées. Flor., avril-mai. Fructif., août.

2. Cotonéaster cotonneux. Cotoneaster touentos.. Lindu.

Voisin du précédent; feuilles du double plus grandes, pubescentes en dessus, blanches-tomenteuses en dessous. Fleurs 5-b, en corymbes diressés, à pédoncule et calice velus-tomenteux. Fruils dressés, conservant souvent encore des traces du duvet du calice. - Arbrisseau de même port que le précédent, mais plus élevé, dont les pousses d'un an sont velues sur toute leur longucur. Escarpements et rochers des hautes régions montagneuses: Alpes, Pyrénées, Jura. Flor., avril-mai. Fructif., roût.

\section{GENRE II. - BUISSON-ARDENT. PYRACANTIIA. T. IIartig.}

Calice turbiné, à 巳̃ lobes courts; כ̃ styles; carpelles et fruit ¿ 2 ou 3 noyaux sernblables à ceux du genre précédent. Arbrisseaux épineux, à feuilles simples, Juisantes, toujours vertes, crénelées, dont les fleurs, blanchcs et moyennes, sont disposées en corymbes multiflores.

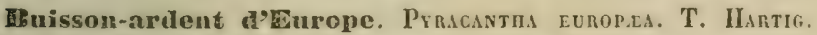
Mespilus pyracantha. Lin.

Feuilles persistantes, courtement pétiolées, ovales, elliptiques ou obovales, aiguës ou obluses, crénelées sur les bords, fermes et coriaces, luisantes, très-glabres et d'un vert foncé en dessus, plus pâles et pubescentes dans la jeunesse en dessous. Fleurs blanches, disposées en corymbes multiflores presque toujours feuillés à la base, nombreux ef rapprochés entre eux. Fruits d'un rouge-corail, globuleux, de la grosseu: d'un pois, mùrs en automne, mais persistant jusru'au printcmpls suivan!. - Arbrissean de 1 à $2^{m}$, très-touffu, à branches diffuses, rameaux divariqués, épineux, d'un brun rougeâtre. IIaies et broussailles de la France. méridionale : Dauphiné méridional, Provence, Languedoc, de Bayonus. ¿ Bordeaux. Fréquemment cultivé comme arbrisseau d'ornement pour son feuillage toujours vert et les fruits nombreux, persistants et d'un rouge vif auxquels il doit son nom. Flor., mai. Fructif., septembre.

\section{GENRE II. - AUBÉPINE. CRATAGUS. Lin.}

Calice urcéolé, à ä lobes courts ; 1-3 styles; ovaire entièrement adhérent, 1-3 loculaire, dont chague loge est bi-orulée. Fruit pelit, peu chamu, assez. Iarecment ombiliqué au sommet et couronue par les dents marcescentes da calice, contenant 1-3 
noyaux monospermes. - A brisseaux épincux, à écorce longrtemps lisse, d'un gris argenté, formant plus tard un rhytidome brun noirâtre, écailleux et densément gercuré, surtout cn long; à feuilles carluques, simples, pennatilobées-partites; à fleurs moyennes, blanches, rarement roses, disposées en corymbes paraissant après les feuilles. Stipules herbacées, persistantes, très-développées sur les rejets et pousses stériles. Bourgeons à écailles imbriquées-spiralées.

A. Feuilles vertes el luisantes, presqute glabres dans leur enlier développement.

B. Feuilles généralement à bै lobes aigus; à nervures divergentes; 1 style el fruit à 1 senl noyau. A. หoxogrsc. 1

B'. Feuilles généralement 5-lobẻes au sommet, à nervures convergentes; $2-3$ styles et fruit à 2-5 noyaux....................... BLANcuE..2 A'. Feuilles pubescentes et d'un vert grisâtre sur les deux faces; ramules velus-tomenteux........ A. Azerorien. 5

1. Aubépiue momoggne. Crategus movogras. Jace. Epine blanche.

Feuilles pétiolées, obovales, cunéiformes et entières à la base, habituellement próondément divisées en $5 \mathrm{rt} \mathrm{le} \mathrm{plus} \mathrm{souvent} \mathrm{en} \mathrm{"̋̉} \mathrm{lobes} \mathrm{aigus,}$ ineisés-dentés, divergents ainsi que leurs nervures médianes; d'un vert clair, luisantes et pres(jue glabres. Divisions du calice lancéolées et rénéchies; 1 seul style. Fruit ovoïle ou globuleux, ronge, farineux et fade, à un seul noyau. - $\Lambda$ rbrisseau ou pelit arbre très-rameux, touffu, épincux, dont les ramules sont souvent velus et dont l'écorce se maintieut lisse et vive, d'un gris cendré elair (épine blanche) jusqu'à un ầge avancé, puis organise un rhytidome lırun rougeâtre, écailleux, finement el densément gercuré. Ilaies, broussailles el forèts, surtout sur les lisieres, dans les régions de plaines, de collines ou de monlagnes peu élevées; Algérie. Flor., mai-juin. Fruclif., oclobre-novembre; les fruits múrs persistent souvent jusqu'au printemps.

Taille. L'aubépine monogyne devient assez souvent un petit arbre, et il n'est pas rare de lui voir atteindre, dans les fonds frais et fertiles, $8-10^{\mathrm{m}}$ de hauteur sur $1^{\mathrm{m}}$ de circonférence. On cite un arbre de cette espèce ou de la suivante, car on les confond souvent l'une et l'autre, qui se trouve dans le comté de Norfolk et était déjì signalé par un acte du commeneement du $15^{\text {me }}$ siècle sous le nom de vieille aubépine; il mesure plus de $4^{\text {th }}$ de circonférence à 1 naj 0 du sol.

Les fruits, assez abondants chaque annćc, lorsque l'arbris-

Germination. scau n'est point sous le couvert, germent au bout de 18 mois ou d'un an, suivant quils ont été scmés vers la tin de 
l'automne ou au premier printemps. Les jeunes plants ont une végétation assez active et s'allongent annuellement de $20-50$ centimètres jusqu'à $6-8$ ans; passé cet àge, l'accroissement se ralentit et reste toujours faible. La longévité est ordinairement assez élevéc.

L'aubépine vient à peu près dans tous les sols; mais elle préfère ceux qui sont légers et frais.

Le hois est dur, lourd, complétement blane ou légèrement teinté de rougeâtre, souvent marqué de taches ou de nouds d'un noir d'ébène, il reçoit un beau poli, est propre aux ouvrages de tour, convient pour faire les pièes des machines qui subissent des frottements; mais il a le défaut de se tourmenter et de se gercer. C'est un bon combustible. Du bois d'une tige de $5 \bar{j}$ ans el de 20 centimètres de diamètre, complétement desséché à l'air, et provenant de Nancy, pèse 0,72 (Coll. Ec. For.). Son retrait est de $\frac{1}{8}$ du volume vert. Le bois d'aubépine ressemble beaucoup à celui de l'alisier blane; mais il n'a jamais la fibre droite, presque exempte de nouds, et les accroissements soutenus et régulièrement circulaires concentriques de ce dernier.

La ramification épineuse et serrée de l'aubépine, la facilité avec laquelle elle se laisse tailler sans se dégarnir la font fréquemment employer pour former des haies qui sont impénétrables et d'une grande durée, si le sol n'est ni trop sablonneux, ni trop aride. On emploie souvent ect arbrisseau comme sujet pour y grefler des végétaux cultivés de la mème famille.

Les fruits sont fades, douceàtres et astringents. Ils n'ont pas d'emploi.

2. Aubépine épineuse. Cratagus oxracantus. Jaco. Epineblanche; Noble-Epine, elc.

Généralement confonduc avec l'espèce précédente, mais bien distincle; se reconnaî̀ à ses feuilles obovales, cunéiformes, dentées presque dès la base, ordinairement 5-loljées au sommet, à lobes peu profonds, incisés-dentés, dont les nervures sont convergentes; plus luisantes et d'un vert plus foncé. Fleurs plus grandes, divisions du calice triangulaires, très-étalées. 2-5 styles. Fruit ovoïde ou subglobuleux à 2-5 noyaux. Arbrisseau de mème port que le précédent, mais devenant plus rarement un petit arbre et n'atteignant pas d'aussi grandes dimensions, à ramules généralement glabres. Se trouve dans les mêmes lieux; Algérie. Flor., mai, 15 jours plus tôl que l'aubépine monogyne.

3. Aabćpho azerolier. Cratiges azanoles. Lis. Epine d'Espagic. 
Feuilles a pétioles tomenteux, obovales-cuneiformes, tres-entieres a la base, profoudement divisées en $5-5$ lobes entiers ou prateidentés a leur extrémilé; fermes, pubescentes et l'un vert grisître sur les deux faces. Fleurs en corymbes peu longuement pédoneulés; pédonenles et caliees tomeuteux; ceux-ci à divisions triangulaires-aiğtës, rélléchies; $1-2$ slyles. Fruits ovoïles à $1-2$ noyaux, beaucoup plus gros que ceux des espèces précédentes, rougeâtres, pulpeux et d'un goût agréable à la malurité (azeroles). - Arbrisseau ou arbre à rameaux épineux, à ramules velus. tomenteux. Région méditerranéenne en France, en Corse el en Algérie. Flor, avril-mai.

Taille. L'azerolier est souvent cultivé comme arbre fruitier, mais il est aussi un arbre forestier et, quoique fréquemment à l'état de buisson, on le voit parfois atteindre les dimensions d'un arbre de 10-12m de hautcur sur 1-2"m de circonférence. Il croit lentement; sa longévité est considérable.

Bois. Le bois de l'azerolier est en tous points semblable à celui de l'aubépine monogyne; mais les taches et les nouds qu'il présente sont d'un brun rougeàtre et non pas noirs. Il est lourd, deur, compacte, mais sans souplesse; il travaille beaucoup) et se geree en se desséchant. C'est un excellent combustible, qui produit un charbon de première qualité.

De l'azerolier d'Algérie, d'une tige de 18 ans et de 12 centimètres de diamètre, pèse, complétement desséché à l'air, 0,81 (Coll. Ec. For. Envoi de M. Royer).

GENRE IT. - NEFLIER. MESPILUS, Lin.

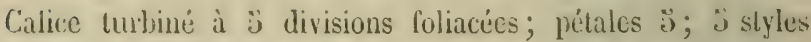
libres; ovaire 5̈-loculaire, dont chague loge est bi-ovuléc. Fruit largement cxcavé-ombiliqué au sommet, à ombilic entouré des divisions foliacées très-accrues du calice, contenamt 5 noyaux 1-spermes. - Arbrisseaux ì feuilles simples, entières ou légèrement denties, cadurgues; ì fleurs grandes et solitaires.

Véflier commun. Mespiles germayica. Ian.

Feuilles courtement pétiolées, oblongues-elliptiques, enlières ou irrésulièrement boralées de tines dentelures; rarement plaues, vertes, mates, presque glabres en dessus, d'un vert plus pâle et cotonneuses en Jessous. Fleurs solitaires, terminales, grandes, presque sessiles; calice tonenteux, à divisions étroites, subulces, dépassant les pétales; ceux-ei prlus longs que les élannines. Fruil (nèlle ou mèle) de 5 -k centimètres de diametre, lurbiné, vert, dur, tres-acerbe, devenant mou, pulpeux, brun, r't offant une saveu aciduléc-vineuse par un commencement de fermenlation, lorsqu'il est blossi. - Arbrisscau ou petil arbre de $\mathbb{b} \cdot 6^{\mathrm{m}}$ de hat lenr, a tronc difforme, reconvert d'un thytidome rouge brunatre écailleux, ¿ rameaux ćlalés, fortueux, inermes ou f́pineux; ramules pubescents- 
tomenteux. Disséniné eà et là dans quelques forèts el dans les laaies des régions accidentées; souvent cultivé comme fruitier. Flor., mai. Fructif, scptembre.

Le néflier est un arbre d'une végétation très-lente, qui produit un bois très-dur, homogène, résistant bien aux frottements et susceptible d'un beau poli. Il est blanc légèrement rougeâtre, moucheté et flambé an cour de rouge brun foncé.

\section{Les feuilles et l'écorce sont astringentes et contiennent du tannin.}

\section{Sectloy II. Fruils à pépins.}

(Le sarcocarpe est formé en partic par le calice accru, en parlie yor l'ovaire, dont la face interne scule est devenue cartilagineuse.)

\section{GENRE Y, - COLGNASSIEL. CYDONIA. Tournef.}

Calice campanulé, à 5 divisions foliacées; pétales suborbieulaires; ร styles; ovaire à 5 loges multi-ovulées. Fruit pyriforme, cotonneux, surmonté 'par les divisions accrues du calice; à loges, doni chacume contient 10-15 graines entourées de mucilage. - Petits arbres ou arbrisseaux ì feuilles simples, entières, dont les fleurs sont grandes et solitaires ou fasciculées.

Coignassier commun. Crdonia vulgaris. Pens.

Feuilles pétiolées, ovales, arrondies ou légèrement cordiformes à la l)ase, obtuses ou très-courtement acuminées au sommet; entières, molles, finalement glabres en dessus, cotonneuses en dessous. Stipules marcescentes, très-glanduleuses. Fleurs blanches ou rosées, solitaires, terminales, subsessiles; calice cotonneux, à divisions grandes et foliacées; pétales du double plus longs que les étamines, laineux à la base. Fruit gros, pyriforme, jaune, odorant, très-âpre, couvert de duvet flocouneux. - Arbre à trone tortueux, de 5 ร $-8^{\mathrm{m}}$ d'élévation, ou arbrisseau buissonnant de $2-4^{m}$, à rameaux étalés, flexueux, brunâtres, ponclués et à ramules grêles, allongés, cotonneux ; bourgecons revètus d'écailles inégales, bordées et terminées par des poils rougeàtres. Originairc de l'Orient, subspontané dans presque toute la France, où il est cultivé pour ses fruils, appelés coings ; commun en Algérie dans les lıaies de jardius. Flor., mai. Fructif., octobre.

Le coignassier sert de sujet pour la greffe des fruitiers que l'on veut maintenir a basses tiges. Son bois est blane lígèrement rougeâtre, flambé de brun au coeur ; i! présente de petites portions de tissu cellulaire interposé qui forment eles taches ou des lignes d'un rouge brunâtre. 
Les fruits sont aipres et astringents; ils ne sont point eomestibles an naturel, mais on les emploie à faire des conserves d'espèces diverses.

geNRe TI, - POIRLER. PYRUS, Lin.

Calice urcéolé, à 5 dents; pétales suborbiculaires; anthères rouges ou purpurines; styles 5 , complétement libres. Fruit turliné, surmonté par les dents marcescentes du calice, à endocarpe cartilagineux, circonscrivant 5ै loges qui contiennent chacune 1-2 graines dont l'épisperme est aussi cartilagineux (pépins). Arbres ou arbrisseaux, généralement épineux ì l'état sauvage, dont les feuilles, simples, offrent au moins 10 paires de nervures secondaires pennées, parallèles, peu saillantes et dont les fleurs, blanches et assez grandes sont disposées en corymbes simples.

A. Pétiole aussi long que le limbe. Arbre. épincux à l'état sauvage, à feuillcs adultes glabres et luisantes.......... P. comsun ........ 1

$\mathrm{A}^{\prime}$. Pétiole beancoup plus court que le limbe.

B. Arbre épineux, à feuilles adultes glabres ou presque glabres sur les 2 faces ... P. amander........2

B'. Arbre inerme, à feuilles adultes blanches-cotonueuses en dessous....... P. A reuHLes desAuge. 3

1. Poirier comman. Pynus comanis. Lix. Poirier sauvage.

Feuilles à pétiole grêle et aussi long que le limbe, ovales ou arrondies, courtement acuminées ou ohtuses, finement dentées en scic ou presque entières, velues-aranéeuses dans la jeunesse; fermes et coriaces, glabres, d'un vert foncé très-luisant en dessus, plus clair en dessous; à l'ćtat adulte. Fleurs blanches, grandes, disposées 6-12 en corymbes simples, longuement pédonculées; pétales elliptiques, glabres; anthères d'un pourpre violet; styles complétement libres, légèrement pubescents à la hase, de la longueur des élamines. Fruits petits, acerbes, turbinés (P. Achras. Wallr.) ou globuleux (P. pyraster. Wallr.). - Arbre de taille moyenne, dont la tigुe se prolonge jusqu'au sommet te la cime qui est allongée-pyramidale; à rameaux épineux, jeunes pousses et bourgeons glabres; ces derniers non appliqués comme ceux des pommiers. L'écorce, d'abord lisse, verdâtre on rongeâtre, forme un rhylidome brun foncé, densément el profondement gereuré, qui persiste ou ne tombe que par petiles écailles. Disséminé dans les bois de plaines el de collines de toute la France; Algéric. Flor., avril-mai. Fructif., septembre.

Le poirier commun n'est jamais que disséminé dans les Taille. furcits. Il y parvient à une hauteur de 10-15\% d'élévation et à $2-5^{\text {m }}$ de circonférenec; on cite un arbre de cette espece, des environs de Bautzen, qui, alsattu par un ouragan, en 1743, mesurait $3^{\mathrm{m}}, 40$ de cireonfërence et produisit, sans 
les menues branches, 24 stères de bois. Sa longévité est fort élevée (plusieurs siècles); mais la lentenr de sa croissance rend sa culture peu avantageuse, malgré les qualités spéciales de son bois. L'enracinement se fait par plusicurs racines principales, profondément enfoncées dans le sol; la souche repousse difficilement et ce mode de reproduction n'a pas de durée.

Le bois du poiricr a beaucoup d'analogie avec celui du pommier, mais il est formé d'une plus grande proportion de lissu fibreux. Il est très-homogène, à fibres très-fines, assez uniformément rouge, moins vivement coloré au cocur que le pommier. Il l'emporte en général sur ce dernier en compacité et en bcauté, se travaille très-aisément et dans toures les directions, recoit un très-beau poli. Néanmoins le bois du poirier est sujet à se tourmenter et ne peut ètre employé qu'à l'état de dessiccation complète. Il prend en sc desscichant un retrait de $\frac{1}{13}$ de son volume rert (Varennes de Fenille). Il pèse : vert, 1,07; complétement desséché ì l'air,0,66 (Baudrillart; moyenne des résultats de différents auteurs). Après le buis et le sorbier domestique, le poirier fournit le bois le plus recherché pour la gravure sur bois; il est employé avec avantage par les sculpteurs, tourneurs ct ébénisies, par les fabricants d'instruments de musique, de mathématiquues (règles, équerres). Il prend et conserve très-bien la couleur noire et remplace souvent l'ébène.

D'après Werneck, la valeur calorifique du bois de poirier, d'une densité de 0,62 , est à celle du hètre, d'une densitć de 0,58 , dans les rapports suivants :

$\begin{array}{lcc} & \text { Poids égaux. } & \text { Volumes égaux. } \\ \text { Plus haut degré de chalenr........ } & 98: 100 & 92: 100 \\ \text { Durée de la combustion avec flammes. } & 64: 100 & 60: 100 \\ \text { Durée de la chaleur............. } & 97: 100 & 91: 100\end{array}$

C'est comme on le voit, un bon bois de chauffage, néanmoins inférieur au hêtre et d'une combustion beaucoup plus rapide.

Les fruits du poiricr sauvage sont très-acerbes; on peut en faire une boisson alcoolique, le poiré, qui a de l'analogic avec le cidre.

On considère génćralement le poirier commun comme le type de tous les poiriers cultivés, mais cette opinion est loin d'itre démontréc; il se peut que la plupart de ces dernicrs

Croissance.

Enracinement.

Bois.

Fruils. 
nous viennent d' Orient et appartiennent à plusicurs cspèces qiui, par des fécondations croisées, ont produit ees nombreuses races hybrides que la grelfe conserve et multiplie.

2. EPoirier amandier. Pruvs amygalifonms. Vill.

Feuilles à pétiole 2-6 fois plus court que le limbe, lancíolées on obovales-spalulées, ćtroites, obtuses ou pointues, entières ou finement lenticulées; épaisses el coriaces, pubescentes en dessus, blanches-tomenteuses en dessous dans la jeunesse, finalement glabres ou à peu près sur les deux faces et alors d'un vert luisant en dessus, plus pâle en dessous. Fleurs en corymbes simples, dont les pédoncules sont laincux et 2 ou 5 lois plus longs que le calice; pétales pubeseents sur l'onglet; anthères l'un pourpre violet; styles 5, laineux à la base, bien plus courls que les ctamines. Fruils petits, sub-globuleux. - Petit arbre ou arbrisseau de 2- $\mathbf{L}^{12}$, à rameaux étalés ou inclinés, sourent épineux el à ramules tomenleux. Lieux secs et arides de la région des oliviers. Flor, avril-mai. Fruclif., septembre.

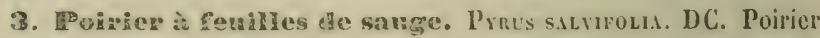
Sauger (Orléanais); Poirier de Cirole (Scine-et-Oise).

Feuilles plus graniles que celles des espèces précédentes, à péliole une ou deux fois plus courl que le limbe; lancéolées, ovales ou obovales, acuminécs, entières ou légèrement dentées, fermes, veloutécs en dessus, blanches-tomenteuses èt cotonneuses en dessous; devenant, à l'automne, glabres et un peu rugueuses en dessus. Fleurs en corymbes simples; pídoncules forts et allongés, laineux-tomenteux ainsi que les calices; pétales glabres; inthères d'un pourpre violet; styles bै, de la tongueur des étamines, laineux vers la base. Fruits longuement pédonculés et fonguement pyriformes à la base, cotonneux daus la jeunesse, presque doubles de ceux des esprèces précédentes. - Petit arbre couvert d'une écorce ruguense, à rameaux inermes, ramules tomenteux. Ilaies, broussailles el forêts de la France centrale; cultivé dans tout l'Orléanais pour la fabrication du poirć. Flor., avril-mai. Fructif., sepr tembre (1).

\section{(1) Poirder longipède. Pynus longrpes. Coss, et Dú.}

Fenilles pétiolées, suborbiculaires et apiculées ou ovales courtement atuminées, légerement dentées sur ius hords, pubescentes-tomenteuses en dessons diuns la jeunesse, glanres ainsi que les pousses al l'état adulte. Fleurs assez grandes, en onbelles-corymbiformes, longuement pédonculies. Fruit trés-pelit, de la srosseur d'une cerise, sub-globuleux el altémuie à la base, supporté par un pédoncule trois fois aussi long que lui ce dépontur au sommet du limbe calicinal guti est caduc. Flor., mars. l'ruct., juillet-août. Arbre souvent élevé, légèrement épineux. Forêts des régions monligneuses, aux bords des torrents. Aigérie, Batna, lambise. 
GEXRE VII, -- POMMIER. MALIS. Tourncf.

Voisin des poiriers, ce genre se distingue par les ¿istyles soudés cutre cux ì la base, par les anthères jaunes et par le fruit ombiliqué à l’insertion du pédoncule. - Arbres à feuilles simples, dentées, d'une insertion variable, parfois représcntée sur los mêmes branches par les indices $\frac{3}{5}$, $\frac{3}{8}$ et $\frac{5}{13}$, et n'ayant pas plus de \{-8 paires de nervures latérales, lesquelles sont saillantes et vagues; it fleurs blanches lavées de rose ou de carmin, disposées en ombelles simpiles; bourgeons pauci-écailieux, exactement appliqués sur les rameaux.

A. Feuilles alultes glabres; arbre épinenx, à fruits trèsaccrbes ........................... P. Acerbe. 1

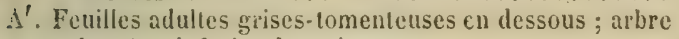
incrme, à fruits douceâtres.................. P. connus. 2

1. Rommier acerbe. Malus acerba. Mérat. Pommier sauvage; l'uradis.

Feuilles à pétiole égal au limbe ou moilić plus court, ovales-acuminées, dencées-crénelées, d'abord plus ou moins pubesentes sur le's deux faces, finalement glabres; de consistance herbacée, peu luisantes, d'un vert clair en dessus, plus pâle en dessous. Flcurs blanches lavécs de ruse ou de carmin, co ombelles sinjules; nidonentes glabres ou pubescents, 2 ou $\mathbf{3}$ fois aussi Iongs que le calice; pétales garnis de quelques longs poils; anthìres jaumes; fruits de $20-23$ mill. de diamècre, de silveur très-acerbe. - Arbre à lige peu élevéc, se ramifiant on une cime ample, ćlalée, arrondie au sommel, dont les rameaux sont épineux ct les bourgeons légèrement velus. L'écorce forme un rhytidome gris-brun, gercuré, qui s'exfolic par plaques; les racines sont pivolantes el peu rameuses. Dissémiué dans les bois de la plaine el des collines.Flor., mai. Fructif., seplembre.

Le pommier accrbe peut atteindre 10-12m de haut et $0^{\mathrm{m}} 70-1^{\mathrm{m}}$ de circonférence; sa tige est irrégulière, canncléc comme celle du charme; son couvert est assez épais.

La végétation est lente, la longévité assez élevée, les souches ont peu de durée et repoussent mal.

Le bois du pommier, très-voisin de eelui du poiricr, offre des vaisseaux un peu plus gros et un peu plus abondants que ceux de ec dernier; il est rougcâtre, veiné ou flambé de brun rougeâtre au cœur. Il a les mimes usages et les mèmes qualités, mais à un moindre degré; il est beaucoup plus exposé cheore à travailler et it se gereer. La pesanteur thoyenne du pommier est de 0,67j (Baudrillart).

D'apres T. Ilartig, du bois de pommier de $2 \vdots$ ans ct pesant

Taille.

Croissance.

Bois. 
0,663 , comparé à dı hètre d'égale densité, a donné pour la valeur calorifique les résultats suivants :

Poids et vol. égaux.

Plis haut degré de chaleur.... \{ clialetr ascendante $96: 100$

Did. rayomante $96: 100$

Furée de la chaleur croissante. $\left\{\begin{array}{lr}\text { i.l. ascendante } & 8 \overline{0}: 100 \\ \text { i.l. rayonnanle } & 100: 100\end{array}\right.$

Durce de la clialeur décroissante. $\{$ ill. ascendante

Total de la chalcur dévelonpée. $\left\{\begin{array}{l}\text { id. ascrudante } \\ \text { i.l. }\end{array}\right.$

Ti.. rayonnante $80: 100$

Eau vaporisée..................... 78:100

Emplois C'est sur le pommier acerbe que se greffent les variétés accessoires. (pte l'on reut élever en quenonilies on en espaliers. Les líuits servent à la fabrication du cidre.

2. Mommicr commuu. Males comurrs. Porr. Pyrus Mulus. Lin.

Voisin du précédent; fetilles plus grandes, blanches ou grises-tomenteuses en dessous, mème au parfait développement; fleurs blanches légèrement rosées, odorantes, plus grandes, supportées par des pédoncules tomenteux, plus robustes et plus courts; fruils te $25-50$ mill. de diamètre, de saveur douceâtre. - Arbre haut de $8-10^{\mathrm{m}}$, à cime arron= die, souvent filus large que haute, à rameaux plus robustes que ceux du pommier acerbe, peu ou point épineux; bourgeons tomenteux; enracinement plus complet, par de fortes raciues rameuses. Ilaies, broussailles et bords des bois; France, Algeirie. Flor., mai. Fruclif., aoútseptembre.

L'indigénat de ce pommier est douteux et il est probab)'c que les pieds que l'on rencontre dans les campagnes et aux bords des bois proviennent de semenees des pommiers cultivés dans les vergersers. Cest sur lui que l'on greffe les variélís élevées en plein vent.

\section{GeNRE VHi. - ALISIER ET SORBIER. SORBUS. Lin.}

Calice ureéolé, it : dents devenant marescentes; ¿ pétales suborbiculaires; styles 2-:̈; ovaire 2-シे-loculaire, chaque loge bi-ovulée. Fruit peu charnu, globuleux ou pyriforme, it endocarpe mince, membrancux-fragile, flont les loges sont généralement 1-spermes. - Arbres ou arbrissenux à feuilles simples ou composées, à nervures saillantes sur la face inférieure; ì fleurs blanches ou roses, de taille moyenue, en corymbes composés multillores. Bourgeons gros.

Le's bois de ce gence sont remarquables par la régularité de 
leur croissance, leurs couches minces, netfement circulaires concentriques, et les taches rougeîtres ou brunâtres de tissu cellulaire qui y sont disséminées.

A. Feuilles simples.

Section 1. ALISIERS.

B. Arbres; Fleurs blanches, dont les pétales sont plus ou moins étalés.

C. Feuilles dentées ou faiblement lobées, à lobes croissants de bas en haut; blanches-tomenteuses en dessous, multinerviées ( $8-12$ paires de nervures secondaires) ................. Brave........ 1

C'. Feuilles lobées ou séquées; à lobes ou segments décroissants de bas en haut.

D. Fenilles lobées, dont les incisions les plus profondes ne dépassent pas la moitié du limbe.

E. Feuilles multinerviécs (10-12 paires de nervures), à lobes inférieurs dressés; grises-tomenteuses en dessous .................. de Sranuinavip... 2

$E^{\prime}$. Feuilles paucinerviées ( $6-8$ paires de nervures), à lobes inférieurs étalés.

F. Feuilles à lobes ovales, courlement acuminés, peu profonds, d'un gris - verl-tomenteux en

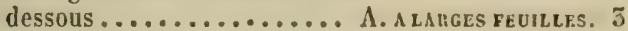

F'. Feuilles à lobes triangulaires-allongés, généralentent vertes el glabres en dessous......... A. тonmusaz...... \&

D'. Feuilles séquées à la base, dont les incisions inférieures alteignent la nervure médiane............. \&yвride......

B'. Petils arbrisseaux; fleurs roses dont les

pélales sont dressés............ A. Nañ........6 A'. Feuilles composées, impari-pennées....... Seccion $\boldsymbol{I}$. SORBIERS.

B. Arbres à écorce noire, densément et fincment gerçurée-rugucuse; fruits pyriformes, verts, puis bruns; bourgeons glabres, visqueux............. S. doMestique.....7

B1. Arbres à écorce grise el lisse; fruit globuleux, rouge; bourgeons velus...... S. Des orseleurs... 8

\section{SECTION I. Alisier's.}

\section{(Feuilles simples.)}

1. Alisier blane. Sonbus afia. Crantz. Craloogus arit. Lin. Pyrus aria. Ehrh. Allouchier. 
Fenilles à pétiole égalant le $1 / 3-1 / 6$ du limbe, ovales, elliptiques ou obovales, entières et rélrécies ì la base, arrondies ou un peu aiguès à l'extrémilé, doublement dentées ou mème lobulées-denlées, à lobules croissants de bas en haut; grises-aranéeuses dans la jeunesse, vertes un peu luisantes el glabres à l'état adulte, en dessus; en dessous, toujours blanches-tomenteuses, arec \$-12 paires de nervures pennées, parallèles, toutes légèrement convexes en dehors el saillantes. Fleurs blanches; pédoncules, calices et onglets des pétales blanes-tomenteux; pétales suborbiculaires ou oblongs, légèrement concaves, étalés; étamines divergentes à anthères blanches; 2 styles velus à la base. Fruits globuleux ou ovoïdes, de la grosseur d'une petite cerise, lisses ou à peine ponclués, luisants, verts, puis rouges, farineux, peu charnus, légèrement sucrésacidulés. - Arbre de taille moyenne, à tige droite, cylintrique, dont l'écorce reste longtemps grise et lisse, puis forme un rhylidome membrancux peu gerȩuré, d'un brun rougeàtre foncé; cime ovoïde; ramules iroits, assez robustes, d'un brun marron, ponctués de gris; bourgeons gros, à larges écailles d'un brun clair ou brun verdàtre, bordées de duvet blanc. Commun dans les bois montueux ou montagneux, mais toujours dissćminé. Flor., mai. Fructif., septembre.

Taille. L'alisier blane peut atteindre, dans de bonnes conditions, $10-14^{\mathrm{m}}$ d'élévation, mais il reste aussi souvent à l'état de

Croissance. buisson. Il a une croissance lente, longtemps soutenụe. Enracinement. Son enracinement est profond, étendu ; il repousse vigoureusement et drageonne quelquefois.

Germination. Les graines, semées à l'automne avec leur péricarpe, germent, partic au printemps suivant, partic au printemps de la deuxième annéc. Le jeune plant lève avec deux feuilles cotylédonaires ovales et entières.

station et sol. L'alisier blane n'est pas difficile sur le choix du terrain et vient sur des sols de toute nature, à moins qu'ils ne soient humides ou.très-compactes; il semble néanmoins préférer ceux de nature calcaire. On le voit se fixer jusque dans les fentes des rochers, et il atteint dans les montagnes des altitudes considérables.

Bois. Le bois est dur, lourd, très-homogine; il est blane marqué de taches foncées de parenchyme; it un îge avaneé, il se: colore parfois très-légèrement de rougeattre et devient veiné ou flambé de brun au cenur. Il pèse co moyenne, à l'état sec, $0,7: j$ (Baudrillart). II convient aux ouvrages de tour, sert it faire des outils et les pieces des machines soumises a des frottements, ete. C'est un trìs-bon combustible, qui produit un charbon estimé.

fruil. Les fruits, sans clte mauvais, ne se mangent point of sont sans usage. 
3. Alisier de Seamalinavie. Sonbus scandra. Fries.

Feuilles pétiolées, à pétiole égalant le $1 / 3-1 / 6$ du limbe, ovales on elliptiques, cunéiformes et dentées presque dès la base, pointues â l'extrímité; lobées-dentées, à lobes arrondis, obtus on courtement acuminés, séparés par des sinus très-aigns ou même fermés vers le bas ę décroissants de la base au sommel; lobes inférieurs dressés ou à peine étalés; ces feuilles, fermes et coriaces, vertes, luisantes el glabres en dessus a l'étal adulte; en dessous, cendrées-tomenteuses et pourvues de 10-12 paires de nervures saillantes, presque parallèles, dont les inférieures néanmoins sont légèrement concaves en dehors. Fleurs blanches, à péiales étalés, tomenteux à l'onglet; styles 2, très-velıs à la base. Fruit faiblement ovoïde, d'un rouge corail, lisse ou légèrement ponclué, farineux-pulpeux. - Pelit arbre de $6-10^{\mathrm{m}}$ ou buisson. Régions montagneuses escarpées : Vosges, Bas-Rhin, Jura, Alpes, Pyrénées. Flor., juin. Fructif., oclobre.

3. Alisier à larges feuilles. Sorbus latifola. Pers. Cratcegus Latifolia. Lam. Alisier intermédiaire; Alisier de Fontaineblean.

Feuilles pétiolées, à pétiole égalant le quart du limbe; très-largement ovales, tronruées ou à peine cunéiformes à la base, pointues à l'extrémité, lobées-dentées, à lobes décroissants de la base au sommel, arrondistriangulaires, acuminés, séparés par des sinus ouverts ou à peine aignns vers le bas; les inférieurs étalés; ces feuilles, assez fermes, verles, luisantes et glabres en dessus, à l'élat adulte; en dessous, grises-verdàtres-tomenteuses, avec 6-8 paires de nervures laterales, peu scrrées, peu saillantes, dont les inférieures sont divergentes entre elles. Fleurs blanches à pétales tomenteux à l'onglet; styles 2 , très-velus à la base; fruits globuleux ou ovö̈des, d'un vert brun, ponctués, âpres, blossissant comme ceux de l'aliser torminal. - Arbre exactement intermiediaire entre l'alisier blane et l'alisier torminal par la forme, les incisions, la nervalion, la couleur et la vestiture inférieure des feuilles. Forêt de Fontainebleau, Lorraine, surtout aux cuvirons de Nancy, Vosges, Bas-Rhin aux environs de Barr. Flor., juin. Fructif., octobre.

4. Alisier tomimal. Sondus tonmanas. Crantz. Pyrus torminalis. Ehrh. Cralcegus torminalis. Lin. Alisier des bois; Alisier antidyssentérique.

Feuilles pétiolées, à pétiole égalant la moitié du limbe, largement ovales, tronquées ou légèrement cordiformes à la base, aiguës au sommet, lobées-aigûment-dentées, à lobes triangulaires aigus ou acuminés, d'anlant plus étalés et séparés par des sinus d'aulant plus aigus et pius profonds qu'ils sont plus inférieurs; cetx du bas entaillés jusqu’à moitie du limbe; ceux du haut passant insensiblement aux dents; ces feuilles, assez fermes, vertes, luisantes et glabres sur les deux faces, mais plus claires en dessous au parfail développement, munies de $5-8$ paires de nervures sccondaires médiocrement saillantes, espacées, divergentes entre elles et dont les inférieures sont étalées-concaves en dehors. Quel. quefois les fenilles restent tonjours puheseentes en dessus, grises-verditres-tomenteuses en dessous, particulièrement sur les jeunes rejets. Fleurs blanches; pétales concares, à onglet presune glabre; anthères

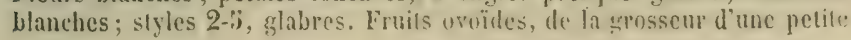


cerise, verls el accrbes, puis bruas piquetés de blanc grisitre, de saveur vineuse, acidulée-suerée à l'etat de blossissement. - Arbre de 10-1弓̈n sur 0,50 de diamètre, à cime ovale assez garuic, dont l'écorce, lisse et d'un gris cendré d'abord, devient, plus promptement que celle de l'alisier blanc, menbraneuse-écailleuse, caluque, varice de roussuttre el de gris; hourgeons plus courls, revêtus d'écailles très-larges, échancrées ou bilobées au sommet, grlabres et verles étroitement bordées de brun. Commun, mais à l'étit de dissémiuation, dans les hois de plaines, de coteaux ou de montagnes peu élevées. Flor., mai. Fructif,, octobre.

Croissance. L'alisier torminal est généralement un arbre de taillis, dc végétation lente; il recherche les terrains frais et lígers, station et sol. calcaires et sablonneux; redoute les sols humides ou secs ; se plait dans les plaines et les pays accidentés, mais n'alteint pas dans les montagnes l'altitude de l'alisier blanc.

Germination. Cet arbre fructifie assez régulièrement. Ses grraines, conservées avec leur péricarpe dans du sable humide pendant lhiver, germent 5 -4 semaines après le semis de printemps. Le jeune plant lève avec deux feuilles cotylédonaires entières, ovales et atteint 20-50 centimètres dans la première année.

L'alisier torminal supporte bien le couvert; il repousse jeu de souches et ce mode de reproduction n'a pas de durée.

liois. Le bois de l'alisier torminal ressemble beaucoup à celui de l'alisier blane, mais il est plus rougeatre. Il est dur, lourd, très-homogène, se travaille très-bien et reçoit un beau poli. Peu sujet à se tourmenter, il ne prend en se desséchant que 2 p. $0 / 0$ de retrait.

D’après G.-L. Ilartig, il pèse vert, 0,88 ; desséché à l'air, 0,75 ; complétement sec, 0,63 .

Suivant le mème auteur, la puissance calorifique de l'alisier torminal de 90 ans, comparie à celle du hètre de 120 ans, l'un et l'autre d'une égale densité et au mème degré de dessiccation, est exprimée par les chiffies suivants:

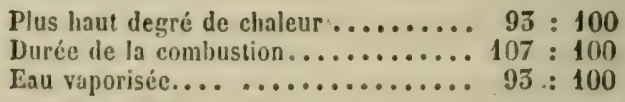

Les graveurs sur bois, tourneurs, mícaniciens, facteurs d'instruments recherehent l'alisier torminal, qui fournit en outre un bon combustible et un charbon estimé.

Frnits. Les fruits de l'alisier torminal, connus sous le nom d'alises ou alosses, sont bons it manger quand ils sont blossis. Les oiscaux en sont très-friands. 
7. Alisier Hyloride. SunBus IrBnida. LNA.

Feuilles oblongues, pointues, divisées à la base par des incisions profondes, qui alleignent jusqu'a la nerrure médiane, en $2-4$ segments lanréolés-oblongs, enticr's et dentés à l'extrémité senlement, subparallèles, dressés el décroissants de la hase au sommet, ouils passent à des lobes, puis à dents doublement dentées; ces feuilles, vertes et glabres en dessus à l'état adulte, grises-tomenteuses en dessous, arec 10-12 paires de nervures secondaires parallèles dont les inféricures ne sont point éta-

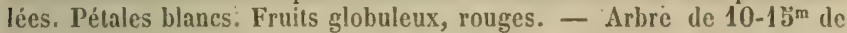
hauteur ou buisson à cime ovale, dont la tige est revêtue d'une écorce lisse et grise et dont les bourgeons, d'un brun rougeâtre ou verdâtre, sont obtus et enveloppés d'écailles poilues sur les bords et au sommet. Riégions montagneuses élevées; Alpes, Jura, Vosges, Auvergne. Flor., juin.

Le bois de eet alisier est inférieur à celui des autres espéces du genre, si l'on en juge par celui qu’il produit dans les jardins, où il est fréquemment cultivé. Ce bois est blane veiné de brunâtre, d'une densité peu élevée. Un échantillon pris sur une tige de 40 ans, provenant de Nancy et complétement desséché à l'air, pèsc 0,62. (Coll. Ec. For.)

6. Alisier main. Sobeus chanamespilus. Crantz. Cratcogus cha. momespilus. DC. Pyrus chamcemespilus. Ehrh. Duby. Hespilus cha. momespilus. Lin. Alisier faux-néflier.

Feuilles dressées contre les rameaux, presque sessiles, eilipliques, alténuées et entières à la base, pointues, doublement et aigûument dentées; vertes, luisantes el glabres en dessus, d'un vert plus clair et plus ou moins tomenteuses dans la jeunesse et quelquefois mème à l'état adulte en dessous; nervures peu nombreuses, $6-8$ paires, vagues, peu saillantes, légèrement confluentes entre elles par leurs extrémitís. Fleurs cn petils corymbes denses; pétales roses, dressés, velus à l'onglet; styles 2, velus à la base; fruit ovoïde, d'un rouge jaunâtre. Joli petit arbrisseau buissonnant de $0^{\mathrm{m}} 30-4^{\mathrm{m}}$, à rameaux dressés, Jruns, verruqueux, dont les fleurs sont entourées de feuilles rapprochées presque en rosette. Escarpements les plus élevés des Yosges, du Jura, de l'Auvergne; Alpes et Pyrénées. Flor., juin. Fructif., septembre.

\section{SECTION II. Sorbiers.}

\section{(Feuilles composées, imparipennées.)}

8. Gorbier domestique. Sonuts nomestica. Lix. Pyrus sorbus. Gortn. Sorbier cormier.

Feuilles oppositi-imparipennées, formées de $\mathbf{1 5}-17$ folioles sessiles, sauf l'impaire, oblongues-aiguës, obliques à la base el entières jusqu'au tiers de leur longueur, dentées-cuspidées sur le resı́e du conlour, colonneuses en dessous au moment de la floraison, mates, glabres sur les 2 faces quand elles sont adultes, plus pitles en dessous quen dessus. Fleurs blan- 
rhes, assez grandes; calice à $\mathbf{Z}$ dents recourbées en dehors; ovaire $\mathbf{b}$-loculaire; 5 styles coudés, laineux dans toute leur longueur. Fruit pyriforme (sorbe ou corme) de 4 centimètres environ de longueur, d'abord acerhe et vert lavé de rouge sur une face, puis brun, mou, pulpeux et acidulévineux à l'état de blossissement. - Arbre de $13-20^{\mathrm{m}}$, à tige droite, recouverte de très-bonne heure d'un rliytidome brun très-foncé, finement gercuré, rugueux et écailleux; cime pyramidale; bourgeons gros, verditres, glabres, visqucux, dressés, mais non appliqués; enveloppe herba . cie des jeunes pousses n'exhalant aucune odeur désagréable quand on la froisse entre les doigts. Disséminé dans les bois de tonte la France; Algérie. Flor., mai-juin. Fruclif., octobre.

Taille. Le sorbier est un bel arbre, d'une croissance très-lente, qui peut néanmoins atteindre $\mathrm{A}^{\mathrm{m}}$ (le circonférence, grâce à une très-grande longévité, 乌̋-600 ans. Il ne saurai convenir à la futaie; mais en raison du prix élevé de son bois, il mériterait d'être admis ou introduit plus souvent qu'il ne l'est

Enracinement. dans la réserve des taillis. Son enracinement est pivotant; les rejets de souche sont assez nombreux. Sa fructification n'est pas constante, au moins dans lés forèts de l'Est et dı Germination. Nord. Les graines, semées à l'automne, germent dès le printemps suivant; le plant parait avec 2 feuilles cotylédonaires ovales, entières et ne dépasse pas 1 décimètre la premic̀re année.

Bois. Le bois de sorbier domestique est l'un des plus durs, des plus homogènes et des plus compactes que produisent nos contrées : vert, il pèse 0,97 ; see, 0,83 (Varennes de Fenille); il est d'un rouge brunâtre. Les graveurs sur bois, sculptcurs, tourneurs, armuriers, mécaniciens, ébénistes cn tirent grand parti; il tient le premier rang pour la fabrication des outils de menuiserie et d'ébénisteric, tels que rahots, varlopes, ete.; et, malgré le prix élevé auquel il s'achète, il n'est pas toujours possible de se le procurer' en quantité suffisante. C'est un excellent bois de chauffage; mais il est trop recherehé comme bois de travail pour étre employé en combustible.

Frnits. Les sorbes sont agréables au gout, quoique astringentes; on en fitit dans plusicurs contrées des boissons alcooliques analogues au poirć; dans quelques autres, on les conserve pour les inanger desséchées comme les pruneaux. Elles sont asser recherehées pour que le sorbier domestique soit fréquemment eultivé comme fruitier.

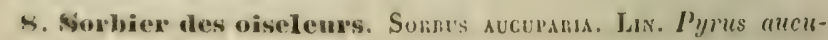
juria. Gurtn. Cochêne. 
Fenilles voisines de celles du sorbier domestique, dentées presque dès ta base, à dents acuminées non cuspidées, glabrescentes à l'élat adulte el légèrement luisantes, surtout en dessus. Fleurs blanches, plus petiles el plus nombreuses; calice à b̈ dents dressées, puis rabattues en dedans apurès la floraison; ovaire 5 -loculaire, surmonté de 5 styles droits, laineux à la base. Fruit sphérique, de 1 centimètre de diamètre, d'un rouge corail, âpre et non comestible. - Arbre moins élevé que le précédent, à tige cylindrique et se prolongeant jusqu'au sommet de la cime longlemps revêtue d'un périderme lisse, gris-clair, qui se transforme à un âge arancé en un rhytidome gris-noiràtre, épais, persistant, Iongitudinalement gerçuré; à rameaux plus élancés, un peu penchés et à ramules d'un rouge brun, pubescents ; bourgeons médiocres, velus, non visqueux, d'un violet-noirâtre, exactement appliquués. Disséminé dans quelques forêts de plaines, plus commun dans celles des pays de coteaux el dans les régions montagneuses, où il s'élève à une grande altitude, croissant sourent, à l'élat de buisson, entre les crevasses des rochers les plus escarnés. Flor., mai-juin. Fructif., septembre.

Le sorbier des oiseleurs peut atteindre 10-14 $4^{\mathrm{m}}$ d'élévation, sur $1^{\mathrm{m}}{ }^{\mathrm{y}} \mathrm{b} 0$ de circonférence; sa croissance est assez active, sa longévité moyenne, 100 ans. Il se reproduit facilement de rejets et de drageons.

La fructification est constante el, chaque année, il se couvre d'une grande quantité de fruits. Les graines, semées en automne ou conservées en jauge pendant l'hiver et semées au printemps, germent au bout de $\overline{5}-4$ semaines. Le jeune plant parait avec 2 feuilles cotylédonaires ovales, entières et atteint 20-50 centimètres la première année.

S'ćtendant de la plaine aux sommets élevés des montagnes, tous les sols lui conviennent, calcaires, siliceux, feldspathiques; il ne prospère cependant que dans ceux qui sont frais et légers.

Le bois est légèrement rougeâtre et devient rouge brunàtre au cœur; il est compacte, dur, lourd, très-tenace ct employé aux mèmes usages que celui de l'alisier torminal. Du bois d'une tige de 80 ans pèse, d'après G.-L. Hartig : vert, 0,90 ; desséché, 0,64 .

Les experiences de T. Hartig sur la puissance calorifique du sorbier de 50 ans, d'une pesanteur de 0,55 seulement, comparée ì celle d'un hêtre de 0,67 , ont donné les résultats suivants :

\begin{tabular}{|c|c|c|}
\hline & clialeur ascendante & $95: 100$ \\
\hline & id. rayonuante & $100: 100$ \\
\hline Durie de la chaleur croissante.. & $\begin{array}{l}\text { il. ascendante } \\
\text { id. rayonnante }\end{array}$ & $\begin{array}{r}90: 100 \\
109: 100\end{array}$ \\
\hline
\end{tabular}

Germination.

Station el sol.

Bois. 


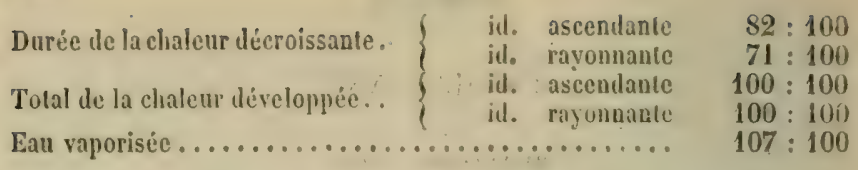

L'écorce contient, suivant Davy, 5,6 p. 0,0 de tannin.

Usages Les fruits renferment du sucre et de l'acide malique et accessoires. néanmoins ont peu d'utilité; on peut eependant en obtenir une boisson alcooligue qui a beaucoup d'analogic avec le: kirsch. Les oiseaux les recherchent et les oiseleurs les emploient pour appiter leur's piégres. L'abondance de ces fruits, leur belle coloration rouge, qui se prononce dès la fin de l'élé, leur persistance jusqu'en hiver font rechercher ce sorbier comme arbre d'ornement; on le voit très-fréquemment planté sur les routes forestières et dans le voisinage des maisons de gardes.

GENRE Ix. - AMÉLANCHIER. AMELANCIIER. Medick.

Calice turbiné, ì כ̃ dents non accrescentes; pétales lancéoléslinéaires; ovaire 5-loculaire, dont chaque loge est bi-orulée; styles ¿̋, rẻunis à la base. Fruit à endocarpe mince, sec et fritgile, ì J̃ loges, dont chacune est incomplétement diviséc par une. fausse cloison, produite par la saillie de la nervure dorsale, et contient 2 graines à épisperme membraneux. - Arbrisscaux ì feuilles simples.

\footnotetext{
Amélanehier commun. Aselancher yuzg.urs. Moexch. Mespilus Amelanchier. Lin.

Feuilles fétiolées, ovales ou elliptiques, arrondies aux deux cxtrémités ou quelquefois aiguës au sommet, dentées, velucs-lomenteuses dans la jeunesse, finalement glabres, fermes, mates et vertes en dessus, plus pites en dessous. Fleurs blanches, longuement pédonculées, disposées $4-\$$ en grappes simples, fenillées à la base, dressées, ferminales; pétales útroits, allongés. Fruits globuleux, couronnés par les dents aignës du calice, de la grosseur d'un gros pois et d'un noir bleutite. - Joli arbrisseau buissonnant de $1-5^{\mathrm{m}}$, à rejets nombreux, ascendauts, grêles, peu rameux, peu feuillés, bruns ou grisatres, dont les bourgeons sont ovoüles-allongés, aigus, d'un brun noir, brillants el glabres. Lieux rocailleux ou rocheux des régions de collines ou de montagnes, aux expositions chaudes. France; Algérie (djurjura). Flor., avril-mai. Fructif., août.

Le fruit de l'amélanchier est comestible et connu en Provenee sous le nom d'amélanche, d'où est dérivé le nom gẻnérique actuel.
} 


\section{FAMILLE XXII.}

\section{MYRTACÉES. JuSS.}

Fleurs hermaphrodites, régulières; calice gamosépale, à 4-7, généralement à 5 divisions; corolle d'autant de pétales alternes, périgyne; étamines nombreuses, insérées avec les pétales, à anthères introrses, biloculaires, longitudinalement déliscentes; ovaire infère, soudé au tube du calice, multiloculaire, à loges inultiovulées; style 1; baie ou capsule à placentation centrale, dont les graines ne sont point périspermées. - Arbres ou arbrisseaux à feuilles simples, entières, non stipulées, formées d'une nervure médiane dominante et de nervures secondaires pennées, peu saillantes, se réunissant à une nervure submarginale qui encadre la feuille.

A. Feuilles persistantes. Baie ............... Mrntr.... I

$\Lambda^{\prime}$. Feuilles cadurgues. Fruit à péricarpe sec, divisé en

loges superposées, multispermes........... Grexadien .. 2

GENRE 1. - MYRTE. MYRTUS. Tournef.

Calice à tube globuleux, 5-partite ; pétales ふै; étamines nomJireuses, libres; fruit charnu, à 2-3 loges oligospermes, couronné par les dents dressées du calice. - Arbrisseaux à feuilles opposées, persistantes, ponctuées-transparentes.

Bois lourd, dur, à grain extrêmement fin, homogène. Fibres lominantes, à parois épaisses; vaisseaux fins, égaux, isolés, ıniformément répartis, mais plus rares dans une zone étroite du hord externe de chaque couche, ce qui rend les accroissements assez sensibles. Rayons fins et égaux.

Aryrte commun. Myrtus communis, Liv.

Feuilles opposées, subsessiles, coriaces, elliptiques-lancéolées, acuminées, entières, à bords étroitenent rélléchis en dessous, finement ponctuées-pellucides, glabres ef luisantes, plus pâlẹs en dessous, à nervures secondaires serrées. Fleur's blanches, axillaires, solitaires, longuement fúdonculées; calice à divisions triangulaires, étalées, plus courtes que les pétales. Baic à peine charnue, ovoide, d'un noir blcuatre un peu slauque. - Arbrisseau toujours vert, à: lige irrégulière, de $2-5^{\mathrm{m}}$ d'élévation, recouverte, dìs les premières années, d'un rhytidome roux, mínce, presque lisse, écailleux, caduc; répandant par toutes ses.parlies une odcuesaromalique qui rappelle celle du gérolie. Assez commun dans la région médilerranéenne; ahondant en Corse; Algérie. Flor, mai-juin. Fruetif, novembre. 
Taille. Le myrte a la croissance très-lente, la longévité considérable; il mesure quelquefois $4-3^{\mathrm{m}}$ d'élévation sur $1^{\mathrm{m}}$ de circonférence, mais il lui faut bien un siècle pour atteindre ces dimensions. Il forme un buisson très-touflu, d'un couvert complet, qui peuple les maquis de la Corse avec les philarias, Station. Sol. les lentisques, les chènes yeuses, etc. Il demande des sols frais et profonds, situés en plaines ou en coteaux.

Bois. Le bois est lourd, dır, remarquable par la finesse et l'homogénéité de son grain; il se travaille très-bien dans toutes les directions, n'est point sujet à se tourmenter et à se gercer.Il est entièrement gris rougeàtre clair, très-légèrement teinté de violacé, à peine veiné, et rappelle assez bien le bois de poirier. Du bois de myrte, d'une tige de 70 ans et de 14 cent. de diamètre, pèse, entièrement desséché à l'air, 0,97. (Coll. Ec. For. Algéric; envoi de M. Royer). On en fubrique de menus objets qui sont recherches, tels que eannes, articles de marqueterie, de tour, etc. Il fournit un excellent combustible et un charbon de première qualité.

Usages accessoires.
L'écorce et les feuilles servent à la préparation du cuir.

Le fruit a le gout àpre et résineux; cependant les Arabes le mangent et l'estiment beaucoup.

\section{GeNRE II. - GRENADIER. PUNICA. Tourn.}

Calice pétalö̈le, coriace, turbiné, à 5̌-7 divisions; pétales §-7; étamines libres; carpelles en deux verticilles sunerposés, formant un ovaire multiluculaire à 2 étages, dont chayue loge est multiovulée. Fruit ì péricarpe sec, minces, indélniscent, dont les loges contiement de nombreuses graines à épisperme pulpeux acidulé (grenade). - Aribrisseaux ì feuilles généralement opposées, cadurgues, à nervure sub!narginale vague.

Gàrenadier commun. Punica granatus. Lin. Balaustier.

Feuilles opposées, allénuées en pétiole, oblongues-lancéolées, entieres, glabres, luisantes, cadurues. Fleurs grandes, sessiles, solitaires ou rétnies par 2-3 à l'extrémité des rameaux, complétement d'un rouge écarlate. Fruit gros, globuleux, couronné par les divisions du calice, d’un janne bruntite, contenant un grand nombre de graines serrées, anguleuses, à épisperme rouge translucide, pulpeux, acidulé. - Arbusic de $2-\mathrm{k}^{\mathrm{m}}$, à lige dressée, irrégulière, très-rameuse, à rameaux étalésdressés, un jeu épincux; revêtu d'un rhylidome minec, jaunatre, écailleux-caduc. Toute la région méditerranécnne, lirance et Corse, foil il s'est complétement naturalisé; $\Lambda$ lgéric, daus le voisinage des jardins. Flor., juin-juillet. 
Le grenadier parait ètre originaire d'Orient; mais il se rencontre à l'état sauvage dans la France méridionale. Il est souvent cultivé, soit pour la beauté de ses fleurs, qui se doublent aisément, soit pour son fruit, la grenade, dont on mange l'épisperme pulpeux.

Le bois est dur, lourd, homogène, d'un jaune clair uniforme. Celui d'une tige de כ̋ว̆ ans, de 12 cent. de diamètre, pèse, entièrement desséché à l'air, 0,72. (Coll. Ec. For.)

L'écoree sert au tannage et donne une matière tinctoriale avec laquelle on prépare, en Afrique, les marocains jaunes. Elle est cmployée en médecine.

\section{FAMILLE XXIII。}

\section{grossulariées. $D C$.}

Fleurs régulières, hermaphrodites, quelquefois dioiques par itvortement ; calice gamosépale, כ̌-fide; curolle de ڤే pétales alternes très-pctits, insérés à la gorge du calice; étamines 5 , alternes avec les nétales et insérés arec cux. Ovaire infère, adliérent, 1-loculaire, multiovulé, présentant 2 placentaires opposés, parietaux. Styles 2; baic pulpeuse succulente, dont la pulpe est produite par la membrane externe des graines; polysperme, couronnée par les dents desséchées du calice; graines périspermées. - Sous-arbrisseaux à feuilles alternes, simples, palmatinerviées et lobées; épineux ou inermes et dont les bourgeons sont revêtus d'écailles imbriquées, spiralées, de nature pétiolacée.

Bois à vaisseaux égaux, fins, isolés, uniformément rúpartis ou disposés en lignes onduleuses circulaires, concentriques, trèsserrées. Thayons indéfinis, inégaux, les uns fins, less autres assez ípais. Parenchyme ligneux ahondlant, mais dispersé parmi le lissu fibreux dont on ne peut le distinguer.

geNRE UNIQUe: - GROSEILLER. RIBES. Lin.

\section{A. Tiges épineuses; fleurs solitaires ou réunies par}

2-3 seulement......................

A'. Tiges inermes; fleurs en grappes.

B. Fcuilles uon aromatiques.

C. Fleurs verdâtres.

D. Grappes de fleurs cl de fruits pendantes; ceux-ci rouges ou d'un blanc jaunâtre. G. nouge. ....2 2

D\%. Grappes de fleurs el de fruils dressés; ccuX-ci toujours ronges........... G. DES AJPES... J

(n)


C'. Fḷeurs rougeâtres, en grappes dressées; fruits rouges, en grappes pendantes.... G. Des rocinens. I

B'. Feuilles aromaliques. Fleurs rougeâtres; fruits noirs, en grappes pendantes .......... G. vorn. ...... b

\section{\$I. Tiges épineuses; fleurs solitaires ou rénnies par 2-3.}

1. Groseiller épinewx. Rubes uvi-crisps. Lix. Groseiller à gros fruits, à maquereaux.

Feuilles petiles, courtement pétiolées, velues-pubescentes, rarement

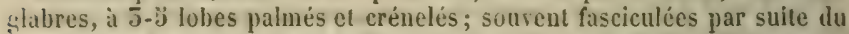
non allongement des rameaux: trois épines, deux stipulaires latérales el une médiane provenant du coussinet, à la hase de ces faisceaux ou à la base des feuilles des pousses stériles qui s’allongent. Fleurs axillaires, sulitaires ou géminées, courtement pédunculées, verdàtres ou rougeâtres. Baie globuleuse ou ovoïde, assez grosse, verte jaunâtre ou rougeàtre, Glabre on hérissée de soies glanduleuses, - Sous-arbrisseau de $1^{\mathrm{m}}$. 1 mbo, très-rameux. Très-commun dans les haies, les bois, les lieux incultes el pierreux de toute la France; Algérie, montagnes de l'Aurès. Fréquemment cultivé sous une foule de variérés pour son fruil. Flor., mars-avril. Fructif., août.

\section{§II. Tiges inermes, flewrs en yrappes.}

2. Groseiller rouge. Rires nuntún. LiN.

Feuilles pétiolées, cordiformes à la base, à $5-3$ lobes palmés et profondément dentés; pulescentes en dessous. Fleurs d’un jaune verdatre, co grappes axillaires loujours peudantes, accompagaées de bractices glabres beaucoup plus courles que leurs pédicelles; calice glabre, à limbe élalé non cilié ; baies rouges ou d'un blanc jaunâtre, acides. - Arbrisseau de $1{ }^{m-1} \mathbf{1} 50$, a rameaux bruns. Spontané, quoique rarement, dans quelques forèts; très-fréquenment cullivé et subsponlané. Flor., arrilmai. Fructif,, août.

3. Croseiller ales Alpes, Runes ápunum. Lin.

Fevilles moyenoes ou petites, pétiolées, légèrement cordiformes à la ?ase, a 5-b lobes palmés el dentés, peu luisantes, glabres ou parsemées de quelques poils rudes sur les deux faces. Fleur's vertes, dioïques ou rarcunent hermaphrodites, accontugagnées de bractées plas longues quellus, en grappes axillaires toujuurs dressées; grappes des pieds males et dies pieds liedmaphirodites multillores $(20-50$ fleurs); celles des pieds femclles pauciflores (2-bj fleurs); calice glabre, à limbe étalé. Baies jouges, fades. - Arbrísseau de $\mathbf{1}^{\mathrm{m}-1} \mathbf{1} \mathrm{n} 30$, à liges et à rameaux gris, Hessé. Commun daus les bois des régions aceidentées jusquaux stations alpestres, Flor., mai, liructif., août.

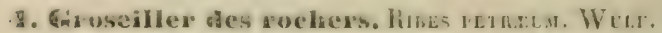

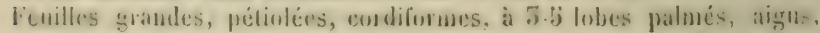
trofondement dentés; légèrement pubescentes on dessous. Fleurs d'un. 
vert rougeàlre, en grappes dressées au moment de la floraison, penchées ¿ l'époque de la malurilé; accompagnées de bractées velues plus courtes que les pédicelles ou les égalant; calice glabre, à limbe campanulé, ciliẻ. Baies rouges, acerbes. - Sous-arbrisseau plus robuste et plus élevé que les prícédents, à rameaux assez gros, d'un gris brun, recouverts d'une écorce exfoliée membraneuse. Régions élevées des Vosges, du Jura, de l'Auvergne; Alpes el Pyrénées. Flor., mai-juin. Fructif., septembre.

5. Croseillex noir. Rines manum. Lin. Cassis.

Feuilles pétiolées, cordiformes à la lase, 5-b̆-palmatilobées, à lobes triangulaires, dentés; glabres en dessus, légèrement pubescentes en dessous. Fleurs d'un jaune rougeâtre, en grappes axillaires toujours penlantes, accompagnées de braclées plus courtes que les pédicelles; calice tomenteux, campanulé. Baies noires, à odeur el à saveur caractéristiques le cassis. - Sous-arbrisseau de $1 \mathrm{~m}$, parsemé sur les feuilles en dessous, sur les fruits et sur les bourgeons de glandes jaunes qui contiennent une huile esseitielle aromatique. Disséminé dans quelques forêts du nordest, en Alsace et en Lorraine; cultivé pour ses fruits el subsponlané dans toule la France. Flor., arril-mai, Fruclif., juillet.

\section{FAMILLE XXIV.}

\section{HÉDÉrACÉES. Lemaout.}

Fleurs hermaphrodites, régulières; calice adhérent à l'ovaire, ¿ limbe très-court, כ̌-denté. Corolle de כ̌ pétales alternes, non onguiculés; étamines en nombre égal, alternes, périgynes, à anlières introrses, hiloculaires, longitudinalement déhiscentes. Style 1. Ovaire infère, 2-5-loculaire, dont cliague loge est uni-ovulée. baic 2-J゙-loculairc, ou moins par arortement, ì graines cartilagineuses, périspermées.

GENRE UNIQUE. - LIERRE. IIEDERA, Lin.

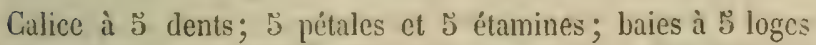
monospermes. - Sous-arbrissenux sarmenteux, grimpants ou rampants, à feuilles alternes, simples, penninerviées et entières, wil palmatinerviées et lobées, toujours vertes, dont les fleurs sont en ombelles simples.

Bois mou, poreux, très-léger, d'un blane grisitre. Vaisseaus ituminants, moyens, presque égaux, à peine plus nombreux au tummencement de chaque couche; isolés, mais inégalement réfrartis suivant des lignes ull des zones concentriglies séparées par itu tissu fibreux. Rayons inctgaux, mosens et gros, ces derniess indéfinis. Pas do parenchyme ligneux. 


\section{8}

HÉDÉnACÉES.

Lierre grimpant. IIEdera uelix. Liv. Lierre-bois.

Feuilles pétiolées, simples, éparses, coriaces, persistantes, luisantes, d'un vert foncé en dessus, d'un vert pâle en dessous; celles des rameaux rampants profondément $5 \cdot b$-lobées, à lobes entiers; celles des rameaux grimpants stériles, à 5 -b lobes moins profonds; celles des rameaux fleuris entières, orales ou rhomboïdes-acuminées. Fleurs petites, d'un jaune verdittre, en ombelles terminales, pédonculées, simples, arrondies. Baie globuleuse, noire (rarement jaune), cerclée vers son sommel par le limbe du calice el apiculée par le style persistant. - Sous arbrisseau à lige sarmenteuse grimpante ou rampante. Commun dans les forèts de toute la France; Algérie. Flor., septembre-octobre. Fructif., avril-mai de l'année suivante.

lort.

Nultition.

Inconvénients.

Le lierre produit des tiges et des rameaux très-allongés, relativement grèles, recouverts d'un rhytidome gris, garnis sur une de leurs faces de très-nombrenx erampons (racines rudimentaires), au moyen desquels il grimpe le long des rochers et des arbres et parvient jusqu’à leurs sommets les plus élevés. Lorsque cette lige ne trouve pas l'appui pour s'élever, elle reste rampante à la surface du sol, ne fleurit jamais, mais se propage de proche en proche en s'enracinant par différents points de sa longueur au moyen de ses crampons qui s'accroissent en racines véritables. Le lierre n'est point eependant un végétal parasite, comme on le dit souvent; il alssorbe dans le sol et élabore lui-même la séve qui le nourrit, et ne puise rien dans l'arbre qui lui sert de soutien. Il n'en est pas moins très-nuisible; cnlaçant et útreignant les tiges et les branches de ses nombreux sarments, il met un obstacle à la circulation de la séve et aı grossissement de l'arbre; recouvrant de son feuillage abondant, serré et persistant les rameaux les plus extrémes, il y produit un couvert funeste au développement des bourgeons et des feuilles. Sa destruction doit done être poursuivie dans les forèts et il suffit, pour l'atteindre, de couper d'un coup de cognée le pied du lierre le plus développé. Sans communication avec le sol, il ne tarde pas à se dessécher et ì périr.

Taille. Le lierre peut arriver ì d'assez fortes dimensions et parvient quelquefois ì se soutenir sans appui. L'on en voyait In, il n'y pas longtemps, it Gignac, aux environs de Montpellier, qui était àgé de $4 \overline{5}$ ans et dont la souche prineipale

livis. avait $2^{m}$ de circonférence. Son bois pise 0,48 lorsqu'il est see (Varemes de Fenille); il est à peu près sans usage.

Produils accessuires.

Dans les pays chutuds, on extrait, par incision, de la tige du lierre, une substance résinoïde, d'un rouge brunâtre, 
IIÉdÉnACÉES. - CORNE์ES.

icre, aromatique comme l'encens quand on la brule et que l'on emploie pour vernis.

\section{FAMILLE XXV.}

CORNÉES. $D C$.

Famille voisine de la précédente, se distinguant par ses verticilles floraux de 4 parties et son fruit (nuculaine) à noyau osseux, 2-loculaire. - Arbrisseaux à feuilles opposées (espèces indigènes), caduques, non stipulées.

\section{Genre UNiQue, - CORNOUILLER. CORNUS. Lin.}

Caractères de la famille. - Arlorisseaux à feuilles simples, entières; ì nervures secondaires peu nombreuses, entières, pennées, arquées-convergentes vers le sommet; à bourgeons grêles, lancéolés, consprimés, revêtus de 2-1 écailles foliacées, velues, opposées-croisées. Ces bourgeons sont quelquefois réunis par 2 it chaque aisselle et, dans ce cas, le plus élevé est le principal.

Bois lourd, homogène, compacte et dur (le nom de Cormus fait allusion à celte durelé, comparable à celle de la corne). Tissu fibreux dominant, à parois très-épaisses, mélangé de quelques cellules ligneuses (non apparentes); vaisseaux égaux, petits, isolés ou à peine réunis en petit nombre, uniformément répartis, si ce n'est à la fin de chaque couche où ils deviennent rares et laissent une zone étroite de tissu fibreux. Rayons égaux, fins, courts.

\section{L'écoree ne forme qu'une scule couche de liber fibreux.}

A. Fleurs jaunes, paraissant avant les feuilles, en ombelles simples. Fruits ovoïles, charnus, rouges, acidulés. C. Male... 1 $A^{\prime}$. Fleurs blanches, paraissant en été, en corymbes composés. Fruits globuleux, petits, presque secs, noirs. C. sanguin. 2

1. Cornouiller mâle. Connus mas. Lin.

Feuilles opposées, courtement pétiolées, à 4 ou bै paires de nervures latćrales arquées-convergentes vers le sommet, cllipliques-acuminées, entières; parsemées, surtout en dessous, de quelques poils couchés qui en rendent le toucher un peu rude; plus pâles et légèrement laineuses aux aisselles des nervures en dessous. Fleurs jaunes, en petites ombelles simples, latérales, paticillores, naissant avant les feuilles et placées an centre d'un involucre de 4 folioles concaves. Nuculaine elliptique, de la laille d'une petite olive, très-àpre d'abord, puis acidulée-sucrée, rougetranslucide. - Arbrisseau ou petil arbre à tige dressée, irrégulière, can- 
nelée, rccourerle d'un rhytidome mince, jaune hrunitre, écailleux-cadue; a branches opposées, ramules couverts de poils abondants, persistants, qui pendant l'hiver affaiblissent et reudent mate leur coloration souvent sanguine; canal médullaire à section hexilgonale. Dès l'été l'on apercoit de gros bourgeons globuleux, qui sont les bourgeons a fleurs du prinremps suivant. Commun dans les bois des terrains calcaires de toute la France. Flor, mars. Fructif, oclobre.

Tailte. $\quad$ Le cornouiller màle parvient à $6-8^{\mathrm{m}}$ de hauteur et à $10-$ 12 centimètres de diamètre en 20-20̈ ans; mais il peut lépasser beaucoup cet âge et vivre des siècles en s'accroissant avee une excessive lenteur.

Buis. Son bois est blanc rougeàtre clair ou foncé, flambé de rougeâtre au cocur, quand il est vieux; ses accroissements sont irréguliers, non concentriques. C'est un des bois les plus durs, les plus tenaces et les plus homogènes de nos forêts. Celui d'une tige de $5 \not{4}$ ans et de 15 cent. de diamètre, provenant de la forcit de Haie (Neurthe), étant complétement desséché à l'air, pèse 0,99 (Coll. Ec. For). Il est très-recherché pour manches d'outils, menues pièees des machines, échalas, échelons, cereles, bâtons, gaules, fourches, ete., mais il faut qu'il soit bien see pour ètre mis en œuvre, parce qu'il est sujet à se gereer et à se tourmenter ; il prend un retrait de $15 \mathrm{p} .0 / 0$ du volume vert.

Prouluits aceessoires.
L'écoree contient du tannin ; 8,7 p. 0/0, d'après Gassicourt. Son fruit, appelé cornouille, cst comestible quand il est parfaitement mùr.

2. Con moniller sanguin. Conves samevives. Lis. Bois punais. Voisin du précédent quand il n'a que des feuilles; se distingue néan. moins par eelles-ci qui sont concolores sur les deux faces, moins fermes, lépourvues de poils laineux aux aisselles des nervures en dessous el ne ront point accompagnées de ces gros hourgeons floraux globuleux du cornouiller mâle. Fleurs blanches, paraissant après les feuilles, en corymbes définis, lerminaux, défourvus d'involucre à leur base. Fruit de la grosseur d'un pois, globuleux, couronné par les dents du calice, à peine charnu, noir, amer, non comestible. - Arbrisseau de 2-5m de hauteur, rameux lies la base, dont la tige est recouverte d'un écoree brune, finement et densément gerçuréc en long et en travers; pousses droites, cfilées, pres(fue glabres, d'un rouge sanguin luisant, surtout an printemps; canal medullaire presque circulaire; feuilles rougissant it l'automne. Très-commun daus les forèts, principalement dans celles des pays de coleaux, à sol liger. Flor., mai-juin. Fructif., commencement d'octobre.

ritlle. I.e cornouiller sanguin nalteint ni les dimensions, ni la longévité du comoniller male. Il se multiplie fapidement de lui-minnc par semis, par drageons, par mareotes naturelles; 
résiste pentant très-longtemps au couvert et devient souvent, par ces motifs, un arbrisseau envahissant ineommode.

Sa végétation est lente. Son bois dur, compacte, souple et lenace, sert aux bâtis des ouvrages de vannerie ef, quand ses dimensions le permettent, il est employé eomme celui du cornouiller måle, bien qu'il soit de moindre valeur.

L'écorec vive du cornouiller sanguin exhale une odeur iere qui, dans quelques pays, fait appeler cet arbrisseau hois punais. Les fruits contiennent dans leur périearpe de l'huile que l'on peut extraire et qui cst bonne pour l'échairage; on en obtient 54 p. $0 / 0$ de leur poids:

\section{CLASSE II.}

\section{GAMOPETTALES:}

Fleurs à périgone double (exceptionellement nul), dont les pétales sont soudés entre eux à partir de la base sur une longueur plus ou moins grande.

\section{ORDRE III.}

\section{GAMOPÉTALES PÉRIGYNES.}

Corolle insérée sur le calice ; étamines insérécs sur la corulle ou avec la corolle. L'ovaire est toujours infère, adhérent. 


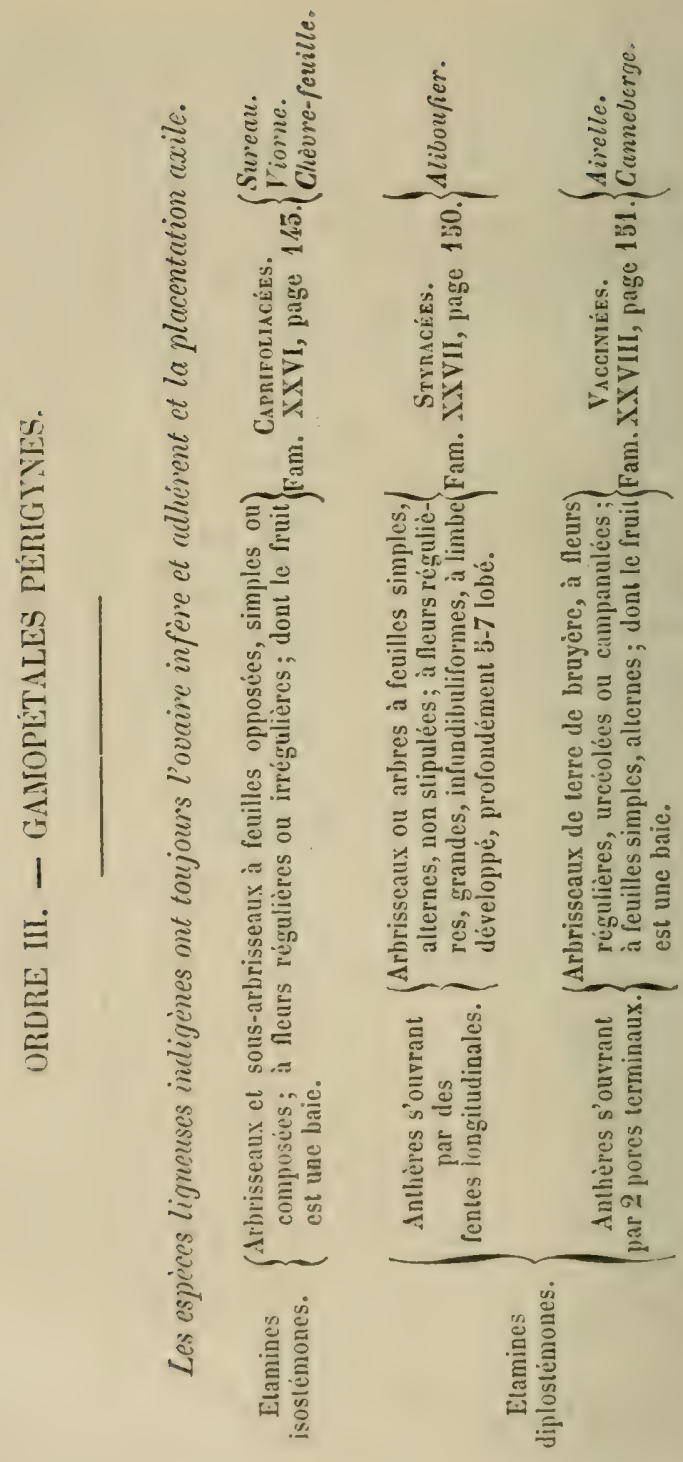




\section{FAMILLE XXVI.}

\section{CAPRIFOLIACÉES.JuSs.}

Hleurs hermaphrodites, régulières ou irrégulières; calice adhérent, ì limbe très-court, כૅ-denté. Corolle gamopétale, insérée au sommet du tube calicinal, 气̀-fide ; étamines 气̆, alternes avec les divisions de la corolle, insérées sur le calice; ovaire it 3-\% loges uni-pluri-ovulées. Baie à 3-כ loges mono-polyspermes; graine périsperméc. - Arbrisseaux et sous-arbrisseaux à feuilles simples ou composées, stipuléeś on non, opposées; parfois sarmenteux-volubiles. Bourgeons souvent multiples à une même aisselle, superposés ou placés les uns ì côté des autres, nus on écailleux à la base, dont l'évolution, à peine arrêtée par l'hiver, produit quelquefois, contrairement à la majorité des végétaux ligneux, plusieurs générations de rameaux en une seule annéc.

Bois ì tissu fibreux fin, homogène, à parois assez épaisses: vaisseaux égaux, petits, entourés de parenchyme ligneux, isolés ou réunis 5-6, uniformément répartis. Rayons fins.

A. Fleurs en corymbe ou en thyrse, à corolle régulière, étalée; ovaire à loges 1 -ovulées.

B. Fevilles impari-pennées; fruits 5 -spermes.... Sure.u. ...... 1

B $^{\prime}$. Feuilles simples; fruits 1 -spermes........ Vronse.......2

$\mathrm{A}^{\prime}$. Fleurs axillaires, géminées ou fasciculées, à corolle irrégulière, tubuleuse. Ovaire à loges pluri-ovulées. Fruit polysperme.......... Cǜve - Fevilte. 5

GEXRE 1. - SUREAU. SAMBUCUS. Toumef.

Corolle régulière, étalée en roue; ovaire ì 3 loges 1-ovulées, à stigmates sessiles, produisant une baie globuleuse 3 -sperme, dont les cloisons ont été résorbées. - Arbrisseaux et quelquefois plantes herbacées vivaces, à feuilles oppositi-impari-pennées. à fleurs en corymbes ou en thyrses, dont les jeunes pousses stériles sont robustes et ont le canal médullaire très-développé. Bourgeons écailleux à la base, disposés 2-4 à charque aisselle et dont le supérieur est le principal.

Bois homogène, lourd et dur, uniformément jaune clair; vaisseaux dominants.

A. Fleurs en corymbe, blanches, paraissant après les fevilles. Baies noires.

B. Arbrissean; anthères jaunes; feuilles non stipulées. S. xorn... 1 


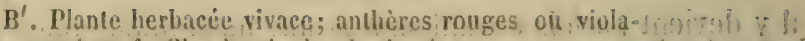

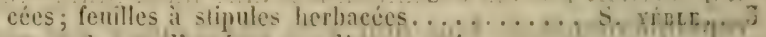
A'. Fleursen thyrse, d'un jaune verditre, paraissant arant on avec les feuilles; baies rouges............ S. nocke.. $\Rightarrow$

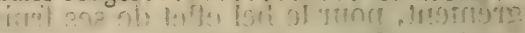

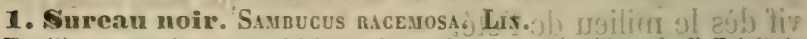

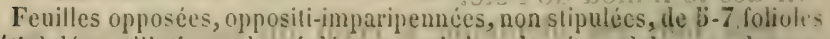
péliolulées, elliptiques-lancéolées, acumipées, dentées, glabres en lessus, parsemées de queliques poils en dessous. Fleurs blanches, odorantes, pn corymbe ombelliforme terminal, ample, dressé, puis penehé rers la int.¿urité, formé de 3 rayons principaux; authères jaunes. Baies ggloluleuses, noires, trìs-rarement verles on blanches. - Arhrisseau ou petil arbre de $4.5^{\mathrm{m}}$ et mème $10^{\mathrm{m}}$ de hauteur, sur $0^{\mathrm{m}} 50$ de diamètre, dont l'écorce passe rapidement à l'élat de rlyblidome subéreux jaune brunàtre, gerçaréécailleux; émettant de son pied des rejets vigoureux, droits, allongés; moclle blanche, très-aboudante; bourgeons ovö̈les-aiggus, revêtus à la base de 2 -4 écailles seulement, opposées-croisées. Conmun dans les haies, aux bords des chemins el dans les clairières des forêls; toute la France; Algérie. Flor:, juin. Fructif., septembre.

Stalion et sol.

Le sureau habite les plaines et les régions peu élevées, et recherche particulièrement les sols frais et légers. Il se reproduit facilement de boutures:

Bois. $\quad$ Son bois est d'une dessiccation très-difficile et très-sujet à gauchir et à se fendre. Complétement see, il sert à fabriquer de menus objets de tour et de tabletterie (peignes, ctc.); il équivaut à peu près au bouleau pour le chauflage et le charbonnagre. Ce bois est d'un jaune clair uniforme, à peine lustré. Celui d'une tige de 40 ans et de 28 cent. de diamètre, pèse, entièrement desséché à l'air, 0,68 (Nancy. Coll. Ec.For.).

2. Śn rean rouge. Sambuccs raccuosa. Lix. Sureau à grappes.

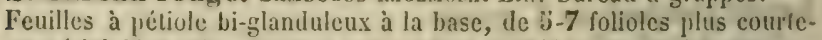
ment péliolulées, plus étroitement ovales-lancéolées et plus longuenent acuminces que celles du sureau noir. Fleurs en thyrse dense, d'un jaune verdâtre, terminant les rameaux latéraux el paraissant avant ou avee les fenilles. Baics globulenses, d'un rouge corail. - Arbrisseau de $2-f_{\mathrm{m}}^{\mathrm{m}}$ de hauteur, revètu d'une écorce d'un gris-brtun, longitulinalement gereurce, n'alteignant ni les dimensions, ni la longévité du sureau noir; produisant de sa suuche de nombrenx rejels qui remplacent les tiges les plus ágres et forment un buisson tris-touffu; moelle de coulcur fauve. Bourgeons ovoüdles-globuleux, entourés d'écailles nombrenses et le plus sourent géminés à l'extrémité des rameaux. Très-commun dans les forèts de la région des sapins; descend quelquefois au-dessous. Flor., avrilmai. Fructif., juillet-septembre.

Slation el sol.

Le sureau rouge se plait particulièrement dans les sols frais et fertiles récemment découverts par les exploitations; 
il y devient parfois envahissant et fort incommode pour les repeuplements et l'on doit s'en débarrasser par des nettoiements. Il est fréquemment planté dans les jardins d'agrément, pour le bel effet de ses fruits qui sont d'un rouge vif dès le milieu de l'été.

Son hois est identique à celui du sureau noir; provenant d'une tige de 12 ans et de 9 cent. de diamètre, de la forèt de Levier (Jura), il pèse, complétement séché à l'air, 0,61 (Coll. Ec. For. Envoi de M. Gurnaud).

\section{Sureau yéble. - Simbucus ebulus. Lix.}

Feuilles oppositi-imparipennées, composées de 7-9 folioles pétiolulées, longuement lancéolées-acuminées, dentées, pourvues de stipules foliacées. Fleurs blanches ou rosées, formant un ample corymbe ombelliforme terminal, complosé de trois rayons principaux et toujours dressé. Anthères rouges ou noires violacées. Baies globuleuses, noires. - Plante lerbacée, fétide, dont la souche produit de longs rameaux souterrains rampants, qui émettent, chaque année, un grand nombre de rejets herbacés annuels, haut de $1^{\mathrm{m}}-1^{\mathrm{m}} \mathrm{j} 0$. Lieux frais, argileux ou argilo-calcaires, aux bords des fossés et des routes, dans les champs et dans les clairières des forêts; se retrouve en Algérie. Flor., juin-juillet. Fruclif., septembreoctobre.

Le surcau yéble est une plante envahissante et nuisible par l'abondance et la vigueur de ses rejets.

\section{GENRE II, - VIORNE: VIBURNUM: Lin.}

Corolle régulière, campanulée-étalée; ovaire 3-loculaire, à loges 1 -ovulées; stigmates 3 , sessiles. Fruit charnu monosperme. - Arbrisseaux à feuilles simples, à fleurs en corymbes ombelliformes composés de 7 rayons.

Bois lourd, dur, très-compacte, à grain très-fin. Vaisseaux égaux, fins, isolés ou à peine groupés, uniformément distribués. Rayons très-fins. Parenchyme peu abondant et disposé parmi le tissu fibreux dont on ne peut le distinguer à la loupe.

A. Feuilles persistantes entières............... V. Tıs.... 1 $A^{\prime}$. Feuilles caduques

B. Feuilles dentées; fruits comprimés, noirs...... V. FLexıele. 2

B'. Feuilles 5-\$ lobées; fruits globuleux, rouges.. V. obier... 5

1. Viome tin. Vibunnum tinus. Lav. Laurier-lin.

Feuilles courtement pétiolées, ovales-aiguës, entières, brillantes, d'un vert foncé en dessus; plus claires, glanduleuses et poilues aux aisselles des nervures en dessous; non stipulées; à nervures secondaires pennées, espacées et irrégulièrement rameuses. Fleurs blanches, inodores, toutes 
semblables, en corymbe ombelliforme terminal, serré. Baies subglobu. leuses, d'un bleu noir a la malurité. - Arbrisseau rameux el touffu, de $1-2^{m}$, dont l'écorce, d'abord lisse, d'un gris brun, forme ensuite un rhytidome écailleux-membraneux d'un rouge brun; jeunes pousses tétragones. Région des oliviers : France, Corse el Algérie. Floraison continuc de février à̀ juin. Fruclif., août.

Cet arbrisseau est souvent cultivé sous le nom de laurier tin, quoiqu'il n'ait de conımun avec le laurier véritable que la persistance des feuilles.

Bois. Son bois, rougeâtre clair, a le grain très-serré, très-fin, très-homogène. Celui d'une tige de 50 ans et de 4 cent. de diamètre, pèse, complétement desséché à l'air, 0,86 . (Algérie, Envoi de M. Royer. Coll. Ec. For.).

2. Viorne flextule. Vinurvum lintaxa. Liv. Viorne mancienne. Feuilles grandes, caduques, courtement pétiolées, ovales-aiguës ou obtuses, cordiformes à la base, bordées de fines dents apiculées; vertes et parsemées en dessus de poils simples, presque appliqués; d'un vert grisâtre et couvertes en dessous de poils rameux, particulièrement abondants sur les nervures, qui sont assez serrées, pennées, très-saillantes, ct dont les ramifications, toutes dirigées vers le bas, commencent d'autant plus près de la nervure médiane qu'elles sont plus inférieures; stipules nulles. Fleurs blanches, odorantes, toutes semblables, en corymbe ombelliforme serré, terminal. Baies ovoïdes-comprimées, vertes, puis rouges, finalement noires. - Arbrisseau de $1-2^{\mathrm{m}}$ d'élévation, produisant constamment de la souche des rejets robustes, droits, très-flexibles, recouverts, ainsi que toute la plante, de poils grisâtres rameux, serrés el courts. Bourgeons revêtus de deux petites écailles très-caduques; par le fait, nus et formés extérieurement par deux feuilles allongées, plissées, entre lesiquelles toutes les autres sont renfermées. Ecorce d'abord lisse, d'un brun jaunâtre clair; rugucuse et longitudinalement gerçurée avec l'àge. Haies et bois des régions de collines, principalement sul les sols argileux et calcaires. Flor., mai. Fructif., juillet-août.

Bois. Cet arbrisseau, très-commun dans beaucoup de forèts, fournit par la souplesse de ses rameaux d'excellents harts et liens. Son bois est rougeâtre, passant au jaune brunatre au cour. Il est très-compacte, homogène et d'un grain trèsfin. Celui d'une tige de 28 ans et de 6 cent. de diamètre, pèse, complétement desséché à l'air, 0,84 (Coll. Ec. (ior.).

Liber. Le liber de la viorne flexible est entièrement cellulaire. Le manque absolu de fibres avait mème fait nier l'existence de cette zone; mais on sait maintenant que le tissu fibreux n'en est point la partie caractéristique (Hugo Mohl).

Produit accessoire.

On fait de la glu avec l'écorce interne; les baies sont, a la rigueur, comestibles. 
3. Viome obier. Viburnum oputus. Lis. Sureau d'eau.

Feuilles caduques, garnies, sur leur pétiole, de glandes cupuliformes

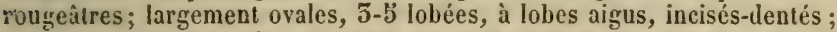
vertes et glabres en dessus, plus pâles et pubescentes en dessous, à nervures secondaires espacées, pennées, dont les inférieures, divisées dès la base, tendent à constituer une nervation palmée; stipules linéaires, herbacées. Fleurs en corymbes ombelliformes peu serrés el plans, de deux sortes : celles de l'extérieur, stériles, à corolle blanche, plane, dont les divisions sont inégales; celles du centre, hermaphrodites, à corolle régulière, petite, d'un blanc verdàtre. Baies globuleuses, succulentes, d'un rouge vif. - Arbrisseau de $\mathbf{3}-5^{\mathrm{m}}$, assez touffu, dont l'écorce lisse et d'un jaune brun se gerçure longitudinalement avec l'àge; à rameaux fragiles, glabres, d'un gris blanchâtre. Bourgeons ovoïdes, rougeâtres, étroitement enveloppés d'une membrane entière ou déchirée au sommet, résultant de la soudure de deux écailles. Bois de toute la France, sur les sols frais et aux bords des ruisseaux. Flor., juin. Fructif., septembre.

Cet arbrisscau, malgré sa fréquence dans certaines forêts, n'a aucune valeur. On en cultive souvent une variété, connue sous le nom de boule de neige ou de rose de Gueldre, dont les fleurs, toutes stériles et à grandes corolles, sont disposées en corymbe globuleux.

Le bois est rougeàtre, à grain très-serré et très-fin. Celui d'une tige de 20 ans, de 5 cent. de diamètre, pèse, complétement desséché à l'air, 0,72. (Coll. Ec. For.)

\section{genre H. - CHÈVRE-FEUILLE. LONICERA. Lin.}

Corolle tubuleuse ou campanulée, à limbe bilabié ou subrégulier, 5-fide; ovaire à loges pluri-ovulées; style allongé, terminé par un stigmate 3-lohé. Baie polysperme. - Sous-arbrisseaux, souvent sarmenteux-volubiles, à feuilles simples, entières, à nervation pennée, dont les fleurs sont disposées en petites cymes axillaires 2-ou 3-flores, et semblent quelquefois verticillées ou capitulées par la réunion des inflorescences opposées; revêtus d'une écorce ì rhytidome membraneux-fibreux, caduc, presque toujours grisàtre clair. Bourgeons très-étalés, généralement multiples et en série longitudinale à chaque aisselle, l’inférieur dominant, à écailles opposées-croisées, généralement nombreuses, de consistance sèche ou herbacée. Baics non comestibles, émétiques.

Bois de même structure que celui des viornes.

A. Tige volubile.

B. Feuilles voisines des inflorescences toujours libres. Inflorescences partielles non feuil- 
lées, aggglomérées à l'extrémité des rameaux et formant une sorte de capitule éloigné des dernières feuilles......... C. nes rots..... I

B'. Feuilles voisines des inflorescences toujours soudées entre elles par la base.

C. Feuilles coriaces, persistantes. Inflorescences contiguës aux feuilles........ C. des Baréares, „7 $\mathrm{C}^{\prime}$. Feuilles caduques.

D. Feuilles ovales; inflorescences contiguës aux feuilles.............

$\mathbf{D}^{\prime}$. Feuilles obovales; inflorescences en capitules distants des feuilles......

C. connun..... 2 capitules distants des fe

A1. Tiges frutescen distinctes sur un pédoncule axil-
B. Deux baies C. n’Etrune.... 4 laire.

C. Baies rouges.

D. Feuilles velues, ovales.......... C. A Basas.... b

$D^{\prime}$. Feuilles glabres, oblongues....... C. des Pxnénées. 7

C. Baies noires. Feuilles finalement glabres, oblongues-elliptiques............ C. vorr.......6

$\mathbf{B}^{\prime}$. Baies soudées en une seule sur un pédoncule axillaire

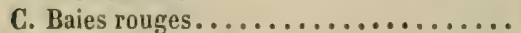

C'. Baies d'un bleu noir............

C. Des Alpes...8 8

C. Br.EU...... 9

\section{SECTION I. Tiges volubiles.}

Fleurs longuement tubuleuses, à limbe bilabie, en pelites cymes 3-flores axillaires et opposés, simulant des verticilles superposís dont la réunion constilue des capitules terminaux. Baics couronnées par les dents du calice; bourgeons à écailles herbacées.

1. Chère-fenille des bois. Lonicera periclymenum. Lin.

Feuilles caduques, elliptiques ou ovales-oblongues, aiguës, un peu glauques en dessous, courlement pétiolées, à l'exception des supéricures des rameaux fleuris qui sont sessiles, mais jamais soudées entre elles. Fleurs d'un blanc t'osé, odorantes, en capitules Ionguement pédonculés. Baic ovoïde, d'un rouge vif. - Sous-arbrisseat grimpant et volubile, i jeunes rameaux pubescents. Très-commun dans les haies et les bois. Flor., juin-août.

En s'enroulant en spirale sur la tige des jeunes arbres, ce chèvre-feuille, comme tous ceux de cette section, finit par y produire une forte constriction, qui oblige la séve descendante à circuler dans les intervalles des tours de spire. Le grossissement plus considérable qui se produit sur son trajet donne naissance à une tige torse d'une régularité souvent remarquable. 
2. Chèvre-fenille comimuit. Lonjcera carnifoliuar. LiN.

Feuilles caduques, glanques en dessous, pétiolées et ovales sur les rameaux stériles, sessiles dans le roisinage des inflorescences, devenant, en s'en rapprochant, de plus en plus orbiculaires; se soudant finalement 2 à 2 par leurs bases élargies, de manière à simuler une feuille uuique traversée par la lige. Fleurs purpurines ou d'un blanc jaunâtre, odorantes, en capitule terminal sessile au centre de la dernière paire de feuilles. Baie ovoïde, d'un rouge écarlate, Rameaux pubescents. - Très-fréquemment cultivé et subspontané ; spontané en Lorraine dans les bois du calcaire jurassique. Flor., mai-juin.

3. Chèvre-feuille des Baléares. Lonicena imflexa. Ait. L. Balearica. DC. Chèvre-feuille de Minorque.

Feuilles persistantes, très-coriaces, luisantes en dessus, très-glauques en dessous, ovales-apiculées, sessiles; celles des rameaux fleuris d'aulant plus largement soudées entre elles qu'elles se rapprochent davantage des fleurs. Celles-ci en capitules terminaux, sessiles. Baie fovoïde, d'un rouge écarlate. Jeunes rameaux ğlabres. - Région des oliviers, France, Corse et Algérie. Flor, mai-juin. Frucl., août.

4. Chèvre-feuille aretrurie. Lonicera etrusca. Sinti.

Feuilles caduques, obovales, glanques en dessous, courtement pétiolíes; les supérieures des rameaux fleuris sessiles, puis soudées entre elles par leurs loases. Fleurs formant 1-3̄ capilules longuement pédonculées, à corolle glabre. Baic ovoïde, d'un rouge vif. Jeunes rameaux pubescents-liérissés. - Région méditerranéenne, remonte jusqu’à Lyon, Gap, Auvergne, Corse et Algérie. Flor., juin-août.

\section{SECTION II. Tiges diessées, non volubiles.}

Flours non longuement tubuleuses, bilabiées ou presque régulières, géminées sur des pédoncules axillaires el non rapprochées en verlicilles capilulés; baics non couronnées par les dents du calice; buurgeons à écailles sèches.

5. Chève-feuilie à balais. Lonicena xylostevm. Lix. Camérisier.

Feuilles caduques, molles et mollement velues, ovales-aiguës, pétiolées, d'un vert clair en dessus, d'un vert blanchâtre en dessous. Fleurs petites, bilabiées, velues ainsi que leur pédoncule qu'elles égalent ; d'un blanc jaunâtre; bractée linéaire plus longue que l'ovaire. Deux baies globuleuses, rouges, distincles, mais soudées par la base. - Sous-arbrisseau à tige dresséc, rameuse, de $1^{\mathrm{m}}-\mathrm{I}^{\mathrm{m}} 0$, grisâlre, à rameaux opposés, grêles, blanchâtres, dont les bourgeons sont très-élalés. - Trèscommun dans les bois, surtout dans ceux dont le sol est calcaire. Flor., mai-juin.

On fait des balais grossicrs avee les rameaux de ce chèvre-feuille. 
6. Chèvre-feuille noir. Lovicera nigra. Liv.

Voisin du précédeut; feuilles oblongues-elliptiques, pubescentes en dessous dans la jeunesse, finalement très-glabres. Fleurs d'un blanc rosé, bilabićes, slahrescentes, $\mathbf{5}-4$ fois plus courtes que leur's pédoncules qui sont glabres. Braclées ovales plus courtes que l'ovaire. Baies ovoïdes, distincles, quoique soudees par la base, noires. - Sous arbrisseau de 1$2 \mathrm{~m}$, à tige dressée, à rameaux bruns, ainsi que les bourgeons, qui sont très-élalés. Régions montagneuses : IIautes-Vosges, IIaul-Jura, IIauteAuvergne, Cévennes, Alpes et Pyrénées. Flor., mai-juin.

2. Chèvre-feuille des gpyrénées. Lonicera prnenaïca. Lis.

Feuilles caduques, un peu coriaces, glabres, oblongues, alténuées à la base. Fleurs blanches à peine rosées, odorantes à corolle presque régulière, campanulée; glabres ainsi que le pédoncule qu'elles égalent; braclée lancéoléc-aiguë, un peu plus courte que l'ovaire. Baies globuleuses distinctes, mais soudées par la base, rouges. - Sous-arbrisseau le $1^{\mathrm{m}}$ au plus, d'un vert glauque, à tiges et rameaux blanchàtres, don les bourgeons latéraux sont étalés à anģle droit. Pyrénées. Flor, juin.

8. Chèvre-feuille des Ipes. Lonicera alpigena. Liv.

Fevilles grandes, ovales-oblongues, acuminées, pétiolées, glabres et d'un vert foncé luisant en dessus; pubescentes, plus clair et aussi luisantes en dessous, parfois verticillées par 5; nervation plus marquéc que dans les autres espèces du geure. Fleurs jaunitres à la base, d'un brun pourpre at sommet, bilabiées, 3 - $\$$ fois plus courles que leur pédoncule qui est glabre; braclées linéaires plus longues que l'ovaire. Baies soudées en une seule, ovoïles, rouges. - Sous-arbrisseau de $1^{\mathrm{m}}$, a ćcorce fibreuse, d'un gris-clair, dont les rameaux sont assez robustes, Iressés, et les bourgeons gros, d'un roussâtre clair, étalés, dressés. Jura, Ilaute-Auvergne, Alpes et Pyrénées. Flor., mai-juin.

9. Chèvre-feuille bleu. Lonicera coerulea. LiN.

Feuilles caduques, ovalıs ou ovales-oblongues, obtuses, molles, ciliées dans la jeunesse, finalement glabres. Fleurs presque régulières, campanulées, jaunatres, velues, $\ddot{b}-6$ fois plus longues que le pédoncule, qui e'st pubescent; bractées linéaires, plus longues que l'ovairc. Baies soudées en une scule, globuleuses, glauques, d'un noir bleuâtre. - Sousarbrisseau de $1^{\text {in }}$ au plus, à tige dressée, rameuse, revêtue d'une écorce d"un brun rougeàtre; à bourgeons multiples, différents de ceux des autres espèces, protégés par la base persistante de la feuille et revêtus seulement de 2-kécailles opposées, allongées, qui cacheut loutes les autres. Ilaut-Jura, Npes, Pyrénées. Flor., avril-mai.

\section{FAMILLE XXVII.}

\section{STYRACEEs. Rich.}

Fleurs hermaphrodites, régulières; calice le plus souvent allérent ì l'ovaire et, daus ce cas, corolle pérygine; étamines habituellement diphostemones, les unes alternes, les atules opl- 
posées, insérées à la base de la corolle ; anthères introrses, biloculaires, longitudinalement déhiscentes. Style simple. Ovaire ordinairement infère, de 3-4 loges plariovulées, opposées aux divisions du calice. Fruit charnu. Graine perispermée. - Arbres et arbrisseaux à feuilles alternes, simples, non stipulées.

\section{GENRE. - ALIBOUfIER, STYRAX. Tourn.}

Calice cupuliforme, entier ou à $气$ dents, au fond duquel adhère l'ovaire ; corolle infundibuliforme, à tube court, limbe grand, 5-rarement 3-7-partite; étamines diplostémones; ovaire adhérent par sa base, 3-loculaire, à loges pluri-ovulées, à placentation axile. Fruit charnu, ovoïde, coriace, 1-loculaire, 1-3sperme.

Alibonfier officinal. Struax officinale. LiN.

Feuilles alternes, caduques, pétiolées, simples, ovales, entières, vertes et presque glabres en dessus, convertes en dessous d'un duvet très-blanc, qui revêt aussi les pédoncules, calices et jeunes rameaux. Fleurs blanches, disposées 5-6 en cymes terminales, plus courtes que les feuilles; calice presque entier; corolle grande, profondément divisée en rement en 6-7 lobes lancéolés. Fruit blanchâtre-cotonneux, soudé par la base au calice persistant. - Petit arbre et plus souvent arbrisseau formant un buisson torlueux, très-rameux, rappelant le coignassier par le porl et par les feuilles, l'oranger par les fleurs. Commun dans quelques parties du département du Var, où il peuple à lui seul des collines entières; forêts de la Sainte-Beaume et de la Chartreuse de Montrieux; parâ̂t être originaire de l'Orient. Flor., mai.

On extrait de l'aliboufier, au moyen d'incisions longitudinales faites dans l'écorce, une térébenthine d'un jaune brunàtre et d'une odeur agréable analogue à celle de la vanille. Elle cst connue dans le commerce sous le nom de storax solide et sert en pharmacie. Les aliboufiers àgés et bien exposés peuvent seuls produire du storax et il parait qu'on n'en pourrait obtenir de ceux du Var.

\section{FAMILLE XXVIII.}

\section{VACCINIÉES. $D C$.}

Fleurs hermaphrodites régulières; calice adhérent a l'ovaire, à limbe 4-5̌-denté, quelquefois entier; corolle périgyne, ur-

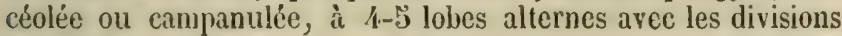
du calice; étamines en nombre double des pétales, insérées avec

Prodinit accessoire. 
Ja corolle, ì anthères biloculaires, s'ouvrant par 2 pores terminaux; 1 style; ovaire infère, à 4 -5-loges pluriovulées; placentation axile. Baie polysperme, graine périsperméc. - Petits. sous-arbrisseaux it feuilles simples, alternes, dont la nervation est pennée-réticulée; à racines très-rameuses, longuement rampantes et drageonnantes, pourvues d'un chevelu très-délié et très-abondant ; généralement sociaux et envahissants, caractéristiques des sols siliceux, granitirues et schisteux et des terres acides, dites terres de bruyère, qu'ils contribuent à former par leurs principes astringents.

Bois â vaisseaux abondants, lins, égaux, cntourés de parencliyme ligneux et arrangés en lignes tangentielles évidentes. Rayons fins.

^. Tige dressée; corolle urcéolée ou campanulée..... ArrebLe.....1 A'. Tiges filiformes, rampantes; corolle à \& divisions profondes, rélléchies.................... Cavarabraz.

Tige dresséc; corolle urcéolée ou campanulée. I th jiusin.

A. Feailles dentées, caduques, vertes. Fleurs solitaires. Truils bleus, doux-sucrés. Rameaux

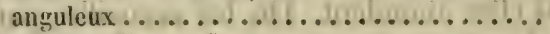

$\Lambda^{\prime}$. Feuilles entières; fleurs en grappes; rameaux

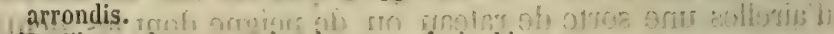

B. Feuilles caduques, très-glauques; fruits bleus,

B?. Feuilles coriaces, persistantes, luisantes; fruits

A. Uligineuse.. 2 rouges, acidulés................. canene....

1. Airelle myrtille. VAccinium ayntulus. Lin. Raisin des bois;

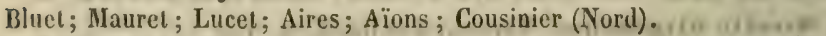

Feuilles caduques, vertes, ovales-aigues, dentées. Flcurs solitaires, penchées; calice à limbe entier; corolle urcéoléc, d'un blanc verdâtre et rosé. Baie dressée, d'un noir bleu, couverte d'une efflorescence glaugue; louce el sucréc. - Sous-arbrisseau de 0 m引0 de bauteur au plus, trèsglabre, à rameaux verts et anguleux, pourvu de racines très-longuement iracantes, drageonnantes, formant à la surface du sol un lacis très-serré de librilles et de chevelu. Régíns montagneuses, surtout aux expositions froides, liumides: Vosges, Jura, Auvergne, Alpes et Pyrénées; disséminé dans l'ouest de Nantes à l'aris, dans la Côte-d'Or, dans SaôneLoire, dans le Nord, elc. Manque dans le Mlidi el en Corse; se retrouve néanmoins dans l'Allas, suivant Desfontaines. Flor., mai. Fructif, juilletaoût.

Station el sol. L'airelle myrtille, ou le myrtille comme on l'appelle comnumément, est une plante sociale très-envahissante, exclu- 
sivement forestière. Formant des tapis très-serrés à la surface des terrains schisteux, graveleux et arénacés qu'il caractérise et que des massifs interrompus ne protégent plus suffisammient, le myrtille est l'indice certain que le moment propice à l'ensemencement naturel est dépassé, que le sol est en voie d'appauvrissement, sans néanmoins avoir encore perdu toute sa fertilité et surtout sa fraicheur. L'épais et impénétrable lacis de ses racines, les gazons touffus que lorment sés tiges le rendent redoutable pour la levée des graines, pour le développement des jeunes plants. Il faut néanmoins se hâter de profiter de l'indication qu'il fournit, quant à l'état du sol, qui n'est point eneore détérioré complétement, pour y tenter des repeuplements. Sans cette précaution, les myrtilles ne tardent pas en général à céder la place aux bruyères, dont l'envahissement est l'indice certain d'un appauvrissement complet.

Les baies de myrtilles, connues sous le nom de brimbelles, (Pouriot, Saône-et-Loire; Cousines, Nord), se mangent crues ou cuites et servent à la préparation de différentes conserves ct liqueurs; on les emploie aussi pour donner de la couleur aux vins rouges. Elles sont l'objet d'un petit commerce dans les localités où elles abondent. On les recueille, particulièrement dans les Vosges, en passant sur les fourrés d'airelles une sorte de rateau ou de peigne dont les dents sont assez rapprochées pour retenir entre elles les brimbelles, qui vont se réunir dans un petit auget placé sur le dos de l'instrument.

Les tiges de l'airelle myrtille servent à faire des balais.

2. Airelle uligineuse. Vacciviom vigrnosum. Liv.

Feuilles caduques, entières, obovales, obtuses ou échancrées au sommet, d'un vert clair et mat en dessus, très-glauques en dessous. Fleurs cn petites grappes pencliées; calice à divisions arrondies; corolle urcéolée, blanche ou rougeâtre. Baic globuleuse, d'un noir bleuàtre, couverte d'une efflorescence glauque, fade-sucrée. - Sous-arbrisseau de $\mathbf{1}^{\mathrm{m}}$, grlabre et glauqque blenâtre, à tige et rameaux arrondis, écorce grisâtre, racines rampantes. Caractéristique des marais tourbeux des Vosges, du Jura, des Alpes, de l'Auvergne, des Pyrénées; se trouve en plaine à Haguenau (Bas-Rhin). Flor,, mai-juin. Fruclif., août-septembre.

3. A ipelle canche. VAciniun vitis in xa. Lin.

Feuilles persistantes, très-coriaces, rappelant les feuilles du buis, obovales, à bords entiers ou très-faiblement dentés au sommet, enroulés cn dessous; vertes, luisantes en dessus, plus pâles et poncluées en dessuus. Fleurs en petites grappes terminales penchées, à corolle blanche,

Produit accessoire. 
campanulée, à lobes roulés en dehors. Baies rouges, aciles. - Sousarbrisseau de 1-2 décimètres, à tiges radicantes, racines rampantes, émellant de nombreux rameaux arrondis, dressés, grèles, pubescents. Hautes-Vosges, Jura, Alpes, Monts-Dore, Cantal, Lozère; se retrouve en plaine à Hagueneau (Bas-Rhin), dans l'Oise et dans le Nord. Flor., mai-juin. Fructif., août-septembre.

Station et sol. L'airelle canche est aussi une plante sociale envahissante, mais qui généralement ne se rencontre qu'à une altitude assez élevée et, le plus habituellement, sur les sols forestiers découverts ou fort peu abrités.

\section{gENRE II. - CANNEBERGE. OXYCOCCOS. Tourn.}

Corolle en roue, divisée presque jusqu'à la base en 4 segments réfléchis et arqués en dehors; tiges très-grêles filiformes, couchées, radicantes; feuilles persistantes.

Canneberge commune. Oxycoccos rulgaris. Pers.

Feuilles petites, ovales, persistantes, entières, à bords cnroulés en dessous, vertes et un peu luisantes en dessus, blanches efflorescentes en dessous. Fleurs roses, solitaires, géminées ou ternées au sommet des rameaux, pendantes à l'extrémité de longg et grêles pédoncules dressés. Baie rouge, acidulée. - Plante élégante, à tiges presque capillaircs, rampantes et radicantes, croissant sur les buttes de sphagnum (mousses) des lieux tourbeux. Alsace, Vosges, IIaut-Jura, Auvergne; centre ct nord-ouest jusqu’à Nantes. Flor., juin-août. Fructif., juillet-septembrc.

\section{ORDRE IV.}

\section{GAMOPÉTALES IIYPOGYNES.}

Corolle liypogyne, indépendante du calice; étamines insérées. sur le réceptacle ou sur la corolle. Ovaire libre, supère. 


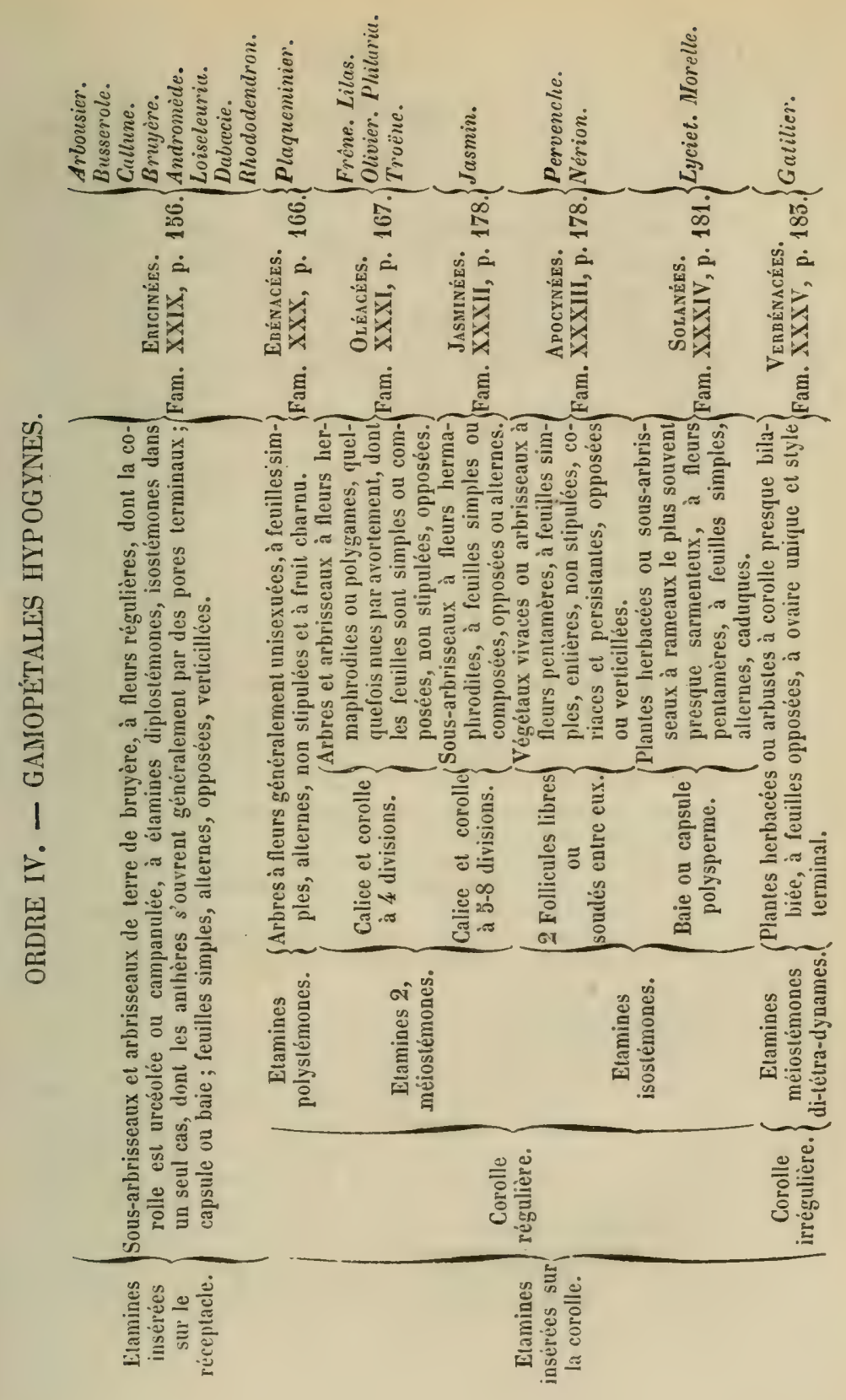




\section{FAMILLE XXIX.}

\section{ERICINEES. JiSS.}

Fleurs hermaphrodites, régulières ou presque régulières. Calice gamo-polysépale, à 4 -5 divisions, persistant ; corolle gamopétale, hypogine, urcéolée ou campanulée, à 4-5 divisions ; 'tamines libres, diplostémones, très-rarement isostémones, insérées sur le récepiacle, à anthères biluculaires, s'ouvrant généralement, par leurs extrémités apiculées, au moyen de 2 pores terminaux. Style 1. Ovaire libre, supère, à $4-5$ loges pluri-ovulées, à placentation axile, produisint une capsule, plus rarement une baie. - Sous-arbrisseaux et quelquefois arbrisseaux à feuilles simples, allernes, opposées ou verticillées, souvent aciculaires, presque toujours vertes; pourvus de racines très-rameuses, ù chevclu très-abondant; souvent sociaux et envahissants; caractéristiques des sols siliceux, feldspathiques ou schisteux et contenant des principes astringents propres au tannage et à la fabrication des teintures noires.

Bois presque identiques pour tous les genres, à tissu fibreux très-fin, très-serré, très-compacle ; vaisseaux égaux, fins ou trèsfins, isolés ou légèrement groupés, uniformément répartis ou à peine plus abondants au bord interne de chaque couche. Rayons assez fins ou fins, serrés ou espacés. Couleur rouge dominante.

A. Baie. Corolle caduque. Feuilles à limbe développé, alternes. Etamines diplostémones.

B. Tige dressíe; fruit granulé-luberculeux à la surface, à ${ }^{\prime}$ loges adhérentes, plurispermes.

Feuilles persistantes ...................... Arbousier ....... 1

B'. Tiges élalées-rampantes; fruit lisse, à "̈ loges libres, monospermes. Feuilles persistantes ou caduques................... Busserole.... 2

$\Lambda^{\prime}$. Capsule. Feuilles persistantes.

B. Corolle persistante; élamines diplostémones ; feuilles aciculaires, opposées ou verlicillées.

C. Corolle campanulée plus courte que le calice; capsule septicide. Feuilles opposées, imbriquées sur 4 rangs....... Calluve......

C'. Corolle urcéolée, plus longue que le ealice; capsule loculicide. Feuilles ver-

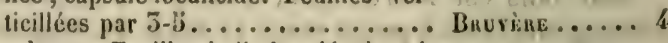

B'. Corolle caduque. Feuilles à limbe développé, alternes, rarement opposées.

C. Capsule lóculicide. Corolle ircéolée; élamines diplostémones. Feuilles alternes. ANDronìo .... b 
$C^{\prime}$. Capsule septicide.

D. Etamines isostémones. Corolle campanulée.

Feuilles opposées............... Lorsbrevara.....6

D'. Etamines diplostémones. Feuilles alter-

nes.

E. Corolle urcéolée.............. Daвoecıe.....7

E'. Corolle infundibuliforme, légèrement

irrégulière............... Rnododendron.. 8

\section{SEction I. Baie. Corolle caduque.}

(Feuilles à limbe développé, alternes.)

GENRE I. - ARBOUSIER. ARBUTUS. Tournef.

Calice 5-partite; corolle urcéolée, à 5 dents; 10 étamines s'ouvrant par 2 pores terminaux; baie à surface granulée-tu. berculeuse, à 5 loges, dont chacune contient 4-5 graines.

Bois à tissu fibreux très-fin et très-serré; vaisseaux fins, disposés en petits groupes assez uniformément rẻpartis, formant sur la tranche de petites et très-courtes lignes irrégulières et blanchâtres, généralement rayonnantes; rayons assez fins, serrés, peu longs, peu hauts.

Arbousier commun. Ansutus unedo. Lix. Arbre à fraises; Frôle, etc.

Feuilles persistantes, rappelant celle du laurier, à peine péliolées, clliptiques-lancéolées, dentées, coriaces, glabres et luisantes, d'un vert foncé en dessus, plus pâles en dessous. Fleurs blanches, en grappes composées, courtes et larges, terminales; étamines à filets velus-laineux. Baie globuleuse et rouge de la taille d'une cerise, couverte de nombreux tubercules. - Arbrisseau rameux, à rhytidome d'un brun rouge, longuement et finement gerçuré, écailleux, mince et caduc; à jeunes pousses rougeâtres, rudes et poilues, couvertes d'un feuillage dressé, abondant, épais. Littoral de la Méditerranée et de l'Océan; assez commun en Corse; Algérie. Flor., octobre-fívrier. Fructif., au bout d'un an.

L'arbousier croît lentement et peut atteindre $4-5^{\mathrm{m}} \mathrm{de}$ hauteur sur $1^{\mathrm{m}}$ de circonférence; il entre dans le peuplement des maquis; vient en plaine ou en coteaux, à toutes les expositions et protége très-efficacement le sol par son feuillage abondant.

Son bois est lourd, dur, d'un' grain extrêmement fin et homogène; il est à peine veiné et varie du rougeảtre au rouge légèrement cramoisi et au rouge brun. Il a la fibre courte et cassante, se tourmente beaucoup, a peu de durée; il prend du reste un très-beau poli, est d'un travail facile et peut

Taille.

Station.

Bois. 
servir, quand il est bien sec, à fabriquer des objets de tour, de tabletterie, etc. C'est un excellent combustible, qui produit un charbon de bonne qualité.

Du bois d'une tige de 120 ans, de 21 cent. de diamètre, provenant de la Corse et complétement desséché à l'air, pèse $0,95 ̋ 8$. Celui d'une tige de 50 ans, de 29 centimètres de diamètre, venant d'Algérie et complétement desséché à l'air, pèse 0,903 (Coll. Ec. For. Envois de MII. Simon et Royer).

Les fruits, connus sous le nom d'arbouses, sont comes-
tibles.

GENRE II. - BUSSEROLE. ARCTOSTAPIIYLOS. AdanS.

Toisin des arbousiers, ce genre se distingue par la baie qui est lisse, à 5 loges libres, monospermes. Il ne contient que des sous-arbrisseaux à tiges étalées rampantes.

A. Feuilles caduques, denticulées au sommel; baie d'un bleu noirâtre...................... B. des Alpgs. 1 $\Lambda^{\prime}$. Fcuilles persistantes très-entières; baie rouge.... B. officinas. 2

1. Busserole des A1pes. Arctostapirlos Alpina. Spresgel. Arbulus Alpina. Lin. Arbousier des Alpes.

Feuilles caduques, obovales, atténuées en un long pétiole, subaiguës au sommel, denticulées dans leur moilié supérieure, réticulées sur les deux faces, verles en dessus, plus pâles en dessous. Fleurs blanches, réunies 2 ou 5 au sommet des rameaux, naissant avant ou avec les feuilles. Baie globuleuse, de la grosseur d'un pois, d'un bleu noiråtre, acidulée et âpre, rappelant la saveur du cassis. Tiges allongées, grêles, élalées-rampantes, à jeunes rameaux glabres. IIaut-Jura, Alpes el Pyrénées. Flor., mai. Fruclif., juillet-août.

2. Busserole officinal. Anctostaphislos officinalis. Wimis. et Grab. Arbulus uva-ursi. Lin. Arbousicr raisin-d'ours; Buxerole; Arbousier trainant.

Feuilles persistantes, coriaces, courtement pétiolées, obovales, obtuses, très-entières, vertes et luisantes, plus pâles en dessous, rappelant les feuilles de l'airelle canche ou du buis, mais a bords non enroulés en dessous. Fleurs blanches-rosées, en petites grappes serrées, terminales, naissunt apres les feuilles. Baic globuleuse, de la taille d'un pois, rouge, âpre. - Sous-arbrisseau à tiges grêles, allongées, étalées-rampantes, radicantes. Régions montagneuses : IIaut-Jura, Alpes, Pyrénées, les Corbières, le Mézenc, la Lozère; Recey (Cûte-d'Or). Flor., avril-mai. Fructif., août. 


\section{Section II. - Corolle persistante. Capsule.}

Feuilles petiles, aciculaires, opposées ou verticillées par 3-5; bour. geons axillaires rares et le plus souvent distribués sans ordre, de sorle que la ramification est souvent éparse.

genre iIf. - CALLUNE. CALLUNA. Salisb.

Calice 4-partite, pẻtaloïde ; corolle beaucoup plus courte que le calice, campanulée, 4-fide, marcescente. Etamines 8. Capsule à 4 loges polyspermes, à déhiscence septicide. - Sous-arbrisseaux toujours verts, à feuilles très-petites, opposées, imbriquées.

Bois identique à celui des espèces du genre suivant.

Callume bruyère. Calluna vulgamis. Salisb. Erica vulgaris. Lin. Bruyère commune.

Feuilles très-petites, opposées et imbriquées-dressées sur 4 rangs, linéaires-lancéolées, obluses, prolongées à la base en deux appendices subulés; convexes en dehors, un peu concaves en dedans, vertes, luisantes et généralement glabres. Fleurs roses, plus rarement blanches, disposées en longues grappes simples et lâches, terminant les rameaux; entourées à la base de petites bractées qui semblent ètre le calice; celui-ci scarieux, coloré, cache la corolle qui est moitié plus courte. Capsule globuleuse, velue. - Sous-arbrisseau tortueux, rameux, s'élevant à $0^{\mathrm{m}} 50-0^{\mathrm{m}} 70$, à écorce $d^{\prime}$ un brun rougeàtre, rameaux effilés, nombreux, dressés. Très-commun sur les sols siliceux, feldspathiques et schisteux déconverts. Flor., juillet-septembre.

C'est cette plante qui est si connue sous le nom de bruyère et qui recouvre parlois, à elle seule, de vastes étendues de terrain. Elle est sociale, éminemment envahissante, surtout aux expositions méridionales, essentiellement silicicole. Son abondance sur le sol forestier est l'indice certain d'une terre épuisée, que le couvert des arbres, la couverture de feuilles mortes ne garantissent plus depuis longtemps et qui, sous l'action directe du soleil et des vents, a perdu toute fraicheur et tout terreau.

La bruyère oppose de grands obstacles aux repeuplements, par le couvert épais et immédiat qu'elle produit sur les jeunes plants, par ses racines nombreuses, bien moins abondantes et moins superficielles néanmoins que celles des myrtilles.

Les détritus de la bruyère sont lents à se transformer en terreau et celui-ci est toujours acidc. Mélangés à la silice ils constituent la terre de bruyère. 
Si la bruyère a des exigences très-spéciales quant à la composition minérale de la terre, elle n'en présente aucune sous le rapport de l'humidité et on la voit prospérer dans les sols les plus arides et les plus secs, comme dans les sols marécageux et tourbeux.

Bois. Le bois a de trop faibles dimensions pour être de quelque autre utilité que celle de servir au chauffage.

\section{GENRE T. - BRUYÈRE. ERICA. Lin.}

Calice de 4 sépales libres ou soudés à la base, verts ou colorés; longuement débordé par la corolle urcéolée, 4-dentée; 8 étamines; capsule à 4 loges polyspermes, dont la déhiscence est loculicide. Sous-arbrisseaux toujours verts, à petites feuilles aciculaires, verticillées par $3-5$, , dont les bords s'enroulent sur la face inférieure et y circonscrivent un espace triangulaire enfoncé ou simplement un sillon large ou étroit, d'égale dimension, qui parait double ou simple, suivant que la nervure médiane est saillante ou effacée. Leur écorce passe de bonne heure à l'état de rhytidome libérien brun rougeâtre, fibreux et finement gerçuré. Les bruyères appartiennent d̀ l'ouest, au centre et surtout au midi de la France, mais ne sont point envahissantes comme la callune bruyère.

Bois à grain très-fin, très-compacte, très-homogène. Tissu fibreux fin, à parois épaisses; vaisseaux très-petits, isolés, assez abondants, uniformément répartis ou à peine décroissants du bord interne au bord externe; rayons assez fins, peu hauts, espacés.

A. Anthères plus ou moins saillantes.

B. Anthères à demi-saillantes. Fleurs portées par des pédicelles plus courts qu'elles, à corolle deux fois aussi longue que large...................... B. de la Míditerrayée. 1

$B^{\prime}$. Anthères très-saillantes.

C. Fleurs 2 fois aussi longues que larges, portées sur des pédicelles $2-3$ fois aussi longs qu'elles.............. B. MULTIFLONE.....2 2

C'. Fleurs aussi larges que longues, por-
tées sur des pédicelles 5 - 4 fois aussi longs qu'elles.................

B. VAGABONDE.....5

A. Anthères non saillantes.

B. Fleurs blanches, roses ou purpurines.

C. Feuilles fortement ciliées; pédoncules plus courts que la fleur.

v. Fleurs oblongues un peu courbées, 2 fois el demi aussi lengues que larges, à style saillant........ 
$D^{\prime}$. Fleurs ovoïdes, 2 fois aussi longues que larges, à style à peine saillant.....................

B. Quatenné...... \&

C'. Feuilles glabres ou à peine ciliées. Pédicelles égaux ou presque égaux à la fleur.

D. Fleurs moyennes, plus longues que larges.

E. Rameaux glabres ou courtement pubérulents.

F. Feuilles verticillées par 3, produisant à leur aisselle un ramule raccourci à feuilles fasciculées ...............

F1. Feuilles verlicillées par 4 , dépourvues à leur aisselle de ramules raccourcis........

El. Rameaux fortement poilus, d'un

blanc-ggrisâtre............ B. DE Portugal..... 8

$\mathrm{D}^{\prime}$. Fleurs petites, aussi larges que

longues ................. B. en arbre.......9

$B^{\prime}$. Fleurs d'un jaune verdâtre, petites, aussi larges que longues, à pédicelles aussi longs qu'elles.................

B. cendrér.......6

B. DRESSÉE.......7 7

B. A malais.......

1. Hruyère de la Bréditerranée. Erica meditenanea. Lin.

Feuilles verticillées par 4 , linéaires, de 5.7 mill. de long, un peu convexes en dessus, finement et également 1 -sillonnées en dessous. Fleurs roses, géminées, axillaires, formant des grappes unilatérales à l'extrémité des rameaux; plus longues que leurs pédicelles, de 7 mill. de long sur 5 de large, à corolle ovoïde-tubuleuse; anthères à demi-saillantes, terminales et placées sur le prolongement du filet, à loges contiguës dans toute leur longueur et sans appendices à la base. - Sousarbrisseau glabre, à tige rameuse et à rameaux dressés. N'est connu pour la France que dans une seule lande de la Gironde. Flor., janvier. Fructif, mai.

2. Bruyère multiflore. Erica multiflora. Lin.

Feuilles verticillées par \& à 6 , linéaires, longues de 10 mill., planes en dessus, convexes, finement et également 1-sillonnées en dessous, glabres et luisantes. Fleurs géminées ou ternées, roses, axillaires, à pédicelles 2-5 fois aussi longs qu'elles, formant de longues grappes bien fournies le long et à l'extrémité des rameaux; corolle ovoïde-allongée, de $\mathbf{5}$ mill. de large sur 2 mill. de long. Etamines longuement saillantes, à anthères latérales, dont les loges sont disjointes dans leur tiers supérieur et non appendiculées à la base. - Sous-arbrisseau glabre, de $0^{\mathrm{m} 20}$ $0 \mathrm{~m} 80$, à tigge rameuse, rameaux dressés, pubérulents. Provence, Hérault, Algérie. Flor., septembre-octobre.

3. Iruyère vagabonde. Erica vagans. Lin.

Feuilles verticillées par 4 ou 5 , étroitement linéaires, longues de 7 . 
9 mill., presque planes eu dessus, convexes, fiuement et ígalement 1 sillonnées en dessous, glabres et luisantes. Fleurs géminces ou teruées, axillaires, à pédicelles $5-4$ fois aussi longs qu'elles, formant des grappes allongées et fournies le long des rameaux; corolle rose, ovoïde, de 5 mil. de loug. sur 5 mill. de large; étamines longuement saillanles, à anthères latérales, dont les loges sont complétement disjointes daus toute leur longueur, non appendiculées à la base. - Sous-arbrisseau de $0^{\text {m }} 30$ $1^{\mathrm{m}}$, glabre, à lige rameuse, rameaux allongés, dressés, presque tonjours prolongés et feuillés au-dessus de l'inflorescence. Dans les bois secs et sablonneux et dans les landes de la France occidentale, de Paris ¿̀ Pau; Toulouse, Baguères-de-Bigorre, Isère. Flor., mai-juin.

4. Bruyère ciliée. Erica chiaris. Lin.

Feuilles verticillées par 5-4, de $2-5$ mill. de long, ovales-aiguës, planes, vertes en dessus, blanches en dessous, où les bords enroulés circonscrivent un large espace $\overline{5}$-angulaire partagé par la saillie de la nervure médiane; munies de longs cils raides, espacés, étalés. Fleurs axillaires, très-courtement pédicellées, en grappes serrées au sommet des rameaux; corolle grande, de 10 mill. sur 4 , purpurine, tubuleuse-urcéolée, légèrement arquée; étamines non saillantes, à anthères non appendiculées à la base, dont les loges sont presque entièrement disjointes. - Sous arbrisseau de $0^{\mathrm{m}} 20-0^{\mathrm{m}} 60$, à tige très-rameuse, torlueuse-dressće, cylindrique ct velue, à rameaux grèles. Landes et bois sablonneux de l'ouest, de Dunkerque à Bayonne; environs de Paris. Flor., juin-septembre.

5. Bruyère quaternée. Enica tetnalix. Liv. Bruyère des marais.

Feuilles verticillées par 4, longues de 4 mill., linéaires-oblongues, pubescentes, vertes en dessus, blanches et à bords enroulés en dessous où ils circonscrivent un espace étroitement triangulaire; bordées de cils ćtalés, glandulcux. Fleurs roses, rarement blauches, de 7 mil. sur 4 , courtement pédicellées, disposées $\vdots-12$ en ombelle simple, terminale, dense el globuleuse; corolle ovoïde-urcéolée; étamines non saillantes; anthères à loges disjointes au sommet, pourvues à la base de 2 longs appendices subulés. - Sous-arbrisseau de $0^{\mathrm{m}} 50-0^{\mathrm{m}} 70$, à rameaux trèsgrèles, redressées, pubescents ou hérissés. Landes humides et marécageuses de tout l'ouest, Sologne et France centrale; environs de Paris, de Bar-le-Duc, de l'agnères-de-Bigorre, etc. Flor., juin-septembre.

6. Hruyère cendrée. Ema cinerea. Lin.

Fenilles verticillées par 5, longues de 5-7 mill., linéaires, étroites, glabres, vertes, luisantes, à bords élroilement blanes-scarieux, accompagnées à lcurs aisselles de ramules raccourcis qui produisent des feuilles fascieulées; planes en dessus, très-finement et ígalement 1-sillonnées en dessous. Fleurs roses, violetles ou blanches, de 6 mill. de long sur de large, à pédicelles aussi longs qu'elles, disposées 1-5 a l'extrémité de très-courls rameaux latéraux et formant par leur ensemble des grappes composées, denses, terminales; corolle ovoüde-urcíolée; élamines non saillantes, dont les loges sont presque complétement soudées entre elles, pourvaes d'appendices subulés à la base. - Sous-arbrisseau de $0^{\mathrm{m}} \mathrm{j0}$ 0 m60, rancux, à rameaux dressés, pubescents. Terrains arides et sablonneux de l'ouest, du centre et du midi. Flor., juin-septembre. 
ซ. Intuyère dresséc. Enica stricta. Donv. E. corsica. $D C$.

Feailles verticillées par 4 , longues de $4-\$ 3$ mill., linéaires, obtuses, peu convexes en dessus, marquées en dessous d'un large sillon déeroissant de la base au sommet, glabres, mais très-courtement et peu distinctement ciliolées aux bords, non accompagnées à leur aisselle de faisceaux de feuilles. Fleurs roses, de $\mathbf{6}$ mill., sur $\mathbf{3}$, à pédicelles plus courts qu'elles, disposćes $\$-6$ en petites ombelles simples, terminales; corolle ovoüde-urcéolée; étamines non saillantes, dont les anthères ont les loges presque entièrement disjointes et sont pourvues à la base de deux longs appendices subulés. - Sous-arbrisseau de $0^{\mathrm{m}} 4-\mathbf{1}^{\mathrm{m}}$, à tige dresséc, divisée en rameaux simples, droits, nombreux, serrés contre l'axe de la plante, courtement pubérulents. Montagnes de la Corse. Flor., juilletaoût.

\section{Bruyère de Bortugal. Erica lusitanica. Rudolpir.}

Feuilles verticillées par 5-4, longues de 50 $\mathbf{6}$ mill., très-étroites-linéaires, glabres, faiblement el uniformément 1-sillonnées sur le dos. Fleurs roses, de $\&$ mill. sur 5 , à pédicelles aussi longs qu'elles, disposées 1-5 à l'extrémité des ramules latéraux et formant par leur ensemble une longue panicule composíe; corolle campanulée, un peu resserrée à la gorge ; anthères non saillautes, à loges disjointes dans leur moitié supérieure et pourvues à la base d'appendices hérissés. - Arbrisseau de $1-5^{\mathrm{m}}$, à tige rameuse, rameaux dressés, ramules blancs-grisâtres, velus-hérissés, à poils simples. Landes de la Teste-de-Buch. Flor., janvier. Fruclif., juillet.

9. Iruyère en arbre. Enica anbonea. Lis.

Feuilles verticillées par 5-4, longues de 5-4 mill., linéaires, étroites, glabres, finement et uniformément 1-sillonnées sur le dos. Fleurs petiles, de 5 mill. sur 5 , blanches ou rosées, odorantes, à pédicelles aussi longs qu'elles, disposées $2-4$ au sommei de ramules dont l'ensemble forme une grande panicule composée, pyramidale; corolle campanulée, non resserrée à la gorge; anthères non saillantes, à loges disjointes dans la plus grande partie de leur longueur, pourvues à la base de courts appendices obtus, ciliés. - Arbrisseau de 1- $\mathbf{4}^{\mathrm{m}}$ de hateur, sur $0^{\mathrm{m}} 50-0^{\mathrm{n}} 50 \mathrm{de}$ circonférence, à tige dressée très-rameuse, rameaux blanchâtres, couverıs de poils très-nombreux, inėgaux, la plupart rameux. Terrains secs et sablonneux de la région méditerranćenne; France, Corse et Algérie. Flor., mai. Fructif, juillot.

Le bois de la bruyère en arbre ressemble beaucoup à celui de l'arbousier; il s'en distingue néanmoins par' ses vaisseaux plus petits, isolés, par ses rayons espacés, par une croissance plus lente encore et une densité plus élevée. Comme lui, il a le grain très-fin, très-homogène, très-serré, est susceptible d'un fort beau poli; mais il a la fibre courte et cassante, il se geree et se tourmente beaucoup. Il est généralement d'un rouge rosé clair. Le bois de la souche, qui est trèsvolumineuse, est recherché pour menus ouvrages et parti- 
culièrement pour la fabrication des pipes, en raison de son grain très-serré et de sa fibre noucuse et contournée.

Du bois de tige de 52 ans et de 8 cent. de diamètre, pèse, entièrement desséché à l'air, 1,15゙ (Coll, Ec. For. Algéric, envoi de M. Royer). C'est un excellent combustible, dégageant une vive chaleur, dont le charbon est considéré comme l'un des meilleur's que l'on puisse produire.

10. Bruyère à balais. Erica scoparia. Lin.

Feuilles verticillées par 5-4, longues de $4-5$ mill., glabres, luisantes, bi-sillonnées sur le dos. Fleurs très-petites, de 2 mill. sur 2 , d'un jaune verdâtre, à pédicelles aussi longs qu'elles, disposées 1-4 à l'aisselle des feuilles et formant par lcur enscmble, le long des rameaux, des grappes simples, allongées, étroites; corolle campanulée-globuleusc; anthères non saillantes, à loges disjointes au sommet seulement, sans appendices

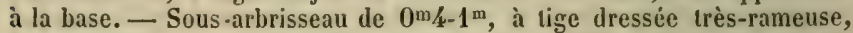
à rameaux droits, grèles, glabres et grisâtres. Bois arides et landes de l'ouest, du centre (jusqu'à la Loire) et du midi. Flor., mai-juin.

Les rameaux de cette bruyère et ceux de quelques autres espèces servent à faire des balais.

\section{SEction III. Corolle caduque; capsule loculicide.}

(Feuilles à limbe développè, alternes.)

GENRE จ. - ANDROMÈDE. ANDROMEDA. Lin.

Calice 5-partite; corolle urcéolée, eaduque, à 5 dents ; 10 étamines; capsule loculicide.

Andromèle à fenilles de polium. Andronema polifolla. LiN.

Feuilles persistantes, alternes, presque sessiles, elliptiques-oblongues, mucronées, vertes el luisantes en dessus, blanches et a bords entiers fortement enroulés en dessous. Fleurs d'un blanc rosé, longuement pédonculées, réunies $4-8$ en ombelles simples, terminales. Capsule globuleuse, noire et glauque, surmontéc d'un style simple aussi long qu'elle. Petit sous-arbrisseau à tiges-grêles, couchées, radicantes à la base, ascendantes à leurs extrémités, s'élevant à $0^{\text {m50 }} 50$ environ. Lieux lourbeux des régions montagneuses : Vosges, Jura, Haute-Auvergae, Alpes et Pyrénées. Flor., mai-juin. Fructif, août. 


\section{SECTION IV. Corolle caduque; capsule septicide.}

(Feuilles à limbe développé, allernes ou opposées.)

genRe Yi. - LOISELEURIA. LOISELEURIA. Desv.

Calice 5-partite; corolle campanulée, 5̆-lobée; 5 étamines à déhiscence longitudinale ; capsule 2-3-loculaire, septicide.

Loiseleuria couchée. Loiseleuria procumbers. Desv. Azalea procumbens. Lin.

Feuilles opposées, persistant jusqu'aux feuilles nouvelles seulement, petites, pétiolées, ovales, coriaces; vertes et brillantes sur les deux faces, convexes et sillonnées en dessus, marquées en dessous d'une large nervure médiane et largement enroulées par les bords. Fleurs axillaires, longuement pédonculées, réunies $2-\$ 3$ en une grappe courte, terminale, dressée; corolle rose, régulière, campanulée, 5-lobée. - Petit sousarbrisseau de 1-3 décimètres, à tige grêle, rameuse, couchée sur le sol. Sommet des Alpes et des Pyrénées. Flor., juillet-août.

genre vit. - DABOECIE. DABOECIA. Don.

Calice 4-partite; corolle urcéolée, 4-dentée. Etamines 8. Capsule 4-loculaire, septicide.

Daboecie à feuilles de Polium. Daboecia polifolia. Don, AnUromeda dabacii. Lin. Menziesia polifolia. Juss.

Feuilles éparses, coriaces, ovales-ellįtiques, courtement pétiolées, cntières, vertes et luisantes en dessus, blanches-tomenteuses et à bords enroulés en dessous. Fleurs pendantes, axillaires, disposées $5-6$ en grappe làche, terminale; corolle urcéolée, violelte; anthères d'un violet foncé, sagittées à la base. Capsule oblongue, hispide, dressée. - Joli sousarbrisseau de $2-50$ décimètres, à tige grêle, rameuse, brune, à rameaux ascendants, hispides-glanduleux, racines longues et rampantes. Se trouve dans quelques forêts de Maine-et-Loire, Tarn-et-Garonne, Hautes et Basses-Pyrénées. Flor., juin-octobre.

GENRE VII. - RHODODENDRON. RHODODENDRON. Lin.

Calice 5-partite; corolle infundibuliforme, כ̌-lobée, légèrement irrégulière; 10 étamines, dont les anthères s'ouvrent par des pores terminaux; capsule 5 -loculaire, septicide.

A. Feuilles d'abord blanchâtres en dessous, puis ferrugineuses, non ciliées............. R. Fernugiveux . I

A'. Feuilles vertes, poncluées de ferrugineux, ciliées ....................... R. Jérassí.....2 
1. Rhododendrou ferrugineux. Ruododendion ferRugineun. Lis. Rosage ferrugineux; Laurier-rose des Alpes; Rose des Alpes.

Feuilles coriaces, persistantes, légèrement pétiolées, ovales-lancéolées, entières, glabres, vertes et luisantes en dessus, densément écailleuses, d'abord blanchàtres, puis ferrugineuses en dessous. Fleurs disposées 4-7 en grappe courte ombelliforme terminale, à pédoncule allongé, tuberculeux; calice très-petit; corolle à limbe large et ouvert, d'un beau rouge, très-rarement blanche. - Joli sous-arbrisseau de $0^{\mathrm{m}} \mathbf{z}-0^{\mathrm{m}} 6$, à tige dressée, rameuse dès la base. Sommets du Jura, hautes régions des Alpes et des Pyrénées, entre $1500-2500 \mathrm{~m}$ d'altitude; montagne noire de l'Aude, (I. Jollyel). Flor., juillet.

2. Rhododendron hérissé. RHododendron IInSutum. Lis.

Voisin du précédent, dont il se distingue par ses feuilles légèrement crénelées, bordées de longs cils étalés, d'un vert pâle en dessous, poncluées par de nombreuses glandes ferrugineuses; par ses pédoncules et ses jeunes rameaux hispides; par les divisions du calice el de la corolle cilićes. - Sous-arbrisseau plus petit que le précédent. Régions élevées des montagnes; il n'est pas certain que celle espèce ait élé trouvée en France. Flor, juillet.

\section{FAMILLE XXX.}

\section{ÉBÉNACÉs. Vent.}

Fleurs uniséxuées, rarement hermaphrodites, régulières; calice persistant, gamosépale, à 3-6 divisions ; coro!le hypogyne, 3-6-fide; étamines en nombre égal, double ou multiple, insérées à la base de la corolle, à anthères presque sessiles, introrses, biloculaires, longitudinalement déhiscentes. Ovaire libre, tri-pluri-loculaire, à loges 1-2-ovulées; styles distincts, au moins au sommet. Fruit clırnu, oligosperme; graine périspermée.

\section{gexre unique. - PLAQUEhiNiER. DIOSP yros. Lin.}

Fleurs dioïques; calice 4-6-lohé; corolle urcéolée, 4-6-fide; ordinairement 16 étamines parfaites dans les fleurs mîles, 8 avortées dans les fleurs femelles; ovaire à 8-12 loges 1-ovulées. Baie pluriloculaire. - Arbres ì feuilles alternes, simples, non stipulées, à nervation pennée-réticulée et ì bourgeons petits, ovoïdes-aigus, enveloppés de deux écailles latérales libres.

Bois très-dur. Tissu libreux fin cl dominant, à parois épaisses; parenchyme ligneux dessinant dans son intéricur de très-fines et nombreuses lignes circulaires (difficilement aprarentes et ì la loupe seulement). Vaisseaux assez gros, presque uniformément distribués, quoirgu'un peu plus serrés à l'extrême bord interne, 
ipars ou réunis 2-5 en petites lignes simples, rayonnantes. Rayons très-fins.

HPIaqueminier faux-1otier. Drosprnos lotus. Lin.

Feuilles grandes, alternes, courtement pétiolées, simples entières, ovales-oblongues, aiguës à la base et au sommet, vertes et glabres en dessus, blanchâtres et pubescentes en dessous. Fleurs petites, solitaires et axillaires, presque sessiles, d'un pourpre foncé; calice accrescent, à 4 lobes obtus. Baie globuleuse, de la grosseur d'unc cerise, à 8 loges 1 spermes, jaune, couverte d'une légère efflorescence glauque ; sucrée et farle, mais laissant une âpreté prononcée dans la bouche. - Arbre de 15$20^{\mathrm{m}}$, à branches et rameaux élalés-ascendants, ramules droits, effilés. Originaire de l'Asic-Mineure, cultivé et subspontané dans le midi de la France. Flor., mai-juin. Fructif., septembre.

Le plaqueminier est un arbre à végétation lente, à bois lourd, dur, homogène, se colorant en brun ou en noir au cœur' il a une partic des qualités de l'ébène (Diospyros ebemis. Lin.), qui appartient au mème genre. Les fiuits sont d'abord acerbes; ils deviennent mangeables lorsqu'ils sont blossis. Quoique de saveur peu agréable, on avait cru reconnaitre en eux le lotus des anciens; il est prouvé maintenant que ce dernier est le fruit d'un jujubier (zizyphus lolus. Desf.).

\section{FAMILLE XXXI.}

\section{OLÉACÉES. Lind:}

Fleurs régulières, hermaphrodites ou polygames, dont le périgone est quelquefois nul ou simple; calice gamosépale, persistant, à 4 divisions. Corolle hypogyne, à 4 divisions alternes ; 2 étamines alternes, soudées sur la corolle, à anthères introrses, Łiloculaires, longitudinalement déhiscentes; 1 style court. Ovaire biloculaire, à loges biovulées. Graines périspermées. - Arbres et arbrisseaux à feuilles simples ou composées, onposées, non stipulées; offrant souvent à chaque aisselle 2 bourgeons, dont l'inféricur est le plus petit.

Bois de structure variée, suivant les genres.

A. Fruits secs.

B. Samare oblongue. Arbres à fcuilles composées, oppositi-imparipennées, à fleurs polygames, souvent nues.................................... 1

B'. Capsule bivale. Arbrisscaux a feuilles simples el entières; à fleurs hermaphrodites, infundibuliformes. Lıas.... 2 $\Lambda^{\prime}$. Fruits charnus. Feuilles toujours simples.

Croissance.

Bois.

Fruils. 
B. Feuilles caduques nt élamines non saillantes. Baie globuleuse, polysperme................ Trok̀n... 5

$B^{\prime}$. Feuilles persistantes et étamines saillantes.

C. Nuculaine ovoïde, à noyau osseux........... Otrvier... 4

C'. Nuculaine globuleuse, à noyau mince el fragile... Puи.ına . "5

GENRE I, - FRENNE. FRAXINUS. Tourn.

Fleurs polygames, disposées en panicule, à perigone nul, simple ou double et à 4 divisions profondes; samare foliacée, oblongue, 1-loculaire et 1-2-sperme par avortement, provenant d'un ovaire à 2 loges 2-ovulées. - Arbres à feuilles opposées, oppositi-impari-pennées, dont la nervation secondaire est pennée et rameuse; à ramification peu serrée, terminée par des pousses robustes; bourgeons terminaux gros et courts, 4-angulaires, enveloppés extérieurement de 2-4 écailles pétiolacées, souvent soudées.

Bois lourds, durs, souples el très-tenaces, blancs, étroitement et irrégulièrement flambés de brun au cour dans les vieux arbres. Tissu fibreux dominant, à parois épáisses, groupé en longs faisceaux. Vaisseaux inégaux; ceux de la zone interne gros et serrés; ceux de la zone moyenne fins, espacés, épars; ceux du bord externe très-fins, groupés et formant avec du parenchyme ligneux de courtes lignes concentriques, régulières ou en zigzzag. Rayons égaux, fins, serrés, courts, peu hauts.

\. Fleurs nues, en panicules latérales non feuil-

lés à la base; anthères presque sessiles.

B. Bourgeons gros, d'un noir-velouté ..... F. comsun ........

$B^{\prime}$. Bourgeons bruns, moyens.

C. Feuilles étroitement lancéolées, longuement acuminées, à dents écartées, très-étalées...........F., oxyphyıle...... 2

C'. Feuilles ovales ou ovales-lancéolées, dentées en scie.............. F. ^ petites feullzes. 5

A $^{\prime}$. Fleur à périgone double, en panicules terminales feuillées à la base; anthères à filets allongés. Bourgeons bruns...... F. A Fueuns........ 4

$\S$ I. Fleurs nues, ¿ antheres presque sessiles; en panicules latérales sur les rameaux.

1. Frêne commun. Fraxinus exceisior. Lis.

Feuilles de 9-15 folioles oppositi-imparipennées, sessiles, ovales-lancéolérs, atténuées à la base, acuminées au sommet, aigüment dentées, glabres et vertes en dessus, plus pâles et pubescentes auprès de la cóte en dessous. Fleurs en panicules latérales dressées, paraissant avant les feuilles; complétement nues; antlieres d'un pourpre uoiratre. Sa- 
mares pendantes, oblongues, arrondies à la base, tronquées ou échancrées à l'extrémité. - Grand arbre à ramification jeu scrrée, à branches élalées-dressées, à rameaux el ramules dressés; ceux-ci robustes, à gros bourgeons d'un noir velouté.

Var. a. Frène commun à une feuille. F. excelsion, Monoritula.

Feuille représentée par sa foliole terminale seulement, qui est trèsléveloppée. Celle variété se produit quelquefois dans les semis, ainsi qu'une foule d'intermédiaires cntre elle et le type (frênes à 3-5-7 feuilles); elle est souvent cultivée.

Var. B. Frêne commun ausiral. Fraxinus excelsion, austhalis. Gr. et God. F. Australis. Gay.

Feuilles plus étroites que dans le type, oblongues-lancéolées.

Bois de plaines, de collines ou de montagnes peu élevées, particulièrement dans les sols frais et fertiles. La variété $\beta$, appartient à la région méditerranéenne et atteint dans le Djurdjura, en Algérie, une altitude de $2000^{\mathrm{m}}$ (Cosson). Flor., avril-mai. Fructif, septembre. Dissémination, hiver el printemps.

Le frène est un grand arbre qui, dans de bonnes conditions, peut atteindre et dépasser $55^{\mathrm{m}}$ de hauteur sur $5^{\mathrm{m}}$ de circontérence (un frène coupé vers $185 \overline{\text { s }}$, dans la Frise, à Cabaso, mesurait $8^{\mathrm{m}}$ de circonférence), bien que son aptitude à croitre dans des terrains très-divers, mème dans les sols sees, le fasse souvent rester en dessous de ces dimensions. Sa tige est droite, cylindrique, élevée s'il croit en massif ; peu droite et ramifiée à $6-8^{\mathrm{m}} \mathrm{s}^{\prime}$ il est isolé. La cime, peu branchue et à rameaux redressés, est, dans la jeunesse, ovale-pyramidale, souvent ramiliée dans le genre de celle des sapins, par verticilles; plus tard elle s'arrondit. La tige s'y prolonge jusqu'à l'extrêmité.

Le feuillage est léger, le couvert faible.

L'écorce, lisse et d'un gris verdàtre ou jaunàtre d'abord, a le liber non feuilleté, constitué par des faisceaux épars. Ce n'est qu'à un àge assez avancé qu'il se forme dans son intérieur des plaques de périderme, qui donnent naissance à un rhytidome persistant, semblable à celui du chêne, mais plus densément gerẹuré. Les portions extérieures du liber qui le composent se transforment en une sorte de liége granuleux pierreux.

La racine s'enfonce profondément dans la jeunesse et forme une souche considérable, de laquelle partent quelques racines latérales, quelquefois drageonnantes, qui ne tardent pas à prendre le dessus et à se développer beaucoup en longueur et en grosseur. La totalité du bois souterrain équivaut à $14-15$ p. $0 / 0$ du volume entier.

Taille.

Port.

Feuillage.

Ecorce.

Enracinement. 
Fructification. La fructification du frène se produit assez régulièrement chaque année dans les pays de plaine ou de collines, mais dans la montagne, elle devient intermittente; à une annéc très-productive succèdent une ou plusieurs années pendant lesquelles il serait souvent difficile de se procurer une seule semence. Elle a lieu en automne; la dissémination ne se fait habituellement qu'au printemps suivant.

Germination. Récoltée en automne et semée immédiatement, la graine germe quelquefois dès le printemps suivant, mais le plus. souvent au bout de 18 mois; semée au printemps, elle ne germe jamais que l'année d'après. II en faut 1̄̄-15000 par kilogramme et généralement elle est de bonne qualité.

Le jeune plant parait en soulevant hors de terre la samare, dont le périsperme épuisé forme une coiffe qui réunit ses deux cotylédons, comme chez les conifères; puis il produit 2 feuilles cotylédonaires longuement elliptiques-lancéolées, entières. Il s'élève fort peu dans les premières années, et toute l'activité de sa végétation est concentrée sur la racine qui pivote alors profondément. Vers 5 ans il prend son essor ct le frène peut être placé au nombre des essences à bois dur dont la croissance est la plus active et la plus soutenue.

Station el sol. Le frêne vient dans des conditions très-diverses. C'est dans les plaines basses, dans les grandes vallées, dans les vallons à sol frais et fertile qu'on le rencontre le plus communément et qu'il atteint les plus belles dimensions; il y est habituellement le compagnon de l'orme, de l'aune, du chêne pédonculé. Mais on le trouve aussi dans les montagnes, sans qu'il y atteigne cependant l'altitude du hêtre, et dans les sols sees des collines, pourvu qu'ils soient suffisamment meubles. Il ne refuse de croitre que sur les terres. compactes et tenaces.

Bois. Le bois de frène est llane, blanc légèrement rosé, nacré et onetucux au toucher quand il est travaillé, parfois flambé de brun au cœur; ses qualités essentielles sont l'élasticité et la tenacité; aussi est-il très-recherché pour le charronnage (brancards, timons, ete.), pour la fabrication des rames, avirons, cercles de tonneaux, etc. Il se tourmente peu, n'est guère exposé à la vermoulure, reçoit un beau poli et peut servir à la menuiserie. Employé dans les constructions, il a unc durće supérieure à celle du hêtre et du 'harme, néaumoins la pourriture l'atteint encore assez rapidement, surtout s'il est exposé à des alternatives de sécheresse el d'humidité. 
Le frène qui a été émondé forme quelquefois des sortes de broussins dont le bois est très-ronceux; on le recherche pour les ouvrages de tour et on le débite mème en placage pour l'ébénisterie.

La densité du frène, comme celle de tous les bois à vaisscaux fortement inégaux, est très-variable et dépend beaucoup du mode de végétation. Si la croissance est lente, chaque couche est en majeure partie formée de la zone interne des gros vaisseaux et le bois qui en résulte est poreux, mou et léger; si au contraire, elle est active, chaque couche, sans offrir une épaisseur notablement plus grande de cette zone poreuse, présente un développement beaucoup plus considérable de la zone externe, constituée par du tissu fibrcux serré et dominant et des vaisseaux fins; dans ce cas le bois acquiert naturellement beaucoup plus de dureté et de pesanteur. Cependant lorsque cet arbre croit dans un sol trop liumide, malgré la rapidité de sa croissance, le bois qu'il produit perd beaucoup en densité, en tenacité et en souplesse.

Du frène complétement desséché à l'air, originaire de Nancy et provenant d'une lige de $2 \breve{3}$ ans, de croissance moyenne, d'un diamètre de 16 cent. a fourni une densité de 0, 789. (Coll. Ec. For.).

Les recherches de T. II Irtig sur la combustibilité, du frène de 100 ans, d'une densité de 0,69 , comparé à du hètre de 120, d'une densité égale, l'un et l'autre à l'état sce, ont donné les résultats suivants :

\begin{tabular}{|c|c|c|c|}
\hline \multirow{3}{*}{ plus haut degré de chaleur.... } & \multicolumn{3}{|c|}{ Vol. et poids égaux. } \\
\hline & Chalcur & ascendante & $101: 100$ \\
\hline & id. & rayonnante & $86: 100$ \\
\hline Durće de la chaleur croissante. & & ascendante & $107: 100$ \\
\hline & & rayonnante & $100: 100$ \\
\hline Duríe de la chaleur décroissante. & id. & ascendante & $\begin{aligned} 100: 100 \\
60: 100\end{aligned}$ \\
\hline & id. & ascendante & $92: 100$ \\
\hline Total de la chalcur develop & id. & rayonnante & $76: 100$ \\
\hline Eau vaporisée. & & ........ & $83: 100$ \\
\hline
\end{tabular}

Le frène est par conséquent un bon combustible, mais il est bien inférieur au hètre pour le chauffage des appartements à foyers ouverts, puisque sa chaleur rayonnante est peu ćlevée. Il fournit un bon charbon.

La feuille du frène est, après celle de l'orme, l'une de celles qui produisent le meilleur fourrage. Son écoree ne

Produits accessoires. 
contient presque pas de tannin, mais on y trouve une substance cristallisable encore peu connue, la fraxinine, qui est réputée fẻbrifuge.

2. Frêne oxyphylle. Fraxinus oxpphyla. Bieb.

Voisin du précédent avec lequel on le confond souvent; feuilles à folioles souvent moins nombreuses, 7-11, plus étroites, prolongées en coin a la base, plus longuement acuminées, bordées de dents espacées et peu profondes, très-aiguës, très-étalées et même réfléchies vers le sommet dont cliacune correspond à une nervure qui aboutit à son extrémilé (dans le frène commun chaque nervure correspond à 2 dents et aboutil à leur intervalle). Samares lancéolées-linéaires, atténuées aux deux extrémilés, cunéiformes à la base, arrondies ou aiguës ( $F$. Rostrata, Guss.), et souvent mucronées au sommet. - Arbre moilié moins grand que le précédent, à bourgeons moyens et glabres, d'un brun jaunâtre. Commun dans la France méridionale; Algérie. Flor., avril-mai.

Le bois est identique à celui de l'espèce préé́dente; provenant d'une tige de 60 ans et de 52 cent. de diamètre, il pèse, complétement desséché à l'air, 0,86 (Coll. Ec. For. Envoi de II. Royer. Algérie).

3. Frêne à petites feuilles. Fraxinus parvifolid. Lai.

Feuilles à pétiole commun pubescent en dessus, de 7-15 folioles sessiles, petites, ne dépassant pas en général 5-4 centimètres de long, ovales-lancéolées, à base cunéiforme, dentées dans leur moitié supérieure, minces, d'un vert pâle et pubescentes à la base en dessous. Samares étroiles, linéaires-oblongues, non cunéiformes à la base, tronquées ou faiblement échancrées au sommet. - Arbrisseau de 2-5in d'élévation, sans aucune importance forestière, à bourgeons petits, glabres, d'un brun ferrugineux. Littoral des environs de MIontpellicr. Flor., mars-avril. Fructif., juin-juillet (1).

(1) L'Algérie produit deux espèces de frênes qui ne se rencontrent point en France et sur lesquels les renseignements forestiers manquent entièrement.

1. Frêne à fenilles étroites. Fraxinus avgustirolia. Vahl.

Feuilles composées de \$-7 folioles sessiles, longues de 9-10 centimètres sur 2 de large, glabres, lancéolées et lâchement dentées en scie; samares ovales-oblongues, obtuses el mucronées à l'extrémitć. Bourgeons veloutés.

Le frêne à feuilles étroites appartient aux espèces de la première section, dont les fleurs sont nues et les inflorescences en panicules latérales mon feuillés; l'espèce suivante, par ses fleurs à périgone simple, apparlient ì une section intermédiaire entre la première et la deuxième.

Frêne dimorphe. Fraxinus duorrua. Coss. el Dur.

Feuilles variables; celles des rameaux mal venants, petites, composces 
$\S$ II. Fleurs à périgone double, en thyrses terminaux. Filets des étamines allongés.

4. Frêne à fleurs. Fraxinus ornus. Liv. Ornus eqropoca. Pers, F. Florifera, $D C$. Fl, fr.

Feuilles de 7-9 folioles sessiles, ovales ou elliptiques-lancéolées, atlénuées aux deux extrémités, dentées; vertes et glabres en dessus, un peu plus pâles et légèrement pubescentes sur la côte en dessous dans la jeunesse. Fleurs paraissant avec les feuilles, généralement hermaphrodites, à corolle blanche, bien plus longue que le calice, divisée presque jusqu'à la base en 4 lobes étroits, linéaires. Samares longuement oblongues-elliptiques, atténuées à la base, échancrées au sommet. - Arbre de $7-\$^{\mathrm{m}}$, à ramilication bien plus fournie que celle des précédents, à inflorescences terminales dressées, formant des panaches très-élégants, feuillés à la base; dont les bourgeons sont bruns, saupoudrés de gris.

Var. ๔. Frêne à Reurs, argenté. Feuilles blanchâtres-argentées en des sous. $F$, argentea. Loisel.

Cultivé comme arbre d'ornement et souvent subspontané dans la France méridionale. Contribue au peuplement des maquis de la Corse, où se trouve aussi la variété argentée. Flor., mai-juin. Fructif, aoûtseptembre.

Du bois d'une tige de 22 ans, de 11 cent. de diamètre, provenant de Nancy et complétement desséché à l'air, a donné une densité de 0,78 (Coll. Ec. For.).

C'est du frène à fleurs qu'on obtient, dans l'talie méridionale, la substance connue sous le nom de manne.

geNRE II. - LILAS. LILAC. Tourn.

Fleurs hermaphrodites; calice persistant, 4-denté ; corolie tubuleuse, 4 -partite ; capsule presque ligneuse, biloculaire, locu-

de 2-5 paires de folioles sub-orbiculaires ou obovales-oblongues, à dents obtuses, écartées; celles des rameaux supérieurs florifères plus grandes, de 3-5 paires de folioles oblongues-lancéolées, aiguës, dentées en scie. Fleurs hermaphrodites, apétales, mais pourvues d'un calice, brièvement pédicellées, groupées en ombelles simples. Samares oblongues, un peu aiguës, entières et obtuses ou légèrement échancrées au sommet, accompagnées du calice persistant et 4 fois aussi longues que leur pédicelle. Arbre à tigc tantôt buissonnante, tantôt simple et droite, s'élevant à 8$12 \mathrm{~m}$. - Vallons des régions montagneuses de l'Algérie (Bathna, DjebelTougour, Monts-Aurès), à une altilude de 1200-1800". Flor., avrilmai. Fruclif, juin-août. 
licide, dont chaque loge est bi-sperme.-Arbrisscaux à feuilles simples, entières, caduques, dont la nervation secondaire est pennée-rameuse, dont les bourgeons sont gros, aigus, revêtus d'écailles imbriquées presquue herbacées, opposées-croisćes, ct dont les fleurs sont en thyrse terminal. Le bourgeon terminal du lilas avorte généralement et chaque rameau présente ì son sommet 2 gros bourgeons floraux axillaires.

Bois à tissu fibreux serré, à parois épaisses; vaisseaux fins, abondants, devenant très-fins et moins serrés au bord externe, ce qui rend les accroissements bien distincts. Rayous très-fins, très-rapprochés.

Gilas commun. Lilac vulgaris. Lam. Syringa vulgaris. Lin.

Feuilles pétiolées, fermes, lisses el glabres, cordiformes à la base, ovales-orbiculaires, acuminées au sommet. Fleurs odorantes, lilas on blanches, à corolle infundibuliforme, dont les lobes sont concaves. Arbrisseau de 5-5 $\mathrm{g}^{\mathrm{m}}$, rameux dès la base. Originaire d'Orient, mais trèsfréquemment cultivé et subspontané en beaucoup de lieux. Flor., avrilmai. Fructif, septembre.

Le bois du lilas a le grain très-serré et très-homogène; il est blanc, brunâtre clair légèrement veiné au cocur. Provenant d'une tige de 18 ans, de 10 cent. de diamètre, et complétement desséché à l'air, il pèse 0,95 (Coll. Éc.For.). Contrairement à la plupart des bois, il est plus coloré au bord interne qu'au bord externe de chaque couche.

\section{GENRE HI. - TROËNE. LIGUSTRUMI. Tournef.}

Fleurs hermaphrodites; calice très-courtement 1-denté; c0-. rolle infundibuliforme, à limbe 4 -partite; étamines non saillantes; baie à 2 loges 2-4-spermes. - Arbrisseaux à feuillcs simples, entières, caduques, à tleurs en thyrses terminaux et à bourgeons ovö̈des-aigrus, petits, dont les écailles sont imbriquées, opposées-croisées, presque herbacées.

Bois constitué comme celui des lilas.

Troéne commun. Ligustnum yulgane. Lix. Frésillon; Bois noir; laisin de chien.

Feuilles courtement pétiolées, elliptiques-lancéolées, un peu coriaces, parfois persistantes pendant une partie de l'hiver, entieres, verles el glabres sur les deux faces; nervure médiane dominante, les latérales a peine visibles. Fleurs blanches, odorantes. Baie globuleuse, noire, persistante jusqu'au printemps. - Arbrisseau de 2-5'm, à rameanx droits, allongés, flexibles, a ćcorce d'un gris brunatre, un peu verruqueuse. Trèscommun dans les haies et dans les bois, surlout sur les sols sees et pierreux; France, rare en Algérie. Flor., mai-juin. Fructif, septembre. 
Le troëne, en raison de ses dimensions restreintes et de la lenteur de son accroissement, n'a qu'une très-faible importance forestière, quoique son bois ait de bonnes qualités, soit lourd, dur, tenace, élastique. Ce bois est blanc, flambé et veiné de brunâtre au cour. Pris sur une tige de 32 ans, de 5 cent. de diamètre, il pèse, complétement desséché à l'air, 0,92 (Coll. Ec. For.).

On plante fréquemment le troëne dans les jardins et on en fait de jolies haies et bordures, qui restent bien fournies et supportent très-facilement la taille.

Les jeunes pousses servent à la vannerie fine; les baies renferment une matière tinctoriale d'un noir violacé, utiliséc par les chapeliers, gantiers, teinturiers ; les graines peurent produire une huile bonne à brủler.

\section{GENRE IV. - OLIVIER. OLEA. Tournef.}

Calice 4-denté; corolle courtement tubuleuse, à limbe 4-partite; étamines saillantes. Nuculaine ovoïde, ì noyau osseux 1-2sperme. - Arbres à feuilles simples, entières, persistantes, à fleurs en petites grappes axillaires dressées.

Bois extrêmement dur, hornogène, compacte, lourd, dont il est à peu près impossible de distinguer les accroissements. Tissu fibreux à parois épaisses. Vaisseaux assez abondants, égaux, lins, épars ou réunis en petit nombre et formant alors des lignes courtes, simples, rayonnantes; uniformément répartis ou ayant une tendance à se disposer en zones concentriques. Rayons trèsfins, courts.

Divier a'Europe. Olea Europea. Lin.

Fcuilles simples, coriaces, persistantes, ovales-oblongues, allénuées en un court pétiole; pointucs ou mucronées, très-entières et enroulẻes sur les bords; glabres, vertes et ponctuées de blanc en dessus, blanchesécailleuses en dessous; nervure médiane seule apparente. Fleurs blanches; calice en coupe, à 4 dents larges, peu profondes; corolle à 4 lobes arrondis. Nuculaine ovoïde, verte. - Arbre souvent rameux dès la base, inerme ou légèrement épincux, à rameaux d'un blanc grisâtre, feuillagre d'un vert cendré, écorce formant à un cerlain âge un rhylidome jaune brunàtre, rugueux-écailleux, densément crevassé en long et en travers. France méridjonale, où il caraclérise une région très-nalurelle, la région des oliviers; Corse; très-commun en Algéric. Flor., mai. Fruclif, septembre-octobre.

L'olivier est cultivé en France sous un grand nombre de variétés et son indigénat y semble douteux; mais il 
parait étle véritablement spontané en Corse et en Algéric. Taille. II forme le plus souvent un buisson de $\overline{\bar{j}}-7^{\mathrm{m}}$, mais il peut s'élever en arbre de $10-15^{\mathrm{m}}$ d'élévation et de $1-6^{\mathrm{m}}$ de eirCroissance. conférence. Sa végétation est lente; il a le tempérament très-robuste et ne supporte ni le couvert, ni l'état de massif. Il repousse vigoureusement de souche.

Station et sol. Il recherche les sols secs, légers et les expositions chaudes des pays de collines.

Bois. Le bois est l'un des plus compactes et des plus homogènes que l'on connaisse; il est de couleur chamois, jaunâtre ou olivâtre, très-irrégulièrement marbré au cœur de veines fines, nombreuses, entrelacées, d'un brun noirâtre. Il est susceptible d'un très-beau poli, se travaille bien, se tourne encore mieux; on le recherche pour de menus objets d'ébénisterie, pour la marqueterie, tabletterie, sculpture, etc. Du bois d'une tige de 60 ans, de 29 cent. de diamètre, pèse, complétement desséché à l'air, 1,15 (Coll. Ec. For. Algéric; Envoi de M. Royer). C'est un des meilleurs bois de chauffage connus; il produit un charbon de première qualité.

Fruit. L'huile d'olive est extraite du péricarpe; ses qualités et sa valeur rendent l'olivier très-précieux et en font, dans les contrées méridionales, un arbre de grande culture. On peut également obtenir de bonne huile de l'olivier à l'état sauvage, mais en moindre quantité.

\section{gexre v. - PIILARIA. PIIILLYREA. Tournef.}

Fleurs hermaphrodites; calice 4-denté; corolle 4-partite, à tube court et limbe étalé ; étamines saillantes ; drupe globuleuse, ì noyau monosperme (par avortement), pourvue d'une enveloppe mince et fragile. - Arbrisseaux à feuilles simples, coriaces, persistantes, entières ou dentées, dont la nervure médiane est seule bien apparente; à fleurs blanchâtres, odorantes, disposées en grappes courtes axillaires; ì fruits petits, d'un noir bleuître.

Bois bien caractérisé, très-dur, homogène ; blanc, blanc légèrement jaunâtre, irrégulièrement et étroitement flambé et veiné de brunitre ou de brun noirître au côur des pieds îgés. Tissu fibreux très-serré, à parois très-épaisses. Vaisseaux trèsfins, égaux, réunis par du parenchyme et complétement groupés, de manière à produire sur la section transversale des lignes rayonnantes ondulées et rameuses, d'un blanc mat, formant par 
leur ensemble un dessin fincment et régulièrement réticulé, très-nettement accusé. Rayons très-lins, très-serrés. Accroissements difficilement distincts, séparés cependant par des lignes mates très-fines.

A. Feuilles jamais cordiforme à la base. Fruit surmonté par une pointe:

B. Feuilles étroitement elliptiques, entières ou à peine dentées au sommet..... P. \& feullegs Étroites. 1

$B^{\prime}$. Feuilles ovales-lancéolées, entières ou dentẻes . ................. P. intenMédiatre..... 2

$\mathbf{A}^{\prime}$. Feuilles, au moins les inférieures, légèro. ment cordiformes à la base, toujours dentées-épineuses. Fruit non surmonté d'une pointe................ P. dnessé........ כ

1. Philaria à feuilles étroites. Pullurea angustifolia. Lix. Feuilles courtement pétiolées, persistantes, étroitement elliptiqueslancéolées, entières ou avec quelques traces de dentelures vers l'extrémité, glabres, luisantes en dessus, vertes sur les deux faces. Fruits apiculés. - Arbrisseau de 1-2m d'élévation, commun dans la région des oliviers, surtout en Corse, dont il peuple les maquis, en compagnie des chênes yeuses, lentisques, myrthes, arbousiers, etc. Remonte verśs l'Ouest jusqu'aux environs de Nantes; Algéric. Flor., avril-mai. Fruclif., août-septembre:

2. Philaria intermédiaire. Purllynea media. Lin.

Feuilles ovales ou ovales-lancéolées, entières ou dentées; fruit apiculé au sommet. - Arbrisseau voisin du précédeut, dont il n'est peut-être qu'une variété; croît dans les mêmes lieux. Flor., avril mai. Fruclif., aoûl-septembre.

3. Philaria dressé. Puhluyea stricta. Bertol. Philaria à larges feuilles (ce dernier nom se donne souvent par confusion à l'espèce précédente).

Feuilles ovales-lancéolées ou ovales-oblongues, dentées-épineuses; les inférieures légèrement cordiformes à la base. Fruit non apiculé, obtus, ombiliqué. - Arbrisseau et petit arbre de $6 \cdot 8^{\mathrm{m}}$ de hauteur sur $1^{\mathrm{m}}$ à 1 ing0 de circonférence. Corse; Algéric. Flor, avril-mai. Fructif, aoûtseptembre.

Ce philaria, particulièrement commun en Algérie, se plait dans les sols légers et rocailleux des pays de collines ou de montagnes peu élevées. Il croit lentement, vit trèsvieux, repousse bien de souche, produit un bois très-lourd, très-dur, d'un grain serré, qui se travaille bien, prend un heau poli, mais est sujet à se tourmenter. Complétement desséché à l'air, d'un diamètre de $0^{\mathrm{m}} 20$ et âgé d'au moins 60 ans, il pèse 1,02. (Coll. Ec. For. Corse; Envoi de M. Si-

Station el sol.

Bois. 
mon); provenant d'Algérie; d'une tige de 67 ans, de $0^{\text {m }} 19$ de diamètre, il pèse 1,08 (Coll. Ec. For. Envoi de M. Royer).

Il peut servir de menu bois de charronnage et donne un rombustible et un charbon de première qualité.

\section{FAMIILLE XXXII.}

\section{JASHMÉEs. $R$. Brown.}

Celte famille diffère à peine de la précédente; les différences les plus grandes sont : calice et corolle de $5-8$ divisions; loges de l’ovaire généralement uniovulées; graines à peine périspermées; feuilles quelquefois alternes.

\section{GENRE UNQQUE. - JASMIN. JASMINUM. Tournef.}

Calice campanulé, 5-8 dentẻ; corolle à tube allongé, à limbe plan, 5-8-fide; 2 étamines non-saillantes; baic globuleuse, mono-sperme. - Sous-arbrisseaux à feuilles alternes ou opposées, caduques, simples ou composées.

Bois à tissu fibreux dominant; vaisseaux fins et très-fins, isolés, épars, décroissants en grosseur du bord interne au lord externe. Rayons fins.

Jasmin arbrisseau. Jasminum fnuticans. Lin.

Feuilles alternes, 1-5-foliolées, à folioles obovales, obtuses, cunéiformes à la base, entières, glabres et luisantes. Fleurs jaunes, odorantes, disposées 2-4 à l'extrémité des rameaux; calice à longues dents subulées; lobes de la corolle ovales. Baie d'un pourpre noirâtre, de la grosseur d'un pois. - Sous-arbrisseau de $0^{\mathrm{m}} 50$ à $1^{\mathrm{m}}$ el mème $2^{\mathrm{m}}$, à rameaux el ramules allongés, grêles, verls, anguleux et flexibles. France méridionale; remonte le Rhône jusqqu'au delà de Lyon; les côtes de l'Océan jusqu'au delà de Bordeaux; Corse; Algérie. Fréquemmeul cultivé comme plante d'ornement. Flor., mai. Fructif, juin-juillet.

\section{FAMILLE XXXIII.}

APOCYNÉES. Juss.

Fleurs hermaphrodites, régulières ; calice persistant à š divisions; corolle liypogyne, tubuleuse, ì li lobes; 5 étamines alternes, incluses et épipétales, à filets nuls ou très-courts. 2 carpelles libres ou soudés entre eux, multiovulés, produisant 1 ou 2 fruits secs, déhiscents par la suture ventrale (follicules), qui contiennent de nombreuses graines, aigrettées ou non, péri- 
spermécs. - Végétaux vivaces ou ligneux, à feuilles simples, entières, non stipulées, opposées, coriaces et persistantes.

A. Plantes herbacées, rampantes et radicantes; fleurs dépourvues d'écailles à la gorge de la corolle; graines non aigrettées..................... Pervencue. 1

A'. Arbrisseaux à fleurs pourvues d'écailles à la gorge; graines aigreltées.................... Nérion ... 2

AENHE I. - PERVENCHE. VINCA. Lin.

Corolle en coupe, à gorge nue, à š lobes obliquement tronqués; 5 étamines, dont les filets sont coudés à la base; style simple, garni en dessous de son sommet, qui est renflé et poilu, d'un rebord annulaire stigmatifère. Follicules à graines non aigrettées. - Plantes vivaces, à tiges stériles grêles, très-allongées, rampantes et radicantes, à tiges fertiles courtes, dressées; dont les feuilles sont entières, luisantes, toujours vertes, composées l'une nervure médiane dominante et de quelques nervures pennées-rameuses, peu apparentes; formant dans les forêts, dont le sol est frais et couvert, des tapis de verdure d'une grande étendue.

A. Pédoncules plus longs que les feuilles..... P. пвтьте....... 1 $\mathrm{A}^{\prime}$. Pédoncules plas courts que les feuilles.

B. Feuilles pubescentes et ciliées sur les bords; souvent cordiformes à la base... P. A graxdes TLEuns. 2

$\mathrm{B}^{\prime}$. Feuilles complétement glabres, jamais cordiformes à la base.............. P. interméduane... 3

I. Pervenehe petite. Vinca Minor, LiN.

Feuilles opposées, courtement pétiolées, luisantes, coriaces et persistantes, clliptiques et entières. Fleurs solitaires, axillaires, portées sur des pédoncules plus longs que les feuilles; calice à divisions. lancéolées, beaucoup plus courles que le tube de la corolle; celle-ci grande, bleue, rarement violette, rose ou blanche; tiges fleuries hautes de $10-15$ cent. Très-commun dans les bois frais et couveris et dans les haies de toute la France. Flor., mai-juin.

2. Pervenche à grandes fleurs. Vinca masor. Lin.

Feuilles ovales-lancéolćes, souvent légèrement cordiformes à la base, courtement et densément ciliées sur les bords. Fleurs solitaires, axillaires, poríes sur des pédoncules plus courts que les feuilles; calice à divisions linéaires, ciliées, égalant la longueur du tube de la corolle. Plante plus robuste que la précédente, à fleurs et à feuilles plus grandes, dont les tiges fleuries s'élèvent à $50-40$ centimètres. France méridionale, centrale et occidentale. Flor., mars-juin.

3. Hervenche intermédiaire. VINCA MEdia. LiNk el Hoffr. Espèce très-voisine de la précédente ; fcuilles ovales-lancéolées, jamais 
cordiformes a la base, glabres ef point ciliées sur les bords. Divisions du calice linéaires, glabres, plus courtes que le tube de la corolle. Région méditerranéenne en France, en Corse et en Algéric. Flor., avril-mai.

\section{GENRE II. - NÉRION. NERIUM, Lin.}

Corolle en coupe, munie à la gorge de 5 lames multifides opposées aux lobes; étamines non saillantes, dont les anthères sont soudées au stigmate. Style simple, dilaté à son extrémité, à stigmates obtus. Graines aigrettées. - Arbrisseaux à feuilles opposées ou ternées, coriaces, simples, entières, persistantes, composées d'une nervure médiane dominante et de nervures secondaires fines, entières ou quelquefois fourchues, parallèles, très-serrées (־0-70 paires).

Bois. Canal médulaire 3-angulaire; tissu fibreux dominant, à grosses fibres dont les parois sont minces; vaisseaux médiocres, presque égaux, disposés les uns à côté des autres en lignes rayonnantes, simples, assez espacées; rayons égaux, fins, serrés.

Nérion lamrier-rose. Nenum oleander. Lin.

Feuilles étroitement oblongues-lancéolées, opposées ou ternées, altéuućes à la base et à peu près sessiles; entières, coriaces, persistantes, ģlabres et mates, plus pâles et ponctuées en dessous. Fleurs grandes, roses ou blanches, en corymbes terminaux. - Arbrisseau de 5 ou $4^{\mathrm{m}}$, à tige droite, écorce grisittre, rameaux longs, grèles et dressés. Littoral de la Médilerranée dans le Var, en Corse et en Algérie. Flor. juinjuillet.

Station. Thille. Le nérion laurier-rose croît dans les mêmes stations que les saules, au bord des eaux, et peut atteindre $1^{\mathrm{m}}$ de circonférence. Comme eux il se reproduit abondamment de se-menees, de rejets de souche, de boutures, et, par ses racines nombreuses et profondément enfoncées, il contribue puissamment à consolider les rives des cour's d'eau.

Bois. $\quad$ Son bois est blane, léger, tendre, poreux, chargé d'humidité et n'a pas de grands usages; cependant il produit un charbon léger, qui, dans les pays ou cet arbrisseau est abondant (Âlgérie), est très-recherché pour la fabrication de la poudre.

Le nérion fournit un extrait qui est un violent narcotique, ct, dans les régions méridionales, les émanations que ect arbrisseau répand dans l'air peuvent oceasionner de graves aceidents aux persomes qui se reposent sous son ombrage. 


\section{FAMILLE XXXIV.}

SOLANĚUS. JuSS.

Fleurs hermaphrodites, régulières; calice persistant, au moins par la base, généralement à 5 divisions; corolle hypogyne, caduque, 5้-lobée; 5 étamines épipétales, alternes, à anthères intrurses, biloculaires, déhiscentes Jongitudinalement ou par des pores terminaux; style simple. Ovaire libre, à 2 loges multiovulées, à placentation axile, produisant un fruit polysperme charnu, baie, ou sec et déhiscent, capsule. Graines périspermées. -Plantes le plus souvent herbacées, quelquefois ligneuses, mais sans importance forestière; à feuilles alternes, caduques, dont la nervation est pennée; contenant fréquemment des alcaloïdes très-énergiques (Datura, Beliadone, Jusquiame, etc,).

A. Corolle en entonnoir; anthères écartées entre elles, s'ouvrant par des fentes longitudinales.......... Lxciet... 1

A'. Corolle étalée en roue; anthères rapprochées entre elles, s'ouvrant par 2 pores terminaux......... Mlonelle. 2

\section{GENRE 1. - LYCIET. LYCIUM. Lin.}

Calice bilabié ou inégalement 5̆-denté ; corolle en entonnoir ; anthères écartées entre elles, longitudinalement déhiscentes. Baie. - Sous-arbrisseaux souvent épineux par transformation dc rameaux; à rameaux allongés, grêles, flexueux, étalés ou pendants, recouverts d'une écorce d'un blanc grisittre; à feuilles simples, entières, caduques, alternes, souvent fasciculées, subuninerviées ou à nervures secondaires pennées, rares, peu apparentes.

Bois à tissu fibreux dominant; vaisseaux fins, rapprochés en une zone étroite au bord interne; très-fins et groupés avec du parenchyme en lignes peu nombreuses, disposées en zigzags obliques ou rayonnants dans la zone médiane et externe. Rayons fins, égaux.

Espèces de la France méridionale, peu stables dans leurs caractères et sur lesquelles les auteurs ne sont pas d'accord. Les suivantes sont celles de la Flore de France de MII. Grenier et Godron.

A. Calice bilabié; tube de la corolle égal au limbe; élamines saillantes...... L, de Barrarie........ 1

$\Lambda^{\prime}$. Calice à $\breve{b}$ dents inćgales. 
B. Tube de la corolle égal au limbe; élamines saillantes........... L. de Curne......... 2

$B^{\prime}$. Tube de la corolle $1-6$ fois aussi long que le limbe.

C. Tube une fois aussi long que le limbe; étamines saillantes...... L. de ha Méditerranée. 5

$C^{\prime}$. Tube 6 fois aussi long que le limbe; étamines incluses........

L. D'Afrique ........4

1. Kyeiet de Barbarie. Lycium Barbanum. Lin. Jasminoïde.

Feuilles vertes, planes, étroitement lancéolées et atlénuées en un court pétiole. Fleur's dressées, solitaires ou fasciculées à l'aisselle des feuilles, pédonculées; calice bilabié; corolle d'un violet clair, à lobes finalement réfléchis, aussi longs que le tube. Baie oblongue, rouge. Suns-arbrisseau de 1 à $2^{m}$, touffu, épineux, à rameaux allongés, grêles, flexueux, pendants, légèrement anguleux. Commun dans les haies et les broussailles du midi de la France; disséminé ęà et là dans le centre et dans le nord; Algérie. Fréquemment cultivé en haies ou pour garnir les. rochers, berceaux, palissades. Flor., juin, Fructif., septembre-octobre.

2. Lyeiet de Chine. Lrcium sinense. Lam.

Voisin du précédent; feuilles plus påles, un peu glauques en dessous, assez largement ovales et assez brusquement rétrécies en pétiole; calice à 3 dents inégales; corolle violette, veinéc. Plus rare et dans les mêmes régions. Flor., juin-octobre.

3. Cyeiet de Ia Méditeranée. Lycium mentennaneun. Dunat. Feuilles d'un vert grisâtre, légèrement charnues, obovales-oblongues, insensiblement rétrécies à la base en un court pétiole, uninerviées. Fleurs dressées, disposées 1-5a à l'aisselle des feuilles; calice à bै dents inégales; corolle blanche ou purpurine, à lobes finalement réfléchis, une fois plas courts que le tube. Baie globuleuse, de la grosseur d'un pois, rouge ou oraugée. - Sous-arbrisseau de $1-2^{\mathrm{m}}$, à tiges dressées, fermes, trèsrameuses, armées d'épines robustes; rameaux blanchàtres, étalés, non pendants. Littoral de la Méditerranée; France et Ilgérie. Flor., mai-juin.

\section{Dyciet d'arique. Lycium Afrum. Lin.}

Feuilles étroiles et linéaires, insensiblement rétrécies en un court pétiole, un peu charnues, uninerviées et canalieulées en dessus. Fleurs penchées, solitaires; ealice à 5 dents; corolle d'un pourpre livide, à lubes étalés non réfléchis, 6 fois plus courts que le tube. Baie globuleuse, jaune, de la grosseur d'une cerise. - Sous-arbrisseau de 1-2m, à tige lloite, rameuse, assez longuement épineuse; à rameaux grisâtres, élalés, non pcudants. Ilaies à Perpignan; Algérie. Flor., mai-juin.

GENRE II. - MORELLE. SOLANUM. Lin.

Calice it \$ divisions; corolle rotacée; anthères conniventes atu centre de la flemr, s'ouvrant par 2 pores terminaux. Baie. Vergetaux le plus souvent herbacés, dont une seule espèce indi- 
gène est lignneuse. C'est à ce genre qu'appartient la pomme de terre (Solanum tuberosum. Lin).

Horelle douce-amère. Solanum dulcamara. Lin.

Feuilles alternes, caduques, pétiolées, cordiformes, ovales-aiguës, entières ou comme trifoliolées par le développement de deux lobes accessoires à la base. Fleurs violettes, en cymes divariquées, longuement pédonculées, paraissant presque opposées aux feuilles; lobes de la corolle réfléchis. Baie presque globuleuse, rouge. - Sous-arbrisseau de 1-2m, dont les tiges sont allongées, grèles, rampantes, sarmenteuses ou mème volubiles, à gauche ou à droite indifféremment. Bois humides et hords des eaux; France et Algérie. Flor., juin-août.

Ce petit sous-arbrisseau est remarquable par l'amertume prononcée et peu durable de son écorce, par la saveur sucrée et persistante de son bois.

\section{FAMILLE XXXV.}

VERBENACÉES. JUSS.

Fleurs hermaphrodites, irrégulières (espèces indigènes); calice de 4-5 divisions, persistant; corol!e hypogyne, tubuleuse, presque labiée, à ๖̊ divisions; étamines épipétales, didynames, à anthères biloculaires, longitudinalement déhiscentes. Ovaire 2-4loculaire, à loges 1-2-ovulées. Style simple terminal. Graines non périspermées. - Végétaux herbacés ou ligneux, à feuilles opposées.

GeNRE unique, - GATILIER. VITEX. Lin.

Calice 5'-denté; corolle presque bilabiée; la lèvre supérieure à 2 lobes, l'inférieure à 3 , dont le médian est le plus développé; 4 étamines didynames, saillantes. Fruit presque charnu, nuculaine, contenant un noyau à 4 loges monospermes.

Bois à vaisseaux inégaux, assez gros et rapprochés au bord interne, où ils forment une zone étroite bien limitée ; fins, isolés, uniformément répartis dans la région médiane et externe. Rayons minces et serrés.

Gatilier agneau-chaste. Vitex agive-castus. Lis. Arbre au poivre.

Feuilles opposées, caduques, composées de $\ddot{\xi}$, rarement de $\mathbf{5}-\mathbf{7}$ folioles palmées, lancéolées, aiguës, presqute toujours entièrcs, glabres et d'un vert sombre en dessus, couvertes en dessous d'un tomentum presque ras et blanchâtre, qui s'éteud sur les pétioles, pédicelles, calices et 
jeunes pousses. Fleurs pelites, en grappes globuleuses, opposées, simulant des verticilles à l'aisselle des feuilles supérieures réduites à une seule foliole, et formant dans leur ensemble de longs épis terminanx dressés, interrompus; corolle bleue, violetle ou blanche. Fruit globuleux, petit, de 5-4́ mill. de diamètre, à péricarpe noir-rougeàtre, très-mince el à peine charnu, contenant un noyau 4 -sillonné. - Arbuste de 1-2m, sur 0ing0 de circonférence, à tige droite et simple, recouverte d'un rhytidome sris-jaunâtre, épais, longuement gerçuré; produisant à son sommet beaucoup de rameaux faibles, pliants, blauchàtres, tétragones; exhalant par toutes ses parties, et particulièrement par ses fruits, une odeur qui rappelle celle du poivre, sans en avoir cependant toute la force. Lieux humides du littoral de la Méditerranće; France, Algérie. Flor., juin-juillet.

Le bois du gatilier est gris brun, lourd, dur et formé d'accroissements très-minces. Celui d'une tigge de 50 ans, de 16 cent. de diamètre, des environs de Port-Vendres, pèse, complétement desséché à l'air, 1,28 (Coll.Ec. For.).

\section{CLASSE III.}

APÉTALES.

Fleurs à périgone simple, quelquefois nul.

\section{ORDRE V.}

ARÉTALES NON AMENTACÉES.

Fleurs hermaphtrodites ou unisesuées, à périgone pétaloïde ou sépaloïle; nun disposées en chatons. 


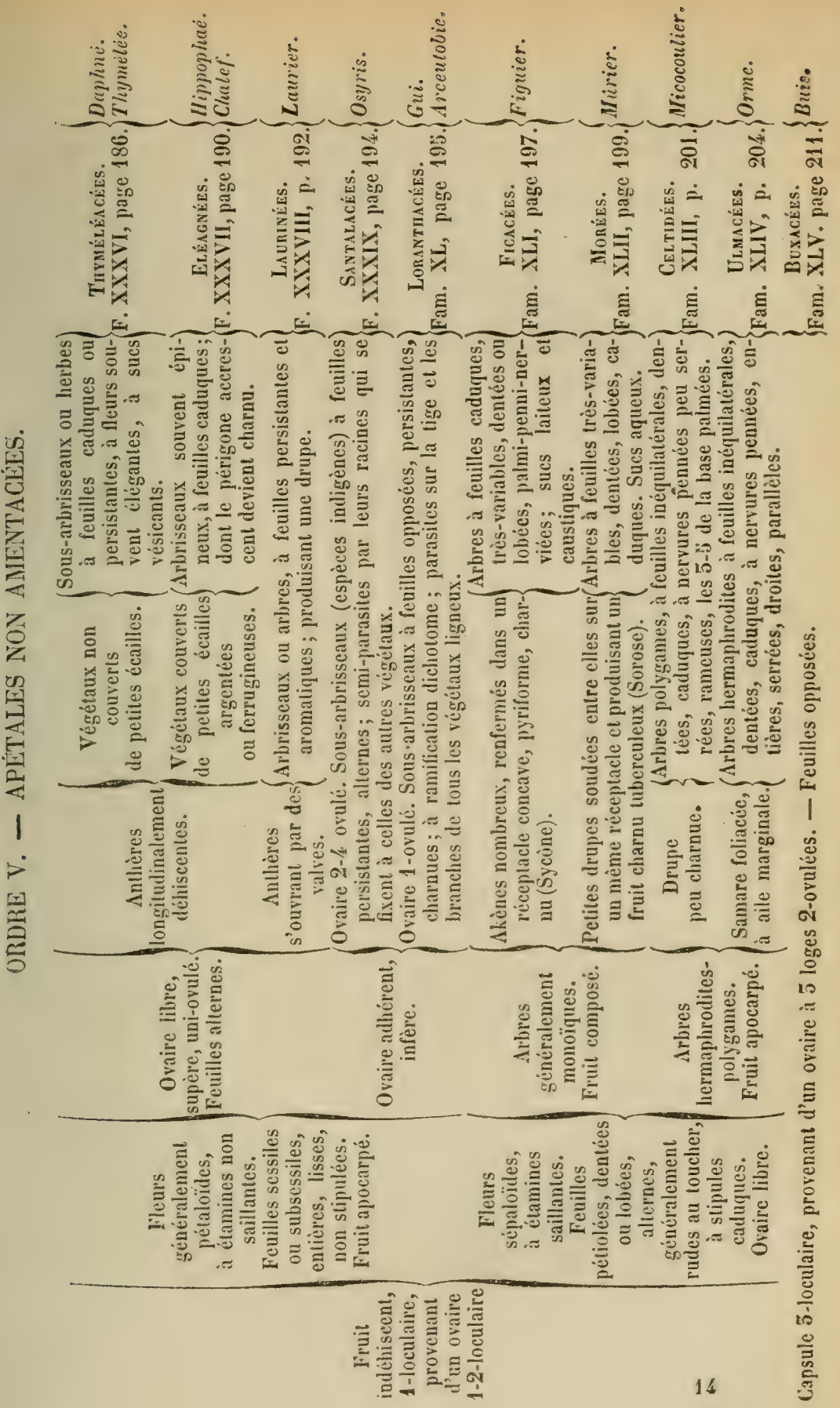




\section{FAMILLE XXXVI.}

TrYuélíacécs. Adans.

Fleurs hermaphrodites, plus rarement uniséxuées, à périgone régulier, tubuleux, 4-5゙-fide, le plus souvent pétaloïde; étamines 8-10, les externes alternes avec les divisions, les internes opposées, insérées sur le périgone; à anthères introrses, biloculaires, longitudinalement déliscentes. Ovaire libre, 1-loculaire, 1-ovulé; style simple ou nul; fruil indéhiscent, sec on charnu; graine habituellement non périspermée. - Sous-arbrisseaux ou lierbes dont les feuilles sont simples, très-entières, non stipulées, éparses, à nervation formée d'une nervure médiane dominante et de nervures pennées fines, fréquemment cachées par le parenchyme; dont les fleurs sont souvent élégantes, odorantes; les hourgeons revêtus d'écailles nombrcuses, imbriquées et spiralées. Le-liber en est fibreux, très-tenace, feuilleté, et ils contiennent dans l'écorce, les feuilles et les fruits, quand ils sont charnus, des sucs très-vésicants (garou).

Bois identiques dans toute la famille. Vaisseaux égaux, trèspetits, associés ì du parenchyme ligneux et formant avec lui des lignes composées rayonnantes, dendritigucs, blanchittres, qui produisent un dessin réticulé. Rayons fins. Ecorce interne et moelle vertes.

A. Drupe ; pẻrigone caduc.................. DapHNÉ... 1 $\Lambda^{\prime}$. Akène, entouré du périgone persistant.......... TirméLée . 2

\section{geñe I. - DAPIINÉ. DAPIINE. Lin.}

Fleurs hermaphrodites; périgone caduc, infundibuliforme, 4-fide; étamines 8, en 2 verticilles; style presque nul ; drupe charnue ou presque sèche, à noyau crustacé. - Sous-arbrisscaux ou arbustes à bourgeons écailleux, à fleurs généralement tièsodorantes.

A. Feuilles herbacées, caduques.

B. Fleurs latérales, paraissant avant les feuilles, rouges, très-rarement blanchátres........ D. BOIS-GENTIL. 1

B'. Fleurs terminales, en faisceaux, blanches.... D. Des ALPES.. 2

$A^{\prime}$. Feuilles coriaces, annuelles ou persistantes.

B. Feuilles annuelles; fleurs blanches, en grappes composées terminales............... D. canou..... 3 $\mathrm{B}^{\prime}$. Feuilles persistantes.

C. Fleurs terminales, en faisccaux. 
D. Feuilles obovales, épaisses, à nervures peu ou point distincles; pubescentes-soyeuses dans la jeunesse. Fleurs blanches.. D. ockioïns.... \&

b'. Feuilles linéaires-oblongues ou linéairesobovales, à nervure médiane distincte; toujours glabres.

E. Tube du périgone et ovaire pubescents ; fleurs roses............ D. CAMÉLÉE.... כ̈

$\mathrm{E}^{\prime}$. Tube du périgone et ovaire glabres; fleurs roses............... D. strié.....6 6

$\mathrm{C}^{\prime}$. Fleurs en petils faisceaux latéraux, d'un jaune verdâtre ............... D, LAưnćoLe...7 Garou.

1. Đaphané bois - gentil. Dapune mezereum. Lin. Joli-bois;

Feuilles minces et molles, alternes, caduques, oblongues-lancéolées, atténuées à la base et subsessiles; glaurues en dessous, glabres dans Icur enlier développement, formant, dans l'origine, des roselles al sommel des rameaux. Fleurs très-précoces, d'un rose rouge, très-rarement blanchâtres, sessiles, disposées 2-4x en petit faisceaux latéraux non feuillés, écailleux à la base; périgone velu. Drupe ovoïle, rouge. - Pelit arbuste peu rameux, s'élevant à 5-10 décimètres au plus à l'état sauvage; alteignant $2-5^{\mathrm{m}}$ par la culture dans les jardins; à rameaux dressés, grisâtres, souples et très-tenaces; bourgeons étalés-dressés. Drupes très-vénéneuses. Commun dans les bois couverts, accidentés ou montagneux de presque toute la France. Flor., février-mars. Fruclif., juinjuillet.

\section{Baplnué des Alpes. Dapnne Alpina. Liv.}

Feuilles molles, caduques, oblongues-lancéolées, alténuées à la base, subsessiles, d'abord velues-soyeuses, puis glabres; d'un vert pâle en dessous; éparses, disposées en roselles à l'extrémité des rameaux et naissant avant les fleurs. Fleurs blanches, subsessiles, disposées $4-8 \mathrm{cn}$ faisceaux terminaux; périgone velu, à segments étroits, allongés, acuminés. Drupe rouge. - Pelit arbuste très-rameux et touffu, haut de $0 \mathrm{~m} 50-1 \mathrm{~m}$, a tige noueuse, blanc grisâtre, et à rameaux ascendants, puhescents à l'extrémité. Lieux pierreux et rocheux des monłagnes: Alpes, Pyrénćes, Cévennes, Auvergne, Côle-d'Or. Flor., mai-juin.

3. Daphné garou. Dapine gnidium. Lin. Sain-bois.

Feuilles subcoriaces et persistantes pendant une année, étroites-lancćolées, très-pointıes; glabres, vertes et luisantes, plus pâles en dessous; éparses, serrées et garnissant les rameaux sur loute leur longucur. Flcurs petites, blanches, disposées en grapne ramense multiflore terminale, dont les axes et les pédicelles sont blanes-tomenteux; périgone velu, à divisions ovales-aiguës. Drupe rouge. - Sous-arbrisseau de 1$2^{\mathrm{m}} \mathrm{et}$ plus, à tige dressée, rameuse, à rameaux longuement fenillès, cylindriques, recouveris d'une écorce brune et lisse. Lieux arides et montueux de la région médilerranéenne; se retrouve dans la Gironde; très-commun en Algérie. Flor., juillet-septembre.

4. Daphué olcoine. Daphe oleoïdes. Schineb.

Fcuilles épaisses et coriaces, persistantes, sans nervures apparentes, 
nbovales-aiguës, subsessiles, d'un vert pàle sur les deux faces, luisantes. en dessus, d'abord pubescentes-soyeuses, au moins en dessous, finalement glabres; formant les roselles à l'extrémité des rameaux. Fleurs sessiles, disposées $\mathbf{5} \cdot \mathbf{6}$ en faisceaux terminaux, dépourvues de bractées; périgone velu, à divisions lancíolées-aiguës, égales au tube ou plus courles. Drupe ovoïde, rouge. Montagnes de la Corse, dans les pâturages et les clairières des forêts. Flor, juin-juillet.

5. Daphué caméléc. Dapune creoruar. Lin.

Feuilles coriaces, persistantes, linéaires-oblongues ou obovales-oblongues, obtuses ou légèrement échincrées, faiblement mucronées, sessiles; glabres, vertes et luisantes, plus pâles en lessous, paraissant 1-nerviées ; fleurs d'un rose vif, subsessiles, très-odorantes, disposées en faisceaux terminaux de 6-10 et accompagnćes de bractées foliacées; à tube étroit, allongé, pubescent, 2.5 fois aussi lonğ que les divisions du limbe, qui sont ovales. Drupe jaunâtre, puis brunâtre. - Pctic sous-arbrisseau à tiges grêles, filiformes, rameuses, longuement étalées, s'élevant au plus i $0^{\mathrm{m}} 30$, recouverles d'une écorce rousse ou brunc. Disséminé sur différents points de la France, sur les sols picrreux, siliccux ou calcaires : Lorraine, Cùte-d'Or, Jura, Alp̣es; centre el ouest de la France; Nîmes, Pyrénées. Flor, juin-juillet.

\section{Baphué strié. Dapine striata. Tratt.}

Très-voisin du précédent, dont il se distingue par ses feuilles plus étroites, plus allongées et moins coriaces; par ses fleurs à tube glabre et strié, accompagnées de bractées colorées, cadurues. - T'rès-petil sous-arbrissean à liges couchées, rameuses; à rameaux grềles et bruns. Alpes. Flor., juillet.

8. Daphué Lauréole. Dapune Laureola. Liv.

Feuilles coriaces et persistautes, oblongues-lancéolées, alténuces à la hase, sulsessiles, tris-glabres et luisantes, plus pâles en dessous. Fleurs d'un jaune verdâtre, peu odorantes, courtement pédicellées, disposées $\mathbf{b}-10$ en petiles grappes axillaires latérales, pendantes, pourvues de bractées herbacées; périgone glabre. Drupe noire à la malurité. - Sous arbris-

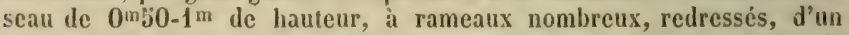
gris jaunatre, tres-souples. Bois montagneux, surtout sur les sols calcaires. Flor., Février-avril. Fructif., juin-juillet.

Ce Daphué est recherché des horticulteurs pour grefler les daphnés exotiques à feuilles persistantes que l'on cultive pour la beauté de leur's fleurs.

GENIE H, - TIYMLLEE. TII YUELAEA. Tournef.

lileurs polygames; périgone marcescent, infundibuliforme, -linle; élumines 8, en 2 verticilles; style court; akene i parois Jinnenses, renferme dans le cillice persistant. - Tres-pelits sousarbriscalux ì feuilles pelites, serrés, presque imbriques, sonvent iprasses et rhamues; ì flems sessiles, axillaires, petiles 
ct peu apparentes; appartenant à la France méridionale et sans aucune importance.

A. Feuilles planes, à nervure médiane, au moins, saillante.

B. Feuilles herbacées, spatulées-linéaires, trèsglabres.................... T. drö̈one..... !

B' $^{\prime}$. Feuilles coriaces.

C. Feuilles ovales-lancéolées, aiguës, glabres ou très-légèrement poilues........... T. comun...... 2

$C^{\prime}$. Feuilles obovales, obtuses, recouvertes d'un duvet épais, soyeux-argenté......... T. tarton-raire. 5

$A^{\prime}$. Feuilles concaves en dessus, convexes en tessous, épaisses, sans nervures saillantes.

B. Feuilles linéaires (1 cent. de long).

C. Feuilles glabres ou simplement ciliées aux bords.................... T. A CALICE.... \&

C'. Feuilles recouvertes d'un duvel gris cendré. T. тіnctorial. . . ๖

B'. Feuilles ovales ( $4-6$ mill. de long), glabres, ou blanches-lomenteuses, au moins dans la jeunesse .................. T. cotonneux...6

1. Firgmélée dioique. Thymedea doïca. Alt.

Feuilles nombreuses, linéaires-spatulées ( $̋-10$ mill. de long.), planes, licrbacées, glabres, d'un vert clair en dessus, un peu glauques en dessous, à nervure médianc saillante. Fleurs jaunâtres, solitaires ou cn pelits faisceaux axillaires, bractéolées à la base; périgone glabre, du double aussi long que le fruit, qui est pubescent. - Sous-arbrisseau glatbre, rameux, torlu, élalé, de 50 cent. au plus de hauteur, à écorce grise, subéreuse; rameaux feuillés au sommet seulement. Régions élevées des Pyrénées, des Corbières et des Alpes du Var. Flor., mai-juin.

2. Thymélée commun. Tirmeles saxamexos. All. Daplene lhymolcea. Lin. Passerina thymelcea. DC.

Feuilles ovales lancéolées, aiguës (12-20 mill. de long.), planes, un peu coriaces et charnues, à nervures saillantes; luisantes, glabres, quel(que. fois légèrement poilues, d'un vert glauque. Fleurs d'un jaune verdâtre, axillaires; les inférieures solitaires, beaucoup plus courtes que les fcuilles; les supéricures égalant presque les feuilles, en faisceaux de 2-b; dépourvues de bractées. Fruit de moitić plus court que le périgone. - Sous-arbrisscau glabre, de $0 \mathrm{~m} 50$ de hauteur, à tige ligneuse el rameuse inférieurement, émellant des rameaux annuels dressés, simples. feuillés dans toute leur longueur. Départements mérliterranéens. Flor., juin-juillet.

3. Thymélée tarton-raire. THYmelea ranton-ratra. Ale. Daphne tarton-raira. Lin. Gros retombet; Tritanelle Malherbe.

Feuilles obovales ou obovales-oblongues (de 10-20 mill. de long.), obluses, planes, épaisses cl coriaces, à nervures distincles, couverles sur les deux faces d'un épais duvet soyeux-argenté. Fleurs très-pelites, nombreuses, axillaires, bractéolées; périgone soyeux extérieurement, 
glabre et jaune intéricurement. - Sous-arbrisseau de 50 cent. all plus de hauteur, entièrement blanchâtre-soycux, à rameaux étalés-ascendauts, feuillés à leur extrémité, tomenteux dans la jeunesse. Bords de la Méditerranée en Provence, en Corse et en Algérie. Flor., avril-mai.

4. Thymélée à calice. Thumela calycina. Lareyr.

Feuilles linéaires (1 cent. de long.), alténuées-aiguës à l'extrémité, épaisses, concaves en dessus, convexes en dessous, sans nervures saillantes, glabres et plus ou moins ciliées sur les bords. Fleurs d'un jaune verdàtre, solitaires et axillaires, bi-bractéolécs. Périgone court, à la fin ovoïde-urcéolé, pubescent, dépassant à peine le fruit, qui est légèrement pubescent. - Sous-arbrisseau de 10-20 cent., à tiges couchées à la base, rameaux peu nombreux, étalés, pubescents à l'extrémité, feuillés dans presque toute leur longueur. Iautes-Pyrénées. Flor., juin-septembre.

5. Thymélée tinctorial. Tuymeles tinctoria. Pourr.

Trés-voisin du T. à calice, dont il se distingue par les feuilles et les rameaux cotverts d'un duvet gris cendré et par ces derniers dressís et feuillés aux extrémités seulement. Gard. Flor., mars-avril.

6. Thymélée cotonneux. Thymelea miruta. Lix.

Feuilles ovales, ovales-oblongues ou arrondies ( $4-6$ mill. de long.), obtuses, épaisses, concaves en dessus, convexes en dessous, sans nervures saillantes; d'un vert foncé et glabres, ou blanches-tomenteuses dans Ia jeunesse. Fleurs trés-petites, disposées $2-3$ aux aisselles des feuilles supérieures, saus bractées. - Sous-arbrisseau de $0 \mathrm{~m} 50-1 \mathrm{~m}$, à lige trèsrameuse, à rameaux grêles, mous, étalés, diffus, blanes-tomenteux el fenillés dans toute leur longucur. Lieux sablonneux ou rocailleux des bords de la Méditerrance en France, en Corse et en Algérie. Flor., octobre-avril.

\section{FAMILLE XXXVII.}

\section{élégNées. R. Brozun.}

Fleurs hermaphrodites ou unisexućes; périgone de 2-4 divisions, généralement urcéolé. 4-8 étamines, en nombre égal et alternes, ou double, alternes et opposées, it filets presque nuls, insérées à la gorge du tube périgonal; antlères biloculaires, longitudinalement déhiscentes. Ovaire libre, 1-loculaire, 1-ovule; ; style simple, allongé. Akène drupacé, dont la portion charnue est formée par le périgone accrescent; graines périspermécs. - Arbrisscaux et petits arbres, fréquemment épineux par Irinsformation de rameanx, à hourgeons écailleux, souvent multiples ì charyue aisselle, it feuilles simples, alternes, entières, non stipulées, uninerviées ou à peine penninerviées, recouvertes, ainsi que les jeunes pousses et les fleurs, d'écailles caractéristiques inppliquées, argentées ou ferrugineuses.

Bhis brun jaunitre, lrun marron, à aubier blanc ou blane 
jaunître, peu lourd, pou dur. Vaisseaux inégaux, isolés ou à peine groupés; ceux du hord interne assez gros, nombreux, associés à du parenchyme ligneux, formant une zone de tissu mou; décroissants jusqu'au bord externe où ils sont petits, rares, sans parenchyme, irrégulièrement épars ou disposés entre eux de manière à ébaucher des zones circulaires concentriques. Rayons fins. Accroissements très-distincts.

A. Fleurs à périgone bifide ou biséqué, diö̈ques...... IIıpropisá.. 1 $\mathbf{A}^{\prime}$. Fleurs à périgone de 4 divisions, hermaphroditespolygames ........................ Cualrz.... 2

GENRE 1. - HIPPOPHAÉ. HIPPOPHAE. Lin.

Dioïque; fleurs mâles à périgone biséqué, disposées en petits ępis axillaires; 4 étamines; fleurs femelles solitaires, axillaires, à périgone tubuleux, limbe dressé, bifide; les unes et les autres subsessiles. - Arbrisseaux épineux, à feuilles très-entières, íparses, rapprochées.

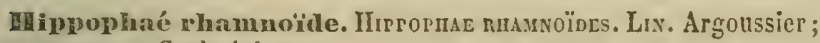
Faux-nerprun; Saule épineux.

Feuilles caduques, presque sessiles, étroitement oblongues-lancéolées, obtuses, fermes, 1-nerviées, d'un vert sombre en dessus, en dessous d'un gris argenté écailleux, parsemées d'écailles ferrugineuses qui recouvrent aussi les jeunes pousses. Fleurs jaune verdatre, naissant à l'aisselle des feuilles inférieures des rameaux de l'année et représentant, par leur développement précoce, alors que les pousses, sur lesquelles elles sont situées, ne sont point encore allongées, une sorte d'épi feuillé à son sommet. Fruit de la grosseur d'un pois, ovoïde, d'un jaune orangé, acidulé. - $\mathrm{\Lambda rbrisseau} \mathrm{de} 2-^{\mathrm{m}}$, très-rameux, épineux, souvent tortu; à rameaux étalés; ramules densément feuillés; bourgeons ferrugineux, globuleux ou obovoïles et lobés; écorce d'un brun foncé, lisse et luisante sur les rameaux et les jeunes tiges, formant plus tard un rhytidome gerçuré, écailleux-fibreux, assez épais. Commun au bord des eaux dans les vallées des Alpes; descend tout le long de leur cours jusqu'à la Mléditerranée et le long du Rhin jusqu'au delà de Strasbourg ; se retrouve à Dunkerque. Flor, avril-mai, Fructif., septembre.

Cet arbrisseau, qui rappelle beaucoup certains saules, le saule drapé entre autres, par son feuillage et ses exigences, produit de très-longues racines traçantes, abondamment drageonnantes, et devient très-précieux pour fixer les attérissements des cour's d'eau et les rives mobiles des torrents. Sa ramification serréc, ses épines nombreuses, vulnérantes, le font aussi rechercher pour haies de clôture. Le bois est brun jaunàtie, moyennement lourd et dur.

Usages.

Bois, 
Apres la coupe, il pèse 0,76 ; complétement desséché à l'air, 0,53. Il produit beaucoup de polasse par sa combustion (T. Hartig).

On cultive quelyuefois l'hippophać dans les jardins ì cause de l'effet agréable de son feuillage qui est discolore et argenté en dessous; il devient, dans ce cas, un petit arbre irrégulier de $4-5^{\mathrm{m}}$ de hauteur.

Les fruits peuvent ètre mangés sans inconvénients.

GENRE II. - CHALEF. ELAEAGNS. Lin,

Fleurs hermaphrodites-polygames; périgone campanulé, à 4 divisions; 4 étamines insérées à leur base, alternes. - Arbres de petite taille, peu ou point épineux.

Chalef à feuilles étroites. Eleagnus axgustifolia. Lix. Olivier de Bohême; Olivelier.

Feuilles non persistantes, courtement pétiolées, alternes, lancéoléesoblongues, un peu aiguës, d'un vert grisâtre en dessus, écailleuses, blanches-argentées en dessous, ainsi que les pétioles et les jeunes pousses; peu distinctement peuninerviées. Fleurs solitaires ou en petits faisceaux de 2-3 à l'aisselle des feuilles des pousses latérales de l'année, pédicellées, argentées en dehors, jaunes en dedans, d'une odeur suave. Fruit elliptique, de la taille d'une petite olive, jaunatre on rougeâtre, de saveur douceàtre el à graine oléagineuse. - Pelit arbre de 7-10 $\mathrm{m}$ de hautenr ou arbrisseau, à tige peu droite, rameuse, revêtue d'une écorce fonguement gereuríe, fibro-écailleuse, d'un brun foncé; cime irrégulière el vagute; racines traçantes, drageonnantes. Provence, où il n'est pas certain ru’il soit spontané; fréquemment planté dans les jardins. Flor., mai-juin, Fructif, août-septembre.

Le bois du chalef est poreux, brun plus ou moins foncé, à aubicr blanc jaunâtre ; il est cassant, sans résistance.

\section{FAMILLE XXXVIII.}

\section{JAURINEES. DC.}

Fleurs hermaplirorlites ou unisexuées par avortement; i périgone pétalö̈de, régulier, dont le limbe, presque nul ou 46-fide, a les divisions alterncs sur deux rangs ; étamines insérées sur un disque adhérent au périgone, en nombre égal à celui des divisions de ce dernier ou multiple; anthères introrses ou introrses et extrorses dans une même fleur; ì 2 loges, ou ì 4 loges superposées 2 ì 2 , s'ouvrant de bas en haut par des valves. Ovaire libre, uni-loculaire, uni-ovulé; style simple. Drupe; graine non périspermée. 
gexre uniQue, - LAURIER. LAURUS. Toumef.

Fleurs diö̈ques, pourvues d'un involucre; périgone à 4 divisions; fleurs mâles terminales, offrant 8-12 étamines, dont les intérieures, au moins, ont les filets bi-glanduleus ; fleurs femelles latérales, pourvues de 2-4. étamines stériles et d'un ovaire libre, uniloculaire, uniorulé. Drupe globuleuse. - Arbres ou arbrisseaux à feuilles alternes, simples, entières, non stipulées, persistantes et aromatiques, dont la nervation est pennée-réticulée; ì fleurs blanchâtres, en inflorescences axillaires et à bourgeons écailleux, parfois disposés par deux à chaque aisselle, le supérieur dominant.

Bois à vaisseaux égaux, assez petits, isolés ou réunis 9-4, entourés de parencliyme ligneux et uniformément répartis. Rayons minces, peu longs, peu hauts.

Eaurier commun. Launus nobitis. Lis. Laurier-sauce; Laurier d'Apollon; Laurier franc.

Feuilles fermes, coriaces, persistantes, courtement pétiolées, lancéolées-oblongues, aiguës ou obtuses, entières, glabres, vertes et brillantes en dessus, d'un vert pâle et très-finement glanduleuses en dessous. Fleurs pédicellées, disposées $4-6$ en pelites ombelles pédonculées, solitaires, géminćes ou teruées à l'aisselle des feuilles. Drupe de la grosseur d'une cerise, globuleuse, noire, dont l'endocarpe est membraneux el ne forme pas de noyau. - Arbrisseau ou arbre toujours vert, à tige daite, à rameaux, ramules et feuilles redressés. Région méditerranéenne; France, Corse et Algérie; remonte vers l'ouest jusqu’i Cherbourg. Flor., mars-avril. Fruclif., octobre-novembre.

Arbrisseau dans le midi de la France, le laurier devient un arbre de $8-10^{\mathrm{mi}}$ d'élévation sur $1^{\mathrm{m}}-1^{\mathrm{m}} 80$ de circonférence, dans les contrées plus chaudes (Corse, Italic, Algérie). Ses rameaux redressés forment une cime allongée, aiguë, rappelant quelque peu celle du peuplier pyramidal.

L'écorce est très-minee, brune, très-finement verruqueuse ou presque lisse à la surface.

Les racines sont traçantes et drageonnantes.

Le laurier aime les sols frais et substantiels; il repousse facilement de souche.

Le bois est spongieux, peu dur, peu tenace, moyennement lourd; il est d'un gris clair, légèrement brunàtre, sans aubier distinct; ses accroissements sont minces, assez bien marqués.

Ce bois est petr estimé, soit pour le travail, soit pour le

Taille. Port.

Ecorce.

Racines.

Sol.

Bois. 
chauffinge et il ne produit qu'un charbon médiocre. Le bois d'une tige de 84 ans, de $0^{\mathrm{m}} 20$ de diamètre, prorenaut de Corse, pèse, complétement desséché à l'air, 0,68 ; celui d'une tige de 53 ans et de $0,24^{\mathrm{m}}$ de diamètre, également desséché et d'origine Algérienne, pèse 0,69 (Coll. Ec. For. Envoi de MIII. Simon et Royer).

Usages accessoires.

Les feuilles du laurier renferment une huile essentielle, plus ou moins répandue aussi dans tous les autres organes de la plante, dont l'odeur est caractéristique; on connait leur usage dans la cuisine et l'on sait que la baie (drupe) du laurier était autrefois l'insigne des bacheliers (Bacca Lauri).

\section{FAMILLE XXXIX.}

\section{SANTAlacées. R. Brown.}

Fleurs hermaphrodites ou dioïques; périgone à 3-5̆ divisions, généralement persistant; autant d'étamines, insércees à la base des divisions et leur étant opposées, à anthères biloculaires, longitudinalement déhiscentes; ovaire infère, adhérent, uniloculaire, 2-4-ovulé. Fruit sec ou charnu, monosperme, ordinairement surmonté par le limbe persistant. Graine périspermée.

\section{gente unique. - OSYRIS. OSyris. Lin.}

Fleurs diö̈ques; périgone à 3 divisions, persistant; 3 étamines, 3 stigmates. Fruit drupacé, à noyau monosperme. Sous-arbrisseaux à feuilles persistantes, alternes, simples, entières, non stipulées.

Végétaux parasites de nombreuses espèces dicotylédonées, hcrbacées ou ligneuses, par leurs racines qui s'attachent à celles des antres plantes, les embrassent sur leur pourtour et s'y implantent, en se prolongeant à travers leur écorce et même dans leur corps ligneux, au moyen de suçoirs hémisphériques dont la taille varie depuis celle d'une tête d'épingle jusqu'à celle d'une cupule de gland.

Bois à vaissenux inégaux; les uns fins, formant une zone trìs-étroile au bork interne; les autres solitaires, rares, très-fins, uniformément disséminés, de plus en plus espacés vers le bord externe. Rayons médiocrement épais, indélinis.

Osyris blanc. Osymis alba. Lin. Rouvet.

Fenilles persistantes, alternes, presque sessiles, dressées, lancéolées- 
linéaires, aiguës, allénuées à la base, coriaces, vertes, entières, uninerviées. Fleurs petiles, jaunâtres, odorantes, disposées latéralement vers le sommel des rameaux; les mâles, pédicellées, réunies en petils faiscraux; les femelles, solitaires et sessiles. Drupe de la grosseur d'un pois, rouge, peu charnue, se desséchant rapidement. - Sous-arbrisseau de $0^{\mathrm{m} 50-1^{\mathrm{m}}}$ de hauleur, à tige très-branchue, rameaux dressés, allongés, grêles, relevés de nervures saillantes, verts, rappelant ceux du genèt à balais. Commun dans les terrains secs et sablonneux de la région des oliviers; remonte assez haut le long du Rhône, de l'Isère, de la Durance, ct le long des côtes de l'Océan jusqu’à Rochefort; Algérie. Flor., avrilmai. Fructif., juillet.

\section{FAMILLE XL。}

\section{LORANTíaCÉES, JuSS.}

Fleurs régulières, dioïques. Fleurs mâles : calice charnu gamosépale, 2-4 partite ; étamines 4 , introrses, réduites aux anthères qui sont opposées et appliquées contre les divisions du calice; fleurs femelles : calice double, composé d'un tube adhérent ì l'ovaire, terminé par un léger rebord 4-denté et d'un limbe à 4 lobes écailleux alternes avec les dents, parfois nul (1); ovaire formé d'un seul carpelle 1 ovulé. Fruit charnu mucilagineux, 1-sperme. Graine sans épisperme, périspermée, contenant un ou plusieurs embryons. - Végétaux parasites, toujours verts, à feuilles simples, entières, opposées, dont les bourgeons terminaux, toujours florifêres, sont précédés de 2 bourgeons axillaires et foliifères. Tiges dichotomes, à rameaux articulés.

Bois composé, comme dans les autres végétaux angiospermes, de fibres, de cellules ligneuses, de vaisseaux et de rayons; canal médullaire nul.

A. Anthères pluriloculaires, s'ouvrant par des pores.

Feuilles bien développées...................... 1

$A^{\prime}$. Anthères 1-loculaires, transversalement déhiscentes.

Feuilles réduites à l'élat d'écailles............. Arcevtorir. 2

GENRE I. - GUI. VISCUM. Tournef.

Fleur mâle : calice 4-fide, corolle nulle, 4 étamines dont les anthères sont sessiles, pluriloculaires et s'ouvrent par des

(1) On a considéré jusqu’ici ce limbe comme représentant une corolle; mais sa lexture, l'opposition de ses lobes aux élamines dans les fleurs hermaphrodites de quelques loranthacées exotiques prouvent qu'il représente véritablement un calice. (MM. Decaisnc et Planclon.) 
pores; fleur femelle : calice à peine 4 -denté; corolle de 4 pétales charnus, à base élargie. Fruit charnu-mucilagineux.

Gui blane. Viscum albun. Lix.

Feuilles coriaces, persistantes, sessiles, oblongues, obtuses, entierrs ; fleurs jannàtres, sessiles, terminales et axillaires, en petits capitules. Fruit globuleux, blane translucide, à sue visqueux et sucré. - Sous-arbrisseau glabre, d'un vert jaumàtre, à tiges dichotomes-articulées, croissant en parasite sur les arbres de toute espèce, sous forme de petites touffes arrondies. Toute la France; Algérie. Flol., mars-avril. Fructif, aoûlnovembre.

Station. Le gui croit sur tous les grands végétaux ligneux; il est commun sur les sapins (Vosges), a été obscrvé sur le pin sylvestre, le pin laricio; il se trouve fréfuemment sur tous les fruitiers des vergers, vient sur les charmes, hètres, ormes, tilleuls, peupliers, saules, etc., sur les chênes! quoique très-rarcment et mìme sur les arbres d'origine étrangère, tels que marronniers, robiniers, etc.; enfin sur lui-mème. Sun port et sa coloration se modifient sensiblement suivant les espèces sur lesquelles il est implanté.

Mode de propagation.

La dissémination se fait de diverses sortes, le plus ordinairement par l'intermédiaire des oiseaux qui sont friands de ses fruits et particulièrement par celui de la grive draine (Turclus viscivorus. Lin.), qui, après en avoil mangé la pulpe, fixe les graines sur les branches, en se frottant le bec contre elles pour s'en débarrasser.

Parasilisme.

Quelle que soit la position de la graine, la radicule se dirige toujours ver's l'axe de la branche, perce l'écoree et se soude au corps ligneux. Le jeune plant au bout de 2 ans, ne consiste encore qu'en ses 2 fcuilles cotylédonaires et ce n'est qu'à la $5^{\text {me }}$ année qu'il produit de nouvelles feuilles et que parfois il commence à se ramifier. Le gui devient de la sorte un véritable parasite de l'arbre sur lequel il est implanté, se nourrit de sa séve et exerce sur lui une action épuisante prononcée; il provoque en outre à sa base la formation d'un empàtement qui arrête la circulation et ocensionne la formation de bourrelets défectueux sur les branches; enfin, par le couvert constant et immédiat qu'il fournit, il est encore un obstacle à sa honne végétation.

La racine du gui trace dans toutes les directions, en pereant quelquefois de part en part le rameau sur lequel elle est implantée; elle drageonne sur tout son parcours.

Usages. Le gui est, daus quelques contrées, très-recherché pour 
LORANTIIACÉES, - FICACÉES.

l'engraissage du bétail et donne lieu dans certaines parties des Vosges à un petit commerce. Des élrancheurs parcour'ent les sapinières et ne craignent pas d'escalader les arbres les plus élevés pour se le procurer. Dans le Perche on estime qu'il améliore la qualité du lait. On le fait manger crù ou cuit.

L'enveloppe cellulaire verte et la pulpe des fruits servent à faire de la glu, analogue à celle du houx.

GENRE \%. - ARCEUTOBIE. ARCEUTOBIUM. Bieb.

Flcur mâle : calice 2-\$ partite; corolle nulle; anthères adhérentes aux divisions du calice, 1-loculaires, transversalement déhiscentes. Fleur femelle : calice à limbe bidenté ; corolle nulle. Péricarpe s'ouvrant par une partie de sa base, tout en persistant sur le réceptacle et expulsant par sa contraction la graine à une certaine distance.

Arcentobie de l'oxycèdre. Arceutobium oxycedri. Bien. Gui de l'oxycèdre.

Feuilles opposées, réduites à de petites écailles; fleurs axillaires et terminales, disposćes 1-5 à l'extrémité des rameaux, pelites, jaunàtres. Fruit finalement pédicellé, ovoïde, verdâtre, de 2 mill. sur 1 mill. Très-petile plante ligneuse, de 1 décimètre de hauteur au plus, à liges vertes, glabres, plusieurs fois dichotomes, formant des touffes serrées le long des branches et des rameaux du genévrier oxycèdre et du genévrier commun, dans quelques localités des Basses-Alpes. Algérie. Flor., septembre. Fructif., décembre de la même année.

Ce curieux parasite pousse, entre l'écorce et le bois des végétaux sur lesquels il s'implante, de longues racines drageonnantes, de sorte qu'un pied, unique d'abord, envahit de proche en proche tout le végétal.

\section{FAMILLE XLI.}

\section{FICACÉEs. Gaudich.}

Fleurs monoïques, trìs-petites et nombreuses, réunies sur un réceptacle charnu très-développé, concave, dont les bords, en se prolongeant, forment une cavité dans laquelle les fleurs mâles occupent la partic supérieure, les fleurs femelles l'inférieure. Périgone mul ou it 3-ö divisions; oraire libre, 1-loculaire, 1ovulé. Fruits secs, très-petits et très-nombreux (aliènes), enfermés dans la cavité du réceptacle qui est accrescent. Graine perispermée.-Arbresà feuilles alterues, simples, souvent très-diver- 
setnent dentées-lubées pour une même especce, scabres au toucher, à stipules libres, caduques, très-grandes, protégeant les feuilles dans le bourgeon; contenant des sucs propres laiteux, caustiques, qui renferment du caoutchouc.

Bois jaune clair, teinté parfois de brunâtre, spongieux, assez lourd. Vaisseaux peu nombreux, égaux, médiocres, uniformément répartis, isolés ou groupés, 2-4, en petites lignes rayonnantes; rayons fins. Chaque couche est subdivisée en un grand nombre de zones par du parenchyme ligneux très-apparent, indépendant des vaisseaux et formant des lignes blanchâtres, fines, concentriques, régulières et parallèles ou ondulées et anastomosées, ce rui confond les accroissements annuels entre eux et rend leur distinction très-difficile ou impossible.

GeNire unique. - FIGUIER. FICUS, Lin.

Fleurs pourvues d'un périgone 3-sépalé chez les mâles, 5sépalé non accrescent, dont les sépales sont soudés inférieurcment en un tube décurrent sur le pédicelle, chez les femelles; 3 étamines; 1 ovaire uniloculaire, légèrement stipité. Fruit composé (sycòne), formé d'akènes très-pctits et très-nombrcux, renfermẻs dans un réceptacle très-concave, pyriforme, charnu, dont les parois, relevées et rapprochées au sommet, circonscrivent une cavilé close de toutes parts.

Figuier commun. Ficus carica. Liv. Caprifiguier.

Feuilles caduques, pétiolées, de forme très-variable sur un même rameau, entières et à nervation pennée ou 5-7-lobées, à lobes dressés, oblus, sinués ou sous-lobés, séparés par des sinus superficiels ou trèsprofonds et à nervation palmée; épaisses, pubescentes-seabres en dessus, subtomenteuses et plus claires en dessous. Fruits axillaires, solitaires, gros, pyriformes, glabres. - Arlorisseau ou arbre peu rameux, à pousses robustes, revêtu d'une écorce assez mince, grisâtre, finement rugueuse, dont le liber, peu développé, est recouvert d'un périderme subéreux d'un faible accroissemeut. France méridionale, Corse el Algéric. Flor., avril. l'ructif., fin d'août.

Origine. Le figuier, originaire des régions méditerranéennes orientales et méridionales, est introduit et cultivé en Europe depuis la plus haute antiquité et se rencontre fréquemment subspontané dans la France méridionale. Il est commun dans les forêts de l'Algérie.

Taille. Il est le plus souvent à l'état d'arbrisseau, ecpendant il devicent aussi un arbre de $4-3^{m}$ de hauteur sur $1^{m}-1{ }^{m} 50$ de circonférenec. Sa croissanecest aetive dans la jeunesse, mais ello 
FICACÉES. - MORÉES.

se ralentit de bonne heure. Il aime les sols légers; repousse très-bien de souche, se reproduit facilement de boutures.

Le bois est jaune, mou, spongieux, riche en parenchyme ct gorgé de sucs laiteux; aussi est-il peu estimé, se pourrit-il rapidement et ne fournit-il qu'un médiocre combustible. Cependant celui du figuier sauvage, parvenu à un certain âge et bien desséché, scmble supérieur à sa répution et acquiert de la dureté et de la densité. Un échantillon d'une tige de 50 ans environ, de $0^{\mathrm{m}} 25$ de diamètre,complétement desséché à l'air, pèse 0,81 (Coll. Ec. For. Algérie, envoi de M. Royer).

Le figuier sauvage fructifie abondamment tous les ans, mais son fruit est de mauvaise qualité et ne se récolte pas.

On connait les qualités et les usages de la figue obtenue par la culture, qu'elle soit fraiche ou desséchée.

\section{FAMILLE XLII.}

\section{sonÉES. Endl.}

Fleurs monoïques ou dioïques, en épis denses, non feuillés à la base ; périgone simple, à 4 divisions ; 4 étamines opposées, à anthères introrses, biloculaires, longitıdinalement déhiscentes. Ovaire libre, à 2 loges inégales uniovulées, dont la plus petite est stérile; 2 stigmates filiformes, marcescents. A la maturité, le périgone devient charnu et entoure l'ovaire qui s'est développé en akène, pour former une sorte de petite drupe; toutes celles d'un même épis se soudent entre elles et constituent un fruit composé, charnu, tuberculeux, nommé sorose. Graine périspermée. - Arbres à feuilles alterncs, simples, dentées et très-diversement incisées-lobées pour une même espèce, à nervation palmée, dont la nervure médiane est dominante, alternativement pennée de chaque côté, et dont les nervures latérales sont pennées du côté inférieur seulement; ì stipules libres, écailleuses, caduques; bourgeons revêtus de plusieurs écailles imbriquées, spiralées.

Bois à tissu fibreux dominant, à parois épaisses; vaisseaux inégaux; ceux du bord interne gros et serrés en une zone trèsdistincte; ceux de la zone médiane et externe plus petits, plus espacés, associés à du parenchyme ligneux et groupés, sans contiguité complète, suivant de courtes lignes concentriques ou dendritiques. Rayons moyennement épais. 
GEXRE UXIQUE, - MURIER. MORUS. Tournef.

Fleurs monoüques, exceptionnellement diö̈ques ou mêtne polygames, en épis cylindriques, denses, axillaires; les mîles à la base, les femelles vers le milieu des pousses de l'année. On trouve cependant des pieds dont les fleurs sont toutes d'un même sexe et, plus rarement, des arbres à fleurs hermaphrodites.

A. Feuilles d'un vert clair, à peu près glabres ; fruits pelits, longuement jédonculés...................... вLAxc.1 \$. Feuilles d'un vert foncé, pubescentes-scabres; fruits gros, courtement pédonculés.............. M. Norn.. 2

1. Mrûrier blane. Monus ALBa. Lix.

Fcuilles longuement péliolées, largement ovales-aiguës, obliquement cordiformes a la base, bordées de grosses dents inégales ou très-diversement incisées-lobées, à sinus arrondis, enliers et à lobes llentés; minces, herbacées, d'un vert clair el glabres sur les deux faces, à l'exception des nervures et des aisselles qui sont légèrement pubcacentes, surtout en dessous. Epis femelles égaux à leurs pédoncules qui sont grèles, ou plus longs; sépales glabres aux bords. Fruits pelits, blanes, rosés ou noirs, de saveur fade et sucrée. - Arbre de taille moyenne; cultivé. Flor., arril-mai. Fructif., août-septembre.

Origine. Le mùricr est origginaire de la Chine, d'où il passa aux Indes, en Perse, puis dans l'Europe méridionale et arriva en France à la fin du $\mathrm{xv}^{\mathrm{e}}$ siècle; il y est cultivé sur une grande échelle pour ses feuilles, qui forment la nourriture des vers à soie, et l'on en connait un grand nombre de varićtés.

Taille. Abandonné à lui-mème et croissant dans de bonnes conditions, le murrier peut atteindre $15.18^{\mathrm{m}}$ de hatteur sur $1^{\mathrm{m}}-1^{\mathrm{m}} \mathrm{30}$ de diamètre. Il a la croissance assez lente, une Sols. longévité assez élevée; recherehe les sols légers, redonte ccux qui sont humides et tenaces, et, dans les contrées du Nord, où il craint les gelées pendant la jeunesse, il demande des situations abritées.

Bois. Nalgré la distance qui sépare le mûrier du robinier en nomenclature, le premier produit un bois presque exactement semblable a celui du second par la texture, la couleur et les qualités superieures. Cependant le parenchyme lisneux qui relic les groupes des pecits vaisseaux y est plus

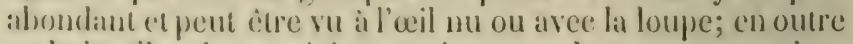
re bois, d'un jaune chair, acpuict avee le temps une teinte

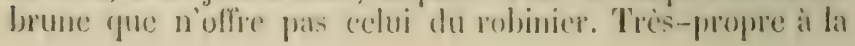


boissellerie, au charronnage, il fournit de bons échalas ct d'excellents gournables (chevilles) pour les constructions navales; sa couleur jaune et le beau poli qu'il reçoit le font aussi rechercher pour meubles. Du bois d'une lige de 53 ans et de $0^{\mathrm{m}} 2$ 彳 de diamètre, pèse complétement desséché à l'air, 0,81 (Coll. Ec. For.). Il prend un retrait de 15,04 p. $0 / 0$ en se desséchant.

L'écorce, à un certain ìge, forme un rhytidome épais, gris brun, largement gereuré, subécailleux, persistant, composé de l'enveloppe subéreuse qui s'accroit el entre les lames de laquelle il se déreloppe irrégulièrement, comme dans les vieux bouleaux, des plaques de tissu cellulaire extrêmement dur et presque pierreux. Le liber, qui présente aussi de semblables amas de cellules pierreuses, est formé de faisceaux très-déliés qui ne sont ni groupés, ni anastomosés et qui, par leur isolement, peuvent fournir des matières textiles d'une grande finesse.

2. Brîn no noir. Monus nigra. Lin.

Feuilles plus grandes que celles du mùricr blanc, à pétiole 4 - $ٌ$ fois plus court que le limbe; largement ovales-aiguës, régulièrement et profondément cordiformes à la base, inégalement dentées, mais plus rarement inciscés-lobées; fermes, d'un vert foncé et pubcscentes-scabres sur les 2 faces. Epis femelles presque sessiles ou courtement pédouculés; séplales à bords hérissés. Fruils noirs, plus gros, acidulés-sucrés. - Arbre de même taille que le précédent, originaire de l'Asie el cultiré comme fruitier. Flor., avril-mai. Fructif., août-scptembre.

Le bois est entièrement semblable à celui du mutrier lilane. Provenant d'une tige de 18 ans, de 24 centimètres de diamètre, il a domé, complétement desséché à l'air', una densité de 0,82 (Coll. Ec. For.).

\section{FAMILLE XLIII.}

\section{CELTIDÉes. Endl.}

Fleurs hermaphrodites, exceptionnellement polygames, solitaires et axillaires ou en petites grappes, qui proviennent d'un rameau raccourci à fleurs solitaires, axillaires, à feuilles peu

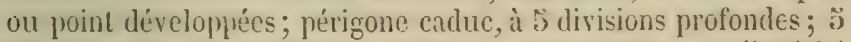
étamines oprusées, à filets courbés, se redressant avec élasticité at mument de la floraison; à anthères intrurzes, biloculaires, s'ouvrant en fentes longitudinales plus ou moins prolongées: evaire libre, miloculaire, uniovule; I stigmate Jifide. Irupe à 
peine cliarnue, contenant un noyau monosperme. Graine périspermée. - Arbre à feuilles simples, alternes, aigûment dentées, rudes et scabres, inéquilatérales, à stipules caduques; nervures pennées, rameuses, les $3-5$ de la base palmées. Sucs aqueux.

Bois lourd, dur, très-tenace, blanc ou blane jaune très-clair. Vaisseaux inégaux; les uns gros, serrés et formant une zone étroite au commencement de chaque couche; les autres, assez gros, unis à du parenchyme et groupés dans le bois d'automne, de telle sorte qu'ils dessinent de longues lignes concentriques plus ou moins ondulées. Rayons moyennement épais.

\section{genRe unique. - MiCOCOULIER. CELTIS. Lin.}

Mêmes caractères que ceux de la famille.

micoconlier de Provence. Certis australis. Lin. Fabre-coulier; alisier (dans certaines parties du Midi).

Feuilles distiques, pétiolées, ovales-lancéolées, inéquilatérales à la base, très-fonguement el finement acuminées au sommet, aigûnent dentées jresque dès la base; d'un vert foncé et scabres en dessus, mollement pubescentes, subtomenteuses et d'un vert grisâtre en dessous. Fleurs vertes, solitaires, naissant à l'aisselle des feuilles et en mème temps qu'elles, longuement pédonculées, hermaphrodites et quelquefois mâles ou femelles par avortement suivant les pieds. Drupe globuleuse, de la laille d'un gros pois, presque sèche, brunàtre, supportée par un pédoncule grêle, 2-5 fois aussi long que les pétioles. - Arbre de moyenne taille, à lige droite, canneliee, pell élevée, recotiverte d'une écorce mince, grisâtre, lisse, mème à un âge avancé, rappelant celle du hètre par sa siruclure et les cellules pierreuses de son parenchyme extérieur; parfois parsemée d'excroissances verruqueuses; à cime ample, touffue, arrondie, dont les branches inféricures sont allongées et horizontales, les ramules grêles, llexibles, souvent pendants. Région méditerranćenne; I'rovence, Languedoc, Corse, Algérie. Flor., avril. Fructif, octobre.

Taille.

Le micocoulier atteint $20^{\mathrm{m}}$ de hauteur sur $5^{\mathrm{m}}$ de circonférence; il peut mème dépasser ces dimensions et l'on en cite un pied, sur la place d'Aix, qui s'élève au dessus de tous les édifices qui l'environnent, mesure $5^{\mathrm{m}} 61$ de circonférence à $1^{\mathrm{m}} \mathrm{du}$ sol, et dont l'ìge est d'environ ${ }^{\mathrm{m}} 00$ ans.

Enracinement. L'enracinement est puissant, pivotant et traẹant. Les racines drageonnent; les souches produisent des rejets abondants, d'une grande vigueur. Le couvert est léger.

Fructification. Le micocoulier fruetific assez jeune, mais par intermittences et il reste quelquefois deux années sans rien produire.

Germination.

La graine, semee en atutomne, germe dès le printemps; si l'on attend rette derniere saison pour le semis, le fruit reste géneralement un an en terre ef le jeune plant ne parait 
qu'au printemps suivant. Ce jeune plant est pourvu de deux grosses feuilles cotylédonaires, échancrées au sommet et il atteint dans la première année $15-20$ cent. de hauteur. Sa croissance est rapide dans les années suivantes.

Cet arbre prospère en plaine, en cotcaux et même en montagnes, à toutes les expositions, réussit bien dans tous les terrains, pourvu qu'ils ne soient ni trop légers, ni humides ou marécageux; on le voit végéter jusque dans les pierrailles et même sur les ruines; ce sont néanmoins les sables gras et frais qu'il prélère. Il supporte assez bien le climat du nord de la France, mais il a besoin d'y ètre abrité pendant la jeunesse.

Le bois de micocoulier, qui a été caractérisé plus haut, ressemble beaucoup à celui du frène; il en a toutes les qualités, à un degré plus élevé encorc, mais il n'en a pas le satiné; il est mat, d'une teinte jaune verdâtre extrêmement légère, et il présente un groupement plus prononeé de ses vaisseaux.

Sa densité, comme celle de tous les bois à gros vaisseaux dans la zone de printemps, est très-variable, suivant que celte zone est plus ou moins dominante, ou ce qui est la mème chose, que la végétation est moins ou plus active. Elle est de 0,66 seulement pour du micocoulier d'Algérie, sle 50 ans et de $0^{\mathrm{m}} 17$ de diamètre; 0,88 pour du mico coulier d'Espagne, de 28 ans et de $0^{\mathrm{m}} 10$ de diamètre; ces bois étant complétcinent desséchés à l'air (Coll. Ec. For.). Le retrait, par la dessiccation, est de 18 p. $0 / 0$ du volume primitif.

Le micocoulier est essentiellement un bois d'industric, particulièrement recherché pour tous les usages qui exigent de la souplesse et de la tenacité. Il occupe le premier rang pour avirons, gournables ou chevilles des vaisscaux, cercles, échalas, baguettes de fusil, fourches, attelles, gaules, cannes et surtout manches de fouet, bien connus sous le nom de Perpignan; on le cultive souvent en taillis, qui se maintiennent très-serrés, pour la production de tous ces menus objets. C'est un excellent bois de charronnage, dont tirent aussi parti les tourncurs, sculpteurs, luthiers et menuisiers; un très-bon combustible dont le charbon est estimé.

Les drupes sont comestibles, mais fades et à peine charnues. Les graines renferment une huile analogue à l'huile

Station et sol.

Bois.

Emplois.

Produits accessoires. 
douce; les racines et les écorces donnent une matière tinctoriale jaune; les feuilles, enfin, forment un bon fourrage pour le bétail.

\section{FAMILLE XLIV.}

\section{vLMACÉES. Mirbel.}

Fleurs hermaphlrodites ou polygames, pourrues d'un périgone sépaloïde, persistant, campanulé, 4-8 lobé; de 4-8 étamines dressées, opposées aux divisions et ì anthères extrorses, et de 1 ovaire libre, uni-loculaire et uni-orulé, surmonté de 1 sligrmate bifide et marcescent. Fruit sec, uniloculaire et monosperme par arortement, indéhiscent, à graine non périspermée.

GEXRE UNIQUE. - ORME. ULHUS. Lin.

Fleurs hermaphrodites, en faisceaux non feuillés, sortant des loourgeons axillaires des pousses de l'année précédente; pédicelles 1-2 bractéolés, articulés au-dessous de la flenr; samare plane, orbiculaire, à graine lenticulaire, à aile marginale, grande, foliacée. - Arbres à feuilles distiques, penni-nerviées, inéquilatérales à la base, généralement rudes au toucher; rameaux distiques et dans un même plan; stipules grandes, presque herbacées, caduques; fleurs très-précoces, paraissant arant les feuilles, à périgone rouge verdìtre et à anthères d'un pourpre foncé. Bourgeons revêtus d'écailles nombreuses, imbriquées sur leux rangs; les axillaires insérés obliquement au-dessus de la cicatrice de la feuille.

Bois Jjien caractérisé, très-tenace et très-élastique, à aubier blanc jaunâtre, cocur brun ou brun rougcâtre plus ou moins prononcé tr varié. Fibres à parois épaisses; vaisseaux inégaux, les internes sros, serrés, formant une zone poreuse, étroite, continue; ceux ¿lu milieu et du bord externe pelits, groupés en grand nombre, assuciés à du prarenchyme ligneux et dessinant des lignes concentriques, réğgulières, onduleuses ou en zigzag ; rayons médullaires fins-moyens, assez longs, assez lauts, serrés.

A. Samare sessile, non cilice.

13. Graine rapprochée du sommel de la samare. Arbre à cime bien fournic, a rameaux el

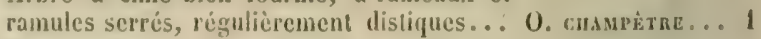

'3', Graine centrale. Arbre à cime peu fournie, i rameaux el ramules écartés, peu régulièrement distiques............... 0. ve montagng. ? 
A'. Samare pédonculée, ciliée, petite. Arbre d'un port diffus, à tige relevée de côtes saillantes; écorce lisse, puis écailleuse-caduque, finalcment gercurée-persistantc.............

0. Diffus.....

1. Orme champêtre. Uluus campestris. Surth. Orme à petiles feuilles; Orme rouge. Ulmus suberosa. Lin. el Auct. Gers.

Feuilles plus pelites que celles de l'orme de montagac $(8-10$ cent. de longueur), ovales ou elliptiques, inéquilatérales à la base, pointues ou acuminées au sommet; doublement dentées en scie, à dents peu aiguës ou presque obtuses, généralement plus larges que longues; fermes, plus ou moins rudes, rarement lisses au toucher, barbues en dessous à l'aisselle des nervures. Fleurs brièvement pédicellées, à $4-30$ étamines. Samare obovale, alténuée à la base, glabre, non ciliće, échancrée au sommet, à graine placée au-dessus de son milieu et alteinte par l'échancrure; aile de consistance assez sèche et ferme, jaunâtre à la maturité, généralement plane. - Habituellement grand arbre à longue tige droile et nue, à cime fournie, conique, formée de fortes branches ascendantes, terminées par des rameaux rapprochés, garnis de ramules serrís, rigulièrement distiques.

Var. a. Orme champétre proprement dit. Arbre élevé, à feuilles ovales ou elliptiques-acuninées, rudes; jeune écorce peu ou point subéreuse. $U$. Campestris. $L$.

Var. $\beta$. Orme à feuilles de coudrier. Arbre élevé, à feuilles cordiformes-ovales, brusquement-acuminées, très-rudes; jeune écorce lisse. U. Corylifolia. Host.

Var. $\%$. Orme glabre. Arbre élevé, à feuilles coriaces, très-obliquement ovales-acuminées, presque lisses, glabres et luisanies; jeune écorce lisse. U. Nitens. MIench. U. Carpinifolia. Ehrh.

Var. $\delta$. Orme tortillard. Petit arbre à tige tortueuse, à cime diffuse, ou buisson; feuilles petiles ou très-petiles, ovales-acuminées, un peu rudes, $\boldsymbol{U}$. Minor Hill. $\boldsymbol{U}$. Torluosa. Ilost.

Var. $\varepsilon$. Orme subéreux. Pelit arbre ou arbrisseau à rameaux étalés, ailés-subéreux, à feuilles ovales-acuminées, rudes. U. Suberosa. Ehrh.

Sols fertiles, frais ou humides des vallées et des plaioes de toute la France; Algérie. Flor., mars-avril. Fructif, fin de mai.

L'orme champètre est un arbre de la plus grande taille. Un pied de cette espèce, auprès de Worms (Allemagne), a $47^{\mathrm{m}}$ de hauteur et $2^{\mathrm{m}} 50$ de diamètre à $2^{\mathrm{m}} 30 \mathrm{du}$ sol; il est estimé à $110^{\mathrm{mc}}$. Un autre orme des environs de Rouen, sans doute détruit maintenant, mesurait $14^{\mathrm{m}}$ de circonférence et cubait 200 stères; quelques-uns de ceux que Sully a fait planter au bord des routes, avaient, à la fin du XVIII ${ }^{\mathrm{e}}$ siècle, 6 à $7^{\mathrm{nt}}$ de circonférence. La lizye est élevée, nue, rarement trèsdroite; la tête, large et touffue, quand l'arbre croit en liberté. Tous les ormes champètres, néanmoins, ne présentent point ces caractères; on en rencontre parfois, dans les lieux sees, qui restent à l'état de petits arbrisseaux diffus, à feuilles 
très-petites, qui ne fleurissent point ou presque jamais; il en est d'autres à tige irrégulic̀re, dont la fibre ligneuse cst entrelacée et contournée et que l'on connait sous le nom d'ormes tortillards, d'ormes à moyeux.

Ecorce. L'écorce a de l'analogie avec celle du chẻne; lisse, dans la jeunesse, sauf le cas dont il va ètre parlé, elle forme plus tard, vers 10 ans, par suite du périderme qui se développe de plus en plus profondément dans les couches extéricures du liber, un rhytidome fibreux, d'un brun noir, à gercures larges, profondes, nombreuses et rapprochées. Sur certains pieds, ecpendant, avant la production du rhytidome, l'enveloppe subéreuse se développe activement et constitue un liége brun, très-fragile, qui, en raison de sa rapide croissance et de son défaut d'élasticité, se gereure profondément et largement et rend les jeunes tiges ou les rameaux ailéssubéreux. Ce liége tombe naturellement dès que le rhytidome se produit. Cette production est d'ailleurs toute individuelle.

Enracinement. L'orme développe un faible pivot, qui s'arrète dès l'àge de 6 à 10 ans, mais se ramifie beaucoup et émet généralement 2-5 maitresses racines, qui pénètrent obliquement et profondément dans la terre. En mème temps, de nombreuses racines latérales, traçantes, superficielles, très-divisées et chargées de chevelu, partent du collet et s'étendent au loin, le plus souvent en drageonnant. Le bois de souche fournit 15 - 20 p. $0 / 0$ du volume total.

Fructification. La fécondité de l'orme est extrêmement développée et, malgré cela, régulière et continue chaque annéc; elle est telle que parfois cet arl)re ne se feuille qu'à la seconde séve, parceque ses fruits ont absorbé, pour se développer, toute celle du printemps. Il est vrai que ces fruits sont de consistance foliacée, remplissent les fonctions des feuilles et concourent à l'élaboration; aussi l'arbre ne parait-il pas épuisé par cette grande fécondité.

Les fruits des jeunes ormes ont presque toujours la graine vaine; des ormes d'ìge convenable en offrent au plus $25-50$ p. $0 / 0$ qui soient aptes à germer, et, dans certaines anníes, on n'en trouve aucune. Le kilogramme en contient 150000 150000.

Germination. Si l'on sème en juin, immédiatement après la dissémination, le jeune plant leve au bout de $5-4$ semaines et parvient, dans l'annce mème, à une taille de 15 -20 centimètres. 
Si l'on conserve la semence jusqu'à la fin de l'hiver et qu'on ne sème qu'au printemps seulement, beaucoup de plants ne lèvent que l'année suivante et, en tout cas, ils sont chétifs. Le jeune plant parait avec deux feuilles cotylédonaires vertes, obovales, généralement un peu échancrées au sommet et offrant, chacune, sur un de leurs côtés, à la base, une sorte de dent saillante; les feuilles qui suivent ont la serrature simple, puis enfin apparaissent les feuilles normales. La croissance est rapide, de 5-5́ décimètres en hauteur chaque année; mais, comme le pivot s'enfonce peu,dans les terrains secs ou dans les années chaudes les plants sont exposés à périr.

L'orme champètre est généralement rare dans les forêts et n'y croit pas en massifs ; il est très-fréquemment et, avec raison, planté le long des routes, des avenues, sur les glacis des places fortes, etc.

Le bois de l'orme champètre est bien supérieur à celui de l'orme de montagne et de l'orme diffus; sa couleur rougeâtre le fait le plus souvent désigner par ceux qui l'emploient sous le nom d'orme rouge; l'aubier en est blanc jaunâtre. Il est dur, élastique, extraordinairement tenace, d'une fente difficile, d'une durée égale au moins à celle du chêne, surtout employé dans les licux humides, tels que caves, puits et galeries des mines. Complétement desséché à l'air, du bois de cette espèce, provenant de la forêt de Haguenau et d'une lige de 76 ans environ, pèse 0,687 (Coll. Ec. For.). Il est recherché pour une foule d'usages et tout particulièrement dans le charronnage pour jantes de roues, dans la construction des machines et, dans l'artillerie, pour affuts des canons, etc. L'orme tortillard, à fibre entrelacée, est excellent pour faire les moyeux. Mais il faut avoir-soin de n'employer ce bois que longtemps après son exploitation, parce qu'il est lent à se dessécher, qu'il prend du retrait, 12 p. $0 / 0$ environ de son volume, se tourmente et se gerec beaucoup. L'aubier est exposć à la vermoulure et doit être rejeté.

L'orme soumis à un émondage répété produit souvent des broussins qui donnent un joli bois ronceux, recherché par les ébénistes, tourneurs, armuriers, etc.

Les excellentes qualités de l'orme comme bois de travail ne se retrouvent plus au mème degré quand on l'emploie comme combustible et l'on verra plus loin, à propos de l'orme de montagne, des résultats d'expériences qui lui sont applicables. 
Le bois d'orme est un de ceux qui produisent le plus de cendres; il est à eet igard très-voisin des bois de frène et de saules; il en fournit en moyenne 4 fois plus que le hètre, et elles contiennent 2 lois plus de potasse. Ceci s'applique aussi à ses feuilles.

Produils accessoires.

Après le tilleul, e’est l'orme qui, parmi nos végétaux forestiers, produit le liber le plus fibreux, le plus tenace et le plus durable; on peut l'employer à faire des nattes et des cordages grossiers. Son écorce contient, dans des cellules spéciales, un principe mucilagineux abondant $(20$ p. $0 / 0)$, et du tannin ( 6 p. 0/0); elle n'est pas utilisée néanmoins. Les feuilles renferment un mucilage analogue et constituent le meilleur fourrage que puissent offrir les arbres de nos forèts. Desséchées à l'air libre, c'est-ì-dire, fanées, elles sont presque aussi riches en azote que les luzernes et les trifles des prairies artificielles et sont supérieures à eet égard aı foin des prairies naturelles.

Leur analyse a clonné les résultats suivants: (II. J. Pierre, 1856.)

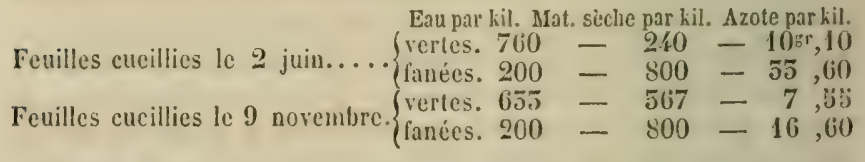

2. Orme de montague. Uluus montaya. Sirtir. Orme blanc; Orme à grandes feuilles. Ulmus campestris. Liv. ef Auct. Gena.

Feuilles plus grandes que celles de l'orme champètre $12-15$ centimetres de longucur), d'un vert plus foncé, plus rudes en dessus; obovales, inéquilatérales à la base, longuement et étroitement acuminées au sommel, doublement dentées, à dents aignës, recourbées ver's l'extrémité; glaljres ou pubescentes en dessous, peu harbues aux aisselles des nervures. Fleurs briéremeat pédicellés, a $5-7$ élamines. Samares plus grandes, ovales, à graine centrale non alleinte par l'échancrure; aile de consistance plus molle, herbacéc, plus ou moins verte, mème lorsqu'elle est desséchée; ondulée, rarement plane. - Grand arbre à cime ample el moins fournie, à branches étalées, ramules flexueux, velus, plus ćcartés et moins régulièrement distiques, souvent tombants.

Var. $\alpha$. Orme de montagne proprement dit. Jeunes rameaux peu velus; feuilles rudes, légèrement velues aux nervures en dessous.

Var. $\beta$. Orme à larges feuilles. Jeunes rameaux hérissés; feuilles grandes, ćpaisses, très-rudes, pubescentes-grisitres en dessous. Orme de IIollande. U. IIollandica, IIIll. U. major. Sm. U. excelsa. Bork.

Disséniné dans les bois des pays de plaines, de coteanx et de montagnes, sur des sols variables. Flor., mars-avril. Fructif, fin de mai.

Port. L'orme de montagne, comme l'orme champitre dont il 
est voisin, est sujet à quelques variations dans la forme, la vestiturc, la rudesse de ses feuilles; mais le caractère trèstranché qu'offrent ses fruits et les qualités inférieures de son bois, jointes à des différences constantes de feuillage, de port, etc., en forment une espèce facile à reconnaitre et qu'il est important, au point de vue forestier, de ne pas confondre avec la précédente. La tige n'est point aussi élevée que celle de l'orme champêtre; la cime est plus ample, moins fournie et n'offre plus cette symétrie remarquable des ramules distiques et serrés qui distingue ce dernier; ceux-ci sont plus espacés, plus gros et plus souples; l'écorce, qui n'est jamais subéreuse, reste lisse jusqu'à un àge moyen, puis se gereure superficiellement et forme un rhytidome platement écailleux; la longévité, enfin, n'est pas aussi grande.

L'orme de montagne vient partout; il est fréquemment disséminé parmi les chènes, les hêtres et même les sapins dans les forèts de coteaux ou de montagnes; aimant les terrains légers et frais, il se trouve en assez bon état de croissance encore sur les sols secs du calcaire jurassique et jusque dans les crevasses des rochers.

Le bois de cette espèce est très-inférieur à celui de l'orme champêtre; il est relativement plus riche en vaisséaux, qui sont plus gros et groupés en lignes plus continues; il est plus léger, plus mou, moins durable et moins tenace; sa coloration est plus claire, plutòt brunâtre que rougeàtre; enfin il contient beaucoup d'aubier. Les charrons savent très-bien le distinguer; ils le désignent sous le nom d'orme blane et refusent habituellement de l'employer.

Du bois d'une tige de 60 ans, provenant de la forêt de Ilaguenau, complétement desséché à l'air, pèse 0,626 (Coll. Ec. For.).

D'après les expériences de T. Hartig, la puissance cnlorifique du bois d'orme de 100 ans et d'une densité de 0,68 , desséché à l'air', est à celle du hêtre de 120 et d'une densité de 0,73 , également desséché, dans les rapports suivants :

Poids égaux. Vol. égaux. Plus haut degré de chaleur.... $\left\{\begin{array}{l}\text { ascendante } 92: 100 \quad 85,7: 100 \\ \text { rayonnante } 92: 100 \quad 85,7: 100 \\ \text { Durée de la chaleur croissante.. } \\ \text { ascendante } 158: 100128,3: 100 \\ \text { rayonnante } 157: 100127,6: 100\end{array}\right.$ 


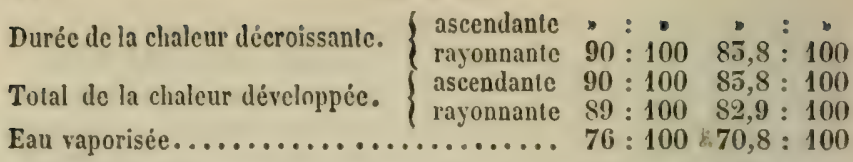

C'est un bois qui brùle très-lentement, avec une flamme courte, peu active, sans dégager beaucoup de chaleur.

Le charbon d'orme est léger; pes. sp. 0,193 . Sa puissance calorifique est à celle du charbon de hètre comme 879 : 1000 d'après Werneck.

3. Orme diffus. Ulaus effusı. Wrild. Orme pédonculé; Orme blane (en Alsace).

Feuilles peu fermes, ovales ou obovales, légèrement acuminées, inéquilatérales à la base, doublement dentées en scie, à dents grandes, aiguës, fortement recourbées vers le sommet; point ou peu rudes en dessus, mollement pubescentes $\mathrm{en}$ dessous, surtout dans la jeunesse. Fleurs longuement pédicellées, pendantes; pédicelles grêles, longs de $8-15$ centimètres; $\breve{b-8 ~ e ́ t a m i n e s . ~ S a m a r e ~ b e a u c o u p ~ p l u s ~ p e t i t e ~ q u e ~ c c l l e ~}$ des espèces précédentes, par suite d'un moindre développement de l'aile, car la graine est aussi grosse; elliptique-orbiculaire, alténuée aux deux extrémités, mollement et densément ciliće sur les bords; graine centrale, atteinte par l'échancrure de l'aile, qui est plane el de consistance ferme.Grand arbre à cime irrégulière, élalée, diffuse; tige relevée au pied de côtes très-saillantes qui correspondent aux racines et très-disposée à se garnir, en dessous de la cime, de branches gourmandes; à écorce lisse d'abord, assez largement écailleuse et caduque ensuite, d'un brun jaunâtre, rappelant celle de l'érable sycomore, finalement gercurée en long et brune comme celle des autres espèces du même gevre, jamais subéreuse; écailles des bourgeons glabres, non ciliées. Commun en Alsace, dans les forêts des bords du Rhin à sol léger el humide; rare et disséminé çà et là dans le reste de la France. Flor., avril. Fructif., juin.

Port.

L'orme diffus est très-facile à reconnaitre, non-seulement à ses caractères botaniques proprement dits, mais à sa cime étalée, irrégulière, à sa tige pourvue au pied de côtes relevées en lames de couteaux. Des bourgeons proventifs nombreux y produisent quantité de petites branches gourmandes; souvent même ces bourgeons, sans rien donner à l'extérieur, se développent et se ramifient sous l'écorce et constituent des broussins ou excroissances remarquables. Les racines drageonnent abondamment.

Bois. Le bois présente de larges aceroissements annuels et les vaisscaux y forment des lignes circulaires continues et réunies, plus nombreuses, plus larges et moins ondulées que dans les autres especes de ce genre. Il est jaunitre ou jaune brunattre très-clair, à peine et irrégulièrement taché ou 
veiné de brun. Il est assez fréquemment rempli de petits nouds produits par les branches gourmandes de la tige; sa fibre n'est jamais droite.

Du bois d'une tige de 70 ans environ, de la forêt de Haguenau, complétement desséché à l'air, pèse 0,566 (Coll. Ec. For.).

En Alsace, où l'orme diffus est commun, on ne l'apprécie ni comme bois d'ouvre, ni comme combustible; il y est connu sous le nom d'orme blanc et rangé dans la catégoric des bois blancs.

\section{FAMILLE XLV.}

\section{Buxacées. Baillon.}

Fleurs monnïques. Fleur mâle : calice 4-sépalé ; \& étamines opposées aux sépales, biloculaires, introrses, longitudinalement déhiscentes; au centre on observe un organe glanduleux solide (ovaire rudimentaire ?). Fleurs femelles : périgone formé de 4-7 folioles, dont les \& internes paraissent représenter un calice 4sépalé et dont les cxternes semblent appartenir à des bractées; ovaire libre, 3-loculaire, dont chaque loge est biovulée et à placentation pariétale; couronné par 3 styles distincts, périphériques et non terminaux. Capsule ou baie; graines arillées à la base; périspermées. Végétaux à feuilles opposées, à sucs non laiteux.

\section{genRe UNiQUe. - BUIS. BUXUS. Tournef.}

Fleurs 4-sépalées, 3-bractéolées, en glomérules axillaires, dans lesquels les fleurs femelles sont terminales; capsule à 3 cornes formées par lis styles persistants, 3-loculaire, dont chaque loge est 2-sperme. A la maturité l'épicarpe et le mésocarpe tombent sous forme de 3 valves septicides et laissent l'endocarpe seul; celui-ci, déhiscent avec élasticité, se sépare suivant les sutures ventrales et dorsales en 6 pièces et expulse au loin les graines. Arbustes à feuilles opposées, coriaces et persistantes, entières, subuninerviées, dont les nervures latérales sont à peine apparentes, pennées, très-nombreuses, droites et parallèles, simples ou une ou plusieurs fois fourchues; à fleurs blanchâtres; exhalant par toutes leurs parties une odeur désagréable.

Bois jaune, dense, très-homogène, à accroissements très-minces. Tissu fibreux dominant, très-fin, très-serré, à parois épaisses; vaisseaux très-petits, égaux, isolés, uniformément rẻpartis, entourés de parenclyyme ligneux; rayons très-fins. 
Buis commuu. Bexus sempenvinens. LiN.

Feuilles persistantes, subsessiles, ovales ou elliptiques, entières, fermes, glabres, d'un vert foncé luisant en dessus, plus clair el presrjue mat en dessous. Fleurs petites, blanchâtres, fétides, en petits glomérules axillaires, dont la centrale est généralement femelle. -- Arbustes trèsrameux, à écorce jaunâtre, subéreuse, éeailleuse, eaduque; à rameaux opposés, tétragones, très-feuillés; à végétation très-lente. T'errains arides des coteaux el montagnes calcaires; manque dans le Nord. Flor., marsavril.

IIabitation. Le buis est un arbuste social qui couvre souvent presque à lui seul de grandes étendues de sol forestier, dans le Jura, le Dauphiné, la IJaute-Provence, le Languedoc, les Pyrénées

Taille. et la Corse. II a une Iongévité très-prolongée, à la faveur de laquelle il peut atteindre, malgré l'excessive lenteur de sa végétation, $2-5^{\mathrm{m}}$ et mème $7^{\mathrm{m}}$ de hauteur, sur $2^{\mathrm{m}}$ de circonférence. Mais de semblables buis sont de très-rares exceptions et souvent eet arbuste reste nain (buis nain, buis stérile). Tel est celui que l'on emploie pour bordures dans les jasdins. Il supporte parfaitement bien la taille et prend toutes les formes qu'on veut lui donner.

Bois. Le bois de buis est l'un des plus denses et des plus homogènes de nos contrées; il a le grain très-fin, d'un jaune citron uniforme, se coupe avec une grande nelteté dans tous les sens, et recoit un beau poli. Celui d'une tige de 1533 ans, d'un diamètre de 0,19 complétement desséché à l'air et provenant de Corse, pèse 1,09 (Coll. Ec. For .). C'est un bois précieux, qui se paie très-cher; il est particulicrement recherché par les graveurs, tourneur's, tablettiers, fabricants d'instruments de tous genres et il entretient une certaine industrie dans les pays où il est abondant; mais il devient de plus en plus rare, par suite d'exploitations abusives et de l'extraction des souches, dont le bois, trìsfinement noucux, est particulièrement recherché.

reuilles. Les feuilles du buis sont très-estimées comme engrais et contiennent 2,89 d'azote p. $0 / 0$ de matière sèche (le fumier d'étable en renferme 2 p. 0/0.). Elles forment, pour eet usage, un produit important de certaines forcts du midi.

\section{ORDRE VI.}

\section{APÉTALES AMENTACÉES.}

Fleurs uniséxuées, monoïques on dioïques; à périgone sépaloïle ou nul; accompagnées d'écailles bractéales; les males, au moins, disposées en chatons (amentacées). 


\section{FAMILLE XLVI.}

\section{JUGLANDEES DC.}

Floraison monoïque. Fleurs mâles en chatons denses, cylindriques, composées d'une écaille bractéale peu distincte et confondue, à part son extrémité, avec un périgone de ̋̌-6i divisions, et d'un grand nombre d'élamines, dont les anthères sont biloculaires, longitudinalement déhiscentes. Fleurs femelles agrégées 1-4 au sommet des jeunes rameaux; chacune d'elles formée d'un involucre 3-4-fide ou-denté, soudé à un périgone 3-4-fide, qui lui-même est réuni à l'ovaire jusqu'en dessous du style. Ovaire infère, uniovulé ; styles 1-2, très-courts; stigmates $\mathbf{2}-4$. Noix monosperme, revêtue d'une enveloppe charnue (brou) provenant de l'involucre et du périgone accrescents, à $2-4$ valves ligneuses. Graine non périspermée, à cotylédons féculentshuileux, 4-lobés - Arbres à feuilles alternes, composées, oppositi-imparipennées, non stipulées; nervation pennée, à nerrures serrées, parallèles; bourgeons extra-axillaires, revêtus de 2 écailles opposées, qui cachent presque entièrement toutes les autres; disposés en série longitudinale de 3 , dont le plus élevé est le principal.

\section{GENRE UNIQUE, - NOYER. JUGLANS. Lin.}

Fleurs mâles de 14-36 étamines, à filets courts, pétaloïdes ; fleurs femelles à 2 larges stigmates papilleux; noix bivalve.

Bois assez lourd, homogène, gris, à cœur brun plus ou moins veiné et flambé de nuances noirîtres et rougeâtres. Tissu fibreux divisé, par du parenchyme disposé en lames minces, en zones concentriques très-rapprochées (visibles à la loupe seulement). Vaisseaux presque gros, isolés ou à peine groupés, uniformément répartis; rayons égaux, minces, très-peu longs et très-peu hauts, assez serrés.

Noyer commun. Juglans Regia. LiN.

Feuilles de 6-9 folioles ovales-aiguës, entières ou sinuées, coriaces, glabres. Fleurs mâles en chatons cylindriques, denses, pendants, verdàtres. Noix, dégagée de son brou, ovoüle, ridée et sillonnée superficiellement. - Grand arbre à écorce blanchâtre, lisse et unie ou plus ou moins profondément gerçurée suivant l'àge; à lige cylindrique, nue, peu élevee, se partageant en grosses branches qui forment une cime ample ct haute, arrondie, dont les rameaux extrêmes sont peu nombreux, ipais, toruleux, et dont le couvert est complet. Cultiré. Flor., avritunai. Fructif., septembre-octobre. 
Lc noyer commun est originaire de la Perse el l'un des arbres que l'on plante et eultive le plus fréquemment. Il ne prospère et ne fructifie abondamment que lorsqu'il est isolé ct ne pourrait ètre introduit avec avantage dans le peuplement des forêts, malgré les bonnes qualités de son bois. Sa floraison précoce le rend sensible aux gelées tardives qui détruisent fréquemment tout espoir de récolte de ses fruits.

Le bois est très-recherché en ébénisteric et en menuiserie, à cause du beau poli qu'il reçoit et des nuances riches et variées de ses nombreuses veines; il est indispensable aux armuriers; sert en carrosserie pour panneaux de voitures ; est employé par les tourneurs, tablettiers, etc. D'âge moyen il pèse ; vert, 0,78 ; complétement desséche à l'air, 0,62 (Baudrillard). Il fournit un bon combustible, produit un charbon estimé.

L'écorce, qui contient de l'acide tannique, est employée en tcinture; il en est de même du brou.

Tout le monde connait la noix ; comestible lorsqu'elle est fraiche, elle produit une huile siccative qui sert à l'éclairage et à beaucoup d'autres usages, qui mème est comestible quand elle est nouvelle et faite à froid.

\section{FAMILLE LXVII.}

\section{CUPUlifères. A. Rich.}

Floraison monoïque. Fleurs mâles en chatons cylindriques, quelquefois globuleux, composées chacune d'un périgone de 5-9 divisions et d'étamines en nombre égal ou multiple, à filets allongés et dont les anthères, biloculaires, sont longitudinalement déhiscentes. 1-3 fleurs femelles au centre d'un involucre accrescent, formé de plusieurs rangs de bractées soudées entre elles par la base, entier ou à 4 valves et représentant une inflorescence dont l'axe ne s'est point allongé et qui se trouve réduite à des bractées presque toutes stériles, sauf 1-3; chaque fleur femelle formée d'un périgone tubuleux adhérent et d'un ovaire à 3-8 loges biovulées, à placentation centrale. Involucre fructifère cupuliforme-écailleux ou péricarpoïle-épineux, contenant 1 ou 2 rarement 3 fruits (glands) secs, indéhiscents, à péricarpe mince et coriace, presque toujours uniloculaires et monospermes par avortement, largement ombiliqués à la base et terminés par les débris desséchés des styles. Graines non périspermées, à cotylédons charnus, féculents, 
Arbres à feuilles alternes, simples, penni-nerviées, ì stipules caduques; bourgeons écailleux.

A. Involucre fructifère péricarpoïle-épineux, à 4 valves.

B. Glands trigones (faines); fleurs mâles en chatons globuleux, pendants................. HÈTnR....1

B' . Glands arrondis (ehàtaigne); fleurs mâles en chatons allongés, cylindriques, dressés............ Chatalgsier 2

A'. Involucre fructifère cupuliforme-écailleux, entier. Fleurs mâles en chatons cylindriques, làches et pendants ............................ Chìène...

GENRE 1. - HÊTRE. FAGUS. Tournef.

Fleurs mâles réunies 6-16 en un chaton globuleux, pendant à l'extrémité d'un long et grêle pédoncule, qui est pourvu, au delà de son milieu, de quelques écailles stipulaires linéaires et allongées, et qui naît à l'aisselle des écailles ou des feuilles de la base des jeunes pousses. Chacune d'elles, pédicellée, composée d'un périgone campanulé à 5 divisions, de 10 -20 étamines à filets allongés et d'un ovaire rudimentaire. 2 fleurs femelles dans un involucre 4-lobé, hérissé extérieurement de pointes molles, allongées et poilues, supporté par un pédoncule axillaire, solitaire, dressé, égal au pétiole ou un peu plus long, assez épais, naissant à l'aisselle de feuilles véritables au-dessus des fleurs mâles et pourvu à sa base d'écailles identiques à celles du pédoncule de ces dernières. Chaque fleur femelle composée d'un périgone adhérent, dont le limbe est libre et se divise en $4-9$ filets sous forme de pinceaux plumeux, et d'un ovaire trigone, 3-loculaire, 6-ovulé, surmonté de 3 stignnates allongés. 1 ou 2 glands (faînes) trigones, monospermes, à péricarpe mince, sec, brun et luisant, renfermés dans un involucre péricarpoïde ligneux, épineux, à 4 valves. Graine à cotylédons adhérents, plissés irrégulièrement, féculents-huileux, épigés lors de la germination.

Bois lourd, dur, à tissu fibreux dominant, asssocié à du parenchỵme ligneux disséminé (non apparent, même à la loupe); vaisseaux égaux, petits, isolés, régulièrement disséminés, si ce n'est au bord externe oì ils deviennent rares; rayons inégaux, les uns larges, indéfinis, peu hauts, assez espacés, les autres très-fins, invisibles à l'œil nu. Couches régulièrement circulaires, concentriques, légèrement rentrantes au passage des gros rayons.

Hêtre commun. Fagus syluatica. Liv. Fau; Fayard.

Feuilles pétiolíes, ovales ou ovales-oblongues, courtement acuminéc 
entières on sinuées-denticulées sur les $2 / 5$ supéricurs ou même fortement et largement dentées; ciliées sur les bords, glabres, d'un vert clair, brillant et presque semblable sur les 2 faces, minces et coriaces; nervure médiane et nervures secoudaires saillantes en dessous; celles-ci simples, parallèles, au nombre de 6-8 paires; les unes el les autres garnies, dans le premier âge, de longs poils blanes soyeux. - Grand arbre à ligge droile, cylindrique, à cime ovoïde-conique, revêtu d'une écorce mince, lisse et toujours vive jusqu’à la surface, grise ou blanchàtre; à bourgeons fusiformes allongés, pourvus d'écailles nombreuses, imbriquées, presque distiques.

Var. $\alpha$. Ilètre parasol. Branches, rameaux et ramules dirigés vers la tcre. Celte forme qu'il ne faut pas confondre avec celle de beaucoup d'arbres, dont les rameaux grêles et effilés pendent vers la terre, est l'analogue de celle du frène parasol que l'on voit si souvent dans les jarlins. Les hêtres qui la présentent, offrent, même à un âge avancé, une cime hémisphérique appliquée contre le sol et s'élèvent au plus à 2-5 Forêt de Verzy, près de lieims, où généralement elle ne se reproduit pas de semis.

Var. $\beta$. IIètre pourpre. Feuilles d'un pourpre noiråtre, un peu métallique, surtout au printemps. Cette variété, si fréquemment cultivée dans les jardins, a été observée à l'état sauvage dans la forêt de Darney, par M. Mailly, garde général.

Il n'est pas très-rare de rencontrer, en outre, des hêtres dont les fevilles sont panachées de blane pur et de vert (la Petite-Pierre, le Hohwald, Bas-Rhin), ou dont les branches et les rameaux sont pendants dans le genre de ceux du saule pleureur (forêt de Brotonne, Seine-Inférieurc).

Abondant dans toute la France, où il forme seul ou mélangé au chêne, all sapin, elc., des forêts étendues; Corse, en mélanģe avec les pins laricios et les sapins. Flor., avril-mai. Fructif., fin de septembre. Dissémination, octobre.

Le hètre est une des essences forestières les plus répandues et les plus importantes; il atteint de grandes dimensions, sans jamais parvenir cependant à celles des chènes et des sapins, en raison de sa longévité bien moins élevée. Il dépasse rarement 5-400 ans et ne parvient qu'exceptionnellement à $40^{\mathrm{m}}$ de hauteur sur $6^{\mathrm{nt}}$ de circonférence au maximum.

La tige, droite ct circulaire, se maintient remarquablement cylindrique jusqu'à une grande hauteur et reste distincte jusqu'à l'extrémité de la cime, quand l'arbre s'est développé en massif, sans accidents. Elle est souvent nue sur une longueur de $20^{\mathrm{m}}$ en dessous des branches principales. Quand le hêtre a cru isolément ou en futaie sur taillis, il se ramifie à 10-

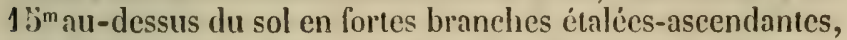
qui forment une cime ample, ovoüle, pointue au sommet ; Les jeunes pousses de première année sont d'un vert oli-

Taille.

Port. 
vàtre foncé, couleur qui se maintient jusqu’à 10 ans environ;

passe cet àge, les tiges et les branches sont d'un gris cendré.

Ecorce. L'écorce du liétre, après la chute de l'épiderme, offre à la surface une mince couche subéreuse; en dessous, du parenchyme vert et, à la face interne, une couche de liber. Ces trois régions conservent, pendant toute la vie de l'arbre, les mêmes relations et toute leur vitalité ; jamais il ne s'y développe de périderme interne et par conséquent il ne s'y produit jamais de rhytidome. L'écorce reste toujours lisse et les zones qui la composent ne font que se distendre par l'interposition de nouveaux tissus, pour se prêter à l'accroissement ligneux interne, sans s'épaissir notablement. Seulement certaines grandes cellules du parenchyme vert sincrustent de substances minérales et deviennent en quelque sorte pierreuses.

La coloration blanchâtre de l'écorce du hètre ne lui est pas propre; elle est le résultat de nombreux lichens qui envahissent sa surface, dès l'àge de 10 ans et lui forment un enduit de leurs très-minces thallus.

Bourgcons.

Les bourgeons des hètres sont plus effilés, plus longs, plus pointus que ceux de la plupart des autres essences; ils sont glabres et luisants. Ils se développent en grand nombre; mais heaucoup d'entre eux ne produisent que des pousses très-courtes, qui conservent longtemps leur vitalité et dont les feuilles, très-rapprochées, scmblent fasciculées. Ce fait est la conséquence du tempérament du hêtre, qui permet aux ramules et aux bourgeons inférieurs de croitre et de former des feuilles malgré le couvert des parties supérieures ; il produit naturellement une ramification serrée, un couvert très-épais.

Feuilles. Les feuiles sont alternes, $\frac{1}{2}$; l'hectare de futaie, en massif complet d'une belle végétation, en produit, dès l'àge de 50 ans, des quantités sensiblement égales jusqu'à l'exploitabilité; en moyenne annuelle : 11,600 kil. à l'état vert; 3,100 kil. desséchées à l'air; 4,360 kil desséchées à $60^{\circ}$. Ces feuilles suffisent pour recouvrir 11 fois toute la surface qui les a produites. Elles se décomposent assez lentement, généralement en 6 ans, et constituent, par leur accumulation, une épaisse couverture sur le sol ('T. Ilartig).

Fruetification. Le hètre ne fructifie qu'à un àge avancé, vers $60-80$ ans en massif, 40-50 ans quand il est isolé; il ne produit de fainées abondantes que tous les $5-6$ ans, sous les circon- 
stances les plus favorables, et quelquefois tous les $13-20$ ans seulement. Dans ce dernier cas, dans l'intervalle des pleines fainées, il y a des fainées partielles. Il est remarquable, à ce sujet, que, dans certaines années, il y a manque tellement absolu de faines, qu'on ne parviendrait pas souvent à en recueillir un litre, mème en parcourant des surfaces considérables. Les fainées complètes sont généralement plus communes dans les plaines et dans les coteaux que dans les régions montagneuses élevées, mais en retour les années de disette absolue n'y sont pas rares. En montagnes, si les fainées complètes ne viennent qu'à de longs intervalles, les fainées partielles s'y succèdent presque sans interruption.

Les bourgeons floraux se forment dès le mois d'aoùt et sont d'une distinction très-facile; leur abondance, leur rareté, leur manque absolu règlent, dès ce moment, d'une manière presque certaine, le sort de la fainée de l'année suivante. On ne saurait donc expliquer par l'action seule des gelées printanières les irrégularités que l'on remarque dans la fructification de cette essence.

La faine est d'une conservation très-difficile, même jusqu'au printemps suivant, et il vaut mieux, en général, la semer dès l'automne. Le kilog. en contient environ 5, 500 .

Semée en automne, elle germe de très-honne heure au printemps, vers la fin d'avril. La tigelle s'allonge immédiatement en dessous du corps cotylédonaire, repousse celui-ci hors de terre à environ 1 décimètre et les deux cotylédons, repliés irrégulièrement les uns sur les autres, se développent en 2 larges feuilles opposées, charnues, réniformes, entières, vertes en dessus, d'un ḅlanc soyeux en dessous. Celte précocité, ce grand développement de la tigelle et des feuilles cotylédonaires au-dessus du sol, la consistance molle tes tissus accrus rapidement rendent le jeune plant trèssensible aux accidents de température, surtout aux gelées printanières.

Pendant les premières années qui suivent le semis, le plant s'accroit lentement, environ de 1 décimètre de hauteur

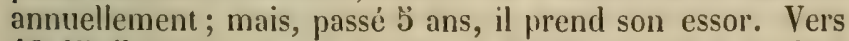
40-45, il parvient à son maximum d'allongement annuel; à 100 ans, l'arbre ne s'accroit plus sensiblement en hauteur.

Chaque couche annuelle est $2-3$ fois plus épaisse ver's le sommet qu'à la base; cette circonstance, que l'on remarque dans toutes les autres essences, mais à un moindre

Germination.

Croissance. 
degré, assure à la tige du hère eette forme cylindrique qui se maintient jusqu’à une grande élévation.

Enracincment. Dans les premières années, la racine pivote, reste simple et s'enfonce ì peu près autant dans le sol que la tige s'élève dans l'air. Vers 5 ans, 2-3 racines latérales obliques, pourvues d'un chevelu abondant, se développent; vers 12-13 ans, elles prennent une grande extension, aux dépens du pivot qui s'arrète pour toujours; à 50 ans, elles cessent elles-mèmes de croitre et sont alors remplacées par des racines superficielles, traçantes, souvent en partie saillantes hors du sol jusqu'à une certaine distance du pied de l'arbre. Dans les sols pierreux ces racincs s'entre-greflent fréquemment entre efles. En somme, l'enracinement total est peu profond, $0^{\mathrm{m}} 50-0^{\mathrm{m}} \mathrm{\jmath} 0$, mais très-étendu en superficie; il présente un volume de bois souterrain qui est au volume du bois superficiel (tige et eime) comme 1 : כै environ.

Bourgcons. La plupart des bourgeons du hètre se développent en pousses, allongées ou tuberculeuses, et peu d'entre eux restent à l'état d'œils dormants (bourgcons proventifs); cncore ces derniers perdent-ils assez vite leur vitalité, en

Reproduclion par rejets.

Station.

Sol.

Tendance envahissante. général vers 20 ans. La reproduction par rejets ne peut done avoir lieu abondamment par les bourgeons de cette nature, comme dans la plupart des autres essences; elle est souvent presque uniquement basée sur les bourgeons adventifs, s'organisant sur un bourrelet qui sort d'entre le bois et l'écoree au printemps qui suit l'exploitation.

Le hètre ne dépasse pas, vers le midi, l'Espagne et la Sicile et manque en Algéric. Dans les contrées méridionales, il caractérise les regions montagneuses; mais, vers le nord, il vient très-bien en plaine, les plaines basses et humides exceptées, et il se plait surtout dans les pays légèrement accidentés. Dans les Vosges, il s'élève encore à une altitude de $1200^{\mathrm{m}}$; à la vérité, il y est rédluit à l'état de buisson. En général, son aire d'habitation se confond avec celle du sapin; mais, bien plus développée suivant la verticale, elle la dépasse quelque peu dans la montagne et se prolonge beaucoup plus qu'elle dans les régions basses. Les sols calcaires lui sont particulièrement favorables, bien qu’il prospère sur des terrains de composition différente.

$\Lambda$ la faveur de son couvert épais et de l'aptitude qu'il possède de résister assez longtcmps à son action, le hêtre est une essence cnvahissante qui, en beaucoup de contrées, 
s'est substituée aux espèces à couvert léger, telles que les chẻnes, les pins et les boulcaux. C'est ce qui est arrivé en Danemarck, en Ilollande, etc., où, comme l'attestent les nombreuses tourbières qui s'y rencontrent, cet arbre n'existait pas autrefois, tandis que les pins, à en juger par la fréquence de leurs débris, y étaient abondants; le hẻtre est actuellement l'essence principale des forèts de ces contrées, le pin en a disparu. Jules César ne trouva pas de hêtres en Angleterre, quoiqu'ils y soient communs aujourd'hui.

Malgré les analogies botaniques, le hêtre produit un bois d'une structure bien différente de celle du chène et du châtaignier. Cette structure a été donnée plus haut.

Ce bois est blanc quand on le coupe; il devient rougeâtre à l'air ct passe au gris rougeâtre clair' et uniforme lorsqu'il est sec; son aubier est blanc. Il a peu de souplesse, se tourmente et se gerce aisément, cst sujet à la vermoulure et ne prend pas un beau poli ; soumis à des alternatives de sécheresse et d'humidité, il se conserve peu longtemps, mais il acquiert assez de durée sous l'eau ou dans les lieux constamment humides.

Le hètre n'est pas, par conséquent, un bois de construction; mais, d'une fente et d'un travail facile, il est fréquemment employé dans l'industrie, particulièrement par les charrons, pour les jantes de roues, par les menuisiers, mécaniciens, boisseliers, sabotiers.

La densité est très-variable. Des expériences nombreuses de T. Hartig, sur des bois de taillis et de futaie, ont donné à cet égard les résultats suivants.

Densité du bois de hêtre coupẻ en sc̉ve, 0,822 à 1,04.

Id. desséchć à l'air, 0,64 à 0,84 .

En général les bois de futaie de 80 ans et au delà restent en dessous de la moyenne; ceux de futaie de 40-80 ans et de futaie sur taillis l'atteignent; ceux de $\mathbf{4 0}$ ans et au-dessous, futaie ou taillis, la dépassent.

En outre, pour un mème arbre, la densité varie suivant que le bois soumis à l'expérience provient d'une région de la tige plus ou moins élevée au-dessus du sol, suivant qu'il appartient au cœur ou à l'aubier. Mais les résultats obtenus à cet égard sont tellement contradictoires qu'il est impossible d'en rien conclure de général.

L'emploi le plus important du hètre est de servir de com-

Bois.

Densité.

Valeur calorilique. 


\section{2}

bustible. Sa puissance calorifique a été prise pour unité par les principaux auteurs qui se sont occupés de cette matièrc (G. L. Hartig, Werneck, T. Hartig), non qu'elle soit la plus élevée, car elle est surpassée par celle de quelques autres bois (charme, sorbier, etc), mais parce qu'clle est la mieux connue, en raison de l'abondance de l'espèce et de son fréquent emploi pour le chauffage.

Cette valeur calorifique est d'ailleurs aussi variable que l'est la densité, à laquelle elle est proportionnelle.

Le bois de hêtre brủle avec une flamme vive et claire et produit un charbon qui se maintient incandescent jusqu’à complète combustion; il a le défaut de passer un peu vite au feu.

Son charbon est très-estimé ; il sert dans l'économie domestique et, dans l'industrie, pour le traitement des minerais.

Produit accessoire.

On retire de la faine une huile grasse non siceative, qui est comestible et bonne à l'éclairage. L'amande dépourvue de son péricarpe et de son épisperme peut en fournir 15-17 p. $0 / 0$ de son poids. C'est un produit assez important pou" que, dans les années favorables, on vende, par voie d'adjudication, le droit de récolter ce fruit.

\section{gente II. - CHATAIGNIER. CASTANEA. Tournef.}

Fleurs mâles en petits glomérules munis d'une bractée et disposés en longs chatons cylindriques, interrompus, dressés, naissant à la base des feuilles inférieures de la jeune pousse; chaque fleur composée d'un périgone campanulé de 5-6 divisions et de 10-12 étamines longuement saillantes. Fleurs femelles, au nombre de 3 , dans un involucre commun formé de nombreuses bractées soudées entre elles par la base, involucre dont 1-3 sont placés à la base des chatons mâles supérieurs; chaque fleur composée d'un périgone adhérent, terminé par 6-8 petites dents libres; de 6-8 étamines opposćes, stériles ou rarement fécondes et d'un ovaire infère à 6-8 loges bi-ovulées, surmonté d'un style court à 6-8 stigmates. Involucre fructifìre péricarpoïde, de consistance presque ligneuse, s'ouvrant en 4 valves et revêtu d'épines raides, subulées, fasciculées-divergentes; contenant 1-3 fruits arrondis ou tronqués suivant leur nombre (châtaignes), à péricarpe mince, sec, luisant et brun, marrué à la loase d'une large cicatrice (hile); ces fruits renferment 1, plus rarement 2 graines à cotylédons très-développés, adhérents entre eux, féculents, hypogés en germant. 
Bois à tissu fibreux serré et ì parois épaisses, subdivisé, dans chaque couche, par du parenchyme ligneux, en zones concentriques mal circonscrites et peu apparentes; vaisseaux inégaux, gros dans la zone interne, petits et groupés en lignes rayonnantes flexueuses, quelquefois rameuses, dans la zone médiane et externe. Rayous médullaires très-minces.

Châtaignier commun. Castanea yulgaris. Lam. Castanea vesca. Gortn. Fagus castanea, Lin.

Feuilles pétiolées, longues d'environ 2 décimètres, oblongues-lancéolées, acuminées, bordées de fortes dents cuspidées, qui correspondent aux nervures; fermes, glabres et luisantes sur les deux faces ou pourvues en dessous, dans la jeunesse, de poils raides, appliqués; d'un vert plus foncé en dessus qu'en dessous; à nervure médiane et nervures secondaires saillantes en dessous, ces dernières droites, simples, parallèles, nombreuses (15’-20 de chaque côté). Bourgeons n'offrant que 2 écailles à l'extérieur, glabres, courtement ovoïdes, oblus, d'un vert jaunâtre. Arbre de grande dimension, caractéristique des sols granitiques ou siliceux des régions montagneuses peu élevées. France, Corse, Algérie. Flor., fin de juin - mi-juillet. Fructif., octobre.

Le chàtaignier est un grand arbre à végétation rapide, particulièrement depuis sa jeunesse jusque vers 50.60 ans; il est doué d'une très-grande longévité, atteint une hauteur de $50^{\mathrm{m}}$ et une circonférence énorme. Sans parler du châtaignier si connu de l'Etna, dont le trone, mesurant $53^{\mathrm{m}}$ de circonférence et d'ailleurs complétement creux, pourrait bien être le produit de 5 arbres différents, on peut citer celui des environs de Sancerre (Cher), qui, à hauteur d'homme, a $10^{\mathrm{m}}$ de tour, est parfaitement sain, au moins en apparence, et a, dit-on, 1000 ans. Un autre châtaignicr, des bords du lac de Genève, mesure $15^{\mathrm{m}}$ de circonférence.

Lorsqu'il croit en massif, le châtaignier s'élève droit et se ramifie à peu près comme le chène pédonculé; isolé, sa lige n'acquiert pas d'élévation, se ramifie beaucoup et produit une ample cime très-étalée.

L'enracinement est formé d'un pivot assez allongé et de nombreuses et fortes racines latérales.

Quoique la ramification ne soit pas serrée, le couvert est assez épais, en raison de la grande dimension des feuilles et de leur direction horizontale. L'insertion de ces organes est $\frac{2}{5}$ sur les pousses principales, $\frac{1}{2}$ sur les pousses latérales.

Les jeunes pousses sont d'un brun olivàtre, marquées de lenticelles allongées; vers $3-6$ ans elles prennent une couleur olivâtre et les lenticelles se sont étendues en travers.

Taille.

Port.

Enracinement.

Couvert.

Ecorce. 
Plus tard l'ćcorce a la coloration, d'un gris argentí, de celle du jeune chine et, comme elle, reste lisse et lirillante jusque 1:3-20 ans. A cet àge un périderme intérieur s'organise par plaques dans l'épaisseur des feuillets du liber et repousse ceux-ci au dehors, sous forme d'un rhytidome épais, persistant, largement et profondément gerẹuré en longucur, de coulcur brune assez foncée, qui rappelle complétement celui des vieux chènes.

Fructification. Le chảtaignier fructifie ver's $20-50$ ans s'il est isolé, vers 40-60 ans s'il est en massif; ses années de semences sont assez rapprochées, à $2-3$ ans de distance, et sont génćralement abondantes.

Germination. Lorsque le jeune plant se développe, il laisse pourrir en terre ses cotylédons, après les avoir épuisés ; ses premières feuilles, qui proviennent de la plumule, sont semblables à celles qui se produiront par la suite. Sa végétation est rapide dès les premières années.

Rejels. Celte essence possède à un haut degré la propriété de se reproduire de souches et celles-ci, lorsque leur âge n'est point trop élevé, fournissent des cépées d'unc végritation extraordinaire.

Station et sol. Le châtaignier est essentiellement silicicole et se plait partieulièrement dans les sols accidentés granitiques, sablonneux ou schisteux; les sols calcaires ne lui conviennent pas. Il n'atteint pas une grande altitude, et dans les Vosges, où du reste il ne parait pas indigène, il ne dépasse pas $600^{\mathrm{m}}$. Il est particulierement commun dans le centre et dans le midi de la France, dans le Dauphiné, le Limousin, le Périgord, les Céremnes, la Provence et la Corse. Mais dans ees contrées il ne forme pas de massifs étendus, complets, et le plus souvent il est isolé et plutôt considéré comme arbre fiuitier que comme arbre forestier.

Il est douteux qu'il soit indigène dans le nord et le nord-est ct l'opinion populaire que eet arln'e était autrelois beaucoup plus abondant dans ces contrées et entrait dans la composition du peuplement des foréts, d'où il aurait disparu à la suite de l'hiver de 1709 , ne parait pas fondée. Il n'y était évidemment, alors comme aujourd'hui, que cultivé et, à imcune éporque, les sols calcaires de ces régions n'ont pu lui convenir.

Bois. Le hois de chataignier est de meme couleur que echir du chene; l'aubier en est également blance et nettement tran- 
ché; il a le mème grain, les mèmes lissus, mais non les larges rayons médullaires; les siens sont très-minces et par conséquent il n'est jamais maillé. Rien de plus facile que de distinguer, mème sur le moindre fragment, les bois de ces deux essences, fussent-ils mis en œuvre depuis une époque très-reculée. Depuis longtemps déjà Daubenton avait reconnu et signalé cette différence et restitué au chène le mérite de bien des vieilles charpentes ( $\mathbf{S}^{\text {te }}$-Chapelle, Notre-Dame), altribuées jusqu'à lui au châtaignier. Une tradition semblable sur l'essence qui a servi à la construction des édifices anciens se retrouve en beaucoup d'autres points de la France et ne parait nulle part mieux fondée; le plus léger examen prouverait indubitablement que le chêne a fait à peu près partout les frais de ces charpentes réputées indestructibles et que celles en chàtaignier véritable sont tout aussi chimériques que les forèts qui les auraient produites (1).

Le bois pèse, vert, 0,84 ; desséché à $60^{\circ}, 0,58$ (T. Ilartig). Celui d'une tige de 70 ans, provenant de la Corse, a donné, complétement desséché à l'air, 0,63 (Coll. Ec. For". Envoi de M. Simon).

Le chàtaignier a une grande disposition à se carier au coeur et l'on ne peut généralement en obtenir de pièces d'un fort équarissage. Employé à couvert, à l'abri des variations atmosphériques, il a de la clurée; mais il se pourrit promptement sous des alternatives de sécheresse et d'humidité. Il est bon bois de fente et fournit un merrain estimé. Exploité en taillis, il occupe le premier rang pour la fabrication des échalas et des cercles de futailles et, en Alsace, il se paie pour ce premier usage un quart en sus du chene (de Salomon).

Comme bois de chauffige, il parait inféricur au chẻne, avee lequel il partage l'inconvénient de pétiller au feu et de produire un charbon qui noireit rapidement. Le charbon est diversement apprécié; il sert néanmoins à la forge dans les pays où cet arbre est abondant.

L'écorce est très-peu riche en tannin et n'est point uti- Produits divers. liscic à cet égard.

(1) M. S. des Estangs, Sous-Inspecteur des forcits, a constaté en effet que toutes les charpentes, prélendues en chataignier, des édifices de Troyes, Hheims, Seus et Chartres, sont ca chene. (Annales forestieres, 1. vi, P. 189.) 
La chàtaigne est un des produits importants, souvent le principal, de cette essence; elle est la base de l'alimentation des populations pauvres du plateau cential de la France et de la Corse.

Améliorée par la culture, plus grosse et régulièrement arrondie, par suite de son développement solitaire dans l'involucre, elle constitue le Marron, dont on connait un grand nombre de variétés, qui toutes se propagent par la greffe sur le châtaignier commun.

\section{GENRE MI. - CHÊNE. QUERCUS. Tournef.}

Fleurs mâles en chatons cylindriques, grêles, làches, interrompus, pendants, sortant par faisceaux des bourgeons axillaires de l'extrémité de la pousse de l'année précédente, ou naissant solitaires à la base des pousses de l'année, à l'aisselle des feuilles ou de 2 écailles stipulaires caduques; chaque fleur bractéolée, composée d'un périgone de 5-9 folioles plus ou moins réunies par leur base et de 5-9 étamines, à anthères biloculaires, extrorses. Fleurs femelles sessiles, naissant en petit nombre, agglomérées ou espacées sur un axe court ou allongé, dressé, défini, solitaire à l'aisselle des feuilles de l'extrémité de la pousse de l'aunée; chacune d'elles unique dans un involucre formé de petites et nombreuses écailles imbriquées et accompagné à la base de 1-3 bractéoles; périgone adhérent, à très-petites dents libres; ovaire infère, 3-loculaire, dont chaque loge est bi-ovulée, surmonté par 1 style et 3 stigmates rouges. Gland ovoïde, apiculé au sommet, à involucre cupuliforme écailleux, à péricarpe coriace, mince, luisant; généralement 1-loculaire et monosperme par avorlement ; cotylédons épais et charnus, plans-convexes, féculents, hypogés par la germination. - Arbres à feuilles simples, spiralées suivant l'indice $\frac{2}{5}$, caduques ou persistantes, à maturation annuelle ou bisannuelle; à bourgeons revêtus d'écailles nombreuses, imbriquées-spiralées, superposées en 5 séries longitudinales.

Bois dur et lourd, d'un brun fauve, à aubier blanc, en général nettement circonscrit. 'Tissu fibreux très-serré, à parois épaisses, de consistance presque cornée, partagé en zones concentriques crénelées par du parenchyme ligneux féculifère, de couleur plus claire, surtout apparent dans les bois du midi. Vaisseaux inégaux; gros et serrés dans le bois de printemps, décroissants jusqu'au bois d'automne ou ils sont petits et peu abondants; rarement presque égaux; groupés avec du parenchyme suivant des lignes 
rayonnantes ondulées. Rayons inégaux ; les uns épais, longs ou indéfinis, hauts, assez espacés, produisant de larges maillures nacrées, quand le débit du bois est fait dans une direction convenable; les autres très-petits et serrés. Canal médullaire pentagonal.

Le genre chène appartient presque entièrement à l'hémisphère boréal, dont il habite les régions tempérées ou les hautes montagnes des contrées équatoriales; les espèces qu'il renferme sont nombreuses et dépassent le nombre de cent ; comme c'est le cas pour les genres très-naturels, la délimitation en est pleine de difficultés et d'incertitudes (1). C'est à lui que se rapportent les arbres les plus majestueux de nos forêts, sinon par la hauteur, du moins par le caractère de force que leur impriment une tige robuste, une ramification puissante; à ces espèces de grande taille, s'en ajoutent d'autres de dimensions plus humbles et quelquesunes de ces dernières restent toujours à l'état d'arbrisseaux chétifs et buissonnants.

Les chènes exigent une insolation directe pour s'accroitre; aucun d'eux ne résiste à l'action du couvert. Il résulte de ce tempérament que les bourgeons les plus élevés et les mieux ćclairés se développent seuls et que, tous les autres restant stationnaires ou proventifs, la ramification est claire, le feuillage peu abondant, le couvert léger.

(1) Cette remarque s'applique non-seulement aux espèces exotiques, mais encore à celles qui habitent nos contrées; connues imparfaitement des botanistes, elles le sont bien moins encore des forestiers. C'est le genre chène cependant qui renferme les essences les plus précieuses et l'on ne saurait méconnaître tout l'intérêt qu'il y aurait à en distinguer nettement les espèces diverses, à en caractériser les races probablement nombreuses, à déterminer avec précision leurs exigences, leur mode de croissance, la qualité des bois que chacune d'elles peut fournir à la consommation. Une étude bien faile dans cette voie constitnerait certainement un progrès réel de là sylviculture, mais il ne faut pas s'en dissimuler les difficultés. Les organes auxquels les botanistes ont l'habitude d'emprunter les caractères spécifiques, les fruits et les feuilles principalement, paraissent se modifier dans de larges limites et l'âge avancé auquel la plupart des chènes fructifient rend presque impossible la voic expérimentale des semis pour constater si les différences que l'on observe se perpétuent sur des générations successives et dans des conditions diverses de sol et de situation, ou si elles sont fugitives; si en un mot elles caractérisent des espèces véritables ou de simples variétés. 
Rejels. Non-seulement les bourgeons proventifs sont nombreux, mais ils conservent leur vitalité jusqu'à un àge fort avancé, parfois au delà de 100 ans; cette double circonstance explique l'aptitude très-prononcée des arbres de ce genre à se couvrir de branches gourmandes et à repousser abondamment de souche, lorsqu'on a placé ces bourgeons dans des conditions meilleures, soit que, par l'éclaircissement des massifs, on leur' ait assuré une participation plus directe à l'action solaire, soit que, par la coupe ou la taille des arbres et la suppression de tous les bourgeons actifs qui en est la conséquence, ils aient pu prendre une plus large part d'alimentation.

Enracinement.

La racine des jeunes plants se compose d'un pivot simple et remarquablement allongé; cette disposition à pivoter se maintient plus ou moins longtemps suivant les especes, mais en tout eas l'enracinement est puissant.

Feuillage. Le feuillage des espèces septentrionales se dessc̀che à l'automne et tombe immédiatement ou persiste en cet état jusqu'au printemps suivant, surtout sur les jeunes plants ou rejets et sur les branches gourmandes; à mesure qu'elles deviennent plus méridionales, sa persistance s'accrołt; on le voit rester vert pendant toute la mauvaise saison et ne tomber qu'au moment ou les nouvelles feuilles se produisent chez les unes; chez les autres il se maintient vert pendant plusieurs années, il est persistant.

Station. Les pays de plaines ou de coteaux sont ceux où les chencs prosperent, et dans la plus grande partie de la France ils ne se rencontrent point dans les régions montagneuses, ou au moins ils n'y pénètrent qu'à l'état de dissémination et sans atteindre jamais une grande altitude. Cependant en s'avancant vers le sud, on voit leur station s'élever de plus en plus et en Algérie le chène zeen prospère encore à $1400^{\mathrm{m}}$ et plus, au-dessus du niveau de la mer.

Sol. Lespréférences à l'égard du sol varient suivant les espèces et se règlent, en partie du moins, sur la nature du feuillage. Tendre et herbacé, produisant en conséquence une transpiration abondante, il rendra l'espèce exigeante sous le rapport de la fiaicheur du sol (chène pédonculé). Cette exigeance sera moindre à mesure que la feuille prendra de la consistance (chène rouvre); clle sera très-faible dès que les organes loliacés, devenus persistants et coriaces, ne seront plus le siége d'une active transpiration (chène yeuse).

Glands. Rien riest moins stable que la grosseur et la forme des 
glands, mìme pour des chènes d'une seule espèce; leurs différences en longueur et en diamètre vont du simple au quadruple; généralement ovoïdes, ils présentent toutes les transitions entre les formes cylindriques et globuleuses, sont tantòt obtus au sommet, tantòt plus ou moins aigus. Il ne faut pas attacher plus d'importance à leur nombre, car ils peuvent être solitaires ou agglomérés par 2-6 sur un seul axe, qui lui-mème s'allonge ou reste très-court. Il n'en est pas de même de la maturation, qui peut être annuclle ou bisannuelle; dans ce dernier eas, le gland grossit à peine pendant l'annce de la floraison et e'est sur le rameau de seconde année qu'il est inséré à son complet développement. La dissémination est toujours automnale.

Les glands que l'on conscrve sont sujets à se dessécher entièrement et à perdre ainsi toute vitalité ; d'un autre còté leur substance féculente, dont l'état d'agrégation est sans doute peu avancé, se transforme très-aisément en matière stucrée sous l'influence d'une légère humidité et de la moindre température $\left(3-4^{\circ}\right.$ au-dessus de $\left.0^{\circ}\right)$, et détermine une germination anticipéc; si, pour éviter cet inconvénient, on les place sous l'eat, ils se trouvent exposés à fermenter dès que la température s'élève un peu, et comme ils ne disposent pas d'assez d'oxigène, celte fermentation ne provoque pas leur germination, mais engendre des produits acides noirâtres (acide humique) et leur pourriture complète. Cet accident survient aussi fréquemment dans les semis, lorsque les glands sont enterrés profondément, lorsque la terre est très-compacte ou fortement humide, ou bien encore lorsque sa surface s'est tassée et durcie et a perdu toute perméabilité pour l'air.Il résulte de ces circonstances que les glands ne se conservent que difficilement et pas au delà du printemps.

La germination est prompte et a lieu, pour peu que la température soit douce encore, à l'automne mème de la dissémination; mais le plant n'a point habittellement le temps de se développer et bien des glands chez lesquels ce travail est commencé perdent leur vitalité par les froids rigoureux de l'hiver. Semés en automne et convenablement recouverts, ils germent au premier printemps; semés en celte dernière saison, ils germent au bout de 4-5̆ semaines. La radicule apparait la première sous forme d'un long pivot simple qui s'enfonce dans le sol; 8 jours après sculement la plumule se dégage et s'élève dans l'air en produisant im- 
médiatement des feuilles alternes et caractéristiques; quant aux cotylédons, ils sont hypogés, c'est-à-dire qu'après s'ètre épuisés de toute leur substance alimentaire au profit de l'embryon, ils restent en terre et finissent par y pourrir. Le jeune plant a acquis à la fin de l'année 1-2 décimètres de hauteur au plus.

Il n'est pas rare qu'en raison de la basse température sous laquelle germent les glands, ils aient à l'époque du semis une radicule déjà plus ou moins saillante et souvent brisée, à cause de sa fraglité. De semblables glands ne doivent pas ètre rejetés; ils produisent des plants qui, au lieu d'avoir un long et unique pivot, sont pourvus de racines latérales et d'un chevelu abondant et offrent plus de facilités pour l'extraction et la transplantation.

On voit parfois un seul gland donner naissance à plusieurs radicules et à plusieurs plants distincts, jusqu'à 6 . Ce fait n'aura rien de surprenant, si l'on se rappelle que ce gland provient d'un ovaire à 5 loges biovulées et qu'il n'est monosperme que par suite d'avortements; ceux-ci sont à la vérité assez constants, mais néanmoins ils peuvent ne pas se produire, soit en partie, soit en totalité.

Les glands renferment beaucoup de fécule et sont souvent alimentaires; cependant dans les contrées du nord ils ont un goùt d'une âpreté prononcée et ne peurent convenir qu’à la nourriture du bétail et surtout à l'engraissement des pores; dans le midi cette àpreté disparait souvent et fait place à une saveur douce et agréable analogue à celle de la châtaigne. Lion ne peut établir aucune distinction spécifique sur celte difference, qui se produit fréquemment sur des chènes de mème espèce et parlois sur un pied unique. On peut en extraire de l'alcool, comme de toutes les matières amylacées; on les emploie quelquefois torréfiés comme succédanés du calé.

Ecorce.

L'écorce offre deux types bien distinets; dans l'un le liber s'accroit activement pendant toute la vie et vers un certain âge il se produit dans ses feuillets extérieurs des lames nombreuses de périderme qui déterminent la mort de l'enveloppe subéreuse et de l'enveloppe herbacée et forment un rhytidone épais, noiratre, plus ou moins profondément et largement gerẹuré, suivant les espèces. Dans l'autre, toute l'activité de la végétation corticale se porte sur l'enveloppe subéreuse qui ne cesse de s'épaissir de dedans en dehor's et devient le liége véritable; l'enveloppe herbacée et le liber, 
qui se trouvent en dessous, restent vivants, mais sans s'accroitre beaucoup et il ne s'organise jamais de lames de périderme dans leur intérieur.

Les chènes renferment abondamment dans la plupart de leurs organes des substances astringentes, antiseptiques, connues sous le nom de tannin ou d'acide tannique. Le libcr actif en est particulièrement pénétré et fournit par ce motif presque tout le $\tan$ que l'on emploie en France pour la préparation des cuirs. Les noix de galles, sortes d'excroissances globuleuses qui se développent sur le limbe des feuilles, par suite de la piqùre de certains insectes appelés cyniips, et les cupules contiennent aussi beaucoup de tannin. Dans le Levant, ces galles et ces cupules, connues sous la dénomination de vélanèdes, du nom du chẻne velani qui les fournit le plus habituellement, sont recueillies et forment une branche de commerce assez importante; elles servent principalement à la teinture en noir et surtout à la préparation de l'encre.

On observe de grandes différences dans la valeur du tan, suivant les espèces qui le fournissent. Cette valeur s'accroit en général à mesure que la latitude devient plus méridionale et que le développement cortical se fait avec plus d'activité, ce qui se traduit par l'épaisseur considérable que peut atteindre l'écorce des vieux arbres. C'est pour ces motifs que les chènes à feuilles persistantes du sud produisent un meilleur tan que les chènes à feuilles caduques du nord; que parmi les premiers le chêne liége est préféré, tandis que parmi les seconds le chène tauzin et le chène chevelu passent avant le chène rourre et le chène pédonculé, lors mème que les conditions de leur croissance se sont trouvées identiques sous tous les rapports. Des différences semblables se présentent dans les écorces d'une mème espèce, suivant l'àge et les circonstances sous lesquelles les arbres se sont développés. Une végétation active, produisant une écorce épaisse et séveuse, lisse et argentée à la surface, en accroit la qualité; une exposition vivement et longtemps éclairéé, favorise la production et la concentration du tannin; l'àge enfin, en faisant passer les portions externes à l'état inerte, les prive de séve, par conséquent de matière astringente, et en amoindrit la valeur.

Les chiffres suivants donnent une idée générale de la teneur en tannin des écorces et de quelques autres organes des chênes. 
L'écorce entière d'un vieux chène (pédonculé?) (6,5 p. 0/0 (Darys).

Le rhytilome

Le lilier actif

Le lilier d'un jeune chêne

La noix de galle

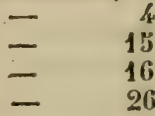

Il faut, d'après Ilermbstaedt, pour tanner $0^{k}, \vdots 0$ de peau desséchée :

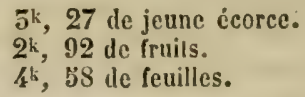

Dosage du tannin.

Il peut ètre utile de déterminer la richesse d'une écorce en tamnin ou de comparer entre elles les écorces de diverses provenances afin d'en régler la valeur vénale; on y parviendra avec une approximation suffisante par le procéclé suivant. On compose une liqueur titréc, contenant du tannin pur et desséché à 110 , soit 1 gramme de ce dernicr dans 100 grammes d'eau; on y verse goutte à goutte, au moyen d'une burette graduće, une dissolution de gélatine, jusqu’ì ce qu’il ne se forme plus aucun précipité. On connait par celle première épreuve la quantité de dissolution gélatineuse nécessaire pour neutraliser un gramme de tannin.

On prend alors des poids égaux des écores que l'on veut étudier, après les avoir amenées à un même degré de dessiccation; on les pulvérise et on les épuise par l'eau à la température ordinaire, pourr se placer dans les conditions de l'industrie qui les emploie. On filtre, on recucille les diverses solutions dans des vases séparés et l'on ajoute dans chacunc d'elles la quantité d'eau nécessaire pour lui donner un poids qui soit exactement un mulliple de cclui de la liqueur titréc sur laquelle on a précédemment opéré, c'est-à-dire, de 100. Cela fait, on sépare 100 grammes de chacune de ces solutions et l'on y verse séparément et avec les mèmes précautions que dans le premier essai la liqueur gélatineuse léjà employée. La lecture de la quantité verséc dans les épreuves suecessives et sa comparaison avec celle qui a été nécessaire pour précipiter un gramme de tannin donnent la richesse de chaque solution; il suffit de multiplier les résultats par les nombres qui expriment les rapports existants entre les 100 grammes sur lesquels on a opéré et le poids total de la solution pour connaitre la valeur des écorces soumises à l'analyse et pour être à méme de les comparer entre elles. 
L'acide tannique est sujet à fermenter quand il se trouve en présence de matières azotées et sous l'influence de l'air, de l'humidité et d'une certaine chaleur. Il absorbe de l'oxygène, dégage de l'acide carbonique et se transforme en acide gallique, qui a bien encore les propriétés tinctoriales du premier quand on le met au contact de sels de fer, mais qui ne s'unit plus à la gélatine et ne peut servir au tannage. Il faut done garantir les écorces contre l'effet de l'humidité ct les faire dessécher rapidement.

L'écorce pulvérisée qui, sous le nom de $t a n$, a servi au tannage, prend le nom de tannée et s'emploie comme combustible, sous forme de mottes. Elle est en outre recherchée des horticulteurs pour faire des couches dans lesquelles on place les pots de fleurs; la lente fermentation qui s'y développe produit une douce chaleur, très-favorable à la bonne venue des plantes délicates.

Le bois des chènes est le plus précieux de tous ceux que produisent nos forèts et, parmi les essences exotiques, il en est bien peu qui l'égalent pour les usages auxquels on l'emploie. Par ses grandes dimensions, sa résistance, la durée sous l'eau et à l'air, que lui assure, en partie du moins, l'acide tannique dont il est pénétré, il occupe sans contestation le premier rang pour les constructions civiles et militaires, hydrauliques et navales; c'est avec lui qu'on fait les pièces principales des machines, les arbres de couche des usines, tout ce qui enfin exige de la force et de la durée ; il fournit la plupart des traverses des chemins de fer et si on lui substitue parfois des bois d'autres essences, qu'il est nécessaire d'injecter de matières préservatrices avant de les mettre en ouvre, il ne faut l'attribuer qu'à sa rareté et à son prix élevé. Le charronnage et la menuiserie l'emploient à des usages nombreux, rais des roues, parquets, meubles, etc., l'ébénisterie mème en tire un très-bon parti sous forme de placage, surtout quand il est convenablement débité sur mailles; son merrain est très-recherché en tonnellerie; enfin on en fait des lattes, des échalas, des treillages, etc., etc. Toutes ces qualités ne se trouvent pas développées au mème degré chez tous les chênes; la nature de l'espèce y apporte des modifications importantes qui seront indiquées à propos de chacune d'elles, mais on peut dire dès à présent que plus leur aire est méridionale, plus leur bois est compacte et lourd, plus le tissu fibreux en est serré et domiuant, 
plus aussi les vaisseaux du bois de printemps sont petıts, rares et se rapprochent par leurs dimensions de ceux du bois d'automne. C'est à ce point que, dans le chêne yeuse, ils manquent à peu près complétement, de sorte que les accroissements se confondent entre eux et qu'il est le plus souvent impossible de déterminer à leur aide l'àge de cet arbre. Le sol, le climat, l'exposition, le mode de culture exercent aussi à cet égard une influence très-prononcée, qui se traduit par l'épaisseur des couches annuelles et par la quantité et probablement aussi la qualité de la lignine qui en incruste les lissus.

Les chèncs qui ont les accroissements minces offrent un bois poreux, dont la majeure partie est constituée par la zone de gros vaisseaux due à la végétation du printemps. Ils proviennent de mauvais sols qui perdent toute humidité dès que les chaleurs de l'été se font sentir et sur lesquels conséquemment la végétation s'arrète de très-bonne heure. Les chènes qui ont les couches annuelles épaisses présentent un bois compacte, lourd et nerveux, dans lequel la zone poreuse interne est à peine plus large que chez les précédents, où domine au contraire, dans unc proportion d'autant plus grande que les accroissements sont plus forts, le tissu fil)reux avec les petits et rares vaisseaux de la zone externe. Ils eroissent sur les sols de bonne qualité, qui, conservant leur fraicheur pendant toute l'année, alimentent la végétation jusqu’a la lin de la saison et lui permettent d'organiser les lissus résistants de l'été et de l'automne. Quant ì la quantité de la lignine, elle dépend de la somme d'insolation que recoit chaque arbre, de l'ampleur de cime et du développeinent du fenillage sur lesquels cette action s'exerce. Elle est done plus grande dans les climats chauds et aux expositions méridionales que partout ailleurs, à une condition cependant : e'est que l'insolation ne produira pas le dessechement du sol et l'arrèt de la végétation juste au moment où la lignine pourrait se produire.

Le bois parfait a seul les excellentes qualités qui viennent d'ètre énumérées; l'aubier, dont les larges rayons et l'abondant parenchyme ligneux sont remplis de matières féculentes ou sucrées, suivant la saison, est au contraire rapidement athaqué par la vermoulure dans les lieux sees, par la pourriture et les champignons dans les lieux humides; il doit toujours étre rejeté. Pour aucune essenee cette différence n'est aussi prononece que dans les chènes. 
Le bois de chène a une puissance calorifique élevée, qui s'accroil naturellement avec la densité; mais sa valeur vémale ne lui est pas toujours proportionnelle, parce que le mode de combustion offre pour quelques espèces (chène rouvre et chène pédonculé) certains inconvénients, tels que celui d'éclater, d'exiger un tirage actif, de produire une braise qui noircit aisément. Celte valeur se relève pour les charbons, qui sont tous de bonne qualité.

A. Feuilles caduques, soit en automne, soit au premier printemps; presque toujours inembraneuses; sinuées-lobées, pinnatifides ou crénclées.

B. Glands à maturation annuelle, placés sur les ramules fcuillés de l'année; cupules à écailles apprimées.

C. Feuilles glabres ou plus ou moins pubescentes en dessous à l'état adulte; racines non drageonnantes.

D. Feuilles totalement glabres, subsessiles; style allongé en colonne; axe fructifère allongé, grêle et glabre, le plus souvent pendant à la malurilé; écailles de la cupule largement triangulaires au sommet.

C. rénoxcuré.. I

D!. Feuilles plus ou moins pubescentes en dessous, au moins aux aisselles des nervures; pétiolées; style nul; axe fructifère nul ou faiblement allongé, robuste, diessé, pubescent, dépassant rarement la longueur du pétiole; écailles de la cupule longuement triangulaires au sommet.................

C. Feuilles adultes mollement et densément to-
menteuses en dessous, parsemées en dessus de poils rameux-étalés; racines abondamment drageonnantes...............

'B'. Glands à maturation bisannuelle, placés sur les ramules défeuillés de 2 année; cupule à écailles allongées, saillantes. Ecailles extérieures des bourgeons et stipules; longtemps persistantes, allongées-subulées.

C. Feuilles peu coriaces, caduques; concolores sur les deux faces................. c. creveru... \&

$\mathbf{C}^{\prime}$. Feuilles coriaces, sub-persistantes; vertes en dessus, blanchâtres en dessous.......... C. FAuX-Líck. b

$A^{\prime}$. Feuilles persistantes, restant vertes $1-5$ ans; $c 0$ riaces, très-entières ou dentées-épincuses.

B. Glands à maturation annuelle, placés sur les ramules de l'année.

C. Ecorce non subércuse; cupule à écailles apprimées ....................... 
$\mathrm{C}^{\prime}$. Ecorce subér'euse; cupule à écailles légèrement saillautes, d'autant plus longues qu'elles sont plus élevées; les supérieures molles et dressées.................

C. แน์ $\mathrm{R}, \ldots 7$

B'. Glands à maturation bisannuelle, placés sur les ramules, nus ou feuillés, de la $2^{\mathrm{e}}$ année.

C. Arbre à écorce subéreuse. Feuilles entières ou dentées-épineuses, grises-tomenteuses en dessous. Cupule à écailles apprimées; les inférieures légèrement prismatiques et réfléchies à leur base................

C. occidental. 8

C. Arbrisseau à écorce non subéreuse; feuilles toujours dentées-épineuses, vertes, glabres et luisantes en dessous.

D. Ecailles de la cupule prolongées en pointes courtes et rigides, presque vulnérantes.

C. Kermès.... 9

D'. Ecailles de la cupule apprimées, non prolongées en pointes............ C. des garrigurs. 10

\section{Section I. Chênes à feuilles caduques el à maluration anmuelle.}

(Feuilles sinuces-lobées ou-partiles, ì lobes arrondis ou aigus; gland ì cupule lisse ou, au plus, tuberculeuse.)

1. Chêne pédonculé. Quercus redunculata. Eirair. Q. robur. Lin. Q. racemosa. Lam. Duhamel. Chêne blanc (Gironde, Landes, Picardie); Chêne à grappes; Chène femelle; Gravelin; Châgne (France centrale); Chêne noir (dans le Blésois).

Feuilles brièrement pétiolées ou subsessiles, obovales-oblongues, se rétrécissant insensiblement jusqu'à la base, toujours formée de 2 petites oreilletles échancrées et contournćes; sinueuses ou pennatilobées, à lobes entiers, irréguliers, arrondis, obtus, mutiques; de consistance herbacée, d'un vert clair mat ou à peine luisant en dessus, un peu glauques en dessous, toujour's entièrement glabres sur les deux faces, même aux aisselles des nervures. Fleurs femelles éparses sur un axe allongé, grèle, souvent coudé, glabre; chacune d'elles terminée par un style cylindrique, en colonne, entouré vers son milieu d'un anneau formé par les dents libres du périgone et surmonté par des stigmates d'un rouge noiràtre, généralement au nombre de 5 , assez profondément séparés, dressés, d'égale largeur et dont l'extrémité seule est réfléchie en dehors sous forme de bourrelet. Glands variables, mais le plus souvent ovoïdes, oblongs, de 20-40 mill. de long sur 7-24 mill. de large, revêtus d'un péricarpe mince, lisse et luisant, parfois longitudinalement rayé de brun, insćrés, au nombre de 1-5, sur un axe commun, allongé, grểle, généralement pendant. Cupule hémisphérique, plus ou moins embrassante, à ćcailles planes-apprimées, relativement peu nombreuses, largement triangulaires et émoussées à l'extrémité, brunes et glabres ou très-faiblement et courtement grisìtres-tomenteuses. - Arbre de tres-grande taille, dont 
la cime est composée de quelques grosses et longues branches principales, plusieurs fois et irrégulièrement coudées, garnies de rameaux peu nombreux, sur lesquels le feuillage, d'une teinte générale claire, glauque et mate, est ramassé en touffes que séparent de grands espaces vides. Commun dans tout le nord, l'Est, l'Onest, le Sud-Ouest et le centre de la France où il forme des forêts importantes, rarement des futaies pures; se plaît particulièrement dans les plaines à sol frais ou même lumide; se trouve en mélange avec le chêne rouvre dans les pays accidentés de coteaux et de collines, disparaît dans les régions montagneuses. Flor., fin d'avril et commencement de mai. Fructif., annuelle, fin de septembre - mi-octobre.

Var. a. Chène pédonculé pyramidal. Chêne cyprès. Rameaux grêles et redressés contre la tige, qu'ils garnissent presque depuis la base, en formant une longue cime étroite, analogue à celle du peuplier d'Italie. Q. fastigiata. Lam. Fréquemment cultivé (1).

Le chène pédonculé est une espèce nettement caractérisée, qui atteint les dimensions les plus considérables. II présente, dans sa jeunesse et jusque vers $40-50$ ans, une tige irrégulière, anguleusement dressée; plus tard son fủt devient droit et cylindrique et parrient quelquefois, sous branches, à une hauteur de $20^{\mathrm{m}}$. Cet arbre peut arriver à une élévation totale de $50-55^{\mathrm{m}}$ et acquérir une énorme circonférence, grâce à sa longévité très-élevée. Le chène de Nontravail, près de Saintes (Charente-Inférieure), a 6-7 ${ }^{\mathrm{m}}$ de diamètre à hauteur d'homme; ses branches principales mesurent $1^{\mathrm{m}}$ de diamètre à leur base; la hauteur totale est de $20^{\mathrm{m}}$, l'envergure de $40^{\mathrm{m}}$; on porte son àge à 2000 ans.

La ramification du chène pédonculé se fait essentiellement par les bourgeons terminaux et fort peu par les bourgeons latéraux qui ne produisent que des rameaux et ramules grêles; aussi donne-t-elle à la cime de cet arbre un cachet particulier qui le fait distinguer de loin. Au lieu d'être composée d'une succession de branches d'un ordre décroissant, qui passent insensiblement des plus fortes aux plus faibles et assurent l'égale répartition du feuillage, cette cime n'est formée que de quelques grosses et longues branches principales, irrégulièrement coudées et flexueuses, portant sans

Taille.

Port.

(1) Le chêne pyramidal n'est certainement qu'une variélé du chène pédonculé. Une trentaine de glands, que j’ai recueillis sur des chênes pyramidaux el mis cu terre, n'ont reproduit qu'une douzaine de ces derniers; tous les autres ont donné des chênes à rameaux élalés. 
transition des rameaux et ramules rapprochés et peu allungés.

Couvert. Le feuillag̣e se trouve dès lors ramassé contre les grosses branches en touffes serrées, entre lesquelles on aperçoit de larges et nombreuses trouées. De là résulte un couvert trèsincomplet, inférieur à celui du chène rouvre.

Feuilles. La feuille du chène pédonculé se dessèche à la fin de l'automne et tombe immédiatement, si ce n'est celle des rejets de taillis et des branches gourmandes des vieux arbres yui est marcescente. Toutefois, il n'est pas rare de la voir persister verte jusqu'au printemps sur les très-jeunes rejets, aux expositions abritées et dans les hivers doux. D'un vert clair, parfois jaunàtre au commencement de l'été, elle esı peu luisante ou tout à fait mate et présente, dans son ensemble, une teinte glauque assez prononcée; elle est friquemment recroquevillée, enfin sa consistance est herbacée et devient à peine coriace lors de son développement complet. A l'état vert et cueillie en septembre, son poids est en moyenne à celui des feuilles du chène rouvre, pour des surfaces égales, cornme 5/4: 40 (A. Mathieu). Employéc comme engrais en agriculture, on estime (T. Hartig) que, bien desséchée, il en faut $500-530$ kil. pour équivaloir à 100 kil. de paille.

Le chène pédonculé est, d'après ce qui précède, bicn moins propre que le chène rouvre à former des peuplements sans mélange, puisquil a, d'une part, le couvert plus léger, et d'autre part, les détritus moins abondants. Aussi les futaies pleines de chène pur et en bel état de croissance sontelles constitućes par cette dernière essence el quand, cà ct là, quelques petits massifs sont formés par le chéne pédonculé seul, il est rare qu'ils présentent un aspect satisfaisant (1). Cette espèce parait éminemment propre aux futaies sur taillis cn sols argileux compactes ou même humides, et aux futaies mélangées d'essences à couvert complet; mais il faut lui préférer le chène rouvre toutes les fois que, par une dérogation à la règle de culture sur les essences à couvert léger et à détritus faibles, on procède à des travaux de repeuplements en chène sans y introduire de mélange.

(1) Voir le Mémoire de M. I. Dubois, inspecteur des forèı : Considérations culturales sur les fuluies de chènes du Blésuis. Blois, 1836. 
Le chène pédonculé fructifie vers $60-100$ ans, suivant qu'il est isolé ou en massif; les rejets de souche portent mème des glands dès l'àge de 20 ans; mais les glandées abondantes n'apparaissent que tous les 5 - 4 ans et mème 3-10 ans, suivant que le climat est plus ou moins convenable. Il est rare néanmoins qu'il y ait manque absolu de glands, comme cela arrive pour le hêtre dans l'intervalle iles fainées, et l'on en trouve toujours quelques-uns sur les arbres isolés et de lisière.

La germination des glands est prompte et se produit sous une basse température $\left(5^{\circ}-4^{\circ}\right.$ au-dessus de $\left.0^{\circ}\right)$; la conservation en est difficile, même jusqu'au printemps. L'hectolitre pèse en moyenne 50 kil. et contient environ 22-26000 de ces fiuits.

La racine du chêne pédonculé est essentiellement pivotante dans la jeunesse; à 1 an elle atteint souvent $0^{\mathrm{m}} 50$ de longueur. Vers 6-8 ans seulement elle produit quelques racines latérales; à 60-70 ans, ces dernières prennent le dessus et, plus tard, le pivot n'est que la moindre partie de l'enracinement total, qui dépasse rarement $1-1^{\mathrm{m}} \mathrm{0} 0$ de profondeur. Le bois de souches et de racines, en coupant ì $0^{\mathrm{m}} 50 \mathrm{du}$ sol, est de 14-17 p. 0/0 du volume total.

Les bourgeons proventifs se maintiennent longtemps vivants et assurent aux souches une grande puissance de reproduction, mème à un àge avancé; en revanche, ils exposent les réserves des taillis à se garnir de nombreuses branches gourmandes après chaque exploitation. Le chène pédonculé est bien plus sujet que son congénère, le rouvre, à cet inconvénient.

Les bourgeons adventifs ne se forment que rarement, dans les sols très-fertiles seulement, et ils prodiuisent des rejets mal attachés, que le vent, la neige, le givre cassent facilement. Le rejet de taillis a un enracinement superficiel et n'exige pas un sol profond.

L'écorce du chêne pédonculé esı lisse, brillante et d'un gris argenté jusqu'à l'àge de 20-50 ans; elle est alors formée d'une enveloppe subéreuse très-mince (périderme externe), de l'enveloppe herbacée verte et de couches de liber, qui s'accroissent pendant toute la vie du végétal. Mais, passé cet àge, il se produit dans l'épaisseur de ces dernières des lames de périderme interne, qui font mourir et repoussent au dehor's tout ce qui les recourre. Il se forme alors un

Germinalion.

Euracinement.

Rejels el branclies gourmandes.

Ecorce. 
rhytidome brun, longitudinalement gerçuré, qui s'épaissit de plus en plus, parce que, tout en s'accroissant par le dessous, il se détruit peu par l'extérieur.

Station et sol. Le chène pédonculé s'avance bien plus vers le nord, bien moins vers le midi que le chène rouvre; il est le seul indigène en Suède, tandis que vers le sud, il dépasse peu les Alpes; il est néanmoins abondant dans le nord de l'Espagne. Nalgré cette aire plus septentrionale, il reste en arrière du rouvre de 5-400 mètres dans les régions montagneuses. Habituellement mélangé avec ce dernier dans les pays accidentés de collines ou de coteaux, il devient dominant ou se rencontre seul dans les plaines (Alsace, Normandic, Landes), se trouve encore en parfait état de croissance et atteint les plus belles dimensions dans les terrains humides et mème marécageux.

Il ne manifeste aucune préférence exclusive pour la nature minérale des terres, pourvu qu'elles aient en elles l'humidité fondamentale qu'il ne saurait leur procurer, ni par son couvert ni par ses détritus. Il s'accommode d'un plus haut degré de compacité que ne pourrait le faire le chêne rouvre, et réussit encore sur les sols franchement argileux.

Bois. Le bois est d'un brun fauve clair uniforme et l'on y distingue difficilement les zones de parenchyme ligneux; l'aubier est blanc, nettement limité.

Densité. La pesanteur est très-variable et s'accroit généralement avec l'épaisseur edes couches; elle est naturellement plus èlevée pour les bois du midi que pour ceux dı nord. Suivant G. L. Hartig, elle est en moyenne de 0,920 à l'état vert; 0,786 , desséché à l'air ; 0,596 , complétement desséché à l'étuve.

Des ćchantillons de la collection de l'Ecole forestière, parfaitement desséchés à l'air et provenant d'arbres âgés ont fourni les chiffres suivants :

Chène de la forêt de Sclıélestadt (Alsace), croissance moyenne. . 0,637

- de Normandie, arbre de haies, croissance assez rapide . 0 0,889

- de Bayonne, - croissance rapide ... . 0,940

Lxages. Le bois de chène pédonculé est l'un des plus employés en raison de son abondance, de ses qualités et des grandes dimensions qu'il atteint; on peut lui appliqguer tout ce qui a été dit à ce sujet dans les généralités sur le genre. (Voir page 25j.) C'est lui guii, planté cn Normandic autour des 
propriétés, fournit ces bois courbes, très-nerveux, si fort estimés pour la membrure des vaisseaux sous le nom de chènes de haies ou de chènes champètres. Le chêne dit de Bayonne, très-apprécié dans les arsenaux maritimes, est aussi du chêne pédonculé qui provient des Landes.

Employé comme combustible il ne conserve point son rang, quoique, en réalité, il vaille mieux que sa réputation. Sa puissance calorifique à poids égaux, est en moyenne, à celle du hêtre, comme 91 : 100, d'après G. L. Hartig ; comme $85: 100$, d'après IVerneck. Cependant la valcur vénale de son bois de chauffage est généralement en dessous de ce rapport, parce qu'il a l'inconvénient d'éclater beaucoup en brùlant, d'exiger un tirage actif et de produire un charbon qui s’éteint aisément. La vieille écorce, au contraire, a une puissance calorifique très-ćlevée, qui est à celle du bois de hêtre comme 108: 100; elle brùle lentement et avec une flamme courte, il est vrai, mais elle produit un charbon ardent qui se consume entièrement.

Le charbon de chẻne est estimé; il est en poids, à celui du hêtre comme $91: 100$.

L'écorce fournit du tan de bonne qualité, généralement inférieur cependant à celui des autres espèces du genre; la plus estiméc est celle des jeunes taillis de $20-50$ ans. A 20 ans son volume varie, suivant la fertilité, entre le $\frac{t}{8}$ et le $\frac{1}{15}$ de celui du bois exploité.

Les glands sont toujours âpres.

Chêne rouvre. Quercus sessiliflora. Suitu. Chène mảle; Chẻne noir (dans quelques contrées); Durelin; Roure; Drille ou Drillard (Conpiègne); Chêne blanc (Blésois et Provence).

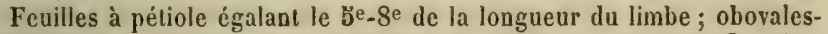
oblongues, insensiblement prolongées en coin ou échancrées en 2 petites oreilleltes à la base; sinuées-lobées ou pennatipartites, à lobes plus ou moins nombreux, arrondis, oblongs ou triangulaires, entiers ou sinuéslobés, obtus ou aigus; fermes et presque coriaces dans leur entier développement, glabres, luisantes el d'un vert foncé en dessus; plus claires, ou mème glauques, mates et toujours plus ou moins pubescentes, au moins aux aisselles, parfois grises-tomenteuses, en dessous; nervation plus ou moins serrée, formée de 3-8 paires de nervures pennées. Fleurs femelles sessiles, agglomérées aux aisselles des fcuilles; stigmates d'un brun rougeâtre, presque sessiles, triangulaires, étalés dès la base. Glands solitaires ou agglomérés, insérés contre les rameaux ou portés par un axe velu ou lomenteux, dressé, robuste, dont la longueur excède rarement cellc du pétiole; de forme très-variable, subglobuleux, ovoïdes, cylindriqques-oblongs; de taille très-diverse, $\mathbf{1 5 - 4 0}$ mill. de long sur 10 -

Usages accessoires.
Valeur calorifiqué. 
23 de large; terminés par une pointe courte, sur laquelle on reconuait souvent encore la structure caractéristiqque des stigmates, el contenus dans une cupule hémisphérique, dont les écailles soot serrées et nombreuses, apprimées, planes ou tuberculeuses à la base, triangulaires-allongées el obtuses à l'extrémilé et plus ou moins grises-pubescentes ou tomenteuses. - Arbre de taille et de port non moins variable que ses feuilles et ses fruils, dont la cime est plus régulièrement ramifiée que celle du chène pédonculé, dont le feuillage, plus coriace et d'un vert plus sombre, est assez uniformément réparti et produit un couvert plus complet. Commun dans toute la France, soit mélangé avec le chêne pédonculé, le hètre et mìme le sapin, soit en peuplements purs et constiluant à lui seul des futaies considérables. Flor., fin d'avril et commencement de mai. Fructif., fin de septembre et commencement d'octobre.

Var. «. A larges fcuilles. Lam. Feuilles grandes, sinuées-lobẻes, à lobes arrondis; alténuées et prolongées à la base sur le pétiole; planes, luisantes, à peine pubescentes en dessous aux aisselles, lorsqu'elles sont complétement développées. Glands sessiles, réunis par 2-5 ou isolés; cupule presque glabre, à éeailles apprimées. - Arbre de première grandeur, à tige droite, élevée, nue. Sols frais. Type de l'espèce.

Var. B. A trocliels. Q. robur glomerala. Lam. Chêne rouvre à pctits glands. - Feuilles de taille moyenne, mollement pubescentes en dessous. Glands petits, ramassés par bouquets, sessiles ou agglomérés en grappes légèrement pédonculées; cupule lisse, grise tomenteuse. Arbre médiocre, à cime ample, étalée. Sols secs, particulièrement sur les collines calcaires.

Var. \% Lacinié. Lam. - Feuilles petites, plus ou moins pubescentes en dessous, élégamment et profondément découpées en lobes ondulés, habituellement aigus, crispés sur les bords; ramassées par touffes sur des ramules effilés, droits, grêles. Glands petits, agglomérés, scssiles, souvent peu saillants hors de la cupule. - Arbre médiocre ou plus souvent arbrisseau très-rameux. Lieux pitreux et montueux, surtout sur les sols calcaires.

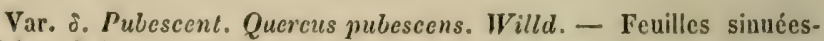
lobées, à lobes obtus, entiers ou peu dentés, tomenteuses en dessous dans la jeunesse, fortement pubescentes dans leur entier développement. Glands sub-sessiles, à cupule grise-tomenteuse, souvent tuberculeuse. - Arbre tortueux, peu élevé. Sols secs, principalement sur le ealcaire jurassiqque, surtout dans le centre et le Midi.

Var. E. Des Apennins. Q. Apennina. Lam. Chêne bàtard (Gironde). - Feuilles semblables à celles du chène pubescent, mais plus courtement pétiolées. Glands anglomérés sur un axe épais, gris-tomenteux, plus long que le pétiole; cupule grise-tomenteuse, à écailles apprimées.-Arbre peu élevé, à feuillage touffu, d'un vert foncé. Terrains secs du Sud (1).

(1) Il est impossible de se figurer les innombrables modifications du chene rouvre stivant les climats, les exprositions et les sols, si on ne les 
Le chène rouvre à larges feuilles, que l'on peut considérer coinme le typc de l'espèce, offre des caractères assez constants et doit être cultivé de préférence aux autres variétés, toutes les fois que la nature du sol le permettra. C'est

GIÉNE nOUTRE

A LAligks

FEULLES. un grand et bel arbre, qui ne le cède en rien pour la taille

Taille.

a observées soi-même avec attention et sur une grande échelle. Elles offrent, principalement sur les terrains secs el calcaires, une véritable anarchie. Les inflorescences, les cupules, les glands, les feuilles et jusqu'aux écorces présentent successivemen des caractères qui, dans bien des genres, seraient saus contredit suffisants pour distinguer des espèces nouvelles; mais ici leur inconstance est telle et ils se fondent si bien les uns dans les autres qu'il a été impossible, jusqu'à présent, de les employer utilement, mème pour reconnaitre les variétés avec une certitude suffisante.

L'étude du chène rouvre a donc besoin d'ètre complétée. Soit qu'elle n'aboutisse qu'à en contïmer l'unité spécifique, à mieux en caractériser les races et les origines diverses; soit qu'elle conduise à y démêler plusieurs espèces légitimes, jusqu'alors confondues, elle est digne de tout l'intérêt du forestier et du botaniste; mais elle exige, pour être bien conduite, des observations nombreuses, des matériaux abondants, sans quoi l'on est exposé à méconnaître les transitions qui relient les types extrêmes et à considérer ces derniers comme autant d'espèces véritables, dont la mine pourrait être inépuisable.

Bose (Hémoire sur le chène) décrit un chêne osier, $Q$. viminalis, qui ne s'élève jamais à plus de $12-15$ décimètres; ses rameaux, dit-il, se recourbent vers la terre et les inférieurs rampent toujotirs; son gland est sessile et caché presque entièrement dans la cupule; ses feuilles ressemblent beaucoup à celles du chêne pédonculé et sont complétement glabres. Ce chêne ferait d'excellentes haies; ses jeunes pousses trèsgrêles, très-droites, très-nombreuses et très-liautes serviraient, comme les osiers, à la vannerie; enfin il serait commun en Alsace, dans les Vosges, dans le Jura, dans les terrains jurassiques d'entre Langres et Dijon et serait connu sous le nom de chêne de haie. Bosc est le seul qui ait signalé ce chêne, sans doute l'une des nombreuses variélés du chêne rouvre, dont la pubescence, parfois très-faible, n'aura pas été remarquée, Personne, depuis lui, ne l'a vu ni cilé.

Secondat, dans son Mémoire sur l'histoire naturelle du chêne, dit, et après lui Thore, Bosc, Poirret, etc., ont répété, que dans la Gironde, il y a un chêne, qu'il nomme chêne Auzin et qui serait connu dans les Landes sous le nom de chêne de malédiction, dont les fevilles seraient très-velues en dessous et un peu en dessus, à divisions peu profondes, très-ouvertes, aiguës, quelquefois mucronées, elc., qui produirait un bois presque incorruptible et du plus grand ressort, d'excellentes courbes pour la marine, un meilleur chauffage que celui duchêne blanc. Ce chêne, qu'aucun botaniste moderne ne signale, est très-probablement une variété pubescente du chène rouvre. Quant au nom de chène de malédiction qu'on lui attribue, il ne lui convient pas plus qu’à toute autre espèce du 
et la longévité au chẻne pédonculé, dont la tige, plus droite, plus cylindrique, moins sujette à se garnir de branches gourmandes, se partage en un plus grand nombre de branches principales, qui se ramifient elles-mèmes par unc transition mieux ménagée en branches sccondaires, en rameaux et en ramules. Le feuillage, qui se distingue de loin par une teinte d'un vert plus foncé, est plus uniformément distribué et produit un couvert plus égal et plus complet. Suivant T. Hartig la tige est moins exposée à se carier au cour à un âge avancé.

On cite quelques pieds remarquables de chène rouvre à larges feuilles; tels sont : le chène des Partisans, des environs de Lamarche (Vosges), qui mesure $15^{\mathrm{m}}$ de circonférence à la base, 55 mètres de hauteur, cube $40^{\mathrm{mc}}$ et dont l'àge est évalué à 650 ans; le chêne Saim-Jean, de la forêt de Compiègne, qui a $6^{\mathrm{m}} \mathbf{4} 0$ de circonférence à $0^{\mathrm{m}} \mathrm{5}^{0} 0 \mathrm{du}$ sol, $55^{\mathrm{m}}$ de hauteur, cube 85 stères et ne doit pas dépasser 500 ans.

Station.

L'aire d'habitation du chène rouvre à larges feuilles diffère sensiblement de celle du chène pédonculé; se confondant avec elle dans les régions de collines où les deux espèces croissent en mélange, elle s'abaisse moins et s'élève davantage. Aussi dans les grandes plaines ne faut-il chercher que le chène pédonculé, tandis que dans les montagnes le rouvre le dépasse de quelques centaines de mètres en altitude et pénètre à peu près seul à l'état de dissémination jusque dans la région des sapins. On ne saurait attacher trop d'importance à ce fait dans les travaux de repeuplements et l'on peut c̀tre sùr que les semis ou les plantations cxécutés contrairement à cette loi de dispersion ne seront Sol. jamais couronnés d'un succès complet. Les exigences à l'égard du sol offrent aussi des dissemblances notables. Le pédonculé se plait particulièrement dans les terrains argileux, il y prospère encore lors mème que par leur situation

mème genre. Celte dénomination tire son origine de la croyance superstitieuse de quelques habitants des Landes, qu'il y a dans leur pays un cerlain chêne, dont le bois, employé à la construction d'une maison, altire sur ses habitants les plus grandes calamilés. Nécessairement on ne le reronnait que par sa funeste influence el nullement à des caraclères botaniques spéciaux. 
ils sont très-humides ou marécageux; le chène rouvre ne s'accommode ni de cette compacité, ni de cette humidité et préfère les sols graveleux, sablonneux ou mẻme calcaires, pourvu qu'ils soient doués d'une certaine fraîcheur (1).

Le bois ressemble entièrement à celui du chêne pédonculé; cependant il est en moyenne un peu plus lourd et par conséquent d'une puissance calorifique supérieure, de 7 p. $0 / 0$ suivant G. L. Hartig, 1,5 p. $0 / 0$ suivant WVerneck.

Il est difficile de différencier exactement les qualités des bois de ces deux espèces voisines et les appréciations les plus contradictoires ont été exprimées à ce sujet. Ces divergences sont, dans beaucoup de cas, bien plutôt le résultat de la diversité des exigences de l'une et de l'autre et de la possibilité qu'elles ont trouvée de les satisfaire plus ou moins complétement, suivant les sols, les situations, le mode de traitement, qu'une conséquence de leur nature spécifique. Cependant, considéré en masse, le rouvre est moins nerveux, moins raide, moins élastique que le pédonculé et lui cède le pas pour les grandes constructions civiles, militaires et navales; mais en revanche il est moins noueux, sa fibre est plus droite, son grain est plus fin et plus doux, sa couleur un peu plus claire et il reprend le premier rang comme bois de fente et de travail.

L'écorce du chẻne rouvre est en général supérieure à celle du chène pédonculé pour le tannage; c'est une conséquence de la faculté qu'a cette espèce de croitre, avec vigueur encore, sur des sols moins humides et sous l'influence d'une plus vive insolation.

Les glands sont toujours plus ou moins àpres.

Toutes ces variétés se nuancent entre elles et avec la précédente de tant de manières qu'il n'a pas été possible jusqu'à présent de les limitel avec précision, bien que les différences qui les séparent soient très-prononcées, quand on observe les types extrêmes de chacune d'elles. Elles ne CHĖNES ROUYRES A TROCHETS, LACINIÉS, PUDEscents ET DES APENYINS. produisent le plus souvent que des arbres peu élevés, dont le fùt est court, la cime étalée, diffuse et arrondie.

L'action prolongée d'un sol sec, d'une exposition chaude,

(1) M. de Boisd'hiver, conservaleur des forèts de la couronne, a trèsbien signalé celte différence. (Voir Annales forcstieres, t. 6, p. 533.) 
d'un climat méridional, en modifiant le type spécifipue, semble exereer une influence décisive sur leur production et leur abondance. Exclues des terrains frais du nord, du nord-est et du centre, sur lesquels prospère le chène rourre ì larges feuilles, elles apparaissent dans ces régions avec les sols secs et chauds, surtout avec ceux du calcaire jurassi-que et sur les versants exposés au sud; elles deviennent de plus en plus abondantes lorsqu'on s'avance vers le midi, oú, de l'est à l'ouest, elles représentent presque à elles scules l'espèce, à l'exclusion du type qui ne s'y rencontre plus ou y devient très-rare. A mesure que leur abondance s'accroit on voit les caractères qui les distinguent se développer davantage : les feuilles deviennent plus pubescentes ou mème. tomenteuses, ainsi que les axes d'inflorescence et les cupules; leur limbe se réduit, leur consistance augmente, leurs découpures se diversifient; la taille des arbres, enfin, s’amoindrit et le port en devient de plus en plus défectueux.

La distinction entre toutes ces races est certainement tresdigne d'intérét et peut-ètre mème pourrait-elle conduire a démèler parmi elles quelques espèces véritables; cependant, dans les travaux de repeuplements, on devra toujours leur préférer le chêne rouvre à larges feuilles, quand le sol aura la fraicheur nécessaire à sa réussite. Dans le cas contraire, et surtout dans les départements méridionaux, il est souvent préférable de leur substituer d'autres espèces mieux appropriées au climat, et le genre chène lui-mème en présente de nombreuses : chène tauzin, chène chevelı, chêne faux-liẻge, chène yeuse, etc.

Bois. Le bois de toutes les variétés en question est plus colori et plus riche en lignine que celui du type; il est aussi plus dur et plus nerveux; sa densité est supérieure, comme l'attestent les chiffres suivants, fournis par des échantillons complétement desséchés à l'air, de la collection de l'Ecole for'estière.

Chène rouvre à larges feuilles, 93 ans, Nancy, pèse. . . . . 0,69

— pubescent, 95 ans, Angoulème, _ ..... 0,71

- - très-pubescent; 65 ans, Pyrénées-Orientales, pèse. . 0,95

Les dimensions labituellement restreintes et la forme souvent défectucuse des tiges en diminuent l'importance comme hois de construction, de fente et mème de travail; mais il regagne en puissance calorifigue ce yuil a perdu de 
ce cóté ct il fournit un combustible estimé, un charbon de fort bonne qualité.

Cependant la marine utilise et apprécie beaucoup, sous le nom de chêne de Provence, les bois du Sud-Est, où manque le pédonculé et où le rouvre ne parait être représenté que par les variétés pubescentes ou des Apennins. C'est probablement cette dernière qui s'appelle chêne båtard dans la Gironde, parce qu'elle offre des caractères intermédiaires entre ceux des deux autres chènes à feuilles caduques de la contrée, le pédonculé et le tauzin. Le bois, comme celui du chêne de Provence, en est remarquablement dur, lourd et nerveux; l'aubier en est abondant, les maillures grandes, la couleur très-foncée.

L'écorce des arbres âgés présente souvent d'assez fortes modifications; tantôt elle est dure, noirâtre, longuement et largement crevassée, persiste et acquiert une épaisseur assez grande; tantôt, au contraire, elle est d'un brun rougeảtre ou blanchâtre, finement gcrçurée; son périderme, composé d'une matière subéreuse fragile, en produit l'exfoliation superficielle et ellc reste toujours relativement mince.

3. Chêne tamzin. Quercus rozza. Bosc. Chène angoumois; Chêne noir (Gironde et Landes); Chène brosse (Anjou); Chêne doux, $Q$. humilis $D C^{\prime}$. (environs de Nantes); Chêne des Pyrénées, Q. Pyrenaïca, Willd. Q: stolonifera, Lapeyr.

Feuilles pétiolées, fermes et épaisses, oborales-oblongues, sinuéeslobées ou plus souvent irrégulièrement pinnatifides, à lobes oblongs, obtus ou sub-aigus, dont les bords, généralement parallèles, sont entiers ou sinués-lobés; le plus souvent prolongées à la base sur le pétiole, parfois échancrées en deux petites oreillettes contournées; mollement et densément tomenteuses-blanchàtres ou jaunâtres dans la jeunesse, à l'âge adulte, d'un vert sombre et toujours parsemées de poils courts très-fins el étoilés en dessus, conservant en dessous un duvet, épais comme du velours, qui en cache tolalement la surface. Glands variables, cylindriques, ovoïdes ou globuleux, agglomérés, $2-4$, sur un pédoncule Uressé, robuste, long de $1-b$ centimètres au plus ; plus rarement espacés sur un pédoncule allongé, grêle et pendant; cupule hémisphérique, grisetomentense, à écailles prolongées en lanières acuminées, lâchement apprimées el même un peu ouvertes au sommet. - Arbre peu élevé, à lige revètue d'une écorce épaisse, noire, profondément et largement crevasséc, à longues racines tracantes, ahondamment drageonnantes. Sols sablonneux des landes de l'oues! depuis Jac Nans et Angers jusqu'aux Pyrénces. Flor., mai-juin. Fructif., septembre de la mème année.

Le chine tauzin est le plus souvent un arbre tortueux,

Taille. Porl. 
dont le füt n'a point d'élévation; dans quelques circonstances exceptionnellement favorables on lui voit néanmoins une tige parfaitement droite et assez élancée. Il est possible, d'après cela, que le port disgracieux qu'il affecte tienne moins à sa nature qu'aux mauvaises conditions de sol et de traitement sous lesquelles il se développe. Quoi qu'il en soit, ses dimensions sont inférieures à celles du chêne rouvre et il parait ne pas dépasser $20^{\mathrm{m}}$ de hauteur sur $5^{\mathrm{m}}$ de circonfërence.

Sol. Station. Les sols siliceux, purs et mélangés d'argile, secs ou humides, sont le domaine de ce chène, qui s'accommode mème des terrains les plus ingrats, où aucune autre espèce du mème genre ne pourrait se maintenir. Arbre de plaines, de collines ou de montagnes peu élevées, il se rencontre à toutes les expositions, mais sans quitter la région littorale de l'ouest qu'il ne peut franchir en raison des froids rigoureux de certains hivers du centre, de l'est et du nord de la France. Dans les Landes mène, un dixième des chènes tauzins y périt pendant l'hiver de 1829-1850, sous une température de $-15^{\circ}$. (M. Léon Dufour.)

Enracinement. Quoique pourvu d'un pivot, ce chène est particulièrement remarquable par des racines latérales traçantes, qui possèdent au plus haut degré la faculté de drageonner, alors mème qu'on ne les y provoque pas par des exploitations. II se reproduit également par rejets de souches avec une vigueur exceptionnelle; aussi forme-t-il des taillis très-fourrés et d'une durée illimitée. Cette propriété, jointe à celle de croitre dans les plus mauvais terrains, rend le chène tauzin précieux pour le boisement des landes.

Ecorce. L'écorce ne reste lisse et vive jusqu'à la surface que pendant peu d'années; dès l'àge de 7-8 ans elle se gercure et forme un rhytidome sec et dur, brun noir, qui atteint une épaisseur considérable et se marque de larges et profondes crevasses longitudinales, séparées par des côtes tranchantes. C'est à celte écorce caractéristique que le tauzin doit sans doute le nom de chène noir, sous lequel il est souvent désigné dans la Gironde.

Couvert. La ramification est claire, le feuillage peu abondant; le couvert léger', le tempérament robuste.

Eeuillage. Le feuillage est beaucoup plus tardif que celui du chène rouvre, mais il dure aussi plus longtemps et la différence entre la production et la chute de l'un et de l'autre est d'au 
moins un mois. Au moment où il se développe, ce feuillage, couvert, ainsi que les pousses nouvelles, de poils en velours très-serrés, est d'un blanc argenté, lavé de teintes purpurines; il donne aux massifs de cette essence un aspect tout caractéristique.

Les feuilles sont pétiolées comme celles du chène rouvre, mais elles restent presque sessiles sur les jeunes rejets et sur les pousses très-vigoureuses; plus épaisses et plus coriaces, elles fournissent à la terre un engrais plus abondant. C'est probablement aussi pour la mème cause et en raison des poils nombreux qui recouvrent leur surface qu'elles échappent à l'abroutissement, dès qu'elles sont entièrement développées.

Le tauzin offre rarement la régularité et les dimensions suflisantes pour être employé comme bois de construction; il y est d'ailleurs peu propre, quoiqu'il soit très-nerveux, parce que l'aubier en est très-abondant, qu'il est trèsdisposé à se gercer et à se tourmenter et que les insectes s'y logent de préférence à tout autre chène. Ces défauts, joints à celui d'être généralement noueux, le font aussi rebuter comme bois de travail.

En revanche, il tient un des premiers rangs parmi les combustibles et it fournit un charbon très-estimé. C'est pour ce motif qu'il est le plus souvent exploité en taillis simple à très-courtes révolutions ou même en tétards.

Ce bois offre à peu près la structure de celui du chène rouvre, mais le parenchyme associé aux vaisseaux est plus abondant et les grands rayons sont plus nombreux. C'est sans doute la prédominance du tissu cellulaire et, par suite, la grande quantité de fécule à laquelle il sert de réservoir qui déterminent ses défauts.

Un échantillon d'une tige de כ̌š ans, provenant du bois des hospices d'Angers et parfaitement desséché à l'air, pèse 0,809 . Cette tige mesure 57 centimètres de diamètre, dont 7 pour l'écorce, et présente 22 couches d'aubier. (Coll. Ec. For. Envoi de M. Charril, garde général à Baugé.)

L'ćcorce est supérieure à celle du chène rouvre pour la production du tan, sous le double rapport de la quantité et

Produits accessoires. de la qualité. Les glands, tantôt doux, tantôt âpres, sont préférés à ceux des autres espèces et très-recherchés, sur- 
tout aux environs de Bayonne, pour l'engraissement des porcs; leur production est assez constante chaque année (1).

(1) L'Algérie possc̀de, de cette section, l'espèce remarquable suivante :

Chêne zeen. Quencus Minbecku. Dunieux. Quercus robur, Desf. nun Smilh, nec Lin. Zeen ou zân des Arabes. Quercus lusitanica, B. Boutica, IVebl.

Feuilles pétiolées, caduques ou parfois persistantes jusqu'à la fin de l'hirer, largement elliptiques, elliptiques-lancéolées ou obovales, planes, légèrement échancrées-cordiformes à la base, régulièrement et peu profondément sinuées-lobées, à lobes arrondis ou aigus et mucronés comme celles du chataignier; pourvues de 10.14 paires de nervures secondaires régulières, bien marquées, parallèles et prolongées jusgu'aux bords; rertes et glabres en dessus, en dessous recouvertes dans la jeunesse d'un duvet floconneux-tomenteux, épais et court, blanegrisàtre, très-caduc; glabres el glaucescentès, fermes et coriaces à leur entier développement. Fleurs tomenteuses; périgone des fleurs màles formé de folioles soudées jusque vers le milieu; glands agglomérés, subsessiles, ovoïdes, à maturation annuelle; cupule courle et évasée, grise-tomenteuse, à écailles apprimées, triangulaires et planes au sommet. Très-grand arbre rappelant beaucoup le chène rouvre par les dimensions et par le port; commun sur certains points de l'Algérie, oú il forme de vastes forèts, principalement aux environs de Bône el de la Calle. Flor., mai. Fructif., novembre.

Tuille. Le chêne zeen est l'un des arbres les plus beaux el les plus uliles de l'Algérie; la longévité en est fort considérable et il peut atteindre $50-55^{\mathrm{m}}$ de hauteur, sur $6^{\mathrm{m}}$, et mème davantage, de circonférence, à $1^{\mathrm{m}}$ du sol. L'écorce en est épaisse, dure, noirâtre, largement et profondément crevassée.

Station. Sol. Il croil dans les riggions montagneuses, seul ou mélangé avec le chène Ballote, le chàtaignier et méme le cèdre, jusqu’à une altitude de 1000 $1400^{\mathrm{m}}$ el au delà; recherche les expositions du nord et de l'est et se plait particulièrement dans les terrains substantiels, frais et profonds.

Reproduction.

Il repousse de souche avec une vigueur remarquable.

Les glandées se suecèdent ordinairement à des intervalles de 5-4 ans. La germination s'opère $\mathbf{b}-\mathbf{6}$ jours après la chute naturelle du gland, dès l'automne par conséquent.

Bois. Les vaisseaux du bois de printemps sont moins gros et moins nombreux dans le clıêne zeen que dans le chêne rouvre; souvent ils ne sont représentés que par un seul rang et c'est à peine si la zone qu'ils forment devient apparente; c'est par conséquent le bois d'automne, dans Irquel le tissu fibreux est très-tominant, qui forme la plus grande partie de chaque couche. Les rayons sont larges, indéfinis et moyennement hauls, nombreux et rapprochés. Le grain est très-serré, homogènc, susceptible d'un beau poli. La densité est fort élevée; celle d'un échantillon parfaitement desséché à l'air et provenant d'une tigge de 26 ans et de 20 centiniètres de diamètre est égale à 1. (Coll. Ec. for. Envoi de M. Hoyer) (Algérie). Malgré sa grande pesanteur et l'inconvénient de 
Section II. Chènes ì feuilles caduques ou persistantes jusqu au printemps seulement; à maturation bisannuelle.

(Feuilles pinnalifites, à lobes aigus, ou incisées-dentées. Glands à cupule hérissée.)

4. Chêne chevelu. Quencus cerris. Liv. C. crinite; C. cerris; C. de Bourgogne. C. lombard (environs de Besançon).

Stipules des feuilles supérieures et écailles externes des bourgeons longuement sétacées; feuilles légèrement pétiolées, oblongues, glabres en dessus, d'un vert plus clair, pubescentes ou velues en dessous, à incisions très-rariables, à lobes aigus ou arrondis et mucronés-calleux. Glands ovoïdes-oblongs, de taille variable, solitaires ou agglomérés 2-4 sur un pédoncule court et très-robuste, à cupule longuement embras. sante, hérissée de longues lanièrus molles ct pubescentes, étalées ou rélléchics, crochues ou enroulées. Maturation bisannuelle, de sorte que les glands mûrs sont latéraux sur la pousse non feuillée de l'année précédente.

V. $\alpha$. Fenilles régulièrement échancrées-dentées, à dents triangulaires, pointues. Q. fulhamensis. Hortul.

Var. ß. Feuilles sinuées-pinnatifides, à lobes égaux, entiers ou paucidentés. Q. austriaca. Willd. Q. crinila. Desf. Q. lanuginosa. Lam.

Var. \% Feuilles pinnatipartites ou-séquées, à segments divariqués, écartés, entiers on irrégulièrement lobés; lobes ordinairement aigus. $Q$. Tournefortii. Willd. Q. haliphleos. Lam.

Disséminé dans quelques départements : Doubs, Jura, Vienne, Maineet-Loire, Loire-Inférieure, Provence, etc. Flor., avril-mai. Fructif., automne de la seconde année.

Le chène chevelu est abondamment répandu dans tout le sud-est de l'Europe et dans une partie de l'Asie; il est toujours rare et disséminé en France. Cependant, dans le Doubs, il peuple quelques forêts communales, celle de SaintVit particulièrement, tantôt subordonné au chêne pédonculé et au chène rouvre, tantòt à l'état d'essence dominante.

se gercer profondément, ce bois est propre aux construclions et convient aux mèmes emplois que celui des chênes rouvres et pédonculés; il fournit un chauffage beaucoup meilleur, quoiqu'il ait comme eux l'inconvénient d'éclater au feu; on en fabrique de bon charbon.

L'écorce produit un tan excellent, recherché par le commerce. Le gland, cn raison de son âpreté, n'est point comestible.

Répartition.

Usages accessoires. 
On estime à 100 hectares environ le sol quil y occupe en cette dernière qualité.

Taille, port. C'est un arbre d'une longévité prolongée, de dimensions au moins égales à celles du chène rourre et dont la tige, revètue d'unc écorce épaisse et noiritre, se partage cn branches longues et très-rameuses qui forment une cime ample, arrondie. Dans le Doubs, oú il se trouve à la limite nordouest de son arre d'habilation, on lui voit encore atteindre $25^{\mathrm{m}}$ de hauteur sur $2^{\mathrm{m}} \mathrm{\textrm {v }} 0$ de circonférence, et nul doute qu'il n'y dépasserait ces dimensions s'il n'y était exposé, dès l’àge de 50 ans, à des gelivures qui le déprécient beaucoup et engagent à ne pas le choisir dans les balivages pour constituer la réserve.

Tempérament. Le chéne chevelu a le tempérament robuste et le couvert léger de ses congénères; sa régétation est en retard de 15 jours environ sur celle du chène pédonculé. Il pivote Enracinement. très-profondément dans la jeunesse et, quand le sol le permet, les plants de 4 à 5 ans présentent une racine de près d'un mètre de longueur.

Station. Il n'est pas exigeant sur la nature du sol et prospère encore là où le chène pédonculé languit; il recherche l'exposition de l'est ou du sud-est.

Croissarce. Des chènes pédonculés, rouvres et chevelus, tous de 50 ans et provenant d'une mìme coupe de la forèt de SaintVit, mesurent :

Chène rouvre. . 0,80 de circonférence, à $1^{\mathrm{m}}$ du sol.

- pédonculé. 0,80

- cherelu . 0,90

Il semble résulter de ces chiffres que le chène chevelu a une croissance plus active que les deux autres espèces, mais en revanche l'aubier en est beaucoup plus abondant, et, tandis que ces dernières n'en présentent que 10-15 couclies sur 50, on en compte chez lui 20 et plus.

Fruclifieation. Malgré une maturation bisannuelle, qui expose le fruit à des accidents atmosphériques plus nombreux, la fructification est généralement constante, même daus le Doubs.

Bois. Le bois a les vaisseaux inégaux comme celui du chène rourre; les plus gros ne forment au bord interne qu'une zone etroite, et, lors même que la végétation est lente, c'est le lissu dense qui domine dans la composition de chaque couche; l'aubicr est moins blanc, le coeur plus foncé, quelque- 
fois veiné de brun. Les grands rayons offrent une disposition toute caractéristique : ils sont moins larges et moins hauts que ceux des espèces voisines, mais, par compensation, ils sont plus nombreux, plus serrés, plus égaux entre eux et ils produisent dans le débit des maillures fortement colorées qui rappellent presque entièrement celles du hỉtre, bien que sur une plus grande échelle.

La densité est élevée; prise sur un échantillon complétement desséché à l'air et provenant du Doubs, elle est de 0,86 (Coll. Ec. For. Envoi de M. Virion.), elle s'élève à 0,93 pour un échantillon d'Italie.

Le bois du chène chevelu rappelle celui du chène tauzin; il est dur et très-nerveux, mais chargé d'aubier, exposé à se gercer, peu apte à la fente; on l'emploie en Orient pour les constructions navales et le chène que les arsenaux francais tirent d'Italie parait devoir lui ètre rapporté. Sa rareté en France et surtout les gelivures dont il est atteint dans le scul département où il croît avec quelque abondance en font méconnaitre les qualités; on ne peut douter cependant que, propagé dans les dípartements méridionaux, il serait à l'abri de ces accidents et y atteindrait d'utiles dimensions; il y remplacerait parfois avec avantage le chêne rouvre et rendrait certainement des services importants pour en reboiser les terrains arides.

On en fait, dans le Doubs, de la menue charpente, des échalas, ete.; mais le débit produit beaucoup de déchet en raison de l'abondance de l'aubier qui est très-sujet à la vermoulure et qu'il faut rejeter. La qualité essentielle qu'on lui reconnait dans ce pays est d'ètre un excellent combustible, égal, sinon supérieur, au hêtre.

L'écorce, épaisse et séveuse, est préférée pour le tannage à celles du chène pédonculé et du chène rouvre.

Les glands sont âpres, au moins en France; on les dit comestibles en Orient (Spach) (1).

Usages.

Ecorce.

Produits accessoires.

5. Chêne faux-liége. Quencus pseudo-surer. Savri. Chène Drouis ; Chêne Drouino.

Stipules et écailles extérieures des bourgeons longuement sétacées. Feuilles à pétiole égalant le 1/6-1/8 de la longueur du limbe; ovales ou

(1) MM. Schuler, inspecteur, et Virion, garde général, out cu l'obligeance de me fournir la plupart des matériaux de cet article. 
elliptiques-lancéolées, légèrement cordiformes ou jasensiblement alténuées à la base, bordées d'échancrures arrondies qui séparent de fortes dents cuspidées, ou légèrement dentées suivant l'àge et la vigueur de la croissance ; vertes, glabres et luisantes en dessus, blanchâtres et trèscourtement tomenteuses eu dessous; coriaces et persistantes jusqu'à la foliaison nouvelle; nervures secondaires au nombre de 7-9 paires. - Glands solitaires ou réunis 2-5 sur un axe assez robuste, trèscourt ou quelque peu allongé, et supportés par la pousse défeuillée de l'année précédente; ovoïdes el gros, alteignant jusqu'à 6 centimètres de long, mais parfois moitié plus petits; cupule grise-tomenteuse, dont les écailles se prolongent en pointes d'autant plus grandes qu'elles se rapprochent davantage du bord supéricur et sont tantôt réflćchies, tantôt courbées (Quercus pseudo-suber, Santi ex Gay.), tantôt droiles et dressées (Quercus hispanica, Lam.; Quercus fontanesii, Guss. ex Gay). - Arbre de grande taille, d'un port élancé, revêtu d'une écorce noirâtre, légèrement subéreuse; à cime conique, à rameaux redressés, à ramules gris-tomenteux. Disséminé, mais loujours rare, dans quelques parties du littoral de la Provence: Grasse et Montouroux, où il est représenté par 5 à $\&$ pieds de la taille des plus grands chènes de nos forêts; se retrouve aussi, par pieds isolés, lans l'Allas en Algérie, principalement dans la province d'Oran, à Tlemsem et à Sebdou. Flor., avril-mai. Fructif., septembre de la seconde année.

Porl. On sait très-peu de choses sur ce chène, qu'une croissance plus active, un port plus élancé, une cime plus aiguẻ distinguent aisément, en Provence et en Algérie, des autres chènes plus ou moins rabougris au milieu desquels il croit. Cette circonstance et la propriété qu'il a de réussir sur des sols de médiocre qualité, lui mériteraient plus d'attention qu'on ne lui en accorde. Insignifiant aujourd'hui en sylviculStation. ture à causc de sa rareté, il pourrait probablement acquérir de l'importance pour le boisement des terrains sees et chauds du midi, sur lesquels il semble mieux prospérer que ses congénères.

Bois. Le bois est formé de tissu fibreux compacte et dominant, de vaisseaux inégaux et de rayons, qui produisent des maillures semblables à celles du chène chevelu; il cst entièrement blane ou blane-rosé jusqu'au coeur, mème sur des échantillons d'un àge avancé, sans qu'il soit possible de reconnaitre de limite entre l'aubier et le bois parfait. La densité en est considérable. On ne sait rien de ses qualités. Ecorce. L'écorce subẻreuse n’est point assez développée et d'aillcurs sa consistance est trop dure pour qu'on puisse l'utiliser; le liber doit fournir un tan de qualité supéricure, à en juger par l'épaisseur qu'il atteint. 


\section{SEctiox III. Chínes à feuilles persistantes el à maturation annuelle.}

\section{(Feuilles entières ou dentées-épineuscs. Glands à cupule lisse ou légèrement hèrissée.)}

6. Chêne yeuse. Qurncus ilex. Lin. Chêne vert.

Feuilles persistantes, jusqu'au commencement de la $5^{e}$ année, extrè mement variables sur un même arbre suivant la vigueur des pousses ef, à plus forte raison, sur des arbres différents; étroitement elliptiques, ovaleslancéolées ou orbiculaires, avec tous les passages entre ces trois formes extrênıes; arrondies, légèrement cordiformes ou faiblement alténuées à la base, pointues ou obtuses à l'extrémité; très-entières quand la végétation est ralentie par l'àge; plus ou moins profondément dentées-épineuses sur les bords, dans le genre de la feuille du houx, pendant la jeunesse, tant que l'arbre n'a pas fructifié; petites ou moyennes, 7-10-nerviées, vertes, glabres et luisantes en dessus; grises ou blanclıătres-tomenteuses en dessous chez les individus adultes, d'un vert pâle et glabrescentes cliez ceux qui sont jeunes. Glands solitaires ou géminés, sur les pousses feuillées de l'année, sessiles ou portés par des pédoncules courts, gros, gristomenteux; de forme extraordinairement variable, oblongs-cylindroïdes ou ovoïdes-subglobuleux, surmontés d'une pointe robuste, allongéc, glabre dans sa moitié inférieure; de taille très-diverse, 2-4 cent. de long, plus ou moins âpres ou doux; cupules grises-tomenteuses, légèrement coniques et à bords droits, ou largement ouvertes à lords rentrants ou réfléchis (Q. expansa, Poiret.), quelquefois très-profonles et enveloppant le gland anx $\mathbf{3} / 4$ (Q. calycina, Poir.), à écailles petites, triangulaires, planes ou légèrement granulcuses à la base, exactement apprinées.

Var. \%. Ballote. Feuilles plus blanches-tomenteuses en dessous; glands gros, quoique variables pour la forme, toujours doux el de saveur agréable. Q. Ballota. Desf. Chène à glands doux.

Arbre de taille movenne, plus grande dans la variété Ballote, dont la cine est ovale-arrondie, l'écorce finement et densément gerçurée en long el mème en travers, brune, rugueuse, non subéreuse; à ramules gris ou blancs-lomenteux. Lieux arides el découveris de la France méridionale; pénètre assez avant dans les vallées des Alpes, de la Provence et des Pyrénées, remonte vers l'Ouest jusqu'à la Loire. La variété Ballote est très-commune en Algéric, surtout dans la région montagneuse. Flor., avril-mai. Fruclif., septembre de la même année.

L'yeuse est un arbre de $13-18^{\mathrm{m}}$ de hauteur au plus, sur $2-5^{\mathrm{m}}$ de circonférence, dont la tige est rarement droite, la cime ovale ou arrondie, la croissance lente. Les feuilles et les fruits, semblables en cela à ceux du chène rouvre, présentent des modifications innombrables qui défient toute nomenclature. Cet arbre n'est le plus souvent, cn France, qu’à l'état de broussailles et constitue rarement des forèts

Taille. Port. 


\section{6}

CUPULIFÈRES.

régulières; il est abondant et acquiert, comme végétal forestier, plus d'importance en Corse et surtout en Algérie, Sol. où la variété Ballote forme des massifs réguliers et étendus. Il semble préférer les sols calcaires à tous les autres et, contrairement à la plupart de ses congénères, il a le couvert épais et parait peu apte à se reproduire de souche.

Fructification. La fructification est précoce, commence vers 12-15 ans et se soutient régulièrement jusqu’à un àge avancé.

Bois. Le bois de l'Yeuse, et celui de la variété Ballote qui lui ressemble entièrement, est très-caractérisé. Chaque couche, essentiellement composéc de tissu fibreux, est subdiviséc en zones concentriques très-étroites et souvent crénelées par du parenchyme ligneux, de teinte plus claire; les vaisseaux, sensiblement égaux et fins, ne forment pas de zone poreuse distincte au bord interne et sont groupés, avec des cellules ligneuses, en longues lignes flexueuses rayonnantes, qui se prolongent sans interruption d'une couche à l'autre, de sorte que les accroissements successifs sont presque toujours complétement confondus. Quant aux rayons, ils sont inégaux, très-larges, très-nombreux, et produisent des maillures rapprochées et serrées, toujours plus foncées que le reste. Ce bois est de teinte claire, uniforme, sans aubier blanc nettement tranché; il se colore souvent au coeur et sur les nouds de brun noir plus ou moins intense. Il est dur, homogène, compacte, d'un grain très-fin, susceptible d'un beau poli.

Densité. Des échantillons, complétement desséchés à l'air, mais dont il n'a pas été possible de déterminer l'ìge par suite de la confusion des accroissements, ont donné pour densité les chiffres suivants : (Coll. Ec. Lor.)

Algérie (envoi de M. Royer, sous-inspecleur). . 0,97

Pyrénées-Orientales................ 1,00

Corse (envoi de MI. Simon, garde général) .... 1,11

Usages. Le chène yeuse est sujet à se déjeter et à se gereer en se desséchant; mais on peut, dit-on, éviter ect inconvénient en le laissant préalablement séjourner sous l'eau pendant quelque temps. A cela près, il convient aux mèmes usagges que le chêne rouvre, autant du moins que ses dimensions réduites peuvent le permettre; il est très-propre à la menuiscrie, au tour, à l'ébenisterie à laquelle il fournirait, at moyen d'un débit convenable, un superbe placage bien maillé, susceptible de recevoir et de garder un très-beau 
poli; enfin, il est employé dans les constructions navales. C'est un combustible de premier ordre, dont le charbon est très-cstimé.

Les glands, lorsqu'ils sont doux, ont une saveur agréable et scrvent à la nourriture de l'homme, qu'ils soient crus ou cuits. On les récolte pour cet usage dans quelques département du Micli, Gard, Var, Vaucluse; mais c'est surtout en Espagne et en Algérie, où la variété Ballote domine, qu'ils acquièrent de bonnes qualités et qu'ils entrent pour une part importante dans l'alimentation des habitants, qui les préfèrent aux fruits du chàtaiggnier. Le chène ycuse Ballote y devient autant un arbre fruitier qu'un arbre foresticr.

\%. Chêne liégge. Quercus suber. Liv. Suro; Sioure; Surier; Suvi (Provence); Alcornoque (Espagne).

Feuilles persistantes jusqu'à la fin de la deuxième année, ou quelquefois jusqu“à la troisième, ovales-oblongues, entières ou dentées, à dents mucronées ou spinulées, légèrement cordiformes et prolongées sur leur pétiole à la base; fermes, coriaces, slabres, un peu luisantes en dessus, grises ou blanchâtres-tomenteuses en dessous, b-7 nerviées. Glands variables, solitaires ou géminés, porlés sur de courts pédoncules, épais, renflés, gris-lomenteux et axillaires sur les pousses feuillées de l'année; généralement gros, ovoïdes ou ellipsoïdes, surmontés d'une pointe courte et velue depuis la base, à demi enfoncés dans la cupule; celle-ci est allongée-conique inférieurement, grise-lomenteuse; les écailles en sont légèrement saillantes, de longueur croissante à partir de la base et se terminent au sommet en lanières molles, fragiles, assez allongées, dressées ou un peu étalées. - Arbre d'assez grande taille, à écorce subéreuse très-épaisse produisant le liégre, à rameaux de 1-5" ans lisses, les plus jeunes gris-lomenteux. Littnral de la Médilerranée, France, Corse, Algérie. Flor., avril-mai. Fructif, el dissémination: commencement d'octobrefin de décembre de la même année, et même janvier-fivrier de l'année suivante.

Arbre trapu, d'une longévité très-prolongéc, s'élevant à $10-12^{\mathrm{m}}$, exceptionnellement à $20^{\mathrm{m}}$ et atteignant 4 et mème $5^{\mathrm{m}}$ de circonférence.

La fructification est précoce et se produit dès l'àge de 15 ans; ce n'est que vers 50 ans qu'elle devient abondante et soutenue; en France, où le chêne-liége se trouve à la limite septentrionale de son aire d'habitation, elle n'est même le plus souvent qu'intermittente. Les glands, sans être très-âpres, ne sont point ordinairement comestibles.

Le feuillage, quoique persistant 2 à 5 ans, est grêle et rare, la ramification peu serréc, le couvert léger. Les jeunes plants dépassent rarement $0^{\mathrm{m}} 15$ de hauteur la première

Produils accessoires.

Taille.

Fruclification.

Feuillage. 
année; à 5 ans ils ont environ 0 "' 30 ; à partir de cet àge ils s'élèvent rapidement, mais pour s'arréter de bonne heure et prendre une végétation lente, mais soutenue, jusqu'à un åge avancé, $150-200$ ans.

Enracinement. L'enracinement se modifie et reste pivotant ou devient traçant suivant les terrains; il est composé de fortes et longues racines qui fixent solidement le végétal, mème dans les sols les plus rocheux.

Reproductiou par rejets.

La reproduction par rejets est abondante et quand la vitalité des souches a été détruite par des incendies, comme cela arrive souvent dans les forèts de l'Algérice, les racines ont la propriété de drageonner quelque peu.

Station. Le chène liége croit sur les coteaux ou sur les montagnes de moyenne ćlévation et s'écarte peu du bassin de la Méditerranée; dans les Pyrénées-Orientales il s'élève à la limite supérieure de la vigne, $500^{\mathrm{m}}$ environ, en Algéric il atteint une altitude de $1,000^{\text {m }}$ (II. Rousset (1)). Les sols feldspathiques et schisteux lui sont particulièrement favorables, les sols calcaires paraissent ne pas lui convenir.

Limité à quelques contrées du midi de la France, il devient l'essence dominante des forèts algériennes et y constitue seul ou mélangé des masses boisées d'une grande étendue (2).

Ecorce. Le liber et l'enveloppe herbacée de l'écorce du chène liége conservent leur vitalité jusqu'à la mort de l'arbre; mais ces régions s'épaississent peu et s'étendent simplement en largeur pour se prèter au grossissement du corps ligneux qu'elles recouvrent. Toute l'activité de la végétation corticale se concentre sur l'enveloppe subéreuse qui prend une grande épaisseur et produit le liége du commerce.

Ce n'est qu'au bout de 1 à 2 ans que l'enveloppe subéreuse apparait immédiatement sous l'épiderme, sous forme de quelques couches de cellules à minces parois, dépourvues de chlorophylle. Elle est nécessairement dans l'origine une production du parenchyme vert sous-jacent, mais une fois constituée, elle s'engendre d'elle-mème par division vers le dedans de ses cellules les plus internes et l'enve-

(1) Voir Annales forevières, octobre, novembre el décembre 1858.

(2) Voir l'intéressant Mémoire de M. Lambert, inspecteur des forèts, sur les forits de chine liége el d'olivier de l'Algérie. Paris, 1860 ; Burcau des Annules forestières. 
loppe herbacée ne participe plus à son déreloppement que par la séve qu'elle fournit (1).

Jusque vers כ้ ans l'enveloppe subéreuse s'accroit lentement; mais à cet âge l'épiderme se fendille, tombe, ct désormais libre de toute entrave, elle se développe avec rapidité. Sa face interne devient alors le siége d'une active production de cellules cubiques, de couleur claire et rosée, qui, s'ajoutant les unes aux autres de dehors en dedans, repoussent celles qui sont précédemment formées vers l'exférieur et constituent le liége proprement dit. Chaque année une zône de cellules aplaties (cellules tabulaires), d'un rouge brun, s'organise et divise toute la masse du liége en couches concentriques qui restent adhérentes entre elles et rappellent les accroissements du bois.

Le liége ne se produit que sur les organes aériens; les racines en sont dépourvues, à moins qu'elles ne soient saillantes au-dessus du sol.

L'enveloppe subéreuse, livrée à elle-mẻme, acquiert une grande épaisseur, que l'on a vue atteindre 20-50 centimètres; mais en mème temps. elle se crevasse largement et profondément, perd toute homogénéité et devient impropre aux usages auxquels le liége est destiné. Arrivée à une certaine limite, elle sc décompose à la surface, comme cela se passe pour la plupart des vieilles écorces des arbres, bien quavec une lenteur infiniment plus grande; mais jamais elle ne tombe d'elle-même par larges plaques.

A mesure qu'il s'épaissit, le liége réagit de plus en plus sur les tissus générateurs qu'il recouvre et produit sur eux une constriction croissante; aussi les couches qui se forment chaque année vont-elles en diminuant d'une manière marquée, jusqu’à ce qu’enfin la pression devienne constante par la destruction ou le fendillement de la surface; les ac-

(1) Ce mode de production et d'accroissement a été élabli par des observaleur's éminents, MII. Dutrochet et Hugo Mohl; M. Sanio l'a confirmé récemment. (Voir Bulletin Soc. Bot. de France, tome 5, 1850.)

Cet observateur a vu, dans l'aune commun, la viorne obier, elc., les cellules les plus exterves du parenchyme vert engendrer par division vers le dehors le premier rang des cellules de la couche subéreuse et a constaté que celle zone, une fois ébauchée, s'épaissit par ses propres cellules, qui, eu se partageant, organisent à leur face interne un second rang de cellules semblables, celles-ci un troisième et ainsi de suite. 
croissements se maintiennent alor's sensiblement égaux, mais ils sont toujours d'une faible épaisseur.

On comprend d'après cela que l'enlèvement du liẻge en active la production, puisqu'en débridant les tissus générateurs on leur rend toute liberté d'action.

Démasclage el levée.

Il faut, quand on enlève le liége, ménager avec le plus grand soin l'écorce active intérieure, c'est-à-dire, le liber, le parenchyme vert et la zone subéreuse la plus récente, qui, en raison du moment de l'année où se fait l'opération, est en pleine voic d'accroissement et se trouve formée de tissus jeunes et mous, semblables à un mucilage, suivant lesquels s'opère la séparation (1). Cetle écorce active est le gage des accroissements futurs du liége; c'est elle que les ourriers (Rusquiers, dans le Var) appellent la mire ou la pecue.

On choisit pour cette opération la saison d'été, de la mijuin à la fin d'aoủt, en évitant les moments de pleine activité de la séve, les temps pluvieux, les vents secs et brùlants, afin que la mère, trop gorgée de liquide et composée de tissus à peine organisés, ne soit pas exposée à ètre arrachée, surprise par les intempéries ou desséchée par l'ardeur du soleil. On commence par ouvrir, avec une hache bien tranchante et d'une forme spéciale, une ou plusieurs entailles longitudinales, suivant le diamètre de l'arbre, $\mathrm{ct}$, à partir du sol, deux ou plusieurs incisions circulaires et transversales, distantes de $1^{\mathrm{m}}$. Puis avec le manche de l'instrument, qui est légèrement courbé et aminci en coin à l'extrémité et dont on se sert comme d'un levier, on soulève le

(1) Quclques auteurs prétendent que l'enlèvement du liége met tolalement à nu l'enveloppe herbacée, sans rien laisser de l'enveloppe subéreuse et en concluent que cette dernière est une production permanente de la précédente; quand mème il en serait ainsi de fait, la conséquence serait forcée. L'enveloppe herbacée dénudée se retrouverait dans sa premiere situation, alors que sur le jeune rameau elle n'était point recouverte encore de tissu subéreux et qu'elle en a constitué les premiers éléments, ou dans la position de tout tissu actif, cortical ou ligneux, qu'une lésion met à découvert et dont le premier besoin est de s'abriter sous un lissu subéreux qu'il a le pouvoir d'engendrer, comme l'ont pronvé les expririences de MM. Trecul et T. IIartig. En tous cas, une fois la couche suberense ébauchéc, e'est jar ses propres forces qu'elle s'aceroit, comıne cela a été précédemment exposé. 
liégc avec précaution et on le sépare soit sous forme de troncons cylindriques, appelés canons, soit sous forme de planckes. On facilite l'opération en frappant légèrement de temps à autre sur l'écorce, afin de diminuer l'adhérence entre le liége et la mère. Il faut éviter le plus possible de blesser et surtout d'écorcher l'écorce active pendant cette opération, car toute lésion se traduirait plus tard par autant de défauts dans le liége qui recouvrira les cicatrices; l'on doit s'efforcer d'en maintenir la surface bien lisse.

On pratique quelquefois dans la mère une entaille longitudinale allant jusqu'au bois, afin de faciliter l'extension de l'écorce et d'empécher' que le liége de nouvelle production ne se couvre de ces gerçures multiples qui le déprécient. L'utilité de cette pratique est contestée (M. Rousset), et en effet elle ne se justifierait qu'autant que l'écorce pourrait glisser sur le bois qui se développe, pour ne se distendr' que suivant l'incision, dont les bords seuls s'écarteraient. Or, on sait que c'est impossible, puisque partout et toujours l'écorce adhère au bois et forme avec lui un tout coninu.

Le liége vierge ou naturel est connu sous le nom de liége mâle; il est inègal, crevassé et à peu près sans emploi. Son enlèvement, qui s'appelle le démasclage (démasculer), est une opération dispendieuse, mais nécessaire, si l'on veut obtenir plus tard du liége de bonne qualité. On le pratique dès que l'arbre mesure 25-50 centimètres de circonférence.

Lc liége qui succède au démasclage se nomme liége femelle ou de reproduction; la levée s'en fait dès qu'il a atteint l'épaisseur requise par le commerce, $2 \bar{\jmath}-2 \bar{\imath}$ mill. au moins.

Les levées se strcèdent ordinairement de 8 en 8 ans, parfois plus tòt ou plus tard, suivant l'activité de la végétation, et l'on peut en faire $12-13$ et mème davantage sur un scul arbre. Les premières levées sont peu productives, parce qu'on ne peut Pes prolonger à plus de $2^{\mathrm{m}}$ au-dessus du sol sans compromettre la vie de l'arbre; mais on les remonte ensuite à chaque exploitation de $0^{\mathrm{m}} 60$ environ, pour s'arrêter définitivement à $1^{\mathrm{m}}$ au-dessus de la première ramification de la tige. C'est à l'àge moyen qu'on obtient le plus de liége et quiil présente la meilleure qualité.

Au moment du démasclage ou de la levée, la tige dépouillée est d'une teinte rosée; mais bientòt elle passe 
au rouge ocreux plus ou moins vif, puis au rouge brun trèsfuncé; en se desséchant entièrement à la surface, elle devient grise ou brune.

Préparalion du lieige.

Qualités el usages du liége.

Dès que le liége est récolté, on l'expose dans un lieu bien aéré pour le dessécher; puis à l'aide d'une plane on en ricle la surface extérieure et on enlève ainsi la couche dure et rugueuse qui le recouvre; enfin on le plonge dans l'eau bouillante pendant quelques minutes pour l'assouplir et le gonfler. Après ces diverses préparations il a perdu un tiers environ de son poids primitif (M. Rousset) et on peut le livrer au commerce.

On passe quelquefois les liéges grossiers et gerçurés au f'u, afin d'en resserrer les pores et d'en dissimuler les défauts sous la couche superficielle qui se carbonise. Cette pratique, qui n'améliore réellement pas la marchandise, semble tomber en désuétude.

Le liége de bonne qualité doit ètre léger, souple, élastique, homogène, de couleur claire légèrement rosée; il faut qu'il ne soit ni ligneux, ni poreux. Son principal emploi est la fabrication des bouchons; il sert en outre à faire les bouées en usage dans la marine, les chapelets flotteurs deslinés à soutenir les filets de pêche, des semelles imperméables, etc... Dans les contrées où il croit, on le façonne en une foule d'ustensiles de ménage et même en tuiles pour la couverture des maisons. Brùlé en vase clos, il produit un clıarbon que l'on pulvérise et emploie dans la peinture sous Je nom de noir d'Espagne; enfin on en fabrique du noiv de fumée.

L'écorce vive est très-riche en tannin et fournit un tan fort estimé, bien supérieur à celui du chène pédonculé et du chène rouvre. Suivant M. Epailly (1), le rapport entre l'un et l'autre serait en moyenne de 1,62:1. Cependant dans une exploitation bien conduite on a trop d'intérèt à soutenir la vie de l'arbre le plus longtemps possible et à ménager cette écorce comme mère du liége, pour qu'on songe à la livrer à l'industrie du tannage. Une spéculation imprévoyante n'a malheureusement pas toujours raisonné ainsi et bien des forêts du Var, de la Corse et de l'Algérie ont été rava-

(1) Voir Annales Foreslieres, tome 9, page 253. 
gées sans ressources par un écorcement complet. Le liẻge proprement dit, semblable en cela à la portion externe et inerte de l'écorce des vieux arbres, ne renferme que pcu de tannin; il est d'ailleurs trop précieux sous d'autres rapports pour ètre utilisé à ce point de vue. Celui du commerce n'en offre plus que des traces, puisqu'il a subi une préparation dans l'eau bouillante qui a dissous ce principe.

Le bois, quoique voisin de celui du chène yeuse, en est très-distinct. Le tissu fibreux est dominant et partagé peu visiblement en zones étroites par du parenchyme ligneux; les vaisseaux, sensiblement inégaux, sont plus abondants et plus gros au bord interne de chaque couche et, sans y dessiner la zone poreuse si apparente du bois des chènes rouvres et pédonculés, rendent néanmoins cette partie bien différente de la zone externe, qui n'est composée que de petits vaisseaux associés à du parenchyme et groupés suivant des lignes flexueuses rayonnantes ne se prolongeant pas d'une couche à l'autre. Il résulte de là que les accroissements annuels sont suffisamment apparents pour ètre comptés. Les rayons sont inégaux, nombreux, très-épais, assez hauts, presque indéfinis; ils forment de larges mailiures brunes très-rapprochées. Ce bois est de coulcur inégale, gris, brunàtre, brun, brun rougeâtre ; l'aubier en est peu nettement tranché; il est extrèmement lourd, compacte, sans ètre aussi homogène ct à grain aussi fin que celui de l'yeuse. Complétement desséché à l'air, il a fourni les densités suivantes : bois d'Algérie de 52 ans, 0,92 ; bois des PyrénéesOrientales de 50 ans, 1,49; d'Algérie de 50 ans, 1,56 (Coll. Ec.For.).

Ce bois est peu propre aux constructions en raison de ses dimensions habituellement restreintes, de sa pesanteur extrème, de la disposition qu'il a à se gercer très-largement et longuement et même à se pourrir lorsqu'il est exposé à des alternatives d'humidité et de sécheresse; employé dans la marine pour des pièces d'échantillon inférieur, il a l'inconvénient d'attaquer le fer qui sert au chevillage, en raison de sa richesse en tannin. Il se fend difficilement et irrégulièrement et ne peut produire de merrain. Il convient néanmoins à la menuiseric, à la construction des machines, etc., fournit un chanffage tout particulièrement estimé et un excellent charbon.

Densité.

Usages. 
SECTION IV. Chénes à feuilles persistantes el à maluration bisammelle.

\section{(Feuilles dentées-épineuses ou entières; glands à cupule presque} lisse ou hérissée-épineuse.)

8. Chène occidental. Quencus occidentalis. Gay. Corcier ou Corsier (dans les Landes).

Feuilles persistantes jusqu'à l'entier développement de celles de l'année suivante, arrondies ou lígèrement prolongées sur le pétiole à la base, ovales ou elliptiques, dentées-mucronées ou spinulées, coriaces, glabres et luisantes en dessus, d'un vert faiblement grisâtre-tomenteux en dessous, 6-8-nerviées. Glands solitaires ou géminés, à maturation bisannuelle, de taille et de forme variables, 11 -22 sur $8-16$ mill., portés sur les rameaux défeuillés de l'année précédente par des pédoncules peu allongés, assez trapus et gris tomenteux; cupule hémisphérique, à écailles petites, les supérieures ovales obtuses, les inféricures à base épaisse, presque prismatique, réfléchie; les unes el les autres apprimées. - Arbre de taille moyenue, dont l'écorce est subéreuse comme celle du liége, dont les branches et les rameaux sont lisses et glabres, les ramules de l'année blancs-tomenteux. Forme de vastes forêts, seul ou mélangé avec le pin maritime, entre la Gironde el l'Adour, le long du golfe de Gascogne; disséminé entre l'Adour et Bayonne. Flor., juin. Fructif., milien de septembre de la seconde année.

Nalgré les différences remarquables de maturation et de glands qui séparent le chène occidental du chène liége, ces deux espèces ont été jusqu'à présent confondues. C'est ce qui explique les assertions contradietoires des différents auteurs qui ont traité l'histoire du liége et qui ont attribué à l'arbre qui le produit une maturation tantòt annuelle, tantôt bisannuelle, suivant qu'ils avaient en vue l'une ou l'autre de ces espèces.

Tempérament. Le chène occidental est l’arbre à liége du littoral de l'ouest; le chène liége véritable appartient is la région méditerranćenne. Le premier se plait dans les terrains de transport, siliceux ou argilo-siliceux des Landes, aux expositions chaudes et abritées des vents; il s'accommode particulièrement bien du mélange avec le pin maritime sous lequel il trouve protection, sans qu'il ait à souffrir de son couvert très-léger; il a le tempérament beaucoup moins méridional que le second et la culture l'a propagé avec assez de suecés jusgu'ì la hauteur de Belle-lste-en-mer.

Il fleurit et fructifie plus au nord, à Trianon (Versailles), 
où l'on en voit, en pleine terre, un pied àgé, qui mesure

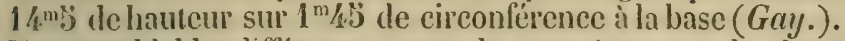
Une semblable différence entre le tempérament de deux espices aussi remarquables doit faire attacher une grande importance culturale à leur distinction (1).

La croissanec du chêne occidental est assez lente; vers 100 ans cel arbre mesure $1^{\mathrm{m}} 50-2^{\mathrm{m}}$ de circonférence, mais il peut avec l'àge dépasser ces dimensions et l'on en voit qui atteignent $4^{\mathrm{m}}$. Sa longévité s'élève à trois siècles et plus.

La fructification commence vers 20 à 30 ans et se soutient assez régulièrement chaque annéc.

Le chêne occidental est principalement cultivé pour le liége qu'il produit et, à quelques variations près, est soumis au même traitement que le liçge véritable. C'est vers 50 ans, alors qu'il mesure $0^{\mathrm{m}} 70-0^{\mathrm{m}} 80$ de circonférence, qu'on en fait le démasclage sur une hauteur d'environ $2^{\mathrm{m}}$; chaque levée se répète ensuite à un intervalle de 7 à 8 ans, et le liége obtenu a une épaisseur moyenne de 50 millim. It est appelé sans doute à jouer un róle important dans la misc en valeur des terrains improductifs des Landes, où les essais de sa culture ont généralement bien réussi. Les produits en argent qu'on en retire dépassent, par pied d'arbre, $\overline{5}$ ou 4. fois ceux du pin maritime (2).

Les vaisseaux du hois sont sensiblement inégaux; les uns, assez gros, forment au bord interne une zone très-étroite; les autres, petits et rares, sont distribués parmi le tissu fibreux dominant d'automne en séries simples, espacées, rayonnantes. Les grands rayons sont épais, nombreux et peu hauts. Il résulte de cette structure un bois un peu diflérent de celui du chêne liége, à couches annuelles nettement tran-

Fruclification.

Liége.

Bois.

(1) Des semis el des plantations de chêue liége ont été faits à Belle. Isle-en-Her, vers 1826 ; les plants et les glands furent tirés de Calalogne et des Landes. Les chênes de la première provenance sont tous morts, ceux de la seconde sont encore vivants. On a voulu trouver là un fail d'acclimalation de proche en proche. (Voir Thouin, Annales foresticres: 1. 1..) La vérité est que les chênes de Calalogne élaient de vrais chênes liéges et que ceux des Lantes sont des chênes oecidentaux, bien plus rustiques que les premiers pour supporter les froids.

(2) Je Jois à MIM. Monerie de Cabrens el de Monteil, gardes généraux, la plupart des renseignements forestiers qui couceruent cette essence. 
chées et à maillures plus petites, plus ígales et plus serrées; la coloration en est aussi plus claire et la densité bien inféricure. Un échantillon d'une tige de $2 / 4$ ans, mesurant 14 centimètres de diamètre, non compris l'écorce, et provenant des Landes, n’a pour densité que 0,78. (Coll. Ec. For. Envoi de M. Legros Saint-Ange.)

Ce bois est très-propre au chauffige et produit d'execllent charbon; on l'emploic rarcment a d'autres usages parec quion ne l'abat que lorsqu'il est sur le retour et plus ou moins vicié, et qu'en outre, semblable en cela au bois du chine liége, il supporte mal les alternatives de sicheresse et d'humidité el se tourmente beaucoup.

9. Chêne liermès. Qucreus coccirent. Lis. Q. pserdo-coccirena. DEsF. (1). Chène à coclienille.

Fenilles courtement pétiolées, persistantes pendant 1-2 années, pelites, 13̈-50 mill. de long, ovales ou oblongues, dentées-épineuses, ondulées, coriaces, verles, luisantes et glabres sur les deux faces. Glands solitaires, rarement gúminés, subsessiles ou courtement pédonculés sur les pousses de l'année précédente, ovoïdes ou oblongs, de taille variable, moyenne ou petite; cupule hémisphériquic, grise, à écailles prolongées en pointes carénées, droiles, presque vulnérantes, dressées au sommet, étalées à la base. - Arbrisseau de $2-3 \mathrm{~m}$ d'élévation au plus, formant un buisson très-touffu, dont l'écorce, d'ahord grisc el lisse, devient avec l'âge très-fincment et densément gercurée en long et cn travers, rugueuse, d'un brun presque noir. 'Trés-commun dans les lieux secs, pierreux ou sablonneux de la région méditerranéenne. France el Algérie. Flor., avril-mai. Fructif., août de la seconde année.

Taille. Le chène kermès, qui ne forme en France que des broussailles et n'y atteint jamais de dimensions qui permettent de l'utiliser', si ce n'est pour le chauffige, parait devenir dans des contrées plus chaudes un arbre de moyenne

Bois. taille. Le bois en est très-compacte et très-homogène

(1) Desfontaines décrit sous le nom de cliêne faux-kermès, Quercus pseudo-coccifera, un chêne d'Algéric qui semble n'ètre tout au plus qu'une variété du kermès proprement dit. II n'en diffère que par de plus grandes dimensions, $\xi^{-7} 7$ de hauteur, des feuilles plus altongces, des glands plus gros. Rien de plus variable que sa cupule, dont la forme est conique ou hémisphérique, resserrée ou très-évasée, et dont les épin's sont nombreuses et rapprochées ou assez rares et espacées, plus ou moins longues, dressérs, élalées ou réfléchies. En tenant compte de loutes ces différeners il y aurail aussi là de quoi créer bièn des espèces nouvelles. 
et ressemble beaucoup à celui de l'yeuse; il n'a, comme ce dernier, que des vaisscaux fins et égaux, qui forment des lignes rayonnantes ondulées, se prolongeant sans interruption à travers les accroissements annuels, dont la distinction est difficile ou mème impossible. Les grands rayons sont rares et peu épais, le parenchyme ligneux y est en général tris-apparent et forme avec le tissu fibreux des zones minces, alternativement plus foncées et plus claires. Provenant des Pyrénées-Orientales, d'une tige de 14 ans et de 4 cent. de diamètre, il a pour densité : 1, lorsqu'il est complétement desséché à l'air. (Coll. Ec. For.)

L'écorce est estimée pour le tannage.

C'est sur ce pelit chène que vit un insecte voisin des cochenilles, le liermès du chène vert (Fermes ilicis. Fab.), dont la femelle se fixe sur les rameaux et ressemble à une verrue de l'écorce, d'un noir violacé, de la forme et de la taille d'un pois. On recueillait autrefois l'insecte en cet état, et, de son corps desséché et pulvérisé, on obtenait une belle teinture écarlate. Cette industrie est à peu près totalement délaisséc depuis l'introduction et l'emploi de la cochenille du cactus nopal.

10. Chêne garrigue. Quercus auzandr. Gren. et God, Quencus rseudo-coccifera. IVerb. non Desp.

Feuilles semblables à celles du cliene kermès, mais plus allongées et relativement plus étroites et plus planes; glabres et luisantes sur les deux faces, dentées-épineuses ou parfois entières sur les bords. Glands ovoïdes, perlés au nombre de 2.5 sur un axe épais, plus lonğ que les pétioles; cupule hémisphérique, grise-tomeuteuse, à écailles longuement triangulaires et planes à l'extrémité, non saillantes, laclıement apprimées. Pelit arhrisscau buissonnant de 1 m:j0 environ de hauteur; lerrains secs et arides de la Provence : environs de Marseille, d'Arles et de Toulon. Flor. avril. Fructif., septembre de la deuxième année.

Ce chene est connu en Provence sous le nom de chène garrigue parce que c'est sur les sols arides, auxquels on applique la méme dénomination, qu'il se rencontre toujours. Il forme un buisson rabougri, que l'on confond le plus souvent avec le chène kermès, quoiqu'il s'en distingue nettement par le feuillage et surtout par la cupule. Il est surtout abondant dans la Crau, à l'embouchure du Rhòne, où il couvre des étendues considérables de terrains. Il n’a jamais attiré l'attention des forestiers et l'on ne sait rien des usages, peu importants sans doute, auxquels il peut être propre. Il doit, sous ce rapport, se rapprocher beaucoup du chène kermès.

Tan.

Kermès. 


\section{FAMILLE XLVII!}

\section{Comylacees. Schacht (Der Baum), carpinges, Doell.}

Floraison monoïrque. Fleurs mîles en chatons cylindriques, denses et pendants; chacune d'elles dépourvue de périgone el simplement composíe d'une écaille sur laquelle sont directement. insérúes 6-12 étamines à filets très-courts, divisés presque dès la base et dont cliaque branche supporte une anthère nécessairement uniloculaire, introrse, longitudinalement déhiscente. Fleurs femelles en chatons allongés ou raccourcis en fascicules, disposées 2 à 2 ì l'aisselle d'une écaille caduque, formée de 2 stipules soudées; cliacune d'elles composée d'un involucre de 1-4 bractées, d'un périgone généralement adhérent (toujours, dans le fruit) et d'un ovaire à 2 loges 1-ovulées. Involucre fructifère simple, foliacé, contenant un seul fruit, sec, indéhiscent, uniloculaire et monosperme par avortement, largement ombiliqué à la base, terminé nar les débris desséchés des styles et souvent couroné par les dents du périgone; il péricarpe ligneux ou crustacé (gland). Graine non périspermée, ì colylídons charnus, féculents-lıuileux. - Arbres ou ailbrisseaux à feuilles simples, caluques, alternes, penninerviées, pourvues le stipules écailleuses et caduques.

A. Périgone adhẻrent à l'ovaire au moment de la floraison; involucre ouvert au sommet.

B. Involucre formé d'un verlicille de 4 feuilles charnues à la base; gland ovoïde-pointu, lisse, à yéricarpe

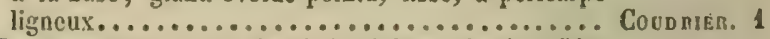

B1. Involucre d'une seule feuille à 5 lobes; gland ovoüdecomprimé, à nervures saillantes, largement tronqué et couronné au sommet par les dents du périgone; péricarpe erustacé.................. Cuanme.. 2

$\Lambda^{\prime}$. Périgone libre au moment de la floraison, adhérent au fruit. Involucre vésiculeux, clos au sommet. Gland ovoüde-comprimé, lisse, à péricarpe crustacé..... Osrnara .. 5

genne 1. - COUDRIER. CORYLUS. Toumef.

Fleurs naissant des bourgenns axillaires ou terminaux des rameaux de l’annéc précédente. Fleurs milles en chatons cylindriques, scrrés, pendants, réunis 2-¿i sur 10 axe ramifié et paraissant dès l'antomne de l'annéc rui pricède cello de la floritison; clacune d'elles composée d’une écaille bractéale d̀ la face 
mterne de laguelle sont attachíes 8 countes étamines, ì anthùres 1-loculaires, disposées en 2 rangs d'égal nombre de chargue côté le la nervure médiane. Fleur's femclles très-rudimentaires au moment de la floraison et dont l'organisation ne se complète que plus tard, renfermées en petit nombre au sommet d'un bourgeon mixte, qui ne se distingue d'un bourgeon à feuilles que par les styles rouges, saillants à l'extrémité; disposées 2 ensemble à l'aisselle d'une écaille formée de 2 stipules soulées. Chacune d'clles composée d'un involucre de 4 feuilles verticillées, d'un périgone adhérent, très-finement denticulé au sommet et d'un ovaire ì 2 loges 1-ovulées, surmonté de 2 longs slyles d'un rouge pourpre. Gland (noisette) ovoïlc et pointu, à péricarpe ligneux, 1-loculaire, monosperme, contenu dans un involucre foliacé, charnu à la base, ouvert au sommet et prolongé en lobes irrégulièrement découpés et plus ou moins allongés. Graine à cotylédons plans-convexes, huileux et amylacés, hypogés pendant la germination.

Bois entièrement blanc, semblable à celui du charme; mais demi-dur et demi-lourd seulement, avec les accroissements régulièrement circulaires. Fibres entremîlées de cellules ligneuses abondantes (non apparentes, mêmè à la loupe). Vaisseaux égaux, petits, disposés en séries rayonnantes de 2-16, à peu près uniformément répartis ou un peu plus serrés dans la zone interne. Rayons inégaux; les uns, très-fins; les autres, gros et hauts, formés de rayons très-minces alteruant avec des lames de tissu fibreux dépourvues de vaisseaux. On remarque souvent au milieu de ce bois de petites traînées d'un tissu cellulaire particulier, rougeâtre.

Coudrier noisetier. Conyus afelzana. LiN.

Feuilles pétiolées, obovales-orbiculaires, dont la plus grande largeur correspond aux $5 / 4$ de la longueur, légèrement cordifoimes à la base, brusquement acuminées el quclquefois subtrilobics au sommet, loublement dentées, vertes, presque concolores, couvertes sur les deux faces, dans la jeunesse, de longs poils mous; à peu près glabres plus tard, si ce n'est aux aisselles inféricures; à nervation habitucllement formíe de six paires de nervures pennées. Chatons mâles sessiles, jaunàtres, très-précoces, fleurissant longlemps avant la foliation. Involucre fruclifère à lolses inégaux, débordant généralement le gland. - Arbrisseau ramenx dès la base, dont les jeunes pousses sont hírissées de prils grlanduleux rougreatres; dont les stipules persistent à la lase des feuilles jus yu'en aoùt; à bour'seons courts, ovales-arrondis, presque obtus, recouverts de plusieurs écailles imbriuguées-spiralées, un jieu frangées sur les bords. Trìs-commun dans les forêts de toute la France, rare en Algérie. Flor., janvier-avril. Fructif., fin de septembre. Dissémin., netobre. 
Taille: Port. Le coudrier est un arbrisseau de $\bar{\jmath}-4^{\mathrm{m}}$ d'élévation, dont les maitresses tiges se couronnent quand elles sont parvenues à une certaine hauteur, et sont renylacées par des rejets droits, gréles, très-allongés, qui partent soit de la souche, soit des racines, et, dans ce deruier cas, finissent par devenir des pieds indépendants qui se sèvrent d'euxmémes. La coupe annuclle de ces rejets peut transformer le coudrier en un petit arbre à tige simple, courte, à cime ample très-ćtalée, assez touffue et à couvert épais.

Fructification. Le coudrier fructific vers 10 ans; les pieds isolés ou situés aux bords des massifs sont à peu près annuellement fertiles; mais ccux de l'intérieur restent quelquefois 5 -4 ans sans produire un seul fruit. C'est, de tous les végétaux forestiers, celui dont la floraison est la plus précoce et, dans certaines années exceptionnelles, elle se produit dìs le mois de décembre.

Germination. La noisette est d'une conservation difficile, mème jusqu'au printemps, et il vaut mieux la semer dès l'autonne. Le jeune plant, dans ce cas, parait de bonne heure au printemps, laisse ses cotylédons en terre et produit immédiatement des feuilles semblables à celles qui lui sont habituelles. Il ne dépasse guère "j-6 centimètres dans la - première année el s'accroit au plus de $13 ̈$ centimètres dans chacune des 3 - 6 années suivantes.

Rejets. Cet arbrisseau repousse peu par bourgeons adventifs, plus fréquemment par bourgeons proventifs, habituellement par drageons qui donnent des plants robustes, indépen-

Croissance. dants. La végétation des rejets est très-rapide; vers 3 ans ils ont atteint leur maximum annuel d'allongement et de grossissement et ver's $10-13$ ans leur plus grand accroissement moyen en volume.

Enracinement. L'enracinement est représenté à l'origine par un pivot droit, couvert d'un chevelu abondant; ver's 5 ans l'allongement du pivot se ralentit, puis s'arrète; les racines latérales se développent, plus tard l'une d'elles prend le dessus ef, à un certain àge, constitue une maitresse racine se prolongeant loin sous le sol, en conservant sur presque toute sa longueur un égal diamètre.

Station et sol. L'aire d'habitation du coudrier est très-étendue, en surface comme en altitude; il se trouve non-sculement du norl au sud, de l'est a l'onest de toute la Franere; mais des planes il s'eleve dans les montagnes, mène an-dessus du hictre. 
Liécorce, d'un gris mat sur les jeunes rameaux, puis d'un brun rouge, marquée de lenticelles assez abondantes. est couverte dans l'origine de débris de fines membranes qui proviennent de l'exfoliation de l'enveloppe subéreuse. Cetle ćcorce devient ensuite d'un gris argenté rougeâtre ct reste lisse, en présentant une disposition à s'enlever par lanières circulaires comme celle des cerisiers. On y trouve alors les trois régions normales : enveloppe subéreuse, parenchyme vert et liber. Ce n'est qu’à un âge avancé qu'il se développe un périderme intéricur, résistant, dans les leuillets clu liber et que celui-ci, repoussé au dehors, forme un rhytidome gerçuré-écailleux, que l'on n'observe habituellement qu’à la base des plus vieux pieds. Cette écorce contient 2,70 p. $0 / 0$ de tannin.

Le bois de coudrier a beaucoup d'analogies avec celui du charme; il est entièrement blane, mais les accroissements sont circulaires et il n'est que demi-dur et demi-lourd. Coupé en février, il pèse 0,92 à l'útat vert; $0, \$ 43$ à l'état sec.

La puissance calorifique, mesurée par l'eau évaporéc, est à celle du hètre comme $90: 100$ pour des poids égaux. Il brûle assez lentement, mais, une fois cmbrasé, il produit un charbon qui dure longtemps au feu et dégage beaucoup de chaleur.

Les faibles dimensions du coudrier restreignent nécessairement son emploi; on n'en retire guère que des perches, utilisées à diffẻrents usages, cercles, tuteurs, etc. On peut en obtenir du charbon propre à la fabrication de la poudre et au dessin.

L'amande de la noisette contient jusqu' à 60 p. 0 p̨0 d'huile grasse non siceative, d'un goùt agréable. On sait que celte noisette est comestible; celle de quelgues variétés cultivées et reproduites par la greffe est surtout recherchíe (aveline).

GENRE II. - CIIARME. CARPINUS. Lin.

Flcurs amentacécs pour les 2 sexes. Fleurs mîles cn chatons solitaires, cylindriques, sessiles, pendants, parfois légèrenıcut feuillés à la base, naissant des bourgeons axillaires, rarement du hourgeon terminal de Ia pousse de l’annće précédente. Chacune d'elles composée d'une écaille, supportant directement à sa base 
10-16 etamines ì filets courts, terminées par un pinceau de poils, it anthères uniloculaires. Fleurs femelles en chatons litches et formant le prolongement et la terminaison des pousses Jatérales ou terminales, normalenent feuillées à la base; disposées par 2 et pédicellées à l'aisselle u’une écaille qui représente 2 stipules soudícs. Chacune d'elles formée d'une griande bractée foliacée, d'un périgone adhérent, à limbe 1-5 denticulé, et d'un ovaire à 2 loges uni-ovulées, surmonté par 2 styles allongés et rouges. Glands en chatons litulies et pendants, contenus chacun dans un involucre très-développé, monophylle, foliacé, trilobé et à lobe médian allongé; tronqqués et surmovités par les dents libres el bien aprrarentes du périgone; uniloculaires et monospermes par avortement ; à péricarpe crustacé-ligneux, vert, relevé de côtes longitudinales. Graine ì cotylédons plansconvexes, féculents et huileux, épigés en germant.

Bois dur, lourd, compacte, entièrement blanc. Tissu fibreux homogène, fortement épaissi, entremêlé de cellules ligneuses (non apparentes, même ì la loupe); vaisseaux presque égaus, petits, disposés 2-7 en séries rayonnantes, à peu près uniformément répartis, si ce n'est sur la zone la plus externe où ils manquent. Rayons inégaux; les uns simples et minces; les autres épais, longs et très-lauts (dans le sens du fil), peu nombreux, surtout dans les branches, et composés de rayons simples alternant avec des lames minces de tissu fibreux dépourvues de vaisseaux.

Charme commun. Canpinus betulus. Lis. Charmille.

Feuilles alteraes, pétiolées, ovales ou oblongues, ordinairement aiguës ou mème acuminées, légèrement cordiformes à la base, dentées, à deuts aigument sous-dentées, surtout sur leur grand côté; peu luisantes, glabres et vertes en dessus, d'un vert un peu plus pâle et faiblement pubescentes près des nervures en dessous; limbe paraissant gaufré entre les nervures secoudaires qui sont saillantes, droites, parallèles, au nombre de 10-15 de charque cûlé. Chatons mâles à écailles ovales-aiguës, ciliées. Gland contenu dans un involucre foliacé très-graud, à lobes enliers ou dentés. - Arbre de taille moyenne, à écorce d'un gris cendré, lisse, très-mince, à tige peu régulière, creusée longitudinalement de larges cannelures arrondies peu profondes; hourgeons ovoüles-aigus, entourés d'écailles nombreuses, inbriquées-spiralées, poilues à l'extrémité. Très-aboudant dans le nord et l'est, dans les taillis ou, à l'élat de sous-bois, dans les futaies. Flor. avec les premières feuilles, avril-mai. Eructif., octobre. Dissémin., it la chutc des feuilles ou au priutemis suivant.

Taille. Port. Le charme n'est point un arlore de première grandeur; 20" délévalion, I'mo de diamètre sont pour lui des dimen- 
sions remarquables. La tige en est droite et se mainticnt dis lincte jusqu'à l'extrémité de la cime ; clle est toujours plus ou moins canneléc et relevée de côtes longitudinales, ce qui permet de la distinguer facilement de celle du hêtre, qui est toujours cylindrique. Elle ne se dénude qu’à une faible élévation au-dessus du sol. Les branches, nombreuses, longues et grèles, s'élèvent droit en faisant avec la lige un angle de $20-50^{\circ}$ et forment dans leur ensemble une cime ovoüle, pointue au sommet. Le couvert est assez épais, inférieur néanmoins à celui du hêtre.

A l'état d'isolement, la tige se garnit, en dessous des branches principales, de petites branches gourmandes, nombreuses, grêles, horizontales, qui persistent sans se développer beaucoup.

L'écorce se compose, après la chute de l'épiderme, d'une mince couche d'enveloppe subéreuse, de parenchyme vert et de liber; ces différentes régions restent vivantes jusqu'à l'àge le plus avancé, ne s'aceroissent pas sensiblement cn épaisscur et ne font que se distendre, par l'interposition de nouveaux tissus, au fur et à mesure que la tigge grossit. Aussi cette écorce, d'un gris cendré, reste toujours unie, lisse, vive, remarquablement mince, surtout sur les côtes saillantes. Son parenchyme re se lignific pas comme celui du hêtre.

Les jeunes pousses, d'abord vertes, puis olivâtres, passent au rouge brun vers 5 ans et, ì 6 ans environ, prennent la couleur grise earactéristique. Les bourgeons sont petits, oblongs-allongés, pointus, moins cffilés et proportiouncllement plus épais que ceux du hêtre.

On observe tress-souvent, entre le coussinet et le bourgeon prineipal, un second bourgeon (sous-bourgeon) qui en beaucoup d'occasions se développe et produit une jeune pousse. C'cst à cela en partic qu'est due la facilité avec laquelle on faconne le charme en berceaux, haics, charmilles, cte., qui se maintiennent très-touflus.

Les bourgeons proventifs du charme conservent leur vitalité jusqu’à un âge avancé, 80 ans. C'est à cux qu'il faut attribuer la repousse vigoureuse des souches de cette essenec et ces nombreux rejets qui naissent au-dessous de la section ou sortent mème de terre. Les bourgeons adventifs se produisent rarement et coustituent ces quelques rejets qui s'élèvent sur un bourrelet de la rertion méme. entre 
l'écorce et le bois. Eufin le charme a la firculcé de former des drageons ou au moins quelque chose qui y r'esscmble. Les vrais drageons, ceux du robinier, du tremble, etc., naissent de racines traçantes, ceux prélendus du charme proviennent de rameaux analogues à ces petites branches horizontales qui garnissent la tige des pieds isolés, et qui, émises par les parties tout à fait inférieures, se marcoltent naturellement, s'allongent considérablement sans grossir et produisent des rejets sur tout leur parcours.

Enracinement. L'enracinement est très-variable. Le jeune plant, élevé dans la terre ameublie d'une pépinière, a une lorte racine pirotante, à peine ramifiće. En forèt, le pirot s'oblitère généralement au profit des racines latérales, qui prennent une grande extension, et il est rare qu’il pénètre à plus de $0^{\mathrm{m}} \mathrm{3} 0$. Le bois de souches et de racines, extrait aussi complétement que possible, équiraut à $20-24$ p. $0 / 0$ du bois superficiel, savoir $2 / \bar{\jmath}$ pour la souche, $1 / \bar{\jmath}$ pour les racines (T. IIartig).

Station el sol. Le charme est très-commun dans les forćts du nord et de l'est de la France; il est rare ou manque mème parfois entièrement dans l'ouest et le midi. Il se plait dans les plaines et surtout dans les pays de coteaux ; reste en dessous du hètre dans les régions montagneuses et, dans les Alpes, ne dépasse pas $1100^{\mathrm{m}}$ d'alcitude.

Fructification. La fécondité du charme est très-déreloppée, se manifeste de bonne heure, à 20 ans et mème au-dessous, et il est peu de végétaux forestiers qui aient des années de semences aussi abondantes et en méme temps aussi répétées. II est vrai que, dans leurs intervalles, il n'est pas rare qu'on ne puisse trouver un seul fruit. Cette abondance est telle, parfois, que chaque pousse se termine par un chaton de fleurs femelles et, plus tard, de fruits, dont les involucres, verts et foliacés, forment la plus grande partie du feuillage de l'arbre.

Germination. Il fiut 23000-50000 glands de charme, déponillés de leur involuere, pour 1 kil. Semés en automne, quelques-uns de ces fruits germent au printemps suivant, la plupart à celui de la seconde année; semés au printemps, les plants ne lèvent qu'au bout d'un an. Pour éviter les dangers qu'ils peuvent courir de la part des mulots, il est micux de les disposer dans la terre it une certaine profondeur pour les préparer à la germination et de ne les en retirer quan printemps de la seconde année, Sences alors, ils germent immédiatement. 
Le jeune charme parait avec deux feuilles cotylédonaires ovales, entières, un peu charnues, très-faiblement pétiolées ; il croit lentement dès les premières années. Sous des circonstances moyennes de végétation, la tige, à 40 ans, ne présente que le $\frac{1}{4}-\frac{1}{5}$ du volume de celle du hêtre; à 100 ans, elle équivaut au $\frac{1}{3}$ ou mème à la $\frac{1}{2}$. Cette lenteur d'accroissement et le peu d'intérèt que peuvent présenter de grandes dimensions chez cette essence l'excluent des futaics. La végétation en taillis est, au contraire, assez aclive, et, à 20 ans, les produits du charme sont deux fois aussi grands que ccux du hêtre.

Le bois de charme est très-facile à reconnaitre à ses accroisscments irréguliers, flexucux, à sa couleur blanche, à son poids, à sa dureté; seul, parmi les bois durs, il présente des rayons (les larges) très-prolongís dans le sens de la filore ligneuse. Il est plus lourd que le hètre, dans le rapport de $112: 100$ d'après G. L. IIartig; de 125: 100 d'après Werneck; de 106 : 100 d'après T. IIartig; desséché à l'air, il pèse, en moyenne, 0,696 suivant ce dernier auteur.

L'importance principale du bois de charme est dans sa puissance calorifique. C'est un des meilleurs combustubles que nous possédions; il brùle avec une flamme vive et produit un charbon qui reste incandescent jusqu'à complète combustion. Sa valeur calorifique dépasse celle du hêtre de $5, ;$ p. $0 / 0$ d’après T. Ilartig. Il n'est pas cmployé comme bois de construction, en raison de son peu de durée; la fibre, souvent entrelacée, le rend d'un travail peu facile, et les menuisiers ne l'utiliseni pas communément; cependant sa durcté, son homogénéité, sa tenacité le rendent précicux pour la fabrication d'outils divers et pour la confection de certaines pièces de machines qui ont à subir des frottements, telles que dents d'engrenage, cames, etc.

Les glands contiennent une huile douce, qui rappelle, au goùt, celle de la noisette, maiș on ne l'extrait pas.

La feuille donne un excellent fourrage, quii, desséchí, équivaut au foin de bonne qualité. Suivant T. Itartig, l'hectare, à 12 ans, peut en donner près de 16,000 kil. à l'état ver', qui se réduisent à 4,100 kil. par la dessiceation ì l'air.

Croissance.

Bois.

Pesanteur.

Puissance calorifique.

Usages.

Produils accessuires. 
GENRE Hir. - OSTRYA. OSTRYA. Mich.

Fleurs amentacées pour les deux sexes. Chatons mîles fasciculés, cylindriques, pendants, serrés; chaque flcur composéc d'une écaille stipulaire, portant it sa base 6-12 étamines it filets courts, à anthères uniloculaires, terminées par des pinceaux de poils. Chatons femelles cylindriques, dressés et denses, composés d'écailles stipulaires ì l'aisselle de chacune ilesquelles sont 2 fleurs; chaque fleur formée d'un involucre vésiculeux, clos au sommet, d'un périgone libre et d'un ovaire ì 2 loges 1-ovulées. Fruits disposés en une sorte de cône ovö̈le et pendant qui rappelle beaucoup, par sa forme, cclui du houblon; chacun d'eux formé d'un involucre foliacé vésiculeux, et d'un gland ovoüde comprimé, lisse et sans côtes longitudinales, entouré par le périgone devenu adhérent, si ce n'est à l'extrémité qui déborde le fruit.

Bois brun, à fibres fortement épaissies, parmi lesquelles est dispersé un parenchyme ligneux abondant (non visible à la loupe) ; vaisseaux égaux, petits, groupés suivant des lignes dendritiques; rayons égaux, minces.

Dstrya commun. Ostuxa carpinifolia. Scop. Carpinus ostrya. Lin. Charme houblon.

Feuilles courtement pétiolées, orales-lancéolées, acuminées, doublement et aigument dentées; en dessus vertes et ģlabres, si ce u'est dans la jeunesse; en dessous d'un vert plus pâle, pubescentes aux aisselles des nervures, qui sont parallèles, très-saillantes et at nombre de 12-15 de chaque còté; limbe plus plan que echui de la feuille du charme. Chatons mâles naissaut plusieurs ensemble d'un mème bourgeon, a écailles arrondies-aiguës, ciliées; involucre blanchâtre, poilu, surlout à la base. Fruil très-petit, grisâtre, lisse, ovoïle-aigu, à sommct légèrement tronqué et surmonté par les dents peu appareutes du périgone. Petit arbre ayant presque entièrement le port du charme; à bourgeons ovoïdes, obtus, cntourés d'écailles nombreuses, imbriquées-spiralées, d'un brun clair et glabres; tige cylindrigue dont l'écorce se transforme de bonne heure en un rhylidome ggris brunàtre, écrilleux el en partie caluc. Rochers qui bordent la Méditerrance dans le Var. Flor., mai. Iructif., seplembre.

Taille. L'ostrya ou charme houl)lon a beaucoup d'analogies avec le charne commun par le port et par le feuillage, mais il est de moindre taille et ne parvient guc̀re qu’à $103-17^{\text {tI }}$ de

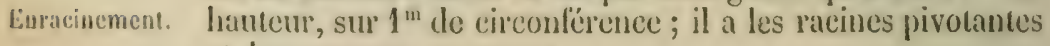
et longuement traçantes.

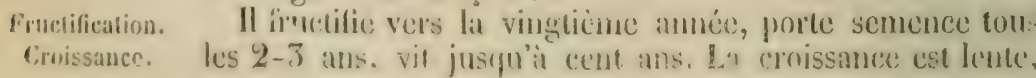


quoiquiun peu plus mapile dans la jeunesse que celle du charme.

Le bois est remarquable, dans ec genre, par le réscau dendritique que les vaisseaux groupés forment sur la tranche transversalc; il est d'un brun foncé, très-tenace, dur et compacte.

L'ostrya appartient aux régions du sud et du sud-est de l'Europe, où il croit mélangé avec le charme ct y devient une essence assez importante; il est trop rare en France pour y ĉtre de quelque intérèt forestier.

\section{FAMILLE XLIX.}

\section{B T บ A ACES. Endl.}

Floraison monoïrue, amentacée pour les deux sexes. Cliatons mâles cylindriques, denses, pendants, composés d'écailles peliées, 3-כ̌-lobées, supportant, à leur aisselle, 3 fleurs, parfois confondues, dont clracune est forméc d'un périgone 1-ব-foliolé et de 2-1 étamines, à antlì̀res biloculaires, longitudinalenıent délhiscentes, ou de 4-8 étamines à anthères uniloculaires par suite de la disjonction des loges et de la division plus ou moius complète des filets. Chatons femelles ovoüdes et denses, composés d'écailles 3-5'-lobées, dont chacune porte ì la face interne 2-3 ovaires nus, biloculaires, binvulés, terminés par 2 styles; produisant un cône dont les écailles, membraneuses et caduques ou ligneuses et persistantes, offrent ì la fice interne 2-3 fruits, généralement monospermes par avortement, secs, indéhiscents, ailés sur les côtés (samares). Graines non périspermées. - Arbres à feuilles simples, alternes, caduques, à nervation pennée.

A. Cônc à écailles 5-Jobées, minces, presque membrancuses, caluques à la maturité, recouvrant, chacunc, 5 peliteg samares à ailes membrancuses el transparentes Bouleau... 1

$\mathbf{A}^{\prime}$. Cône à écailles b̈lobées, ligneuses, épaissies à l'extrẹmité, persistantes, recouvrant, chacune, deux petites samares ................... Aune.....2

B. Ailes du fruit membrancuses et transparentes. Bourgeons aigus, sessiles...................... 5

$B^{\prime}$. Ailes du fruit épaisses et opaques. Bourgeons oblus, stipités ........................... A

Distribution géographique.

\section{Bois:}

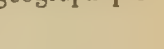


GENRE I. - BOULEAU. BETULA. TuUrnef.

Chatons mâles cylindriques, pendants, formés dès l'automne précident et sortant, au nombre de $\mathbf{1 - 3}$, de bourgeons terminaux non feuillés à la base ; compusés d'écailles pelfées, 3-lobées, supfortant 3 fleurs, dont chacune est formée d'un périgone 1-foliolé, de 2 étamines à filets fourchus et à loges de l'anthère disjointes, représentant 4 étamines à anthères $\mathbf{1 - l o c u l a i r e s . ~ C h a t o n s ~ f e m e l l e s ~}$ cylindriques et grêles, dressés, paraissant avec les feuilles seulement, solitaires et terminant de courtes pousses latérales, feuillées à la base; composés d'écailles trilobées, dont clacune supporte 3 fleurs femelles, réduites à un ovaire sans périgone, à 2 loges uniovulées, surmonté de 2 longs styles filiformes. Còne à écailles minces, coriaces-membraneuses, cadugues avec les fruits, qui sont de petites samares comprimées, lenticulaires, hordées de chaque côté d'une aile membraneuse et transparente. Bourgeons revêtus de plusieurs écailles imbriquées spiralées.

Bois demi-dur, demi-lourd, uniformément blanc. Vaisscaux égaux, assez gros, isolés ou groupés en petites lignes rayonnantes, uniformément répartis. Rayons égaus, minces, peu allongés ; parenchyme ligneux abondant (mais invisible à la loupe), associé au tissu fibreux.

A. Arbres; feuilles de taille moyenne; cônes pendants.

B. Plus grande largeur des feuilles vers la base; ces feuilles, les pétioles etles jeunes pousses glabres, ces dernières verruqueuses. Aile du fruit plus large que lui, atteignant ou débordant l'extrémité des styles...........

$B^{\prime}$. Plus grande largeur des feuilles vers le milieu; ces feuilles, les pétioles et les jeunes pousses pubescents, ces dernières lisses. Aile du fruit moins large que lui, ne dépassant pas la base des siyles...............

B. BLANC...... 1 1

B. Punescent....2 2

$\Lambda$ '. Arbrisseaux; feuilles petites; cònes dressés.

B. Arbrisseau à tige dressée, à petites feuilles ovales-arrondies, aigûment dentées, pubescentes; cône cylindrique; ailes du fruil presque aussi larges que lui.......... B. intersídiatri. 5

- B'. Sous-arbrisseau à lige diffuse, à feuilles trèspelites, arrondies, obtusément dentécs, glabres; cône ovoïle; fruit très-étroilement ailé....................... 
1. Ronleau bIanc. Avct. NoN Lin. Bouleau verruqueux. B. verrucosa. Ehrh.

Feuilles rlıomboïdales, triangulaires ou presque tronquées à la base, parfois mème légèrement cordiformes sur les jeunes rejets, longuenent acuminées au sommet, à contour général plus ou moins anguleux, denté el sous-denté; d'un vert un peu luisant, plus foncé en dessus, complélement glabres ainsi que les pousses, excep!é sur les très-jeunes plants et rejets; vcinules cachées dans le parenchyme et non saillantes en dessous; jcunes pousses verruqueuses, rudes au toucher. Còne pendant, à écailles J-lubées, de forme peu variable, dont les lobes latéraux sont les plus grands et arrondis. Fruit bordé d'une aile 2-5 fois aussi large que lii et le débordant supérieurement, de manière à alteindre ou à dépasser le sonimet des styles. - Arbre droil, élevé, à branches obliquement ascendantes, à rameaux et ramules grèles, arrondis, plus ou moins pendants, formant une cime arrondie-pyramidale; écorce lisse, blanche, papyracée, se gercurant largement et profondément à partir du pied, dès l'àge de $\mathbf{1 0 -}$ 13 ans; bourgeons glabres. Commun dans les forèts à sol frais et sablonneux des régions basses el monlagneuses du nord, de l'est et de l'onest, ou des régions élevées du sud. Flor., avril-mai. Fructif, mi-juin. Dissémin., fin de juin-novembre.

Le bouleau blanc est, tout au plus, un arbre de deuxième grandeur; cependant on en cite un en Courlande qui mesure $5^{m} 30$ de circonfërence et $28^{m}$ de hauteur. II conserve le mème port, qu'il croisse en liberté ou en massif, et, comme tous les arlures à couvert léger, il ne supporte pas l'état serré; il s'éclaircit de bonne heure et présente, sur une surface donnée, à égalité de hauteur et vers l'àge de 40 ans, moitié moins de tiges qu'un massif de hêtres. La tige, circulaire et assez gréle relativement it sa hauteur, se dénude jusqu'à $3-10^{\mathrm{m}}$ au-dessus du sol et se prolonge, à moins d'accidents, jusqu'à l'extrémité de la cime, atteignant en moyenne une élévation totale de $15 \mathrm{~s}-18^{\mathrm{m}}$. La cime est peu ample, ovale-aiguë, composée de branches longues et menues, ascendantes, souvent retombantes à leur extrémité (boulcau pleurcur), ainsi que les rameaux et ramules très-grêles qu'elles supportent.

L'écorce des jeunes pousses est toujours verruqueuse, généralement glabre. Après la chute de l'épiderme, vers 5-4 ans, elle devient lisse et brune et présente : $1^{\circ}$ une enveloppe subéreuse formée de cellules tabulaires résistantes. cxtensibles et disposées en lames minces; $2^{\circ}$ du parenchyme vert; $5^{\circ}$ du liber. Toutes les modifications ultérieures qu'elle subit se produisent dans l'enveloppe subćreuse et, pendant toute la vic, elle maintient actives les mèmes couches de parenchyme vert et de liber, qui, sans s'accroitre

Taille, Port.

Ecorce. 
en épaisseur, se ciéreloppent en largeur, au lur et à mesure rue le corps ligneux s'épaissit. Vers 6-8 ans, un tissu cellulaire cubique, fragile, blane, s'interpose par lames minees cntre les zones du tissu subéreux tabulaire brun. Les parties les plus extéricures de ce tissu blane, distendues par l'accroissement interne, se déchirent et laissent isolées les lames te tissu brun, qui, scmblables à des feuilles de papier, s'enlévent eirculairement et sont blanchics sur les deux faces par les débris des cellules cubiques. L'envelopı̨e subéreuse se maintient ainsi, lisse et d'un blane de neige, s'exfoliant à sa surface, tandis qu'elle se reforme par sa face interne, jusqu'à l'àge de 15 à 20 ans; puis elle subit une nouvelle modification. Un tissu cellulaire brun, dur et cassant, résultant d'une transformation du tissu cellulaire cubique

- blane, se développe abondamment, mais très-inégalement, cntre les feuillets des cellules tabulaires, gereure ceux-ci, les repousse au dehors et constitue une sorte de rhytidome épais, profondément et largement crevassé, qui se produit naturellement au pied de l'arbre d'abord, puis s'éléve de proche en proche avec les annécs. L'écoree unic du bouleau représente 12-18 p. 0/0 du volume total; celle qui est gerȩuríe forme jusqu’à $53 \mathrm{p}$. 0,0 de ce volume.

Enraciument. L'enracinement est laible. Le pivot a, dès la première annéc, une tendance prononcéc à se courber et à devenir traçant; il produit beaucoup de racines latérales et de chevelu et forme une souche très-courte, ramasséc, qui, vers 6-8 ans, est à peine enfoncée de 12-13 centimètres dans le sol. Lne ou deux racines latérales, cependant, finissent par dominer et par s'enfoncer plus avam. Le bois de souche est souvent madré. Le volume réel du bois souterrain est, en moyenne pour des àges différents, au volume tolal :: $16: 100$; il descend jusqu’a 13, s’élève jusqu’à 20 p. 0/0. Il est rare que l'extraction en rapporte plus de $10-12$ p. 0/0.

Bourgcons. Les bourgeons sont courtement ovoüdes, plus ou moins aigus, recouverts d'un petit nombre d'écailles et enduits d'une exerćtion résineuse balsamique; tris-rarement ils sont aceompagnés d'un sous-bourgeon. Les bourgeons proventifs véritables sont rares et périssent de bonne heure ; les bourIrejels. geons adventil's s'organisent diflicilement ef la rejroduction est principalement due à des bourgeons de souche, sortes de hourgeons proventifs souterrains, quu se sout développés cu des places ou jamais il n’a existé de feuilles. Aussi le's 
rejets des bouleaux sortent-ils presque tous de terre. Les souches sont, en somme, peu aptes à repousser et s'usent vite.

Le feuillage du bouleau est beaucoup plus abondant qu'on ne lc suppose ordinairement, car un hectare en produit en poids at moins autant que le hêtre, 15000 kil. environ, qui se réduisent par la dessiccation à l'air à 5200 kil.; plus épais et plus lourd que celui du hètre, il suffit pour couvrir 5̋,2 fois la surface qui l'a produit. Néanmoins le convert du bouleau est un des plus légers que l'on connaisse, parce que les feuilles en sont pendantes et qu'au lieu de présenter leur plus grande surface à l'action de la lumière, comme le font celles de la plupart des autres arbres, elles n'y offrent que leur tranche. Elles se décomposent rapidement sur le sol, en $\mathbf{2}$ années, et n'y forment par conséquent point de couverture épaisse comme eelles du hêtre.

Les feuilles ont l'insertion $\frac{2}{5}$ sur les pousses principales, $\frac{1}{2}$ sur toutes les autres; le pétiole en est plus allongé et plus grèle que celui des feuilles du boulcau pubescent.

Le bouleau, isolé, fructific dès l'àge de 10 ans, plus tôt mème s'il provient de rejet de souche; en massif, ver's 20 ans ; la fécondité en est soutenue et régulière. Suivant les localités, les années, les individus, la dissémination se fait dès la fin de juin ou peut être retardée jusqu'en novembre. Les semences de boulcau ne peuvent ètre démélées des écailles, qui tombent avec elles et sont presque aussi petites et aussi légères et dans la proportion d'une écaille pour trois fruits ou un peu moins. Le kilogramme renferme au moins 788,000 écailles et 1,987,000 fruits.

La meilleure semence de bouleau contient bcaucoup de fruits mal conformés; elle est de bonne qualité quand elle en présente le $\frac{1}{4}$ ou le $\frac{1}{3}$ aptes à germer. Cette semence se conserve difficilement, à peine jusqu'au printemps, non sans perdre encore beaucoup de son aptitude à la germination. En semant en juin, le jeunc bouleau lève au bout de 2-5̃ semaines; en semant au printemps, au bout de $4-\not 3$ semaines. Il parait avec deux très-petites feuilles cotylédonaires semiovoïles, auxquelles sucec̀dent d'autres feuilles simplement dentées et pubescentes; il ne dépasse généralement pas ちँ-6 rentimètres la première année. Les feuilles qui suivent prennent de plus en plus la forme ordinaire, deviennent

Feuillage.

Fructification.

Germination. 
sous-dentées et complétement glabres; rers trois ans, le jeune plant a déja atteint $0^{\mathrm{m}} 60$ au moins et, à partir de ee moment, il s'élance rapidement.

Station et sol. Le bouleau blane est très-souvent confondu avec le bouleau pubescent et e’est ce dernier que Limné a dù décrire. sous le nom de Betula alba, puisque e'est lui qui forme une. grande partic des forets du nord de l'Europe, ou le vrai boulcau blane n’est que très-disséminé. Il a à peu près la même aire d'habitation que le pin sylvestre, parait rechercher les sols légers, sablonneux, frais, sans exiger autant de profondeur que cette dernière eșsence. Dans les régions montagneuses élevées, tout comme dans les plaines basses, humides ou marécageuses et dans les lieux tourbeux il est remplacé par le bouleau pubescent.

Bois. Le bois de boulcau est blane, quelquefois légèrement grisatte ou rougeâtre quand il est vieux, homogène, à grain médiocrement fin; suivant G. L. Ilartig, la densité, à l'état Pesanteur. vert, est, en moyenne, 0,79 ; d'après T.IIartig, il pèse, coupé en été, vert, 0,80 ; desséché à l'air, $0,3 \% 8$; coupé en hiver, vert, 0,84 ; desséché à l'air, 0,616 .

Dans ce dernicr état il renferme encore $10-12$ p. $0 / 0$ de son poids en eau. Il se retire considérablement en se desséchant, de $15-20$ p. $0 / 0$ du volume primitif.

Usages. Ce bois, exposé aux variations atmosphériques, se pourrit très-rapidement et complétement; aussi n’est-il pas employé aux constructions; mais il sert à la menuiserie, au charronnage, au tour; l'ébénistcrie tire mème un assez bon parti du bois madré de sa souche et des broussins de sa tige. On en fait des échiclles, des sabots, des cereles, des harts; les jeunes rameaux sont recherchés pour balais.

Valeur D’après les expériences de T. Ifartig, du bois de la tige calorifique. d'un bouleau de 80 ans, ramené par la dessication à 8 p. $0 / 0$ d'cau seulement et pesant 0,70, comparé à du bois de hètre de même àge et de même dessication, d'une densité de 0,80 , a donné les résultats suivants sur sa valeur calorifique :

Poids cgaux. Vol. égaux.

Plus haut degré de chaleur...... $\left\{\begin{array}{l}\text { ascendante } 104: 10091: 100 \\ \text { rayonnante } 100: 10087,5: 100\end{array}\right.$

Durée de la chaleur ascendante... $\left\{\begin{array}{l}\text { rayondante } 100: 10087,3: 100 \\ \text { rayonnante } 94: 10082,2: 100\end{array}\right.$

Durie de la chaleur décroissante. $\left\{\begin{array}{l}\text { ascendante } 10 /: 10091: 100 \\ \text { rayonnante } 90: 10078,7: 100\end{array}\right.$ 
Totả de la chaleur dévcloppéc... $\left\{\begin{array}{l}\text { ascendante } 98: 100 \quad 85,7: 100 \\ \text { rayonuante } 95: 10085,1: 100\end{array}\right.$ Eau vaporiséc................... 107: 100 95,6:100

Le bouleau cst, comme on le voit, un assez bon combuslible; il brukle avec une flamme claire et vive, produit un liaut degré de chaleur ascendante et convient parfaitement à certaines industries : boulangeries, verreries, ete.

Le charbon en est lourd et dur; il dégage une chaleur intense et soutenue et équivaut à celui du hêtre.

L'écorce de bouleau, particulièrement l'enveloppe subéreuse qui en est la partic la plus active, contient du tannin, 1,6 p. 0,0 d'après Davy; elle est très-recherchíe par les habitants du Nord de l'Europe pour la préparation du cuir, auquel elle communique une couleur particulière et une odeur caractéristique. On en extrait, par voie de distillation sìche, une huile essenticlle avec laquelle on enduit les euirs de Russie. Elle fournit un excellent combustible.

L'écorce blanche renferme presque moitié de son poids d'une rísine particulière, bétuline, que l'on peut extraire par l'alcool, puis faire cristalliser'. C'esi sans doute l'abondance de ce principe qui assure à cette écorce une inaltérabilité et une imperméabilité si remarquables. La première de ces propriétés est telle, que, dans des toubes et même des lignites, on trouve des portions d'écorce rle bouleau parfaitement intactes, tanclis que le bois est totalement détruit ; on la met à profit dans les régions du nord en revêtant d'écorce les portions de picux que l'on enfonce en terre. On sait que Iimperméabilité de cette écorce la fait rechercher pour en fabriquer des tabatières; on peut aussi en faire des semelles aussi bonnes que celles de liége, pour garantir contre l'humidité; enfin, en la distillant dans des fours, elle produit du goudron.

Les verrues et les bourgeons contiennent aussi de la résine; mais elle ne cristallise pas comme la précédente.

On retire de la feuille du bouleau, comme de celles de plusieurs autres végélaux, une matière colorante dont on fait une sorte de pâte, employéc en peinture sous le nom de styl de grain.

La séve du bouleau renferme une notable quantité de sucre, 8,7 sur 1000 kil. On cxtrait cette séve, dans le nord, au moyen de trous pratiqués de bas en haut dans la tige, ì une profondeur de 5 a 6 centimètres. Un arbre robuste

Produils accessoires. 
et de grandes dimensions peut, dit-on, fournir 170-240 litres en 24 heures, quand le temps est favorable. Concentrée, puis soumise à la fermentation avec addition de sucre et de différents aromates, on en fabrique une boisson spirilueuse très-appréciéc dans ces contrées.

\section{Lin.}

2. Bouleau pubescent. Betula pudescens. emrn. Betula Alla.

Feuilles ovales ou ovales-rhomboïdales, à bords de la base courbés et non rectilignes; quelquefois cordiformes sur les jeunes rameaux; moins acuminées et plus courtement pétiolées que celles du bouleau blanc, à contour général arrondi, à dents simples ou à peine sous-dentées; d'un vert plus foncé en dessus qu'en dessous, où elles sont finement réticulées el pubescentes ainsi que les pétioles et les jeunes pousses; ces dernières douces au toucher, toujours dépourvues de verrues. La pubescence est du reste très-variable; très-abondante sur les jeunes plants et surtout sur les jeunes rejets, elle diminue avec l'àge, mais laisse toujours que!ques traces, aux moios aux aisselles des nervures inféricures el sur les pétioles. Còne pendant; écailles du fruil trilobées, de forme très-diverse, à lobes latéraux de contour ordinairement anguleux. Aile du fruil moins large ou à peine plus large que la graine; peu prolongée vers le haut et ne débordant pas la base des stigmates. - Arbre moins élevé que le bouleau blanc, à ramification plus basse, plus forte, à branches inférieures plus étalées; à jeunes rameaux redressés, feuilles presque horizontales donnant un couvert plus épais, bourgeons légèrement poilus ; à écorce ne se gerçurant que peu ou point, mème au pied de l'arbre. Commun dans les bois humides du nord, du nord-est et de l'ouest de la France; atteint les sommets les plats élevís des Alpes el probablement aussi ceux des Pyrćnées où l'on signale le bouleau à $2000^{\mathrm{m}}$ d'altitude. Flor., avril-mai. Fructif., mi-juin. dissemin., fin de septembre.

Le bouleau pubescent croit souvent en mélange avec le bouleau blane; mais il s'avance beaucoup plus que lui vers les régions septentrionales et s'élève davantage dans les régions montagneuses. C'est dans les sols humides, où croit l'aune, qu'il semble se plaire le plus. On le rencontre aussi dans les lieux marécageux et tourbeux, mais sa végétation y est moins belle. Pour tout le reste il resscmble au boulcau blanc.

3. Bouleau intormécliaire. Betula intermedia. Thomas.

Feuilles ovales ou ovales-rhomboüdales, petites, simplement et aigúment dentées en scie, plus ou moins pubescentes, à nervures légèrement réticulées-saillantes en dessous. Cònes cylindriques, redressés, à pédoncules aussi longrs (qu'eux; écailles trilobées, à lobes peu divergents. Fruił at aile ì pen près aussi large que la graine. - Mrbrisseau dépassant à peine 2 mito de hauteur, a rameaux dressés, ordinairement pubescents. 'Tourbières les pllus élevées du Jura (vallées des Rousses el de Joux), en société avec le bouleau pubescent et le bouleau-nain, dont il est sans 
doute un hybride. N'a aucune importance forestière. Flor., mai. Fructif., juillet-2oût.

4. Bouleau nain. Betula nana. Lin.

Feuilles très-petites, rarement de 1 centimètre de longueur, orbiculaires, habitucllement un peu plus larges que longues, crénelées, à dents oblusesarrondies, à nervures réticulées-saillantes en dessous, courtement pétiolées, souvent presqque sessiles, glabres. Cône dressé, ovoïde, presque sessile, à écailles trilobées-palmées. Fruit très-étroitement ailé. - $\mathbf{\Lambda r}$ brisscau alteiguaut à peine $1 \mathrm{~m}$ de hauteur, à branches souvent longuement rampantes, rameaux redressés, tomenteux, sans verrues; écorce d'un pourpre noirâtre. Dans les hautes tourbières du Jura (vallées des Rousses et de Joux). Flor., mai. Fructif., juillet-août.

geNRE It. - AUNATRE. ALNASTER. Spach.

Chatons måles cylindriques, denses, dressés ou pendants, sortant dès l'automne, au nombre de 1-3, du bourgeon terminal et des bourgeons latéraux supérieurs, sans être accompagnés de feuilles; formés d'écailles peltées à bord 5-lobulé, qui supportent, chacune, 3 fleurs confondues en une seule et consistant en un périgone 8-12-partite et 8-12 étamines à anthères biloculaires, dont les loges sont disjointes. Chatons femelles séparés des chatons mâles et n'apparaissant qu'au moment de la floraison, au printemps; disposés, 2-5, en petites grappes latérales feuillées à la base et composés d'écailles épaisses, 4-lıractéolées, sur lesquelles sont 2 lleurs, dont chacune est formée d'un ovaire nu, à 2 loges uniovulées, surmonté de 2 longs styles filiformes. Cône ovoïde, à écailles persistantes, presque ligneuses et épaissics à l'extrémité, portant à la face interne 2 fruits monospermes, comprimés, polygonaux, bordés d'une aile membraneuse et transparente.

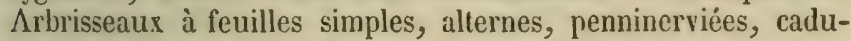
rues; it bourgeons 3-écailleux, ovoïdes-aigus, sessiles.

Bois demi-lourd et demi-dur, blane, ne rougissant pas après la coupe. Vaisseaux fins, égaux, groupés en petites séries simples et rayonnantesque l'on n'aperçoit qu'à la loupe et semblant uniformément répartis; parenchyme ligneux disséminé (non apparent, même à la loupe); rayons fins et égaux.

Ce genre est exactement intermédiaire entre les bouleaux et les aunes; il a l'inflorescence, les samares et le bois des premiers, le feuillage et les cônes des seconds.

A. Feuilles hérisscées en dessous, sur la base des ncrvures et aux aisselles; chatons mâles dressés, sortant plusieurs d'un mème bourgeon... $\Lambda$. vent..... 1

$A^{\prime}$. Feuilles glabres avec quelques poils aux aisselles; chatons mâles solitaires, peudanls... A. sudve..... 2 
1. Aunatre vert. Alnaster viridis. Spacu. Alnus viridis. $D C$. Fl. fr. Alnus ovata. Sclirank.

Feuilles ovales, aiguës ou obtuses, finement et irrégulièrement dentées en scie, glabres et d'un vert peu foncé et peu brillant en dessus, plus pâles et hérissées de poils sul les nervures et aux aisselles, en dessous. Chatons mâles ascendants, réunis plusieurs à l'extrémité des rameaux. Fruit obovale, à ailes membraneuses, plus larges que la graine, el presque semblables à celles du fruit du bouleau blanc. - Arbrisseau de $2-4^{\mathrm{m}}$, rarement plus, sur $10-15$ centimètres de diamètre à la base, à écorce lisse el d'un-gris brunâtre; à jeunes pousses glabres et verruqueuses, bourgeons glabres et visqueux. Régions élevées des Alpes, où il est quelquefois assez abondant pour servir de bois de chauffage; descend arec les cours d'eau dans les vallées alpines (Mont-Viso, la Bérarde, Lautaret, Revel, glaciers de Valgandemar, de Champsaur, d'Oysans, ctc.). Flor., mai. Fructif., juillet-août.

2. Amatre suave. Alasaster suaveolens. Spach. Alnus suavcolens. Requien.

Voisin du précédent, dont il n’est probablement qu’une variélé. Feuilles ovales-orbiculaires, aiguës, très-finement, aigûment et irrégulièrement dentées en scie; glabres, d'un vert sombre et très-visqueuses en dessus, un peu plus pâles, ģlabres, parfois mème aux aisselles, en dessous. Chatons mâles pendants, habituellement solitaires, peu serrés. Fruit elliplịue à ailes membraneuses moins larges que la graine. - Arbrisseau de 1-2in. Région montagneuse de la Corse (Monte Coscione, Renoso, Grosso; Campolite, Incudine, Niolo; forêt de Vuldionello, elc.). Flor., arril. Fructif., juillet.

\section{GENRE U. - AUNE. ALNUS. Tournef.}

Chatons miiles et femelles réunis dans une même inflorescence paniculíe, non feuillée, dont les premiers occupent le sommet et qui se dégage des bourgeons dès l'automme; les mâles, cylindriques, deuses, dressés, puis pendints, formés d'écailles peltées à bord j̃-Jobulí, qui supportent 3 fleurs distinctes, composées chacune d'un périgone 4-partite et de 4 étamines à autheres biloculaires, dont les loges sont presfjuc disjointes. Chatons femelles dressés, à écailles épaisses, peltécs, 1-bractéolées, pourvues de 2 fleurs, dont chacune est formée d'un ovaire un, à 2 loges uniovulées, surmonté de 2 longs styles filiformes. Cûne ovö̈de, ì écailles ligneuses, persistantes, épaissies au somnet, portant i la lize interne 2 fruits monospermes, comprimés, polygonatux, bordés d'une aile opargue et coriace. - Arbres à foruilles simples, penninerviées, caduutues, spiralées suivant l'indice 1/3, quoique uon exactement; ì jeunes pousses triangulitires et à botrgeons obtus ou aigus, stipités, recuuverts de 3 écailles, dont l'externe embrasse les deux autres.

Jois demi-dur et remi-lourl, blanc, milis rougissant aussitô 
après l'exploitation. Vaisseaux égaux, nombreux, petits, isolés ou réunis 2-8 en lignes simples rayonnantes, du reste uniformément répartis; parenchyme ligneux disséminé (non apparent, même à la loupe); rayons médullaires inégaux, les uns très-fins, nombreux, les autres rares, épais, longs et hauts, composés de rayons fins qui alternent avec des lames de tissu fibreux dépourvues de vaisseaux. Canal médullaire 3 -angulaire.

A. Bourgeons obtus; cone de la grosseur d'une noisette au plus.

B. Feuilles vertes sur les 2 faces.

C. Feuilles obluses, tronquées ou même échancrées au sommet, brillantes et glabres sur Ies 2 faces, avec quelques poils aux ais-

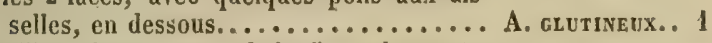

$C^{\prime}$. Feuilles obtuses ou subaiguës, pubescentes ou légérement tomenteuses en dessous... A. pudescext. 2

B'. Feuilles blanchâtres et pubescentes-tomenteuses en dessous ; aiguës ou acuminées....... A. BLANc.... 5

A'. Bourgeons aigus; cône gros comme une noix.

B. Feuilles elliptiques, non cordiformes à la base, barbues aux aisselles................... ElLiptiQue \&

$\mathbf{B}^{\prime}$. Feuilles ovales, cordiformes à la base, glabres

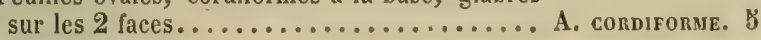

1. Aume glutineux. Alnus glutinosa. Gertn. Betula alnus.

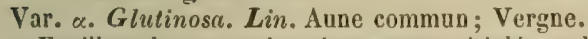

Feuilles plus ou moins visqueuses, pétiolées, obovales ou suborbiculaires, obtuses, tronquées et le plus souvent ichancríes au sommet, habitucllement cunéiformes à la base, à bords entiers sur le tiers inférieur, puis au delà très-irrégulièrement et doublement dentées ou crénclées; à $6-9$ paires de nervures secondaires; insertion peu régulière, 1/5 environ; dessus d'un vert brillant foncé, généralement glabre; dessous d'un vert brillant plus clair, finement glanduleux, avec les aisselles garnies de faisceaux de poils ferrugineux, qui se retrouvent sur la nervure médiane, à la base des nervures secondaires, sur le pétiole et, quelquefois, sur les jeunes pousses. Bourgeons gros, ovoüdes, renflés, obtus, glabres et glauques, visqueux, stipités, munis de 2 a 5 écailles; cône vert, puis brun noirâtre. Samare de forme générale pentagonale, légèrement convexe, brun rougeâtre brillant, à aile plus élroite que la graine. - Arbre de taille moyenne, quelquefois grande, commun dans les forèts humides el au bord des eaux de toute la France; se trouve en Corse et en Algérie. Flor., très-printanière, février-mars. Fructif., fin de septembre-mioctobre. Dissémination en automne ou at printemps, suivant les climals, les expositions, la température de l'année.

L'aune glutineux est plutot un arbre de taillis que de futaie et il est rare de le rencontrer de pied frane et d'un igge avaneé; dans des eonditions tres-favorables, il peut eеpen-

Taille. Port. 
dant atteindre $50-55^{\text {tn }}$ de hauteur sur $0^{\mathrm{m}} 50-\mathrm{1}^{\mathrm{m}}$ de diametre; mais ces dimensions sont exceptionnelles. La ramification, très-variable, rappelle parfois assez bien celle du chẻne rouvre. En taillis il forme des eépées vigourcuses, dont les brins, droits, effilés, divergents, atteignent une grande hauteur. On cite des souches d'aune de plus de $7^{\mathrm{m}}$ de circonférence à la base, portant 11 rejets hauts de $24^{\mathrm{m}}$ et mesurant chacun $1^{\mathrm{m}} 15$ à $1^{\mathrm{m}} 50$ de circonférence au pied.

Ecorce. L'écorce des jeunes pousses est lisse, d'un vert brun, pourvue de glandes résinifères et de grandes lenticelles espacées; dès la seconde année l'épiderme s'enlève en feuillets minces, blanchàtres, et fait place à l'enveloppe subéreuse, lisse et d'un vert olive, qui se maintient jusque vers $15-20$ ans. A cet àge un périderme intérieur s'organisc, sous forme de plaques, en dessous des couches les plus anciennes du liber; celles-ci repoussées au dehors, développent un tissu cellulaire brun, dur, irrégulièrement distribué, et constituent à la surface un rhytidome d'un brun noiràtre, divisé en plaques larges et aplaties. L'écorce forme 15-18 p. 0/0 du bois de petite dimension, 10 à 15 p. $0 / 0$ du bois de 15 à 50 centimètres de diamètre.

Enracinement. L'enracinement de l'aune varie autant que sa ramification, et dépend des sols. Il est d'autant plus traçant que le terrain est plus humide. On estime que dans un arbre de pied frane coupé à $0^{\mathrm{m}} \breve{\jmath} 0$ du sol, le bois de la souche et des racines forme $12-15$ p. $0 / 0$ de la masse. Cette proportion est nécessairement plus forte dans les taillis.

On trouve souvent sur les racines encore grèles de l'aune des excroissances en forme de tubercules, de la grosseur d'un œuf, qui ne sont autres que des broussins souterrains.

Bourgcons. Les bourgeons de l'aune sont faciles à distinguer aux caractères donnés plus haut; sur les pousses robustes, ils sont assez souvent accompagnés d'un sous-bourgeon, qui reste à l'état d'oeil dormant.

Rejets. L'aune commun repousse bien de souche et produit des rejets qui partent de la surface du sol ou d'un peu au-dessous; il ne drageome pas. La fragilité de ses rameaux ne permet pas de le marcotter aisément.

Ficuillage. La production foliacéc de l'aune est une des plus faibles; I'hectare, bien peuplé, produit en moyenne 9,500 kil. de fenilles fraiches, se réduisant par la dessiccation à l'air libre is 4,000 kil., et a 5,300 kil. par une dessiceation parfaite. 
Ces fenilles peuvent recouvrir 4 fois $\frac{1}{2}$ la surface de production (T. Hartig).

La floraison de l'aune suit de près celle du coudrier et précède d'un mois au moins la foliaison. En liberté, cet arbre fructific vers $15-20$ ans, en massif vers 50 - 40 ans; il produit annuellement ou tous les 2-5 ans.

La semence se dissémine au $1^{\text {er }}$ printemps et quelquefois en automne sur la neige. Les samares qui tombent naturellement sont les meilleures, parce que ce sont celles des parties moyennes du cône, les plus complétement développées; on peut en compter 60-70 p. 0/0 de bonne qualité. Lorsque les cones sont cueillis et que le fruit en est extrait par chaleur artificielle, qui doit ètre modérée, on n'en peut pas espérer plus de $50-40$ p. $0 / 0$ aptes à germer, au maximum. Le kil. en contient 1,270,000.

Le fruit conserve assez longtemps. sa vitalité, parfois au délà de trois ans; cependant plus on tarde à semer, moins les chances de succès sont grandes et moins les jeunes plants obtenus sont vigoureux.

L'aune glutineux aime les terrains humides des plaines ou des montagnes peu élevées; il est commun au bord des rivières, des ruisseaux et des torrents qu'il remonte parfois jusqu’à une assez grande altitude; le séjour prolongé des eaux stagnantes à la surface du sol lui est contraire.

Le bois de l'aune glutineux, blane au moment de l'exploitation, prend rapidement à la surface une couleur rouge orangéc caractéristique; desséché et débité, il a cette même teinte, mais plus claire. Il se reconnait aisément à ses larges et hauts rayons, proportionnellement plus nombreux que dans l'aune blane, à ses couches qui sont peu ou point rentrantes au passage des rayons et plus colorées dans le hois d'automne; les taches de tissu médullaire d'un rouge brun y sont communes et forment de petites plaques parallèles aux accroissements.

La densité du bois d'aune est en moyenne, d'après T. P'esantcue. Ilartig.

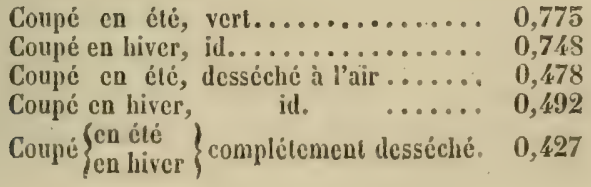

Coupé en été, vert........... 0,775

Coupé en hiver, id............. 0,7kS

Coupé en été, desséché à l'air ...... 0,478

Coupé en hiver, id. $\quad \ldots \ldots .0,492$

Cotipé $\left\{\begin{array}{l}\text { en été } \\ \text { en hiver }\end{array}\right\}$ complétement desséché. 0,427 
Le retrait varie beaucoup, de 10 à $50 \%$. $0 / 0$, suivant que le bois est coupé en liver ou en été.

Usages. L'aune, par ses dimensions, pourrait devenir propre aux constructions, mais il se pourrit presque aussi rapidement que le hètre et le boulcau, quand il est soumis aux alternatives de sécheresse et d'humidité; employé à couvert, il peut fournir des chevrons et des pièces de menue charpente; à une humidité constante et sous l'eau il acquiert une durée presque égale à celle du chène et sert avantageusement pour travaux hydrauliques, conduites d'eau, boisages de puits et de mines, etc. On en fabrique différents ustensiles de ménage, des meubles communs, de la boissellerie, de la saboterie, etc. C'est un bois mou et doux, tris-cassant, qui se gerce et se tourmente bcaucoup.

Valeur calorifique.

T. Ilartig, en comparant la valeur calorifique du bois d'aune de 20 ans, desséché à l'air et d'une densité de 0,12 , à celle du hètre de 50 ans, également desséché et pesant 0,72 , a obtenu les résultats suivants :

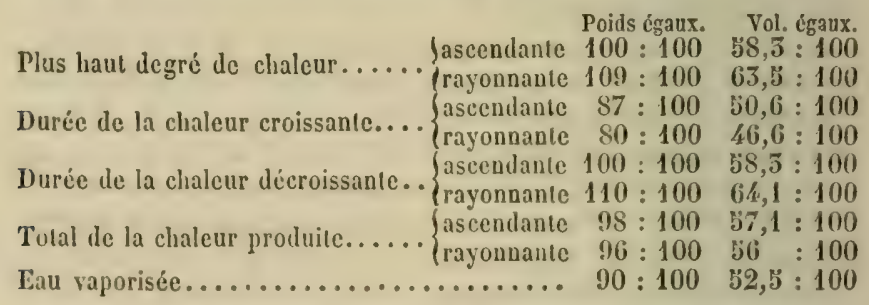

Le bois d'aune est un bois de combustion rapide, produisant une vive chaleur; la flamme en est calme, accompagnéc de peu de fumée; son charbon s'éteint aisément et par ces motifs il demande un fort tirnge. Du reste, de tous les bois, c'est un de ceux qui pétillent et qui éclatent le moins; il convient au chauffige des appartements, est recherché pour la houlangerie, les verreries, ete. Le charbon de l'aune est mou, léger, d'un faible pouvoir calorifique, qui est ì celui du hêtre:: $: 53: 100$, pour des volumes égraux. Il ne convient pas dans les lauuts fourneaux, mais il peut servir à la forge et à la fabrication de la poudre.

Probluil L'écorec d'aune r'enferme, d'apris Gassicourt, $16, \because \mathrm{p} .0 / 0$ acessoire. de lannin, plus mème que la bonne écoree du chène; eependaut on ne s'en sert pas en France pour le tannage; mais les chapelicrs et teinturier's l'utilisent pour teindre en noir, 
en la mélangeant avee du sulfate de fer. Dans le Nord de l'Europe on la recherche pour la préparation des cuirs, auxquels elle communique une couleur jaune rougeâtre estimée.

2. Ane blanc. Alvus ivcana. DC. Betula alnus, Var. $\beta$. Lin.

Feuilles ovales-aiguës ou légèrement acuminées, finement, doublement et aigument dentées en scie; dessus d'abord pubescent, puis glabre, d'un vert peu foncé et peu ou point brillant, à peine glutineux; dessous gris-blanchâtre, pubescent-tomenteux, ainsi que les jeunes pousses ; nervures latérales au nombre de 10-15 paires. Cône vert, puis brun, un peu plus gros que celui de l'aune glulineux, paraissant plus serré, parce que les écailles y sont d'une part plus nombreuses et d'une autre part beaucoup plus élargies à leur sommet, quoique à la vérité plus minces et moins distinctement ら̈-lobées. Fruit déprimé, pentagonal, d'un rouge brun légèrement luisant, à aile presque aussi large que la graine, plus grand que celui de l'aune glutineux. - Arbre à écorce lisse, d'un gris argenté. Bords des eaux de presque toute la France; particulièrement commun sur les bords du Rhin en Alsace. Flor., férrier-mars. Fructif, septembre-octobre. Dissémination, automne ou printemps.

L'aune blane est, comme l'aune glutineux, un arbre de taillis; il en rappelle le port, sans néanmoins atteindre les fortes dimensions, à la vérité exceptionnelles, de ce dernier; il conscrve, jusqu à un àge avancé, une écorce lisse, d'un gris argenté; présente un couvert un peu plus épais, a la propriété très-développée de drageonner, mème à une distance de $50^{\mathrm{m}}$ de la souche mère, sans y ètre provoqué par l'exploitation; il se marcotte et se bouture aisément.

Les bourgeons sont gros, ovoïles, obtus, stipités.

Cet aune à une aire plus septentrionale que l'aune glutineux; il le dépasse de beaucoup dans les contrécs du Nord, mais ne s'avance pas autant vers le Sud. Il habite principalement les régions montagneuses élevées, telles que les Nlpes, d'où il s'est répandu de proche en proche le long des cours d'eau qui en sortent jusque dans les vallées inférieures. Il réelame des terrains plutôt frais et meubles qu'humides, bien qu'il supporte des inondations temporaires.

Le hois d'aune blane a la même structure que celui de l'aune glutineux; il se reconnait, néanmois, à ses gros rayons plus rares, à ses couches plus régulièrement ciretlaires et évidemment rentrantes au passage des rayons, à sa coloration plus claire et plus uniforme.

Ce bois n'est point eassant comme celui de l'aune glutineux et peut servir à faire des cereles; il est plus dur, plus

Taille. Port.

Eeorce.

Drageons.

Station et sol.

Bois. 
tenace, généralement plus estimé et sert aux mêmes usages. Il doit avoir une puissance calorifique supéricure et vaut, dit-on, à cet égard, le bois de bouleau.

3. Aune pubescent. Alnus punescras. Tauscr.

Très-yoisin de l'aune blanc; se distingue à ses feuilles arrondies ou obovales, obtuses ou subaiguës, doublement dentées en scie, vertes sur les deux faces, néanmoins pubescentes ou faiblement tomenteuses en dessous, à reflet légèrement ferrugineux. Cónes et fruits semblables à ceux de l'aune glutineux. - Ecorce analogue à celle de l'aune blauc; exigences semblables.

Cet aune doit probablement se trouver en Alsace, mais par pieds isolés et très-disséminés. On le considère comme un hyloride de l'aune glutineux et de l'aune blane; cependant il a une aire d'habitation plus étendue que celle du premier et en Laponie il se trouve en mélange avec le sccond seulement. T. Hartig l'a observé dans des semis de graines d'aune blane, obtenues, il est vrai, par la voie du commerce. Il en serait peut-être, d'après cela, plutôt une variẻté qu'un hybride.

4. Aune elliptique. Alvus elliptica. Requien.

Feuilles ellipliques obtuses, non échancrées au sommet, non cordiformes à la base, glutineuses, glabres, très-barbues aux aisselles des nervures, régulièrement dentées, à dents presque égales, peu profondes. Cónes très-gros, disposés en petit nombre, $2-5$ seulement, en une même panicule. - Intermédiaire entre l'aune glutineux et l'aune cordiforme. Corse, auprès de l'embouchure de la Salenzara. Flor., avril.

5. Aume cordiforme. Alnus cordata. Loisel. A. cordifulia. Tenore.

Feuilles ovales ou obovales, cordiformes à la base, obluses ou courtement el brusquement acuminées, régulièremeut et peu profondément dentées en scie, glabres sur les deux faces, mais offrant des faisceaux de poils ferrugineux aux aisselles inférieures; glutineuses dans la jeunesse. Cônes solitaires ou géminés, rarement plus nombreux, très-gros. Samare lenticulaire, suborloiculaire, d'un gris verdâtre ou brunâtre, à aile mince, moins large que la graine; bourgeons ovoïdes et pointus. - Arbre de laille moyenne et de végétation rapide dans la jeunesse, couvert d'un beau feuillage persistant jusqqu'à l'entrée de l'hiver ; à écorec d'un gris brun, lisse on faiblement verruqueuse. Corse (borls du Lianone; baius de Guagno, cte.). Flor., février. Fructif,, septembre.

L'aune cordiforme supporte très-bien le elimat du Nord de la France et, cultivé ì Naney, où il fleurit et fruetifie, il a alteint, en 12 ans, $0^{\text {m}} 17$ de diametre.

Le bois en est rougectue, plus coloré dans la zône d'automne; les vaisscaux sont disposés, sans groupement réel, 
en zones circulaires; les grands rayons sont rares et les couches fortement rentrantes à leur passage. Un échantillon, parfaitement desséché à l'air, provenant d'un arbre de 12 ans et de $0^{\mathrm{m}} 31$ de circonférence, pèse 0,65. (Coll. Ec. For.) La culture de cet arbre pourrait probablement offrir quelques avantages.

\section{FAMILLE L。}

\section{PLA T ANES. Lestib.}

Floraison monoïque; fleurs mâles et femelles en chatons globuleux très-denses, disposés au nombre de 1-4, sur les côtés et à l'extrémité de rameaux terminaux et pendants; chaque rameau ne portant que des chatons d'un même sexe.Flcurs 3-5 bractéolées, accompagnées d'un périgone écailleux de 3 courts segments cunéiformes, avec lesquels alternent, chez les mâles, 3 étamines à filets courts et à anthères latérales, biloculaires, longitudinalement déhiscentes, surmontées d'une expansion peltée du connectif. Chez les femelles ces étumines sont représentées par autant d'écailles, au milieu desquelles se trouvent $2-8$, le plus souvent 6 carpelles 1-2-ovulés, à placentation pariétale, terminées par un long style floconneux et crochu, à stigmate latéral. Akène claviforme, monosperme, entourée ì la base d'un faisceau de poils allongés, raides et fragiles. Graine périspermée. - Grands arbres à feuilles simples, caduques, palmatilobées, alternes, à stipules souvent engaînantes, écailleuses ou herbacées, suivant la vigueur des rameaux que l'on observe.

genre unioue. - PlataNe. PLATANUS, Lin.

Mêmes caractères que ceux de la famille.

Bois lourd, dur, brunâtre clair à l'état parfait, se rapprochant beaucoup de celui du hêtre; vaisseaux assez petits, égaux, non ou à peine groupés, uniformément répartis; rayons nombreux, assez épais, longs, peu hauts, produisant par un débit convenable des maillures très-serrées, uniformes, brunes; parenchyme ligneux disséminé parmi le tissu fibreux et non apparent. Couches non ou à peine rentrantes au passage des rayons.

Arbres exotiques de grandes dimensions, revêtus d'une écorce lisse d'un gris-verdâtre ou blanchâtre, s'écaillant régulièrement chaque année; dont les bourgeons sont coniques, bi-écailleux, 
cachés, jusqu’à la chute des feuilles, par la base plus ou moins engaînante des pétioles.

A. Feuilles plus ou moins profondément lobées, à lobes largement triangulaires, entiers ou souslobés, séparés par des sinus très-ouverts qui atteignent rarement la moitié du limbe....... P. D'Occioevt. 1

$\Lambda^{\prime}$. Feuilles profondément lobées, à lobes étroits, lancéolés, entiers ou profondément dentés, séparés par des sinus dépassant la moitié du limbe, à bords parallèles.................. P. D'ORIExt. . 2

1. Platame d'Qceident. Phatanus occidentalis. Lin.

Feuilles peu profondement 5 -b̆-lubées, à lobes largement triangulaires, síparés par des sinus très-ouverts, alteignant rarement la moitié du limbe, ou simplement à $\ddot{b}$ angles obscurément lobés; quelquefois à base un peu saillante et cunciforme, mais plus généralement rentrante et légèrement cordiforme. Pétiole faiblement renflé autour du bourgenn axillaire. Chatons floraux ou fructifères plus petits que dans l'espèce suirante, à akènes égalant les poils de la base. - Originaire de l'Amérique septentrionale; très-robuste el résistant bien aux froids des parties septentrionales de la France où il est fréquemment cultiré, à l'exclusion du platane d'Orient. Flor, avril-mai. Fructif, automne. (1).

Taille. Port.

Le platane d'Occident est un magnifique arbre de l'Amérique septentrionale, d'une longévité remarquablè et néanmoins d'une croissance extrèmement rapide; il n'est pas rare d'y observer des aceroissements annuels de 5-1. centimètres d'épaisseur. La tige droite et eylindrique, nue jusqu'à 10-20 mètres, se ramifie en une vaste el puissante cime, qui est composée de grosses et longues branches coudées-flexueuses, régulièrement déeroissantes en rameaux et en ramules, et qui produit, avec son large et abondant feuillage jamais rongé par les insectes, un cotrert épais, iggal à cclui du hètre. Michaux lui a vu atteindre, en Amérique, $5 \overline{5}^{\mathrm{m}}$ d'élévation et $16^{\mathrm{m}}$ de circonférence à $1^{\mathrm{m}} \bar{\jmath} 0$ du

(1) On eonfond souvent avec le platane d'Orient, dans le nord, le centre el l'Est de la France, une variété du platane d'Occident, décrite par quelıues botanistes sous le nom de platane à feuilles d'irable (l'latanus acerifolia. Willd.) dont les feuilles sont vraiment lobées, et l'on ne considère, à tort, comme platane d'Occident, que la forme à feuilles seulement anguleuses, qui en représente le type linnéen. Tani de transilions t'éunissent ces deux types, souvent sur un mème arbre, ufu'il est impossible d'établir a leur aide une distinction de quelque valeur. Le vrai platane d'Orient paraît ne pas exister dans ces régions. 
sol. Il a été introduit en France vers $164.0 \mathrm{et}$ s'y est parfaitement naturalisé. Un pied de cette espèce, planté en 1732 au Jardin botanique de Naney, mesure actuellement $24^{\mathrm{m}}$ de lauteur sur $5^{\text {m }} 50$ de circonlérence à $1^{\text {m }} 30$ de terre; la cime en est remarquable par l'amplitude et le caractère de vigueur qu'elle présente.

La fructification est régulière et assez abondante chaque année, mais les graines sont souvent incomplètement organisées et c'est à peine si, dans les meilleures conditions, on en obtient 20-50 p. 0/0 de bonne qualité.

Le jeune plant parait 5 -4 semaines après le semis, avec deux petites feuilles cotylédonaires semi-ovoïdes et s'accroit dès l'origine avec rapidité.

Le platane supporte aisément la taille, repousse bien de souche et se reproduit facilement par boutures et par marcolles, quoique les plants créés par ces procédés, et surtout par le premier, ne se développent pas avee la vigueur de ceux qui ont été obtenus de semis.

Les racines sont longuement traçantes.

Cet arbre ne prospère que dans les pays de plaine ou peu accidentés et ne peut supporter le climat des régions montagncuses, mème les moins élevées; il demande un sol léger, frais et fertile, et réussit encore sur ceux qui sont humides. C'est à l'état de dissémination et principalement le long des cours d'eau qu'il se rencontre en Amérique et il n'y fait point habituellement partie du peuplement des forèts. Il offre enfin dans ses exigences beaucoup d'analogies avec les peupliers, auxquels il ressemble encore par la vigueur de la végétation et la facilité avec laquelle il se prète au bouturage.

L'écorce est très-caractéristique par la propriété qu'elle possède de se dépouiller périodiquement, sous forme de plaques, de son ancien périderme et d'être toujours unie et non gerçurée à la surface. Elle est, dans l'origine, constituée comme celle du hètre et l'on y voit, après la chute précoce de l'épiderme, une couche de liber, le parenchyme vert et l'enveloppe subćreuse sous forme d'un périderme superficicl, lisse et gris. Bientòt des lames irrégulières d'un périderme interne, sec et dur, se développent par places dans l'épaisseur du parenchyme vert, font dessécher et tomber tout ce qui les recouvre et, d'année en année, subissent elles-mèmes un sort semblable, parce que des pla-

Enracinement. Slalion. Sol.

Ecorce. 
ques identiques se reforment au-dessous d'elles. Quant au liber, la végétation en est peu active et il ne fait que se distendre sans s'épaissir notablement. Par ce dépouillement annuel, l'écoree ne doit point comprimer la couche génératrice du cambium comme chez les arbres où elle persiste ct mème s'épaissit; c'est sans doute là une des causes dı rapide accroissement du platane.

Bois. Le bois de platane a beaucoup d'analogies de structure, d'aspect, de qualités ou de défauts avec le hêtre; il est plus brun; les maillures en sont plus nombreuses, plus larges et proviennent de rayons tous égaux; placé dans des licux humides, il paraît moins śujet à la pourriture; la puissance calorifique est à peu près équivalente. Du platane de 19 ans et d'un diamètre de 0,23 , complétement desséchéc à l'air et provenant de Nancy pèse 0,66. C'est exactement le poids d'un bois de même espèce et de 70 ans au moins, provenant de l'Etat de Vermont (Etats-Unis, où il est indigène). (Coll. Ec. For.)

Le platane, prenant rang à còté du hêtre pour la valeur calorifique, à côté des peupliers pour la rapide croissance, est l'un des arbres dont la culture est la plus avantageuse. Il ne se trouve point dans les forèts, mais il mériterait qu'on tentât de l'y introduire.

2. Platane dPrient. Platanos ontentalis. Liv.

Feuilles profondément 5-b̆-lobées, à lobes étroits, lancéolés, entiers ou profondément et aigûment dentés, séparés par des sinus larges, à bords presque parallèles; base plus ou moins et souvent très-fortement cunćiforme; pétioles très-renflés à la base, en forme de calolte hémisphérique qui embrasse complétement le bourgeon. Chatons floraux ou fructifères plus gros, à akènes plus forts el plus longs que ceux de l'espèec précédente, débordant les poils de la base. - Cultivé dans le midi; beaucoup plus délicat et plus sensible aux froids que le précédent; ne recherche point des sols aussi frais; originaire d'Orient. Flor., avril-mai. Fructif., automne.

Ceplatane atteint aussi de très-grandes dimensions et l'on en connait, aux environs de Raguse, en Dalmatic, un pied qui mesure plus de 10 mètres de circonférence. Le bois est sans doute idlentique à celui du préeédent et probablement de qualités supéricures, en raison du climat plus chaud sous lequel il se développe. 


\title{
FAMILLE LI.
}

\author{
myricées. $A$. Rich.
}

Floraison diö̈que (espèces indigènes) ou monoïque (espèces exotiques), en chatons dressés pour les deux sexes, à écailles 1-flores. Chatons máles filiformes, composés d'écailles quelquefois 1-2-bractéolées, supportant 2-8 étamines, à anthères extrorses, biloculaires, longitudinalement déhiscentes; chatons femelles ovoïdes ou cylindriques, formés d'écailles 8-1-bractéolées, présentant un ovaire nu, 2-3-loculaire, à loges 1-ovulées, terminé par 2 ou 3 stigmates. Fruit sec, indéhiscent, monosperme, souvent entouré des bractéoles? devenues charnues et lui donnant l'apparence d'une drupe. - Arbrisseaux ou arbres (exotiques) à feuilles alternes, simples, penninerviées, non stipulées, ponctuées de glandes cireuses ou résineuses, à bourgeons petits, entourés de nombreuses écailles imbriquées-spiralées.

\section{GRXRE UNIQUE. - MIYRICA. MYRICA. Lin.}

Mêmes caractères que ceux de la famille.

Bois dur, gris brunâtre, à vaisseaux très-peu abondants, isolés ou groupés irrégulièrement en petit nombre et généralement dans la direction rayonnante, de plus en plus rares du bord interne au bord externe; rayons lérgèrement inégaux, fins et trèsfins. Accroissements circulaires, plus colorés au dehors.

marica galé. Mrnicı grate. Liv. Bois sent-bon; Galé; Piment royal.

Feuilles fermes el coriaces, oblongues, insensiblement rétrécies à la base, courtement péliolées, aiguës ou obtuses au sommet, entières ou denticulées dans leur moitié supérieure; d'un vert glaurque en dessus, jaunâtres et pubescentes en dessous, à bords légèrement enroulés. Claatons ovoüdes, petils, dressés, nombreux, disjosés en grappes allongées à l'extrémité des rameaux. Arbrisseau de $0 \mathrm{~m} 50-2^{\mathrm{m}}$ et mème plus, forlement aromalique, ponclué sur presque toules ses parties, ovaires, fruits el feuilles, de nombreuses goultelettes résineuses-cireuses, jaunâtres et brillantes; à racines longuement tracantes et drageonnantes, à tiges nombrcuses, grêles, dressées, brunes, irrégulièrement rameuses; à jeunes pousses puljescentes, anguleuses. Assez commun sur les sols à bruyères, marécageux ou tourbeux, des forèls du nord, de l'ouest et du sud-ouest. Flor., avril-mai. Fructif., août. 


\section{FAMILLE LII.}

\section{SALICINÉES. $C$. Rich.}

Floraison dioïrue, amentacée pour les deux sexes. Chatons cylindriques ou ovoïdes, solitaires, latéraux sur les rameaux, rarement terminaux, composés d'écailles qui supportent, ì leur face interne, un périgone cupuliforme ou 1- 2 glantes (nectiares) qui le représentent et 9-30 étamines, à anthères biloculaires, longitudinalement déhiscentes ou 1 seul ovaire libre, uniloculaire, formé de 2 carpelles, à ovules nombreux, pariétaux. Capsules petites, en chatons, bivalves ou rarement quadrivalves (quelques peupliers), contenant un grand nombre de très-petites graines, munies d'une touffe de longs poils soycux. - Árbres, arbrisseaux et sous-arbrisseaux à feuilles caduques, simples, alternes, entières, dentées ou rarement lobées, penninerviées, exceptionnellement palmalinerviées; à stipules caduques ou persistantes sur les pousses stériles, ou nulles; ì floraison précoce, précédant ou accompagnant la foliaison; présentant une régétation rapide dans la jeunesse, mais d'une longévité généralement restreinte et ne produisant que des bois mous et légers (bois blancs).

A. Chatons dressés, à écailles entières; púrigone représenté yar 1-2-glandes; 2-5 étamines; feuilles généralement allongées; bourgeons revêlus d'une seule écaille. Arbrisseaux et arbres................ Saule ... 1

A'. Cliatons finalement pendants, à écailles lacéríes ou dentées; périgone cupuliforme; 8 -50 étamines; feuilles généralement élargies; bourgeons revêtus d'un cerlain nombre d'écailles imbriquées. Arbres...... Peuruer. 2

\section{GENRE I. - SAULE. SALIX. Tournef.}

Clıatons cylindriques ou ovoïdes, redressés, paraissant avant ou avec les feuilles; écailles à bords entiers, offrant ì leur base interne 1 ou 2 glandes superposées (nectaires), qui paraissent représenter le périgone; $2-3-5$ étamines libres ou soudées plus ou moins complétement entre elles, à anthères biloculaires, longriludinalement déhiscentes ou $\mathbf{1}$ ovaire libre, sessile ou pédicellé, surmonté d'un style allongé ou presque nul et de 2 stirmates entiers ou bifides. Arbrisseaux et sous-arbrisseaux, ou arbres it feuilles allongées, entières ou dentées, à bourgeons re- 
vêtus d'une seule écaille complétement embrassante el close de toutes parts, laineuse intérieurement.

Bois mou, poreux, léger, blanc ou rougeâtre. Tissu fibreux à fibres larges et à parois minces, mêlé de parenchyme ligneux dispersé et sans relation avec les vaisseaux (non distinct à la vue simple); vaisseaux dominants, presque toujours isolés ou rarement groupés 1-5 ensemble, uniformément répartis. Rayons très-minces, égaux. Canal médullaire pentagonal. On observe çà ct lia de petits amas de tissu cellulaire, qui forment, comme dans cerlains fruitiers, des taches ou lignes brunes disséminées.

Les saules présentent une nombreuse série d'espèces qui, de la taille d'une plante herbacée rampante, s'élèvent aux dimensions d'un grand arbre. Leur ramification est généralement peu serrée, parce que la plupart des bourgeons latéraux sont florifères et se terminent par un chaton. Leurs pousses sont le plus souvent allongées, droites, effilées, lisses et très-souples; cependant cette disposition n'est point générale et chez certaines espèces elles sont toruleuses, c'està-dire qu'elles deviennent noueuses par la forte saillie des coussinets sur lesquels les feuilles s'insèrent et qu'elles ne s'allongent ni ne s'effilent comme dans le cas précédent.

L'écorce offre dans sa structure d'assez nombreuses modifications, suivant les espèces que l'on observe. Tantôt le liber s'accroit avec activité; des lames de périderme s'organisent dans ses feuillets extérieurs, font périr et tomber l'enveloppe herbacée et donnent naissance à un rhytidome brun, persistant, longitudinalement gerȩuré. Cette modification peut se produire de bonne heure et constituer une écorce épaisse, largement crevassće, rappelant celle du chène ou du tilleul (saule blane, saule fragile), ou ne survenir qu'à un certain àge et former une écorce plus minee, plus superficiellement gerçurée (saule viminal). Tantòt, au contraire, le liber ne se développe qu'avec lenteur et emploic $5-4$ ans pour organiser une seule de ses couches; il ne devient plus le siége d'une formation péridermique interne ct l'enveloppe herbacée qui le recouvre reste toujours vivante. Deux cas se présentent alors : vers $8-10$ ans, il se forme un périderme dans l'épaisseur du parenchyme vert et l'écorce, lisse et gris-verdâtre jusque-là, s'écaille en lames à peu près comme celle du platane (saule à feuilles d'amandier), ou bien le périderme reste toujours superficiel, l'écorce, 
scmblable a celle du hétre, s'épaissit peu et se maintient unie jusqu’à un àge avancé (saule marceau, cendré, etc.).

L'écorce des jeunes rameaux et des pousses est fréquemment vivement color'ée en rouge, en jaune, en vert, ete.; mais il ne faut pas entièrement se fier à ce caractère pour reconnaitre les espèces, car il se modifie souvent avec la situation, la saison, les individus.

Croissance. La végétation des saules est extrẻmement rapide dès les premières années et, à part le saule blane qui a une Earacinement. longévité assez élevée, se ralentit de bonne heure. L'enracinement est plutót traçant que pivotant; il est constitué par des racines nombreuses, très-rameuses, terminées par des fibrilles déliées et fournies.

Reproduction. La floraison et la fructification sont très-abondantes et constantes; mais les semences sont rarement bonnes, si l'on en juge par la faible quantité relative de semis naturels que ces végétaux produisent. Néanmoins les saules Marceaux et à oreillettes se propagent rapidement d'eux-mèmes et deviennent sourent gènants dans les forits par leur disposition à envahir le sol et à dlominer les jeunes plants d'essences plus précieuses. La reproduction par boutures et planęons est extraordinairement facile et la seule usitée en culture.

Station et sol. Il faut en ggénéral aux saules des sols légers, frais ou humides; cependant le saule blane et le saule Daphné réussissent encore sur des sols sees, le saule firgile sur des sols tenaces et le saule llarceau vient partout, en terres sèches ou fraiches, légères ou compactes. Suivant les groupes auxquels ils appartienment, ils s'élèvent des grandes plaines basses et humides jusqu'aux régions alpestres, à la limite des neiges perpétuelles. Ils réclament tous une insolation directe et aucun d'eux ne peut se maintenir sous le couvert.

Les saules sont, pour la plupart, du domaine agricole plutòt que du domaine forestier. Deux ou trois especes seulement méritent d'ètre signalées par leur fiéquence dans les foréts ou par leurs dimensions (saule blane, saule Marceau, saule à oreillettes); presque toutes les autres eroissent au hord des caux et forment des saussaies ou oseraies $\mathrm{cx}$ ploitíes à de très-courtes r'évolutions ou sont cultivées en tétards de hautes on de basses tiges; tris-abondants dans les régions tempérécs, leur nombre décroit sensiblement vers le mili et, en Algérie, ils ne sont plus que faiblement représentés. 
Cés végélaux sont très-précieux pour fixer les rives des cours d'eau, les alluvions et les attérissements que ceux-ci déposent sur leurs bords; pour consolider les travaux d'endiguement. Ils produisent la majeure partie du matériel des fascines et clayonnages employés dans les travaux hydrauliques. Cultivés en oserais, beaucoup d'entre eux fournissent à peu près exclusivement à la vannerie les matières premières qu'elle met en ceuvre; les jeunes pousses servent de liens aux jardiniers et aux vignerons.

Le bois des saules est mou, léger et, la plupart du temps, il est impossible de le distinguer spécifiquement; il est tantòt blane (saule fragile, viminal, ete.), tantòt rougecitre (saule blanc, Marceau, cendré, etc.). On en fait de la menue charpente, des chevrons, ete., des planches et de la volige pour menuisiers, ébénistes et layetiers, des cereles de tonneaux, ete. ; lorsqu'il est homogène et qu'il se coupe net en tous sens (saule blanc) il est employé à la sculpture ; réduit, au moyen de machines, en longues et minees lanieres semblables à des rubans, il sert à tresser des ourrages de vannerie, des claies, des tamis grossiers.

Les saules fournissent un médiocre combustible, qui brùle très-rapidement avec une flamme vive et claire, mais en produisant un coup de feu d'une haute température. Ils sont particulièrement recherchés par la boulangerie.

Au surplus, la nature des espèces apporte dans la qualité des bois des modifications assez grandes, qui scront signalées avec la description de chacune d'elles.

L'écorce est riche en principes astringents et, dans les contrées du Nord de l'Europe où le chène fait défaut, on l'utilise pour le tannage. C'est particulièrement colle des saules des sections I et VI, Mareeaux et fragiles, que l'on emploie à ect usage. On peut aussi en extraire dles matières tinctoriales jaunes, rouges, brunes ou noires; cnfin elle contient, surtout dans les groupes II, IV et V (saules amandiers viminals et pourpres), une essence oxygènéc amère, cristallisable, la salicine, qu'on a essayée, mais sans grands succès, comme succédanée du quinine.

Les tentatives faites pour utiliser les aigrettes des graines des saules et des peupliers comme matières textiles, pour cu fubriquer de la ouate ou du papier, pour les substituer, dans certains emplois, au duvet des animaux, n'ont pas réussi. Ces aigrelles sont courtes, cassantes et d'une récolte difficile.

Produils accessoires. 
Les l'euilles des saules, vertes ou desséchies, peurent servir de fourrage pour le bétail (1).

\section{ire DIVISION.}

\section{SAULES OSIER, AxgUSTIFOLIÉS.}

Pousses allongées, simples, lisses, effilées, flexibles. Feuilles 5-10 fois aussi longues que larges (les plus larges, lisses el luisantes). Chatons latéraux, à écailles concolores (jaunàtres), ou discolores (pâles à la base, brunes au sommel), caluques ou persistantes; 1-2-5-5 étamines à anthères jaunes ou pourp̧res; capsules toujours courtement pédicellées ou sessiles.

(1) Le genre saule, l'un des plus naturels que l'on connaisse, est aussi l'un de ceux dont l'élude est la plus difficile; less espèces en sont nombreuses, très-voisines el les organes auxquels on emprunte d'ordinaire les caractères distinctifs, feuilles, fleurs et fruits, y offrent une structure simple et par suite peu variée; encore ne peut-on les observer simultanément en bien des circonstances, puisque la floraison est diö̈que et précède souvent la foliaison. A toutes ces difficultés s'en joint une autre encore, celle de l'hybridité, qui doit naturellement se produire avec facilité entre des végétaux dont les sexes sont séparés et dont les diverses espèces, avec des exigences identiques, croissent d'ordinaire serrées et pèle-mèle aux mèmes lieux. Il naît de là de nombreuses formes intermédiaires, indécises et peu stables, qui tendent à confondre par des transitions les espèces légitimes dont elles procèdent.

Des fécondations artificielles ont mis hor's de doute cette disposition des saules à s'hybrider et l'on esi parvenu, à leur aide, non-seulement à reproduire les liybrides que l'on rencontre dans la nalure, mais à en créer beaucoup d'autres qui n'y ont point encore été observés.

Il est assez aisé de distinguer les hybrides des espèces légitimes, à leur rarcté, au peu de stabilité de leurs caractères qui oscillent entre ccux des types paternel et maternel; à leur dissémination parmi d'autres saules abondants et de type habituellement bien défini, avec lesquels ils offrent des signes le parenté évidents.

Il est indispensable, quand on veut étudier les saules, d'écarler tout d'abord ces lybrides et de s'attacher uniquement à la délermination des espèces légitimes; une fois bien fixé sur les caractères de celles-ci, il deviendra seulement possible de reconuaitre les produits de leurs croisemenls.

J'apres ces considérations, le tableau dichotomique we comprend que les especes proprement dites; quant aux hybrides, il faut en chereher les descriptions dans le texte meme, dans le voisinge de celles des parents dont on peut les présumer issus; le parlage du genre en divisions, sections el sous-sections facilitera d'ailleurs benteoup leur détermination. 
A. Fenilles lisses et luisantes en dessus (pubescence à part si elle existe); chatons feuillés à la base, sinon, rameaux glauques-efflorescents; capsules glabres.

B. Pétioles glanduleux; rameaux non-efflorescents; chatons feuillés à la base, à écailles concolores.

C. Jeunes pousses arrondies; feuilles glabres ou soyeuses; écailles des chatons caduques.

D. Feuilles très-glabres, fortement visqueuses dans la jeunesse; ¿̇la-

D'. Feuilles peu ou point visqueuses; 2 étamines libres.

E. Feuilles vertes ou légèrement glauques en dessous, finalement glabres...................

$\mathbf{E}^{\prime}$. Feuilles plus ou moins poiluessoyeuses, à rellets argentés, surtout en dessous............

S. Pentaydrique... 1 S. Fragile....... 2

S. Blanc...... 3

$\mathrm{C}^{\prime}$. Jeunes pousses sillonnées au sommet; feuilles très-glabres; écailles des chatons persistantes; 5 étamines......

B'. Pétioles non glanduleux; jeunes rameaux glauques-efilorescents; chatons non ou à peine feuillés à la base, à écailles discolores; 2 étamines soudées entre clles par la base...................

$\mathbf{A}^{\prime}$. Feuilles lisses ou finement ridées, mates en

S. Amaydier......

S. Daphné........

dessus; pétioles non glanduleux; chatons non ou à peine feuillés à la base, à écailles concolores ou discolores, persistantes; 2 étamines, quelquefois complétement soudées en une seule; capsules glabres et légèrement pédicellées ou tomenteuses et sessiles.

B. Feuilles finement ridées en dessus, blanches-soyeuses ou tomenteuses en dessous, à bords enroulés; anthères jaunes; capsules surmontées d'un style apparent.

C. Feuilles blanches-soyeuses à reflets prononcés en dessous, lancéolées-allongées ; chatons à écailles discolores, les mâles ovoïdes; capsules sessiles, soyeuses-tomenteuses..........

$C^{\prime}$. Feuilles blanches-tomenteuses et sans aucun reflet en dessous, longuement lancéolées-linéaires; chatons cylindriques, grêles, arrqués, à écailles con- 
colores; capsules glabres, légèrement

pédicellées..................

S. Dasti...... ;

$\mathbf{B}^{\prime}$. Feuilles lisses, glabres et glauques, souvent opposées ainsi que les chatons; ceux-ci à écailles discolores; une seule étamine à anthère pourpre, 4-loculaire; capsules tomenteuses, sessiles ainsi que les stigmates...................

\section{2e DIVISION.}

\section{SAULES TORULEUX, LATIFOLIÉS.}

Pousses non efflées, noueuses (toruleuses) par le développement des coussinets, peu souples, plus robustes et moins allongées que celles de la division précédente. Feuilles au plus 5 fois aussi longues que larges (très-rarement étroites el allongées comme celles de la fre division, mais, dans ce cas, sous-arbrisseaux très-pameux, ì rameaux franchement toruleux); pétioles jamais glanduleux; chatons i écailles discolores, persistantes; 2 étamines à anthères jaunes ou fauves.

A. Feuilles généralement aiguës ou acuminées; chatons latéraux.

B. Arbres ou arbrisseaux à feuilles plus ou moins réticulées en dessous, presque toujours finement ridées ou fortement crépues en dessus. Chatons mâles ovoïdes, sessiles: chatons femelles se feuillant légèrement à la base; capsules longuement pédicellées, dont le pédicelle est 2-6 fois aussi long que la glande.

C. Arbres ou arbrisseaux non rampants; feuilles mesurant au moins 2 centimètres de large, presque toujours ondulées-dentées ou crénelées sur les bords.

D. Feuilles fortement réticulées et restant tomenteuses en dessous; styles nuls ou très-courts.

E. Feuilles en dessus d'abord pubescentes, finalement glabres, pres. que lisses, vertes et luisantes; tige et rameaux arrondis.

F. Feuilles ovales ou elliptiques, le plus souvent terminées en pointe oblique, repliée en gouttière; pousses glabres ou seulement pubescentes au sommet; bourgeons glabres; floraison précoce, précédant la foliaison............... 
F'. Feuilles allongées-obovales, terminées en pointe droite et plane; pousses et bourgeons tomenteux ; floraison et foliaison simultanées.......... S.A GRATdes Fruiless 10

E1. Feuilles restant pubescentes et d'un vert gris en dessus; tige et rameaux irrégulièrement arrondis, comme ceux du charme.

F. Jeunes pousses robustes, grisestomenleuses sur toute la longueur, ainsi que les bourgeons; chatons denses, non feuillés à la base; fcuilles presque lisses en dessus.... $\mathbf{F}^{\prime}$. Jeunes pousses grêles, poilues à l'extrémité seulement; bourgeons glabres; chatons lâches, se feuillant un peu à la base; feuilles fortement réticulées ei

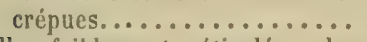

D'. Feuilles faiblement réliculées, les S. a oremletettes... 12 adultes glabres ou seulement poilues sur les nervures en dessous; styles allonges.

E. Feuilles cendrées, ondulées-dentées; les adultes plus ou moins poilues sur les nervures en dessous, noircissant par la dessiccation; stipules grandes, persistantes; pousses et bourgeons hérissés-velus..............

E'. Feuilles très-glauques en dessous; entières ou bordées de dents écartées, pell profondes; les adultes glabres, ne noircissant pas par la dessiccation; stipules nulles ou très-petiles; pousses et bourgeons glabres..........

C'. Sous-arbrisseau rampant, à feuilies petites, de forme très-variable (ovales-arrondies-sublinéaires), le plus souvent brillantes-soyeuses en dessous, plus rarement glauques, pubescentes ou glabres, entières ou denticulées...................

B!. Sous-arbrisseaux très-rameux et toruleux, à feuilles souvent lisses, ovales, elliptiques ou lancéolées, dentées ou entières. Chatons presque toujours pédonculés, souvent longuement, et feuil- 
lés à la base ; capsules sessiles ou dont le pédicelle n'égale pas 2 fois la glande; espèces des régions alpestres et alpines.

C. Feuilles glabres ou glabrescentes à l'état adulte.

D. Feuilles glauques au moins en dessous.

E. Feuilles lisses, les adultes trèsglabres.

F. Feuilles dentées, vertes en dessus, glauqques en dessous.

G. Feuilles arrondies ou cordiformes à la base, accompagnées de larges stipules; capsules glabres, dont le pédicelle déborde un peu la glande.................

$\mathbf{G}^{\prime}$. Feuilles atlénuées à la base
stipules petites; capsules tomentcuses, presque sessiles.................

F'. Feuilles très-entières, glauques

sur les 2 faces............

S. IIASTÉ...... 16

S. arbustr..... 17

S. oleuatre..... 18

$\mathbf{E}^{\prime}$. Feuilles entières, légèrement réticulées, puhescentes en dessus, glauques argentées et hérissées en dessous ; finalement glabrescentes; ciliées sur les bords... S. des Pynévées... 19

$D^{\prime}$. Feuilles vertes et luisantes sur les deux faces, réliculées, munies de quelques longs poils épars; dentées et fortement glanduleuses.......

Cl Feuilles densément et constamment soyeuses ou tomenteuses, au moins en dessous.

D. Feuilles entières, longuement veluessoyeuses sur les 2 faces..........

D'. Feuilles légèrement dentées, d'abord velues-soyeuses sur les 2 faces, puis verles en dessus, blanchestomenteuses en dessous.........

$\Lambda^{\prime}$. Feuilles obtuses ou échancrées à l'extré
mité; chatons terminaux, très-petits. Sousarbrisseaux des régions alpines.

B. Feuilles à peu près orbiculaires.

C. Feuilles longuement pétiolées, vertes, crépues en dessus, glauques, argenlées el réliculées en dessous; pubescentes dans la jeunesse...........

$C^{\prime}$. Fenilles courtement pétiolées, vertes et luisantes sur les deux faces, toujours Glabres.................... 
B'. Feuilles obovales ou spatulées, presque sessiles, très-glabres, d'un vert foncé en dessus, d'un vert clair en dessous.. S. Émoussé ..... 2

\section{$1^{\text {re }}$ DIVISION.}

SAULES OSIERS, ANGUSTIFOLIÉS.

Jeunes pousses allongées, simples, effilées, flexibles. Feuilles $\mathbf{3}-10$ fois aussi longues que larges; les plus larges, lisses et luisantes, non réticulées. Arbres ou arbrisseaux de plaines ou de régions peu élevées en général.

\section{SECTION I. S. Fragiles.}

Jeunes pousses arrondies au sommet; rameaux très-fragiles à lcur articulation en temps de séve. Feuilles lisses et brillantes, au moins en dessus (pubescence à part), à pétiole plus ou moins glanduleux. Chatons latéraux, paraissant avec les feuilles, feuillẻs à la base ; écailles concolores, jaunâtres ou roussâtres; caduques longtemps avant la chute des chatons ; 2 nectaires ; 2-כ étamines à anthères jaunes; capsules glabres, sessiles ou très-brièvement pédicellées. - Arbres et arbrisseaux élevés, dont l'écorce est, avec l'âge, gerçurée-fibreuse comme celle des cliênes. Bords des fleuves, des rivières et des ruisseaux; quelquefois dans les forêts. Plaines et montagnes peu élevées.

1. Faule pentandrique. Salix PENTANDna. Lin.

Feuilles glutineuses dans la jeunesse, ovales, elliptiques ou ovaleslancéolées, acuminées, au plus 5 fois aussi longues que larges, fermes ef coriaces, très-glabres, vertes et très-brillantes en dessus, plus pâles et peu brillantes en dessous, finement el régulièrement dentées-serrées, à dents nombreuses, glandulcuses, presque obtuses; pétiole pourvu de fortes glandes vertes ou noires, dont quelques-unes semblent représenter les stipules, peu ou point développées. Chatons longuement pédonculés et garnis à la base de feuilles dentées; cylindriques, étalés, à axe et écailles velus; les mâles, à fleurs assez serrées, composées de है, rarement 10 étamines libres; les femelles, à capsules oroüdes-coniques, pointues, glabres, à pédicelle court, dépassant à peiue les glandes; style assez court ; stigmates épais, bilobés au sommet. - Arbrisseau et parfois arbre de 10 et même 15 mètres d'élévation sur 0 mb้0-1 m50 de circonférence, facilement reconnaissable à ses feuilles, à ses jeunes pousses et à ses bourgeons qui semblent vernissés et sont très-brillants et trèsglabres. Alpes, Pyrénées, Ilaut-Jura, Haute-Auverģne, Nièvre, Creuse, Haute-Vicnne. Flor., mai-juin.

Le saule pentandrique a la végétation rapide et se prète 
très-bien à l'exploitation en tètards; il convient principalement aux sols froids ot compactes, humides, marécageux et mème tourbeux des régions montagneuses, et s'élève jusqu’aux stations subalpines. Dans le semblables localités, il doit avoir la préférence sur le saule blanc.

La beauté de son feuillage, d'un vert très-luisant, le fait quelquefois culturer comme arbre d'ornement.

2. Sanle fragile. Salis fragilis. Lin.

Feuilles lancéolées, assez longuement acuminées, \& fois an moins aussi longues que larges, fermes et coriaces, d'un vert peu fencé et luisant en dessus, plus pàle el souvent glauque en dessous; glabres, quand elles sont adultes; velues-soyeuses, surtout en dessous, et plus on moins densément ciliées vers l'extrémité dans la jeunesse; finement dentéesserrées, à dents glanduleuses, dont la pointe est courbée en dedans; nervures secondaires nombreuses, parallèles, souvent d'un vert pellucide, ainsi que les veines et veinules qui, par là, tranchent sur le fond du parenehyme. Feuilles, accompagnant les chatons et celles de la base des pousses, souvent très-entières; stipules des pousses vigotureuses réniformes, obtuses, appliquées contre les rameaux. Cliatons pélonculés et bien feuillés à la base, cylindriques, à axe et à écailles velus; les màles assez denses, à deux étamines libres; les femelles làches; capsule ovoïde-conique, aiguë, glabre, dont le pédicellc égale 5-4 fois le nectaire; style médiocre; stigmates assez courts, épais, bifides.

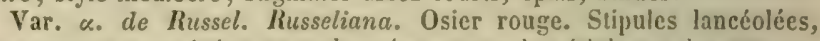
longuement acuminées et redressées contre le péticle sur les pousses vigoureuses, feuilles toujours glauques en dessous, plus abondamment et plus longtemps velues-soyeuses sur les deux faces; rameaux grè̀es, rougeâtres. Salix russelictna. Smilh.

Arbrisseau et souvent arbre de $12-15^{\mathrm{m}}$ de hauteur sur $1^{\mathrm{m}}$ de circonférence; à rameaux particulièrement fragiles au point d'insertion pendant te printemps; souples et liants du reste. Plaines et montagnes peu élevées de toute la France. Flor., avril-mai.

Le saule fragile, l'un des plus répandus du çenre, est commun sur le bord des eaux et le long des chemins; il est très-fréquemment cultivé en oseraies ou en tètards et supporte micux que le saule blane les terres froides et fortes, quoiqu'il réussisse surtout dans celles qui sont légères et lumides; il ne se trouve pas en général dans les forèts.

Le bois ressemble a celui du saule blane; il est d'un jaune rougeatle avec l'aubier jaune-clair; on n'y observe pas de taches médullaires.

+ Saule cuspidé. Salix cuspidata. Schultz. S. Mgyeriana. WVild.

Intermédiaire cutre le saule pentandriguc et le saule fragile, dont on le considere comme un hyluride. Fenilles allongées-lancéolèes, très-Iongnement acuminées, plus étroites que celles du saule peutandrique, plus 
larges que celles du saulc fragile, très-glabres; souvent accompagnées de stipules caduques; toules ou presque toutes les feuilles, qui garnissent la base des chatons, entières. $4-30$ étamines; cajsules à la fin longuement pédicellées, glabres; styles médiocres; stigmates épais, échancrés aı sommet. M. Boreau (Flore du centre de la France) dit avoir observé ce saule dans les oserais de l'Yonne et de l'Indre.

Le saule cuspidé a la croissance plus rapide encore que le saule pentandrique et peut atteindre $12^{\mathrm{m}}$ de hauteur sur $0^{\mathrm{m}} 60$ de circonférence en une douzaine d'annćes; il demande des sols moins compactes.

3. Saule blanc. SALIX ALBA. Lin.

Feuilles lancéolées, longuement acuminées, plus ou moins blanchessoyeuses sur les deux faces, mais surtout sur l'inférieure, bै-6 fois aussi longues que larges, peu fermes et peu coriaces, finement dentées-glanduleuses, à dents aiguës; face supérieure (pubescence à part) assez luisante, inférieure habituellement glauque; nervures secondaires moins nombreuses, moins entières et moins parallèles, veines et veinules moins pellucides, les unes et les autres moins distinctes du parenchyme que dans le saule fragile; stipules étroites et très-petites. Chatons pédonculés, cylindriques, à axe et à écailles velues, garnis à la base de feuilles entières; les mâles, grêles, arqués, à 2 étamines libres; les femelles assez denses; capsule ovö̈de-conique, un peu obtuse au sommet, glabre, à peu près sessile; style court; stigmates épais, simplement échancrés.

Var. a. Vilellin. Osier jaune. Rameaux grèles, allongés, plus souples, d'un janne vif au printemps. Fevilles un peu glauques en dessous, plus étroites et plus finement dentées, à la fin presque glabres. $\boldsymbol{S}$. Vitela lina. Lin.

Var. $\beta$. Soyeux. Feuilles, même adultes, et jeunes pousses totalement couvertes sur les deux faces de poils soyeux-argentés. S. Sericea. Willd. Saule argenté.

Commun dans les plaines et les vallées de toute la France, soit planté el cultivé en oseraies ou en tétards au bords des routes el des cours d'eau, soit spontané dans les forôts, où il devient un arbre de grandes dimensions; se trouve aussi en Algérie. Flor., avril-mai. Fruclif., juin.

Le saule blane est l'espèce la plus importante du genre par les grandes dimensions qu'il peut aequérir, $2 \mathrm{\partial ̆}^{\mathrm{m}}$ de hauteur sur $f^{m}$ de diamètre, et par sa rapide végétation, longtemps soutenue. Il se rencontre disséminé dans les forèts de plaines dont le sol est léger, frais ou humide et, lorsqu'il a atteint un àge avancé, il y présente assez, par le port et l'écorce, l'aspect d'un vieux chêne.Cependant la ramification en est mieux graduée des branches aux ramules ct ceux-ci sont plus allongés, plus grèles et plus droits. Ce saule forme des oseraies et des tètards d'une culture très-productire et fournit des osiers et des liens de premier choix, surtout s'ils

Taille. Port.

Station et sol.

Ecorce.

Ramification. 
proviennent de la variété vitelline. Il réussit encore assez bien dans les sols sees, pourvu qu'ils soient légers.

Les jeunes pousses, qui varient du jaune vil au lrun et au pourpre foncé, sont plus ou moins garnies vers les extrímités de poils soyeux, blanes et appliqués. Elles se désarticulent moins facilement que celles du saule fragile et encore cela n'a-t-il lieu que pendant peu de temps, au moment de la plus forte ascension de la séve.

Bois. Le bois de saule blane est d'un joli rouge tendre, uniforme, quoique parfois marqué de quelques taches médullaires plus foncées; l'aubier en est blane, peu abondant. Il a le grain assez fin, homogène, se découpe aisément et - nettement dans tous les sens et n'est point exposé à se gercer. Il sert à la sculpture; on en fatt de la volige, etc. Suivant G. L. IIartig, du bois d'une tige de 50 ans, pèse, vert, 0,86 ; complétement see, 0,41 .

Valeur D'après les recherches de T. Hartig, du bois d'une tige de calorifique. 10 ans, desséché à l'air et d'une densité de 0,56, comparé à du bois de hêtre d'une tige de 50 ans et d'un diamètre égal à celui de la précédente, également desséché et pesant 0,69 , a donné les résultats suivants sur la valeur calorifique.

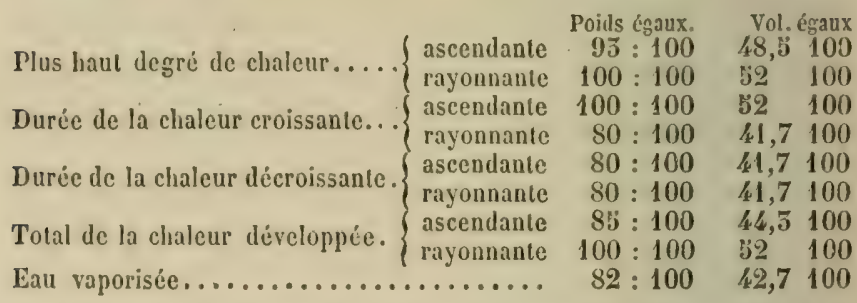

Le charbon est léger, poreux, propre au dessin et à la fabrication de la poudre.

\section{SECTION II. S. Amandiers.}

Jeunes pousses cannelées au sommet. Feuilles lisses et brillantes en dessus, glabres sur les deux faces, quand elles sont adultes, à pétiole plus ou moins glanduleux; chatons latéraux, paraissant avec les feuilles, feuillés à la base ; écailles concolores, persistantes jusqu'it la maturité; 2 nectaires; 2-3 étamines; 
anthères jaunes; ovaires glabres ou tomenteux, dont le pédicelle est court et égrale au plus 2 fois lit glande. - Arbrisseaux élevés dont l'écorce s'exfolie avec l'âge, dans le genre de celle du platane. Bords des eaux, dans les plaines et les montagnes de moyenne hauteur.

4. Sanle amandier. Salix amygdana. Lin. Osier brun; Osier rouge; Osier franc; Saule triandre; Saule à 3 étamines.

Feuilles oblongues-lancéolées ou oblongues-elliptiques, $\mathbf{5}$ - $\mathbf{b}$ fois anssi longues que larges, à bords moyens le plus souvent presque parallèles; acuminées, parfois assez brusquement; très-glabres, même dans la jeunesse, fermes et coriaces, d'un vert foncé luisant en dessus, d'un vert plus clair moins luisant ou complétement glauque et mat en dessous; finement dentées-glanduleuses; stipules des pousses robustes grandes, longtemps persistantes. Chatons pédonculés et bien feuillés à la base, cylindriques, allongés, assez grêles, à axe pubescent, écailles glabres au sommel; les mâles à fleurs presque verticillées, à 5 élamines libres; les femelles, à capsules ovoïdes-coniques, obtuses au sommet, glabres, courtement pédicellées; style très-court, stigmates échancrés au sommet, courts, épais, horizonlalement divergents.

Var. $\alpha$. Concolore. Feuilles vertes ou à peine glauques en dessous. Salix triandra. Lin.

Var. $\beta$. Discolore. Feuilles complétement mates el d'un glauque-blanc en dessous, Salix amygdalina. Lin.

Arbrisseau de $4-5^{m}$ de liauteur, à jeunes pousses effilées, flexibles, lisses et glabres, habituellement d'un rouge brun verdâtre, très-fragiles à leur point d'insertion en temps de séve; revêtu à un âge avancé d'une écorce couleur de cannelle, qui s'exfolie en plaques minces et larges. Très-abondant dans les oseraies et saussaies qui garnissent les rives des cours d'eau de la plaine et des montagnes peu élevées; fréquemment cultivé en télards de basse tige ; manque dans les forèts proprement dites. Flor, avril-mai.

Le bois du saule amandier est mou, marqué de taches médullaires ; d'un brun rougeâtre clair au coeur et passant insensiblement à l'aubier qui est blanc.

†. Saule à fenilles d'hippophaé. S.LIx üPopHä̈fola. TIU⿺LLIER. Saule olivâtre.

Feuilles étroitement lancéolées, 6-7 fois aussi longues que larges, longuement et directement prolongées en pointe très-aiguë, faiblement et irrégulièrement dentées-glanduleuses, à glandes souvent dirigées en dehors; fermes, planes ou légèrement enroulées en cylindre; glabres, luisantes et d'un vert sombre en dessus, légèrement poilues-soyeuses, quand elles sont jeunes, plus tard presque glabres, d'un vert clair e' presque mat en dessous. Stipules petites, en demi-cœur, aiguës et caduques. Chatons pédonculés et feuillés à la base, cylindriques, assez denses, à écailles très-velues et barbues au sommet, axe poilu; les màles, à 2 étamines libres, quelquefois $\mathbf{3}$ d'après T. Harliğ; les femelles, à ca|ısules ovoüdesconirgues, tomenteuses ou glabres, à pédicelle court, égalant la glande ; 
style ordinairement allougé, a stigmales aussi longs que lui, bifides. Arbrisseau de $\overline{5}-k^{\text {ma }}$ de laut, à rameaux olivatres ou jaunatres, luisants, se couvrant vers 6-8 ans d'un rhytidome qui s'exfolic dans le genre de celui du platane. Assez commun dans le nord-est de la France, aux bords des cours d'eau: Rhin, Moselle, Meurthe; plus rare sur les bords de la Seine, de la Marne et de la Loire. Manque dans le midi. Flor., avril-mai. C'est probablement un hybride du saule amandier el du saule viminal, chez lequel les caracteres de ce dernier dominent, principalement dans la forme et l'aspect des feuilles; on n'a encore trouré en France que le sexe femelle. Salix triandra-viminalis. Wimmer.

+ Saule ondulé. Salix uvdulata. Euri.

Feuilles lancéolées, 4 - 6 fois environ aussi longues que larges, longucment acuminées, plus arrondies à la base et plus régulièrement et aigùment dentées-glanduleuses que dans lespèce précédente, à glandes plutòt rentrantes que saillantes; un peu ondulées ou planes; d'abord légèrement poilues-soyeuses arec les bords enroulés, puis completement glabres, vertes, lisses et luisantes, plus claires en dessous. Chatons pédonculés et feuillées à la base, cylindriques, à axe et écailles très-velus, ces dernières barbues au sommet; les mâles, denses, à 2, rarement 5 étamines; les femelles, grèles et peu serrés; capsule ovoïde-conique, aigıë, glabre ou pubescente, à jédicelle aussi long que la glande; style allongé, stigmates l'égalant, bifides, étalés. - Arbrissean très-voisin du précédent, à rameaux bruns, olivâtres, luisants, pubescents dans leur première jeunesse. Disséminé cà et là sur les bords de la Marne, de la Seine, de la Loire, du Cher, de la Vienne. Flor., avril-mai.

Probablement hybride du saule amandier et du saule viminal, comme le précédent, avec prélominance des caractères dı $1 \mathrm{r}$, surtout dans le feuillage, ou peut-être bien lıybride du saule amandier et du saule à feuilles d'hippophaé. (Salix triandra-viminalis. Wimmer.)

\section{Section III. Pruincux.}

Jeunes pousses assez robustes, pubérulentes; rameaux couverts d'une efflorescence glauque (pruineuse) ; feuilles lisses et brillantes en dessus (pubescence à part), à pétiole non glanduleux. Cilntons latéraux, sessiles, non feuillés ì la lase, très-précoces; écailles discolores, persistantes; I nectaire; 2 étamines; anthères jaunes ; capsule sessile, glabre. - Arbres ou grauds arbrisseaux, à écorce lisse jusrjùa un ìge avancé, dans le geure de celle du hêtre; habitant les bords des caux des rigrions montagneuses élevées et descendant leur cours jusque dius les vallées inférieures.

5. Sanle Daphne. Satix dapinoïnes. Vulq. Saule précoce; Saule noir (dans les $A / p e s) ;$ Saule à bois glauque; Saule à feuilles de laurier.

Feuilles-lanciolées-oblongues, 5-4 fois aussi longues que larges, dont 
la pilus grande largeur tombe vers le milieu ou an delà; acuminées, à bords épaissis en dessous, denticulés-glanduleux; planes el fermes quand elles sont adultes, rappelant alors les feuilles du saule pentandrique; couvertes dans la jeunesse, ainsi que les jeunes pousses, de poils blanes soyenx-laineux très-fragiles, bientôt vertes, luisantes et glabres en dessus, plus ou moins glauques, mates et glabres, ou à peu près, en dessous. Chatons sessiles, nus ou garnis de quelques petites bractées foliacées à la base; denses et gros, à écailles très-velues; les mâles, ovoïdes-allongés, à 2 ćtamines ; les femelles, cylindriques ; capsule ovaleconique, glabre, sessile; style allongé, du double plus long que les stigmates qui sont bifides, redressés en tulipe. - Arbrisseau ou arbre parrevant à $10-14^{\mathrm{n}}$ sur $0^{\mathrm{m}} 60-0^{\mathrm{m}} 73$ de circonférence en une douzaine d'années, à rameaux d'un vert jaunâtre, à pousses pourprées, générale-ment assez robustes, pubérulentes dans la jeunesse, couvertes jusqu'à 2 ou 5 ans d'une efflorescence bleue-glauque, qui s'enlève très-facilement; à floraison très-précoce, antérieure à la foliaison et à écorce lisse, ne s'écaillant pas, d'un jaune citron vif intérieurement. Vallées des Alpes; commun en Alsace sur les bords du Rhin. Flor., février-mars-avril.

Ce saule demande des sols légers et humides et languit dans les terres liantes; le bois est d'un rougeâtre clair uniforme, comme celui du saule blane auquel il ressemble beaucoup; il ne présente pas de taches médullaires.

\section{SECTION IV. S. Viminals.}

Feuilles finement ridées et mates en dessus, ì bords généralement plus ou moins enroulés en dessous; face inférieure toujours poilue; pétiole non glanduleux; stipules nulles ou petites et étroites, à peine foliacées, caduques. Chatons latéraux, sessiles, paraissant avant les feuilles, peu ou point feuillés à la base; écailles discolores, quelquefois concolores, persistantes ; 1 nectaire ; 2 étamines; anthères jaunes; capsules sessiles ou courtement pédicellées. - Grands arbrisseaux ct quelquefois arbres à pousses jamais décidément jaunes, à écorce produisant un rliytidome fibreux-gerçuré, analogue à celui du clêne, mais beaucoup moins prononcé. Bords des eaux de la plaine et des montagnes peu élevées.

\section{\$1. Face inférieure des feuilles verte et non glauque, abstrac- tion faite de la pubescence qui la recouvre.}

耳. Écailles des chatons concolores.

† Saule à feuilles molles. Salix Moldissima. Eurir.

Feuilles lancéolées-allongées, 6-7 fois aussi longues que larges, acuminées, finement dentées-glanduleuses, rertes en dessus, couvertes en 
dessous d'une légère pubescence blanche-tomenteuse, persistante; stipules petites, foliacées, caltudues. Chatons droits, sessiles, non ou peu feuillés à la base, denses, à écailles jaune-roussàtre, longuement velues; les mâles, oblongs, à 2 étamines libres; les femelles, cylindriques, à capsules ovoüdes-coniques, tomenteuses, sessiles; style allongé, à stignales linéaires et bifides, plus courts que lui et ne débordant pas les poils des écailles. - Arbrisseau ou pelit arbre très-voisin du saule ondulé, dont il se distingue principalement par les glandes des bords de la feuille qui ne descendent point sur le prétiole et par la pubescence persistante de la face inférieure; voisin aussi du saule viminal, dont il diffère stirtout par les bords non parallèles des feuilles et par la jubescence inférieure beaucoup plus ténue, plus éparse el opaque. Disséminé cà et là aux bords des eaux, sans qu'il soit possible de citer de localités certaines, car.les auteurs qui l'ont indiqué en Alsace, en Anjou, elc., scmblent avoir eu en vue une espèce différente. Paraît être un hybride; Salix triandra-viminalis. Wimmer. Flor., mars-avril.

\section{1. ÉCAILLES des chatons discolones.}

6. Saule vimimal. Salix viminalis. Liv. Saule des vanniers; Osier blanc; Osier vert; Saule à longues feuilles.

Feuilles lancéolées très-allongées, $6-8$ fois aussi longues que larges, insensiblement et directement terminées en pointe, à bords moyens plus ou moins parallèles; face supérieure verte et presque mate, finalement glabre ou pubérulente, face inférieure couverte de poils appliqués, soyeux, serrés, à reflets argentés qui cachent entièrement la couleur verte fondamentale; limbe plan ou plus souvent ondulé; bords ondulés, entiers, ou imperceptiblement et lächement dentés, plus ou moins caroulés en dessous; stipules nulles ou réduites à de petites lanières sèches et caduques. Chatons droits, sessiles, non feuillés à la base, denses, à écailles longuement velues; les mâles, ovoïdes, à 2 étamines libres; les femelles, cylindriques, à capsules ovö̈les-coniques, aiguës, tomenteuses-soyeuses, sessiles; style allongé; stigmates l'égalant, filiformes, entiers, dépassaú les poils des écailles. - $\mathbf{A}$ rbrisseau ou petit arbre de $4-6^{\mathrm{m}}$ de hauteur, à rameaux très-allongés el robustes, droits, effilés, finalement glabres, grisâtres ou verdàtres. Habite les bords des eaux, particulièrement dans les plaines ou les montagnes peu élevées, plus abondamment dans le nord que dans le midi. Flor., mars-avril. Fructif., juin.

Ce saule est l'un des plus répandus; il borde fréquemment les cours d'eau et constitue souvent la majorité du peuplement des oseraies; e'est l'un des plus convenables pour la vannerie commune.

Il demande des sols meubles et liumides et végète péniblement sur ceux qui sont compactes, alor's même qu'ils ont l'humidité convenable.

† Gaule de simith. Salix smitmana. Willi). S. smilhiana, var. nilens. Gir. ET God.

Feuilles oblongues-lancéolées, $5-3$ fois aussi longues que larges, et 
dont la jlus grande largeur correspond à leur milicu ou le précède; à lords non : parallèles, peu ou point glanduleux, superficiellement ondulís-crénelés ou entiers (toujours pour les feuilles inférieures); vertes et mates en dessus; en dessous, assez fortement réticulées, blanches-tomenteuses et soyeuses dans la jeunesse, soyeuses et laissant voir la couleur verte fondamentale à l'élat adulte. Chatons presque sessiles, les mâles ovoïdes, les femelles cylindriques, d'abord denses, puis un peu lâches ; capsules ovoïdes-coniques, tomenteuses, dont le pédicelle égale 1-2 fois la glande; style médiocre; stigmates ordinairement plus longs que lui, entiers ou bifides. Arbrisseau ou arbre alleignant $10^{\mathrm{m}}$ de hauteur, à pousses olivâtres, légèrement grises-tomenteuses; probablement hybride du saule viminal el du saule cendré (salix viminalis-caprea. Wimmer). Disséminé jarmi les parents : Environs de Paris, d'Angers, du Mans, elc. Flor., mars-avril.

Comme beaucoup d'hybrides, dont les organes de reproduction se développent peu abondamment, le saule de Smith végète avec une grande vigueur ct, sur les sols légers et humides, produit des rejets allongés et robustes, très-propres à la grosse vannerie, dont l'exploitation peut se faire annuellement. A ce point de vue, la culture en est ou en peut être développée dans les oseraics avec avantages.

+ Saule de Seringe. Silix seringeana. Gaud. ex Grenien, Fl. de Fr., non Koch. S. smithiana, var. obscura. Gr. eт God.

Ce saule très-voisin du précédent s'en distingue par les fenilles atteignant leur plus grande largeur au delà du milieu, légèrement dentéesglanduleuses dans leur moitié supérieure, blanchâtres-tomenteuses en dessous pendant la jeunesse, plus tard vertes et pubescentes, sans jamais offrir de reflets argentés ou soycux. Arbrisseau d'une végétation moins rapide et probablement aussi lıybride des mêmes espèces, avec prédominence du type du saule cendré (Salix cinerea-viminalis. Wimmer). Disséminé cà et là parmi les parents : Maine-et-Loire, Loire-Inférieure, Calvados, eic. Flor., mars-avril.

† Saule roisin. Salix affinis. Gn. el God. S. acuminata, Koch, non Smith.

Ressemble beaucoup au saule de Smith dont on le distingue par les chatons d'un tiers au moins plus longs el plus larges (les femelles atteignent 5 cent. de long), beaucoup plus longuement velus, toujours compactes; par les feuilles ordinairement plus larges, ondulées-crénelées et glanduleuses sur les bords, recouvertes en dessous d'un duvet tomenteux plus ou moins dense, à reflets soyenx faibles. Le saule voisin parait ètre un hybride du saule viminal et du saule marcean (Salix viminaliscaprea. IVimmer); on le rencontre disséminé çà et là sur les bords du Rhin, de la Seine, elc. Flor., mars-avril. 


\section{\$2. Face inférieure des feuilles glauque, indépendammont de la pubescence qui la recouvre.}

7. Écalles des chitoxs concolones.

2. Saule drapé.. Salix incana. Scitrayk.

Feuilles linéaires ou longuement lancéolées-linéaires, 9-10 fois aussi longues que larges, à bords parallèles; insensiblement et directement terminées en pointe; d'un vert foncé mal, pubérulentes ou finalement glabres en dessus, couvertes en dessous d'un épais duvet blanc-farineuxiomenteux, persistant, qui cache entièrement la couleur glauque du fond; bords marqués de très-fines dentelures à peine apparentes, si ce n'est par les glandes qui les terminent, étroitement enroulés en dessous, exceplé dans l'àge tout à fait adulte. Chatons sessiles, non fenillés ou garnis de quelques bractées foliacées à la base; cylindriques, arqués el grèles, à écailles concolores, presque glabres, légèrement poilues aux bords; les mâles, à 2 étamines ordinairement réunies par la moilié inférieure des filets; les femelles, assez lâches; capsule ovoĩde-conique, aiguë, glabre, pourvue d'un pédicelle court, 1-2 fois plus long que la glande; style allongé; stigmates courts et bifides. - Arbrisseau de $2-4^{\mathrm{m}}$, à jeunes rameaux d'un brun verdàtre ou noiràtre, luisants et glabres ou tomenteux vers leurs extrémités; devenant parfois un petit arbre de $6-7^{\mathrm{m}}$. Ilabite les bords des torrents el des ruisseaux des régions montagneuses; Alpes, Pyrénées, Cévennes; descend le long des rivières et des fleuves : bords du Ihoòne et de ses aflluents, de l'driége, de la Garonne, du Rhin. Flor., mars-avril. Fruclif., mai.

\section{II. ĹCAILLES DES CIIATONS DISCOLORES.}

f Saule neuminé. Salix acumrnata. Surir.

Ce saule a les plus grandes analogies avec les précédents et principalement avec le saule de Smith, mais la coloration glauque fondamentale des feuilles en dessous le fait aisément reconnaître. C'est aussi probablement un hybride du saule viminal, qui doit se trouver en France, quoiqu'il n'y ait pas encore été signalé avec certitude.

\section{† Saule à feuilles d'oliviex. Salix oleifolia. Willars.}

Feuilles elliptiques-lancéolées, fermes, finalement glabres et d'un vert foncé en dessus; en dessous, densément blanches-farineuses-tomenteuses et mates, à peine denticulées et très-légèrement enroulées sur les bords. Chatons femelles cylindriques, un peu làches, à écailles longuement velues; capsule ovoüle, conique, allongée, tomenteuse, pédicelléc; pédicelle 1-2 fois plus longr que la glande; style médiocre; stigmates bifides. - Arbrisseau à rameaux jaunâtres, légèrement toruleux, dont les plus jeunes sont tomenteux; probablement liybride (S. incanacinerea. Grenier). Ilautes-Alpes el Lozère. Flor., avril. 


\section{Section V. Pourpres.}

Pousses grêles. Feuilles opposées ou alternes, subsessiles ou courtement pétiolées, lisses en dessus, mates, glabres et glau(ques ou à pubescence caduque; pétioles non glanduleux. Chatons latéraux, sessiles, précélant la foliaison, pourvus plus tard de petites feuilles à leur base ; écailles discolores, persistantes; 1 nectaire ; I étamines, parfois complétement réunies daus toute leur longueur; anthères d'un rouge pourpre; capsules sessiles ou presque sessilcs, tomenteuses. - Arbrisseaux assez élevés, à écorce lisse, finalement gerçurée. Bords des caux de la plaine et des montagnes peu élevées.

8. Saule pourpre. Salix punpurea. Liv. S. monandra $D C$. Saule a 1 étamine. Osier rouge; osier bleu; Verdiau (France centrale).

Fetilles le plus souvent opposées, presque sessiles, obovales-lancéolées, $4-6$ fois aussi Iongues que larges, dont la plus grande largeur tombc entre le milieu et l'extrémité; courtement et brusquement acuminées, bordées dans leur moitié supérieure de dents fines, aiguës, inégalenent distantes, non glanduleuses; planes, males, glabres; exceptionnellement parsemées de poils soyeux et cadues et toljours couvertes en dessous d'une légère efflorescence d'un glauque blenătre; stipules presque constamment nulles. Chatons sessiles, non feuillés à la base, le plus souvent opposés, cylindriques; les mîles, denses, à écailles Ionguement velues, à 2 étamines complétement soudées dans loute leur longueur et représentant une étamine unique 4-loculaire; les femelles, à écailles tomenteuses et moins longuement velues, à capsules ovoüles, sessiles, tomenteuses; style court ou presque nul ; stigmates courls, ovales, étalés. - Arbrisseau de $2-5^{\mathrm{m}}$, à pousses allongées, grêles, olivâtres, rougeâtres ou pourprées, glabres et brillantes. Bords des eaux des régions basses ou peu élevées; fréquemment cultivé en oseraies et recherché pour des ouvrages de vannerie fine el pour liens; se trouve en Algérie. Flor., mars-ayril. Fruclif., mai-juin.

\section{† Saule rouge. Salix rubra. IIUds.}

Feuilles lancéolées-allongées, environ 6-7 fois aussi longues que larges, dont la plus grande largeur correspond à leur nilieu; longuement et insensiblement eflilées en pointe, bordées de dents superficielles ou de crénelures espacées, presque nulles vers la base; planes, mais à bords très-légèrement enroulés en dessous ; vertes, mates, surtout en dessous, glabres à l'état adulte (dans la jeunesse le dessus est parfois revêtu d'une pubescence d'un gris soyeux el le dessous est poilu-soyeux à reflets légèrement argentés, comme dans la feuille du saule viminal, sans que cette pubeseenee eache jamais la couleur verte fondamentale); stipules étroitement linéaires, assez persistantes. Chalons presque sessiles, nus ou seulement garnis à la base de quelques petites feuilles; denses, à écailles longuement relues; les mùles, ovoïdes-allongés, à 2 étamines plus ou moins réunie's par les tilets à la base; les femelles, cylindriques, 
à capsules ovoïles-aiguës, sessiles, soyeuses; slyle allougć, sligmales aussi longs que lui, entiers ou légèrement échancrés, plus ou moins divergents. - Arbrisseau élevé, à rameaux jaunâtres ou bruns. Disséminé ça et là le loug des cours d'eau, parmi les saules pourpres et viminals, dont il paraît être un hybride. Intermédiaire entre ees denx especes; se rapprochant davantage, par le port et par les feuilles, tantòt du Saule pourpré (Salix purpureu-viminalis, Wimmer), tantồ du Saule viminal (Sulix viminalis-purpurea. Conlejean). Flor., mars-avril. Fructif., juin.

f Saule de Bdimmer. Salix wimmeriana, Gr. el God.

Feuilles obovales-oblongues, pubérulentes en été, devenant fermes, très-glabres, brillantes en dessus, glanques en dessous en automne; cluatons sessiles, à écailles velues; les màles, ovoïdes, très-courts, denses, à 2 élamines libres; les femclles, eylindriques et denses, à eapsules ovoïdes-coniques, fortement hérissées-tomenteuses, soyeuses, subsessiles; style presque nul; stigmates très-courts, enticrs, noiràtres. Arbrisseau de 1-2ın, à écorce grisâtre; très-probablement hybride. (Salix purpurea-caprea, Wimmcr.) Bords du Doubs. Flor., mars-avril.

\section{$2^{\text {me }}$ DIVISION.}

\section{SAULES TORULEUX LATIFOLIÉS.}

Jeunes pousses non effilées, rameuses, peu allongées, (les turminales exceptées) noueuses, ne pouvant servir l'osiers ; feuilles 5 fois au plus aussi longues que larces (exeeptionnellement plus étroites, mais dans ce cas, sous-arbrisseau (rès-rameux, de forme toruleuse très-prononcéc); pétioles jamais glanduleux; écailles des chatons discolores, persistanics; 2 étamines; 1 seul nectaire. Petits arbres, arbrisseaux et sous-arbrisscaux de toutes les régions, depuis les plus basses jusqu'aux plus élevées.

\section{Section VI. Marceaux.}

Feuilles larges, plus ou moins réticulées en dessous, souvent sillonnćes ou crépues en dessus. Chatons latéraux sessiles, paraissant en géníral avant les feuilles, légèrement pédonculés et accompagnés plus tard de petites feuiiles à la base; anthères jaunes; capsules longuement pédicellées, dout le pédicelle égale 3-6 fois la glande. - Arbres peu élevés et arbrisseaux de taille moyenne ou petite, à écorce lisse et grise ou seulement gerçurée ill pied ì un âge avancé. Forêts, prés, bords des eaux et maréages, soit dins les plaines, suit dans les rérgions montagneuses ílevées. 
$\$ 1$. Arbres ou arbrissecux dressés, i feuilles moyernes ou
grandes.

1. feulles Glauques, toujouns tomenteuses et mates en dessous; STYLES PRESQUE NULS.

9. Gaule Marceau. Salix caprea. Lix. Marsaull; Narsaule.

Feuilles ovales, ellipuques ou légèrement obovales, 2 fois aussi longues que larges, quelquefois un peu cordiformes à la base, acuminées au sommet, à pointe oblique et souvent plissée en gouttière; plus ou moins velues-soyeuses dans l'origine, finalement vertes, glabres, lisses et luisantes en dessus; toujours glauques, blanches ou grises-tomenteuses en dessous, avec les nervures, les veines et les veinules saillantes, rendant la surface réticulée; bords entiers ou irrégulièrement ondulés ou crénelés; jeunes rameaux glabres, luisants ou un peu pubescents au sommet, arrondis ; bourgeons glabres; stipules réniformes, dentées, souvent nulles. Chatons sessiles, non feuillés à la base, gros, à écailles longuement barbues; les mâles, ovoïdes et denses; les femelles, ovoïdesoblongs, à capsules ovoïdes-coniqques très-allongées, tomenteuses, portées par un long pédicelle, qui égale $5-6$ fois la glande ; style très-court; stigmates ovales, bifides. - Arbrisseau el arbre ì branches étalées, peu nombreuses, atleignant $10-12^{\mathrm{m}}$ de hanteur sur $1^{\mathrm{m}}$ de circonférence, à écorce d'un gris verdâtre, lisse ou à la fin superficicllement gerçuréc. Flor., mars-avril. Fructif., mai.

Le saule Narceau est très-commun dans toute la France; il abonde surtout dans les forèts, où sa végétation rapide pendant la jeunesse le rend sourent gènant pour les espèces plus précicuses et d'une croissance plus lente. Il constitue, avec le peuplier tremble, la majeure partic de ces bois blancs auxquels on fait la guerre par les nettoiements. Peutìtre se trouve-t-il aussi en Algérie, où il serait confondu avec le saule pédicellé.

Il croit partout, dans les sols frais comme dans les sols les plus sees, jusque dans les fentes des rochers, sur les vieilles ruines, sur les déblais des carrières. L’abondance de ce saule en fait sans contredit l'espèce forestière la plus importante de tout le genre, bien qu'il ne soit pas celtui qui atteigne les plus fortes dimensions.

S'il est souvent gènant par sa tendance envahissante, il est très-précieux dans certaines circonstances, lorsqu'il s'agit, par exemple, de repeupler des sols secs et nus. Il peut ètre employé pour y créer un couvert aussi utile au terrain qu'aux plants qu'on y veut cultiver.

Le bois du saule Marecau est d'un rouge vineux asse\%

Slation.

Sol.

Bois. 
uniforme au cœur; il est le plus lourd de tous ceux du genre et suivant G. L. Ilartig, il pèse, provenant d'une tige de 60 ans, vert, 0,65 ; sec, 0,46 . Cette densité s'accroit singulièrement dans les climats chauds et un échantillon de saule Narceau provenant de Corse et complétement desséché à l'air, d'une tige de 28 ans et de $0^{\mathrm{m}} 28$ de diamètre, pèse 0,74 . On le prendrait par son poids, sa dureté, sa coloration vive et sa compacité pour un pommier ou quelque autre bois de mème famille (Coll. Ec. For.).

D'après le même auteur, du Marceau de tige de $\breve{0}$ ans, comparé à du hètre de 80 ans, donne les résultats suivants sur sa puissance calorifique, pour des volumes égaux de bois vert, puis desséchés à l'air';

Plus haut degré de clıaleur. $91: 100$.

Durée de la combustion... $45: 100$.

Eau vaporisée........ $78: 100$ (1).

(1) L'Algérie produit, de cette section, un saule qu'on ne rencontre pas en France.

Saule pédicellé. (Salix pedicelata. Desf.)

Feuilles elliptiques ou obovales-ohlongues, allénuées il la base, aiguës ou presques obluses, planes au sommet, trois fois au moiris aussi longues que larges, irrégulièrement dentées, parfois entières, vertes, finement sillonnées-rugueuses, à peine luisantes en dessus; réliculées, glanţues el grises tomenteuses, surtout dans la jeunesse, en dessous. Chatons miles sessiles, ovoüdes-cylindriques, plus larges que ceux du saule Marceau, à écailles couvertes d'un épais et long duvę soyeux, paraissant avec les feuilles; chatons femelles, cylindriques et assez grèles, pédonculés et garnis à la base de feuilles complétement développées; capsule glabre, longuement pédicellée, dont le pédicelle égale है-7 fois la glande. Arbrisseau à jeunes pousses densément et courtement grises-tomenteuses, et a bourgeons velus, rappelant beaucoup le saule cendré et parfois le saule Marceau. Flor., février. Fructif., fin d'avril-mai. Lieux humides ę marécageux de l'Algérie.

Station. Le saule pédicellé croil dans les plaines, sur les sols frais et humides, ct le long des cours d'eau; il y est melangé aux frìnes, anx ormes, aux tamarix, ou bien il constitue à lui seul des massifs assez élendus.

Croissance. La végétation en est rapide, et, vers 50 ans, it est parvenu à toute sa croissance; il peut alors mesurer $6-8^{\text {m }}$ de hateur sur $\mathbf{1}^{\text {in }}, \mathbf{4 0}$ de circonférence.

Bois. Le bois et rougeâtre et semblable à celui du saule Mareeau; il a les mèmes usages. Un échantillon provenant d'une tige de 11 ans, de 29 cent. de diamètre, pèse, complétement desséché à l'air, 0,87. (Coll. Ec. For., envoi de M. Royer.) 
10. Sauie cendré. Salix cinerea. LiN.

Feuilles obovales lancéolées, ou oblongues-obovales, ou cllipliques, 2-2 1/2 fois aussi longues que larges; brièvement acuminées, à pointe plane ou creusée en gouttière ou quelquefois obtuses; entières ou irrésrulièrement ondulées ou dentées sur les bords; vertes, non luisantes et finement pubescentes en dessus ; vertes-cendrées, tomenteuses et fortement réticulées en dessous; stipules réniformes, lentées, bien développées sur les rameaux stériles. Chatons d'abord sessiles et non feuillés à la base, denses, à écailles longuement velues; les mâles, ovoïdes; les femelles, finalement pédonculés et feuillés à la base, ovoïdes-allongés ; capsule ovoïde-conique, allongée, tomenteuse, porléc par un pédicelle qui égale $4-\breve{b}$ fois la glande; stigmates presque sessiles, très-courts, ovales, bifides. - Arbrisseau intermédiaire pour la taille et les dimensions de ses feuilles entre le saule Marceau et le saule à orcillettes; à jeunes pousses irrégulièrement arrondies, robustes, à bourgeons densément grisátres-tomenteux; ne croît jamais, comme le fait souvent le premier, dans les lieux secs. Habite le bord des eaux et les lieux humides, rarement dans les forêts. Flor., mars-avril. Fruclif, mai.

1. Sanule à graniles fenilles. Salix grandifolia. Seringe.

Voisin des deux précédents. Feuilles obovales-allongées, aiguës, à pointe droite et plane, ou quelquefois obtuses, plutút dentées en scie que crénclées, vertes, glabres et luisantes à l'ćtat adulte, en dessus; glauques-cendrées, pubescentes plutôt que tomenteuses, réticulées, en dessous; stipules réniformes, presque entières, grandes et persistantes sur les rameux stériles. Chatons paraissant avec ou après les feuilles, ordinairement feuillés à la base, à écailles brièvement barbues, fauves et non brunes au sommet; les mâles, ovoïdes, petits; les femelles, allongés, lâches; capsule ovoüle-conique allongée, lomenteuse, portée par un pédicelle qui égale $5-6$ fois la grlande; stigmates presque sessiles, linéaires, bifides. - Arbrisseau de 1-2m, à rameanx et bourgeons tomenteux. Abondant dans tout le Itaut-Jura et probablement aussi dans les Alpes et les Pyrénées. Flor., mai-juin.

\section{Saule à oreillettes. SAlix aurita. Liv.}

Feuilles plus molles et plus petites que celles du saule Marceau et du saule cendré, obovales ou allongées-obovales, 2 fois environ aussi longues que larges, très-brièvement acuminées, à pointe pelite, pliée en gouttière, quelquefois arrondies au sommet; bords un peu enroulés, ondulésdentés ou presque entiers; dessus pubescent, d'un vert grisâtre, mat, ondulé-crépu; dessous glauque et gris-tomenteux, fortement réticulé; stipules réniforme's, dentées, assez grandes et persistantes sur les pousses vigoureuses. (Le nom de saule à oreillettes repose sur ce caractère, auquel il ne faut pas altacher trop d'importance.) Chatons sessiles, non ou légèrement feuillés à la base, de moitié plus petit que ceux du saule Marceau et du saule cendré, a écailles barbues; les mâles, ovoïdes; les femelles, altongés, ordinairement làches; capsule ovoïde-conique, allongée, tomenteuse, porlée par un pédicelle qui égale 5 -b̌ fois la glande; sligmates presque sessiles, courı, ovales, entier's ou très-faiblement échanerés. - Arbrisseau très-diffus cl étalé, peu élevé, de 1-2m habiiuellement, rarement $5^{\prime \prime \prime}$, à rameaux irrégulièrement arrondis, grêles, 
glabres, les plus jeunes d'un brun rouge, couverts d'une pubescence caduque à leurs extrémités; bourgeons glabres. Très-commun dans les forèts à sol bumide, marécageux et tourbeux et aux bords des eaux; diminutif du saule Marceau, mais feuilles beancoup plus crépues el plus réticulées. Flor., mars-arril. Fructif., mai.

7R. Feuilles glavgues, glabres ou légènement soyeuses en dessous; STYLES ALLONGÉS.

\section{Sanle noircissant. Salix nigrigans. Suitir.}

Feuilles très-variables dans leur taille et leur forme, noircissant par la dessiccation; généralement elliptiques, elliptiques-lancéolées, ovales ou plus rarement obovales, 2-5 fois aussi longues que larges, acuminées; à bords ondulés-dentés, parfois assez régulièrement, ou entiers; d'un vert foncé; d'abord pubescentes, puis glabres et mates en dessus; en dessous, poilues-soyeuses, finalement glabres, glauques, si ce n'est vers la pointe, qui reste généralement verte; réticulées el plus on moins poilues-hérisscies sur les nervures; stipules des rameaux stériles développées, à pointe droite, allongée. Chatons légèrement pédonculés, feuillés à la base, à écailles barbues; les mâles, ovoïdes, denses; les femelles, ¿ la fin làches, allongés; capsule ovoïde-conique, allongée, portée sur un pédicelle $5-4$ fois aussi long que la glande; slyle très-long; sligmates épais, entiers ou bifides.

Var. $\propto$. Capsule glabre ou subpubescente. Salix stylosa. DC.

Var. $\beta$. Capsule tomenteuse. Salix nigricans. DC.

Arbrisseau très-variable, de petite ou de moyenne taille, $1-5 \mathrm{~m}$, à ramcaux redressés, gris-verdàtre, à jeunes pousses et bourgeons hérissés. velus. Lieux tourbeux et bord des caux dans les Hantes-Alpes, le IfautJura; descend le long du Rhin, en Alsace où il est commun. Flor., avril-mai. lruclif, juin.

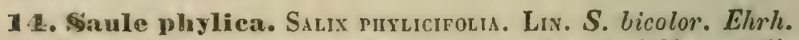

Feuilles de taille moyenne, ovales, elliptiques ou lancéolées, entières ot rarement et très-légèrement dentées; fermes, d'un vert foncé, lisses et luisantes, quelquefois finement ridées et alors mates, en dessus; trèsstaucques en dessous; d'abord un peu pubescentes sur les 2 faces, finalement très-glabres; stipules nulles ou presque nulles. Chatons paraissant avant les feuilles, d'abord sessiles, à écailles très-velues; les mâles, ovoïles-allongés; les femelles, cylindriques, devenant légèrement pédonculés et feuillés à la base; capsule ovoïle-lancéolée, presque toujours tomenteuse, à pédicelle médiocre, égalant 2 fois, rarement 5 fois la glande; slyle el stigmates allongés, ces derniers cylindriques, bifiles. - Arbrisseau dépassant rarement $1{ }^{11}$, à végétation lente, a branches nues, rameuses et feuillées en touffes à l'extrémité seulement; jeunes pousses glabres; bourgeons, péliole et nervure médiane jaunes; rameaux plus àgés verı, puis gris. lieux liumides des régions montagneuses: Monts-Iores, Cantal, Forez, Pyrénées-Centrales. Flor., avril-mai. Fruclif, juin.

15. Sianle rampand. Salix nepens. LiN.

Feuilles petites très-variables, ovales-arrondies, ovales, elliptiques, 
clliptiques-lancéolées, ou même lancéolées-linéaires, obluses ou aiguës, dont la lnngweur peut égaler 5-6 fois la largeur, à pointe généralement courbée et pliée en gouttière; entières ou bordées de dentelures glanduleuses espacćes, à bords souvent réfléchis; réticulées, vertes, luisantes, glabres ou pubescentes en dessus, soyeuses-argentées, plus rarement glabres ou pubescentes-glauques en dessous; stipules nulles ou lancéolíes-aiguës. Chatons petits, globuleux ou ovoïdes, sessiles ou pédonculés et plus ou moins feuillés à la base, à écailles velues; les femelles, à capsules ovales-lancćolées, tomenteuses ou glabres, portées sur des pédicelles allongés, 5-4 fois aussi longs que la grlande; style médiocre ; sligmates ordinairement ovales, bifides, d'un vert-jaunâtre ou pourpres.Petil sous-arbrisseau ne dépassant pas $0^{\mathrm{m}} \mathrm{y0}$, étalé, à tige souterraine traçante, très-rameux, à rameaux cffilés, redressés en partie, pubérulents, couverts de petites feuilles qui sont habituellement de la taille de celles des airelles myrtilles. Prés humides à sols sablonneux et tourbeux lu Centre, de l'Ouest et de l'Alsace dans l'Est; se retrouve aussi dans les Vosges, le Jura, les Alpes et les Pyrénées. Flor., avril-mai. Fruciff., juin,

Parmi les innombrables formes du saule rampant on distingue principalement les suivantes, que beaucoup d'auteurs considèrent comme espèces véritables :

Var. $\propto$. S. rampant argenté. S. argentea sm. Feuilles largement ovales, terminées en pointe recuurbée el plissée; soyeuses-argentées au moins en dessous. Chatons longuement pédonculés et largement feuillés a la base.

Var. $\beta$. S. rampant commun. Feuilles oblongues-lancéolées, au plus 4 fois aussi longues que larges, réticulées sur les 2 faces, presque enlières el couvertes en dessous de poils soyeux (S. repens. Lin.) ou denticulées au sommet et glauques-bleuàtres et à peine soyeuses en dessous. (S. fuscr. sm.); chatons courts, presque sessiies, à peine feuillés à la base.

Var. j. S. rampant à feuilles étroites. (S. Angustifolia Wulf.) Diffère du précédent par les feuilles lancéolées-linéaires et sensiblement terminées en pointe droite, 6 fois au moins aussi longues que larges.

† Sanle ambigu. Salix ambigua, Eirri.

Feuilles obovales ou obovales-lancéolées, ou elliptiques, entières ou superficiellement et rarement dentelées, courtenent acuminées, à pointe recourbée et pliée en goutlière, crépues et ridées en dessus, réticulées en dessons, d'abord recouvertes, surtont en dessous, d'un léger duvet tomenteux-soyeux, finalement glabrescentes; stipules des rameaux stciriles assez grandes et persistantes, demi-ovales. Chatons d'abord sessiles, puis subpédonculés et garnis de quelques bractées foliacées à la base, denses, à écailles velues; les mâles, ovoïdes; les femelles ovoïdes-allongús; capsule ovoïle-conique-allongée, tomenteuse, à pélicelle 5 - 4 fois aussi long que la glande; stigmates presque sessiles, ovales, nou échancrés. - Pelit arbrisseau de $1^{\mathrm{m}}$ au plus, très-rameux, à rameaux glabres, cffilés, dressés. Lieux tourbeux; assez commun dans le Jura. Croit disséminé parmi les saules à oreillettes et les saules rampants dont il paraît ètre un hybride (Salix aurila-repens. Wimmer.) et qu'il relie par une foule de formes transiloires, de sorte qu'il n'est pas toujours aise de le 
distinguer sutrement des parents. Diflère néanmoins du saule à orcillelles par sa taille beaucoup plus petite, les fenilles, surtout les inférieures, moins rugueuses, très-entières ou faiblement dentelées, dont la face inférieure n'est pas couverte d'un duvet franchement tomenteux et persistant; du saule rampant, par les feuilles fortemeut réticulées en dessous et les stipules plus développées. Flor., avril-mai. Fructif., juin.

\section{SECTion VII. Saules alpestres.}

Chatons latéraux, presque toujours pédonculés et feuillés à la base; anthères de couleur variée, toujours jaunes après la déhiscence ; capsules sessiles ou courtement pédicellées, à pédicelle igalant rarement 2 fois la longueur de la glande. - Sous-arbrisseaux peu élevés, mais non rampants, très-rameux, à feuilles presque toujours petites, rapprochées et reilressées en plumets ì l'extrémité des pousses, souvent ponctuées en dessous ; à écorce, lisse; habitant les régions montagneuses élevées et descendant rarement jusqu’à la limite supérieure du hêtre.

\section{$\$ 1$. Feuilles glabres ou convertes de légers poils soyeux et caducs.}

16. Saule hasté. Salix instata. Lin.

Feuilles assez grandes, ovales, ellipliques on lancéolées, parfois arrondies et légèrement cordiformes à la base, régulièrement et finement dentées, verles, glabres et luisantes en dessus, couverles en dessous d'une efllorescence glauque, légère el peu persistante; stipules trèsgrandes, semi-cordiformcs, à pointe dressée, persistantes. Chatons paraissant avec les feuilles, púdonculés, complétement et largement feuillés à la base; les mâles, ovoïdes, à filets slaminaux glabres; les femelles, allongés, à écailles trìs-Ionguement barbues, dont les poils sont d'abord Iroits, puis ensuite frisés ; capsule ovoïde-conique, glabre, dont le court pédicelle égale 1-2 fois la glande; style médiocre; stigmates courts et bifides. - Arbrissean de $1^{\text {in }}$ au plus, à rameaux très-fragiles. Pàturages élevés et humides des Ilautes-Aljes, des P'yrúnées. Flor., juin-juillet.

17. Saule arbuste. Salix arnuscula. Liv.

Feuilles lancéolées, ovales-lancéolées, dépassant rarement 5 centjmètres de long, garnies sur les bords de dents glanduleuses fines et rapprochées; tres-glabres, vertes et brillantes en dessus, plus ou moins glanques en dessous; stipules nulles ou tres-petites. Chatons cylindriques naissant un peu après les fevilles; les mâles subsessiles; les femelles pédonculés et feuillés à la base; écailles poilues; capsule ovoüle-conique, presrque sessile, tomenteuse; style allongé, plus ou moins profondément divisé; stigmates courts, ovales et bifides. - Pelit arbrisseau de $5-6$ décimètres, rarement $1 \mathrm{~m}$, a rameaux lisses, brillants, hruns, divergents dans tous les sens, garnis a leur extrémité de fenillét réunies en paquets. Ilautes-Alpes et Pyrénées. Flor., juillet. 
18. Sanle blenítre. SALIX Cesia. ViLL.

Feuilles petites, ovales ou lancéolées, aiguës, d'un vert blelı-glauque sur les deux faces, entières, un peu enroulées sur les bords, toujours très-glabręs ainsi que les bourgeons et les ramules; stipules développées sur les pousses vigoureuses. Chatons paraissant avec les feuilles, à peine pédonculés, feuillés à la base; ćcailles velues; les mâles, ovoïdesglobuleux; étamines à filets velus dans toute leur longueur et à anthères l'un brun pourpré; les femelles, ovoïdes, à capsules ovoïles-coniques, tomenteuses, presque sessiles; styles courts ou moyens, rarement plus longs que les stigmates, qui sont ovales, entiers ou bifides; les uns et les autres d'un rouge pourpre. - Arbrisseau alteignant $1^{\mathrm{m}} \mathrm{el}$ mème un peu plus, couché et très-rameux. Alpes du Dauphiné, Larche, BassesAlpes. Flor., juillet-août.

19. Gaule des Pyrénées. Salix pynenaïca. Gouan.

Feuilles de 3 centimètres au plus de longueur, elliptiques ou obovales-elliptiques, vertes et pubescentes en dessus, très-glauques et couvertes de poils soyeux hérissés en dessous, à la fin presque glabres, à bords ciliés, dentés-glanduleux à la base ou complétement entiers. Clıatons naissant arec les feuilles, supportés par un pédoncule très-allongé et largement feuillé à la base, nu et sans coloration extraordinaire at sommet; grêles, à écailles fauves ; les mâles, oblougs ; les femelles, cylindriques, à capsules ovö̈des-coniques, blanches-tomenteuses, presque sessiles; style plus ou moins profondément divisé, parfois jusqu'à la base; stigmates bifides, filiformes. - Arbrisseau de 2-3̈ décimètres, rampant, rameux; à rameaux grèles, étalés, d'un brun rougeâtre. Parties élevées de toute la chaîne des Pyrénées. Flor., juillet.

20. Saule myrte. Salix Mynsinites. Lin.

Feuilles elliptioues ou lancéolées, de $\bar{J}$ centimètres au plus de longueur, dentées-glanduleuses ou entières, concolores, vertes el luisantes sur les deux faces, fermes, glabres ou pourvues de longs poils soyeux peu abondants. Chatons paraissant avec les feuilles, portés sur un pédoncule très-long, largement feuillé à la base, nu et pourpré supérieurement; écailles noires; les mâles, presque cylindriques, à anthères violetles; les femelles, allongés et denses; capsule ovoïde-conique, courte, laineuse, presque sessile, d'un bleu-pourpré foncé; style allongé, ainsi que les stigmates, profondément bifides, linéaires. - Sous-arbrisseau de 5 décimètres, couché, très-rameux, à jeunes rameaux velus. La portion nue du pédoncule des chatons, l'axe de ces derniers, les pédicelles et la base des capsules sont d'un rouge pourpre. Hautes-Alpes, Pyrénées. Flor., juillet.

\section{$\S 2$. Feuilles densément couvertes en dessous de poils tomenteux ou soyeux.}

21. Saule glauque. Salix glauca. Lix.

Feuilles presque sessiles, lancéolées ou ellipliques, 5 fois aussi longues que larges, entières, longuement poilues-soyeuses sur les deux faces, verdâtres en dessus, glauques en dessous; stipules ordinairement nulles. Chatons cylindriques, paraissant après les feuilles, longuement pédon- 
culés, très-fenillés à la base ; étamines à filets bruns, barbus à la basc ; anthères d'un bleu violacé; chatons femelles à écailles velues et rosécs au sommet; eapsule ovoïde-lancéolée, tomenteuse, presque sessile; style court, généralement divisé jusqu’à la base, à stigmąles bifides ou échancrés. - Petit arbrisseau de 4-7 décimètres, à ramificalion trèsserrée, diffuse; à rameaux bruns, brillants et glabres, les plus jeunes blancs-tomenteux. Hautes-Alpes et Pyrénées. Flor., juillet.

22. Saule des Capons. Salix Laponum. Liv.

Feuilles allongées-élliptiques, entières ou légèrement denticulées; velues-soyeuses sur les deux faces ou au moins sur l'inférieure, dans la jeunesse; vertes ct crépues en dessus, blanches-tomenteuses et opaques en dessous, dans l'âge adulte; pétiole et nervures d'un brun rouge. Chatons paraissant avec les feuilles, sessiles d'abord, puis légèrement pédonculés et munis de quelques petites feuilles, seulement à la base; à écailles très-velues; les mâles, ovö̈les-allongés; les femelles, cylinulriques, gros, assez denses; capsule ovoïde-lancéolée, tomenteuse, rarement glabre, sessile ou médiocrement pédicellé; style allongé ; sligmates linéaires, bifides. - Sous-arbrisseau très-peu élevé, rameux, rabougrri et tortueux. Marais tourbeux, bords des ruisseaux et des lacs dans les Monts-Dores et le Cantal. Flor., mai-juin. Fructif., juillet.

\section{SEction VIII. Glacials.}

Cliatons terminaux, pédonculés et feuillés. - Sous-arbrisseaux rampants et se marcottant naturellement, s'élevant au plus de quelques décimètres au-dessus du sol; parfois à peine ligneux. Régions montagneuses les plus élevées, jusqu'à la limite des neiges perpétuelles.

\section{Saule réticulé. Salix reticulata. Lin.}

Feuilles longuement et brusquement pétiolées, suborbiculaires, arrondies au sommet ou légèrement échancrées, entières, d'un vert foncé el crépues en dessus, très-glauques, argentées et réticulées en dessous; d'abord légèrement pubescentes ou velues, finalement glabres. Cliatons all sommet d'un long pédoncule nu, à écailles velues; les màles ovoïles, allongés, à anthères noires; les femelles, cylindriques el grêles; capsule ovoïde, tomenteuse, presque sessile; style très-court; stigmales bifides. - Petit sous-arbrisseau étalé, couchí, de 1-2 décimétres de hautcur, à rameaux velus dans la jeunesse. Alpes et Pyrénées. Flor., mai-juin. Fructif., juin-juillet.

24. Gaule émoussé. Salix netusa. Lin.

Feuilles presque sessiles, obovales ou spatulées, à base cunéiforme, à sommet arrondi, obtus ou échancré; entières ou très-légèrement denticulées-glanduleuses à la base, très-glabres, vertes en dessus, plus claires et réticulées en dessous. Chatons légèrement pédonculés et feuillés à la lase, oblongs; les mâles, à écailles ciliées, à anthères pourpres; les femelles, laches, à écailles glabres; capsule ovoüde-conique, glabre, à pédicelle 2 fois plus long que la glande; style court; stig. 
mates filiformes, bifides. - Arbrisseau à tige noueuse, rampante, à rameaux se marcottant naturellement, à racines drageonnantes; feuillage serré, ahondant; ne s'élevant pas au delà de 2-5 décimètres. Jura, Alpes, Pyrénées. Flor., juin-juillet. Fruclif., juillet-août.

25. Saule herbacé. Salix inerbacea. Lin.

Feuilles ovales ou orbiculaires, obtuses ou légèrement échancrées à la base el au sommet, denticulées, glabres, verles et luisantes sur les deux faces. Chatons pauciflores, courtemeut pédonculés, munis à la base de 1-2 feuilles bien développées; écailles glabres; capsule ovoïde-conique, presque sessile; style court; stigmales bifides. - Très-petit sous-arbrisseau à tige souterraine rampante, émettant des rameaux presque complétement herbacés, dont la partie extrème seule perce le sol. IlautesAlpes, Pyrénées, Monts-Dores en Auvergne. Flor., juin-juillet. Fruct., juillet-août.

\section{genne 2. - PEUPLIER. POPULUS. Tournef.}

Chatons solitaires, provenant de bourgeons latéraux, parfois terminaux et mixtes, jamais feuillés à la base, paraissant toujours avant les feuilles, finalement pendants; composés d'écailles incisées sur les bords, dont clıcune supporte un pérygone calycinal cn forme de coupe ou de cornet, $\$-30$ étamines ou un ovaire libre, à stigmates presque sessiles, au nombre de 2-4, diversement découpés, étalés, enroulés. Capsule 2-4-valve, polyssperme. - Arbres le plus souvent de grande taille, à feuilles généralement aussi larges que longues, longuement pétiolées, à anthères rouges et à bourgeons revêtus d'un assez grand nombre d'écailles imbriquées, spiralées. Très-voisins des saules par leurs exigences, leur distribution, leurs qualités.

Bois identique à celui des saules; cependant vaisseaux généralement moins fins, plus fréquemment réunis, 2-7, en petites lignes rayonnantes ou obliques et entourés de parenchyme ligneux (non apparent à l'oil nu); taches et veines du tissu cellulaire brun nulles ou presque nulles.

A. Feuilles lobées ou sinuées-dentées; 8 étamines; écailles des chatons poilues. Ecorce lisse, d'un gris verdâtre, se crevassant assez tard sous forme de pustules en losange.

B. Feuilles grises ou blanches-tomenteuses en dessous; bourgeons secs, poilus.

C. Feuilles souvent palmatilobées ou fortement échancrées-dentées, blanches-tomenteuses ainsi que les jeunes pousses; stigmates bilobés.................. P. вLanc........ 1 
C'. Feuilles sinuées-dentées, jamais palmatilobées, grises-pubescentes ou tomenteuses en dessous, ainsi que les jeunes pousses; stigmates \&lobés................. P. grisathe.......2

$B^{\prime}$. Feuilles pubescentes ou velues, finalement glabres, sinuées-dentées; bourgeons visqueux, à écailles ciliẻes................... P. тREMnLE....... 5

A' Feuilles finement et régulièrement dentées, glabres; $12-50$ étamines; écailles des chatons glabres; bourgeons glabres et visqueux. Ecorce se gerçurant longitudinalement et de bonne heure, comme celle des chênes.

B. Jeunes pousses arrondies; capsules ovoïdes, bivalves (Peupliers de l'ancien monde).

C. Cime ample; branches étalées. ... P. xorn......... \&

$\mathbf{C}^{\prime}$. Cime étroite, allongée; branches apprimées...............

B'. Jeunes pousses anguleuses; capsules globuleuses, 3-4-valves (Poupliers américains).

C. Feuilles à base souvent cunéiforme, pourvues de quelques poils seulement sur les bords, à glandes nulles ou petites; stigmates sessiles, appliqués et enroulés en dessous sur l'ovaire, à base relevée en une forte proéminence........... P. DE Vingrie.....6 6

C'. Feuilles à base droite on légèrement rentrante, densément bordées de très-petits poils raides; pourvues à la base du limbe de 2 glandes jaunàtres bien développées; stigmates pédicellés, élargis, redressés, non enroulés.............

P. pymanidal...... y

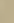


moins verles et glabres par la chule du tomentum; celles des pousses robustes et des jeunes rejets palminerviées, à 5 lobes, rappelant les feuilles des érables. Chatons mâles cylindriques, à écailles crénelćes, ciliées; 8 étamines; chatons femelles grểles, à écailles dentées et ciliées; capsule ovoïde, glabre, bivalve, à stigmates allongés, linéaires, bilobées. - Grand arbre à écorce lisse et unie, grise ou gris-verdâtre jusqu'à un âge assez avancé, puis se crevassant en pustules sous forme de losanges, qui s'allongent de plus en plus et produisent des gerçures en se réunissant; branches étalées, ranules blancs-tomenteux dans la jeunesse, bourgeons dressés-étalés. Sols légers et frais, an bord des fleuves et des rivières; se trouve quelquefois dans les forêts; très-fréquemment planté Toute la France; Corse el $\mathrm{A}$ ggérie. Flor., mars-avril. Fructif., mai.

Le peuplier blane est un grand et bel arbre d'une végétation rapide, qui peut alleindre, en 40 ans, sous des cilconstances favorables, une hauteur de $26-55^{\mathrm{m}}$ et un diamètre de $2^{m}$; avec l'àge, il va jusqu'a $5^{\mathrm{m}}$ de diamètre. La tige, droite, cylindripue, nue, supporte une cime ample, ovale-conique, assez fournie, d'un couvert moyen. Les racines, traçantes, superficielles et très-longues, drageonnent comme celles de tous les peupliers; elles produisent en bois, y compris la souche, coupée à 0,15 du sol, $16-18 p .00$ du volume total.

La fécondité du peuplier blanc est considérable, régulière, annuelle, mais les graines sont rarement de bonne qualité et demandent à ètre semées de suite. Le jeune plant lève au bout de $8-10$ jours avec 2 très-petits cotylédons semi-ovoïrles et atteint, dès la première année, 1 b̆-20 centimètres de hauteur dans des circonstances ordinaires, 50 centimètres dans les circonstances très-favorables; à partir de ce moment, la végétation en devient très-rapide. Au surplus l'extrême facilité avec laquelle le peuplier blanc et tous les peupliers indigènes se reproduisent de boutures et de plançons dispense de recourir au semis pour les multiplier.

La feuille, remarquable par son extrème blancheur en dessous, surtout sur les rejets et sur les pousses les plus élevées, perd quelque?́nis sa vestiture sur les vieux arbres, lorsqu'elle est tout à fait adulte; elle devient alors verte ot glabrescente on méme entièrement glabre. La forme palmati-quinqué-lobéc se maintient parfois et caractérise la variété que les pépiniéristes appellent peuplier à feuilles d'érable (Populus nivea. Willd.).

Le bois du peuplier blane est léger, mou, flexible, hlane, coloré et veiné au coeur de jaune-brunàtre clair ; son homo-

Taille. Port.

Enracinement.

Reproduction.

llFeuiage.

Bois. 
sénité lui permet de se dessicher sans se fendre, parce que fe retrait en est uniforme dans toutes les parties. Il cst généralement exempt de noends ot de taches médullaires et il offre des accroissements épais, riguliers, circulaires, concentriques. Du bois de tige de 25 ans et de $0^{\mathrm{m}} 5 \bar{\jmath}$ de diamitre, venant de Yaney, pése, complétement desséché à l'air, 0,416. Celui d'Ngérie est intiniment plus dense et peut alteindre le chiffie de 0,7:3. (Coll. Er. For. Envoi de M. Royer.) Ce hois est recherehé en menuiseric pour boiseries, en ébénisteric pour charpente des meubles, en charronnage pour panneaux et coffres de voitures; les tourncurs, sculpteurs, layeticers en font aussi une grande consommation. Ses bonnes (qualités pour un bois blane, ses grandes dimensions et sa rareté dans les foréts empeichent de l'employer comme combustible. Il doit, à cet igard, équivaloir au tremble.

Produits accessoires.
L'écoree contient du tannin, mais en moindre proportion que relle des saules, $\bar{\jmath}$ p. 0,0 environ; on y trouve aussi de la salicine.

\section{Peuplier grisaille. Popuzus canescens. Surt. Grisard.}

Espèce très-variable, intermédiaire entre le peuplier blanc et le peuplier tremble el probablement leur hybride. Fenilles ovales, suborbiculaires, sinućes-anguleuses ou crénelées, jamais glandulcuses sur les bords (elles le sont dans te peuplier blane et le peuplier tremble), vertes en dessus, grisâtres, plutòt pubescentes que tomenteuses, en dessous; finalement glabrescentes; celles des rejels ou jeunes pousses robustes plus ou moins cordiformes à la base, acuminées au sommet, ovales ou

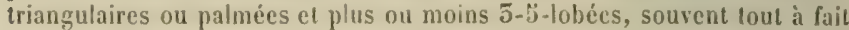
blanches-tomenteuses en dessous. Chatons femelles plus fournis que ccux du peuplier blanc, à écailles plus profondément divisées; chacun des deux stigmales palmati-quadrilobé. - Arbre moins élevé que le peuplier blane, à écorce semblable, à jeunes pousses grisâtres-pubescentes. Disséminé sur le bord des canx, parmi les peupliers blanes et trembles, en Alsace et dans le centre de la France; rarement cultivé. Flor., marsavril. Fructif., mai.

Srctiox II. Fenilles is contour assez régulierement simucrencle, pubescentes ou mollement velues dans la jeunexse, fimulement glubres; bourgeons visquentex, glabres (des cils seulement au bord des écailles); 8 étamines; ricralles barbues; érore romme doms la section meicedevele.

:3. EPearifier 1remhle. Populus tnemula. LIN.

fieuilles ì pétiole longr, grêle, ap̧lati perpendiculairement au limbe, 
qui, par suite, est pendant et presque loujours en mouvement; suborbiculaires, fortement sinuées-dentées, mollement pubescentes dans la jeunesse, glabres, vertes, non luisantes et presque concolores sur Ics ileux faces plus tard; celles des jeunes rejets très-différentes, souvent 2-6 fois plus grandes, brièvement péliolées, cordiformes à la base, ovales-acuminées, crénelées ou dentées, grises-veloutées en dessous el même en dessus, dc consistance très-herbacée. Chatons cylindriques, à écailles profondément incisées, lonğnement el densément barbues; fleurs mâles à 8 élamines; les femelles à capsule ovoïde, glabre; stigmates bifides. - Arbre de moyenne taille, très-commun dans toutes les forêts, dans toutes les situations, à tontes les expositions et dans tous les sols, si ce n'est dans le midi où on ne le rencontre ni dans les Pyrénées, ni en Corse; il se retrouve néanmoins en Algérie.Flor., mars-avril. Fructif., mai.

Le tremble est, de tous nos peupliers, celui qui présente les moindres dimensions; vers $50-60$ ans, ecpendant, il peut parvenir à $2 \tilde{2}-27^{\text {m }}$ de hauteur et à $1^{\mathrm{m}}{ }^{\mathrm{b}} \mathrm{0} 0$ de circonférence. La tige est cylindrique et revètue d'une écoree gris-verdàtre, qui se maintient lisse et vive pendant longtemps, puis ensuite se crève sous forme de pustules rhomboïdales, conme celle du peuplier blane. La éme, peru étendue et peu fournie, est composie de hranches horizontale: ct d'un petit nombre de rameaux toruleux, peu allongés et peu effilés. C'est la seule espèce véritablement forestière du genre.

Le feuillage, très-mobile, ì limbe vertical, ne produit qu' un couvert léger; malgré cela, la rapide croissance dans la jeunesse et l'abondance de ce peuplier le rendent presque tou$\mathrm{j}$,urs fort incommode dans les forets el, si l'on n'intervenait, il deviendrait très-préjudiciable aux peuplements des essences importantes.

Les graines du tremble, cependant, ne sont pas de meilleure qualité que celles de's autre's peupliers et ne paraissent pas jouer le róle principai dans la rapide propagation de cette essence; mais les racines tracent et drageonnent au loin et présentent, à cet égard, une particularité remarquable. Il cxiste, sur toute lemr Inngueur, des exrroissances formées de nombreux hourgeons à l'ćlat d'oil dormant, gui constituent des broussins ou sortes de tubereules sonterrains et demeurent, longtemps après que l'arbre a été exploité, le siége d'une certaine vie passive, s'étendant sur des portions avoisinantes ylus on moins considérables de la racine, tandis que tout le reste pourrit papillement. Ces petits centres vitaux, deveuus de la sorte indiépendants,

Taille. Port.

Convert.

Reproduction. 
peurent se maintenir de fongues anne's vivants, mais innerils, an moins extéricurement ; puis, quand des cireonstances firorables surviennent, leurs bourgeons dormants se réreillent et de nombreux drigeons peuplent le sol aree rapidité, quoique souvent, depuis longtemps et sur de grandes élendues, il nexiste plus de vieux arberes de l'espèce. Toutefois, il faut ajouter que la vigneur extraordinaire de ees dragreons, dont les feuilles sont trés-différentes des feuilles normales, est rapidement épuiséc et que rarement ils donnent des brins de belles dimensions.

Station. Sol. Le tremble, contrairement aux autres peupliers, vient dans les plaines comme sur les hautes montagnes, sur les sols frais et légers comme sur ceux qui sont sees et mème compactes; cependant sa croissance est cutraréc par ces derniers, tout comme par une altitude élevée.

Bois. Le bois du tremble est, parmi ceux de ce genre, celui qui a les raisseatux les plus fins ; los accroissements en sont cilculaires, de moyenne éparisseur' il est blane, peu ou point coloré au coeur et il présente souvent de petites lames rayonnantes ou concentriques de tissu médullaire brun ou b) lane; par un commencement d'altération, qui s'olsecrve fréquemment, il se tache largement en noir blenatre clair. Les dimensions, habituellement faibles, car rarement on lui laisse atteindre celles quil comporte, en restreignent l'emploi au chauflage. Il est à cet égard recherehé pour les boulangeries.

Valeur calorilique el densilé.

Des expériences de T. IIartig sur la puissance calorifiçue du hois de tremble de $6 \ddot{3}$ ans et d'une densité de 0,47 , comparé à du hètre de 80 ans et d'une densité de 0,79 , ont donné, l'un et l'autre étant également desséchés à l'air, les chiffres suivants :

\begin{tabular}{|c|c|c|c|}
\hline & & Poids égaux. & Vol, igzux. \\
\hline Plus lian degré de chalcur.... & & $96:$ & $37: 1$ \\
\hline & & !1: & $\$ 1,1: 100$ \\
\hline & & 100 & $39,5:$ \\
\hline Duréc le la c & & $115:$ & $68,4: 100$ \\
\hline & ie & $86:$ & b1,1: \\
\hline Tol: & & 96 & \\
\hline Eall & ante & & \\
\hline
\end{tabular}

La presinteur du tremble varie de 0,76-0,66 lorspunil est 
vert, de $0,56-0,44$ desséché à l'air, et de $0,400-0,57$ complétement desséché à l'étuve.

La comparaison de tous ces chiffres, avec ceux analogues concernant les autres peupliers, établit que le hois de tremble est le plus lourd et le meilleur combustible de tous ceux du genre.

La puissance calorifique du charbon de tremble est à celle dur charhon de hètre, pour des volumes égaux, comme $61,8: 100$ (Werneck). blanc.

L'écorce a les múmes propriétés que celle du peuplicr

Sectiox III. Fénilles régulièrement el peu profondément dentées, glabres el concolores sur les 2 faces ou à peu mrès; bxurgeons glabres, visqueux; écailles des chatons glabres; 12-20 étamines. Ecorce se gerrurant de bome heure longitudinalement el formant un rhytidome dans le genre de celui des tilleuls.

\section{$\S I$. Jeunes pousses arrondies; capsules ovoïdes, bivalves.}

4. Peuplier noir. Populus ngra. Lin. Pelplier franc; Léard; Liardier; Bouillard (France centrale).

Feuilles un peu plus longues que larges, triangulaires, acuminées; coupces droit, légèrement cordiformes ou obtusément cunéiformes à la base; régulièrement dentées à partir du pétiole, entièrement glabres, vertes, luisantes et presque concolores sur les 2 faces. Chatons cylindriques, denses, à écailles frangées-laciniées; 2 stigmales bilobés, subsessiles. - Grand arbre à branches étalées, à cime ovoïde-conique et à écorce gerçurée; bourgeons exactement apprimés contre le rameatl. T'errains légers et humides, le long des cours d'eall; particulièrement abondant sur les bords du Rhin; souvent planté. Flor., mars-avril. Fructif., mai.

Le peuplier noir est un sorand arbre, d'un port généralement irrégulier, qui, en 40-50 ans, parvient is une hauteur de $20-23^{\mathrm{m}}$ et à un diamètre de $0^{\mathrm{m}} 63$ et mème plus. Un arbre de cette espèce, planté au Jardin botanique de Dijon mesure $12^{\mathrm{m}}$ de circonférence a $0^{\mathrm{m}} 50$ du sol, $57^{\mathrm{m}}$ de hauteur ; il est estimé à $\dddot{3} 3^{m . c}$; l'ige en est d'environ 4010 ans. La cime est généralement tris-ample, composéc de branches nombreuses, étalées, ramifiées, sc terminant en rameaux abondants, allongés et grèles; clle est mierux fournie que celle du peuplier blane et du peuplier tremble et donne un cou- 


\section{$5 \overline{5} 4$}

SALICINÉES.

vert plus complet. Cet arbre s'enracine et drageonne comme tous les peupliers et a une tendance prononcée à se garnir de branches gonourmandes. Plus soutvent cultivé que spontané, il est très-ajpte à ètre exploité en tètards et par émondage.

Bois. Le bois du peuplier noir est mou, poreux, blane, veiné de noiratre an cour; les accroissements en sont considérables, assez exadement eirculaires ; mais il est fréquemment noneux, par suite de la tendanee de l'arbre à se garnir de branches gourmandes et du mode d'exploitation par émondinge qui lui est souvent appliqué. Il est moins estimé, d'un travail moins facile que celui du peuplier blanc.

Coupé rert, la densité est $0,66-0,76$; desséché à l'air elle est de 0,50 ; complétement sec, de $0,50-0,12$ (Th. Hartig.).

Valeur La puissance calorifique est à celle du hètre de 80 ans calorifique. daus les rapports suivants, pour des volumes égaux (G. L. Ilartig).

Puisssance calorifique absolue.........49:100

Plus haut degré de chaleur..........60 60 : 100

Durée de la combustion............... 50 : 100

Il est done à cet égard inférieur au tremble, supérieur au peuplier pyramidal.

Produits La résine qui enduit les jeunes bourgeons produit l'onaccessoires. guent connu en pharmacie sous le nom de Populeum.

Les levilles, donneses en vert ou en sec, forment un bon lourrage pour le bétail; ceci s'applinge du reste a presque tous les peupliers.

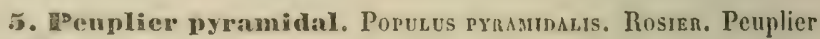
d'llalie.

Feuilles semblables à celles du peuplier noir, cependant en général aussi larges que longues ( $\boldsymbol{P}$. dilutala. dit. $\boldsymbol{K}$ cov.). Fleurs sembiables. - Arbre très-élevé, dont la tige, prolongée jusqqu’à l'extrémité, est garnic presque dès la base de branches el de rameaux relativement faibles, dressés, formant une cime longrue, étroite, pyramidale; bourgeons exactement apprimés contre le rameau. Planté le long des caux el des roules; originaire d'Orient. Flor., mars-avril.

Taille. Port. Le penplier pyramidal, si facile à distinguer par le port, est $111 \mathrm{anl}$ )re l'une vémitation rapide, (pui, co $50-4.0$ ans, atteint une hamear de $5.5^{\mathrm{m}}$ et une circonférence de $2^{\mathrm{m}}$. La tige en est fortement rannclece a lat base et garnic de branches sur presque toute sá longueur. 
Originaire du Caucase et de la Perse, il fut npporté d'Italic en France en 1749; c'est de là que lui vient le nom vicieux de peuplier d'Italie, sous lequel il est fréquemment désigné. Pendant longtemps l'on n'en a connu que des pieds mâles, les seuls encore que l'on troure en France dans les plantations, et leur multiplieation, très-facile d'ailleurs, ne s'est jamais npérée que par boutures. On connait maintenant les pieds femelles; leurs branches s'écartent en ligne droite de la tige sous un angle de $50-40^{\circ}$ et leur cime n'est pas aussi étroitement pyramidale que celle des pieds mâles.

Il pourrait bien se faire que la ramification si remarquable de eet arbre ne füt point caractiristigue et que sa constance, dans nos pays, füt uniquement due au mode de propagation usité, la bouture. Dans ee cas, le penulier pyramidal ne serait qu'une varicté du peuplier noir, tout comme le chine pyramidal rest une varicté du chine pidonculé et le hetre parasol, une varicté du hètre des bois. Des semis que l'on sera en mesure de faire, maintenant que l'on posside des pieds femelles, décideront cette question.

Le bois du peuplier d'Inalie est tris-léger, très-mon, trèsporeux ; entre tous les congénères, c'est lui qui a les vaisseaux les plus gros. Il est blane, coloré de gris brun au coeur; les accroissements en sont ipais, irréguliers, flexueux et non circulaires; les nouls y sont abondants; c'est le moins estimé de tous ceux du genre. Néanmoins la multitule de petits noeuds qui s'y déreloppent par suite d'émondages répétés et le contournement des fibre's ligneuses qui en est la conséquence, produisent, par le poli, de jolis rffets qui rappellent ceux du bois madré d'érable et permettent à l'ébinisterie d'en tirer bon parti sous forme de placage, auquel il convient de laisser une notable épaisseur (4 mill.).

Dessché à l'ais, il pèse $0,5 \overline{3}$; complument see, 0.26 . La puissance calorifigue est à ceelle du hètre de 80 aus dans les rapports suivants, pour des rolumes égaux (G. L. Hartig):

Puissance calorifique absolue...... $59: 100$

Plus haut degré de chaleur........ 69:100

Durée de la combustion.......... 55 : 100

On a beaucoup exagéré autrefois les avantages le la culture du peuplier pyramidal et l'on a cru souvent que le peu

Valcur calorifique. 
d'ampleur de sa cime permeltrait d'en faire croitre, sur un espace donné, un nombre de pieds très-considérable. C'était la une erreur : ce peuplier demande beaucoup d'espacement, parce que, feuillé depuis la base, il ne lui suffirait pas de recevoir la lumière directe dans ses parties élevées seulement, comme cela arriverait s'il croissait en massif, et que, d'un autre còti, par ses fortes et longues racines traeantes, presque superficielles, il exige heaucoup d'étendue jour se développer. Ceue dernicre circonstance explique aussi pourquoi le peuplier pyramidal, planté en bordures le long des prés, exerce au loin une influence ficheuse sur la vérétation du fourrage, influence accrue par la chute de's leuilles, qui, avant de se translormer complétement en un principe fertilisant utile, nuisent à l'herbe parle tannin qu' elles contiennent et mettent en liberté. Considéré en lui-mème d'ailleurs, rien ne le recommande parmi ses congénères; il ne croit pas plus vite que d'autres espèces (P. blane, de Virginie, de Canada), les cannelures prononcées de sa base produisent un déchet notahle dans le débit, enfin le bois en est le plus noueux, le plus diffieile à travailler, le plus mou, le plus léger et le moins bon de tous pour le chauffage. Le principal avantage du peuplier pyramidal, e’est que planté le long des routes il y produit peu d'ombrage et n'y entretient pas la boue comme les arbres à cime ample et à couvert épais.

\section{$\$$ II. Jeunes pousses anguleuses; capsules arrondies, 3-4-valves; style à 4 stigmates.}

G. Peuplier de virumie. Porulus Virgnana. Desf. P. monilifera, .lich. Peuplier suisse; Peuplier du Canada; Penplier monilifère.

Feuilles plus larges que longues, triangulaires, coupées carrément ou souvent prolongées en angle droit ou aigu à la base, acuminces au sommet, à bords glabres ou munis de quelques poils seulement, régulièrement dentées et à dents rccourbées, vertes, luisantes et glabres; ylandes nulles ou peu apparentes à la base du limbe. Chatons à écailles profondément el étroitemeut lacérées; stigmates presque sessiles, euroulés en dessous à leur extrémilé, prolongés à la base en une éminence redressée. - 'T'ès-grand et bel arbre à cime ample, ovoïde-conique, à branches étalées, dont la tige est nue sur une grande hauteur, droite, cylindrigue et dout les bourgeons sont dressés, presque apprimés. Originaire de l'Amerique Septentrionale; très-fréquemment planté atix bords des routes. lilor., mars-avril. Fructif., mai.

Taille, port. Cét arbre, d'une végétation très-rapide, s’élève souvent à 
$40^{\mathrm{m}}$ et peut mesurer $5^{\mathrm{m}}$ de circonférence; la tige se dénude à une grancle hauteur el se ramifie en une cime régulière, ample, fournie, dont les rameaux extrèmes sont nombreux, anguleux et effilés, les bourgeons petits.

Le bois est blanc, parfois légèrement rougeâtre au cour, à couches épaisses, régulièrement circulaires; il n’est point noueux et parait réaliser les qualités du peuplier blane. Provenant d'une tige de 15 ans et de 0,25 de diamètre, il pèse, complétement desséché à l'air, 0,42. (Coll. Ec. For.)

A part l'ombrage et le couvert plus grands, cet arbre est de beaucoup préférable au peuplier pyramidal; il croit pour le moins aussi rapidement et fournit des produits bien meilleurs. Il n'exige pas aussi impérieusement des sols frais et réussit encore sur ceux qui sont secs, pourvu qu'il ne soient point compactes. On cultive surtout les pieds mâles.

3euplier de Canada. Popnlus canadessis, Micir. P. monili. fera. Ail. P. Virginiana. Lin.

Espèce souvent confondue avec la précédente et dont la synonymie est assez embrouillée. Se reconnaît aux feuilles généralement plus allongées, à base droite ou même rentrante, rarement saillante, dont les bords sont couverts de poils raides et courts que l'on ne peut voir qu'à la loupe; enfin, à 2 glandes jaunâtres bien développées, avoisinant le pétiole. Stigmates pédicellés, étalés-redressés, demi-circulaires ou sagittés, non enroulés et non prolongés à la base en une forte éminence redressée. - Arbre de même port que le précédent, à rameaux moins anguleux et de taille moins grande. Originaire de l'Amérique septentrionale; assez souvent planté en avenues. Flor., mars-avril. Fructif., juin.

Le peuplier de Canada paraît s'arrèter dans sa croissance plus tôt que le peuplier de Virģinie et, malgré l'identité entre les bois de ces deux espèces, il est d'une culture moins avantageuse; e'est sans doute parce qu'on ne sait pas le distinguer du précédent qu'on le plante encore assez souvent.

$\mathrm{Du}$ bois d'une lige de 16 ans et de $0^{\mathrm{m}} 21$ de diamètre pèse, desséché à l'air, 0,42 (Coll. Ec. For.).

On ne cultive habituellement que des pieds femelles.

Les feuilles du peuplier de Canada sont à peu près aussi riche en azote que celles des ormes (II. I. Pierre), bien que moins estimées comme fourrage, sans doute à cause de la présence d'un peu de matière résineuse; elles sont plus azotćes que celles du peuplier d'Italie. 


\section{FAMILLE LIII.}

\section{GNÉTACétes. Lindl.}

Floraison monoïque ou dioïque, amentacée au moins pour les màles. Axe des chatons mìles articulé dans sa longueur et présentant, à chaque articulation, des bractées opposées, 1-flores; chacpue fleur, formée d'un périgone tubuleux bifide et de 1-8 étamines monadelphes, à anthères 1-4-loculaires, s'ouvrant par des pores terminaux. Fleurs femelles verticillées le long d'un axe articulé et nues; ou géminées, rarement sulitaires, dans un involucre composé de plusicurs rangs d'écailles plus ou moins soudées entre elles; ovaire urcéolé, ouvert au sommet et non prolongé en stigmate, contenant 1 ovule terminé par un long tube stillant. Fruit bacciforme, dont la portion charuue est formée par les écailles de l'involucre, accrescentes et soudées entre elles. Graine périspermée, 2-cotylédonée. - Arbrisseaux ou arbres rappelant les prêles, à rameaux et ramules jonciformes, opposés ou verticillés, articulés, dont les feuilles sont le plus souvent réduites à l'état de petites écailles membraneuses, opposées-croisées ou verticillées-ternées.

Bois ì tissu fibreux dominant; vaisseaux égaux, fins, isolés, épars au bord interne, nuls au bord externe de chaque couche, qui est crénelée-rentrante au passage des rayons; ceux-ci assez minces, peu serrés.

genRe unigue. - EPHÉDRA. Tourn.

Chatons mâles à bractées opposées-croisces et connées à la base; fleurs femelles géminées, rarement solitiires, dans un involucre écailleux, accresceut, devcnaut charnu à la maturité et contenant alors 2 akènes ou parfois un seul.

Eplsédra commun. Ephedra drstachy. Lin. Uvelte; raisin-demer.

Sous-arbrisseau de 5-4 décimèlres de hauteur, à lige très-rameuse, recouverte d'une écorce membraneuse-fibreuse; à branches couchées, quelquefois radicantes, trè-flexibles; i rameaux opposés, articulés, verts, finement rugueux, pourvus de petites feuilles aiguës, soudées par la base en une gaine cylindrigue, rougeâtre. Fruil rouge, pulpeux, de la grosseur d'un pois, acidulé et comestible, contenant 2 noyaux plans sur une face, couvexes sur l'aulre. Bords de la Médilerranée el de l'Océan, France el Algérie; très-propre à consolider les sables des dunes par ses racines traçantes el drageonnautes. Flor, mars-juin. 


\section{SOUS-DIVISION II.}

\section{DICOTYLÉDONÉES GYMNOSPERMES.}

Fleurs unisexuées, nues, amentacées; feuilles carpellaires ne se reployant pas pour former un ovaire ent restant à l'état d'écailles planes, à la face interne desquelles sont deux ou plusieurs ovules nus. Fruit presque toujours composé, galbule ou còne, rarement simple et charnu ; graine périspermée, à embryon di-multi-aotylédoné.

Bois uniquement formé de fibres et de rayons médullaires, contenant souvent des canaux résiniféres, toujours dépourvu de vaisseaux et de parenehyme ligneux. Feuilles 1-5nerviées, très-genéralement allongèes-linéaires (aiguilles) et persistantes (arbres verts); sues propres le plus souvent formés de térébenthine (arbres résineux).

\section{ORDRE VII.}

\section{CONIFÈRES.}

Mêmes caractères que ceux de la division.

Le bois des conifères est d'une structure très-simple et consiste uniquement en tissu fibreux d'une nature particulière (fibres ponctuées-aréolées) et en rayons médullaires, toujours minces et courts; il manque de fausses trachées et de parencliyme ligneux. Malgré celte uniformité de composition, les accroissements y sont généralement bien marqués, parce que les fibres du tissu d'autımne sont beaucoup plus petites, plus serrées, plus épaissies, plus lignifiées et plus colorées que celles du tissu de printemps.

Les conifères contiennent généralement un suc propre, la térébenthine, qui est un mélange d'essence de ce nom et de résine ou colophane. Quoique ce produit ne leur soit pas spécial et se retrouve dans d'autres familles du règne végé-

Térébenthine. 
tal, les térébinthacies, par exemple, qui lui ont emprunté leur nom, e'est chez lés conilères qu'il est le plus abondamment répandu et e'est d'eux qu'on le retire habituellement.

La térébenthine offre, suivant les espèces qui la fournissent, des proportions différentes d'essence et de résine; elle est par conséquent de consistance plus ou moins fluide ou visqueuse. Tantòt elle est contentte dans la régrion corticale seulement (sapin, cèdre), tantôt elle se trouve dans la rígion corticale et dans la région ligneuse (pins, mélèze, épicéa). Dans ce dernier cas, e’est dans l'aubier qu'elle est le plus fluide et qu'elle circule avec le plus d'ahondance; dans te bois parfait elle se trouve généralement à l'état de résine concrète, qui assure aux bois une durée ennsidérable et une puissance calorilique élevéc, supćrieure à celle que la densité pourrait faire présumer.

Réservoirs résinifères.

Les procédés d'extraction de la térébenthine présentent, suivan les espèces, des différences importantes, qui reposent naturellement sur la répartition des réservoirs qui la contiennent. Il est done utile d'entrer dans quelques détails à leur sujet (1).

Ces réservoirs consistent toujours en cavités circonscrites par une couche simple ou multiple de petites cellules étroitement unies entre elles et secrétant de la térébenthine qu'elles versent dans la cavité centrale. Suivant qu'ils sont sous forme tubuleuse ou élargis à peu près dans tous les sins, ils prennent le nom de canaux ou de vacuoles résinifères.

Les canaux résinifêres se distinguent, d'après leur direction, en canaux longitudinaux ef en canaux rayomants. On reconnait leur présenee, parce fue, sur une section qui leur est perpendienlaire, on voit suinter de leur orifiee une gouttelette de térébenthine; lorsuguils appartiennent is des organes àgés, au bois parfiat, par exemple, ils se distinguent aisement par la coloration brune que leme donne la résine qui s'y est amassée.

(1) Voir l'arlicle de M. IIugo Mohl. Bolanische Zeitung, nos 39, 40,1859 . 
Les canaux longitudinaux se tronvent soit dans l'écorce seulement, soit dans l'écoree et dans le bois.

Les canaux longitudinaux de l'écoree, d'abord droits, deviennent légèrement flexucux avec l'âge et, en se réunissant parfois les uns aux autres, au nombre de 2-4, produisent à leur jonction une eavité dont les parois se rompent tòt ou tard sous la pression de la térébenthine qui s'y accumule, de sorte qu'elle se transforme en une lacune irrégulière qui soulève au-dessus d'elle, sous l'apparence d'ampoule, le périderme superficiel (sapin). Ces canaux résiniferes ne se trouvent jamais que dans le parenchyme vert, dont ils subissent le sort, se desséchant de très-honne heure ou se maintenant actifs pendant un temps plus ou moins prolongé, suivant que la vitalité de cette zone corticale est fugitive ou persistante. En tout cas, ils s'y rencontrent toujours à l'origine et ils y sont disposés en un ou en plusieurs rangs concentriques.

Les canaux longiludinaux du bois sont épars dans chaque couche et apparaissent sur la section transversale sous forme de petit trous ou de ponctuations mates et blanchâtres dans l'aubier, de points rougeâtres dans le bois parfait, où ils sont obstrués par la résine. On les distingue aisément des vaisseaux des bois feuillus par l'ordre inverse suivant lequel ils sont répartis : nuls dans le bois de printemps ils deviennent de plus en plus nombreux de la zone médiane a la zone externe. De leur nombre et de leur grosseur dípend la quantité de térébenthine que le bois renferme; ils unanquent complétement dans certaines espèces (sapin, cèdre), sont pelits et rares (épicéa) ou nombreux et gros (pins et mélèze) dans d'autres.

Les camanx rayomants occupent le centre de certains rayons, plis épais que les autres, et traversent le bois et la partie active du liber; leur présence est subordonnée à celle des canaux longitudinaux de la région ligneuse.

Le diamètre en est très-petit tant qu'ils sont compris dans le bois et rarement on peut les distinguer à l'oeil nu ou mêne avec la loupe; mais parvenus dans le liber ils se dilatent beaucoup et s'y accroissent, surtout en largeur, à mesure que l'arbre vieillit.

Les vacuoles enfin sont des cavités éparses, sans relation avec les canaux, qui s'organisent au bout de quelques années, d'abord dans le parenchyme vert cortical, puis de 
proche en proche jusque dans les couches internes du liber; très-petites et globuleuses à l'origine, elles s'accroissent avec l'àge et prennent une forme lenticulaire. On ne les observe que dans quelques écorces (mélèze, pin Weymouth, cembro, à crochets).

La térébenthine peut se trouver en dehors des organes résinifères; son exurème abondance, qui est en raison inverse de la production ligneuse, la force à s'infiltrer à l'extérieur, dans le tissu fibreux du bois, dont elle incruste les parois et obstrue les eavités. Un ralentissement d'accroissement, un état morbide, favorisent puissamment celtc infiltration et concourent à rendre le bois plus résineux; sourent elle est telle que celui-ci, complétement pénétré, devient dur et translucide comme de la corne et se nomme bois gras.

Influence du mode de végitation sur la qualité du bois.

L'activité de végétation des ronifères se manifeste par une plus grande production du bois de printemps, dont la proportion s'aceroit pendant que celle du bois d'automne reste à peu près constante; il résulte de la que les bois de cette famille qui ont crú rapidement sont en plus grande partie formés de tissus mous et légers, qui fréquemment représentent les $\frac{1}{5}-\frac{5}{6}$ de leur volume, tandis que ceux qui ont poussé avec lentcur offrent heaucoup de bois d'automne, parfois plus de la mnitié. Si l'on se rappelle, en outre, que les canaux résinifères longitudinaux manquent dans le bois de printemps ef deviennent abondants dans celui d'automne, que de leur nombre dépend la proportion de la térébenthine, qu'enfin l'infiltration de la résine dans les tissus s'atgmente avec la faiblesse des aceroissements, il deviendra évident que plus les résineux se développeront avec lenteur, que rela résulte des conditions sous lesquelles ils vivent, de leur àge avancé ou du résinage anquel on les soumet, plus leurs bois seront lourds, durs, résistants et moins ils seront sujets à la pourriture.

It doit ètre entendu que cette riggle ne s'applique qu’à des bois de mème espéce et nullement à ceux d'espèces différentes; que par exemple le pin maritime, malgré l'épaisseur considérable de ses aceroissements sera toujours phlus dense et plus résineux que le pin cembro dont la végétation est très-lente; qu'en outre, pour les premiers cette règle n'en détermine pas seule la qualité; qu'elle peut ètre modifiéc par d'autres circonstances et principalement par le 
climat, de telle sorte qu’i égalité de croissance les boiș du Nord seront moins denses que ceux de mème espèce de provenance méridionale.

Il faut enfin ajouter que si la densité, la résistance, la durée doivent ètre recherchées chez les résineux employés aux constructions et au chauffige, ee ne sont pas les seules qualités que puissent offrir ces bois. La légéreté, l'homogénéité, la finesse et la rectitude de la fibre, l'égalité et la minceur des accroissements leur donnent aussi souvent beaucoup de valeur pour la menuiserie, la boisselleric, la fabrication des instruments de musique, des jouets, etc., ete.

Ces considérations amènent naturellement à cette conclusion : e'est que s'il est vrai qu'on doive pour le moins autant se préoceuper de la qualité que de la quantité des produits, il faut se garder de eultiver les conifères en dehors de la région dans laquelle chaque espèce atteint toutes ses qualités, alors même qu'clle y prospère et s'y développe, parfois avec bien plus de vigueur que dans sa station naturelle. C'est ce qui est souvent arrivé pour l'épicéa introduit dans des régions trop basses, pour le cèdre et surtout le mélèze transportis de leurs hautes montagnes dans les plaines, les collines ou les montagnes peu élevées, pour le pin IVeymouth qui, des climats rudes de l'Amérique du Nord a été naturalisé dans les rígions plus tempérées de l'Europe. Tous ces arbres, dans ces nouvelles conditions, se sont en général aecrus avee une rapidité semaryuable, mais l'abondance de leurs groduits a ité fort loin de compenser la perte de la plupart de leurs qualités.

Les feulles des conifères, que l'on appelle aussi aiguilles, sont snuvent marquées de lignes blanches ou cendrées, résultant de l'arrangement, en séries linéaires rapprochées, de très-nonibreux stomates, qui apparaissent sous forme de petits points blanes. Cetle richesse en stomates assure aux conifêres une nourriture atmosphérique abondante et leur permet en général d'êre peu exigeants à l'égard du sol.

L'embryon est toujours placé an centre d'un périsperme féculent-oléagincux; lorsqu'il se développe par la germination, il pousse hors de terre ce périsperme aminci ct encore recouvert de l'épisperme de la graine, et ses cotylédons y restent enfermés et réunis par leurs extrémités comme dans

Stomates.

Germination. 
une coiffe. Peu à peu, néanmoins, ils se dégagent et, devenus tout a fait libres, ils forment les premieres feuilles du jeune plant.

Ramification.

Les conifères n'ont que peu de propension à former des bourgeons et fréquemment ils n'en organisent d'axillaires qu'aux fenilles du dernier tour de spirale d. chaque pousse, à la base du bourgeon terminal. De là résucie une ramifieation sourent régulière, composée de verticilles, dont le nombre donne le moyen d'évaluer rapidement l'àge des arbres.

Inaplitude ì repousser ile souches.

Puisque la ramification verticillée est tlue au manque presque complet des bourgeons axillaires, il s'en suit que lis conifures qui la présentent n'ont point de bourgeons proventifs et que, impuissants à organiser les bourgeons normaux, ils peuvent bien moins encore en produire d'adventifs : privés de bourgeons proventifs et adventifs; ils ne repoussent pas de souches. 


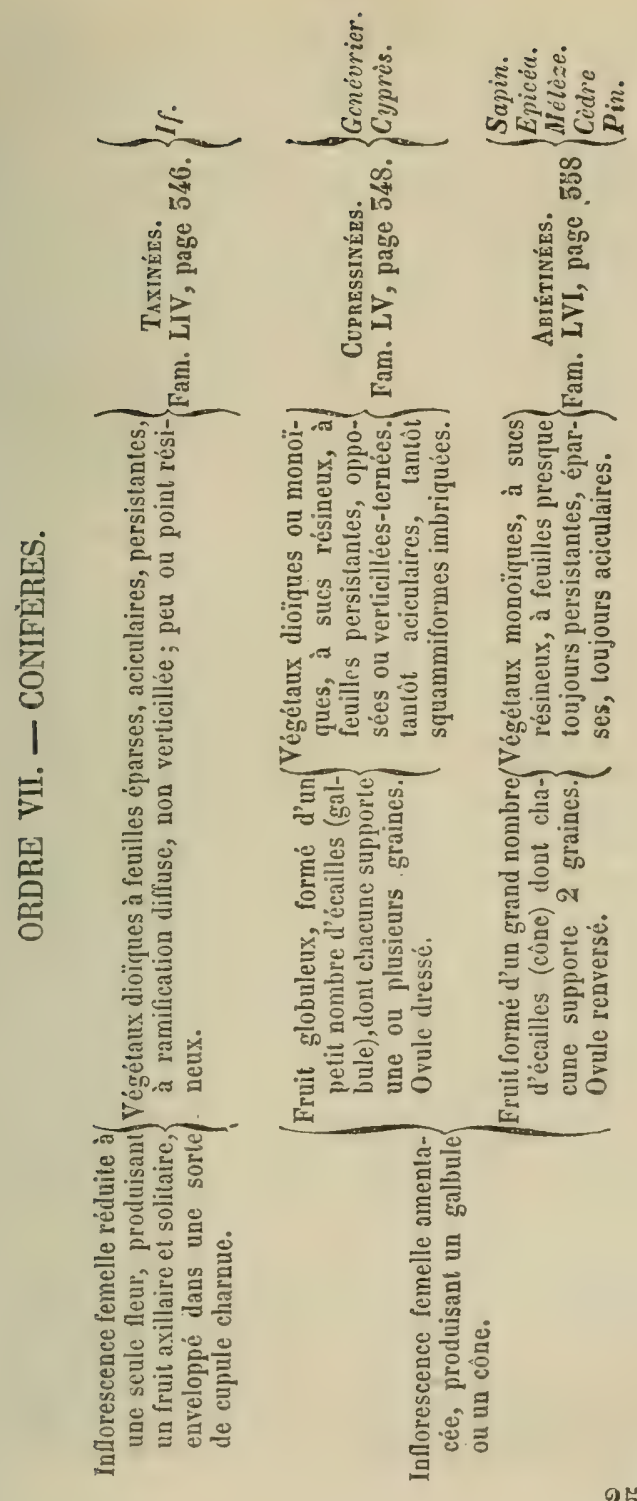




\section{FANILLE LIV.}

\section{TAXINEES.}

Floraison dioïque. Inflorescence mâle accompagnée ì la base de quelques écailles et représentée par un petit chaton solitaire, axillaire, composé d'un axe et d'étamines entièrement nues, dont chacune représente une fleur. Inflorescence femelle également précédée de quelques écailles et réduite à une fleur unique, axillaire, formée d'un seul ovule dressé. Fruit à enveloppe charnue, cupuliforme ou péricarpoïde, due au développement d'un disque? ou de la primine de l'ovule? - $\mathrm{Ir}$ 'bres et arbrisseaux très-variables par le port, la nature et la forme des feuilles, toujours éparses et persistantes néanmoins; peu ou point résineux.

\section{geñe UNIRUe. - IF. TAXUS. Tourn.}

Chatons mâles globuleux, sortant du centre d'une rosette d'écailles, el composés d'une colonne centrale qui supporte des étamines ì filets courts, terminés, chacun, par un connectif pelté, en dessous duquel sont 3-8 loges anthériques. Fleurs femelles solitaires, consistant en un ovule unique, entouré de 6 bractées, qui ne participent point à la formation du fruit. Fruit ovoïde, ì parois ligneuses, contenu dans une espère de cupule, d'abord mince et sèche, puis charnue et le débordant à la maturité, due à l'accroissement d'un léger bourrelet qui existait à la base de l'ovule. Embryon 6-7-colylédoné. - Arbres ì feuilles persistantes, planes, linéaires, solitaires, éparses, paraissant distiques par la torsion de la base de la plupart d'entre elles, ì ramilicition irrégulière, non verticillée et à ramules anguleux.

Bois ì accroissements très-minces et flexueux, dont le nornbre concorde exactement avec l'âge; lourds, durs, vivement colorés et dépourvus de canaux résinifères, qui sont remplacés par quelques cellules éparses (non apparentes, même à la loupe); peu ou point aromatiques.

gr commun. Taxus baccata. Lin.

Feuilles semblables â celles du sapin pecliné, mais acuminées, plus molles, d'un vert noir en dessus, d'un vert clair en dessous, sans raies blanches. Fleurs mâles en petits chatons globuleux, jaunâtres, à l'aisselle des feuilles des pousses de l'année précédente; fleurs femelles trèspetites, verles et semblablement situées. Fruit formé d'une graine ovoüle, hrune a la malurité, a parois ligneuses, enfoncée dans une fausse cupule 
charnue, d'un rouge-vermillon vif. Disséminé dans les bois montagneux; Vosges, Moselle, Jura, Cévennes, Sainte-Baume, près de Toulon, Pyrénécs, Corse et Algérie. Flor., commencement d'ávril. Fructif., fin d'août de la même année. Dissémin., octobre-décembre.

L'if est un arbre d'une croissance excessivement lente, qui s’élève peu, $12-15^{\mathrm{m}}$ au plus, reste généralement branchu dès la base, à moins qu'on ne l'élague, et peut atteindre, en raison de sa prodigieuse longévité, un diamètre considérable. Lif de Grasford, en Angleterre, mesurait, il y a quelques années, $15^{\mathrm{m}}$ de circonférence en dessous des branches, et l'on estimait alors son âge â 1419 ans; l'àge d'un autre if du Derbyshire est évalué à 2096 ans.

La tige est droite, mais profondément cannelée ou sillonnée; les branches sont faibles, allongées, étalées; les rameaux et ramules nombreux, grèles, pendants. Le couvert est trèsépais, le feuillage très-sombre.

L'écorce, d'un gris-brun rougeàtre, reste mince et s'exfolie à peu près comme celle du platane. C'est la conséquence d'un périderme qui se développe dans l'épaisseur des feuillets du liber et qui repousse ceux-ci au dehors, sous forme de larges plaques dont le tissu cellulaire s'accroit en un faux liége fragile, analogue à celui de l'écorce des pins, mais moins abondant. Le périderme, qui réunit d'abord ces plaques, étant peu résistant, se détruit vite et ces dernières, isolées, deviennent caduques. Cette écorce, me̊me jeune, ne contient jamais de réservoirs ni de canaux résinifères, pas plus que les feuilles.

L'if fructifie régulièrement chaque année. La graine, semée immédiatement en automne, germe l'année suivante ou, quelquefois, la seconde année seulement; conservée pendant l'hiver et semée au printemps, elle ne germe souvent qu'au bout de 5-4 ans. Le jeune plant lève avec $6-7$ feuilles cotylédonaires, exactement semblables à celles qui se produiront plus tard; il est alors difficile de le distinguer de celui du sapin pectiné. La croissance en est très-lente jusqu’i 6 ans environ et consiste en un allongement annuel de 2-5 centimètres au plus; passé eet àge le développement devient plus rapide, mais il reste toujour's infiniment au-clessous de celui des autres arbres verts.

Lif ne forme jamais de massifs dans les forèts ; sa rareté ct l'extrème lenteur de sa croissance lui enlèvent toute importance. Préférant les stations montagneuses et s'élevant

Fructification. Germination.

Croissance.

Station et sol. 
jusqu’à $1500^{\mathrm{m}}$ dans les Pyrénées, il se trouve aussi en plaine ou peu s'en faut, dans la Moselle; il semble s'accommoder le mieux des terrains calcaires.

Bourgeons. Les bourgeons axillaires sont abondants et beaucoup d'entre eux restent à l'état de bourgeons proventifs, qui, à un moment donné, peuvent prendre de l'aceroissement. Cette propriété rend les ifs extrèmement dociles à la taille et leur permet de repousser de souches.

Bois. Le bois est l'un des plus durs, des plus compactes et des plus tenaces de nos pays; il se reconnait très-facilement à laubier blanc jaunâtre, peu épais $(10-20$ couches), nettement séparé du bois parfait, ct à la couleur de celui-ci, qui est d'un beau rouge marron, veiné de brun, en raison de la nuance plus fonece dlu bord externe de chaque couche; il n'a pas d'odeur sensible.

Densité. La densité est assez élevée, comme l'indiquent les chiffres suivants, fournis par des bois complétement dessćehés à l'air (Coll. Ec. For., envois de MM. Gurnaud et Royer.) :

$\begin{array}{lllll}\text { If de } 127 \text { ans... Jura } \ldots & 0^{\mathrm{m}}, 22 & \text { de diamètre } \ldots . & 0,742 \\ \text { If de } 63 \text { ans... Algérie.. } & 0^{\mathrm{m}}, 10 & 0,886\end{array}$

Usages. Ce bois, l'un de ceux qui reçoit le mieux et garde le plus longtemps le poli, est très-recherché par les tourneurs, sculptcurs, fabricants d'instruments et de jotets et, sans sa rareté, il serait l'un des plus précieux. Coloré en noir, on le distingue à peine de l'ébène.

Propriétés secontlaires.

L'enveloppe rouge et charnue de la graine est mucilagineuse, sucrée, et n'est point dangereuse à manger, si ce n'est en grande quantité. L'amande a la saveur de la noisette et renferme une huile grasse d'un goùt agréable, mais disposéc à rancir. Quant aux jeunes pousses et aux feuilles, elles renferment, dit-on, un principe toxique trèsactif et l'on a des exemples de chevaux qui sont morts pour en avoir mangé; cependant on assure que les chèves et tous les autres ruminants les broutent impunément.

\section{FAMIILLE LV.}

\section{Cupressinées, $L . C$. Rich.}

Floraison monoïque ou dioïque, amentacée pour les 2 sexes. Chatons mîlus petits, formés d'un axe commun sur lequel sont 
plusieurs étamines, dont chacune représente une fleur, à filets terminés en un connectif écailleux, pelté, sous les bords duquel sont 4-12 loges anthériques. Chatons femelles composés d'un petit nombre de fleurs, toujours dépourvues de bractées; clıcune d'elles représentée par une écaille carpellaire, à la base interne de laquelle sont plusieurs ovules, rarement un seul, ouverts au sommet et dressés. Fruits composés, globuleux, formés d'un petit nombre d'écailles épaisses, charnues ou ligneuses, soudées entre elles ou libres, toujours persistantes sur l'axe (galbule). Graines ailées ou non, 2-, rarement 3-9-cotylédonées, périspermées, parfois en assez grand nombre pour chaque écaille. - Arbres et arbrisseaux à feuilles persistantes, opposées-croisées ou verticillées, étroites et aciculaires ou squammiformes-imbriquées, à rameaux souvent anguleux, à ramification irrégulière et à sucs résineux.

Bois homogènes, souvent colorés, presque aussi durs dans la zone de printemps que dans celle d'automne, dépourvus de canaux résinifères, mais offrant quelques cellules disséminées (non apparentes, même ì la loupe), qui en remplissent les fonctions et les rendent aromatiques. Accroissements rarement circulaires, subdivisés par des lignes fines et plus foncées, semblables à celles qui les limitent extérieurement, en plusieurs zones irrégulières, non continues, qui rendent confuse et incertaine la distinction des couches de chaque année et tendent à en faire exagérer le nombre dans le comptage.

A. Galbule bacciforme par la soudure des écailles, qui sont herbacées, charnues; graines non ailées; floraison diö̈que................................. Genter. i

A'. Galbule à écailles ligneuses, non soulées, multi-słermes; graines ailées; floraison monö̈que ........ Crrpnès... 2

GENRE I. - GENÉVRIER. JUNIPERUS. Lin.

Floraison diö̈que ou accidentellement monö̈que sur des rameaux différents, à chatons solitaires, axillaires ou terminaux. Chatons mâles petits, jaumîtres, ì anthères 3-6-loculaires ; chratons femelles très-petits, verdâtres, à écailles apprimées, dont les inférieures sont stériles et ne s'accroissent pas, dont les 6 supérieures, fertiles, 1-2-ovulées, se développent, deviennent charnues et se soudent complétement pour former un galhule bacciforme indéhiscent ou fausse baie, contenant liabituellement 3 graines anguleuses, non ailées. - Arbrisseaux ct arbres trèsrameux, à feuilles aciculaires ou squammifurmes, opposécs ou 
rerticillées ; à maturation généralement bisannuelle ; revêtus de bonne heure d'un rhytidome libérien, longitudinalement gerçuré, membraneux-fibreux, brun-roux.

Bois aromatiques, légers ou demi lourds, à grain très-doux. Aubier blanc nettement séparé du bois parfait, qui est assez vivement coloré; croissance très-lente; couches anguleuses ou flexueuses, difficiles à distinguer des zones en lesquelles elles se subdivisent.

$\Lambda$. Feuilles toutes semblables, aciculaires et piquantes, articulées, non décurrentes à la base; 5-nervićes et marquées de deux bandes blanchâtres en dessus; 1-carénées et non glanduleuses en dessous.

B. Fruit noir-bleuâtre, couvert d'une efflorescence glauque.

C. Arbrisseau dressé, à feuilles insensiblement atténuées en pointe épineuse.......... G. cosnux.... 1

C'. Arbrisseau couché, à feuilles brusquement rétrécies en pointe courte et forte.......

B1. Fruit rouge, luisant. Feuilles aigûment carénées en dessous....................

$\Lambda^{\prime}$. Feuilles de deux sortes; les unes, les plus rares, aciculaires et piquantes; les autres, squammiformes-imbriquées, munies sur le dos d'une glande résinifère jaunâtre; non articulées; décurrentes, sans nervures saillantes.

B. Feuilles sillonnées sur le dos; fruit rouge et luisant...............................

B'. Feuilles munies sur le dos d'une glande résini-
fère; fruit noir bleuâtre, glauque....... G. de Pirénicie. 4 G. sabine.....

SEctrov I. Feuilles toutes semblables, arliculies, non décurrentes ì la base, aciculaires-piquantes, 3-nerviejes et pourvues de 2 bandes blanchâtres en dessus, 1-car'eneies el non glanduleuses on dessous. Chatons axillaires sur les rameaux de l'année précédente. Bourgeons écailleux.

1. Genévrier commuu. Juntpenus comsunis. Jus.

Feuilles de 7-1/4 millimètres, ternées, étalées, insensiblement effilées en pointe aiguë; glauques en dessus, obtusément carénćes et vertes en dessous. Galbule baceiforme, noir-bleuâtre à la maturité, couvert d'une efforescence glauque, beaucoup plus court que les fenilles. - Arbrisseau et accidentellement petit arbre; commun sur les sols sablonneux et pierreux, particulierement ealcaires, des plaines, des collines et meme des régions montagnenses de toule la France; atteint dans les $\Lambda$ pes une altitule de pries de $1760 \mathrm{~m}$. Flor., avril-mai. Fruclif., automne de l'aunce suivaute. Dissciminat., printemps, au bout de 2 ans. 
Le genévrier commun oflre un port très-variable, suivant les circonstances sous lesquelles il végète; tantòt il forme un buisson touffu, étalé ; tantòt un petit arbre de $4-6^{\mathrm{m}}$ de hauteur sur $0^{\mathrm{m}} \overline{\mathrm{z}}$ de diamètre. Il est vrai qu'en raison de la lenteur de sa végétation il a rarement le temps de parvenir à ces dernières dimensions, si ce n'est dans les pares et dans les jardins. Les jeunes rameaux restent triangulaires jusque vers 4 ans.

L'écorce organise de bonne heure entre les feuillets fibreux du liber des zones minces, continues et concentriques, d'un périderme à cellules peu épaissies, qui se détruisent rapidement. Il résulte de là un thytidome brun, composé des feuillets non modifiés du liber, qui se gerẹurent longitudinalement et s'enlèrent sous forme de minces membranes fibreuses.

La graine germe au printemps, quand elle a été semée à l'automue; le plant ne lève habituellement que l'année suivante si le semis s'est fait au printemps.

Les faibles dimensions du genćvrier commun, l'extrême lenteur de son accroissement, l'irrégularité de sa tige, qui est tortucuse et sillonnéc, le rendent d'un faible intérèt. Le bois en est néanmoins de bonne qualité. Blanc jaunâtre, coloré au cour de jaune brunâtre ou rougeâtre, il est trèstenace, compacte, durable, légèrement aromatique. Il pèse, complétement desséché à l'air, $0,350-0,62$. Les usages en sont accidentels; il produit un bon combustible.

Les fruits renferment une huile essentielle très-odorante, qui les fait employer à différents usages; on en fabrique unc liqueur réputée antiscorbutique (le gin), dont les marins font une grande consommation.

2. Genévrier main. Juniperus naka. Willd. J. alpina. Clus. Genévrier des Alpes.

Très-voisin du précédent; se distingue aux feuilles appliquées contre les rameaux, plus courles, plus trapues et brusquement terminées en une pointe courte et forte; aux fruils ovoïdes-globuleux, aussi longs que les fenilles. - Arbrisseau de $0^{\mathrm{m}} 50-1^{\mathrm{m}} 50$, à tiges et à rameaux couchés, à feuilles très-rapprochées et courbées; IIautes régions du Jura, du Dauphiné, de l'Ardèche, de l'Auvergne, des Pyrénées et de l'Algérie. Flor., juillet. Fruclif.. automne de la seconde année.

3. Genévrier oxycèdre. Juniperus oxycedros. Lin. Genévrier Cade.

Feuilles très-étalées, insensiblement allénuées en pointe épineuse, aigûment carénées en dessous. Fruils plus gros que ceux des espèces prícédentes. 
Var. a. G. oxycèdre moprement dit. Fruits plus courts que les feuilles en général, rouges et luisants, sans efflorescence. J. Rufescens. End.

Var. $\beta$. G. oxycèdre ombiliquce. (J.umbilicala. God. Fl.de Fr. $-J$. Macrocarpa. Tenore. - J. oxycedrus, Desf. Endl.) Fruils plus gros que dans la variété $\alpha$, dépassant les feuilles, rouges ou brun-marron, couverts d'une légère efflorescence glauque.

Arbrisseau ou petit arbre à tige dressée, à ramules obtusément triangulaires, répandu aulour du bassin méditerranéen; la variélé $\alpha$ en Provence, cn Roussillon, en Languedoc et en Corse; la variété $\beta$ en Algérie. Flor., mai. Fruetif., automne de la seconde année.

Taille. Port. Le genévrier oxycèdre atteint de plus grandes dimensions que le genévrier commun et forme un petit arbre de $5-6^{\mathrm{m}}$ de hauteur ou mème davantage, sur $2^{\mathrm{m}}$, et plus, de circonfúrence. Tantòt il reste rameux et branchu dès la base, tantòt il se dénude jusqu'à $5-L^{\mathrm{m}}$ d'élévation. Il croit isolé ou mélangé aux lentisques, térébinthes, philarias, etc.

Bois. Le bois est homogène, à grain très-fin, de coulcur tendre, fauve ou jaune brunàtre très-clair; il offre fréquemment de beaux reflets miroitants dus aux contournements de sa fibre, reçoit un très-beau poli, a une odeur aromatique pénétrante et agréable, persistante, caractéristique. Chacune de ses couches se termine par une ou plusicurs lignes fines et brunes, inégalement distantes, qui rendent la distinction des accroissements annuels très-difficile.

Densité. La densité d'un bois de tige de 150 ans au moins, provenant de Corse, est 0,78 ; celle d'un bois de tige de 110 ans, d'Algérie, de 16 centimètres de diamètre, est 0,668 . (Envois de MII. Simon et Royer. Coll. Ec. For.)

Usages. Le genévricr oxycèdre fournit un joli bois de menue ébénisterie, pour colfrets, nécessaires, etc.; conjointement avec queliues autres espèces du mème genre (J. Virginiana, Lin.; J. Sabina, Lin. ete.), il sert à fabriquer l'enveloppe des crayons de plombagine et se désigne quelquefois sous le nom de cèdre à crayons. C'est un assez bon bois de chauffage, mais il flambe vite et éclate en brulant; le charbon en est de bonne qualité.

Prodnit On extrait du genérrier oxycidre, par la distillation, une accessoirc. Luile empyreumatique, livile de Cade, d'une odleur trèspénétrante, que l'on emploie dans la médecine et dans l'art vétérinaire. 
Section II. Feuilles souvent de 2 sorles; les unes, rares ou nulles, aciculaires el piquanles ; les autres, squammiformes-imbriquées, souvent munies sur le dos d'une glande résinifère jauncitre; non articulées, décurrentes et sans nervures saillantes. Chatons terminaux sur de courts vamules latéraux; bourgeons nus.

4. Aqenévrier de Ehénicie. Junipenus piroenicea. Lin.

Feuilles toutes ou presque toutes squammiformes, étroitement imbriquées, ovales, presque obtuses, creusées d'un sillon sur le dos. Fruits brièvement pédonculés, non réfléchis, globuleux, de la grosseur d'un pois à celle d'une petite cerise, rouges et luisants à la maturité. - Arbrisseau ou petit arbre touffu, pyramidal, pourvu de feuilles aciculaires dans la jeunesse, mais les perdant plus tard plus ou moins complétement, à floraison accidentellement monoïque, recouvert d'une écorce d'un brun rouge, longuement gerçurée, lamelleuse-fibreuse, devenant assez épaisse. France méditerranéenne; s'élève des bords de la mer jusqu'aux montagnes d'une altitude moyenne : Pyrénées-Orientales, Corbières, BassesCévennes; Algérie. Flor., mai. Fructif., automme de la seconde année.

Le genévrier de Phénicie atteint 5 S- $^{\mathrm{m}}$ d'élévation sur $\mathbf{4}^{\mathrm{m}}$ et plus de circonférence, reste rameux dès la base et forme à lui scul, vers l'embouchure du Rhòne, dans la Camargue, des fourrés d'une grande étendue, touflus et presque impénétrables. Il parait se plaire principalement dans les sols meubles et siliceux et il convient très-bien pour la fixation des dunes, car les vents de la mer ne le font pas souffrir.

Le bois a le grain fin; il est tenace, susceptible d'un beau poli ; l'aubier en est blane, ahondant, le cour brun jaunâtre assez vif; il se distingue aisément à son odeur fétide. Provenant d'Algérie, d'une tige de 15 centimètres de diamètre et complétement desséché à l'air, il pèse 0,81 . (Envoi de M. Royer. Coll, Ec. For.)

Ce bois est bon combustible et fournit un charbon estimé.

5. Cenévrier sabine. Junipenus sarina. Lin.

Feuilles vertes, sur 4 , plus rarement sur 6 rangs; les unes, aciculaires, élalées, rares ou nulles; les autres, squammiformes, imbriquées, presquo toujours munies sur le dos d'une glande résinifère d'un jaune brillant. Fruits de la taille d'un pois à celle d'une petite cerise, ovoïdes-subglobuleux, d'un bleu foncé à la malurité, couverls d'une efloresecnce glauque, terminant des ramules latéraux écailleux et plus courts qu'eux.

Var. a. G. Sabine proprement dit. Sabine mâle. Sabine commune. Sabine à feuilles de cyprès. Feuilles rhomboüdales, apprimées-imbriquées, glanduleuses, non carénées, un peu obluses au sommet. Rameaux presque cylindriques, les fructifères réfléchis.

Taille. Port.

Station el sol.

Bois. 
Var $\beta$. G. Sabine thurifere. G. femelle. G. ì feuilles de Tamamsc. G. d'Espagne. - J. Thurifera, Lin. J. Sabinö̈des, Griseb. Feuilles ovales, acuminées, très-convexes, apprimées à la base, plus ou moins liches et étalées au sommet des ramules, qu’elles rendent tétragones. Fruits ovoïdes, plus gros.

Arbrissean ou arbre très-louffu, à rameaux procombants, redressés an sommet, exhalant par toutes ses parties, quand on les froisse, une odeur forte et désagréable. La variété a dans les Alpes et les Pyrénées, la variété $\beta$ en Algérie; fréquemment cultivé. Flor., mai-juin. Fruclif., automne de la mềme année.

Taille. Port. La sabine reste le plus souvent à l'état d'arbrisseau, dont le trone, dressé et rameux dès la base, mesure $1-l^{\mathrm{m}}$ d'élévation; elle devient parfois un arbre de $8-12^{\mathrm{m}}$ de hauteur et de $2-\overline{2}^{\mathrm{m}}$ de circonférence. Le leuillage en est toujours trèstouffu et d'un vert sombre.

Station. Ce genévrier se trouve dans les lieux arides et montagneux et forme quelquefois à lui seul de petits massifs boisés, à St-Crépin, dans les Ilautes-Alpes, par exemple. Il croit lentement, mais la longévité en est très-élevée.

Bois. Le bois, avec l'aubier blane, peu abondant et parfaitement tranché, est, à l'état parfait, d'un joli rouge cramoisi plus ou moins vif; il est léger, d'un grain très-doux et homogène ct se coupe avec netteté dans tous les sens; il possède une odeur agréable, vive et pénétrante, longtemps persistante, jouit d'une résistance remarquable, d'une durée très-prolongée.

Mialgré ces qualités, la sabine n'est en France que d'un mince intérèt, en raison de sa rareté, de la lenteur de sa croissance et de ses failules dimensions. Il en est tout autrement dans l'Amérique du Nord où ce végétal est abondamment représenté par une variété de grande taille ou peutètre par une espéce distincte, mais en tous cas très-voisine, le genévier de Virginie (J.Virginima. Lin.). Le bois en est alors trés-recherché pour les constructions, pour pieux, poteaux, conduites d'eau; on en firt beancoup d'anticles de tour et de marqueterie; l'on en exporte mime pour l'Europe, ou il est employé a confectionner les enveloppes de crayons.

La térébenthine contente dans les feuilles et dans l'écoree de la saline a une sareur àre et amcire; elle possede des propriétés médicinales très-énergiques (1).

(1) Entre les genciricts of les cypris se place le genre suirant, special à l'dfrique seplentrionale : 
GENRE II. - CYPRÈS. CUPRESSUS. Tourn.

Floraison monoïque. Chatons mâles très-petits, cylindriques, terminaux sur les ramules. Chatons femelles également terminaux, presque globuleux, composés de 6-12 écailles multiovu-

\section{CALLITRIS. CALLITRIS. Vent.}

Floraison monoïque; chatons mâles et femelles solitaires, terminant les ramules latéraux ; les màles, petits, ovoüdes, formés de 10-20 écailles, dont chacune produit une fleur de 2-4x sépales écailleux et de 4 étamines; les femelles, composés de 4 écailles opposées 2 à 2 , étalées au moment de la floraison, se rapprochant et se soudant entre elles plus tard; les 2 cxlernes plus grandes, bi-ovulées, les 2 internes plus petites, uni-ovulées. Galbule de 4 écailles ligneuses, épaisses, inégales 2 à 2 , non peltées, largement sillonnẻes sur le dos, s'ouvrant à la maturité et renfermant 6 graines irrégulièrement coniques, bordées de chaque côté d'une aile membrancuse qui du sommet se jrolonge en s'élargissant beaucoup audessous de la base. Embryon 5-b’-cotylédoné; maturation annuelle. Arbrisseaux ou arbres à rameaux articulés, verts, à très-petites feuilles squammiformes, glanduleuses sur le dos, plus courtes que les entrenœuds et verticillées par 4 , mais inégales 2 à 2.

Bois semblable à celui des genévriers pour la structure.

Callitris quadrivalve. Callithis guadr-yalys. Yeat. Tinura articulé, Tiruya articulata. Vaill. Desf.

Seule espèce du genre el reconnaissable aux mẻmes caractères. Arbrc ou arbrisseau à ramules gréles, abondants, verts, paraissant à première vue constituer tout le feuillage du régétal, tant les vraies feuilles restent rudimentaires, et à galbules ovoüdes, de la grosseur d'une petite cerise, bruns, couverts d'une efliorescence glauque; revêtu d'une écorce brunc, assez finement gercurée ct rugueuse, remplie d'un grand nombre de gros canaux résinifères longitudinaux. Flor., fin d'octolre. Fructif., juin-juillet de l'année suivante. Algérie.

Le callitris, plus connu sous le nom de thuya articulé, est un arbre de $\nvdash-6^{\mathrm{m}}$ au plus d'élévation, dont la circonférence atteint $1^{\mathrm{m}}$, exceptionnellement $2^{\mathrm{m}}$; rameux dès la base, il se dénude en vieillissant el forme une cime pyramidale ou plus souvent étalée en parasol, cn raison des dévastalions auxquelles il est exposé dans les forêts de l'Algéric ; la ramification en est diffuse el se termine par des ramules articulés, comprimés, presque dichotomes, qui, par leur coloration verte suppléent à la petitesse et à la rareté des feuilles dans l'accomplissement des fonctions de la nutrition.

Le couvert est léger.

La graine du callitris perd assez promptement sa vilalité et ne peut guère se conserver que de l'automne au printenps; elle germe peu de temps après le semis.

Taille. Port.

Convert. Germination. 

d'écailles opposées-croisées, épaisses, ligneuses, mucronées vers

Station.

Bois.

Produit accessoire.
Le jeune plant lève arec 5-6, habituellement \& fenilles cotylédonaires; les fevilles primordiales sont étalées, sous forme d'aiguilles allongées; mais celles qui se produisent par la suite sont de plus en plus courtes, s'imbriquent les unes sur les autres en se redressant, pour enfin prendre la forme normale, celle de très-pelites écailles appliquées contre les rameaux.

Cet arbre occupe en Algérie de grandes étendues de pays et forme des massifs boisés importants, soit seul, soit mélangé avec le pin d'Alep, l'olivier, les philarias, etc.; il habite les pays de coteaux et les régions moyennes des grands massifs montagneux. Il vient a toutes les expositions et ne demande qu'un sol léger.

La végétation en est toujours irès-lente.

Le eallitris repousse aboudamment de souches et forme des taillis serrés et complets.

Le bois a l'aubier blane, peu abondant ( $1 \%$-40 couches), netlement tranché; il devient rouge brun assez foncé à l'élat parfait; les accroissements en soat minces et sont sublivisés par des zones étroites de tissı plus coloré en couches secondaires qui rendent difficile le comptage des années. Il est parfois abondamment imbibé de térébenthine et possède une odeur vive et caractéristique.

Ce bois a le grain fin et lomogène, se travaille et se polit fort bien; il est lourd et en quelque sorte indestructible, car dans les ruines romaines on le retrouve en parfait étar de conservation, encore doué de toute son odeur. Très-propre à la menue charpente et à la menuiserie, il fournit de plus un excellent chauffage et un charbon de très-bonne qualité.

Les fréquents incendies que les Arabes ont la coutume d'allumer pour se procurer des pàturagres, en détruisant à des reprises répétées toutes les parties superficielles du callitris, provoquent sur les souclies la formation d'une multitude de bourgeons; il en résulte des broussins souterrains qui peuvent atleindre un volume considérable et fournissent à l'ébénisterie un bois de placage de nuances riches et variées, qui, pour la fabrication des petils meubles de fantaisie, ne le cède en beauté à aucun bois cxotique, mème parni les plus précicux. C'est ce bois que les Romains connaissaient sous le nom de Citre et dont ils faisaient des meubles qui étaient potir eux l'objet d'une véritable passion : une table de citre ful payée jusqua i $1,4,00,000$ sesterees (environ $5: 0,000 \mathrm{fr}$.). La production de ces broussins n'est malheureusement qu'accidentelle et due à un système de dévastations qu’il est urgent de réprimer; le déreloppemeut s'en fait d'ailleurs avec une lenteur excessive.

Tous les organes du callitris contiennent abondamment une térébenthine de saveur amère, un peu àcre, d'une odeur analogue à celle du camphre; on l'oblient au moyen d'incisions longitudinales que l'on pratique dans l'éeorce jusqu'au hois. Lorsque l'évaporation a fait disparaitre l'essence, il reste une r'ésine dure, blanclue qui n'est autre que la Sandaraque: 
le centre, persistantes et s'entr'ouvrant pour la dissémination. Graines attachées en grand nombre, sans adhérence complète, au pédoncule de chaque écaille; longues de 4-6 mill., d'un roux peu luisant, très-irrégulières, généralement ovoïles-déprimées, amincies sur les bords en une aile peu développée. Maturation bisannuelle; embryon à 2-3 cotylédons. - Arbres à feuilles squammiformes, étroitement imbriquées, courrant entièrement les rameaux et les ramules, qui sont grêles et extrêmement nombreux.

Bois blanc, assez lourd, à accroissements à peu près circulaires et assez épais, mais subdivisés, plus encore que ceux des genévriers, par des zones de tissu plus dense et plus coloré, qui rendent souvent impossible la distinction des couches annuelles. Odeur aromatique.

Cyprès pyramidal. Cupressus fastigiata. DC. Cyprès d'Italic, Cyprès toujours vert, Cyprès femelle.

Feuilles triangulaires, glanduleuses sur le dos; branches et rameaux redressés contre la tige comme dans le peuplier d'Italie. Galluules de 2-5 centimètres de diamètre, d'un gris brun un peu luisant, composés de 10 écailles ligneuses, renflèes-peltées à leur extrúrnité, légèrement mucronées en leur centre. - Arbre élevé, à écorce très-mince, lisse ou très-superficiellement fendillée en long, d'un gris rougeâtre; originaire de l'Asie, fréquemment planté dans le Midi de la France el en Algérie. Flor., arril. Fructif., aaût de la seconde année. Disséminal., automne ou printemps suivant.

Le cyprès pyramidal attcint $23^{\mathrm{m}}$ de hauteur sur $2^{\mathrm{m}}$ de circonférence; la tige, droite, élancée, cannelée, est garnie, à partir d'environ $2^{\text {ux }}$ du sol, de branches nombreuses, serrées et redressées, qui forment une cime étroite, allongée, pointue. Il croit en plaine, sur les cotcaux et dans les régions montagneuses inférieures, à toutes les expositions, et il se plait dans les sols secs, légers et profonds.

Le bois de cyprès est blane ou très-légèrement teinté de jaune brunàtre, presque comme celui du sapin; il est homogène, à grain fin et serré, se travaille facilement et a une odeur aromatique vive et agréable. Provenant d'Algérie, d'une tige de 29 ans, de 1 decimètre de diamètre, il pèse, complétement desséché à l'air, 0,664. (Envoi de M. Royer. Coll. Ec. For.)

Il est employé et très-estimé comme bois de charpente et de menuiserie; il a une durée presque illimitée sons l'eau et il fournit des échalas qui résistent bien plus longtemps, dit-on, que ceux de chène.

Taille: Port.

Station el sol.

Bois. 


\section{FANIILLE LVI.}

\section{ADIÉtinées. $L$. C. Rich.}

Floraison monoïque, amentacée pour les 2 sexes. Chatolis mâles composés d'un axe garni de quelq̨ues écailles it la base et d'étamines, dont les anthères sont biloculaires, longitulinalement déhiscentes. Chatons femelles dressés, comprosés de fleurs nombreuses, étroitement imbriquées; chacuue d'elles formée d'une bractée accrescente ou qui s'atrophie plus tard et d'une écaille carpellaire, à la face interne de lacguelle allièrent $\mathbf{2}$ ovules renversés, c'est-it-dire, dont le sommet ourert (micropyle) est tourné vers la base de l'écaille. Cônes ou strubiles dressés, horizontaux ou pendants, ì écailles lignetises ou coriaces, persistantes ou caduques. Graines géminées pour chargue écaille et y adhérant par toute leur surface, ì épisperme coriace ou ligneux, accompragnées d'une aile unilatérale, persistante ou caduque. Graine périspermée; embryon '̈-12-cotyléloné. - Arbres élevés, à tige élancée, droite, fré(fuemment raniliée par verticilles, dont les feuilles sont toujours allongées, étroites et linéaires, éparses; riches en essence de térébenthine et en résine.

Bois demi-lourds, demi-durs, blanes ou rougeîtres, à accroissements très-distincıs, circulaires, dont lia zòne de printemps est plus molle et moins colorée que celle d'automne.

A. Chatons mâles solitaires et épars; cònes olılongs-cylindriques ou ovoïdes, à écailles coriaces, minees et tranchantes au sommet, à maturation annuelle (le cèdre excepté); feuilles solitaires, paraissant quelquefois fasciculées par l'atrophie des rameaux qui les supportent.

B. Feuilles toutes solitaires; ramification verticillée.

C. Feuilles planes, distiçues, non piquantes, ì 2 raies blanches en dessous. Cône cylindrique, dressé, à bractées saillantes, à écailles caduques......... s.pris... 1

$C^{\prime}$. Feuilles tétragones, piquantes, entourant le rameau; cône cylindrique, pendant, sans bractées et à écailles persistantes..................... Epı́céa. 2

$\mathrm{B}^{\prime}$. Fenilles en partic solitaires, en partie fascieulées; ramification non verticillée.

C. Feuilles persistantes, coriaces et piquantes; còne ovoïde, dressé, saus bractées, à écailles étroitement imbriquées, caduques; maturation presque bisannuelle....................... Cisone.. 5

C'. Feuilles caduques, herbacces, non piquantes; cône 
oblong, à braclées égalant les écailles; celles-ci

lâchement imbriquées, persistantes.......... Mécìzz. 4

A'. Chatons mảles agglomérés à la base des pousses de l'année; cônes généralement coniques, à écailles ligneuses, persistantes, épaissics à leur extrémilé; feuilles allongées, réunies par 2, 5 ou $\xi$ dans une gaîne écailleuse. Pin .... 3

Tribu I. - SAPINS. - Chatons miles solitaires el épars; muiles et fomelles insérés sur les pousses des amnées précédentes. Coines oblongs-cylindriques ou ovoüdes, it écailles coriaces, minces et tranchantes au sommet, ì maluration ammelle (le cèdre excepté). Fenilles solitaires, quelquefois fasciculées par l'atrophic des rumeaux qui les supportent.

GENRE 1. SAPIN. ABIES. Link.

Feuilles persistantes, solitaires, en spirale, paraissant distiques par la torsion de la base de la plupart d'entre elles; planes, habituellement obtuses ou échancrées au sommet, pourrues en dessous de 2 raies blanches. Cônes toujours dressés, à luraclées développées et généralement saillantes; écailles cariuques à la maturité, tombant avec les graines et litissant l'axe sur l'arbre; ramification verticillée sur la tige principale, opposée dans un seul plan sur les branches.

Bois blanc, sans distinction d'aubier et de bois parfait ; totalement dépourvu de canaux résinifères.

Gapin pectiné. Abres pectrata DC. Pinus picea, Lin (1). Sapin commun, argenté, des Vosges, de Normandie. (Ce derniếr nom vient, dit-on, de ce que ce sapin est fréquemment planté en Normandic, saus y être cependant indigène).

Chalons mâles axillaires, solitaires, globuleux, rouges, puis jaunes, disposés en dessous des rameaux de l'annéc précédente; chatons femelles apparents dès le mois d'aoùt de l'année qui précède la floraison, placés sur les branches les plus élevées de la cime et naissant de l'extrémité de rameaux latéraux qui ne se sont pas allongés. Cône oblong-cylindrique, vert ou vert brunâtre, mat, long de $8-10$ centimètres, dressé, à écailles

(1) Linné s'est évidemment trompé en donnant au sapin la dénomination spécifique de Picea et à l'Epicéa celle d'Abics, et c'est abuser de la loi d'antériorité et mal la comprendre, que de l'appliquer à la consécration d'une erreur qui met le langage scientifique en contradiclion formelle avec le langage usuel. Les droits a la priorité sout d'ailleurs, en celte occasion, incontestablement acquis à ce dernier. 
caduques, débordées par des braclées foliacées-membraneuses, qui sont brusquement rétrécies en pointe allongée, réfléchie. Graines obovéescunéiformes, irrégulières, d'un jaune brunàtre luisant, contenant un réservoir plein de térébenthine, à ailes larges, triangulaires, 1 fois $1 / 2$ plus longues qu'elles, adhérentes, d'un rouge vif jusqu'à la maturité, puis d'un brun foncé. Embryon à 4,5 el mème 8 colylédons. - Grand arbre verticillé, à ram aux et à ramules opposẻs, disposés dans un mème plan, à écorce blanchâtre, longtcmus lisse et vive. Forme, seul ou mélangé, des forèts considérables dans les contrées montagrneuses de toute la France et de la Corse. Flor., fin d'avril, commencement de mai. Fructif., comnencement d'octobre de la même année. Dissémination, courant du même mois.

Taille. Le sapin pectiné est un arbre de première grandeur, qui atteint et dépasse mème $40^{\mathrm{m}}$ d'élévation sur $2^{\mathrm{m}}$ de diamètre à la base, et dont la longévité est considérable. On citc un sapin du Wurzelberg (Thuringe), qui mesure $47^{\mathrm{m}}$ de hauteur, $8^{\mathrm{m}} 4 \ddot{3}$ de circonférence à $0^{\mathrm{m}} 60$ (lu sol, cube 117 stères et doit être âgé de 550-400 ans (Schacht).

Ramification. La tige, droite et élancée, se ramifie régulièrement par Port.

Euracinement. L'enracinement est profond et puissant; il sc compose verticilles; les branches, horizontales, se divisent en rameaux et ramules opposés et situés dans le mème plan et forment une cime pyramidale-aiguë. A un àge avancé cependant, l'axe prineipal cesse de sallonger et la cime de. vient plus ou moins plane au sommet; l'époque de la fruetification est alors arrivée.

La différence entre la ramification de la tige et celle des branches rend la perte de la flèche ou pousse terminale principale plus grave pour le sapin que pour toute autre essence. Souvent cette flèche ne peut se reformer et l'arbre reste couronné; ou, si elle se reconstitue, ce n'est que par une pousse latérale qui, en se redressant pour continuer la lige, n’abandonne sa ramification opposée-distique qu'avec peine et au bout de plusieurs années seulement, pour former enfin des verticilles. d'un pivot qui s'enfonce à $1^{\mathrm{m}}$ et plus et se ramific en longues et fortes racines latérales. En exploitant rez de terre, le bois de souche et de racines est d'environ $16 \mathrm{p} .0 / 0 \mathrm{du}$ volume total.

Feuillage. Le feuillage du sapin est abondant, persistant pendant Couvert. plusieurs années et produit un couvert épais. Les feuilles, spiralées, paraissent distigues par la torsion de la base de la phopart d'entre elles et sont étalcées horizontalement de cha- 
que còté des rameaux et ramules; cependant dans les parlies les plus élevées de la cime, elles se redressent toutes vers le ciel. Généralcment obtuses ou échancrées au sommet, elles deviennent alors aiguës. Ces feuilles et leurs jeunes pousses sont broutées avidement par le bétail et par le gibier.

L'écorce du sapin perd son épiderme dès la première année et présente à nu l'enveloppe subéreuse, qui constitue un périderme superficiel, mince, brillant, extensible et lisse, tantôt d'un jaune brunàtre, le plus souvent d'un gris argenté caractéristique. L'enveloppe herbacée sous-jacente conserve sa vitalité pendant longtemps; clle est parsemée de canaux résinifères longitudinaux qui, en se réunissant par 2-4, produisent au point de jonction une sorte de glande creuse dans laquelle se déverse la térébenthine qu'ils élaborent. Les parois, distendues par l'accumulation de ce principe, ne tardent pas à se rompre et la glande se transforme en une lacune assez grande et irrégulière, au-dessus de laquelle le périderme est soulevé, par le suc très-limpide, incolore et visqueux qui la gonfle, sous forme d'une petite tumeur ou ampoule, qu'il suffit de presser avec l'ongle ou avec une pointe quelconque pour la crever et en faire écouler le contenu. Enfin le liber est composé de couches minces, d'un blane nacré, dont les plus superficielles, vers 6-8 ans, se transforment en un tissu cellulaire rougeâtre, épais et lignifié.

L'écorce reste telle, lisse et vive à la surface, jusqu'à un àge avancé, 40-100 ans, suivant les individus. Puis un périderme interne se développe à l'extérieui des couches actives du liber, fait dessćcher tout ee yui est en dehor's et constitue un rhytidome persistant, de plus en plus gerẹuré, dont l'épaisseur s'aceroit avce l'àge, tout en ne clépassant que rarement 5 -4. centimètres.

La production du périderme intérieur, en desséchant l'enveloppe verte, arrète naturellement la sécrétion de la térébenthine, dont l'essenee s'évapore. La résine, devenue concrète, reste dans le rhytidome et contribue à faire de l'écorce du sapin l'un des meilleurs combustibles végétaux.

La propriété du sapin de conscrver, à la surface, une écorce vive jusqu'à un âge assez avancé, permet aux tiges, branches et racines de s'entre-grefler facilement par approche avec celles des sapins voisins, lorsque les parties se

Grefles naturelles. 
trouvent en contact pendant un certain temps. De là résultent. de nombreur phénomènes de végétation.

L'un de ces phénomènes, des plus fréquents et des plus curicux, est celui qu'oflent certaines souches qui, après l'exploitation de l'arbre et bien que privées d'organes verts, continuent leur accroissement en diamitre, produisent un bourrelet qui en envahit peu ì peu la surface et finissent par se recourrir d'une calotte hémisphérique complète. Cette végétation, qui scmble ètre, an premier aperẹ, une lérogation aux lois physiologiques, est due à une soudure, contractée des longtemps, entre une ou plusieur's racines de l'arbre exploité et celles d'un sapin du voisinage qui n'a point été abattu. C'est ee dernier qui est devenu le notirrieier de la souche qui continue à croitre et dont l'avenir est désormais solidaire du sien.

Fruclification. La fructilication est assez régulière et assez constante et ne présente point les intermittences et les inćgalités que l'on observe à eet égard chez certaines essences, telles que les

Graine. pins, les chènes, les hètres. La graine se distingue aisément à sa forme irrégulière, tronquée, à sa couleur d'un jaune brunattre brillant, à ses dimensions plus fortes que eelles des graines de la plupart des autres abiétinées. Elle contient beancoup de térébenthine, qui lui donne une saveur âce et brủlante, et elle cst accompagnéc d'une aile brunàtre, large et oparque, dont elle conserve toujours des déhris, mème après le désailement. Le kil. en renferme 22-25000, lorsqu'elle est fraiche et ailée. Il parait qu'elle supporte difficilement les emballages et les transports (T. IIartig).

Gormination. La germination des graines semées au printemps se fait au bout de 5 -4 semaines. Après que le jeune plant s'est décoiflé par la chute du périsperme, il présente $4-8$, géné-

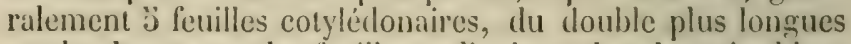
et plus larges que les feuilles ordinaires, dont les raies blanches sont a la face supérieure et qui se maintiennent vertes

Jeune plant. durant plusicurs années. Pendant $2-5$ ans toute l'activité de la végétation se concentre sur la racine, qui s'enfonee profondément, et sur le grossissement de la tige, qui s'allonge a peine. Vers $5-14$ ans, le jeune sapin commence ì se ramifier par la production annuelle de $1-2$ branches latérales, dirigées tantòt d'un còté, tantòt de l'autre; il s'étend cn largeur, fort peu en hautcur et présente, en eet état, un port tout particulier gu'il faut bien se garder de prendle pour 
indice d'un état peu prospère. Enfin, ver's 10 ans, la ramification se verticille et, dès ce moment, la végétation prend un rapide essor, si l'action de la lumière est suftisamment ménagée.

Le sapin est peut-ître l'essence qui résiste le mieux au couvert et l'on voit fréquemment, sous les massils serrés, des sapineaux de $\$ 0-60$ ans qui n'ont pas plus de $1^{\text {m }}$ de hauteur sur $2-5$ centimetres de diamètre et qui n'en peuvent pas moins produire des arbres de la plas belle venue, s'ils viennent à ètre dégagés plus tard.

Le sapin est l'arlure des régyions montagneuses dont l'atmosphère est humide et dont la température movenne de l'hiver ne descend pas au-dessous de-4. $\dot{a}-6^{\circ}$; il sucecide a la région des chines et des céréales et s'éleve à peu pris a la mène hauteur que le hítre, sans desecndre comme lui dans les plaines. L'altitude la plus grmonde quil atteigne eat: cn Corse, $1700^{\mathrm{m}}$; daus les Pyrences (Hont Canigon), 19:80"m; dans le Jura el l'Awrergne, l:00"' ; dans les Yosges, 1000m. Il recherche particulièrement les sols frais et mélangés d'humus, formés du détritus des roches granitiques on de transition.

Le sapin est sujet à ètre attaqué, dans quelques-uns de ses rameaux, par un champignon parasite, l'. Eciclium elutimum ( $A l b$. et Schre.) qui se déreloppe en dessous des fenilles et apparait à l'ceil nu sous forme de petits disyues orangés, disposés suirant 2 séries longitudinalds. Les rameaux enrahis se lignifient peu, sont gortés d'humidite, très-souples, se ramifient fortement et donnent naissance à de petites touffes serrées, arrondies, assez semblables à celles du grii et que les buicherons des Yosges appellent Balai de Sorcier; les feuilles en sont devenues jaunattres, chamues, annuclles. Au point d'insertion du Balai sur la tige ou sur les branches il se forme un empatement, qui, entravant la circulation de la séve et l'obligeant à séjournel, détermine la production d'un bourrelet on excroissance circulaire. Quel que soit ensuite le sort du Balai, dont la durée ne dépasse pas un certain nombre d'années, qu'il persiste desséché on qu'il tombe, le bourrelet auruel il a douné naissance se maintient et s'accroît; bientòt mème son développement devient tel que l'écorce qui le recouvre se gerçure profondément et tombe partiellement. Des écoulements séveux se produisent, le bois dénulé se caric, le courz de la séve descendante est de plus

Station.

Sol.

Maladie du sapin. 
en plus entravé et la production ligneuse devient, en cette région, tout à fait irrégulière. Le bois qui s'y forme a la fibre entrelacée et repliée sur elle-mème; il est rougeâtre, mou, spongieux, les accroissements en sont épais. Si celte difforınité est sur une branche, elle n'atteint pas habituellement de grandes dimensions et disparait avec la branche elle-mème gui tôt ou tard se rompt; mais si elle est placéc sur la tige, elle se développe avec elle, prend des dimensions considérables et constitue un vice connu dans les sapinières sous le nom de Chaudron.

Un sapin chaudronné est très-exposé à se rompre sous l'effort des vents; s'il résiste, au moment de l'exploitation il se brise souvent dans sa chute ; enfin, s'il échappe à ces accidents, la tronce dans laquelle tombe le Cliaudron est à peu près perdue, puisqu'on n'en peut faire de planches. Dans certaines sapinières, le nombre des sapins chaudronnés est quelquefois considérable et occasionne une dépréciation sensible des produits.

Le Chaudron est donc la conséquence du Balai de Sorcier, et l'origine de l'un et de l'autre remonte toujours aux premières années de la tige ou de la branche qui en est affectée, alors que l'Ecidium s'est développé sur les feuilles. Il suit de là que tout jeune sapin qui a un de ces Balais sur la tige sera plus tard chaudronné et qu'il doit disparaitre dans les éclaircies.

Il se pourrait que l'Ecidium, au lieu d'ètre la cause du Balai, n'en fùt que la conséquence. Dans ce dernier eas, quelle est l'origine de cette déformation si remarquable d'un rameau? On ne sait rien à cet égard.

Bois. Le bois de sapin n'est formé que de fibres et de rayons et manque entièrement de canaux et de cellules résiniféres; il n'a par conséquent pas d'odeur prononcée et il ne contient point de résine, ou plutôt cette substance y est extrêmement disséminée, quoigu'on n'en puisse nicr absolument la présenee, puisquion la voit imbiber les noeuds ou se concrétionner dans les fentes ou cavités aceidentelles qui peuvent se produire au milieu de la masse ligneuse.

Ce bois est blane, souvent teinté de brun-rougeàtre trèsclair et ne se colore jamais au cour' il n'offre pas de diflérence bien appréciable, surtout quand il est sec, entre les couches extérieures et celles du centre, entre l'aubier et le bois parfait, quoique le premier n’ait pas les qualités du se- 
cond, qu'il soit plus sujet que lui à la vermoulure et qu'il s'injecte aisément de matières préservatrices, destinées à en prolonger la durée, tandis que le bois parfait s'en imprègne très-difficilement, semblable cn cela du reste à celui des autres résineux, épicéa, mélèze, cèdre et pins.

Les accroissements annuels sont circulaires et très-tranchés, en raison de la coloration et de la dureté très-inégales des tissus de printemps et de ceux d'automne. Le défaut d'homogénéité du sapin, ainsi formé d'une succession de zones cylindriques alternativement molles et résistantes, détermine un dúbit caractéristique quand on le façonne en bois de feu. Il a une tendance prononcée à se partager dans la direction circulaire, alors mème qu'on cherche à le fendre dans le sens des rayons, qui, par leur petitesse, sont peu faits, il est vrai, pour diriger le débit. C'est à la même cause encore qu'il faut attribuer la fréquence des roulures sur le sapin et sur tous les bois de structure non homogène. Lorsque des alternatives de chaud et de froid, des températures extrèmes, un afflux considérable ou une brusque diminution de séve déterminent des dilatations et des contractions dans toute la masse ligneuse, il se produit, si celle-ci n'a point d'homogénéité, des solutions de continuité suivant la direction des tissus les moins résistants, solutions qui, au cas particulier, correspondent aux zônes molles du printemps et deviennent conséquemment circulaires.

La faculté très-développée du sapin, de résister fort longtemps à l'action du couvert et de reprendre immédiatement sa vigueur dès qu'il est dégagé, en rend souvent le bois de consistance très-inégale; à une série d'accroissements trèsminces succède parfois une suite de couches très-épaisses. C'est là évidemment un défaut, qui diminue la résistance, provoque la production de roulures, etc.; la méthode du réensemencement naturel et des éclaircies, en assurant aux bois des conditions de croissance uniformes, est destinée à le faire disparaitre.

La pesanteur spécifique du bois de vieux sapin est : vert, 0,59 ; desséché à l'air, 0,48 ; complètement sec, 0,566 (T. Hartig). Mais ces chiffres ne doivent être considérés que comme des moyennes, qui se modifient singulièrement avec les conditions de la végétation. En général, la densité du sapin est supérieure à celle de l'épicéa.

La résistance horizontale et l'élasticité du sapin sont con-

Densité. 
sidérables et ont été constatées par des cxpériences nombreuses, cntre autres par celles d'une commission composcic d'ingénicur's civils, militaires et maritimes et d'agents loresliers qui, en 1846, a reconnu à cet égard la supériorité du sapin de l'Aude sur tous les autres bois résineux indigènes et mème exoligues, à l'execption du pin des Florides (pinus anstralis, Mich.). La structure du sapin dont le bois d'autome est fortement lignifié tandis que celui du printemps l'est très-peu, en offrant une succession de lames résistanteslàchement unies entre elles, rappelle la disposition de ces ressorts si énergiques, formés de lames superposées, et justifie très-bien les résultats obtenus. Le sapin, par compensation, n'a pas une longue duréc, s'il n’est employé à J'abri de l'humidité.

Usages. Les grandes dimensions, les qualitćs, l'abondance du sapin en font l'un des bois les plus cmployés dans les constructions civiles; la marine marchande l'utilise mème pour la màture. Tout le monde connait d'ailleurs les inmombrables usages auxquels on l'applique; il se débite le plus souvent en planches, madriers, poutres, lattes, etc., qui se transportent fort loin du lieu de production. Il est d'une fente facile et il fournit de bonne boissellerie, des bardeaux pour couvrir les maisons, ete.

Valeur D’après G.-L. IIarlig, la puissance calorifique moyenne calorifique. du sapin est à celle du licure, pour des volumes igaux, comne 69: 100; elle est inféricure à celle de l'épicéa. C'est un médiocre combustible, (jui bruile aree une flamme vire, mais gui pétille beancoup et répand une abondante fumée.

Le manque de résine dans le bois de sapin justifie son infériorité sur le hois des autres abiétinécs, à l'égard de la durée et de la puissance calorifique.

Produits accessoires.

Il a déjì été dit que l’écoree est un cxcellent combustible; elle contient du tamin ct pourrait servir à la préparation du cuir.

On récine le sapin, mais sans lui porter aucun préjudice; on choisit pour eela les arbres dige moyen, sur lespuels les lacunes résinifires ont pris leur julus grande extension, ou, ce yui revient au mène, les portions supéricures de la tige des vieux arbres.

Liopération consiste simplement à pirquer, avec le bee d'un petit vase en ferblane, les ampoules résinifëres de l'écoree vive, afin de recueillir les quelyues grouttes de térébenthine 
qui s'en íchappent. Cette pratique, peu productive et de plus en plus délaissée, produisait la térébenthine dite de Sirasbourg.

\author{
gente 1I. - EPICEA. PICEA. Link.
}

Feuilles persistantes, solitaires, en spirale, entourant régulièrement les rameaux et ramules, tétragones, raides, pointues et piguantes. Cônes terminaux sur les rameaux, pendants, à écailles minces, coriaces et persistantes, à bractées atrophiées. Ramilication verticillée sur la tige, confusément distique sur les branches.

Bois blanc, sans distinction sensible d'aubier et de bois parfait; pourvu de quelques canaux résinifères, apparents à la loupe et même à l'œil nu, sur une section transversale trèsnette.

Espicéa commun. Prcea excelsa. Link. Pinus abies. Lin. Pesse. Sérenté (Alpes).

Chatons mâles ovoïdes, roses ou pourpres avant la floraison, axillaircs ou terminaux sur les ramules de l'année précédente; fleurs femelles en chatons cylindriques, d'un rouge violacé, dressés, terminaux sur les pousses d'un an des parties moyennes et élevées de la cime; les uns et les autres

- produits par des bourgeons reconnaissables dès la fin de l'été de l'année précédente. Cônes pendants, long de 10-13゙ centimètres, oblongs-cylindriques, à écailles rhomboïdales, tronquées cl denticulées, ou légèrement échancrées, ou entières à leur somme minces, sèches et coriaces, d'un roux clair luisant, non accompagnées de bractées. Graines pelites, obovées, atténuées à la base, de la laille et de la forme de celles du pin sylvestre, toutes d'un rouge brun mat uniforme, pourvtes d'une aile 2-5 fois aussi longue qu'elles, dont les 2 bords sont arrondis, d'un roux clair. Embryon 6-10, plus souvent 9-cotylédoué. - Arbre de gुrande taille, à tige verticillée, à branches orlinairement arquées et plus ou moins déclinies, garnies de rameanx ct de ramules nombreux, confusément distiques, piendants; écorce rougeâtre. Forme seul ou mélangé de vastes forêts dans les régions montagneuses: Jura, Vosges, Alpes; rare dans les Pyrénées. Flor., fin de mai, commencement de juin. Fructif, octobre de la mème année. Dissémination, immédiatement après la fruclification, ce qui est rare, ou au printemps suivant.

L'épicéa est un arhre de très-grrande dimension, à tige droite, élancée, pousant atteindlie $\mathscr{f}_{\mathrm{i}} \mathrm{O}^{\mathrm{m}}$ et plus d'élévation, mais dont le diamètre reste généralement inlérieur à celui du sapin. On cite un épicéa de la Silésie, l'Epicéa du Roi,

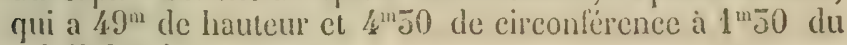
sol (Schacl).

Les branches sont verticillées sur la tige; les ramules et

Taille.

Ramification. 
les rameaux sont opposís-distiques sur les hranches. Malç̣cé cela les aceroissements successifs en longueur y sont moins distincts que sur le sapin, parce que, outre les bourgeons qui produisent la ramification principale, il s'en dércloppe beaucoup d'autres, axillaires et épars, qui donnent naissance à un grand nombre de ramules irrégulièrement disposés. De là résulte une cime plus serrée et d'un feuillage plus toulïu que celle du sapin. Cette cime est longuement et étroitement pyramidale-aiguë, mème à l'àge le plus avancé, et ne se nettoie que lentement de ses branches inférieures, qui persistent longtemps encore après leur mort. Les branches, nombreuses, toujours gròles et chargées d'un abondant feuillage, sont plus ou moins déclinées ou mème pendantes et seulement un peu redressées au sommet; leurs rameaux et ramules sont généralement retombants. Toutes ces circonstances assurent à l'épicéa un port très-caractéristique, auquel on le reconnait de loin.

La faculté que possède l'épicéa de produire facilement des bourgeons axillaires et, par suite, une ramitication serrée, le rend très-propre à la taille. On en fait d'excellentes haies, des palissades, etc.

Enracinement. L'entacinement de l'épicéa est faible et consiste essentiellement en sa souche, qui est dépourvue de pirot et garnic de racines traçantes assez grêles; aussi cet arlore résiste-t-il mal à l'elfort des vents. Liextraction de la souche produit, en moyenne, $16,3 \mathrm{p} .0 / 0$ du volume total, en exploitant rez. de terre, savoir ; 14,7 pour la sourhe proprement dite, 1,8 seulement pour les racines (T. Hartig).

Fructification. La fructification est sujette à plus d'intermittences et d'irrégularités que celle du sapin et, suivant les contrées, clle n'est abondante que tous les $2-6$ et mème 8 ans; elle se produit normalement vers 50 ans et, si l'on voit quelquefois des cones sur des arbres qui n'ont pas attcint cet àge, surtout dans les plantations, il faut se garder de les recueillir, ear, presque toujours, ils n'ont que des graines vaines.

Graine. La moindre chaleur suffit pour faire entr'ouvrir les écailles et provoquer la dissémination; aussi, dans quelques règions, celle-ci se fait-elle dès l'automne méme de l'année de floraison. L'abondance de la graine et sa facile extraction expliquent son bas prix. Fraíche et désailćc, il en faut 12/,000 pour un kilog. 
La graine conserve assez longtemps, 5-4 ans, sa faculté germinative. Semée au printemps, elle germe au bout de 4-5̆ semaines.

Le jeune plant, une fois dégagé de ses enveloppes, parait avec des feuilles cotylédonaires, ordinairement au nombre de 9 , exactement semblables à toutes les autres; puis, dans l'année mème, il allonge sa plumule en une jeune pousse garnie de 1-3 très-petits rameaux latéraux, dont les feuilles sont finement dentées sur les angles. Au bout de l'année, les feuilles cotylédonaires sont déjà desséchées et la hauteur totale du plant est de $5-8$ centimètres. Il prend la ramification verticillée dès les années suivantes et, à $\breve{a n s, ~ i l ~ m e-~}$ sure, dans de bonnes conditions, 25-30 centimètres.

Le pivot de la racine s'arrète à la surface du sol dès la première année et produit de nombreuses radicelles trèsdéliées, qui s'étendent dans toutes les directions. Cette oblitération immédiate de l'axe principal influe sur l'enracinement de l'arbre pendant toute sa vie, mais elle rend les plantations très-faciles et d'une réussite certaine.

L'écorce de l'épicéa est intermédiaire entre celle du sapin ct celle des pins. Après la chute de l'épiderme, elle présente : un tissu subéreux, rougeàtre et fragile, qui s'exfolie à la surface en fines membranes; en dessous, l'enveloppe verte, où l'on remarque des glandes résinifères; enfin le liber, qui est composé de fibres nacrées, dont les plus anciennes paraissent se transformer à l'extérieur en un tissu cellulaire rougeàtre, dur et compacte. Vers $20-50$ ans, un périderme interne s'organise, dessèche et fait tomber tout ce qui le recouvre, y compris les canaux résinifères longitudinaux, et produit un rhytidome rougeâtre, subéreux, qui finit par se gerẹurer et s'exfolier à la surface en petites écailles, couvertes de fines pellicules qui s'en détachent constamment. Le liber actif conserve toujours néanmoins une épaisseur notable et contient des canaux résinifères rayonnants de plus grandes dimensions que ceux de toute autre espèce, 7 fois plus larges que ceux du pin sylvestre par exemple. (Ihugo Mohl.)

L'épicéa est, comme le sapin, un arbre des régions montagneuses dont l'atmosphère est humide, mais il supporte un plus haut degré de froid, il a une aire de dissémination plus étenduc vers le nord et il atteint, dans les montagnes, une altitude plus considérable, qui s'élèverait sans doute eneore, si la sécheresse eroissante de l'air ne venait mettre

Ecorce.

Station. 
un obstacle à sa végétation. Il est abondant dans le Jura, dans les Alpes, est assez commun dans les Vosges, très-rare dans

Sol. les Pyrénées. C'est l'une des essences les plus indifférentes à l'égard du sol, pourvu qu'un certain état d'ameublissement et de fraicheur lui soit assuré, et on la voit se développer avec une égale vigueur sur les terrains granitiques ou siliceux des Vosges et sur les sols calcaires du Jura.

Bois. Le bois d'épicéa ressemble beaucoup à celui du sapin et n'offre pas davantage de distinction entre l'aubier et le bois parfait; cependant il est plus blane et plutôt teinté de jaunebrunâtre très-clair que de rougeâtre; il a le grain plus fin, l'éclat plus satiné. Le bois d'automne y forme en général une zône plus étroite, dont la différence avec le bois de printemps est habituellement moins prononcée, ce qui rend l'ensemble plus homogène, mais un peu plus mou. Il présente des nœuds plus nombreux, plus petits, qui n'ont point d'adhérence et proviennent de la longue persistance des branches mortes, dont la base traverse les accroissements annuels successifs de la tige, sans pouvoir nécessairement se souder avec cux.

Il se distingue sûrement par la présence de canaux résinifères longitudinaux et rayonnants, dont le sapin est toujours dépourvu et qui lui communiquent une légère odeur résineuse. Malgré leur finesse, on apercoit les premiers, soit à la vue simple, soit à l'aide de la loupe, sur une section transversale bien nette, sous l'apparence de petits points blanchâtres et opaques.

Densité. D'après T. Ilartig, la pesanteur spécifique, dans des conditions moyennes, est : vert 0,37 ; séché à l'air $0, \ell_{4} / 4$; complétement sec 0,31 . Ces chiffres confirmés par les densités obtenues d'échantillons de provenances diver'ses faisant partic de la collection de l'Ecole forestière, prouvent que, dans l'ensemble, l'épicéa est un peu plus léger que le sapin.

Usages. L'épicéa a les qualités et les emplois du sapin, mais il lui est préféré dans beaucoup de circonstances et dans les contrées oủ croissent ces deux résineux, dans le Jura, par exemple, la valeur vénale du premier est supérieure de un cinquième à un sixième à celle du second. (M. Lacordaire, Inspect. à St-Claude.)

L'épicéa donne en eflet des charpentes plus légères et plus durables; Müssenbrock lui attribue mêne une résistance horizontale et une élasticité plus grandes que celles du sapin, dans le rapport de $86: 100$ pour la première et de $86: 9 !$ 
pour la seconde; mais il semble permis d'admettre ici que ces chiffres n'expriment que des eas particulicrs beaucoup trop généralisés (voir l'article du sapin, page 359). L'épicéa est en outre d'une fente plus facile et plus nette et préféré pour la fabrication de la boissellerie et des bardeaux; il fournit à la menuiserie des planches d'un choix supérieur, enfin il convient seul à la fabrication des tables d'harmonie des pianos et autres instruments de musique.

La valeur calorifique est à celle du hêtre, en moyenne et pour des volumes égaux, comme 0,70:100. L'épicéa est néanmoins l'un des combustibles les plus avantageux à cultiver, qui rachète largement cette infériorité par une végétation active et l'état serré dans lequel il croit ; en un mot, par une production fort élevée.

Suivant T. Hartig, la puissance calorifique de l'épicéa, rapportée à celle d'autres essences, en tenant compte de la production sur des surfaces égales et dans des conditions identiques de végétation, serait expriméc par les chiffres suivants :

Epicéa. Révolution de 120 ans. Puissance calorifique. $\$ 110$

$\begin{array}{lllll}\text { Pin sylvestre. } & - & 120 \text { ans. } & - & \mathbf{5 6 0 0} \\ \text { Hètre. } & - & 120 \text { ans. } & - & 5500 \\ \text { Chêne. } & - & 120 \text { ans. } & - & 5150 \\ \text { Bouleau. } & - & 60 \text { ans. } & - & 2890 \\ \text { Aune. } & - & 60 \text { ans. } & - & 2200\end{array}$

On résine l'épicéa en dénudant le corps ligneux par des entailles longitudinales, longues et étroites, faites dans toute l'épaisseur de l'écorce; les larges canaux rayonnants du liber laissent suinter la térébenthine avec abondance. Il suffit de prolonger ces entailles de temps à autre, à tı́avers les nouvelles couches libériennes qui s'organisent, pour obtenir ce produit jusqu’à l'áge le plus avancé. Cette opération est assez productive, mais elle affaiblit les arbres ct réduit les dimensions qu'ils peuvent atteindre. Elle est d'autant plus préjudiciable qu'elle est le plus souvent pratiquée par délits, c'est-à-dire, sans aucun souci de l'arbre même. On fabrique, avec le produit du résinage, de l'essence de térébenthine, de la colophane, de la poix dite de Bourgogne, du noir de fumée.

Le bois réduit, à l'aide de machines, en fibres déliées scrt à la fabrication de papier et de carton de fort belle qualité.

Valeur calorifique.
Produits accessoires. 
L'écorce contient du tannin et sert, dans quelques contrées, à la préparation des cuirs; on préfère pour cet usage celle de 60-80 ans. Le liber tendre et non lignifié, charnu et sucré, semblable en cela à celui des autres abiétinées, sert de nourriture aux habitants du Nord.

La graine renferme $20-25$ p. $0 / 0$ d'huile grasse siccative.

\section{GBNRE III. - MÉLÈZE. LARIX. Tourn.}

Feuilles molles et caduques, solitaires sur les pousses qui s'allongent, fasciculées sur celles qui ne se développent pas et restent tuberculiformes. Chatons mâles et femelles terminant de très-courts rameaux latéraux de 2-6 ans et provenant de bourgeons qui ne se distinguent pas à l'avance de ceux à feuilles; les mâles, globuleux; les femelles, dressés, entourés à la base d'une rosette de feuilles et pourvus de bractées oblongues, brusquement prolongées en une pointe longue et étroite qui déborde les écailles. Cônes dressés, petits; écailles peu nombreuses, minces et ligneuses, lâchement imbriquées, persistantes, égalant ou débordant les bractées, qui ne se sont point accrues; maturation annuelle. Ramification éparse, non verticillée.

Bois aubier blanc, bois parfait brun rougeâtre; canaux résinifères abondants, visibles à l'œil nu.

Mélèze d'Europe. Lanix eunopea. DC. Pinus larix. Lin.

Feuilles molles, d'un vert gai, longues de 2-5 centimètres, solitaires et spiralées ou fasciculées, caduques. Chatons mâles globuleux, d'un jaune verdàtre; chatons femelles dressés, d'un rouge violacé, offrant immédiatement plus de moitié de la taille que le cône atteindra, à écailles petites, bractées oblongues, échancrées et denticulées au sommet, prolongées en une pointe longue et étroite, verte. Cônes ovales-oblongs, longs de 5-l centimètres, solitaires, dressés ou horizontaux, d'un gris brunâtre presque mat, formés d'un petit nombre d'écailles minces, rhomboïdales, tronquées ou échancrées au sommet, lâchement imbriquées, égalant ou débordant les bractées, qui we se sont point accrues. Graines petites, obovées, plus ou moins tronquẻes, d'un gris jaunâtre très-clair, luisant sur une face, mate sur l'autre, à ailes $\mathbf{2}$ fois aussi longues qu'elles, d'un roussâtre très-clair; embryon b-7-cotylédoné. Arbre de grandes dimensions, formant des forêts dans les Alpes du Brianconnais, à la limite supérieure de la région des arbres verts. Flor., juin (bien plus précoce, avril, lorsqu'il est cultivé dans la plaine). Fructif., automne de l'année de la floraison. Dissémination, printemps suivant.

Taille. Le mélèze est un grand arbre à tige droite, élancée, grèle, atteignant $30-55^{\mathrm{m}}$ d'élévation et $0^{\mathrm{m}} 70$ de diamètre. Cependant 
on cite rles mélèzes de plus grandes dimensions; l'un d'eux, dans le Valais, a le trone tellement gros que 7 hommes sulfisent à peine pour en embrasser la partie inférieure; il est sans branches jusqu'à une hauteur de $17^{\mathrm{m}}$ et dépasse $50^{\mathrm{m}}$ de hauteur totale; en Silésie, un mélèze mesure $54^{\mathrm{m}}$ d'élévation et $3^{\mathrm{m}} 50$ de circonfërence à hauteur d'homme.

La cime de cet arbre est étroitement et longuement pyramidale-aiguë, forméc de branches grèles, étalées ou réfléchies, redressées à l'extrémité, non verticillées; les rameaux en sont nombreux, effilés, minces, gẻnẻralement pendants. Dans les mélèzes qui ont crù en massif, le volume des branches et des rameaux n'est que le $6^{\circ}$ du volume total, souche comprise.

L'enracinement se fait par plusieurs racines principales obliques, desquelles partent un grand nombre d'autres petites racines plus ou moins traçantes; le pivot véritable s'est oblitéré dès les premières années. Le volume réel du bois de souche et de racines est au volume total comme 10 ou $11: 100$.

Le premier feuillage du mélèze, au printemps, ne consiste guère qu'en feuilles fasciculées; un mois après seulement se produisent les feuilles solitaires et les jeunes pousses qui déterminent l'accroissement en hauteur. Ce feuillage, se renouvelant et tombant en totalité chaque année, fournit au sol bien plus de détritus que celui d'aucun autre conifère, quoiqu'il ne forme qu'un couvert assez léger.

La fécondité du mélèze est précoce, surtout lorsqu'il est cultivé dans les régions tempérées; mais les graines en sont alors vaines et ce n'est qu'à l'àge moyen qu'il fructifie régulièrement. Les cònes s'ouvrent quelquefois dès l'automne, plus constamment au printemps suivant, et ils persistent sur l'arbre plusieurs années après la dissémination. Il est facile de ne pas confondre les cones vides avec ceux qui sont frais; ils sont d'un brun noir, ceux-ci d'un gris roussàtre.

L'extraction de la graine offre certaines difficultés; si l'on dépasse quelque peu la température nécessaire $\left(15-17^{\circ}\right)$, la résine que les cones renferment devient fluide et en agglutine les écailles pour toujours.

La graine du commerce ne contient que $34-45$ p. $0 / 0$ de semences de bonne qualité et cette proportion est souvent bien moindre encore. On peut en faire l'épreuve en la mettant dans l'eau; les meilleures graines tombent au fond,

Enracinement.

Feuillage.

Fruclification.

Graine.

Porı.

Cring

Prictification.

Graine. 
presque toutes celles qui flottent sont vaines. Deux circonstances expliquent ce déchet; la première est l'épaisseur de l'épisperme, qui rend les graines vaines presque aussi lourdes que celle qui sont pleines et ne permet pas de les séparer à l'aide du van; la seconde est la petitesse des cónes de mélèze, qui modifie singulièrement et dans un sens défavorable la proportion entre les semences de bonne qualité de la portion moyenne de tout fruit de ce genre et celles mal conformées et généralement mauvaises qui proviennent de la base et de l'extrémité. Lorsque la graine est fraiche, il cn faut moyennement $193,000-205,000$ pour 1 kilogramme,

Germination. et elle germe rapidement, au bout de 5-4 semaines. Elle peut se conserver 5-4 ans, mais alors il lui faut d'autant plus de temps pour germer qu'elle est plus vieille et le plant ne lève qu'à la $2^{\mathrm{e}}$ et mème à la $5^{\mathrm{e}}$ année. On remédic à cet inconvénient en la laissant digérer, pendant un jour, dans de l'eau aiguisée d'acide chlorhydrique, une goutte par litre environ, que l'on expose aux rayons du soleil; elle germe alors fort peu de temps après le semis.

Jeune plant.

Le jeune plant lève avec $30-7$ feuilles cotylédonaires, ordinairement 6 , et produit immédiatement une pousse à feuilles solitaires non dentées (celles des plants d'épicéas et de pins le sont sur les bords). A la fin de l'année il a, dans de bonnes conditions, 10-12 centimètres de hauteur et son pivot s'est enfoncé de 10-2ว̀ centimètres, suivant les sols. Il mesure $0^{\mathrm{m}} 60-1^{\mathrm{m}}$ d'élévation dès l'àge de 2-5 ans.

Ecorce.

L'écorce du mélèze a les plus grandes analogies avec celle des pins, tant par sa surface gerçurée-écailleuse que par la structure et le mode d'accroissement; elle présente cependant quelques particularités qui lui sont propres.

Dès la $1^{\text {re }}$ année un périderme très-mince se produit dans la région moyenne del'enveloppe herbacée, en-dessous des canaux résinifères qui, tout superficiels qu'ils sont, périssent et disparaissent. Dans le parenchyme inférieur, qui a eonservé sa vitalité, s'organisent alors de nombreuses vacuoles résinifères, dont l'aceroissement en largeur est remarquable. L'écorce reste ainsi, à peu près lisse el grise, jusque vers 20 ans; mais à cet âge un périderme interne se développe, en lames souvent épaisses et d'un rouge eramoisi, dans les feuillets du liber et ceux-ci se transforment en une sorte de liége see ct brun qui s'aceroit rapidement. L'écorce se gereure alors et devient écailleuse, atteigmant parfuis au pied des arbres 
une épaisscur extraordinaire, qui, dans les stations élevées, va jusqu'à $0^{\mathrm{m}} 50$. Il n'y faut plus chercher dès lors d'autres organes résinifères actifs que les canaux rayonnants du liber, dont les dimensions sont d'ailleurs assez grandes.

Le mélèze est indigène des hautes régions montagneuses dont l'atmosphère est sèche et froide; il s'y trouve à la limite supérieure de la région des arbres verts et pénètre plus ou moins dans celle des pâturages alpestres. On ne le rencontre en France que dans les Hautes-Alpes du Dauphiné, où il forme des forêts étendues, soit seul, soit mélangé avec le pin à crochets et, dans ses stations les plus élevées, avec le pin cembro; il parvient jusqu'à $2,000^{\mathrm{m}}$ d'altitude.

On a cherché à répandre le mélèze en dehors de sa région naturelle, jusque dans les pays de plaines ou de coteaux. Il y végète avec une vigueur remarquable dans la jeunesse, mais il présente de bonne heure les indices d'une caducité prématurée; le bois en est de mauvaise qualité. (Voir l'article du cèdre).

Le bois du mélèze a l'aubier blanc-jaunâtre, très-apparent, mais toujours mince, alors mème qu'il croît dans les conditions les plus délavorables; le cour est brun rougeâtre clair et veiné ; il contient des canaux résinifères à peu près aussi nombreux et aussi gros que ceux du pin sylvestre (IIugo $M(h l)$; il est assez lourd et assez dur. Celui d'une tige de 116 ans, de 22 cent. de diamètre, provenant du Briançonnais et complétement desséchẻ à l'air, pèse 0,66 ; il a 20 couches d'aubier. (Envoi de M. Broilliard). Celui d'une tige de 25 ans, de 17 cent. de diamètre et provenant de Nancy, ne pèse plus que 0,55 ; le nombre des couches d'aubier n'est que de 6. (Coll., Ec. For.)

C'est un des bois les plus précieux que produisent nos forêts; une grande richesse en résine, des accroissements minces et réguliers lui assurent une durée très-prolongée, aussi bien à l'air que sous l'eau, une résistance et une souplesse remarquables. Il ne se gercure pas, n'est point attaqué par les insectes et convient aux constructions civiles, hydrauliques et navales (mâture et bordage). En Russie on l'emploie mème à la membrure des vaisseaux et un navire retiré de la mer du Nord, où il était submergé depuis plus de 1000 ans, avait encore du bois de cette espèce parfaitement sain et tellement dur qu'il résistait aux outils les plus tranchants. On en fibrique des bardeaux, du merrain 
et des tonneaux qui ont l'avantage de laisser très-peu évaporer les liquides, des échalas d'une durée presque indéfinie, des tuyaux pour la conduite des eaux, etc.

Le bois de mélèze du Briançonnais a la fibre souvent entrelacée et noueuse; c'est la conséquence d'un délit d'ébranchage, à la suite duquel de nombreux rameaux repoussent tout le long de la tige et forment une cime très-étroite, qui rappelle celle du peuplier d'Italie. (M. Broilliard).

Valeur calorilique.

Résinage.

Comme bois de chauffage, le mélèze a l'inconvénient de pétiller et de lancer beaucoup d'éclats, plus encore que les autres bois résineux; à cela près, il a une puissance calorifique assez élevée, qui est à celle du hẻtre comme $80: 100$. Le charbon qu'on en obtient est de bonne qualité, préfẻrable à celui du pin et de l'épicéa.

La térébenthine est assez abondante dans le liber du mélèze et cependant ce n'est pas de l'écorce qu'on la retire. On l'extrait de la région ligneuse moyenne, où une infiltration de la surface vers le centre l'accumule abondamment, surtout au pied des arbres.

On connait des procédés divers d'extraction; le suivant est pratiqué, dans le Valais, par des Lombards, qui en parcourent les forèts chaque année.

On ouvre, a $0^{\mathrm{m}} 60$ du sol d'abord et remontant ensuite jusqu'à une hauteur de $5-4^{\mathrm{m}}$, avec une tarière de 5 centiincitres de diamètre, plusieurs trous légèrement inclinés de bas en haut et dirigés vers le cœur de l'arbre, mais sans atteindre le cœur. L'opération se fait pendant la belle saison, et les trous se pratiquent de préférence du còté du midi et sur les chicots des anciennes branches. On munit leur orifice de gouttières en bois ou en écorce et l'on place au-dessous un auget. Un arbre de $50-60$ ans peut rapporter annuellement $5-5$ kilog. de térébenthine et cela pendant 40-50 années de suite, si l'on a soin de reboucher exactement les trous pour l'hiver. (Duhamel.)

Contrairement aux faits observés dans la pratique du résinage des pins, il parait que les mélèzes ainsi traités perdent toute leur valeur comme bois de constructions et ne conviennent plus qu'au chauffage. Cette anomalie apparente peut se justifier par la méthode usitée, qui consiste à soutirer du cour de l'arbre la térébenthine qui s'y infiltre et en incruste et solidifie le bois parfait, sans produire de lésions superficielles capables de balanecr ce résultat par unc notable 
diminution d'accroissement ou par une certaine évaporation d'essence et un dépôt proportionnel de résine dans les tissus.

Dans le Tyrol méridional on s'y prend différemment. Au printemps on ouvre au pied des arbres déjà forts, et jusqu'à leur centre, un trou horizontal de 3 centimètres de diamètre; si l'arbre est sur une pente, on choisit le côté qui regarde le bas de la montagne. On bouche l'orifice de ce trou avec un tampon de bois, enfoncé avec force. La térébenthine s'amasse dans la cavité pendant l'été et à l'automne on la retire avec un fer d'une forme particulière, après quoi on replace le bouchon. Au bout d'un an on extrait une nouvelle quantité de térébenthine et ainsi de suite chaque année. (Hugo Mohl.)

Ce procédé est infiniment moins productif que le précédent, mais il ménage bien plus les arbres et l'on n'a point remarqué qu'il nuisit à la qualité de leur bois. (Wesseli.)

Le résinage n'est point pratiqué, au moins régulièrement, dans les forèts francaises du Briançonnais.

La térébenthine du Mélèze esi connue sous le nom de térébenthine de Venise; on en extrait l'essence et différents autres produits. Elle est réputée plus pure et de meilleure qualité que celle que l'on retire des pins.

Les feuilles du mélèze excrètent une substance résincuse particulière, qui se solidifie sous forme de petits grains

Produits accessoires. blanchâtres et que la médecine utilise, comme purgatif, sous le nom de Manne de Briançon.

L'écorce jeune sert au tannage et dans quelques états de l'Allemagne la culture du mélèze a pris une certaine extension en raison de l'excellente qualité de ce produit; elle est aussi cmployée à la teinture en brun.

\section{GENRE IV, - CÈDRE. CEDRUS. Link.}

Feuilles persistantes, coriaces, tétragones, piquantes, éparses et solitaires sur les pousses qui s'allongent, fasciculées sur celles qui restent tuberculiformes. Chatons mâles assez gros, ovoïdes, au sommet de rameaux raccourcis et latéraux; chatons femelles situés de même, à bractées non accrescentes. Cốne gros et ovoïde, dressé, à écailles très-nombreuses et très-étroitement imbriquées, finalement mais difficilement caduques. Graines irrégulièrement triangulaires, largement ailées; embryon 9-cotylédoné. Ramification non verticillée. 
Bois brunâtre clair, dépourvu de canaux résinifères, mais pourvu de quelques cellules disséminées qui les remplacent (non apparentes à la loupe) et lui donnent une odeur aromatique prononcée.

Cèdre du Libau. Cednus Libani. Barrel. Cedrus Allantica. Manetti. Pinus cedrus. Lin. Cèdre de l'Allas.

Feuilles fasciculées, longues de 12-1 3 millimètres; feuilles solitaires, vertes, unicolores, de $25-40$ millimètres. Chatons mâles longs d'environ $\xi$ centimètres, ovoïdes, dressés, jaunàtres; chatons femelles de mème taille, naissant généralement vers le haut de la cime, d'abord pourpres, puis jaunàtres, à bractées obovales, très-courtes, érosées-denticulées ; écailles suborbiculaires, irrégulièrement dentées sur les bords. Cônes ellipsoïdes ou cylindrö̈des, déprimés au sommet, longs de 7-12 centimètres, larges de $5 \mathbf{- 7}$, plus ou moins courtement et fortement pédonculés, bruns et mats à la maturité ; écailles se resserrant sous l'action de la chaleur, s'écartant et finissant par se désarliculer sous l'influence de l'humidité. Graines longues de $12-15$ mill., ayant la forme de celles du sapin et, comme elles, renfermant, sous l'épisperme des vésicules remplies d'une térébenthine très-limpide; d'un gris roux clair et peu luisant, accompagnées d'une aile mince, roussâtre, largement triangulaire, du double plus longue qu'elles.

Var. «. Argenté. Viclor Renou. Feuilles plus courtes, généralement arquées el conniventes, de sorte que les faisccaux qu'elles forment sont presque globuleux; ayant une teinte glauque argentée en dessus, due à 2 raies blanches bien marquées. Cime en cône moins ouvert à la base que celle du type, à branches plus inclinées vers le sol.

Grand arbre à tige trapue, non verticillée, à longues branches horizonlales, densément ramifiées dans un mème plan; cultivé en France, spontané en Algérie. Flor., septembre-octobre. Fructif., juin-juillet de la $2^{\text {me }}$ année, 20 mois après la floraison. Disséminal., automne-fin de l'hiver ct même seulement printemps-élé de la $5^{\mathrm{e}}$ année.

Taille. Port. Arbre de très-fortes dimensions, atteignant $40^{\mathrm{m}}$ d'élévation, $9^{\mathrm{m}}$ et mème plus de circonférence à la base; dont la tige est trapue et puissamment ramifice en branches robustes, très-longues, non verticillées, horizontales ou léçèrement relevées, s'étalant en larges palmes très-planes, dont la face supérieure est densément feuillée, et formant par leur ensemble une vaste cime conique à couvert épais, dont l'envergure dépasse quelquefois $100^{\mathrm{m}}$ sur les arbres isolés. La perte de la fliche est souvent irremédiable et arrète l'accroissement en hauteur.

linracinement. L'enracinement se fait par de robustes racines pivotantes et tracantes.

Ecorce. L'écorce, d'abord lisse et d'un brun grisittre, se gerçure vers 20-30 aus et tombe par plarques; puis elle présente un rhytidone brun, gereurć-écailleux, dù à de très-courtes 
et très-minces lames de périderme, d'un gris-roux clair, qui s'interposent dans les couches extérieures du liber, dont les tissus se sont transformés en une espèce de liége see, d'un rouge brun, constamment repoussé au dehor's sous forme d'écailles peu étendues. On y observe de très-nombreuses vacuoles résinifères.

Le cèdre (cultivé) commence à fructifier vers 40-50 ans, mais peu abondamment. Le còne contient, en moyenne, une centaine de graines.

Pendant longtemps on n'a su obtenir celles-ci qu'avec beaucoup de difficultés, en perforant et détruisant l'axe du còne avec une tarière. On sait maintenant qu'en plongeant ce cône dans l'eau froide pendant 24-56 heures les écailles s'écartent et même se désarticulent, pourvu qu'il soit parfaitement mùr. Les graines ne souffrent pas de cette immersion, si on a le soin de les exposer à un soleil modéré pour les faire sécher.

Le cèdre, que l'on croyait relégué sur le mont Liban et représenté par quelques vieux arbres seulement, forme de vastes forêts dans l'Asie mineure et en Algérie; il couvre les sommets de l'Atlas à une altitude de $1400-1800^{\mathrm{m}}$, dans une région où la neige persiste généralement de décembre en mai.

Il fut introduit en France par B. de Jussieu en 1734 ou 1756 et bien que, comme la plupart des végétaux alpestres, il redoute les gelées dans sa première jeunesse, il s'y est naturalisé et il y fructifie (1).

(1) Le cèdre, cultivé en pays de plaines ou de coteaux, est sensible dans la jeunesse aux froids de l'hiver, parce qu'il ne trouve pas toujours dans ces régions l'épaisse couverture de neige qui l'abrite dans sa contrée natale; il y est aussi endommagé par les gelées du printemps, en raison de sa végétation précoce el des revers qui peuvent l'alteindre, revers qu'il ne saurait redouter dans les hautes montagnes où, à un hiver prolongé, succède brusquement un printemps sans retours. On avait espéré dans l'origine qu'une longue culture fortifierait son tempéramment el, qu'au bout d'un certain nombre de générations, il serait à l'abri des dangers qui menacent sa jeunesse ; qu'il serait enfin complétement acclimaté. Or, on en est encore à cet égard au point de départ et aujourd'hui le jeune cèdre non abrité gêle aussi facilement qu'il y a 120 ans, alors qu'on en tentait pour la première fois la culture. C'est une preuve de plus à ajouter à toutes celles que l'on possède déjà sur l'utopie des acclimatations. Un végétal ou un animal se naturalise d'embléc dens un pays qui lui

Fruclification.

Extraction de la graine.

Patrie. 
Bois. Le bois de cèdre ressemble assez à celui du sapin; il est comme lui dépourvu de canaux à résine; cependant il a une odeur aromatique vive et caractéristique, qu'il doit à quelques cellules résinifères disséminées; il est en outre brun ou brun-jaunàtre, avec l'aubier blanc bien tranché et assez abondant (2כ-30 couches). L'homogénéité en est beaucoup plus grande, parce que le bois d'automne est moins lignifié et se rapproche plus du bois de printemps qui l'est davantage; la fibre en est plus courte, le grain plus fin et plus doux, susceptible d'un poli plus parfait. Ces circons-

cst convenable; il meurt dans celui qui lui est impropre, il ne s'y acclimate pas. "L'acclimatation, cette douce chimère de la culture (du Petit-Thouars). * La limite géographique de chaque espèce est la mème depuis des siècles; cependant on ne trouve pas sur ces limiles de races distinctes; on n'aperçoit aucun indice de celte chimère que les agriculteurs poursuivent sous le nom d'acclimatation. Les espéces ne se plient nullement aux conditions de climat qui leur sont hostiles. Elles périssent plutôt que de changer. "(Alph. de Candolle, Géogr. bot.)

Il ne faudrait pas conclure de ce qui précède qu'il n'y a rien à attendre des essais de naturalisation en sylviculture et qu'il faut entièrement les abandonner. Sans contredit ils peuvent concourir à l'accroissement des richesses forestières du pays, mais il convient de ne s'engager dans cette voie qu'avec la plus grande réserve, sans s'obstiner à acclimater le végétal qui résiste à une naturalisation complète et surtout sans perdre de vue les magnifiques ressources que présentent les essences indigènes, qui, à une appropriation parfaite au climal de la France, joignent le mérite de réunir des espèces de qualités supérieures et assez variées pour satisfaire à toutes les exigences de la consommation, d'aptitudes tellement diverses qu'il s'en trouve parmi elles pour tous les sols, pour toutes les expositions, pour toutes les altitudes.

II faut ajouter qu'il y a des degrés très-divers de naturalisation, depuis celui de la plante qui vit et meurt dans sa nouvelle patrie, sans y fleurir ou au moins sans y fructifier, jusqu'à celui de la plante qui, pendant une longue suite d'années, dont elle a supporté la température variable, fruc. tifie régulièrement et peut, par sa seule puissance de reproduction et sans le concours de l'homme, disputer aux espèces indigènes, au milieu desquelles elle se maintient, la possession du sol nouveau sur lequel elle a été implantée. Or, bien peu de végétaux étrangers parviennent à ce degré de naturalisation, sans lequel, cependant, la culture forestière n'cn peut tirer aucun parti; de plus, cette première condition, déjà difficile à réaliser, n'est point suflisante; il faut encore que le végétal naturalisé produise dans sa nouvelle patric un bois de qualites identiques à celles yui le font rechercher dans son pays d'origine, ce qu'une parfaite simililude dans la marche el la durée des saisons de l'une el de l'autre contréc peut seule réaliser. 
tances rendent le bois de cèdre très-inférieur au sapin pour Ia résistance horizontale et par suite pour les constructions.

Les anciens ont beaucoup exalté les propriẻtés du cèdre, mais il parait que sous ce nom ils ont souvent désigné plusieurs essences différentes. La culture de ce végétal en France et l'usage des bois qu'il y a produits sont loin d'avoir justifiẻ cette antique réputation.

La contradiction n'est cependant point aussi grande qu'on pourrait le croire. Les anciens, en effet, ne connaissaient que peu ou point les Conifères de l'Europe moyenne et septentrionale et, en l'absence d'un terme aussi important de comparaison, ils ont dú être frappés des qualités que possède réellement le cèdre, qualités que les Arabes, qui l'emploient depuis longtemps, s'accordent aussi à lui reconnaitre, et le placer au premier rang. D'ailleurs, et tout en admettant une certaine exagération dans leur appréciation, il faut se rappeler que le cèdre qu'ils vantent provenait spontanément de la région qui lui est propre et se trouvait formé d'accroissements minces et égaux, en raison de la rigueur du climat, de la courte durée de la période de végétation et de la régularité des saisons. La densité d'un bois de cette nature, parfaitement desséché à l'air, s'est trouvéc égale à 0,77 (Coll. Ec. For., Envoi de M. Rnyer.); il provient de l'Atlas, d'une tige âgée de 88 ans et qui, cependant, ne mesurait que $0^{\mathrm{m}}, 17$ de diamètre, dont le $\frac{1}{4}$ consistait en bois d'automne.

Les modernes, avec des éléments plus nombreux de comparaison, n'ont fait reposer leur jugement que sur du bois provenant d'arbres cultivés dans des plaines ou dans des régions peu élevées. Or, dans ces conditions, le cèdre, arrivé à un certain àge, se développe avec une rapidité extraordinaire et produit des accroissements aussi irréguliers que l'est le climat sous l'influence duquel ils se forment, le tout aux dépens de ses qualités. C'est ainsi qu'un des plus vieux cèdres de France, d'environ $12 \%$ ans, qui se trouve dans un pare de Seine-el-Marne, mesure $7^{\mathrm{m}}$ de circonférence à $2^{\mathrm{m}}$ du sol, et qu'un arbre de cette espèce, provenant de Nancy et mesurant, à 19 ans, 26 cent. de diamètre, a fourni un bois dont le $\frac{1}{18}$ seulement est formé par le tissu d'automne et dont la pesanteur, à l'état de complète dessiccation à l'air, n'est que 0,47 . Le rapprochement de ces chiffres avec ceux qui précèdent est plus que suffisant pour 
justifier l'apparente contradiction des jugements portés sur le bois de cèdre.

Valeur Le cèdre est un mauvais bois de chauffage, qui passe vite calorifique. au feu, pétille beaucoup et dont le charbon noircit promptcment.

Résinage. Il peut fournir de la térébenthine et se trouve soumis au résinage, qui se pratique probablement comme celui de l'épicéa.

Tribu II. - PIN's. - Ghatons mâles agglomèrés à la base des pousses de l'amnée; chatons femelles très-petits, axillaires, solitaires ou verticillés au sommet des mêmes pousses, immédiatement en-dessous du bourgeon torminal; cônes à écailles persistantes, ligneuses, épaissies ì leur extrémité en une sorte d'écusson souvent pyramidal, surmonté d'une protubérence mutique ou mucronée; à bractées toujours oblitérées. Graines assez régulièremenl ovoïdes-déprimées, non tronquées comme le sont la plupart de celles des abiélinées de la première tribu, it aile caduque. Maturation 2- rarement 3- anmuelle. Feuilles allongées, réunies à la base par 2, 3 ou 5 dans une gaîne écailleuse.

\section{genre v. - PIN. PINUS. Tourn.}

Mêmes caractères que ceux de la famille.

Arbres à ramification verticillée sur la tige, sur les branches et sur les rameaux.

Bois aubier blanc, bien prononcé ; bois parfait plus ou moins rougeâtre, contenant de nombreux canaux résinifères dans la zone moyenne et externe de chaque couche.

Terébenthine. La térébenthine du bois des pins est formée de proportions très-variables d'essence et de résine, suivant les espèces. Lorsque l'essence abonde on voit s'écouler de l'arbre exploité une tírébenthine très-fluide, très-volatile et, quand le bois est desséché, il est fort peu résineux et généralement léger. Si l'inverse a lieu, la térébenthine est visqueuse, elle laisse par la dessiccation une résine abondante dans les tissus, et le bois est assez lourd. Les pins à erochets, cembro, Weymouth sont dans le premier cas; les pins sylvestre, laricio et maritime dans le second. 
La proportion d'aubier et de bois parfait que les pins peuvent présenter, suivant les cspèces et les conditions de la végétation, a beaucoup d'importance, car la différence entre ces deux régions est non-seulement nettement indiquée par la coloration, mais aussi par la qualité, et l'on peut dire que plus le bois parfait est lignifié, imbibé de résine et devient supérieur par la densité, la résistance et la durée à celui du sapin et de l'épicéa, plus l'aubier en est mauvais, sujet à la vermoulure et à la pourriture, que de nombreuses taches d'un noir-bleuâtre rendent bientòt manifeste. C'est la conséquence d'une loi générale, qui s'applique à la plupart des végétaux ligneux, à savoir : que plus le bois emploie de lignine et de résine pour arriver à l'état parfait, plus dans son jeune âge, à l'état d'aubier, il devra élaborer ou contenir en dépòt de ces principes fermentescibles, fécule, sucre ou gomme, destinés par leur transformation à le lignifier.

Les pins ne supportent pas le couvert et exigent dès l'origine une insolation directe, constante; ils ne s'accroissent donc que sous des influences sensiblement égales, au moins à ce point de vue. C'est pour ce motif que le bois en est d'une structure plus uniforme, quant à l'épaisseur des couches annuelles successives, que celui du sapin et mème de l'épicéa qui, en raison de leur tempérament, subissent souvent de longues périodes de contrainte sans succomber.

Les feuilles que les pins forment dans leur toute première jeunesse sont solitaires, spiralées, raides, insensiblement effilées en pointe aiguë et denticulées sur les bords. Dès la seconde année, en général, ces feuilles ne se produisent plus qu'à l'état d'écailles sèches, triangulaires-aiguës, à l'aisselle de chacune desquelles existe un prompt bourgeon, dont le développement immédiat fournit les aiguilles habituelles des pins. Les écailles inférieures de ce bourgeon, pressées les unes contre les autres, ne s'accroissent pas et constituent la gaine; les 2,5 ou 5 feuilles supérieures s'allongent seules. Celles-ci sont fasciculées et en nombre limité, parce que l'axe qui les supporte ne s'est point allongé et que son extrémité a perdu rapidement sa vitalité. Cependant, si, dans quelques cas, les aiguilles sont détruites immédiatement après leur développement, par des chenilles par exemple, il arrive souvent que le point vital extrème se ranime et reforme des aiguilles nouvelles.

Quelques espèces de pins, le pin pinier entre autres, 
présentent, pendant assez longtemps et indifféremment sur un mème rameau, des aiguilles engainćes ou, à leur place, des ramules allongés et couverts de feuilles solitaires, spiralées et denticulées, dont les aisselles sont généralement stériles.

Les 2,5 ou 5 feuilles des pins représentent en somme un très-court rameau axillaire et rappellent tout à fait les feuilles fasciculées des cèdres et des mélèzes ; seulement chez ces derniers les bourgeons qui produisent les faisceaux n'entrainent pas l'avortement de la feuille mère, ils sont disséminés, n'ont pas un développement immédiat et ils conservent leur extrémité active pendant plusieurs années, de sorte que le nombre de leurs feuilles, toutes semblables, n'est point rigoureusement limité.

II n'est pas rare de voir chacun des rameaux raccourcis ou fascicules des pins se transformer en une inflorescence femelle et produire des cònes qui, quelquefois, garnissent les pousses sur toute leur longueur.

Les aiguilles des pins forment, lorsqu'elles sont rapprochées, un cylindre complet et se touchent par des faces planes. Suivant done qu'elles sont engainées par 2, 3 ou 5 , chacune d'elles a la forme de $\frac{1}{2}, \frac{1}{3}$ ou $\frac{1}{5}$ de cylindre.

Fructification. La floraison des pins n'est pas suivie d'une fécondation immédiate et les tubes polliniques ne parviennent aux embryons qu'au printemps de l'année suivante. Jusque-là les cònes sont restés très-petits, sans s’accroitre; mais, à partir de ce moment, ils grossissent rapidement et ils parviennent à toutes leurs dimensions dans le courant de l'année mème ou de celle qui suit.

A. Feuilles géminées, à gaines persistantes; écusson terminant les écailles des cônes à protubérance centrale; écorce gerçurée-écailleuse, rouge brunâtre.

B. Cône conique, à maturation bisannuelle ; graine grandement ailée, à épisperme crustacé.

C. Cône mal, gris verdâtre ou brunâtre, de 5-6 cent. de long, à écussons plans ou prolongés, sur la partie supéricure du cône, en pyramides étalées ou légèrement réféchies, grêles, à faces concaves. Feuilles glaucescentes, de $5-6$ cent de long............ P. sxuvestne.. 1 $\mathrm{C}^{\prime}$. Cỏne luisant.

D. Ecussons de la partic supéricure du còne prolongés en pyramides réfléchies, 
épaisses, à faces convexes. Feuilles de

5 -6 cent. de long, vertes, non glauques. P. A crochets. 2

DI. Ecussons jamais prolongés en pyramides réfléchies.

E. Cônes de $\breve{-8}$ cent. de long, d'un jaưne roussâtre, coniques-aigus et arqués, à écusson transversalement pyramidal. Feuilles de 10-1 1 cent., épaisses, d'un verl foncé.................. P. Laricio... 5

E'. Cûnes de 8-14 cent. de long, d'un roux vif.

F. Ecussons presque plans, transversalement et finement carénés. Feuilles de 6-17 cent., grêles, d'un vert clair.............................

$F^{\prime}$. Ecussons pyramidaux, très-saillanls, aigus, transversalement carénés. Feuilles de $10-25$ cent., épaisses,

d'un vert jaune............. P. мaRitime... 丂

B!. Cône gros, ovoïde, obtus, à maturation trisannuelle. Graines grosses, à aile très-étroile et très-caduque, revètues d'un épisperme épais et ligneux. Feuilles assez grêles, d'un vert clair,

de 8 à 15 cent. ..................... Piner.... 6

A'. Feuilles quinées, à gaînes caduques; écussons à prolubérance terminale ; écorce lisse el vive jusqu'à un âge avancé, d'un grris brun verdâtre.

B. Cône ovoïle-obtus, gris-brun mat, à graines révêtues d'un épisperme epais el ligneux, dont l'aile est très-courte et caduque. Feuilles de $6-12$ cent., raides................ Р. свмвво...7

B'. Cône grêle, cylindracé, arqué, brun mat, à graines longuement ailées, à épisperme crustacé. Feuilles de $6-8$ cent., très-grêles......

P. D'ALEP.... \&

P. Weysouth. 8

\section{Section I. Pins à 2 feuilles.}

Feuilles géminées, à gaîne persistante ; écailles des cônes terminées par des écussons dont la protubérance est centrale. Ecorce gerçurée-lamelleuse et rougeâtre dès la jeunesse.

1. Pin sylvestre. Pings syluestris. Liv. Pinus rubra Milz. Pin de Haguenau; pin de Genève, de Riga, de Russie, d'Ecosse, de mâture.

Feuilles longues de $50-6$ centimètres, étalées-dressées, glaucescentes, raides, aiguës et piquantes, un peu rudes sur les bords. Chatons mâles rosés ou jaunàtres, oblongs, de $6-8$ mill.; chalous femelles à bractées plus courtes que les écailles. Cònes solitaires, géminés ou ternés, brièvement pédonculés, réflectris dès la première année, longs de 3-6 centimètres, oblongss-coniques el aigus, d'un gris-verdàtre ou brunàtre mat; écailles à écusson plan ou prolongé sur la face supérieure du còne en une 
pyramide étalée on réfléchie, grêle. tronquée, à arêles concaves. Graines petites, de 4 mill. de long, elliptiques-aiguës, légérement luisantes, les unes noires, les autres d'un gris clair: ailes $\overline{3}$ fois plus longues qu'elles, roussàtres, rayées de brunàtre. Embryon है-6-colylédoné. - Grand arhre commun sur les sols sablonneux des plaines el des conlreforts des montagnes du nord.est el de l'est, oủ il forme seul ou mélangé des forèts considérables : abondant aussi dans le centre de la France el dans les Pyrénérs; introduit presque partout par la cullure. Flor., mai-juin. Fruclif., septembre-octobre de la seconde année. Dissémin., printemps suivant, 22 mois après la floraison. Le còne persiste 1 an ou davantage après la chute des graines.

Taille. Le pin sylvestre est un arbre de grande taille, qui atteint 50 et mème $40^{\mathrm{m}}$ d'élévation, mais dépasse rarement $4^{\mathrm{m}}$ de circonférence et reste à cut iggard bien en arrière du sapin

Port. et de l'épicéa. Elevé en massif, la tige en est élancée et complétement dénudée jusqu’à une zrande hauteur, sans conserver de traces des anciens verticilles; la cime, composée de branches e't de raneaux verticillés, est d'abord pyramidale-aig̣uë; pris à un certain âge, loujours élevé, elle cesse de saccroitre en hauteur et, en développant quelques-unes de ses branches latérales, elle devient courte et plane, étalée, irrégulièrement ramifiée. En liberté, le pin sylvestre s'élève peu et se maintient très-branchu à une faible distance du sol.

On a décrit un grand nombre de variétés ou de races du pin sylvestre, qu'on peut rapporter à deux principales; $1^{\circ} l e$ Pin de Riga, à ligge droite et élevée, revétue d'une érorce rougeàtre, dont la cime est aig̨uë, garnie de feuilles allongées, très-glauques, dépassant les cònes, qui sont habituellement verticillés et pourvus sur le còté supirieur d'écussons prolongés en pyramides grèles et légèrement réféchies. 2 le Pin de IIaguencu, remarquable par une tige ordmairement fléxueuse, un feuillage plus court et moins glauque que le précédent, des rónes plus perits, généralement solitaires, dont les écussons restent plans ou se prolongent faiblement.

En réaluté rien n'est plus difficile que de caractériser sủrement ees deux races, yui nont rien de stable et se fondent incessamment fune dins l'autre, et si lon ne peut nier l'action des influenees elimatériques sur leur production, il faut bien reconmaitre que les modificalions quu en résultent n'ont de doree quautint que ees influences persistent et qu'elles s'effacent rapidenuent dès que celles-ci cessent de 
se faire sentir. C'est ainsi que les semis de pin de Riga faits dans les plaines de la France ne donnent pas, à un certain àge, de ré-ulıats supérieurs à ceux de pin de Haguenau. D ailleurs la part du climat parait être ici la moindre et il semble incontestable que ces races sont surtout la conséqquence des conditions de sol et de culture sous lesquelles les arbres s'accroissent, à ce point que dans une seule forèt on les trouve souvent mélangées et qu'il est en quelque sorte possible de les créer à volonté.

Tout en amoindrissant la part du climat dans la production des race-, on ne saurait cependant la méconnaitre entièrement et c'est sans doute un tor't de semer en toutes contrées des graines de race unique et de négliger les races tocales ou celles des régions identiques, dont le succès est plus assuré. C'est néanmoins du perfectionnement des méthodes culturales et de leur arplication assidue qu'il faut attendre les principales améliorations des pineraies.

La lige du pin sylvestre est souvent flexueuse et ce défaut, bien moins inhérent à la race de Haguenau, à laquelle on le reproche principalement, qu'aux conditions sous lesquelles elle se développe d'habitude, se remarque principalement sur les sols sees et maigres des plaines des climats tempérés. Dans de telles circonstances en effet des insectes d'espèces très-diverses (hylobes, hylésines, pyrales, etc.) abondent dans les pineraies et en détruisent les pousses terminales. Des pousses latérales, verticillées comme elles, se redressent, il est vrai, et les remplacent facilement, mais en formant avee la tige qu'elles prolongent un coule ou une courbe plus ou moins marqués que l'àre n'effice jamais complètement. L'action des rents violents peut aussi, dans ces sols meubles, produire un effet identique en ebranlant, sans les renverser, les tiges des pins et 'n leur donnant successivement diffirentes directions oblipues qui, combines avec celle des pousses nouvelies extremes, loujours verticales, déterminent des coubes variées à grands rayons.

Les pins qui croissent en sol fertile, maintenu frais par un massif' subordonné d'essences protectrices ot ceux qui se trouvent dans des elimats rudes nont rien à retouter des insectes, que de semblables circonstances écartent toujours; ils se disting̨uent à leurs tiges droites et élancées, surtout quand un sous-sol rocheux offre à leurs racines un point d'appui convenable pour résister à l'eflort des vents. 
Enracinement. L'enracinement est assez variable: en sol léger et profond, le pivot se développe beraneupi et forme la partie essentielle de la racine jusque vers $50-40$ ans; passé ce terme, les racines latérales s'aceroissent avec vigueur, mais ont aussi une tendance à s'enfoncer. Dans les terrains liants, au contraire, le pivòt s'arrète de très-bonne heure et des racines latérales peu profondément situées ne tardent pas à le remplacer.

Le volume du bois de souche est en moyenne à celui de l'arbre coupé rez de terre comme 12: 100 .

Feuillage. La feuille du pin persiste au moins $\overline{5}-4$ années dans la jeunesse, tout au plus $2-53$ années à un àge avancé; aussi le Couvert. couvert diminute-til d'une manière scusible avec l’àge. D'abord assez complet, il devient tres-lézer et son action, déjà si peu efficace pour protéger le sol, décroil encore rapidement en rasson de la bituleur i laquelle la cime parvient. Les detritus sont petu abondants, fournissent un bon engrais, d'une décomposition lente cependant, à cause de la consistance coriace, de la structure fibreuse des aiguilles et du manque de fraicheur superficielle qui se fait généralement sentir dans les forèts de cette essence. Malheureusement cette litière est très-exposice à ètre enlevée par les habitants des communes riveraines, dont le sol participe plus ou moins à la nature ingrate, au point de vue agricole, de celui de's pineraies. On estime que fe fumier des feuilles de pin équivaut à moitié de son poids de fumier de paille. (T. Hartig).

Ecorce. L'écore de pin peut servir de type à celles de tous les pins à 2 feusilles, pour la structure anatomique. Dans la première jemesse elle est revèue d'un póriderne tout superficiel, qui, dis :5-6 ans, se sipare en écailles minces; en dessous se trouvent le parenchyme vert et les canaux résinilères Iongrudinaux qui en dépendent, puis le liber, de nature entierement cellulaire. Vers 8-10 ans, un poriderme interne, gris-rougeâtre, sorganise d'abord à la surlare des fenill'ts libériens, pus les insahit en plus grande partie et dessèche tout ce yui le recoure, parenchyme ot eanaux. Ce périderme, composé de cellules à minces parois qui se déchirent ansement, forme des lanes nombreuses mais peu étendues, extirieurement concaves, yui partagem le liber en plaques de lorme correspondante. Lin mème temps que le liber se fractionne, il se translorme et s'aceroit en un paren- 
chyme subéreux, sec et fragile, d'un rouge-brun assez foncé. De là résulte un rhytidome écailleux, gerẹuré en tous sens, mais surtout longtudinalement, qui, an pied des arbres, alteint une épaisseur considerable et prend une teinte rougeàtre ou gris-brun, suivant qute l'aclivité de la végétation est plus ou moins gramble el qu' elle provorpue un dépouillement superfirtit plus ou moins rapide. La faible portion interne du liber qui a conservé de l'activité contient des canaux résinifères rayontmants, mais ils y sont peu développés.

A une dizaine de mètres au-rlessus du sol, la formation de l'écorce se modifie grandement dans un vieil arbre. Le périderme s'y organise en courhes continues concentriques très-minces et fait tomber le liher non modifié sous forme de feuillets nembraneux, semblables à du papier. L'écorce alor's ne s'épaissit pas; elle peste minee, lisse, brillante, d'un roux clair, d'autant plus vif yue la végétation est plus vigoureuse.

La fécondité du pin est très-préence et l'on voit des apbres isolés qui, à 1 :̉ ans, produisent déjà des cònes et de bonnes graines; cependant, dans les massifs, ce n'est guère que vers 50 ans et mème au delà qu'clle se prononce. En géuéral on trouve au moins quelques cones chaque annéc, mais il n'y a abondance que tous les $\mathbf{b}-\mathrm{b}$ ans.

L'extraction des graines se fait soit à l'aide du soleil, soit priférablement au moyen de la chaleur" artuficielle, dans des étuves que l'on peut chaufler jusqu'i $58-4.4^{\circ}$, sans craindre d'en altérer la vitalité. On arrose pour faciliter l'ourerture et l'on désaile au fléau plutò quíarec de l'eau, qui gonfle la graine et nuit à sa qualité. I hect. de cònes donne en moyenne $1^{k}-1^{k}, 2 j$ de graines ailées; on en sépare environ

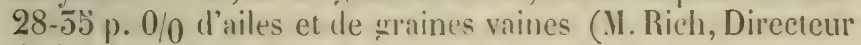
de la sècherie de Haguenau). Les graines ailées se conservent plus longtemps que les autres.

La graine désailée ressemble henucoup à celle de l'épicéa par la grosseur et par la forme, bien yu'elle soit plus régulièrement arrondie et moins aigutë a la pointe; elle se distingue aisément par la couleur et l'éclat.

Considérée en masse, elle présente un mélange de graines blanchàtres et cle graines d'un brun noir; elle est en outre légèrement brillante, tandis que la graine d'épicéa est d'un roux brunatre uniforme et mat. Il est vrai que l'on teint

Fructification.

Graine. 
quelq̧uefois ces dernières en brun pour compléter leur ressemblance arec celles du pin, dont le prix est de $600-70$ p. $0 / 0$ plus élevé; dans ce cas l'absence de graines blanchàtres fera aisément reconnaitre la fraude.

Il ne laut pas rebuler la semence de pin en raison des graines blanchàtres qui s'y trouvent, car elles s'y remontrent toujours et peuvent ètre d'aussi bonne qualité que les brunes.

Il entre environ 160000 graines fraiches et désailées dans un kilog̣ranme. La conservation en est possible pendant 5-4 ans; néanmoins, quand elles sont vieilles, elles ont souvent l'inconvénient de ne lever qu’à la seconde année.

Germination.

Stnsée au printenips, la graine de bonne qualité germe au bout de 3 -4 semaines el produit bै-6 feuilles cotylédo-

Jeune plant. naires, rarement plus ou moins. A leur centre s'élève une pousse presque inujours simple, dont les feuilles sont solitaires, planes, aignës, grlanques et denticulées sur les bords. Le jeune plant ne dépasse pas 5-6 centimètres an bout de l'année, mais la végétation souterraine en a été plus active et le pivot s'est enfoncé d'environ 18-22 centimètres, quand le sol est convenablement mubble. A la seconde année la pousse qui se développe présente encore à la base quelyues feuilles solitaires bien conformées; mais peu à peu celles-ci se réduisent et, à une faihle hauteur, elles n'apparaissent plus que sous forme d'écailles pointues, sc̀ches et brunes. C'est alors que se produisent, à l'aisselle de ces dernières, les feuilles géminées, qui, désormais, seront les seules qui se développeront. Le pin se verticille de bonne heure, vers 5 ans, et prend immédiatement un accroissement rapide.

Station. Le pin sylvestre a une aire d'habitation très-étendue en surface, assez restreinte en altitude, et constiue de vastes forits dans les plaines du nord de l'Europe, jusqu'en Sibérie. En France, on le rencontre, seul ou mélangré avec le chène, le bouleau, le sapin, dans les plaines et sur les contreforts des montingnes du nord et du vord-est. Dans le plateau central de la France, il s’éleve déja a $1100^{\mathrm{m}}$ (M. Iatabussière, imspecteur à Clermont) et dans le midi, dans les Pyrénées, par exrmple, il ne commence à se monsrer qu’à une altitude de $1200^{\mathrm{m}}$ environ. Le poids de la neige et du givre qui s'amoncellent sur son feuillage à longues aigulles, l'action des vents violents et la fragilite de ses branches l'excluent des régions très-élevées. II occupe généralement la zòne immédiatement inférieure à celle du sapin. 
Cette essence préfìre, entre tous, les sols siliceux profonds et frais, mais elle réussit encore sur ceux qui sont secs; elle prospire sur les sols graniriques et mème volcaniques, mais elle s'accommode mal iles terrains calciires, où elle fruclifie prématurément, aux lépens de ses aceroissements; le bois d'ailleurs y devient très-cassant. Comme tous les arbres à couvert très-léxrer, le pin a be'soin d'espace pour prospérer, ne se maimtient pas en massif's scrrés et ne peut, à lui seul, protéger le sol, qu'une végétation parasite ne tarde pas à envahir. Il est néanmoins trés-précieux pour repeupler les terrains vagues ou arides, surtout aux expositions méridionales, où toute autre espèce refuserait de croitre, sort quion venille le maintenir indéfiniment en possession du sol, soit qu'on ne le considère que comme peuplement transitoire.

Le bois aubier est blanc ou hlane jaunàre, de quantité fort diverse suivant les sols (27 a 80 couches sur les échantillons de la collection de l'Ecole forestière); le bois parlait est rougeâtre; les canaux résmufères sont nombreux, les longitudinaux bien apparents et la térébenthine y abandonne beancoup de résine par la dessiceation; on la voil s'écouler de l'aubier avee assez d'abondance quand on fait à l'arbre une section transversale.

La pesanteur est très-variable suivant l'àge et la quantité de la résine, le point de la tige d'nù provient le bois, etc. Du pin sylvestre de la forèt de Haguenau a offert à cet égard les résultats suivants :

Bois de 120 ans - diam. $0^{\mathrm{m}}, 60$ - pèse, desséché à l'air 0,653 .

Bois très-résineux, dit bois gras, Id. 0,807 .

Bois de l'extrémité supérieure de
la tige d'un vieil arbre,
Id.
0,480 .

D'après G. L. Hartig la pesanteur moyenne est : vert, 0,906; desséché à l'air, 0,78 ; complétement sec, 0,54 .

Lit valeur calorifique varıe tout autant; comparée à celle du hètre, elle offre les rapports suivants (T. Hartig):

$\begin{array}{ll}\text { Bois de tige de } 120 \text { ans } & 0,85: 100 . \\ \text { Bois de tige de } 80 \text { aus } & 0,75: 100 . \\ \text { Bois de souche de } 120 \text { ans } & 1,15: 100 .\end{array}$

C'est done un combustible supérieur au méléze, à l'épicéa, au sapin; il produr une chaleur vive, élevée, mais peu durabile. Le charlon, unlisé dans les hauts foumeaux, est, en moyenne, à celui du hètre, comme $0,750,80: 100$.

Densité.

Valeur calorifique. 
Usages. Le pin sylvestre fournit l'un des meilleurs bois de mâture, parce que, à des dimensions considérables, il réunit l'élasticité, la légèreté, la durée. Ces conditions sont particulièrement réalisées lorsque les accroissements annuels sont minces et réguliers, et ce n'est guère que dans les contrées du nord de l'Europe, où la période de la végétation est trèscourte et le climat très-constant, qu'on peut les obtenir (1). C'est en outre un excellent bois pour le's constructions civiles et navales, qui se distingue par une durcée égale à celle de nos meilleurs bois feuillus; il se dibite en madriers, planches, etc., est propre à la fente, fournit d'excellents poteaux pour lignes télégraphiques, etc.

Résinage. On ne résine génćralement pas le pin sylvestre, si ce n'est en délit. La résine s'accumule parfois en très-grande abondance dans quelques parties de la lige et en imprègne complélement le bois, qui devient dur et presque translucide comme la corne. Les délinquants enlèvent tout ce bois, le réduisent en menues buchettes et le vendent sur les marchés, sous le nom de bois srras, pour l'allumage du feu.

Goudron. On retire cependant des produits résineux des souches, où la résine est plus abondante que dans la tige. Il suffit pour cela de les carboniser en vase clos dans des fours en maçonnerie, d'une construction spéciale. La résine se liquéfie, se mélange aux produits empyreumatiques de la distillation et s'écoule sur le sol du fourneau, pour, de là, arriver par un conduit particulier dans des récipients disposés à l'extérieur. On recueille de la sorte un produit visqueux et brun que l'on nomme Goudron.

Produits L'écorce du pin renferme de la fécule et sert, dans les accessoires. contrées du Nord, à la nourriture des porcs et mème, en temps de disette, à celle des hommes.

On fabrique depuis quelques années, avec les faisceaux

(1) MM. Bravais et Martins ont fait voir que le pin, pour être propre à la mâture, doit avoir les accroissements anmuels égaux, d'une épaisseur de 1 millim. au plus; qu'il doit pour cela végéter dans un climat rude, dont l'élé est de 15 à $1 k^{\prime \prime}$ en moyenne et dont l'hiver est rigoureux et ne dépasse pas une moyenne de $-3^{\prime \prime}$ à-/p. Ces condilions ue peuvent être réalisées en France que dans les régions monlagneuses élevées où malheureusement les vents, la neige, le givre, le peu de profond ur du sol sont des obstacles souvent insurmontables a la culture de cette essence. 
fibreux, allongés, et tenaces des aiguilles, une espèce de drap grossier; on en fart aussi du carton.

Les jeunes pousses sont yuelquefois employées dans le Nord, en place de houblon, dins la fabrication de la bière; mais cet usage n'est pas spécial au pin sylvestre et beaucoup d'autres résineux y sont propres.

Les cônes vides sont très-f'echerchés dans l'économie domestique pour allumer le feu el dans le Wurtemberg on les emploie avec succès au tannage des peaux.

2. Rin à crochets. Pinus uncivata. DC. P. Mugho. Poir., Loiscl. Pin suffin; Pincrin; Torche-Pin; Suffis.

Fenilles serrées sur les rameaux, dressées, vertes, raides, pirquantes, de la longueur de celies du pin sylvestre ou un peu plus courtes, mais à gaînes plus longues de 1,5. Chatons mìles blanchâtres, longus de 10-12 mill.; chatons femelles à bractées légèrement saillantes. Còne redressé pendant la première année, puis étalé ou réfléchi, de la taille de celui du pin sylvestre, sessile, ovale-conique, obtus, presque toujours un peu arqué, brun ou jaune bruıàtre, luisant; écussons prolongés en pyramides entièrement réfléchies, épraisses et obtuses, dont les arètes, au moins la supérieure, sont convexes. Graines semblables à celles du pin sylvestre, à ailes 2 fois aussi longues qu'elles seulement. - Arbre élevé, droit, à cime pyramidale très-régulière.

Var. $\alpha_{0}$ Chétif. Tige rameuse dès la base, ne s'élevant pas au-delà de $2^{\mathrm{m}}$, à branches lınguement conchées, tortueuses, redressees au sommet, s'allongeant souvent pendant plusieurs années de suite saus produire de rameaux latéraux ni de verticilles. Pinus pumilio. Honk. Pinus Mughus. Scop. Mugho.

Habite les régions montagneuses élevées et forme des forêts assez étendues dans les Alpes, à une altitule de $1500-2500 \mathrm{~m}$; se retrouve aussi sur les sommeis des Pyrénées, mais à l'état de dissémination. La variété $\alpha$ crô̂l dans les lieux lourbeux des mêmes régions, aux environs de Gap, sur le Mont-Genèvre dans les Alpes et principalement dans le Haut-Jura. Flor., juin-juillet. Fructif., automne de la seconde année. Dissém., printemps suivant.

Le pin à crochets est un arbre droit, de croissance extrèmement lente, qui atteint vers $160-200$ ans $25^{\mathrm{m}}$ de hauteur sur $1^{\mathrm{m}} 20$ de circonfírence à $1^{\mathrm{m}}$ du sol. La cime, peu étalée, en est élancée et très-régulière; les branches sont peu nombreuses et toujours faibles; les feuilles sont serrées el donnent un couvert épais.

L'enracinement est cornposé de plusieurs maitresses racines, plutòt tracantes que pivotantes, qui partent de la partie inférieure de la tige; on n'y remarque pas de pivot principal.

L'écor'ce est analogue à celle du pin sylvestre dans sa

Taille. Port.

Enracinement.

Ecorce. 
structure, mais elle est d’un gris hrun uniforme jusqu'au sommet et des vacuoles résuniferes y sont abondamment disséminées. Elle n'offre jamais ces feurllets mmees qui se séparent el celle couleur d'un roux vif que le premier présente à une certaine élévation.

Le pon plus rígulier, la tige plus élancée, la couleur différente de l'éerce distinguent, an prenter coup d'oeil, le pin à crochets du pin sylvestre, toujours mal-venant et rabongri, lorsque par hasard il croit a la mème altitude. Le feuillage est aussi d'un vert plus sombre, à tel point que, sans offrir la teinte noire des sapinières, les forèts de pins à crochets peuvent se recommaitre à de grandes distances, par leur couleur d'un vert foncé, de celles de pins sylvestres, dont la tente générale est grisâtre.

Station et sol. Le pin à crocheis recherche les climats sees et froids, semble s'accommoder de toutes les expositions et vient dans les plus mauvais terrains, jusque sur les rochers dans les fentes desquels il enfonce ses rucines. Un sol léger parait néanmoins lui convenir le mieux.

Jeune plant. Le's jeunes plants sont robustes et, cependant, souffrent moins sous le couvert que cenx du pin sylvestre; une fois dégarés, ils peuvent reprendre une belle vérétation.

Bois. Le bois est blanc. lexgèrement rougeàtre-rosé au cour; il a le grain fin, très-doux et assez homogène. Vert, il contient une abondante térébenthine très-fluide, qui s’évapore presque en totalité et ne laisse, par la dessication, qu'une faible quantité de résine. Les aceroissements sont très-minces, égaux, limités par une zone étroite de bois d'automne, à peine plus lignifiée que celle du printemps.

Usages. Ce bois semblerat, par ses accroissements minces et réguliers, avoir les qualités requises pour la mâture et nul doute quion ne pourrait l'obtenir des dimensions exigrées pour cet usage, en l'exploilant à une révolution convenablement clevée. Reste a savoir si, par sube de sa paureté en résine et en hois d'antomne, il presenterait des conditions de durée et de résistance suffisantes; cela semble doutenx. C'est en tout cas un bou bois de construction et d'industrie, d'un traval el d'une fente liciles, produisant un combustible estimé, sans doute preférable sous re rapport à l'état vert, alors quil est grorere d'essence de tivibenthme.

Densité. Du brois d'une lige de $112 \mathrm{ans}$, de $0^{\mathrm{m}} 25$ de diamètre, provenant des Alpes du Brianconnais, ne pèse, compléte- 
ment desséché à l'air, que 0,47. (Coll. Ec. For. Envoi de M. Broillard.)

Quant au pin chétif, dont les branches rampantes et entrelacées atteignent quelquefois $10-15^{\mathrm{m}}$ de long, pour ne se relever que par leurs extrémités, il forme souvent dans les tourbières des fourrés inextricaliles de hauteur d'homme. Les fables dimensions auxquellesil est le plus fréquemment restreint ne perneltent d'en tirer aucun parti, si ce n'est pour le chauffige. Le bois en est tout à fait pareil à celui du pin à crochets; provenant d'une tige de 82 ans et de 15 cenumètres de diamètre, orighinaire dı Jıra, il pèse, complétement desséché à l'air', 0,499. (Coll.Ec. For. Envoi de M. Gurnauil).

La médecine populaire utilise, surtout en Allemagne, sous le nom des Baume de Carpathes, une térébentline qui provient du pin à crochets et qui ressemble à celle du pin sylvestre (1).

\section{Fin laricio. Pinus lantgio. Poin.}

Fenilles géminées, souvent contournées sur les jeunes pieds, d'un vert foncé, longues de 10-15 centimères, assez robnstes, aiguës, presque piquantes. Chatons màles jaunàtres, oblongs-cylindriques, longs d'environ 25 mill.; côıes presque sessiles, solitaires, géminés ou ternés, étalés presque horizontalement, longs de כٌ-8 centimètres, luisants, d'un jaune roussàtre clair, oblongs-coniques, aigus el presque loujours arqués; écailles à écussons légèrement pyramidaux, transrersalement carénés, surmontes d'une protubérance cenirale, généralement mucronée. Graines de 6 mill., d'un gris jaunàtre ou brunâtre clair et mat, très-légèrement marbrées; ailes 5-4 fois aussi longues qu'elles, d'un roux brunâtre, droiles sur un bord, régulièrement arrondies sur l'autre, de sorte que leur plus grande largeur; presque égale à la moitié de la longueur, correspond à leur milieu. - Arbre de taille et de port très-variés.

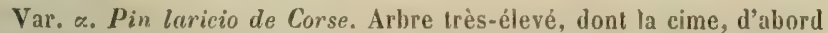
pyramidale, est, à un âge avancé, courte et formée de grosses branches étalées-dressées. Feuilles épaisses et fermes, ćlalces, souvenı contournées. P. poiretiuna. Endlichor. Régions montagneuses de la Corse.

Var. $\beta$. Pin laricio de Calabre. Arbre très-élevé, à tige très-droite, très-régulièrement cylindrico-coniquue, à branches courtes, grèles, élalées ou réflechies, mais redressées au sommel, disposées comme les branches d'un candélabre et formant une longue cime útroite el aiguë; feuilles moins

(1) Je dois à l'obligeance de MI. Broillard des renseignements trèsutiles pour la rédaction de cet article. 
robustes que celles du laricio de Corse Originaire de la Calabre; commun dans les culures. Pinus laricio stricıa. Carrière.

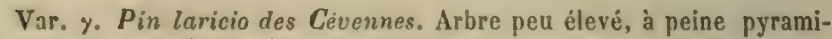
dal, à lète arrondie et à branches horizonlales; rameaux d'un jaune orangé ou rougeàtre, marquís de coussinets larges el plats et garnis, si ce n'est a leur base. de feuilles moins robustes, d'un vert moins foncé que celles des variélés précédentes. ". luricio cebennensis. Gr. el Godr., P. monsp llirnsis. Sulzm. P. Salzmanni Dunul. Forèts des Cérennes, particulièrement à Saint-Guillem-le-Désert près de Montpellier.

Var. ס. Pin laricio d'Autriche. Arbre éleré, à ramification plus touffue, à branches plus nombreuses et plus robustes, à verticilles plus rapprochés, formant une cime plus ample; feuilles serrées, robustes, plus raides, moins longues, peu ou point contourvées, d'un vert plus foncé; cỏne de 8 cent. de long. Pinus luricio austriana, Endl.; P.rustriaca. Host; P. nirricans, Linl., Pin noir; $P$ on de Romanie. Originaire d'Autriche, fréquemment cultivé.

Flor., mai. Fruclif., automne de la seconde année. Dissémination, printemps suivant.

Lanicio Le pin Laricio de Corse est un arbre de première grande Conse. deur, qui parvient quelquefois à une hauteur de $43^{\mathrm{m}}$ et à Taille. Port. une circonférence de $5^{\mathrm{m}} \mathrm{0} 0$. La tige, bien pluı̀t cylindriquse que conique, se dépouille rapidement de ses branches inférieures et reste complétement nue jusyu'en dessous de la cime, qui, dès 80-100 ans, est courte, aplatic, peu développie, formée de quelques grosses branches irréguhèrement ramifiées. Les $\frac{5}{6}$ de la laauteur tolale de l'arbre sont, à Couvert. cet àge, propres à donner du bois de service. Le couvert est très-léger.

Enracinement. L'enracinement est généralement faible et pivotant dans l'origine; il n'est représenté, plus tart, que par quelques racines tracantes peu étendues, comparativement aux dimensions de l'arbre.

Ecorce. L'écorce du pin Laricio est constituée comme celle du pin sylvestre et acepuiert une grande épaisseur; elle se compose d'éailles peu étendues de liber, transformé en un liége sec et fragle d'un rouge violace, que sejarent de minees lames péridermigues d'un heau grris argenté, auxquelles elle doit une couleur caractéristique.

Station el sol. Le pin de: Corse se rencontre dans les régions montasneuses, ou il oceupe une zone supérieure à celle du pin marilime ; il commence a apparaitre à une altitude de $1000^{\mathrm{m}}$,

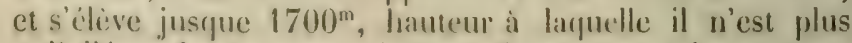
qu'i l'état de buisson rabongri. Il recherche les graviers 
argileux qui resultent de la désagrégation et de la décornposition des granites et il atteint son maximum de croissance lorsqu'ils sont moyennement frais. L'accroissement en diamètre est peu rapide et, vers $140-150$, il diminue et devient très-faible; la longévité est néanmoins fort élevée.

Le laricio a l'aubier blane, très-abondant ( $65-582$ couches sur les échantillons examinés), le bois parfait fortement lignifié et variant du rouge-rosé au rouge-brun, suivant la qualité; le tissu d'automne de chaque couche est nettement accusé et d'une épaisseur relativement grande. Les canaux résintëres y sont bien apparents et contiennent une térébenthine épaisse, qui, en s'infilırant dans les tissus et les imprégnant d'une abondante résine, rend souvent le bois dur et translucide comme de la corne. Ce bois est lourd, d'un grain fin et serré.

Un échautillon de Corse (Coll. Ec. For. Envoi de M. Simon, garde-général), de 70 centimètres de diamètre et de 22) ans, pèse, étant complétement desséché à l'air, 0,91. (Aubıer et bois parfait, le $1^{\mathrm{er}}$ présentant 107 couches qui occtpent à peu près la moitié du diamètre total.)

A part l'aubier, qui se pourrit très-rapidement et n'est propre à rien, le pin laricio est un bon bois de construction et de travail, quoique parfois il contienne trop de résine et devienne alors d'un débit dilficile. Néanmons, la fibre en est courte et peu solidement agrégée, si l'on en juge par la multiplicité des petites gerces rayonuantes et concentriques que le retrait produit dans toute sa masse; aussi les tentatives faites pour l'appliquer à la mâture ontelles jusqu'alor's peu réussi et, outre le reproche d'ètre trop lourd, semble-t-il aussi mériter celui de manquer de souplesse et de réssistance. Cependant l'on peut espérer quil conviendra pour d'atitres usages dans les constructions maritimes et des essais dans ce sens sont maintenant en voie d'exécution à l'arsenal de Toulon. Il doit lournir, espère-t-on, d'excellentes traverses de chemins de fer.

Les qualités du Laricio sont d'ailleurs très-variables et une élude attentive des circonstances, jusquialors peu connues, qui les déterminent permettra sans docite d'en diriger la production de la manière la phus avantageuse à la consommation. Il semble tontefois permis d'affimer que l'exploitabilité en devra toujours ètre fort élevée el que, pour la régler, ce sont bien moins les dimensions des arbres 
et l'épaisseur des dernières couches annuelles que le volume et le développement du bois parfait, le seul utılisable, qu'il faudra consulter (1).

(1) L'élude des échantillons de pin Laricio, dont MMY. Simon et Grosjean, gardes généraux, ont enrichi la colleclion de l'Ecole forestière, mel en évidence, relativement à la quantilé de l'aubier, suivant l'àge el la vigueur de la végétation, quelques lois peu connues et qui méritent de l'être, car très-probablement elles s'appliqueut, à des degrés divers, à toutes les essences. Le tableau suivant, dans lequel les bois sont disposés suivant l'àge, a pour but de les faire ressortir.

Il esi bon de faire remarquer que ces bois ne sont pas rigoureusement comparables puisqu'ils proviernent de localités, d'expositious et d'altiludes diverses, et qu'il ne faut pas allacher de valeur absolue aux chiffres qui les concernent; il n'est pas moins vrai que ceux-ci expriment par leurs relations quelques lois incontestables, d'autant mieux établies que trèscertainement le choix des échantillons qui les ont fournis n'a été fait dans atcun but préconçu.

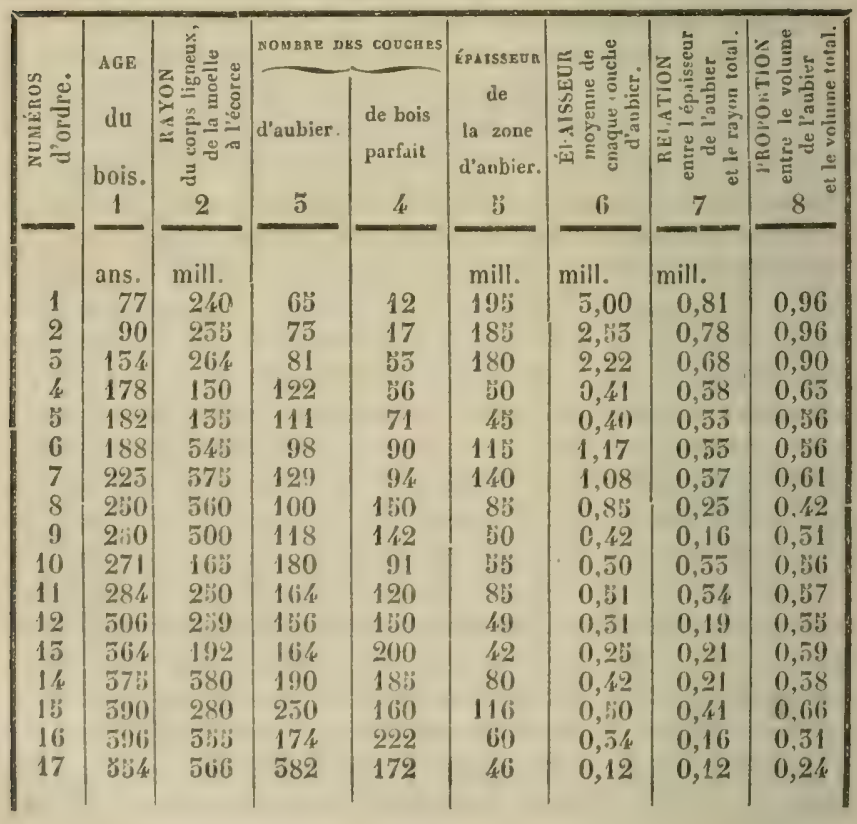


Jusqu’à présent, le résinage n’a point été appliqué aux forèts de Laricio, mais on cherche, en Corse, à l'y introduire. Il peut ètre permis de douter que cet arbre supporte le procédé de gemmage usité pour le pin maritime, dont il est bien loin de posséler la rapide croissance, la merveilleuse vigueur; d'ailleurs il y perdrait ses qualités essentielles, taille et port, et l'analogrie peut faire présumer que le défiut de son bois, d'être trop résineux, ne ferait que s'aggraver par ce mode de traitement.

Peut ètre conviendrait-il mieux de lui appliquer le procédé en usage pour le mélèze; s'il est peu producuf, il a l'avantage de ne pas affaiblir ni délormer les arbres et, en soutirant la résine du corps ligneux, d'améliorer la qualité

A part quelques contradictions inévitables en semblable matière, les chiffres qui précèdent élablissent neltement que :

$1^{\circ}$ Le nombre des couches de l'aubier s'accroît avec l'âge (col. 1 el $\mathbf{3}$, sur les deux types extrêmes de 77 ans el de $25 \% 4$ ans ce nombre s'est quintuplé), d'ou il faut conclure que chaque année il n'y a pas transformation de l'une d'entre elles en bois parfait.

20 Cet accroissement est le résultat de l'affaiblissement de la végélation et lui est proportionnel (voir col. 1,2 et 5 , les 2 pins nos 5 et $\mathbf{6}$, qui, d'âge à peu près égal, offrent l'un 1 il couches d'aubier sur un rayon de 135 mill., tandis que l'autre, beaucoup plus vigoureux, puisqu'il mesure 545 mill. de rayon, n'en présente que 98 ; ou encore les pins $\mathrm{n}^{\mathrm{ns}} 1 \mathrm{5}$ et 16 , de même ầge à peu près, dont le premier a 250 couches d'aubier sur un rayon de 280 mill., et le second 174 seulement, sur un rayon de $55 \%$ mill., qui décèle chez lui une régélation beaucoup plus active).

$5^{\circ}$ L'angmentation du nombre des couches d'aubier ne compense pas la diminution d'épaisseur que chacune de celles qui se forment subit par suile de l'âge el dı ralentissement de la végélation, de sorle que la zone totale va en s'amincissant d'une manière sensible (col. I et 5), et que la proportion entre le bois parfait et l'aubier, soit en dimensions linéaires, soit en volume, s'améliore plus rapidement (col. 7 et 8), jusqu'à l’âge le plus élevé.

Néanmoins, îl doit arriver unc limile d'âge à laquelle les conches annuelles d'aubier qui se produsent, devenues extrèmement minces, sont sensihlement égales entre elles, de sorte qu'avec l'augmentation de leur nombre doit coïncider l'augrmentation d'épaisseur de la zone totale; malgré l'âge avancé de certains échantillons de la collection, celle conséquence n'u pu èrre observée maleriellement.

L'examen du tableau confirme d'ailleurs ce qui a été dit plus haut sur la lente végélalion du pin Laricio, parvenu à un cerlain âge et sur l'extrême abondance de son aubier. 
des bois trop chargés de ce principe et par ce motif peu propres au travail.

Lanicio Le pin Laricio de Calabre est remarquable par la beauté de Calabns. de son port, l'exiguité el la régularité de ses branches, la Taille, Port. forme étroite, allongée, aiguë de sa cime. Il est originaire des montagnes de la Calabre et a été introduit en France vers 1820. Il est devenu commun dans les cultures, mais l'on ne sait rien sur sa valeur forestière.

Lanicio Le pin Laricio des Cévinnes forme des bois étendus des Cérennas. dans la contrée de ce nom. C'est un arbre de petite taille, Taille. Port. $6-10^{\mathrm{m}}$, le plus ordinairement tortueux et très-branchu, souvent dès la base. Il ne parait pas ètre conuu des agents forestiers, qui, sans doute, le coufontent avec quelque autre pin, quoique les caractères et le port remarquables qui le distinguent aient déterminé certains botanistes à le considérer comme une espèce légitime.

Laricio Le pin Laricio d'Autriche ou pin noir a tous les caracD'Aurricie. tères botaniques du pin Laricio proprement dit et n'en est Taille. Port. probablement qu'une variété il se distingue néanmons par un tout autre port. C'est un grand arbre, pouvant atteindre $50-5)^{\mathrm{m}}$ de hauteur, sur $5 \cdot 4^{\mathrm{m}}$ de circonférence, mas qui reste souvent au-dessous de ces dimensions. La tige en est rarement droite; la cime, ample et touffue, ovoïde-pyramidale dans la juunesse, étalée à un àge avancé, est composée de branches nombreuses et robustes et fournit, relativement à la tige, une masse de bois bien plus considérable que celle du pin sylvestre ou de toute autre variété de Laricio : 8,24 p. $0 / 0$ en moyenne.

Earacinement. L'enracinement est composé de racines latérales robustes, allongées, qui pénètrent à travers les pierrailles et dans les fissures des roches, souvent à de très-grandes distances du pied des arbres, et, en leur domant une assietle trèssolide, leur permettent de résister à l'effort des vents les plus vislents. Quant au pivot, toujours grèle, il s'oblitère dès les premières années.

Couvert Le fenillage est tris-serré, d'un vert très-sombre et peret tempérament. siste $3-6$ ans ; il produit, joint a la ramifieatuon serrée, un convert épass et donne au sol beaucoup de: détritus. Aussi le pin d'Aurriche smpporte-1-il menx l'action prolongée du couvert que toute autre espèce du mêne genre.

Ecorce. Liécorce est d'un hrun grssiture, profondément gereuréeécailleuse et très-épaisse jusque dans les parties les plus 
élevées de l'arbre; le volume en est à celui du bois de tige comme 17,6 : 100 (Höss.).

La fícondité du pin d'Autriche est précoce et survient à 50 ans; les années de semences se succident à des intervalles de 2-5̃ ans. Les cônes sont plus gros et plus longs que ceux des autres variétés du Laricio; les graines sont exactement semblables à celles de ces dernières et généralement de bonne qualité.

La germination en est prompte et se produit au bout de 15 jours, lorsque les circonstances sont favorables. Le jeune plant a, dès l'origine, une végélation vigoureuse et se soustrait ainsi rapidement à l'action nuisible du gazonnement.

Le pin d'Antriche croit dans les régions montagneuses de la Carinthie, de la Styrie, de l'Autriche inférieure, etc., où il s'élère a $1500-1400^{\mathrm{m}}$ d'altitude; il prospère aussi dans les régions de collines et mème dans les plaines; très-rustigue et très-frugal, il réussit dans les lieux les plus sees et jusque dans les pierralles, sur les sols siliceux et principalement calcarres ou dolomitigues, pour lesquels il est micux approprié que tout autre pin, en raison de son couvelt épais et de ses détritus abondants. Il peut rendre en France, où il est parfaitement naturalisé depuis 1854, de grands services pour le reboisement des sols de cette nature.

Le bois est semblable à celui du Laricio de Corse; il est plus dur, plus lourd, plus résineux et par conséquenı d'une plus grande durée e't d'une puissance calorifique plus élevée que le pin sylvestre; mais la fibre en est moins élastique. et plus cassante. Les canaux résinifères rayonnants y sont tris-petits, moitić moindres que ceux du pin sylvestre; en revanche les longitudinaux sont plus nombreux et plus apparents.

Il pèse en moyenne : vert, 0,90 ; desséché à l'air, 0,758 ; complétement see, 0,572 ( $\mathrm{T}$. Hartig.).

II ne faut pas demander au pin d'Autriche des pièces de dimensions aussi considérables et de forme aussi régulière qu’au Laricio de Corse; il fournit néanmoins beaucoup de mentues charpentes, du bois de travail et, en raison de sa rapide croissance et de sa puissante ramification, une forte proportion de bois de feu.

On résine avec avantage le pin d'Autriche d'après le

Résinage. 
procédé usité en France pour le pin maritime ; sa térébenthine contient I d'essence sur ह̄, J̃ de résine ou colophane. Les arbres résinés depuis 6-8 ans domnent de meilleurs produits que ceux qui le sont récemment et l'on obtient de pieds de $\overline{0} 0$ centimètres de diamètre un revenu annuel moyen de 4 kilogrammes de térébenthine brute.

Le résinage provoque sur ce pin le mène résultat que sur - le pin maritime et améliore la qualité de son hois.

Usages

L'abondance des détritus du pin Laricio d'Autriche, paraccessoires. liculièrement dans la jeunesse, et la rapidité avec laquelle ils se transforment en terreau et en humus, en raison de leur consistance charnue et de la fraicheur qu'un convert ¿́pais maintient sur le sol, le rendent très-digne d'intérèt au point de vue agricole. Exploite à une comte révolution, 20 ans, non seulement une pincraie do cette espèce rapporte un volume de bois de feu considérable, mas elle devient une source permanante d'un bon engrais, soit qu'on l'enleve pour l'appliquer directement aux trreses arables, soit qu'on le laisse s'accumuler et fertiliser le sol, qui, au moyen de ce système d'assolemsent, devient pendant quelques années propre à la culture agricole, sans qu'il soit besoin d'engrais étranger's.

Le puissant enracinement, la cime ample et touffue du pin Laricio d'Autriche le rentent enfun très-propre à la création de rideaux d'abri contre les vents.

1. Fin d'Mep. Pinus nalepexsis. Mrzl. Pin de Jérusalem; Pin blanc (en Provence).

Fenilles géminées, longues de כ̌-S centimètres, à gaine courle; lâches, dressées et situées au sommel des rameaux; Irès-étroites, peu raides, aiguës, d'un vert clair. Chatons mâles roussâtres, oblongs, longs d'environ 6 mill., peu serrés; cônes solitaires ou verlicillés, porlés sur un pédoncule épais, constamment rifléchis, oblongs-coniques, aigus, d'un rouge brun luisant, longs de 10-12 centimetres; écailles à écusson rhomboïdal, presque plan. finement et faiblement earéé en travers, muni au centre d'une protubérance généralement obluse. Graines de 7 mill., grises d'un còté, d'un gris noir mal, finement marbré de noir profond de l'autre; ailes \& fois aussi longues qu'elles, dilatées d'un cólé, puis a bords droits, parallèles, 5 fois aussi longnes que larges, roussâtres, légèrement rayées de brun - Arbre de 1 - $-16^{\text {m }}$ au $p l u s$, à tige souvent flexueuse el à cime arrondie ou comme écrasée au sommel, composée de branches étalées et de rameaux el ramules grèles, allongés, diffus. Paines et collines calcaires de la région méditerancenue, France et Algérie.

Var.. Pin d'Alep élancé. P. halepensis major. Annal. soc. roy. d'horl. Ue Paris. P'in des Pyrénées. Pinus jyrenaïca. Lapeyr. Arbre 
de plus grande taille, $20-30^{\mathrm{m}}$, ̀̀ port plus élancé, feuilles plus grosses, plus rigilles, rapprochérs à l'extrémité des ramules en espèces de pinceaux : cônes plus courts, $7 \cdot 8$ cent. de long, mais aussi larges à la base, étalés et non pendants à la maturité. Graines un peu plus grosies, à ailes triangulaires, 2 fois aussi longues qu'elles seulenent, brusquement dilalées d'un côté à la base, où elles sont 1-2 fois aussi larges que longues, d'un brun assez foncé. Dissémine dans les vallées des Pyrénées centrales, où il paraîl avoir élé planté ; devient commun el forme des massifs dans les vallées du revers espagnol.

Flor., avril-mai. Fructif., au bout de 2 ans. Dissém., juillet et août de la 5 " année, beaucoup plus tard que pour les autres pins à maturation bisanuuelle.

Le pin d'Alep forme, jusqu'à l'âge de 10-12 ans, un buisson très-touffu, branchu dès la base ; la cime en est alors conique, l'allongement rapide; mais, vers 20 ans, cette croissance se ralentit, la cime s'étale et l'arbre prend le port caractíristique précédemment décrit. Il n'est par rare de le rencontrer dans la jeunesse avec des aiguilles ternées, quaternées ou même quinées.

La feuille ne persiste guère au delà de 2 ans; le couvert est conséquemnient très-léger.

Cet arbre croit dans les sols les plus maigres, sur les terrains calcaires arides, exposés en plein midi.

L'écorce est d'un gris argenté, lisse et brillante dans les premières années; plus tard, elle forme un rhytidome gercuré-écailleux, analogue à celui des autres pins de la première section, d'un rouge brun, dans lequel les lames de périderme sont élendues, minces et à peine plus foncées que les écaulles libériennes entre lesquelles elles s'interposent.

Le bois a un aubier abondant, blanchâtre, mal limité, dont la transformation à l'état parfait semble plutòt due à une infiltration de résine qui se produit irrégulièrement dans le cœur qu'à une lignification vérisable et complète; en cet état, il devient brunâtre clair; il a le grain assez serré et n'est que múdrocrement riche en canaux résinifères. Il est employé ell charpente, en menuiserie, etc. Provenant d'Algérite, d'une ligre de 30 ans el de 0,25 de diamètre, il pèse, complétement desséché à l'air, 0,75 . (Coll. Ec. For. Envoi de $\mathrm{N}$. Royer).

Ou résine en Provence le pin d'Alep de la mẻme manière que le pin maritime dans l'ouest et l'on en obtient des produits identiques, quoique bien moins importants;

Taille. Port.

Couvert.

Sol.

Ecorce.

Bois.

Densité.

Résinage. 
Ils se manipulent et se dénomment semblablement, à quelques différences près.

En général le résinage se pratique quand l'arbre a atteint 20-50 cent. de dianeire et, sil est hien conduit, il peut produire, pendant 15-20 aus, 6-7 kil. de térébenthine chaque année. Les entailles yue l'on fait dans l'écorce pour provoquer léeoulement de la téribenthine ont environ 10 centimètres de largeur et se nomment Surlés. Tous les 15 jours on les rafraichit par l'enlèvement d'un mince copeau à la partie supérieure $\mathrm{ct}$, de la sorte, clles atteignent dans lannév: 50 cent. de hautcur. On les conduit jusqu’à $4^{\mathrm{m}} 60$, ou mème divantage si l'on se sert d'échelles, puis on les abandome pour en vurrir de nouvelles à còté, en laissant entre elles une bande d'écorce que l'on appelle Nerf. Lou recucille la térébenthine dans des trous ouverts en terre à la base des surlés. Cette térébenthine est connue sous le nom de: Pírinne Vierge. Après l'avoir fait cuire, on la coule en pains et l'on appelle Raze la résine ainsi obtenue. La distillation du bois de souches et de tiges produit du goudron.

5. Pin maritime. Pinus pinaster. Soland. P. maritima. Lam. Pin de Bordeaux; Pin des Landes.

Feuilles longues de 10-25 centimètres, épaisses, cliarnues, d'un vert jannâtre, légerement luisantés, sourent contournées sur elles-mêmes. Chatons mâles ovoïdes, jaunàtres, lonğ de 1 cent. environ. Cônes presque sessiles, réféchis, oblongs-coniques et aigus, longs de $1 / 4-18$ centimetres, d'un roux vif el luisant; écailles i écusson rhomboïdal prolongé en pyramide élalée, transversalement carénée el presque trancliante, surmontée d'une protubirance centrale. Graine assez grosse, longuc de 8-10 mill., dépriméc, d'un noir luisant uniforme sur une face, d'un gris mat finement marbré de noir sur l'aute; aile bois aussi longue qu'elle, dont un des hords est droit el l'autre assez régulièrcment convexe, de sorte que la plus grande largeur, a peu près égale au 1/3 de la longueur, tombe vers le nilieu; d'un roux brunâtre clair', longitudiualement rubanée de violacé. Embryon 8-colylédoné. - Arbre élevé, de port variable suivant le traitement auquel il est soumis. Commun dans les landes et dans les dunes de l'oụest, où il forme des forèts appelées l'ignadas; se retrouve en Provence, en Languedoc et en Corse. Flor., avril-mai. liruclif., automne de la seconde année. Dissém., printemps suivant.

T'aille. P'ort.

Le pin maritime peut devenir un grand arbre de $50^{\mathrm{m}}$ de hauteur sur in $^{\text {mon }}$ de circonférence et mime plus, et offrir une lige dronte, clancée, une cime pyramidale régulierement verticillé; mais le résinage, auguel il est habiturllement sommis, le déforme la plupart du temps et il devient tortueux, grêle et présente une cime étalice, irrégulière. 
Les racines sont très-développées, pivotantes et traçantes à la fois. Cette disposition, jointe à une croissance trèsrapide dans la jeunesse et au peu d'exigences de cette essence à l'égard slu sol, a fait choisir avee succès le pin maritime pour fixer les sables mouvants des dunes, pour rehoiser ceux des Landes.

On a vu quelquefois des souches de pin maritime s'accroitre encore apres l'exploitation de l'arbre et l'on a constaté que leurs racines se tronvairnt soudées avec celles de pins réservés, qui se trouvaient dans le voisinage.

La fructification est très-précoce et, dans les sables des dunes, elle apparait guelyuefois dis 13 ans; mais alors les graines sont souvent vaines. Elle devient très-abondante et presque continue à l'àge moyen. La transformation des bourgeons à feuilles en inflorescenres et plus tard en cónes cat plus fréquente chuz le pin maritime que chez tout autre; elle produit des agglomérations de fruits urès-remarquables. On en comple quelquefois sur une mème pousse 40-100, dont la plupart parviennent ì un entier développenent, autant du moins que l'espace le leur permet.

La feuille persiste 5 ans en moyenne; le couvert est légerer.

L'écorce, analogue à celle du pin sylvestre, est plus épaisse, plus profondément gercurée, plus largement écailleuse; clle est d'un rouge-violacé sombre, composée de lames péridermiques étendues et minces de couleur plus foncée que celle des écailles en lesquelles elles partagent le liber.

Le pin maritime forme en France des forèts considérables (Pignadas en Gascogne), principalement dans les Landes et le long du littoral de l'Océan jusqu'au Mans; il remonte mème jusqu'en Bretagne, mais il y provient de semis artificiels. On le retrouve sur le littoral de la Méditerranće $\mathrm{ct}$, en Corse, il s'élève dans les régions montagnenses jusqu'à une altitude de $1000^{\mathrm{m}}$. Il recherche particulıèrement les sols légers, siliceux.

Dans le elimat qui lui convient, la croissance en est remarquablement aclive et souvent, dans la jeunesse, il développe annuellement deux verticilles.

Le bois, ì l'état d'aubier, est blanc jaunâtre ; à l'état parfait il est rongeatre plus ou moins foncé; il est lourd et dur, a la fibre grossière et manque de souplesse C'est le plus résineux de toutes les abrétinies et les nombreux et

Fructification.

Couvert

Ecorce.

Station et sol.

Bois. 
gros canaux résinifères, longitudinaux et rayonnants, qui apparaissent dans le bois parfait, sous forme de lignes colorées en rouge brunâtre par la résine concrète qui s y est amassée, le font reconnaitre très-facilement. Il est assez fréquent d'observer deux zones distinctes de bois d'automne vers le hord extéricur de chayue couche annuelle, surtout dans la jeunesse ; re fait est intumement li!: à celui Densité. de la production de 2 verticilles par année. Du bois d'une tig̣e de 450 ans et de 28 cent. de diamètre, mrovenant d'Algérie, pèse, entièrement desséché à l'air, 0,68 (1).

Usages. Le pin maritime sert aux constructions navales pour des usages secondaires; il est employé à la charpente, se liébite en madriers, planches, échalas de bome qualité (Carassous, Médoc), etc., est utilisé par les tomneliers pour doubles fùts, par les layetiers pour caisses d'emballages, fournit de bons pilotis pour les constructions, etc. Enfin il sert de combustible, donne en brùlant une flamme claire et brillante, dégage une chaleur vive, mais peu soutenuc, et a l'inconvénient d'éclater au feu et de projeter au loin des étincelles.

(1) L'observation, déjà faite à propos du pin Laricio, que le nombre des couches de l'aubier s'accroit avec l'âge, se vérific de nouveau pour le pin maritime et avec une telle exactitude, que, sans une affirmation tres-nelte du contraire, on pourrait croire que les échantillons examinés (Coll. Ec. For.) ont été choisis dans le but préconçu de la confirmer.

Pin de 28 ans Puy-de-Dòme.

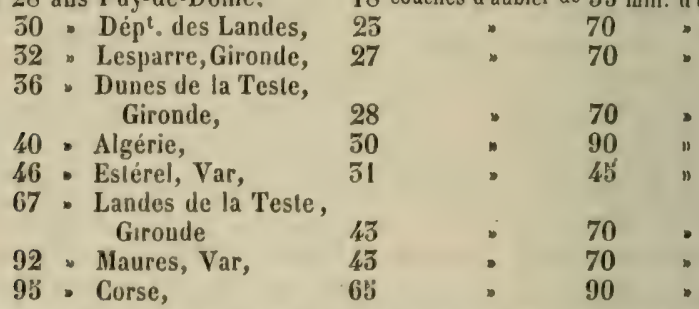

Sans doute icil'on ne voit pas l'épaisseur de la zône décroitre à mesure que le nomire des couches angmente, comme cela se produit pour le pin laricio, mais l'on peut en trouver aisément la raison dans la jeunesse relative des bois observes; sans nul doute que dans un âge arancé le ralentissement très-marqué de la végétation y produirait un résultat du mème genre. 
Le pin gemmé ou résiné est considéré, dans les Landes, comme bien supérieur en durée et en résistance à celui qui ne l'a pas été, et cela avec raison. Si le résinage en effet épuise les arbres et en réluit les dimensions, il produit en revanclie des bois d'accroissements plus faibles et relativement plus charésés de bois d'automne; il ditermine en outre de lintérieur a la surface, un comrant actif de térébenthine, dout la portuon la plus fluide s'ćpanche, en abandonnant dans les tissus de l'abbier gu'clle traverse une notable quantité de résine. Lés bois gemmés ont donc moins d'aubier ou, ce qui revient au mème, un aubier de meilleure qualité, ils sont en nutre plus lourds, plus durs et plus résineux, conséquemment plus résistants, plus durables et d'une puissance calorifique plus élevée.

Le bois n'est pas tonjours le produit essentiel des Pignadas et bien souvent la production en est sacrifiée à celle de la térébenthine ou de la Genme, qui en forme le revenu principal. C'est surtout dans les Landes que l'on pratique le résinage sur une grande érhelle. L'abondance et la grosseur des canaux résinifères, Inngitudinaux et rayonnants, l'active circulation de teréhembine à laquelle ils servent de conduits dans la région de l'aubier, justifient le procédé d'extraction que l'on suit généralement. (1)

Un pin est propre au résinage ou au gemmage dès qu'il mesure $1^{\mathrm{m}} 20$ de circonférence à la base. Le Résinier ou Gemmier, pour le mellre en aurere, dégrossit l'écorce du còté qu'il veut atlaquer, en l'amineissant à la cognée et en la rendant lisse et unie; puis, arec un instrument spécial, hache dont le tranchant est rombé pour laire des incisions coneaves (abchotte ou hachor), il y pratique, vers le pied, une entaille rectangulaire, dite Quarre ou Carre, qui entame l'aubier et qui a généralement 10 centimètres de large sur 5 cent. de haut. A la base de la quarre, il creuse un petit auget (Clot) dans quelque portion saillante du pied de l'arbre pour recueillir les produits; si cela n’est pas possible, il y place un auget portatif.

Dans celte méthode, à mesure que la quarre s'élève, la gemme, qui ne suinte que de sa partie supérieure, doit

Résinage.

Procédé du résinage.

(1) Voir la notice de M. Loreniz, dans les Annales forestières, t. Ier. 
parcourir un trajet de plus en plus long; aussi perd-ellc par évaporation la plus grande partie de son principal élément, l'essence, et se charge-t-elle d'une foule d'impuretés, débris d'écorce, aiguilles, insectes, etc. On remédie à ces inconvénients par l'emploi de réservoirs mobiles, consistant en pots de terre vernissée, qui, au moyen d'un trou pratiqué près de leur bord supéricur, s'accrochent à un clou planté dans l'arbre et se remontent avec chaque quarre. Une lame rectangulaire en zine se fixe transversalement dans la quarre par un de ses grands côtés, taillé dans ce but en bisean, et forme, immédiatement au-dessus du récipıent, un plan incliné qui arrête la gemme et la dirige dans son intérieur. Par cette modification, on réalise une notable économie de main-d'œuvre, on recueille une gemme plus abondante, plus fluide, plus pure, qui se vend 20 p. 0,0 plus cher que celle obtenue par l'ancien procédé. (II. L. Javal; concours général d'agriculture de 1860.)

Toutes les semaines la quarre est rafraichie par le Piquage, c'est-à-dire par l'enlèvement d'un mince copeau à sa partie supérieure, de sorte qu'elle s'agrandit toujours en hauteur, en conservant une largeur constante ou, mime mieux, décroissante et parvient, en 5 ans, à une élévation de $5^{\mathrm{m}}$ environ. On l'abandonne alor's et l'on en commenee une seconde, que l'on conduit comme la premiere, dont elle est séparée par unc bande d'écorce laruge de 5-6 centimètres tout au plus, nommée Ourle ou Bourrelet. On fait de la sorte tout le tour de l'arbre, en ayant soin de conduire chaque nouvelle quarre un peu plus haut que la précédente; puis l'on altaque les ourles, qui se sont acerus ct ont recouvert les anciennes plaies avec une facilité et une rapidité remarquables, et on les entaille, toujours d'après le mème système. Un résinage bien conduit peut durer 130 ans et mème plus, surtout, si dans les preniers temps, alors que le pin était encore faible, on a en la précaution de lui domner une anuée de repos après chanue période d'extraclion de 7-8 ans.

Parlois, lorsque l'arbre peut le comporter par' sa vigueur, on y ficit deux entailles a la fois, une quarre haute et une quarre basse on Basson. Enfin au lieu d'nuvir les quarres les unes a cóté des antres, on peut les disposer opposées entre elles et entailler les nouvelles au milieu de l'intervalle qui sépare les plus anciennes. 
Le gemmag̣e, pratiqué de la sorte, en ménageant la santé des arbres, est appelé gemmağe à vie. Si, au contraire, le pin doit ètre exploité dans un bref délai, on ne garde aucun de ces ménagements, on le taille sur toutes les faces à la fois, en conduisant les quarres en une seule année à une hauteur triple et l'on dit qu'on le gemme à mort ou à pin perdu.

Le résinier se sert, pour arriver à la hauteur à laquelle les quarres parviennent, d'une perche, dite Crabe, Changue, entallée de larges crans ou encoches sur un côté ou sur detrx còtés opposés, ou garnic de marches coniques, clonées alternativement sur deux de ses faces.

On procède au gemmage du 13 février au $13 ̈$ novembre. La réribenthine qui s'écoule s'amasse dans les augets où on la recueille de temps à autre, à intervalles d'autant plus rapprochés que la température est plus élevée. Elle contient naturellement d'autant plus d'essence qu'elle est plus souvent recuenllie. Un bon ouvrier peut tailler $200-500$ arbres par jour.

Un pin vigoureux et isolé produit annuellement jusqu'à 20-40 kil. de matière première; en massif, ce chiffre no s'èlève pas à plus de כ̌-6 kil. Les pins des dunes de Gascogne sont, sous ce rapport, bien plus productifs que tous les autres. Cenx de la Provence, que l'on a voulu soumettre au mème traitement, n'ont pas donné des résultats à beaucoup près aussi salisfaisants.

Les produits bruts du gemmage sont de trois sortes: $1^{\circ}$ la Gernme ou Résine molle, partie fluide qui s'ust réunic dans les angets; $2^{\circ}$ le Galipot, portion solidifiée le long des quarres et qui se délache par morceaux, sans ètre mélangée de débris d'écorces; 50 le Barras, qu'il faut rieler pour obtenir et ufui n'est antre qu'un galipot impur, mèlé à des copeaux, à des fragments d'écorces, ete.

Tous ces produits sont formés d'essence de térébenthine et de résine ou colophame; ils ne diffèrent que par la proportion des derux éléments L'industrie les épure, les manipule, les mélange d'aurès des mrocédés très-variés et en fabrique une multitude de substances diverses, dont les principales sont :

$1^{\circ}$ Les pattes de térébenthine, liquides visqueux, extraits des maticres premières par une ilouce chaleur aruficielle et un filtrage sur des claies en paille (pàte de térébenthine

Produils bruts du résinage.

Produils fabriqués. 
commune) ou par une exposition à la chaleur solaire sur des plans inclinés, formés de planches mal joıntes (pàte dc térébenthine fine ou au soleil).

$2^{\circ}$ L'essence ou huile de térébenthine, liquide incolore, de consistance légèrement oléagineuse, provenant de la distillation des matières premières et surtout de la résine molle ou des påtes de térébenthine.

$5^{\circ}$ Le Brai sec, Colophane ou Areanson, résidu de la distillation qui a produit l'essence; c'est une résine d'un éclat vitreux, dont la couleur varie du jaune blond au brun. Fondu et hrassé avee de l'eau chaude, le brai sec fournit la Résine jaune on Poix-résine, sulsstance très-voisine, opaque, d'un jaune-clair. La Poix blanche est un galipot filuré et blanchi par un mélange de 2 p. 0,0 d'eau.

$4^{\circ}$ La Poix noire, matière visquense, d'un brun roux, provenant de la carbonisation, dans un four en briyues, des claies de filtrage et de tous les débris et résidus de la labrication. Le Brai gras est un mélange de poix noire et de goudron.

Après l'exploitation, les souches de pins sont débitées en menus moreeaux et carbonisées dans des fours en terre ou en maçonnerie; on en retire un dernier produit, le Goudron, et un charbon de qualité médiocre.

Toutes ees matieres sont d'une grande importance. La marine ne saurait se passer de goudron et te brai gras; l'essence sert à des usages nombreux, particulicrement de dissolvant pour les vernis; la colophane est appliquée directement à l'éclairage; la résine d'huile et la résine jaune sont employées à l'extraction du graz d'éclairage, à la fabrication des savons, à l'encollage des papiers, aux enduits, etc., etc. Le Barras traité par les alcalis produit la graisse végétale, si employée aujourd hui pour graisser les marlines, les essieux, elc.

Produits Enfou une combustion incomplète des détritus résineux accessoires. de la fabrieation fournit le noir de fumée, yui s’allache it des toiles tapissant la chambre ou se fait l'opération. Il suffit d'une serousse ligrere pour le faire tomber' sur le sol, où on le recueille aisément.

Les rones (Pignes dans le Sud-Onest) sont tris-recherchés pour allumer le fen; les racines, qui ont la fibre grosse, tenace, flexhle et enduite de résine, servent a tresser des corbeilles, paniers et autres ustensiles de ménage. 
6. Pin Pinier. Prnus pinea. Lin. Pin bon ; pin parasol; Pin d'Ilalie; Pin de pierre; Pin frane (Gironde el Landes); Pignon.

Feuilles géminées, dressées ous un peu étalèes, longues de 8.1 mètres, moyennement épaisses, vertes, lâchement disposées sur les rameaux; chatons màlcs oblongs, jaunàires, longs de 1 centimètre. Cônes solitaires, géminés ou ternés, très-gros, ovoïles-oblus ou presque globuleux, longs de $10-15$ crnlimètres, larges de $8-10$, presinue sessiles, d'un rouge-brun luisaut, réfléchis ou élalés horizontalement. Ecailles grandes, à écusson rhomboïdal, bombé nu légèrement pyramidal, muni au centre d'un mamelon obtus. Graines très-grosses, longues de 16-20 mill., obovées, comprimées, arrondies aux 2 extrémilés, logées dlans 2 cavilés correspondantes de la face interne de chaque écaille, couvertes d'une efflore-cence d'un noir violacé très-caduque; d'un roụe brun mat quand elles l'ont perdue, à enveloppe épaisse, dure et ligneuse, à aile trèscourle el très-caduque. Amande féculente-huileuse; graine 10-12 colylédonée. Disséminé dans la région méditerranéeune. France, Algérie. Flor., avril-mai. Fruclif., fin de la 5" année. Dissem., printemps suivant.

Le pin pinier est un grand arbre qui peut atteindre $50^{\mathrm{m}}$ d'élévation, $5-6^{\mathrm{m}}$ de circonférence et qui croit plus souvent isolé ju'en massir. La tige en és nue, cylindrique, élevée; la cime, courte, très-étalée, ( $50^{\mathrm{m}}$ d'envergure quelquefois) et tout à fait plane à la partie supérieure, lui donne un port très-remarquable et lui a valu le nom de Pin Parasol. Il est un des éléments caractéristiques des paysages des contrées méditerranéennes.

L'enracinement est profond.

L'écorce, semblable à celle du pin sylvestre, est gerçuréeécailleuse; le périderme y forme des lames étendues, minces, blanchâtres, qui séparent, sous forme d'écailles, le tissu libérien transformé en un liége sec et dur, d'un rougeocreux-clair.

Le pinier fructifie à l'àge moyen et, seul entre tous les pins indigènes, il a la maturation trisannuelle. Les cònes ou Pignous sont recherchés pour leurs graines, dont l'amante, comestible et d'un goùt qui rappelle celui de la noisette, est surtout fréfluemment employée par les confiseurs. On peut en extraire une humle grasse alunentaire. L'enveloppe, dure et ligneuse de ces grames, est difficile à briser; mais on cultive une variété à coque mince et fragile (P. pinea fragilis. Loisel).

Le jemne plant, au sortir du périsperme, est beancoup plus grand et plus gros que celui des autres végétaux résineux indigènes. Ill a 10-12 grandes feuilles colylédonaires très-glauques, planes, pointues et dentées sur les

Taille, Port.

Enracinement.

Ecorce.

Fructification.

Germination. 
bords. Des feuilles semblables, mais plus petites, se produisent pendant longtemps pèle-mèle avec les aiguilles géminées.

Station. Le pin pinier se rencontre dans toute la Provence, mais à l'état d'isolement, et il n'est pas certain qu'il y soit indigène; il y est bien plutòt considéré comme arbre fruitier que comme essence foresticre. II ne peut d'ailleurs croitre en massif, en raison de l'ampleur de sa cime et, en Algérie, où on le rencontre dans les forèts, il ne prend d'accroissement que du moment où il est parvenu à dominer les autres vígétaux avec lesquels il se trouve en mélange, de manière à pouvoir développer au-dessus d'eux sa cime Sol. en parasol. Il recherche les terrains frais et profonds de la plaine ou des régions peu élevées.

Bois. Le bois est léger, souple, résistant et rappelle beaucoup par la structure et la couleur celui du pin maritime, avec lequel il est difficile de le distinguer; cependant les canaux résinifères y sont moins abondants et moins développés et Densité. les tissus n'en sont pas aussi imprégnés de résine. Provenant d'Algérie, d'une tige de 18 ans et de 15 cent. de diamètre, il pèse complétement desséché à l'air, 0,57. (Coll. Ec. For.

Usages. Envoi de M. Royer). II fournit des charpentes de première qualite, est employé en Turquie dans la marine pour bordages et mème, dit-on, pour màture; est très-propre à la menuiserie. C'est un bois de chauffage médiocre, qui brùle vite et éclate beaucoup (1).

\section{SECTION II. Pins à 5 feuilles.}

l'euilles quinées, ì gaîne caduque; écailles des cônes terminées jar des écussons plitus, dont la protubérance est terminale;

(1) L'examen des échantillons de la rollection de l'Ecole forestière confirme une fois de plus celle observation du nombre des couches d'aubier croissant avec l'âge.

Pin pinier de Brignolles, Var, 293 ans, 20 conclses d'aubier.

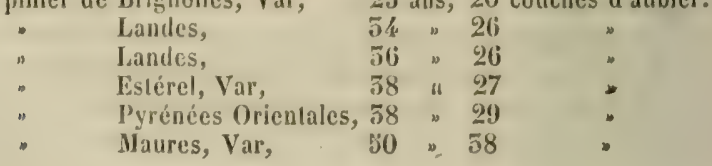


écorce grise, lisse et vire superficiellement jusqu’à un âge avancé.

7. Pin Cembro. Prnus cemara. Lix. Ceinbrot; Alviés; Auvier ; Tinier; Eouve; Héoux; Haiou, etc.

Feuilles quinées, dressées ou un peu élalées, longues de 6-12 cent., raides, aiguës, vertes en dessous et aux hords, glanques en dessus, rudes sur les angles vers le sommet, à gaines allongées et très-caduques. Chatons mâles oblongs, serrés, rouges, puis jaunes; chalons femelles et jeunes cônes d'un rouge violacé. Cônes mûrs sessiles, dressés ou étalés-dressés, jamais pendants, ovales-oblus, lungs de $8-10$ cent., larges de $5-6$, d'un brun grisâtre ou verdàtre, terne $\cdot$ l mal; écailles presque caduques, de consislance à peine ligneuse, peu serrées, à écusson ridé longitudina'ement, à peine épaissi, terminé par un petit mamelon saillant. Graines grosses, obovées, longues de 8-12 mill., brunes et mates, à enveloppe lignense assez dure, paraissant privées d'ailes, parce que ceilles-ci, très-courtes, restent achérentes à l'écaille. Embryon 9-10cotylédoné. - Arbre de port varsable suivant l'altitude à laquelle il croît, à végélation toujours lente. IIautes-Alpes du Dauphiné el de la Provence. Flor., juin. Fructif., automne de la seconde année. Dissém., printemps suivant.

Le pin cembro atteint de plus grandes dimensions qu'on ne l'avait supposé et l'on en trouve dans le Brianconnais qui mesuren $15-20^{\mathrm{m}}$ d'élévation sur $5-4^{\mathrm{m}}$ de circonférence. Comme chez la plupart les arbres des rigions très-élevées, la ramification est irrégulière, formée de grosses branches et de rameaux tortueux, étalés, ne présentant pas de traces de la disposition verticillée. La longévité est prolongée et peut aller jusqu’à $\breve{~ s i e ̀ c l e s . ~}$

L'écorce d'un gris verdattre, lissc on verruqueuse, offre des réservoirs à prisine conme celle du sapin el ne forme de rhytidome qu’à un àģe avancé; elle se geręure alors largement, surtoud en travers, devient fincment écailleuse et prend une teinte gris-rougeittre; le périderme y forme des lames minces, grisàtres, à peine plus claires que le tisssu subéreux du liber; des vacuoles résinifères très-nombreuses y sont disséminées. Les jeunes rameaux sont recouverts de poils entremèlés, d'un jaune rouge, tout ì fait caractéristiques.

L'enracinement se fait dans la jeunesse par un pivot et de fortes racines latérales; vers $150-20$ ans, le premier s'atrophie et les sccondes seules continuent à s'aceroittre avec vigueur en tracant au loin.

Le feuillage est interrompu, ağgloméré à l'extrémité des rameaux; il est néanmoins touffuct donne un couvert assez ipais.

Taille. Port.

Eeorce.

Enracinement.

Convert. 
Fructification. La fiuclification ne commence que ver's 60 ans et n'est abondaute que tous les 4 - ̋̆ ans. Les cònes, appelés Auves dans le Brianȩonnais, sont très-recherchés à cause de leurs graines assez grosses, dont l'amande, comestible et savoureuse, rappelle celle du pin pinier; ils se vendent sur les marchés. Les casse-noix t't le's écureuils en font, d'un autre còté, une grande consommation. Aussi sont-ils généralement assez rares.

L'amande contient un tiers de son poids d'une huile grasse d'un goút ag̣réable, mais sujelte à rancir.

Germination. La graine, seméc avant l'hiver, germe dés le mois de février'; semée au printemps, elle ne germe souvent qu'un Jeune plant. an et mème 2 ans apres. Le jeune plant parait avec 9-10 feuilles celylédonaires el ne dépasse pas 5-4 centimètres la premiere année; toutes ses feuilles sont alors solitaires. Les accroissements des années suivantes sont encore plus faibles, 5̈-10 mill. seulement, mais les feuilles sont dès lors engaînées, par 5-6, généralement par 5. Jusque vers $6-12$ ans la ranification ne se fait que par des rameaux solitaires; passé cet àge, elle se verticille, les branches deviennent horizontales, se redressent au sommet; l'arbre, enfin, prend peu à peu son port définitif.

Station. Le pin centbro eroit à une altitude très-considérable, $2000^{\mathrm{m}}$ au moins, et forme la dernière zone de la végétation forestière. En France il est peu répandu et il ne se trouve que dans les $\Lambda_{p e s}$ du Brianeonnais, mélangé avec le mèlèze et avec le pin à crochets; il n'y constitue en peuplement pur qu'une seule forè de 200 hechares. II disparaitra mème de ectle contre, si l'on n'y prend garde, quoique sa conserration et sa propagation y soient d'une grande importance, non pas precesement pour ses produits, mais pour l'abri protecteur gu'il peut procurer aux massifs inférieurs at pour le parti quion peut en tirer dans le rebosement des contrées dénudées qu’il domine.

Croissance. La croissance du cembro, a l'allitude ì laquelle on le trouve, est naturellement tres-lente; il est remaryuble qu'elle reste la mène lorsqu'on le cultive dans des régions basses on pen álevees. Il est bien different en cela du mélize et du cedre qui, dans de semblables circonstances, s'aceroissent avee une rapidité extraordinaire.

Bois. Le bois est léger, hlanc, peu veinc, d'un grain très-doux et assez homogèe, en raison de la faible différence qu’il y 
a entre la zone de printemps et celle d'automne, qui est très-mince; il est à peine teinté de rongre an cnur, de sorte que le bois parfait et l'aubier different peu l'un de l'antre; ce dernier est peu abondant $(21-54$ couches sur les échantillons de la collection de l'Ecole forestière, quoiqu'ils soient d'un âge èlevé); les accroissements sont mince's et égaux. La térébenthine en est très-fluide et très-abondante, mais elle laisse fort peu de résine dans lés tissus après la dessiceation. Provenant du Branconmais, d'une lige de 88 ans et de $0^{\mathrm{m}} 50$ de diamètre, il pèse, ilesséché à l'air, 0,448 . Ce bois est peu propre aux constructions, mais la finesse et l'homogénéité de son grain le rendent très-convenable pour la menuiserie, surtout pour la sculpture, et les montagnards tyroliens en fabriquent loutes sortes de jouets d'enfants. Il fournit d'excellents hardeaux, qui s'usent très-uniformément, au point qu'ils ne cessent pas d'ètre utiles, alors gu'ils sont réduits à une très-faible épaisseur. C'est un médiocre combustible, qui occupe à peu près le mène rang que le sapin el qui produit une fumée insupportable. (1)

8. Pin eymonth. Pinus stronus. Lin. Pin du Lord.

Feuilles longues de 6-8 centimètres, très-grêles, trigones, vertes et luisantes sur la face dorsale, glauques el mates sur les 2 autres, finement denticulées sur les hords vers l'extrénilé et par suite rudes au toucher' quand on les passe à rebours entre les doigts; redressées en plumels ou légèrement étalées, à gaîne très-caduque. Chatons màles ovoïdes, peu nombreux, longs de 1 cent. Cônes grèles, cylindracés, allénués à l'extrémité, longs de $11-14$ cent., sur 25 mill., de diamètre, légèrement arqués, pédonculés el pendants dès le commencement de la $2^{e}$ année, d'un brun violacé à la maturité, tout à fait mats; écailles à écusson ridé longitudinalement, peu épaissi, à protubérance terminale Grane longue de b̈-6 nill., de mème forme el de même taille que celle du pin Laricio, mais luisante el d'un gris légèrement brunàtre, pourvue d'une aiłe aiguë au sommet, 2-1/2 fois aussi longue qu'elle. Embryon 7-9-cotylédoné el mème plus. - Arbre très-élevé, ̀̀ lige droite, élancée, à cime allongée, conique-aiguë, très-régulièrement verlicillée; à écorce gris verdâtre, lisse jusqu'à un àge avancé. Originaire de l'Amérique septentrionale el de l'Asie occidentale, parfaitemeut naluralisé et souveut cultivé en France. Flor., fin de mai, Fructif. et dissém., automne de l'année qui suil celle de la floraison.

Le pin IVeymouth est un très-grand arbre, qui, dans sa

Densité.

Usages.

Taille. Port.

(1) C'est encore ì M. Broilliard que sont dus la plupart des renseignements de cet article. 
patrie, atteint $60^{\mathrm{m}}$ d'élévation, $6 \cdot 8^{\mathrm{m}}$ de circonférence; la croissance active et soutenue qu il conserve en Europe donne à penser, qu'arec le temps, il y alteindra des dimensions semblables. Il a la tige très-droite, ćlancée, très-régulièrement rerticillée; la cime en est allongće et toujours aig̨uë, composée de branches relativement gréles. A l'état d'isolement, les branches inférieures ne périssent pas, gardent tout leur feuillage et s'allongent horizmtalement, de sorte que l'arbre tout entier forme une large pyramide, feuillée dès la base et du plus bel effet. En massif, les branches inlërieures se dessèchent, mais persistent longtemps en cet état à la manière de celles de l'épıcéa.

Enracinement. L'enracinement est très-pussant, plus déviloppé cncore que celui du pin sylvestre. Il se compose d'un pivot lour et longr et de grosses et longues racines latérales. Le volume réel de la sonche et des racines est estimé à $20 \mathrm{p}$. $0 / 0$ du volume superfieiel (T. Hartig).

Convert. La feuille persiste peu de temps, 2 ans, et souvent mène, à la fin de l'hiver, l'arbre ne possede plus que celles de lannée précédente. Néanmoins le convert est assez complet, en raison du développement de la cime en longueur.

Exorce. L'écorce a la plus grande analogie avec celle du sapin, nais elle est d'ume consistance beancoup plus molle, at point de céder sous la pression du doigt. On y observe un périderme externe, lisse et brillant, d'un girls verdhtre satiné, souleré ega et li en forme de petites ampoules par une terebenthine tres-fluide, incolore et transparente, rui s'est acemulce dans les nombrenx réservor's de l'enveloppe herbacée sous-jacente. Ces réservoirs sont de deux sortes: de larges canaux résnifires, dont les plus gros sont disposés suivant une zone cireulaire interne, en dehors de layuelle s'en trouvent heaucoup d'autres plus petits et épars ; puis des vacuoles sans relation avec les eanaux, qui commencent a sorganiser des 10 ans et se développent de plus en plus jusque dans le liber. Vers 13 i $\bar{\partial}()$ ef meme 4.0 ans seulement, un perriderme interne s'organise, par plinces d'abord, dans les condhes superficielles du liber, detruit tontes les parlies parrenchymalense's qui le reeourent; il s'ètend ensuite de proche en proche, envahit coute l'éeoree et provoyue la formation d'un rhytidome gereguré, mais non lametleux au mine degré que celui des antre pins. Le liber interne encore vivant se distingue nettement de eelui des antres es- 
sences de cette famille par le grand nombre de cavités résinifères qu'il renferme; on y trouve de plus des canaux rayonnants.

La fructification a lieu de bonne heure, surtout pour les pins isolés; en massif, cè n'est que vers 50 ans qu'elle devient abondante et régulière et que les graines sont de bonne qualité. Les années de semenees se suecèdent alor's tous les $2-5$ ans, sans qu'il y ait jamais disette absolue. Les cônes ont les érailles très-lichement imbriquées et s'ouvrent sous la moindre chalcur; aussi la dissémination se fait-elle dès l'automne. Il faut se garder, si on les réenlte, d'employer pour les ouv'ir une chaleur arlificielle, d'ailleurs inutile, parce qu’alors ils laissent suinter une térébenthine qui agrglutine les écailles et les graines.

Le jeune plant lève $\overline{\tilde{J}}-4$ semaines après le semis de printemps, avec 7-8 feuilles cotylédonaires et, comme tous les pins, ne produit pendant la première année que des feuilles solitaires. Dans lés années suivantes apparaissent les feuilles engainées par $4-5$; à 5 ans í plant se verticille et il n'est pas rare qừ̀ 10 ans il produise déjà des pousses annuelles de $0^{\mathrm{m}} 60$ de hauteur.

Le pin Weymouth présente des exemples d'accroissements extraordinaires et l'on en a vu qui, à 50 ans, mesuraient $22^{\mathrm{m}}$ de hauteur et $0^{\mathrm{m}} 63$ de diamètre.

Le Weymouth habite, en Amérique, les réggions de collines ou de montagnes peu élevées et particulièrement les grandes plaines à sol profond et frais; il est commun le long des cours d'eau et réussit encore dans les lieux tourbeux.

Le bois est blanc,très-faiblement rougeâtre au cour, léger, mou, homogène, à peine résineux; la zone d'automne en est mince et peu différente de celle du printemps; les canaux résinifères sont gros et rares; la térébenthine qu'ils contiennent est presqu'entièrement composée d'essence volatile. Coupé vert, il pèse $15-20 p .0 / 0$ moins que le pin sylvestre, $10-150$ p. 0/0 moins que le sapin et l'épicéa; desséché à l'étuve, il perd presque moitié de son poids (T. Hartig). C'est donc un bois peu recommandable, qu'on prendrait aisément pour du peuplier, s'il présentait des vaisseaux au lieu de canaux résinifères; qui, de plus, manque d'élasticité, se dẻjette fortement et manque de durée. Ce doit être un combustible inférieur encore au sapin, surtout lorsque la

Fructification.

Germination.

Jeune plant.

Croissance.

Patrie.

Bois.

Densité.

Qualités. 
dessication lui a fait perdre presque tous ses principas surliydrogénés.

Cette appréciation est bien différente de celle que plusieurs auteurs ont faite de ce bois en Amérique, où ils le représentent employé très-fréquemment à toutes sortes d'usages : charpente des édifices et des maisons privées, construction des ponts, menuiserie, tonnellerie, layeterie, etc. C'est, disent-ils, l'unique bois de mâture des états du nord et du milieu de l'Union et il résiste mieux qu'aucun autre aux injures du temps.

Les conditions différentes de végétation que le pin Weymouth rencontre en Europe et en Amérique peuvent justifier une partie de cette divergence d'opinions, d'autant mieux que dans nos contrées on n'a pu soumettre à l'expérience que des bois jeunes encore, tandis que ceux que les Américains emploient sont sans doute d'un àge élevé; mais elles ne sauraient l'expliquer entièrement. En effet, si la comparaison de bois jeune, ayant crù à Naney, et de bois d'àge moyen, originaire de l'Etat de Vermont (Etats-Unis), (Coll., Ec. For.) fait reconnaitre que le premier offre des accroissements plus larges que le second et une moindre proportion de bois d'automne, elle établit néanmoins qu'ils sontlun et l'autre mous, lígers et dépourvus de résine. Celui de Nancy, d'un diamètre de 12 cent. et ágé de 20 ans, pèse, complétement desséché à l'air, 0,45 ; celui de l'Etat de Vermont, de 28 cent de diamètre et de 80 ans, pèse, dans les mèmes conditions, 0,42 .

Il faut donc admettre qu'en attribuant des qualités éminentes au bois du Weymouth il y a eu de l'exagération. Qu'on ait employé ce bois, faute de mieux, à la màture, c'est très-possible; mais il est certain qu'il ne s'est distingué ni par la résistance, ni par la souplesse et la durée; aussi la marine impériale a-t-clle renoncé à son usage.

Térébenthine. La térébenthine est abondante dans toutes les parties du Weymouth; mais contenant trés-peu de résine, elle se volatilise rapidement et ne donne lieu à aucune extraction importante. 
CLEF ANALYTIQUE 



\title{
CLEF ANALYTIQUE
}

\author{
POUR LA DÉTERMINATION
}

DES

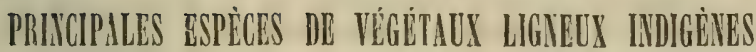

\author{
PENDAN'T' L'HIVER
}

\section{OBSERVATION.}

La seule méthode certaine pour léterminer spécifiquement un végétal consiste à en examiner les organes essentiels, fleurs, fruits et feuilles ; or, à part certaines feuilles et quelques fruits qui persistent en hiver, ces organes manquent pendant la mauvaise saison, de sorte que la distinction des espèces, basée sur les caractères qu'ils fournissent, devient tout à fait impossible pendant une notable partie de l'année. Il est néanmoins important de pouvoir reconnaître en tout temps dans les forêts les végétaux qui les peuplent et il m'a semblé que ce but pouvait être atteint aisément au moyen de caractères d'une facile observation, tels que l'insertion des feuilles et celle des bourgeons et des rameaux qui en est la conséquence, l'alssence ou la présence d'épines ou d'aiguillons, la caducité ou la persisfance des fenilles, enfin la nature des ramenux, la direction, la forme et la structure des bourgeons qui les garnissent.

Afin de ne pas trop compliquer le tableau dichotomique qui, à l'aide de ces caractères, conduit à lia détermination de l'espéce, je n'y ai admis que les végétaux ligneux les plus importants, soit par leurs dimensions ou leur utilité, soit par leur abondance générale ou au moins locale dans certaines régions de la France.

Il faut faire remarquer que les caractères empruntés aux bourgeons le sont en plein hiver, alor's que ces organes, complétement formés. sont en repos et bien clos; que ces caractères ne sauraient leur convenir plus tard, quand, gonflés par la première séve du printemps, ils moditient leur forme, leur taille et, en s'ouvrant et s'allongeant, accroissent le nombre de leurs écailles apparentes. 
A. Végétaux à feuilles et par conséquent à bour- $1^{\text {re }}$ DIVISION. geons el à rameaux alleraes.

B. Feuilles caduques.

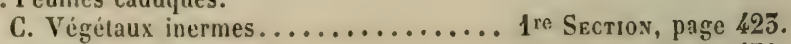

$\mathrm{C}^{\prime}$. Végélaux épineux................ 2e $2^{\mathrm{e}}$ Secrion, page 451.

$B^{\prime}$. Feuilles persistantes.

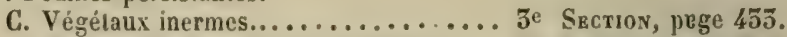

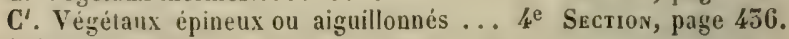

$A^{\prime}$ Végétaux à feuilles, bourgeons et rameaux opposés (1).

2e DIVISION.

B. Feuilles caduques.

C. Végélaux inermes............... ğ Section, page 437.

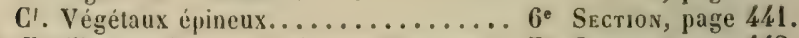

B' Feuilles persistantes; végétaux inermes... 7е Sестіох, page 442.

(1) Quelques espèces à feuilles opposées on verticillées ne produisent que de rares bourgeons latéraux, irrégulièremeut distribués, de sorte que la ramification n'en est point opposée; elles sont néanmoins comprises dans celte division. 


\section{$1^{\text {re }}$ SECTION.}

\section{Végétaux incrmes, à feuilles caluques, alternes, aingi que les bourgeous et les rameaux.}

A. Branches garnies de gros tubercules arrondis, provenant de rameaux qui ne s'allongent pas.-Arbres revêtus d'une ćcorce rouge-brun, gerçurée-écailleuse, dont la cime est étroite, allongée, aiguë et porte de petís cônes à écailles minces sur les bords.................... Mélèze d'Eunore.

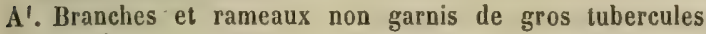
arrondis.

B. Rameaux et ramules arrondis ou obtusement anguleux, rarement anguleux chez quelques arbres, mais dans ce cas jamais verts.

[p. 450] (1)

C. Ramules ligneux, non jonciformes. [p. 430]

D. Bourgeons n'étant point en partie cachés par la base persistante et stipulée des feuilles de l'année précédente.

E. Bourgeons écailleux.

F. Bourgeons 1-écailleux.

G. Bourgeons alternes ou spiralés.

II. Rameaux toruleux. - Arbrisseaux ou petils arbres dont l'écorce reste lisse et grise jusq̨u'à un àge avancé; ramules d'un vert-jaunâtre, plus ou moins colorés de pourpre-noirâtre; bourgeons ovoïdes, tranchants sur les bords, dressés, mais non appliqués, si ce n'est sur les pousses peu robusles des arbres déjà âgés.

I. Arbre à lige et à rameaux régulièrement arrondis; bourgeons glabres, ramules à peine velus. Saule Manceav.

I'. Arbrisseau à tige et rameaux irrégulièrement arrondis, comme ceux du charme.

J. Bourgeons et ramules densément gris-tomenteux. - Arbrisseau dressé, à pousses assez

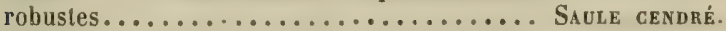

$\mathrm{J}$ '. Bourgeons et ramules glabres. - Petil arbrisseall diffus, à pousses grêles............ Saule A oneillettes.

H'. Rameaux lisses, effilés, allongés el souples.

(1) Quand les deux lettres correspondantes ne se trouvent pas dans la même page, un numéro de renvoi placé en regard de la première indique la page à laquelle il faut chercher la seconde. 
I. Bourgeons appliqués, tranchants sur les bords.

J. Rameaux de $1-5$ ans couveris d'une efflorescence glanque; ramules pubérulents vers l'ex-

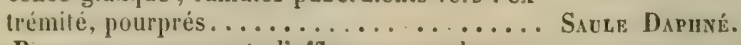

$\mathbf{J}^{\prime}$. Rameaux non couveris d'efflorescence glauque.

K. Ramules complétement glabres, luisants, se caisant aisément à l'articulation.

L. Arbrisseau revètu d'une écorce écailleuse, caduque el d'un roux clair, dès l'âge de 8-10 ans; bourgeons allongés, à bords parallèles, arrondis au sommet; ramules olivàtres, plus ou moins teintés de pourpre, se cassant neltement et aisement un peu au-dessus de

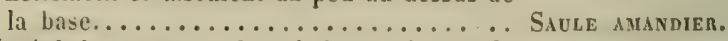

$L^{\prime}$. Arbrisseaux et arbres à écorce longitudinalement gerçurée; bourgeons triangulaires, aigus ; ramules variant du brun-verdâtre au pourpre, se cassant net à l'articulation.. Saule fragile.

K'. Ramules plus ou moins velus à l'extrémité, n'ayant pas l'articulation très-fragile.

L. Ramules plus ou moins couverts de poils appliqués et blancs-soyeux, de coloration très-variable, allant du jaune vif à l'olivàtre, aul brun-rougeảtre et au pourpre-noirâtre. - Grand arbre dont l'écorce rappelle celle des vieux chênes.....................

L'. Ramules tomenteux-pulvérulents, au moins à l'extrémité, verts, d'un vert-jaunâtre ou jaunt-brun .........................

I'. Bourgeous dressés, non exactement appliqués,
arrondis sur les bords; ramules très-luisants et glabres, d'un vert-jaune ou d'un brun clair ou rougeatre............................

$\mathrm{G}^{\prime}$. Bourgeons le plus souvent opposés, appliqués.-
liamules dressés, grêles, glabres, variant du jaune au jaune-verdâtre et au rouge-pourpre........ Saule pourpne.

$F^{\prime}$. Bourgeons pluri-multi-écailleux.

G. Bourgeons 2-3-écailleux, dressés-élalés. [p. 125]

II. Bourgeons latéraux sessiles, distiques. [p. 425]

I. Bourgeons ovoïdes, à écailles alternes, inégales, imbriquées. - Arbres à écorce lisse et grise d'abord, puis longitudinalement geręurée, d'un brun-noir.

J. Ramules et bourgeons glabres; écailles presque herbacées, vertes ou rouges.

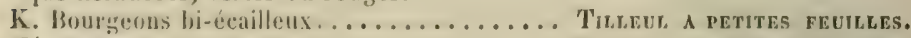

$\mathrm{K}^{\prime}$. Bourgeons tri-écailleux. ........... Thlleul a Ginandes revilles.

$\mathbf{J}$. Ramules et bourgeons pubérulents; écailles

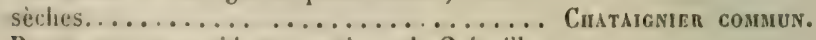

I'. Bourgeons pyramidaux, revètus de 2 écailles 
égales, sèches, un peu poilues, presque juxtaposées. - Arbre à écorce gris-verdâtre, lisse et mince, s'écaillant annuellement par larges plaques......................... Peatane n'Occidext.

H'. Bourgeons latéraux stipités; insertion 1/5. -

Ramules triangulaires; inflorescences en chatons, libres dès l'automne.

I. Ramules glabres. - Arbre à écorce écailleuse,

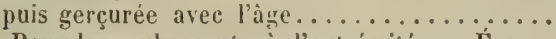

11. Ramules pubescents à l'extrémité. - Écorce

lisse et d'un gris-cendré jusqu'à un àge avancé. Auve blanc.

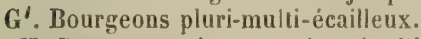

H. Bourgeous plus ou moins régulièrement distiques sur les rameaux latéraux.

[p. 426]

I. Bourgeons ovoïdes ou pyramidaux. [p. 426]

J. Bourgeons oblus, presque globuleux. - Arbrisseau à écorce gris-argenté, lisse ou s'exfoliant en fines membranes, pourvu dès l'antomne de chatons mâles, cylindriques, qui passent l'hiver à nu........................

$\mathbf{J}^{\prime}$. Bourgeons aigus.

K. Bourgeons pyramidaux, revêtus d'écailles peu nombreuses.

L. Ramules et bourgeons glabres; ceux-ci dressés, non appliqués. - Arbre à écorce devenant gerçurée-subécailleuse.........

L'$^{\prime}$. Ramules et bourgeons pubescents ; ceuxci exactement appliqués. - Arbre à écorce mince, lisse et grise comme celle du hêtre. Micocoulier de Provence.

$\mathrm{K}^{\prime}$. Bourgeons ovoïdes, revètus d'écailles nombreuses.

L. Bourgeons placés obliquement au-dessus de la cicatrice de la feuille. - Grands arbres à écorce noir-brun, longitudinalement crevassée.

M. Bourgeons plus ou moins poilus.

N. Arbre à ramification serrée, dont les ramules sont régulièrement distiques et dans uu même plan; écorce souvent subéreuse jusqu'à un certain àge.............. $\mathrm{N}^{\prime}$. Arbre à ramification lâche, à ramules souples el pendants; écorce jamais su-

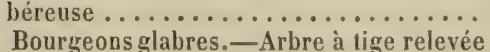

Coudrier noisetier. Aune glutineux.

(1)


M. Pousses rerruqueuses ou pubescentes, grêles et tombantes. - Arbre à écorce d'un blanc pur, s'exfoliant circulairement en minces membranes dès l'àge de $10-15$ ans; inflorescences mâles en chatons, dégagées des bourgeons dès l'automne.

N. Pousses verruqueuses, glabres ou à peine pubescentes.. ............ Bovleav blanc.

NI. Pousses non verruqueuses, pubescentes. Bouleau pubescent.

M'. Pousses lisses el glabres. - Arbre à tige irrégulièrement cannelée, revêtue d'une écorce grise, mince, toujours lisse; feuilles marcescentes.................. Chiarme commun.

II. Bourgeons longuement fusiformes, très-aigus, élalés-dressés. - Arbre à tige régulièrement cylindrique, revêtue d'une écorce gris-clair, mince 't toujours lisse; feuilles marcescentes sur les jeunes plants ou rejets............ Hètne comuun.

$\mathbf{H}^{\prime}$. Bourgeons spiralés, mème sur les pousses latérales.

I. Derniers bourgeons de chaque rameau agglomérés, par suite de l'arrêt d'allongement de leurs entre-nouds. -- Bourgeons ovoïdes, dressésétalés, multi-écailleux, dont les écailles forment plusieurs séries longitudinales; ramules sillonnés, pentagonaux; feuilles marcescentes sur les rejets el branches gourmandes; arbres dont l'écorce, lisse et gris-argenté d'abord, devient gercurée-rugueuse, épaisse, d'un noir-brun.

J. Ecailles prolongées en grèles el longues lanières Chène crevelu.

$\mathbf{J}^{\prime}$. Ecailles non prolongées en lanières.

K. Arbre très-drageounant; ramules et bourgeons garnis de poils gris étoilés........ Guène tauzin.

K'. Arbre non drageonnant.

L. Ramules el bourgeons glabres......... CirÉne pénonculé.

L'. Ramules vers l'extrémité ou au moins bourgeons plus ou moins pubescents...... Cirke nouva.

11. Bourgeons non ou à peine agglomérés à l'extrémité des rameaux, pluri-écailleux

J. $1^{\text {re }}$ écaille inférieure des bourgeons placée en avant, grande, cmbrassante et cachant parfois plus ou moins toutes les autres, en rapyelint alors l'écaille unique du bourgeon des saules. - Arbres à pousses droites, allongees, effilées.

[p. 427]

K. Bourgeons et ramules luisanls et glabres, les premiers visqueux.

[p. 127]

L. Bourgeons dressés-appliqués; ramules d'un jaune-verdatre. -- Arbre à écorce épaisse, Jongitudinalement gerẹrée-rugucuse, grisbrun.

[p. 127] 
M. Ramules arrondis.

N. Cime étalée................. Peuplier noir.

N1. Cime étroite-allongée, pyramidale..... Peuplter pyrambar.

$\mathbf{M}^{\prime}$. Ramules les plus vigoureux anguleux-ca-

L'. Bourgeons dressés, non appliqués, trèsaigus. - Arbre à écorce lisse et gris-verdâtre jusqu'à un âge avancé ; ramules d'un jaune-verdâtre ou rouge-brun........... Peuplien tremble.

K'. Bourgeons et ramules, surtout à l'extrémité, blancs ou gris-tomenteux, peu ou point luisants; les premiers dressés-élalés. - Arbre à écorce gris-verdâtre et lisse jusqu'à un àge avancé.

L. Duvet des ramules blanc et fortement feutré. Peurlien buanc.

$L^{\prime}$. Duvet des ramules gris et faiblement feutré. Peuplier grissille.

J'. 1're écaille inféricure des bourgeons placée latéralement.

K. Petits arbrisseaux ou sous-arbrisseaux dont les bourgeons et les ramules sont couveris à l'extrémité de glandes résinifères jaunes, d'une odeur aromatique prononcée.

L. Glandes nombreuses et apparentes. - Petit arbrisseau à ramules grêles, nombreux, dressés, pubescents, à bourgeons ovoïdes. aigus, étalés-dressés............. Mrñca galé.

$\mathbf{L}^{\prime}$. Glandes peu nombreuses el peu apparentes; odeur de cassis très-prononcée. Sous-arbrisseau à ramules assez épais, grisjaunâtre, accompagnés de débris membraneux du périderme; dont les bourgeons sont un peu stipités, dressés-étalés, de cousistance à peine écailleuse............. Groserluer norr.

K'. Ramules et bourgeons dépourvus de glandes résinifères el d'odeur aromatique.

L. Ecorce s'exfoliant en membranes sèches. Sous-arbrisseaux.

[p. 428]

M. Exfoliation de l'écorce prononcée, même sur les rarrules; ceux-ci assez robusles; bourgeons assez gros.

N. Bourgeons effilés, très-aigus, dressés presque appliques, à écailles herbacées d'un blanc-verdâtre.............. Groseiller des Altes.

$N^{\prime}$. Bourgeons ovoïles, à écailles sèches el brunes.

O. Ramules robusies, à périderme fortement exfolié en minces membranes........ Groseiller des rochers.

0'. Ramules médiocres, à périderme faiblement exfolié............... Grosetller rouge.

MI. Exfoliation marquée au pied seulement.

- Sous-arbrisseau à ramules grêles et bourgeons petits; écorce d'un gris-roux. Ainelle uligineuse. 
L'. Ecorce ne s'exfoliant pas en membranes sur les rameaux (chute de l'épiderme exceptée).

II. Bourgeons latéraux dressés, exactement appliqués, coniques, plus ou moins déprimés et velus ; écailles sèches et brunes.

N. Ramules gris-pubescents au moins à l'extrémité. - Arbre à tige irrégulière, peu élevé, revêtue d'une écorce d'abord lisse, d'un jaune ou d'un rouge brun, puis lamelleuse-écailleuse, gris-brun ; à cime étalée....................... Pomurer comun.

$N^{\prime}$. Ramules glabres, iroils, arrondis.

0. Arbrisseau émettant de terre un grand nombre de rameaux dressés, luisants et bruns; ramules grêles; bourgeons petits.

$0^{\prime}$. Arbre à ramules assez robustes, dont la lige est cylindrique et revêtue jusqu'à un âge avancé d'une écorce grise el lisse ; bourgeons gros. - L'enveloppe berbacée exhale une odeur forte quand on la

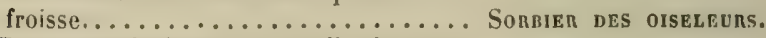

$\mathbf{M}^{\prime}$. Bourgeons latéraux non appliqqués contre le rameau.

N. Ecailles herbacées, vertes, étroitement bordées de brun. - Bourgeons gros ou assez gros, luisauts, à peu près glabres.

o. Bourgeons ovoïdes ou coniques-aigus.

P. Bourgeons visqueux. - Arbre dont l'écorce est de bonne heure finement fendillée-rugueuse, d'un brun-noir; à ramules brun-olivâtre, luisants et lisses,

dont les lenticelles sont peu apparentes. Sorbietr domestique.

P/. Bourgeons non visqueux. - Arbre à écorce lisse, brun-olivâtre, devenant ensuite faiblement écailleuse; ramules olivâtres, à lenticelles nombreuses et grandes....................... bre à écorce gercurée, gris-brun, finement écailleuse, dont les ramules sont rouge-brun, ponctués de nombreuses et grandes lenticelles..............

Amélanciner commun.

- Ecailles sèches et brunes.

0. Ecailles extérieures du bourgeon non rétrécies, ni prolongées en lanières. [p.450]

P.Licailles étroitement imbriquées. [p. 129]

Q. Bourgeons latéraux plus ou moins dressés.

[p. 429]

R. Ecorce lisse el satinéc-luisante, variant du gris-clair au brun-rougeâtre, disposée à s'enlever circulairement.

Alisier blanc.

Alisier torminal. 
-Bourgeons ovoïdes, dressés-étalés.

S. Ramules glabres. - Arbre à ramification claire, subverticillée.

T. Ramules ordinairement dressés ; bourgeons aigus........... Cerisier merisier.

T'. Ramules grêles, ordinairement pendants; bourgeons presque obtus .................. Cerisier a fruits acines.

$S^{\prime}$. Ramules courtement velus. - Arbrisseau à ramification assez serrée, parfois subépineuse.......... Cerisier Manaleb.

$R^{\prime}$. Ecorce peu ou point luisante, sans disposition Irès-prononcée à s'enlever circulairement, lisse el d'un brunnoir, finalement gerçuree-rugueuse.

S. Bourgeons ovoïdes-allongés.

T. Bourgeons exactement dressés, presque appliqués, à écailles larges. - Pelil arbre revêtu d'une écorce noir-brun et lisse pendant longtemps, marquée de larges et nombreuses lenticelles étendues en travers; exhalant une odeur désagréable par toutes ses parties quand on les froisse...........

$\mathbf{T}^{\prime}$. Bourgeons dressés légèrement étalées, à écailles allongées. Arbrisseau à tige lisse et gris-brun, à ramules lisses, d'un brun-rouge ou violet, marqués de petites lenticelles ..................

$\mathrm{S}^{\prime}$. Bourgeons coniques ou courtement ovoïdes. - Petit arbre à tige revêtue d'une écorce d'abord brun-rougeâtre lisse et un peu luisante, ayant une légère tendance à s'enlever circulairement; finalement noirâtre, rugueuse gerçurée.

T. Ramules glabres Qu à peu près, pourvus de lenticelles nombreuses. Prenier domestiqua.

$\mathbf{T}^{\prime}$. Ramules finement tomenteux; lenticelles rares ............ Prunier étraxger.

$Q^{\prime}$, Bourgeons latéraux presque étalés.

- Arbuste peu rameux, à rameaux gris, très-souples et très-tenaces; enveloppe herbacé à odeur balsamique;

floraison presque vernale ......... Darniné joli-BoIs.

$\mathbf{P}^{\prime}$. Ecailles lâchement imbriquées; les deux externes entr'ouvertes, laissant apercevoir toutes les autres. - Sousarbrisseau à rameaux allongés, bruns,

Cerisier a grappes.

Nenprun des Alpes. 
luisants, glabres, ordinairement réfléchis; bourgeons pauci-écailleux, tranchants sur les bords, velus au sommet. СотолÉaster commus.

$0^{\prime}$. Ecailles externes prolongées et amincies cn lanières. - Arbrisseau à écorce gris-brun, dont l'enveloppe herbacée exhale une odeur de térébenthine..... Sumac vuster.

$\mathrm{E}^{\prime}$. Bourgeons nus et petits.

F. Arbrisseau à rameaux droits, dressés, effilés, presque simples, revêtus d'une écorce lisse et brune jiquetée de gris; bourgeons effilés, aigus, couverts de poils brun-rougeâtre.................

F'. Arbrisseau à tige dressée, se divisant en rameaux et ramules très-grêles, insensiblement atténués à l'extrémité et garnis de bourgeons très-nombreux à l'aisselle d'une petite feuille squammiforme terminée en lanière grèle.

G. Rameaux finement verriqueux, brunâtres, ligneux. Tamanix dE France.

G'. Rameaux lisses, couverts d'efflorescence glauque, d'un gris-verdàtre clair; souvent compressibles...

$D^{\prime}$. Bourgeons abrités à l'aisselle de la base de la feuille

Myricahe d'Allemagne. de l'été précédent, laquelle base est garnie de 2 stipules grêles et allongées et devient persistante.

E. Rameaux recouveris d'une écorce fibreuse, grise et sèche. - Arbrisseau émellant du pied de nombreux

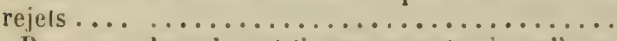

$\mathbf{E}^{\prime}$. Rameaux, branches of tige reconverts, jusqुu’à un àge assez avancé, d'une écorce lisse et verte.

F. Ramules soyeux-pubescents............. Cytise faux-Ébéxier.

$F^{\prime}$. Ramules veris el glabres................ Cyrise des Alpes.

$\mathrm{C}^{\prime}$. Ramules jonciformes, verts. - Arbuste......... Spartien d'Espagne.

$B^{\prime}$. Rameaux el ramules cannelés et anguleux, verts. -

Sous-arbrisseaux.

C. Bourgeons distiques, bi-écailleux, d̀ressés-étalés, rendant les ramules flexueux, 1-angulaires. - Sous-arbrisseau social, dépassant rarement $0^{\mathrm{m}}, \mathbf{3 0}$ de hauteur. Ainelle myrille.

$C^{\prime}$. Bourgeons spiralés; ramuies pentagonaux.

D. Rameaux et ramules dressés, verts, à bै arêtes prononcées; bourgeons extrèmement petils.......... Sarothamme a balats.

$D^{\prime}$. Rameaux et ramules étalés; port diffus; bourgeons abrités par un coussinet saillant, formé par la base persistante de la feuille.

E. Ramules très-grêles, velus-soyeux, souvent pourvus vers l'extrémité de qquelques feuilles persistanles... Genkr poluu.

$\mathbf{E}^{\prime}$. Ramules moyennement grèles, allongés, flexueux et

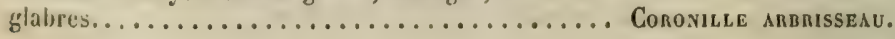




\section{$2^{\circ}$ SECTION.}

\section{Végétaux épineux, à feuilles caluques et alternes ainsi que les bourgeons et les rameaux.}

A. Végétaux pourvus d'épines véritables (organes transformés, rameaux, feuilles, stipules, etc.).

B. Epines en relation avec les bourgeons (feuilles ou parties de feuilles modifiées).

C. Epines géminées, placées à droite et à gauche des coussinets et des bourgeons (stipules transformées).

D. Epines égales, robustes, comprimées à la base ; bourgeons inclus entre elles dans une cavité corlicale. - Arbre dont la tige est revêlue d'une écorce grisbrun, épaisse, longuement et largement crevassée. rugueuse; ramules lisses et luisants, d'un rouge -

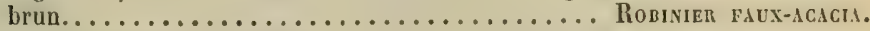

$D^{\prime}$. Epines inégales, l'une droite, dressée et allongée, l'autre crochue, réfléchie et plus courte. Arbrisseau. Paliune épineux.

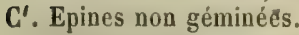

D. Epines ternées et égales, 2 latérales et une médiane - Sous-arbrisseau à écorce d'un gris clair........ Grosellerr ḱpineux.

D'. Epines solitaires ou fasciculées, simples ou tri-multipartites, souvent élargies à la base en un limbe sec et membraneux et situées en dessous des bourgeons. - Arbrisseau à écorce grise, fibreuse, d'un jaune vif intérieurement, surtout près de la souche. Epixe-rinetre commune.

$\mathbf{B}^{\prime}$. Epines sans relations avec les bourgeons et provenant de rameaux transformés.

C. Ramules et bourgeons converts d'écailles ferrugineuses; bourgeons lobés. - Arbrisseau diffus, dont la tige est revêtlue d'une écorce brun-foncé, longuement gerçurée, écailleuse et dont les rameaux sont lisses et luisants, d'un brun-rougeâtre foncé............. IIıpropuá́ riramoïoE.

C'. Ramules glabres ou pubescents, mais non couverts d'écailles ferrugineuses.

D. Bourgeons exactement appliqués. - Ramules glabres, si ce n'est vers l'extrémité; petit arbre dont la vieille écorce est écailleuse-membraneuse et caduque, l'écorce plus jeune olivâtre et lisse, la tige irrégulière, la cime étalée............... Pommier Acerae.

D'. Bourgeons dressés-étalés.

E. Ramules robustes, en même temp̧s velus et rugueux par suite des nombreuses et fortes lenticelles qui les couvrent; bourgeons coniques, ai- 
gus, poilus sur le bord des écailles. - Arbrisseau ou petit arbre à peine épineux, à lige tortueuse, cime très-élalée, dont l'écorce devient écailleuse, d'un brun-gris.................... Néflter d'Allenage. $E^{\prime}$. Ramules effilés, glabres, pubescents ou veloutés, lisses el sans lenticelles ou peu s'en faut.

F. Bourgeons sub-globuleux, arrondis ou émoussés au sommet.

G. Arbrisseau ou petit arbre dont l'écorce est lisse et gris-clair ou gris-olivâtre sur la tige et les branches, et devient à un âge avancé brun-rougeâtre, densément et finement ger-

H. Ramules glabres ou à peine pubescents... AubÉPINe $\left\{\begin{array}{l}\text { ÉPINEUSE. } \\ \text { MONOGYNE. }\end{array}\right.$

II'. Ramules gris-tomenteux, plus robustes.. AUbépine AZÉrorier.

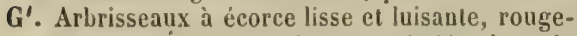
brun. - Épines nombreuses, étalées à angle droit; ramules courtement pubescents ..... Prunier Épixeux.

$F^{\prime}$. Bourgeons coniques-aigus.

G. Ramules veloutés ; écailles arrondies. - Arbrisseau ou petit arbre à peine épineux ou ne l'étant pas, à écorce lisse et gris-rougeâtre, légèrement satinée et disposée à s'enlever circulairement, finalement brune, gerẹurée-rugueuse ..................... Prunier étranger.

G'. Ramules glabres et luisants; écailles très-aiguës. - Arbre à écorce d'abord lisse, grisolivâtre, puis rugueuse-gerçurée el brune; tige droite, cime aiguë............. Pormen commun.

A'. Végélaux pourvus d'aiguillons (productions corticales disposées sans aucun ordre).

B. Tige d'une durée illimitée, frutescente ........ Genre Rosın.

$B^{\prime}$. 'T'ige bisannuelle

C. Tiges dressées, frutescentes, arrondies, grises, à aiguil-

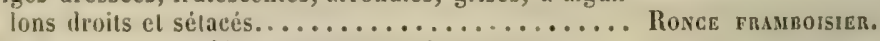

$C^{\prime}$. Tiges rampantes, décombantes ou grimpantes.

D. Tiges arrondies, rampantes .............. Ronce Bleuatre.

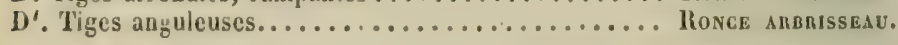




\section{$3^{\text {e }}$ SECTION.}

\section{Végétaux inermes, à feuilles alterues, persistantes.}
A. Feuilles à limbe plan, étalé.
B. Feuilles simples.
[p. 454$]$
[p. 454]

C. Tige très-longuement rampante ou grimpante. -

Arbrisseau à longues tiges grêles, s'enracinant sur tout leur parcours ou se fixant simplement par des crampons quand elles s'élèvent; à feuilles 3-כ̆-lobées ou entières.................. Likrne comun.

C'. Tige frutescente, arborescente ou peu longuement rampante.

D. Feuilles obovales-oblongues, entières.

E. Feuilles $b$ fois aussi longues que larges, à bords plans. - Sous-arbrisseaux neu rameux, à rameaux gris, très-souples el très-lenaces, terminés par les feuilles disposées en plumets. Dapiné lauréole.

$E^{\prime}$. Feuilles 2-3 fois seulement aussi longues que larges, rappclant celles du buis.

F. Feuilles à bords enroulés en dessous. Très-petit sous-arbrisseau social, de 1.2 décimètres, à tiges radicantes et à racines tracantes.................... Ainelde canctie.

$F^{\prime}$. Feuilles à bords plans. - Sous-arbrisseau à tiges étalées, rampantes el radicaules... Bussenole officinal.

$D^{\prime}$. Feuilles elliptiques ou ovales.

E. Feuilles glabres et vertes en dessous. [p. 454] F. Feuilles entières. - Arbuste ou arbre revêtu d'une écorce mince et lisse, non luisante, à cime presque pyramidale; odeur pénétrante caractéristique. . . . . . . . . Laurien comun.

$F^{\prime}$. Feuilles dentées.

G. Feuilles dentées en scie.

H. Feuilles làchement et superficiellement dentées, apiculées au sommet. Arbrisseau................ Nerprun alaterne.

$H^{\prime}$. Fenilles densément dentées en scie, lancéolées au sommet. - Arbrisseau. Arbousier commun.

$\mathbf{G}^{\prime}$. Feuilles dentées-épineuses, au moins en parlie.

H. Rameaux revêtus d'une écorce longtemps verte et lisse. - Arbrisseau à ramification làche, dont les feuilles sont parfois entières.......... [p. 454] Houx commus. 
$\mathrm{H}^{\prime}$. Rameaux revêtus d'une écorce grise ou brune. - Arbrisseaux buissonnants.

I. Feuilles en ovale court, à surface ondulée; glands à cupule épinense Chève renmès.

$I^{\prime}$. Feuilles en ovale allongé, presque planes; glands à cupule lisse.... Chève des ganngues.

$\mathbf{E}^{\prime}$. Feuilles tomentelıses ou écailleuses en dessous.

F. Feuilles grises ou blanches tomenteuses en dessous. - Arbres.

G. Ecorce non subéreuse. - Arbre dont les feuilles sont très-variables, entières, dentées, épineuses, elc., et dont l'écorce, lisse el grise d'abord, devient finement gerçurée-rugueuse, d'un brun-noir. . . C Cnène yeuse.

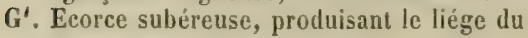
commerce,

H. Glands annuels. - Tombés dès l'automne, l'arbre n'en porte jas en hiver. Cuêne liége.

II'. Glands bisannuels. - L'arbre porte en hiver des glands très-petits, de pre-

$\mathrm{F}^{\prime}$. Feuilles écailleuses-ferrugineuses, a bo bo enroulés en dessous. - Petit arbuste. . . Rhododendron ferrugineux.

B'. Feuilles composées, oppositi-paripennées. - Arbres de pelites dimensions.

C. Folioles étroites, elliptiques, mucronées; pétioles étroitement ailés ................... Pistacmier Lentisque.

$\mathrm{C}^{\prime}$. Folioles larges, ovales, obtuses ou échancrés au sommet; pétioles non ailés.............. C.nounien commun.

$A^{\prime}$. Feuilles aciculaires ou squammiformes-imbriquées.

B. Feuilles solitaires, spiralées.

C. Ramification irrégulière; feuilles planes, acuminées, non piquantes, vertes en dessous. - Arbre revêtu d'une écorce lisse et mince, écailleuse-caduque, roux-canelle.................... lf commun.

C'. Ramification verticillée; feuilles toujours aciculaires. - Arbres de grande taille.

D. Feuilles semblant distiques, planes, obtuses ou ćchancrées au sommel, marquées de deux raies blanches en dessous. - Arbre à écorce lisse et vive, d'un gris-argenté, ne devenant gercuréerugeuse et brun-noir qu'à un âge avancé ; branches verticillées sur la tige; rameaux opposés et dans un mème plan horizontal sur les branches. Sapin pectivé.

D'. Feuilles spiralées, tétragones, pointues et piquantes. - Grand arbre à écorce membraneuseécailleuse, rougeâtre; à branches verticillées sur la tige, ì rameaux el ramules nombreux et distiques, tombant de chaque cólé des branches... Eprcéa comaun.

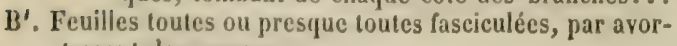
tement des rameaux. 
C. Faisccaux composés d'un nombre considérable, illimilé, de feuilles. - Grand arbre à ramification diffise, à fenilles piquantes, spiralées et espacées sur les quelques pousses qui s'allongent....... Cépre du Libar.

$\mathrm{C}^{\prime}$. Faisceaux limités à 2 ou bै feuilles allongées. - Arlires dont la ramification verticillée se maintient de la lige aux branches et aux rameaux; cônes à écailles épaissies (écussonnées) à l'extrémité.

D. Feuilles géminées, accompagnẻes d'une gaîne persistante. - Ecorce gerçurée-écailleuse, persistante, variant du rouge-ocreux au rouge-violacé ; écussons des cônes à ombilic central.

E. Feuilles de à à 6 centimètres de longueur au plus.

F. Feuilles glaucescentes. - Cône mûr gris mat, à écussons plans ou, sur un côté, prolongés en pyramides grêles, étalées-réfléclies; écorce sans vacuoles résinifères... Pin sylvestra.

F'. Feuilles d'un vert sombre. -- Cône mûr gris-brun luisant, à écussons prolongés en pyramides convexes, réfléchies; écorce avec des vacuoles résiuifères. ......... PIN a сnосnетs.

1: Feuilles de $6-15$ centimètres et p'us.

F. Feuilles robustes et épaisses.

G. Feuilles d'un vert sombre, de consistance sèche, de 10-15้ centimètres. - Cône gris brunâtre clair et luisant, de $5-8$ centimètres de long, à écussons transversalement carénés; écorce formée de lames alternativement gris-argenté et rouge-brun................. Pin laricio.

(i'. Feuilles charnues, d'un vert-clair un peu jaune, de 10-25 centimètres de long. Cônes de 14-18 centimètres, d'un rouxvif el luisant, à écussons élevés, transversalement carénés ; écorce d'un rougeviolacé, à grandes écailles.......... PIn maritime.

$\mathbf{F}^{\prime}$. Feuilles grètes, d'un vert clair.

G. Feuilles de $6-17$ centimètrés de long, plus grêles, dressées sur les rameaux en forme de plumels. - Cônes de 10-12 centimètres, d'un roux vif et luisant, dont les écussons sont presqque plans, finement et transversalement carénés. . PIN D'A LEP.

$G^{\prime}$. Feuilles de $8-1 b^{\circ}$ centimètres de long, moins grêles, étalées, diffuses. - Cônes de 3 âges sur le même arbre, très-yros, ovoïles-obtus, d'un rouge vif et luisant. PIN pinteir.

D'. Fenilles réunies par $\mathbf{5}$ dans une gaîne caluque. - Écorce lisse et vive, grise jusqu'à un âge assez 
avancé, finalement gercurée-écailleuse ; écussons des cônes à ombilic terminal.

E. Feuilles assez robustes; ramules couverts de poils rougeâtres. - Cônes ovoïles globuleux et obtus, bruns, mats et lâchement imbriqués. Pix cesnno.

$\mathbf{E}^{\prime}$. Feuilles grèles; ramules glabres. - Cònes cylindriques, brun-violacé, déhiscents avant l'hiver.

Pix WeYuovti.

\section{$4^{\mathrm{e}}$ SECTION.}

Wégétanx épineux, à feuilles alternes, persistantes.

A. Feuilles à limbe plan, elliptiques ou obovales, crínelées, luisantes. - Arbrisseaux à rameaux bruns, couveris en hiver de petits fruils globuleux d'un rouge-corail, disposés

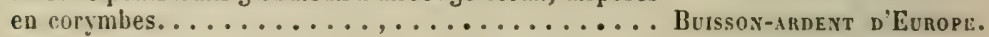

$\AA^{\prime}$. Feuilles aciculaires-épineuses; rameaux et ramules verts; striés. - Sous-arbrisseaux touffus, hérissés de toutes parls d'épines qui proviennent de feuilles et de rameaux transformés.

B. Epines robustes; teinte générale d'un vert cendré.

C. Rameaux el ramules velus. . . . . . . . . . . . Asonc D'Eunope.

C'. Rameaux el ramules glabres ou à peu près........ Ajonc a Petrites reeurs.

$\mathbf{B}^{\prime}$. Epines grêles, très-nombreuses; teinte générale d'un

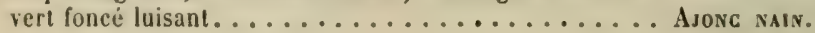




\section{马 SECTION.}

\section{E'́gétaux inermes, à feuilles opposécs, caluques.}

A. Tige frutescente et arborescente. [p. 441]

B. Bourgeous nus. - Arbrisseaux peu rameux, à pousses arrondies, robustes, droites et flexibles, recourertes, ainsi que les bourgeons, d'une couche épaisse de poils gris, étoilés................ Vionne Flexible.

B'. Bourgeons écailleux, quoique parfois les écailles extornes, petites et entrouvertes, laissent voir les parties herbacées centrales.

C. Bourgeons 1-écailleux. - Arbrisseaux dont les rameaux se terminent souvent par 2 bourgeons, par suite de l'avortement du bourgeon terminal.

D. Bourgeons latéraux appliqués, ovoüdes-aigus, rougeâtres. - Arbrisseau à écorce d'un gris jaunàtre, dont les rameaux sont jaunâtres ou rouge-brun, fragiles, légèrement héxagonaux.. Viorno orier.

1): Bourgeons latéraux dressés, non appliqués, verts, ovoïdes-comprimés et tranchants sur les còtés. - Arbrisseau à ramules cylindriques et verdâtres, dont l'écorce devient gris-foncé finement strié de blanchâtre............ Stapiryugr Pervó.

$C^{\prime}$. Bonrgeons pluri-multi-écailleux.

D. Bourgeons 2-4-écaillenx. [p. 458]

E. Bourgeons terminaux gros, pyramidaux, obtusément 4-angulaires, à écailles sèches et pulvérulentes. - Arbres d'une ramification claire, sub-verticillée, à ramules robustes, non effilés; dont l'écorce est lisse et gris-ver. dâtre ou jaunâtre d'abord, puis assez densémenl gercurée-rugueuse et brun-noir.

F. Bourgeons noirs, trapus.......... Frève comsux.

$F^{\prime}$. Bourgeons bruns ou gris.

G. Bourgeons brun-jaunâtre, plus effilés que les précédents............... Frêne oxypHirle.

$G^{\prime}$. Bourgeons gris, saupoudrés de gris-clair el de brun .................. Frène a fleurs.

$\mathrm{E}^{\prime}$. Bourgeons grêles (à part les florifères), effilés, aigus. - Arbrisseaux.

$F^{\prime}$. Bourgeons dressés, poilus, souvent stipités, de consistance herbacée. [p. 438]

G. Ramules d'un pourpre noirâtre, presque glabres, luisants, généralement cylin- 
Uriques, exhalant mne odeur fétide quand on les froisse. - Arbrisseau ì écorce brune, finement gercurée rugueuse.... Consovu.rer sivguiv.

$G^{\prime}$. Ramules ver's ou rongeâtres sur une face, couverts de poils appliqués; mats, oblusément létragones, sans odeur quand on les froisse. - Arbrisseau ou petit arbre à écorce gris-jaunâtre, lamelleuse-caduque, offrant dès l'automne de gros bourgeons globuleux florifères. Conxoutu. ar mate.

$F^{\prime}$. Bourgeons étalés presque à angle droit, glabres, multiples en série longitudinale décroissante à chaque aisselle, sessiles et de consistance sèche, pourvus à la base des débris des feuilles de l'été. - Sousarbrisseau à ramules lisses, d'un rougebrun luisant, dont l'écorce s'exfolie sous forme de lanières membraneuses ...... Cuívne-ffuicle blev.

$\mathrm{D}^{\prime}$. Bourgeons multi-écailleux.

E. Bourgeons non visqueux.

$\left[\begin{array}{ll}\text { p } & 440\end{array}\right]$

F. Bourgeons latéraux très-étalés ou verticillés par 3. - Sous-arbrisseaux revètus d'une écorce sc̀che el lisse, sans lenticelles, membraneuse-fibreuse, et dont les bourgeons sont multiples à chaque aisselle, en série longitudinale décroissante.

G. Bourgeons gros, étalés-dressés; souvent verlicillés jar 3. - Ramules robustes, d'un gris-clair ................. Chtène-fevilte des Alpes.

G'. Bourgeons grêles, très-étalés; opposés. - Ramules effilés.

H. Bourgenns poilns, surtont au sommet. - Rameaux el ramules d'un gris.

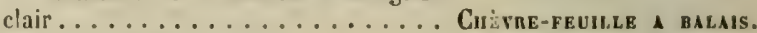

II'. Bourgeons glabres

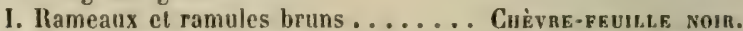

I'. Rameaux et ramules d'un gris-'lair. Chèvae-feuille des P'ynéníes.

F'. Bourgeons latéraux dressés ou appliqués.

G. Bourgeons ouverts par le sommet.

Arbrisseau à écorce grís-jaunâtre, finement gerçurée-rugueuse; poussant des rejets gros el fragiles, creusés d'un large canal médullaire, à moelle blanche; dont les ramules sont gris, glabres et luisants, relevés de légères côtes lon. gitudinales et dépourvus de gros bourgeons floriferes.............. Suneav xoln.

G'. Bourgeons complètement fermés.

II. Ramules surmontés pour le plus grand nombre par 2 bourgeons latéraux, 
par suite de l'avortement du bourgeon terminal en un ramule grêle et stérile, allongé ou sub-épineux.

1. Bourgeons arrondis-globuleux, courtement acuminés. - Arbrisseau produisant des rejets assez gros, fragiles, creusés d'un large canal médullaire, à moelle brunâlre ; ramules bruns, légèrement angu. leux, dont les bourgeons, gros et multiples à chaque aisselle, sont florifères et enveloppés d'écailles herbacées, d'un vert lavé de pourpre foncé............... Surbau nouge.

I'. Bourgeons 4-angulaires, ovoïdes-aigus. - Arbrisseau à ramules ligneux, arrondis et gris, dont les bourgeons sont enveloppés d'écailles carenées sur le dos, verles, bordées de jaunâtre.......... Lilas conauv.

$H^{\prime}$. Rameaux habituellement surmontés d'un bourgeon terminal.

I. Bourgeons latéraux nuls ou au nombre de 1-2 paires seulement sur chaque ramule. - Arbrisseau à ramification làche, dont les ramules sont arrondis, luisants, verts lavés de rouge-brun sur une face et les bourgeous fusiformes, très-aigus, veris ou rougeâlres. .......... Fusaix A LARges FEULLES.

1'. Bourgeons latéraux réguièrement développés.

J. Bourgeons globuleux-obtus, petils. 4-lobés sur le pourtour, herbacés. - Arlorisseau à rameaux et ramules d'un vert mat, souveut 4-angulaires par suite du déveioppement de 4 côtes longitudinales de tissu subéreux brun. Fusars d'Eunopr.

$J^{\prime}$. Bourgeons ovoïdes-aigus.

K. Coussinets brusquement saillants à l'cxtrémité de chaque entre-nœud. - Arbrisseau à rameaux et ramules droits, eflilés, arrundis, à écorce grise et lisse, à bourgeous exactement appliqués et dont les feuilles persisteut souvent jusqu'à la fin de l'hiver.... Troexe commux.

$\mathbf{K}^{\prime}$. Coussinets peu saillants, se 
raccordant insensiblement avec l'entre-noud qut'ils terminent.

I. Bourgeons terminaux 4-angulaires.

II. Bourgeons gros, à écailles herbacées, glabres.

N. Bourgeons dressés-étalés, à écailles vertes, bordées de brun. Grand arbre dont l'écorce, d'abord lisse et gris-jaunâtre, s'écaille ensuite comme celle du platane......... Emable sтcomore

$N^{\prime}$. Bourgeons appliqués, à écailles rouges ou vertes terminées de brun. - Grand arbre à écorce lisse el grise, devenant avec l'âge finement gercurée-rugueuse, mais non écailleuse comme la précédente......... Ehable plaxe.

$\mathbf{M}^{\prime}$. Bourgeons petits, dressés, à écailles herbacées, vertes ou rouges, largement sèches et brunes au sommet, un peu poilues. Arbre dont les rameaux vigoureux et les jeunes rejets sont presque toujours recouverts d'un liége jaune-brun, fragile, largement et profondément crevassé........ Енarle champétuc.

L'. Bourgeons terminaux arrondis sur le pourtour.

M. Bourgeons moyens, fusiformes-aigus, les latéraux dressés; écailles sèches et brunes, grises. tomentenses, avec les bords glabres et luisants. Eranle a fevilles b'obien.

II'. Bourgeons petils, ovoïdes, dressés-élalés, à écailles, sèches et brunes, à peu près glabres.......... Erable ue Muntrelles.

$E^{\prime}$. Bourgeons viśqueux, très-gros, ovoïdes-aigus, brun-rougeatre. - Arbre à ramules trapus, 
A'. Tige grimpante.

souvent terminés, quand ils ont fleuri, par 2

bourgeons latéraux. ............. Marronnier d'INde.

B. Tige irrégulièrement sarmenteuse, cannclée, revêlue d'une écorce grise, fibreuse, portant des débris des feuilles et des inflorescences axillaires de l'été.

Bourgeons très-pelits

C. Sarments marqués vers l'extrémité de $\mathbf{6}$ sillons, séparés par des côtes arrondies qui les rendent hiéxagonaux.................... Clématite des ilaies.

$C^{\prime}$. Sarments arrondis, relevés de côtes nombreuses, alternativernent plus saillantes............ Clématite odorante.

B'. Tige volubile, arrondie, lisse, d'un gris-blanchâtre. - Bourgeons étalés, effilés, aigus, 4-angulaires,

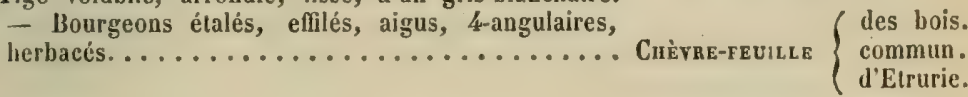

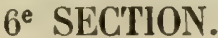

\section{Végétaux épineux, à feuilles opposées, caduques.}

Arbrisseaux épineux par avortement des bourgeons terminaux, se ramifiant par dichotomie et revêtus sur la tige et les branches d'une écorce d'un brun luisant, disposée à s'enlever circulairement. - Bourgeons pluri-écailleux, dressés, à écailles sèches, brunes et glabres.

A. Arbrisseaux dressés.

B. Bourgeons assez gros, ovoïdes-aigus, arrondis.

Arórisseau d'assez grande taille ou mème petit arbre. Nerprun purgatif.

B'. Bourgeons petits, ovoïdes-comprimés. - Arbrisseau

à ramification très-serrée, de moindres dimensions

que le précédent................... Nerprun des teinteriers.

$A^{\prime}$. Sous-arbrisseau diffus, formant un buisson bas, épineux de toutes parts, dépassant rarement 1 mètre de

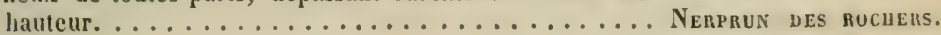




\section{7' SECTION.}

\section{Végétaux inermes, à feuilles opposées, persistantey.}

A. Limbe des feuilles bien développé.

B. Tige volubile.

$B^{\prime}$. Tige frutescente ou arborescente.

Cilèvie-feullle des Baléahes

C. Feuilles pétiolćes, luisantes, entières, poilues sur les bords et sur les nervures en dessous; cellesci rameuses et anastomosées. - Arbrisseail revètu d'une écorce mince, cadug̨ue, d'un brun canelle....................... VIonne Tin.

C' Feutlles sessiles ou courtement pétiolées, glabres.

D. Feuilles uni- ou sub-uni-nervices, au moins en apparence.

E. Feuilles d'un vert grisâtre et mat, ovalesoblongues, aiguës, entières et à bords enroulés. - Petit arbre ou arbrisseau, parfois subépincux, dont l'écorce devient rugeuseécailleuse, jaune-brunâtre........... Otwren n'Eunore.

$\mathbf{E}^{\prime}$. Fenilles verles et luisantes.

F. Feuilles pointues. - Arbrisseanx

G. Feuilles, au moins les inférieures, cordiformes à la base, toujours dentéesépineuses................ Puhanak naessé.

$G^{\prime}$. Feuilles jamais cordiformes à la base.

II. Feuilles ovales-lancéolées, entières ou dentées................. Philaha intermématre.

I'. Feuilles étroitement elliptiques, entières ou à peine denticulées au som.

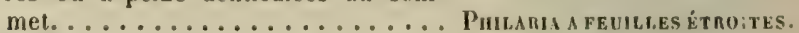

$F^{\prime}$. Feuilles obtuses ou échancrées au sommet.

- Arbuste à écorce mince, finement rugucuse-gerçurée, gris-jaunâtre, dont les feuilles sont petites et très-rapprochées et qui exhale par loules ses parties, surtout quand on les froisse, une odeur fétide Bess common.

1)'. Fenilles à nervation évidemment pennée.

L. Feuilles ponctuées-transparentes, entières el légèrement enroulées sur les bords, acuminées, luisantes, à nervures secondaires rapprochées. - Arbrisseau exhalant une odeur de gérofle, à écorce mince, écailleuse-caduque, roux-brun. ........... [ [ . 445] Mrnte conuun. 
E'. Feuilles non ponctuées-iransparentes, entières et à bords plans, longneinent elliptiquesaigües, mates, souvent ternées, pourvites d'un très-grand nombre de nervures secondaires entières el parallèles. - Arbrisseau revètu d'une écorce mince et grise. . . . . . Némon laünter-au.

$A^{\prime}$. Feuilles petites, étroitement imbriquées ou aciculaires.

B. Sous-arbrisseaux non aromatiques. . [p. 444]

C. Fcuilles élroirement imbriquées sur 4 rangs, prolongées à la base en 2 appendices. - Sous-arbrisseau social..................... Callune bauyére.

$C^{\prime}$. Feuilles aciculaires, non imbriquées et non appendiculées à la base; verticillées par $\mathbf{3}-50$.

D. Feuilles ciliées sur les bords.

E. Feuilles ovales-aiguës, bordées de cils raides, espacés el non-glanduleux, à bords enroulés en dessous et y produisant un large sillon triangulaire, au milieu duquel la nervure médiane forme une légère saillie . . . . . . Bruyène cilí́.

$\mathbf{E}^{\prime}$. Feuilles linéaires-oblongues, bordées de cils glanduleux; sillon de la face inférieure triangulaire, étroit ............. Bruyène quatennée.

D'. Feuilles non ciliées, entières ou très-faiblement denticulées sur les bords.

E. Ramules droits, simples, dressés et nombreux, courtement pubérulents; feuilles largement 1-sillonnées en dessous, à sillon décroissant de la base au sommet, faiblement convexes en dessus................. Bnữène nกEssée.

$\mathbf{E}^{\prime}$. Ramules plus ou moins diffus.

F. Feuilles étroitement blanclies-scarieuses sur les bords, pourvues à leur aisselle de faisceaux de feuilles plus jeunes; planes en dessus, très-finement el uniformément 1-sillonnées en dessous............ Bruvíra cendríb.

$F^{\prime}$. Feuilles n'étant pas blanches-scarieuses sur lcs bords et sans faisceaux à leur aisselle.

G. Ramules velus.

H. Ramules couverts de poils simples; feuilles presque capillaires, finement et également 1-sillonuées en-dessous. Bruxirr br Portugat.

II'. Ramules couveris de poils rameux; feuilles moins étroites que les précédentes, sillonnées de meme... . . . B Buyère ex arare.

$\mathbf{G}^{\prime}$. Ramules glabres ou à peine pubérulents.

P. Feuilles bisillonnées en dessous ...... Bruyére a bazais.

II'. Feuilles unisillonnées en dessous ; sillon fin, égal.

I. Feuilles planes en dessus, aignës au sommet, plus longues (10 mill.) 
et surlout plus larges que celles

des espèces suivantes......... Bnuyène multiflone.

I'. Feuilles convexes en dessus

J. Fruit (capsule entouréc de la corolie marcescente) porté par un pédicelle plus court que lui. . B Buxére de la Médrterranée.

J'. Fruil (capsule comme la précédente) porté par un pédicelle 34 fois aussi long que lui ..... Bruyère vagabonde.

['. Arbrisseaux el petits arbres aromatiques.

C. Toules les feuilles aciculaires.

D. Feuilles oblusément carénées en dessous; fruits petits, bleus............................ Gévnter commun.

$D^{\prime}$. Feuilles aigûment carénées en dessous; fruits

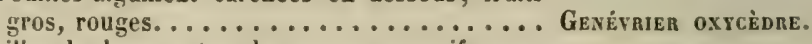

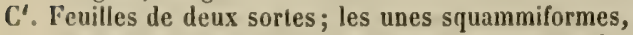
les autres, plus rares ou nulles, surtout sur les pieds âgés, aciculaires.

1). Feuilles sillonnées sur le dos; fruit rouge..... Genévrien de Piénicie.

1)'. Feuilles glanduleuses sur le dos; fruit bleu... Genévmer sabine. 


\section{TABLE DES MATIÈRES.}

Préface . . . . . . . . . . . .

IV. $\mathbf{x} I 1$

Dictionuaire des mots techniques employés dans la Flore forestiere. . . . . . . . . . . xill-xxrm Flore forestière. . . . . . . . . . . . .

Clef analytique pour la déterminalion des principaux végétaux

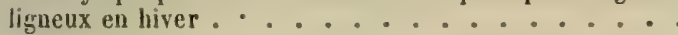

Abies . . . . . . 589 Alisier blanc. . . . . 125

- pectinata. . . . 559 - de Scandinavie. . . 127

ABı́tinées ..... . 558 - hybride..... 129

Alsticotier. . . . . 102 - nain...... 129

- commun .... . 102 - torminal ..... 127

Acer. . . . . . . 25 Alnaster. . . . . . 283

- campestre..... 50 - suaveolens.... 286

- monspessulanum. .. 31 - viridis. . . . . 286

- opulifolium. . . . 28 Alnus . . . . . 286

- plalanoïdes. . . . 29- cordala..... 292

- pseudoplatanus.... 26 - elliptica. . . . . 292

ACÉRINÉES. . . . . 24 - glulinos . . . . 287

Adénocarpe. . . . . 85 - incana. . . . . 291

- à feuilles pliẻes. . . . 84 - pubescens. . . . 292

- à grandes fleurs . . . 83 Amandier . . . . . . 95

- transposé ..... 84 - commun ..... 95

Adenocarpus . . . . . 83 Amélanchier. . . . . 152

- commutatus. .... 84 - commun...... 152

- complicalus..... 84 Amelanchier. . . . . 152

- grandiflorus. . . . . 83 - vulgaris . . . . 152

Esculus . ....... 52 AMpélidées . . . . 57

- hippocastanum. ... 55 AMYgdaléES . . . . . 95

Airelle ........ 152 Amygdalus ...... 95

- Canche. . . . 155 - communis. . . . 95

- Myrtille. . ... 152 Anagyre ....... 66

- uligineuse. . . . . 155 - félide . . . . . 67

Ajonc. . . . . . . . . . . 67 Anagyris. 66

- à petites fleurs. . . 6 69 - fatida. . . . 67

- de Le Gall.. . . . . 69 Andromeda. . . . . 164

- d'Europe . . . . 68 68 polifolia . . . . 164

- nain. . . . . 68 Andromède . . . . 164

Aliboufier. . . . . . 150 - à feuilles de Polium. . 164

— officinal. . . . 151 APÉTALES. . . . 184

Alisier . . . . . 12 12 - AMENTACÉES. . . 212

- à larges feuilles . . 127 - NON AMENTACÉES . 184 
Apocysées. . . . . 178|Bruyère de la Médilerranéc . 161

Arbousier. . . . . 157 - du Porlugal . . . 163

- commun .....157 - dressée..... 163

Arbutus . . . . 157 - en arbre . . 165

- Unedo...... 157 - multiflore..... 161

Arceutobie. . . . 197 - quaternée....162

— de l'Oxycèdre... 197 — vagabonde.... 161

Arceutobium. . . . . 197 Bugrane ....... 84

-Oxycedri. .... 197 — arbrisseau. .... 85

Arctostaphylos. . . . 158 - champêtre. . . . 8

- officinalis .... 158 - des anciens.... 85

- ulpina ...... 158 - rampante. . . . 85

Armeniuca . . . . 102 Buis . . . . . . 211

- vulgaris..... 102 - commun .... 212

Aubépine .......115 Buisson-ardent. . . . 115

- Azerolier ......117 - d'Europe.....115

- épineuse . . . . . 117 Busserole. . . . . . 158

- monogyue. . . . . 116 - des Alpes. . . . 158

Aunàtre. . . . . . 285 - officinal. . . . . 158

- suave.......286 ruxacÉes. . . . . 211

- vert......2286 Buxus .......211

Aune. ......2286- sempervirens. ...2212

- blanc. . . . . . 291 Callitris. . . . . 585

- cordiforme. . . . 292 - quadrivalve.... 355

- elliptique ... . . 292 Callitris . . . . . 555

- glutineux... . . 287 - quadrivalvis. . . . 558

-. pubescent. . . . 292 Calluna. . . . . . 159

Baguenaudier...... 89-vulgaris .... 159

- arborescent.... 90 Callune. . . . . 159

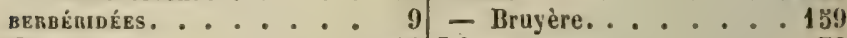

Berberis. . . . . . 10 Calycotome. . . . . . 70

- atnensis..... 11 - épineux. .... 70

- vulgaris. ..... 10 - velu. .... 70

Betula...... 278 Calycutome. . . . 70

— alba...... 279 - spinosa. . . . 70

- intermedia.....284 - villusı ..... 70

- nana. . . . . 285 Camarine ...... 44

- pubescens. . . . 284 - à fruits noirs. . . 44

пе́тULAcÉes. . . . 277 Camélée. . . . . 63

Bouleau. . . . . . 278 - tricoque. . . . . 65

- blanc. . . . 279 Canneberge. . . 154

- intermédiaire ... 284 - commune. . . . 15/

— nain ...... 283 capnifoliacées .... 145

- pubescent. .... 284 Caroubier. . . . . . 92

Bourdaine. . . . . . \$35 - commun. . . . . 92

- commune ...... 35 Carpinus. . . . . . 271

Bruyère. . . . . 160 - Betulus. . . . . 272

- à balais. . . . . 164 Castaner.. . . . . 222

- cendréc. . . . 162 - vulgaris. . . . 223

- ciliée. . . . . 162 Cèdre . . . . . 577

- conmmune . . . 159| - du Liban . . 378 
TABLE DES MATIÈRES.

Cedrus. . . . . . 578|Cistes à feuilles de Peuplier. . 14

- Libani. . . . . 577 - à feuilles de Sauge . . 14

célastrinées ...... 40 - à longhes feuilles. . . 14

Celtidées. . . . . . 201 - blanchâtre .... 15

Cellis...... 202 - cotonneux .... 15

- australis...... 202 - crépu ....... 14

Cerasus . . . . . 96 - de Monipellier. ... 15

— acidu ..... 98 - de Pouzolz.... 14

— avium ...... 96 - hérissé..... 14

- Mahaleb..... 98 - ladanifère..... 15

- Padus. . . . . 99 - Lédon...... 15

Ceratonia........ 92 Cistinées. . . . . 11

- Siliqua....... 92 Cistus ........ 11

Cercis. . . . . 92 - albidus.... 13

- Siliquastrum . ...92 - crispus...... 14

Cerisier........996- hirsutus...... 14

- à fruits acides....99- incanus..... 15

- à grappes..... 99 - ladaniferus.... 13

- Nahaleb .....98- laurifolius .... 13

- Mérisier ..... . 96-Ledon. ...... 13

CÉSALPINÉES . . . . . 91 - longifolius ..... 1 la

Chalef ...... 192 - Monspeliensis.... 15

- à feuilles étroites. . . 192 - populifolius .... 14

Charme.......271-Pouzolzii..... 14

- commun ... . . 272 - salviafolius.... 14

Châtaignier. . . . . 222 Clematis. . . . . 8

- commun ..... 223 - cirrhesa . . . . 9

Chène ....... 226 - fammula..... 9

- chevelu. . . . . 251 - vilalba. . . . . 9

- faux-liége. . . . 2555 Clématite....... 8

- garrigue ......267 - cirrheuse. . . . . 9

— kermès. . . . . 266 - des haies. . . . 9

- liége. . . . . 257 - flammule . . . . 9

- occidental. . . . 264 Cncorum. .....63

- pédonculé. .... 256 - tricuccon..... 63

- rouvre ...... 241 Coignassier. . . . . 119

- tauzin ...... 247 - commun ..... 119

- yeuse ...... 255 Colutea . . . . . . 89

- zecn. . . . . 250 - arburescens. . . 90

Chèvre-feuille . . . . 147 CONIFÈRES . . . 559

— à balais ..... 149 Coriaria ..... 37

- bleu. ..... 1 ๖0 - myrtifolia..... 37

- commin ..... 149 coniariées .... 36

- des Alpes. . . . . 150 connées . . . . . 159

- des Baléares .... 149 Cornouiller...... 159

— des bois ..... 148 - mâle...... 159

- des Pyrénées . . . 150 - sanguin. . . . . 140

— d'Etrurie . . . . 149 Cornus. . . . 159

- noir. . . . 150 - mas.... 139

Ciste. ..... 11 - sanguinea ... 140

- à feuilles de Laurier. . . 13/Coronilla. . . . . . . . 90 
Coronilla Emerus . . . . 90|Cylisus triflorus. . . . . 82

- glauca. . . . . 91 Dabrecia........ 165

- juncer.......99- 91 - polifolia ....163

Coronille. . . . . 90 Dabocie . . . . . 163

- Arbrisseau . . . . 90 - à feuilles de Polium. . 165

- glauque ...... 91 Daphné. ...... 186

- jonciforme .....91-Bois Gentil . . . . 187

Corroyère...... . 57 - Camélée . . . . 188

— à feuilles de Myrte . . 57 - des Alpes. . . . . 187

conYlacées . . . . 268 - Garou . . . . 187

Corylus . . . . . 268 - Lauréole . . . . 188

- Avellana.....269 - oléoîde. ..... 187

Cotonéaster. . . . 114 - strié. ..... 188

- commun ...... 114 Daphne...... 186

- cotonneux. . . . . . . 115 - alpina 187

Cotoneaster. . . . 114 - cneorum..... 188

- tomentosa. . . . 115 - gnidium ... 187

- vulgaris ..... 114 - Laureola. ..... 188

Coudrier . . . . . . 268 - mezereum .... 187

- Noisetier. . . . . 269 - oleö̈des . . . : 187

Cratagus. ...... 115 - striata. . . . . 188

- Azarolus. . . . 117 DIALYPÉTALES. . . \& \&

- monogyna . . 116 - HYPOGYNES ... 4

- oxyacrntha. . . 117 - PÉRIGYNES ....4 45

cupnessinées . . . . . . . . 1648

Cupressus . . . . . 535 - Lotus. . . . . 167

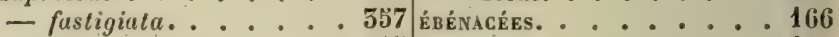

clpulifínes. . . . . 215 éléngnées. . . . . 190

Cydonia....... 119 Eleagnus....... 192

- vulgaris ..... 119 - angustifolia..... 192

Cyprès. . . . . . . 55J EMpétrées ...... 44

- pyramidal. . . . . 557 Empetrum . . . . . . 4t

Cytise ............ 79 - . 44

— à feuilles sessiles. . . 81 Ephédra . . . . . 538

- allongé ..... 82 - commun ... 538

- à trois lleurs..... 82 Ephedra. ..... 558

- couché. . . . 83 - dislachya.... 558

- des Alpes. . . . . 81 Epicéa . . . . . 567

- en tête. ..... 85 - commun ..... 567

- Faux-Ébénier . . . S0 Epine-vinetle ...... 10

- rampant ..... 82 - commune..... 10

- Velu...... 82 - de l'lina.... 11

Cytisus. . . . . . 79 Erable . . . . . 23

- alpinus. . . . . 81 - a feuilles dobier. . . 28

- capilatus.... 85 - champêtre ... 50

- decumbens . . . 82 - de Montpellier. . . 31

- elongalus. .... 82 - plane ..... 29

- hirsulus ..... 82 - Sycomore..... 26

- Laburnum . . . 80 Erica ....... 160

- sessilifolits. . . . 81 - arborea ..... . 16.

- supinus..... 85 - cilisris..... 162 
Erica cinerea. . . . . 162|Genêl aspalathoïle . . . . 76

- lusitanica..... 165 - blanchâtre. . . . . 79

- mediterranea.... 161 - cendré. . . . . 76

- multiflora..... 161 - d'Allemagne. . . . 77

- scoparia ..... 164 - d'Angleterre..... 77

- stricta...... 163 - de Corse ..... 77

- Tetralix..... 162 - de Delarbre..... 76

- vagans. . . . . 161 - d'Espagne. ... 78

- vulgaris . . . . 159 - des teinturiers. . . 75

Éricinées. . . . . . 156 - éphédrö̈de . . . 78

Erinacea. . . . . 69 - épine-fleurie. . . . 76

- pungens ..... 69 - poilu. .... 75

Erinacée.. . . . . 69 - sagitté ...... 75

— épineuse . . . . 69 - très épineux. . . . . 78

Evonymus. . . . . . 41 Genévrier. . . . . 549

- europaus. ..... 41 - commun ...... 350

- latifolius...... 42 - de Phénicie .... 555

Fagus ........ $216-$ nain...... 551

- sylvatica.....216 - Oxycèdre.....551

FICACÉES . . . . . 197 - Sabine. . . . . 355

Ficus ......... 198 Genista. . . . . 75

- Carica. . . . . 198 - anglica. ..... 77

Figuier. . . . . 198 - aspalathoïdes ... 76

- commun ..... 198 - candicans. . . . . 79

Frangula. . . . . . 55 - cinerea. . . . . 76

- vulgaris . . . . 58 - corsica. . . . . 77

Fraxinus. . . 168 - Delarbrei. . . 76

- angustifolia. .... 172 - ephedrö̈des.... 78

- dimorpha.... 172 - germunica..... 77

- excelsior..... 168 - hispanica:.... 78

- Ornus . . . . 173 - horrida..... 78

- oxyphylla .... 172 - linifolia..... 79

Frêne ....... 168-pilosa .... 7 . .

— à feuilles étroites... 172 — sagillalis...... 75

- à fleurs. ..... 175 - scoparia .... 72

- commun ..... 168 - Scorpius...... 76

- dimorphe. ..... 172 - tinctoria..... 75

— oxyphylle. . . . 172 GNétacérs. . . . . 535

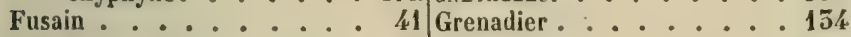

- à larges feuilles ... 42 - commun .... 134

- d'Europe....... 41 Groseiller. . . . . . 135

Gainier. . . . . . 92 - des Alpes. . . . 156

- Arbre de Judée. . . . 92 — des rochers . . . . 156

GAMOPÉTALES. . . . 141 - épineux. . . . 156

- HYPOGYNES. ... 154 - noir....... 157

- PÉRIGYNES . . . 141 - rouge ...... 156

Gatilier................ 183

- Agneau-Chaste. . . 185 Gui ....... 195

Genêl ....... 75 - blanc..... 193

— à balais. . . . . 72 GYMNOSPERMES . . . 559

- à feuilles de Lin. . . 79|IIederu. . . . . . 157 
Ileslera Ilelix. . . . . 158|Loiseleuria . . . . . 16\%

иĹnénicérs...... 157 - couchée . . . . 163

Hélianthème . . . . 15 Loiseleuria . . . . . 163

Heliunthemum ..... 151 - procumbens . . . 165

llêtre ........216 Lonicera. . . . . . . 147

- commun. ....216-alpigena ..... 150)

hippocastaxées . . 52 - Caprifulium... 149

Hippophaé. ..... 191 - cœrulea ..... 150

- rhamnoĩde. . . . 191 - etruscr . . . . 149

Ilippophae........ 191 - implexa . . .... 149

- rhamnoïdes.....191 - nigra. .....150

Houx ....... $42-$ Periclymenum. .. 148

- commun ..... 45 - pyrenaĩca ..... 150

If . . . . . . 507 Xylosteum . . . 149

- commun...... 507 LORANtiacées ..... 195

Ilex. . . . . . . . 42 Lyciet . . . . . . 181

- rquifolium .....43 - d'Afrique...... 182

ILlicisées. . . . . 42 - de Barbarie. . . . 182

Jasmin . . . . . 178 - de Chine : .... 182

- Arbrisseau .... 178 - de la Méditerranée.. 182

JASMINÉES. . . . . . 178 Lycium . . . . . . 181

Jasminum . . . . 178 - afrum . . . . . 182

- frutians. . . 178 - burbarum..... 182

JUGLANDÉES ..... 214 - medilerraneum ... 182

Juglans . . . . . 214 - sinense ..... 182

- regia....... 214 Malus ...... 123

Jujulier. . . . . . 49 - acerba .... 123

- commun ..... 49 - communis. .... 124

- des Iotophages. . . . 50 Marronnier....... 52

Juniperus. . . . . 549 - d'Inde . . . . 53

- alpina.......... 512 Mélèze.... 572

- communis. .....550 - d'Europe.... . . 572

- nana. ...... 351 Melia. . . ... . 56

- Oxycedrus .... 351 - Azadarach. . . . 56

- phicnicea. . . . 555 Mélia ...... 56

- Sabina. . . . 555 - Azédarac . . . 56

Larix . . . . . . 372 Mćlacées. . . . . 55

- europaca. . . . . 572 Mespilus. . . . . 118

Laurier. . . . . 195 - germanica. . . . 118

- commun . . . . 195 Micocoulier...... 202

zaunixérs. . . . 192 - de Provence. . . 202

Laurus. . . . . 195̄ Moníf. ..... 199

- nobilis..... 195 Morelle. . . . . 182

Lierre . . . . . 157 - douce-amère. . . . 185

- grimpant. . . . 158 Morus . . . . . . 200

Ligustrum . . . . 17/4 - alba . . . . 200

- vulgare ..... 174 - nigra.......201

Lilas. . . . . . . 175 Mürier . . . . . . 200

- commun . . . 174 - blanc. . . . 200

Lilac . . . . 201 201

- vulyaris...... 17k|Myrice. . . . . . 297 
Myrica Gale . . . . 297|Oxycoccos. . . . . . 154

Myrica........ 297 -. vulgaris . . . 154

- Galé. . . . . 297 Paliure. . . . 48

Myricaire...... 18 - épineux. . . 49

- d'Allemagne. .... 18 Paliurus...... 48

IIyricaria...... 18 - aculealus. ... 49

- germanicu..... 18 papilionacÉEs . . . . 64

мүнсе́е́ . . . . . . 297 Pècher. . . . . . . 96

MiYRTACÉEs. . . . . 153 - commun . . . . 96

Myrte . . . . . . 155 Persica. . . . . . 96

- commun .....155 - vulgaris ....996

Myrtus. . . . . . 155 Pervenche. . . . . . 179

- communis. . . . . 155 - à grandes fleurs . . 179

Néflier. . . . . . 118 - intermédiaire . . 179

- commun ....118 - nelite..... 179

Nérion. . . . . 180 Peuplier. . . . . 527

- Laurier-Rose. . . . 180 - blanc. . . . . . 528

Nerium. . . . . . 180 - de Canada. . . . 357

- Oleander. . . . 180 - de Virginie.... 556

Nerprun ...... 51 - Grisaille .... 330

— à feuilles d'Olivier ... 55 - noir...... 555

- Alaterne ..... 52 - pyramidal. ... 554

- des Alpes. . . . . 55 - Tremble . . . . 550

- des rochers. . . . 5̋

— des teinturiers. . . . 544 - à feuilles étroites. . . 177

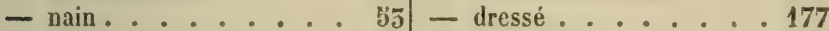

- purgatif. . . . . 55 - intermédiairc. . . . 177

Noyer........214 Phyllirea. . . . . 176

- commun......214 - angustifolia..... 177

Olea........ 175 - mediu...... 177

- Europcea. . . . 175 - stricta.. . . . . 177

oléacées. . . . . 167 Picea . . . . . 567

Olivier. . . . . . 175 - cxcelsa. . . . 567

- d'Europe..... 175 Pin.. . . . . . 582

Ononis. ...... 84 - à crochets. .... 593

- antiquorum..... 85 - Cembro......415

- campestris ..... 85 - d'Alep ..... 402

- fruticosa. .... 85 - Laricio...... 595

- repens..... 85 - maritime .... 404

Orme. . . . . . 204 - Pinier . . . . 411

— champêtre. . . . . 208 - sylvestre. . . . . 585

— de montagne. . . . 208 - Weymouth . . . . 418

- diffus....... 210 Pinus. . . . . . 582

Ostrya. . . . . . 276-cembra . . . . 413

- commun . . . . 276 - halepensis. . . . 402

Ostrya. . . . . 276 - Laricio..... 595

- vulgaris. . . . 276 - Pinaster. . . 404

Osyris........ 194 - Pinea..... 411

- blanc. ...... 194 - Strobus......415

Osyris. . . . . . 194 - sylvestris. . . . 585

- alba. .... 194 - uncinata. ...595 
Pistachier. . . . . . J77|Punica Granatum . . . 154

- commun . . . . . 59 Pyracantha. . . . . 115

— de l'Atlas. . . . . 59 - europea . . . . 115

- Lentisque. . . . . 60 Pyrus. . . . . . 120

- Térébinthe . . . 58 - amygdaliformis.... 122

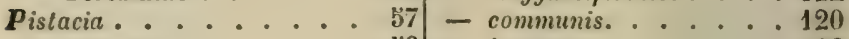

- allantica. . . . . 39 - longipes. . . . . 122

- Lentiscus. . . . . 60 - salvifolia. . . . . 122

- Terebinthus... . . 58 Quercus......... . 226

- vera. . . . . . 59 - Auzandri......267

Plaqueminier ..... 166- Cerris ..... 251

- Faux-Lotier. . . . 167 - coccifera. . . . 266

Plalane. . . . . 295 - Ilex....255

- d'Occident. . . . . $295-$ Mirbeckii. . . . . 250

- d'Orient. . . . . 296 - occidentalis. . . . 264

platanées. . . . . 295 - pedunculata. . . 256

Plalanus...... 295 - Pseudo-suber. ... 255

— occidentalis.... 295 - sessiliflora..... 241

- orientalis. . . . 296 - Suber.... . 257

Poirier. . . . . 120 - Tozza . . . 2/7

— à feuilles de Sauge. . . 122 nenonculacées. . . . . 8

- Amandier. .... 122 Rhamnus....... 51

- commun . . . . $120-$ Alaternus...... 52

- longipède. . . . 122 - alpina...... 55

POMACÉES...... 112 - calhartica...... $\$ 5$

Pommier . . . . 123 - infectoria...... 54

— acerbe . . . . 125 - oleoüdes. . . . . 55

- commun ..... 124 - pumila..... 55

Populus....... 527 - saxatilis...... 83

- alba....... . 528 rmannées....... . 49

- canadensis . . . . 537 Rhododendron. . . . . 163

- canescens. . . . . 550 - ferrugineux . . . . 166

- nigra...... 555 - hérissé. ... 166

- pyramidalis. . . . 554 Rhododendron. . . . 163

- Tremula . . . . 550 - ferrugineum. . . . 166

- virginiana .... . 556 - hirsulum. . . . 166

Potentilla....... 104 Rhus.........61

- fruticosa . . . . 104 - coriaria . . . . 62

Polentille. . .... 104 - Cotinus....... 61

- arbrisseau. ..... 104 - pentaphylla.....65

Prunier. . . . . . 100 Ribes ......... 153

- de Briançon. . . . 100 - alpinum . . . 156

- domestique.....100 - nigrum. .....157

- épincux...... 101 - pelrcum.... 156

- sauvage...... 101 - rubrum...... 156

Prunus. . . . . 100 - Uva-crispa . . . 156

- brigantiaca .... 100 Robinia ...... 86

- domestica. . . . $100-$ Pscudo-Acacia. . . . 86

- insititia. ..... 101 llobinier ...... 86

- spinosa. . .... 101 - Faux-Acacia. . . . 86

Punica. . . . . . 154konce..... . . 104 
Ronce Arbrisseau. . . . . 106|Salix daphnoïdes. . . . . 512 - bleuàtre..... 106 - fragilis. ..... 508

- des rochers. ... 105 - glauca.....52!

- Framboisier.... 105 - grandifolia....521

Rosa ....... 106 - hastata. . . . 524

- alpina.....110 - herbacea. ....527

— arvensis..... 109 — hippophaëfolia ... 511

- canina......111 - incana..... 516

- cinnamomea..... 110 - Laponum..... 526

- gallica ...... 108 - mollissima. . . . 515

- pimpinellifolia. . . 109 - myrsinites. . ... 525

- pomifera..... 112 - nigricans.... 522

- rubiginosa .... 111 - oleïfolia .... 516

- rubrifolia. . . . 110 - pedicellata.....520

- sempervirens .... 109 - pentandra. . . . 507

- sepium......111 - phylicifolia..... 522

- stylosa...... 109 - purpurca..... 517

- tomentosa .... 111 - pyrenaïca. . . . 52:

ROSACÉES ...... 102 - repens.... 522

Rosier . . . . 106 - reticulata. . 526

- à feuilles rouges . . 110 - retusa ..... 526

- à longs styles . . . 109 - rubra . . . . 517

- cannelle.... 110 - Seringeana....515

- des Alpes......110 - Smithiana.....514

- des champs.... 109 - undulala..... 512

- des chiens. .....111 - viminalis..... 514

- de France. . . . 108 - Wimmeriena.... 518

- des haies...... 111 Sambucus. . . . . 145

- Pimprenelle.... 109 — Ebulus. . . . . 148

- pomifère .....112 - nigra......141

- rubigineux. ....111 - racemosa.... 144

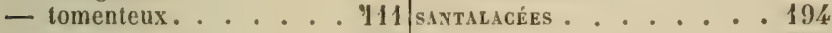

- toujours vert. . . . 109 Sapin. . . . . . 589

Rubus ....... $104-$ pectinć . . . . 559

- cresius ...... 106 Sarothamne ...... 71

- idceus. ...... 10s̈ - arborescent .... 75

- fruticasus.....106 - commun .... - 72

- saxalilis. . . . . 103 - purgalif. ..... 75

SALICINÉES . . . . . 298 Sarothamnus. . . . . 71

Salix . . . . . 298 - arboreus . . . 75

- acuminata.....516 - purgans..... 75

- affinis ..... 815 - vulgaris .... 72

- alba ...... 509 Saule. . . . . . 298

- ambigua .....525 — acuminé .....516

— amygdalina..... 511 — à feuilles d'Hippophaé. . 511

- arbuscula. . ... 524 — à feuilles d'Olivier...516

— aurita...... 521 — à feuilles molles ... 515

- ccesia. . . . . . 525 — à grandes feuilles. . . 521

- Caprea. ..... 519 - Amandier.... . . 511

- cinerea .... 521 - ambigu. .... 52.5

- cuspidala. ....508 - à oreillelles... . 521 
Saule arbuste ..... 52 \{1 Spirée . . . . 105

- blanc. . . . . . . 509 - à fenilles de Millepertuis. 105

- bleuảtre. . . . . . 520 Staphylea . . . . . 40

- cendré . . . . . 521 - pinnatr .... 40

- cuspidé. . . . . 508 staphtréacÉEs. . . . . 59

- Daphué. . . . . 512 Staphylier . . . . 40

- de Seringe . . . 515 - penné. ....40

- des Lapons. . . . 526 strracées . . . . 148

— de Smith. . . . . 514 Styrax. . . . . 150

- des Pyrénées.. . . . 52ə๊ - officinale. . . . 151

- de Wimmer. .... 518 Sumac. . . . . .. 61

- drapé ...... 516 - des corroyeurs. . . 62

— émoussé . . . . 526 - Fustet. . . . 61

- fragile.....508 - Thézéra.....63

- glauque . . . . 52s Sureau . . . . 143

- hasté ......524 - noir...... 144

- herbacé .....527 - rouge..... 144

- Marceau . . . . 519 - Yèble. . . . 145

- Myrte...... 523 tanariscinées. .... 13

- noircissant . . . . 522 Tamarix. . . . . . 17

— ondulé. .... 512 - d'Afrique. . . 18

- pédicellé.... 520 - d'Allemagne . . 18

- pentandrique ... 507 - d'Angleterre. ... 17

- Phylica. . . . . 522 - de France .... 17

- pourpre..... 317 Tamarix ..... 17

- rampant..... 322 - africana..... 18

- réticulé. ....526 - anglica. .... 17

- rouge. . . . . 517 - gallica. . . . 17

- viminal. . . . . 514 - germanica. ... 18

- voisin ..... . 515 raxixées. . . . . 546

soLANÉEs. . . . . 181 Taxus. . 346

Solanum. . . . 182 - baccata ... 546

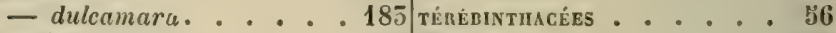

Sorbier . . . . . 124 Thuya . . . . 555

- des oiseleurs. . . . 150 - arliculata. . . . 553

- domestique. . . . 129 Thuya. . . . . . . 553

Surbus . . . . 124 - articulé. . . . 555

- Aria. . . . . 125 Thymelca . . . . 188

- aucuparia . . 150 - calycina ... 190

- Chamcemespilus. . . . 129 - dioïc九 . . . . . 189

- domestica. . . . . 129 - hirsuld. . . . . 190

- hybrida... . 129 - Sanamunda. . . 189

- lalifolia.....127 - Tarlon-raira....189

- torminalis. . . . . 127 - tincloria..... 190

- scandica. . . 127 TIYYMÉLÉACÉES . . . 186

Spartier...... 71 Thymélée...... 188

- d'Espagne. . . . 71 - à calice. . . . 190

Sparlium .... 71 - commun . . . 189

- junccun . . . . 71 - cotonnetr. . . . 190

Spirea. . . . . 105 - diö̈que. . . . 189

- hypericifolis. . 105 - Tarton-Raire.... 189 
TABLE DES MATIÈRES.

Thimélée tinctorial : . . 190|Vaccinium Vilis-idca. . . 1344

Tilic ....... 19 verbénacées. . . . 183

- grandifolia..... 25Viburnum.......143

- intermedia..... 25 - Lantana..... 146

- parvifolia . . . . 20 - Opulus..... . 147

tiliacées....... 19 - Tinus ... 143

Tilleul. . . . . . 19 Vigne . . . . . . 58

— à grandes feuilles . . $25-$ commune..... 58

- à petites feuilles . . . 20 Vinca . . . . . 179

- intermédiaire .... 25 - major. . . . . 179

Troëne........ 174 - media..... 179

- commun ..... 174 - minor ...... 179

Ulex . . . . . . 67 Viorne.......143

- europceus ......68 68 flexible..... 146

- Gallii...... 69 - obier..... 147

- nanus...... 68 - Tin.... 143

- parviflorus . . . 69 Viscum. . . . . 195

ulmacées. . . . . . 204 - . . . 196

Ulmus . . . . . . 204 Vitex . . . . . . 185

- campestris . . . . 203 - Agnus-Castus. . . . 185

- effusi ...... 210 Vitis......... 58

- montana..... . 208 - vinifera ..... 58

vaccinı́́es。...... 151 Ziziphus. . . . . 49

Vaccinium ...... 152 - Lotus ...... . 50

- Myrtillus. . . . 152 - vulgaris ..... 49

- aliginosum .... 155

FIN DE LA TABLE. 






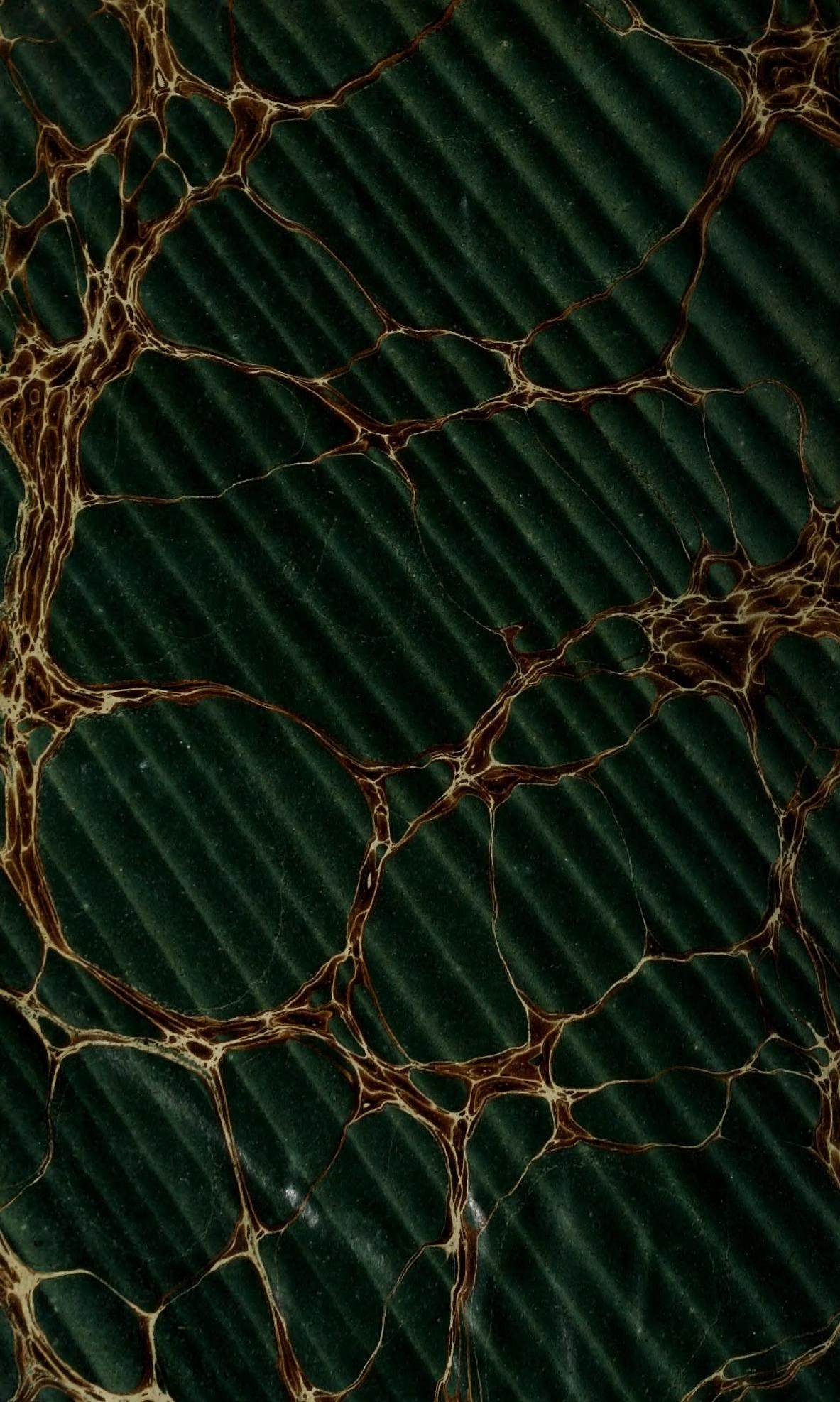




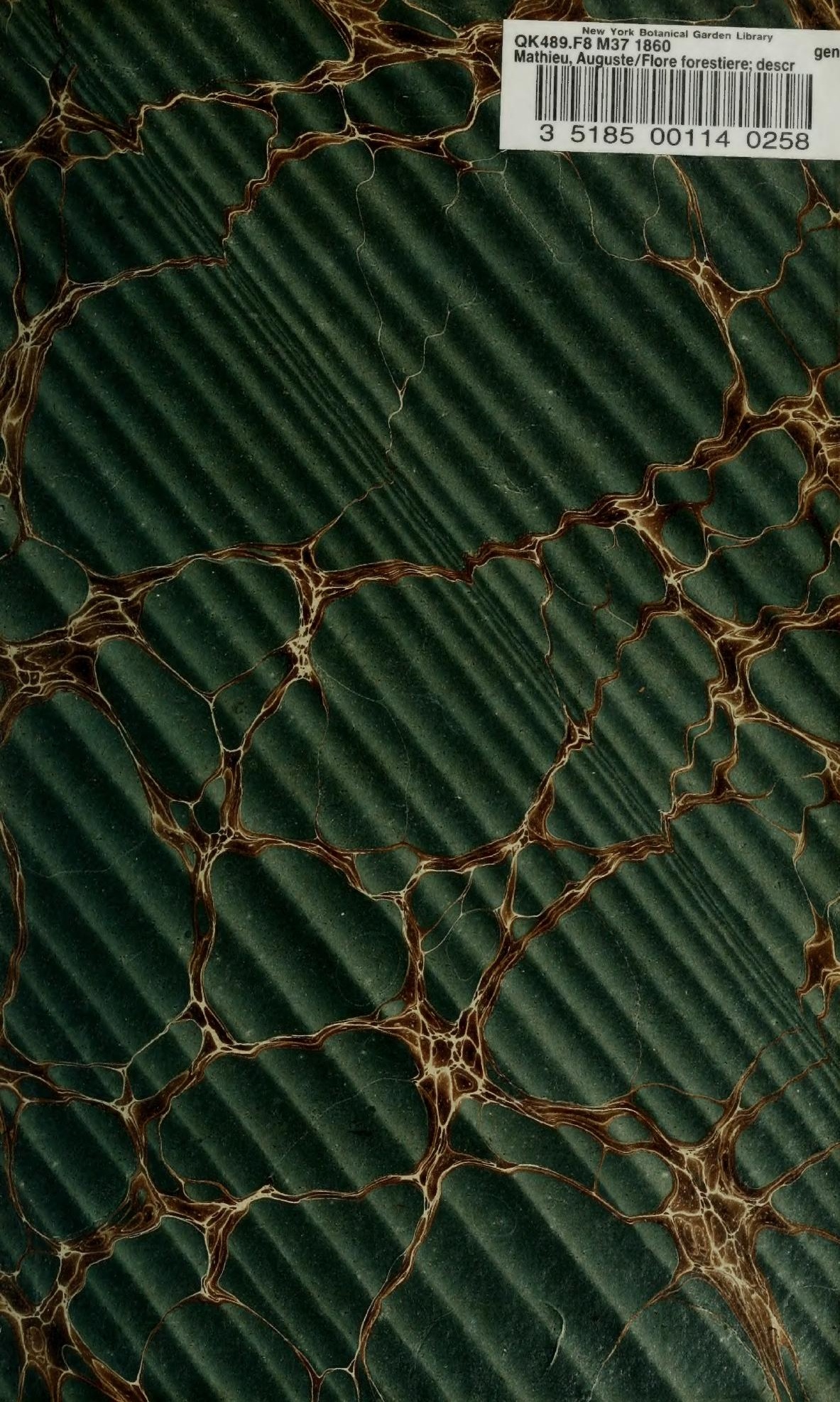




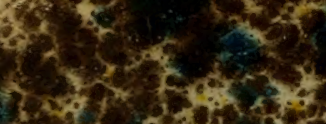

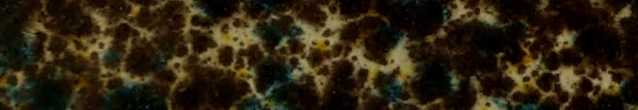

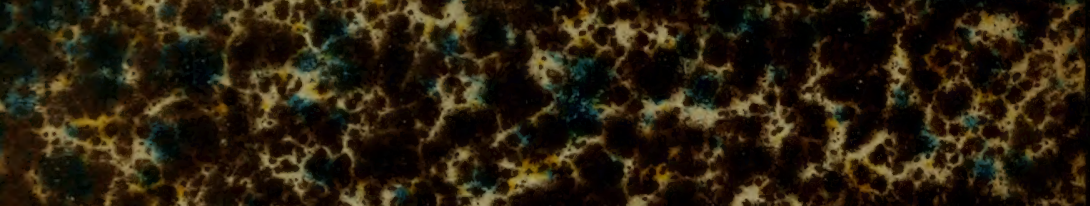

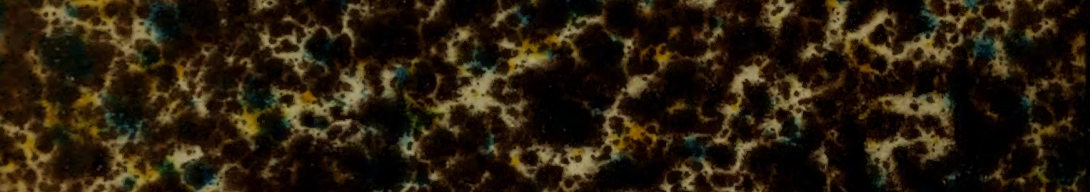

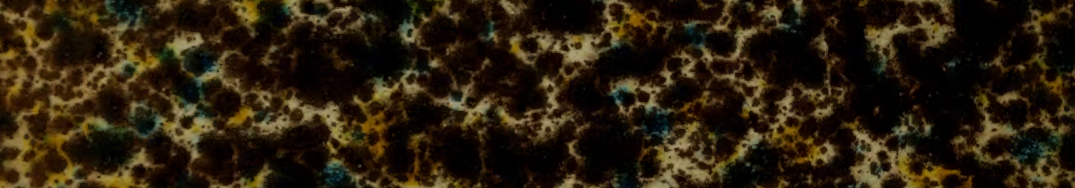

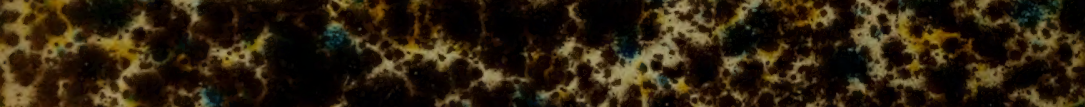

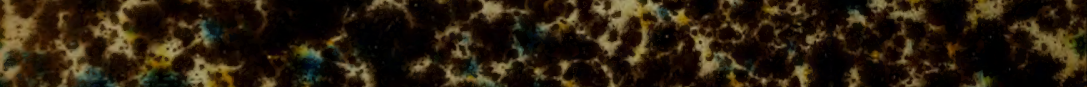

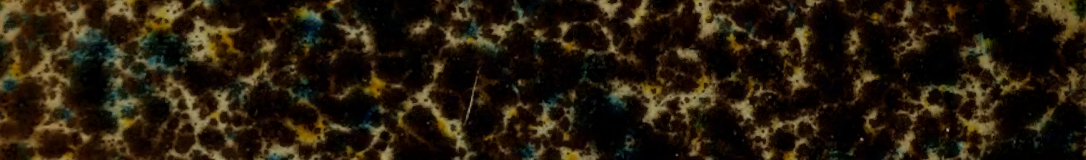

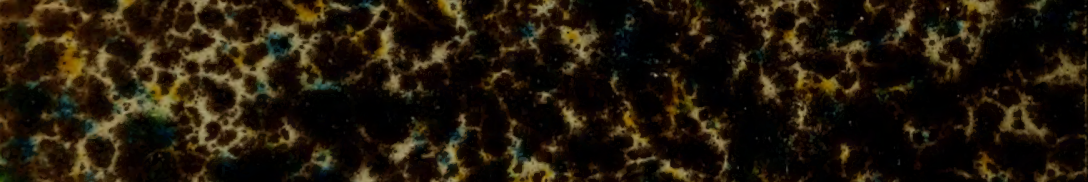

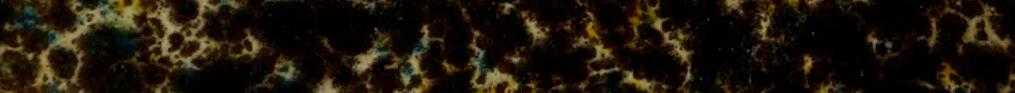

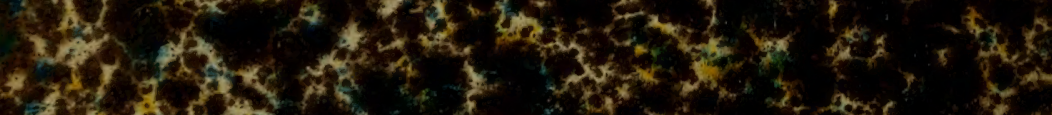

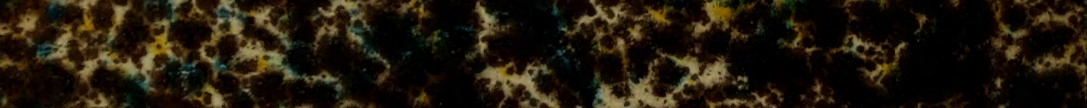

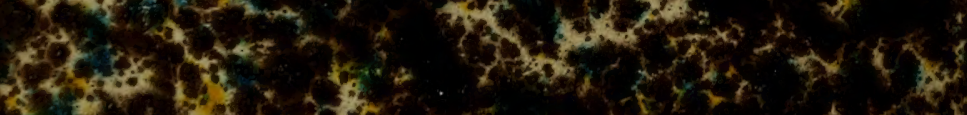

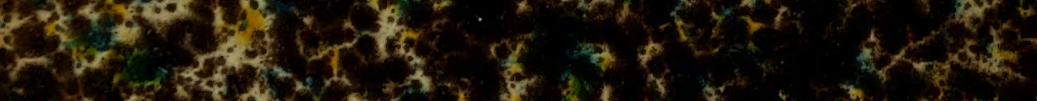

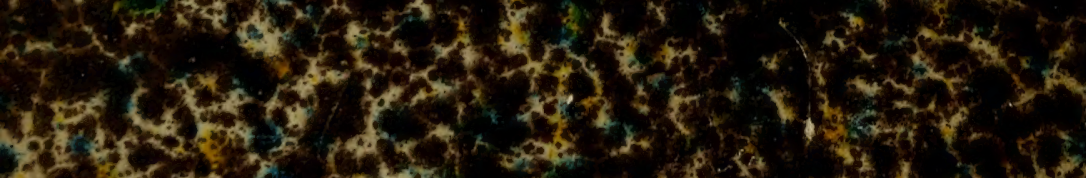

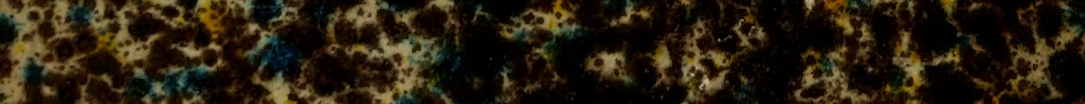

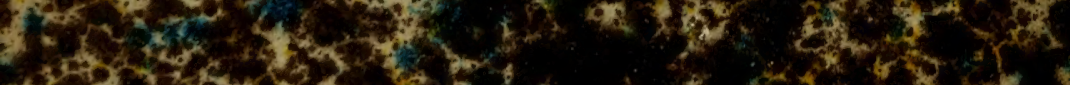

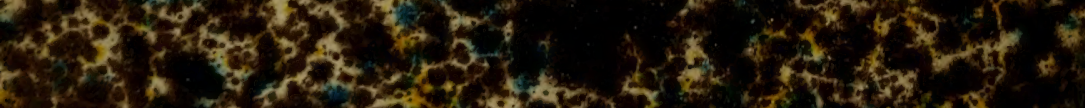

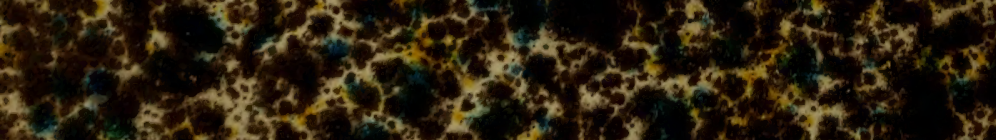

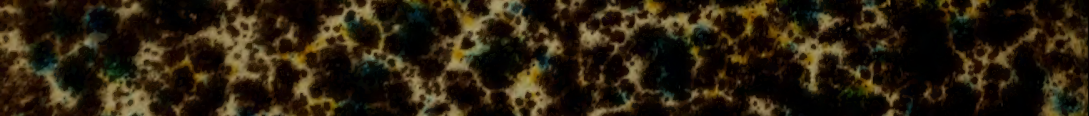

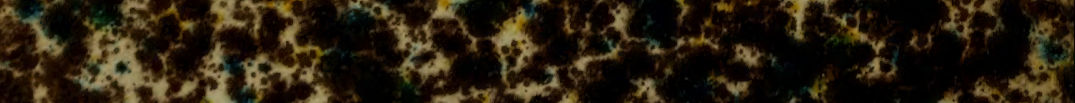

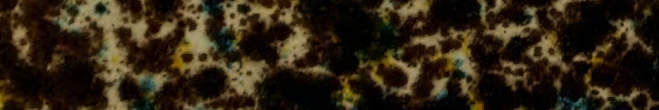

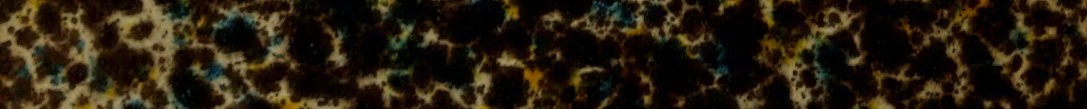

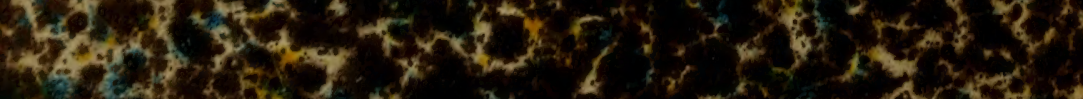

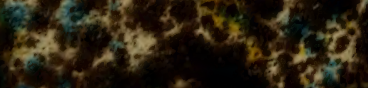

$x^{2} x^{2}$

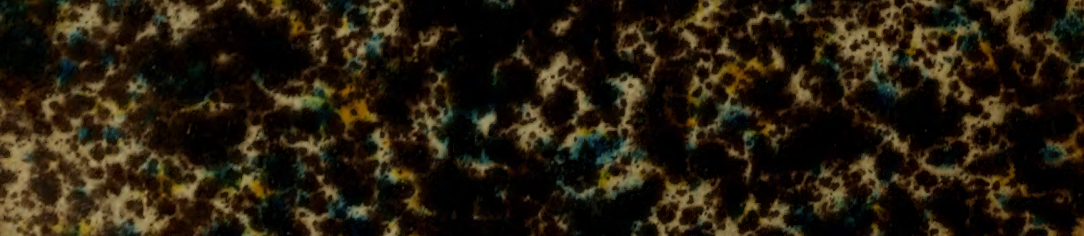
res $8+2$ 